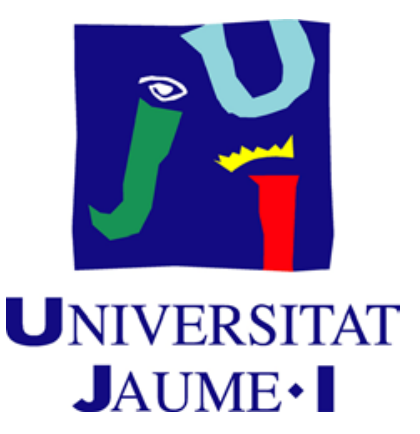

FACULTAT DE CIENCIES HUMANES I SOCIALS

Departament d' Educació

\title{
LA EDUCACIÓN ARTÍSTICA EN LOS PLANES DE ESTUDIO DE MAGISTERIO DE LA COMUNITAT VALENCIANA. VISIÓN PARA EL SIGLO XXI.
}

\section{TESIS DOCTORAL}

\author{
Presentada por: \\ Silvia Martínez Gallego \\ Dirigida por: \\ Dra. Amparo Fosati Parreño \\ Dra. Maria del Carmen Pellicer España
}

CASTELLÓN, 2015 

En Magisterio es de obligación observar a los profesores. Se debe aprender de ellos, aunque sea por antítesis, analizar su rol, como han decidido desenvolverse y enfrentar su asignatura. Aunque sea diferente la educación universitaria a la básica, hay muchos puntos en común y se pueden establecer analogías, por muy adultos que seamos todos. Así, al menos , pienso yo. En este caso tuve una profesora-guía, una creadora de ambientes provechosos de trabajo. Me gustó el espíritu de la clase, como se respiraba, era bonito ver tanta acción creativa. El dejar lanzarse a la gente, pero cumpliendo unos mínimos. En esta asignatura, cualquier otro papel que no fuera el de supervisar, el de ayudar por el camino, habría sido contraproducente. No hubo contradicción entre materia, enfoque y práctica.

Isaac Pastor Lozano

(Alumno curso 2013-14) 



\section{AGRADECIMIENTOS}

Han sido muchas las personas que han contribuido y ayudado, de una u otra forma, a la realización de esta tesis y por esto quiero manifestarles mi más sincero agradecimiento.

En primer lugar, quiero agradecer a mis directoras de tesis, Amparo Fosati, de la UV y Carmen Pellicer de la UJI, sus aportaciones y orientaciones en la realización de este trabajo. Amparo por los años que llevamos conociéndonos y trabajando. Y a Carmen, le quiero reconocer especialmente el apoyo y la ayuda que me ha brindado desde que nos conocemos, así como la confianza que depositó en mí desde que inicié mi trabajo en la Universidad Jaume I de Castellón en la formación del profesorado de Infantil.

Agradecer su colaboración a todos los que me han ayudado en esta investigación y me han facilitado la obtención de la información necesaria:

Al alumnado de toda mi etapa docente, que me ha ayudado a ir encontrando las respuestas que buscaba, ya sea de forma explícita, respondiendo a mis preguntas, como con sus actitudes en el aula, que han ido orientando la mejora de mi trabajo docente.

A mis compañeros y compañeras de trabajo que fui conociendo en los distintos centros donde me destinaron y que me apoyaron y animaron a seguir en la docencia compartiendo nuestra labor a lo largo de estos años.

A mis colegas de la UV que desde que llegué, de una forma u otra, me animaron y apoyaron para conseguir esta meta.

A mi familia y amigos por estar siempre ahí, por su ánimo y confianza en mí. A mis padres, en especial a mi madre, que siempre ha apoyado lo que yo quería hacer. A mi hija a la que he privado de tiempo y compañía, y a mi marido, Paco, por su comprensión, su ánimo y sus aportaciones a este trabajo, sin los que no hubiera podido llegar hasta aquí. 

ÍNDICES 


\section{ÍNDICE DE CONTENIDOS}

\section{CAPÍTULO I.}

INTRODUCCIÓN

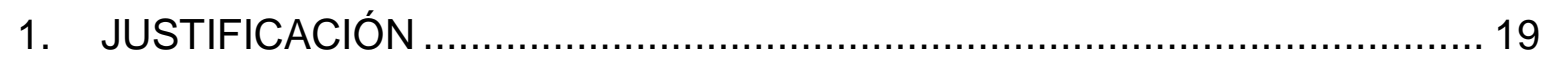

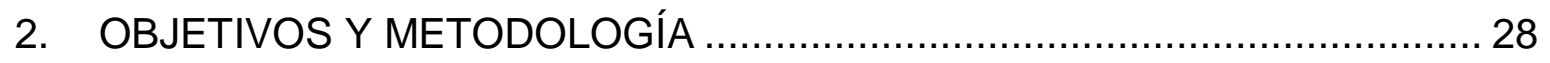

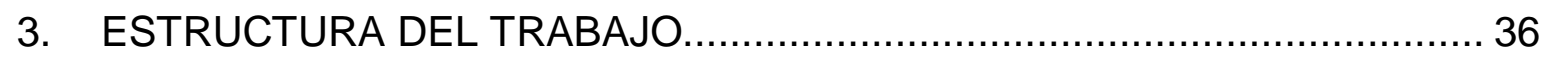

\section{CAPÍTULO II.}

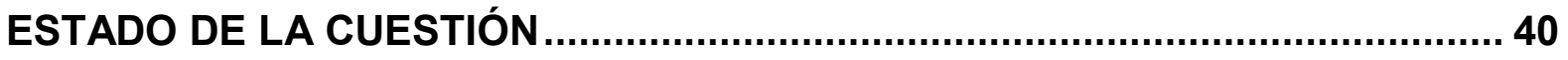

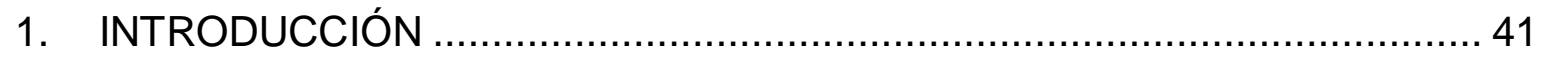

2. ESTUDIOS DE MAGISTERIO. LEGISLACIÓN Y PLANES DE ESTUDIO ... 41

2.1. Orígenes y evolución histórica de los estudios de Magisterio en el

Estado Español. Historia de las Escuelas Normales............................ 42

2.1.1. La situación de la educación en la España llustrada..................... 43

2.1.2. Comienzos y asentamiento del sistema educativo nacional, finales del XVIII y siglo XIX....................................................... 45

2.1.3. Primer tercio del siglo XX. La Escuela Nueva y la estabilización de la formación del Magisterio. ............................... 53

2.1.4. La II República y la universalidad de la enseñanza....................... 58

2.1.5. La guerra civil y la dictadura franquista..................................... 63

2.1.6. La época de apertura y la transición democrática. ......................... 67

2.1.7. La LOGSE y el nuevo concepto del Magisterio............................. 70

2.1.8. El Espacio Europeo de Educación Superior ................................. 71

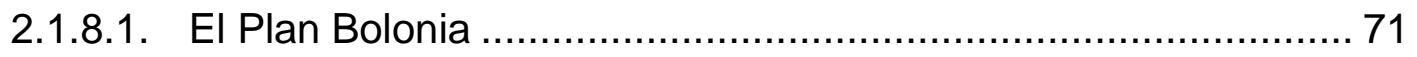

2.1.8.2. La aplicación del Plan Bolonia en los estudios de Magisterio. ... 72

2.1.8.3. Las competencias en el Grado de Infantil y Primaria. ................ 76 
2.2. La formación de los maestros. Los Planes de Estudio. .80

2.2.1. La España Ilustrada y los comienzos del sistema educativo nacional. .80

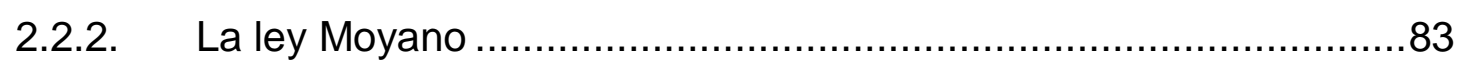

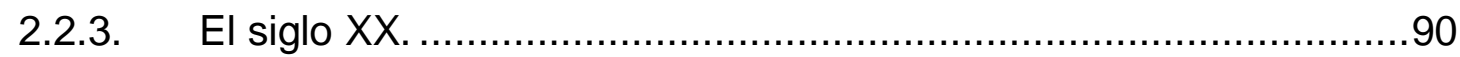

2.2.4. El Plan Profesional de la II República....................................93

2.2.5. La dictadura franquista y el Plan Bachiller. ...............................96

2.2.6. El Plan del 67 y la Ley Palasí. ...................................................99

2.2.7. La LOGSE. Ley Orgánica de Ordenación General del Sistema Educativo. 102

2.2.8. El EEES. Los nuevos Grados en Magisterio.............................103

2.3. Los estudios de Magisterio en la Comunitat Valenciana. ..................105

2.3.1. La Universidad de Alicante y los estudios de Magisterio. 106

2.3.2. La Universidad Jaume I de Castellón y los estudios de Magisterio

2.3.3. La Universitat de València y los estudios de Magisterio. 117

3. CONCLUSIONES 123

\section{CAPÍTULO III.}

MARCO REFERENCIAL

1. INTRODUCCIÓN 128

2. DEFINICIÓN DE LA EDUCACIÓN ARTÍSTICA 130

2.1. El término Educación Artística. 131

2.2. La Educación Artística y el curriculum. 133

3. NUEVAS CONSIDERACIONES FORMALES SOBRE EDUCACIÓN ARTÍSTICA

3.1. La EA y el desarrollo humano. 140 
3.2. Planteamientos curriculares.

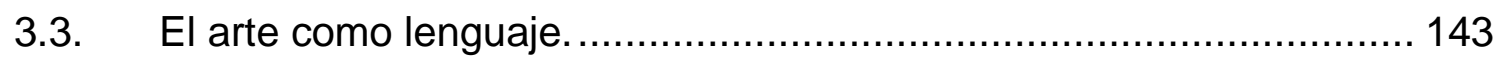

3.4. La Educación para la Comprensión de la Cultura.............................. 147

3.4.1. Estudios de la Cultura Visual. ................................................ 148

3.4.2. Estudios de Cultura Material.................................................. 150

3.4.3. Práctica del Arte Contemporáneo. ............................................ 152

3.4.4. La visión global del hecho artístico............................................ 153

3.5. La Creatividad y la Educación Artística........................................... 156

4. LA ENSEÑANZA ARTÍSTICA Y LA EDUCACION PARA LAS ARTES....... 162

5. LAS ENSEÑANZAS ARTÍSTICAS EN ESPAÑA.................................... 164

6. LA PRESENCIA DE LA EDUCACIÓN ARTÍSTICA EN LOS ESTUDIOS

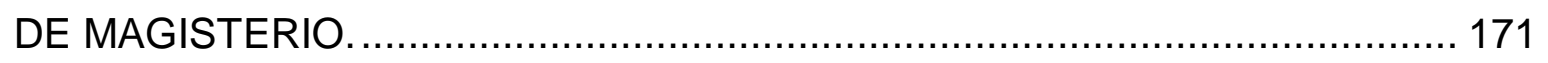

6.1. Educación artística y planes de estudio de Magisterio...................... 172

6.2. Curriculum de Educación Artística en la escuela Infantil y Primaria... 229

6.2.1. De la Ley de Instrucción Pública de 1857 al año 1939................ 230

6.2.2. De 1939 a 1975. Dictadura del General Franco. ........................ 237

6.2.3. De 1970 a 1990. Ley General de Educación y Financiamiento de la Reforma Educativa..................................................... 238

6.2.4. LOGSE, 1990. Ley Orgánica de Ordenación General del Sistema Educativo. ................................................................... 243

6.2.5. LOCE, 2002. Ley Orgánica de Calidad de la Educación. ............ 247

6.2.6. LOE, 2006. Ley Orgánica de Educación. ................................... 247

6.2.7. LOMCE, 2013. Ley Orgánica de Mejora de la Calidad en

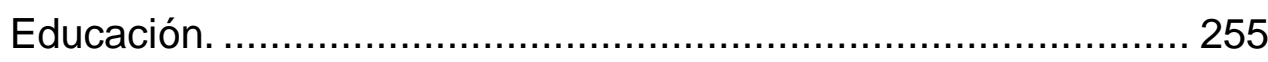

7. LOS AGENTES EN LA EDUCACIÓN ARTÍSTICA EN MAGISTERIO:

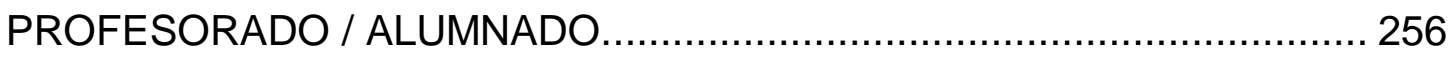

7.1. Perfil del profesorado de EA en los estudios de Maestro................. 263 
7.2. Perfil del estudiante de Grado de Magisterio.

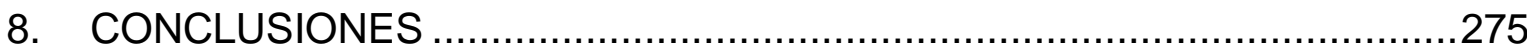

CAPÍTULO IV.

CONSIDERACIONES FINALES

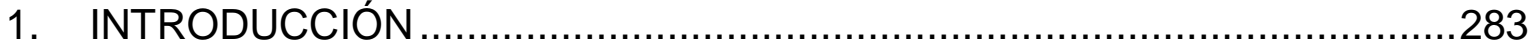

2. LA IMPORTANCIA DE LA EDUCACIÓN ARTÍSTICA EN EL S. XXI..........283

3. COMPETENCIAS ARTÍSTICAS DE FUTUROS MAESTROS DE PRIMARIA E INFANTIL

4. CONCLUSIONES

\section{CAPÍTULO V.}

CONCLUSIONES Y PROPUESTAS DE MEJORA

1. CONCLUSIONES

2. PROPUESTAS DE MEJORA Y PROSPECTIVA

CAPÍTULO VI.

REFERENCIAS BIBLIOGRÁFICAS

1. FUENTES DOCUMENTALES

2. REFERENCIAS LEGISLATIVAS

CAPÍTULO VII. 


\section{INDICE DE TABLAS}

Tabla 1. Plan de Estudios Nacional 1857. 84

Tabla 2. Programas culturales de las Escuelas Normales Elementales 84

Tabla 3. Programas culturales de las Escuelas Normales Superiores 85

Tabla 4. Plan de estudios de 1900

Tabla 5. Plan de estudios de 1901. Elemental 88

Tabla 6. Plan de estudios de 1901. Superior. 88

Tabla 7. Plan de estudios de 1903 89

Tabla 8. Evolución de los contenidos por bloques de conocimiento. 91

Tabla 9. Plan de Estudios Nacional de las Escuelas Normales (1914). 92

Tabla 10. Asignaturas voluntarias para Maestras. 92

Tabla 11. Plan de estudios de 1931. Plan Cultural. 94

Tabla 12. Plan de estudios de 1931. Profesional. 94

Tabla 13. Plan de estudios de 1940 96

Tabla 14. Plan de estudios de 1942. 97

Tabla 15. Plan de estudios de 1950 99

Tabla 16. Plan de estudios de 1967 100

Tabla 17. Extinción (D.Maestro) / implantación (Grado). Alicante. 108

Tabla 18. Organización Planes de Estudio de Grado. Alicante. 109 
Tabla 19. Organización del Plan de Estudios de Grado Infantil. Alicante...... 110

Tabla 20. Organización del Plan de Estudios de Grado Primaria. Alicante... 110

Tabla 21. Extinción (D.Maestro) / implantación (Grado). Castellón............... 115

Tabla 22. Organización Planes de Estudio de Grado. Castellón.................. 116

Tabla 23. Organización del Plan de Estudios de Grado Infantil. Castellón.... 116

Tabla 24. Organización del Plan de Estudios de Grado Primaria. Castellón. 116

Tabla 25. Extinción (D.Maestro) / implantación (Grado). Valencia............... 121

Tabla 26. Organización Planes de Estudio de Grado en Valencia................ 122

Tabla 27. Organización del Plan de Estudios de Grado Infantil. Valencia..... 122

Tabla 28. Organización del Plan de Estudios de Grado Primaria. Valencia. . 123

Tabla 29. Organización Planes de Estudio de Grado. C.Valenciana. ........... 123

Tabla 30. La Plástica en las Esc. Normales Elementales. ......................... 172

Tabla 31. La Plástica en las Esc. Normales Superiores......................... 173

Tabla 32. Cursos de perfeccionamiento en España (1912-1930). ............... 179

Tabla 33. Porcentajes mínimos y máximos de EA / Universidades.............. 228

Tabla 34. Créditos mínimos y máximos de EA / Universidades. .................. 278

Tabla 35. Denominación Troncales del área de Did. de la Exp. Plástica. ..... 294

Tabla 36. El cambio del modelo de profesorado............................... 308

Tabla 37. DECRETO 111/2007, de 20 de julio, del Consell, por el que se establece el currículo de la Educación Primaria en la Comunitat Valenciana. [2007/9730). 365 


\section{INDICE DE FIGURAS}

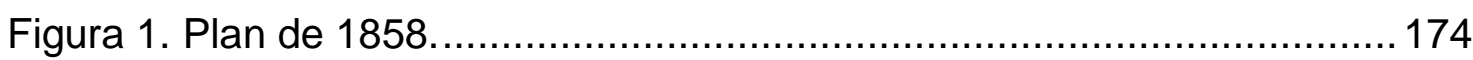

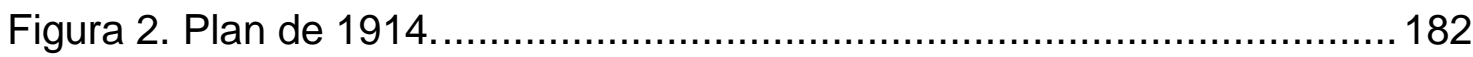

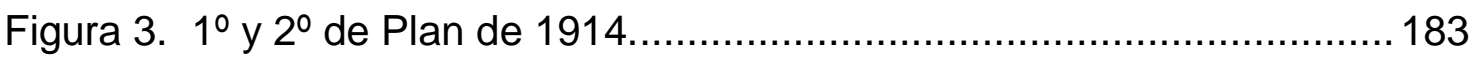

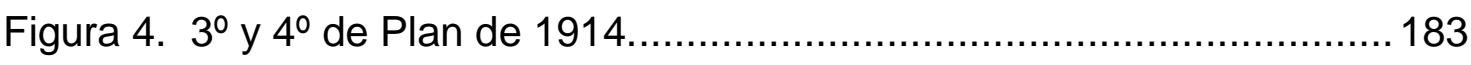

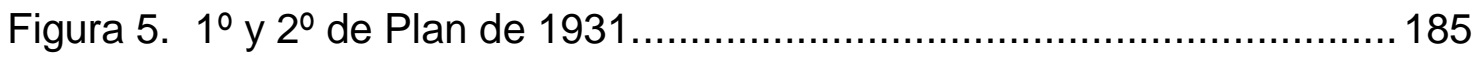

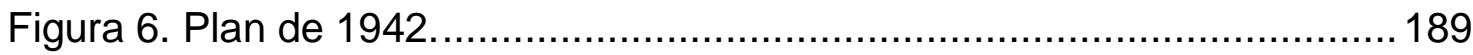

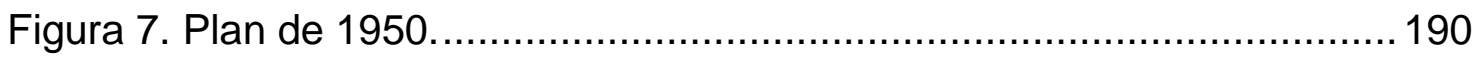

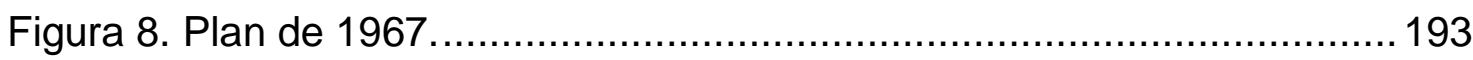

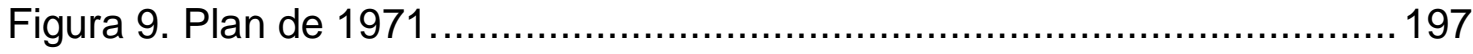

Figura 10. Educación Primaria. 1992 y 1996. Alicante.............................. 204

Figura 11. Educación Primaria. 2000. Alicante..................................... 204

Figura 12. Educación Infantil. 1992 y 1996. Alicante................................ 205

Figura 13. Educación Infantil. 2000. Alicante. ................................... 205

Figura 14. Primaria. Especialista en L. Extranjeras. 1992 y 1996. Alicante. .. 206

Figura 15. Primaria. Especialista en L. Extranjeras. 2000. Alicante.............. 206

Figura 16. Primaria. Especialista en E. Física 1992 y 1996. Alicante........... 207

Figura 17. Primaria. Especialista en E. Física. 2000. Alicante.................... 207

Figura 18. Primaria. Especialista en E. Musical. 1992 y 1996. Alicante......... 208 
Figura 19. Primaria. Especialista en E. Musical. 2000. Alicante 208

Figura 20. Educación Primaria. 1992. Castellón. 209

Figura 21. Educación Infantil. 1992. Castellón 209

Figura 22. Primaria. Especialista en Educación Física. 1992. Castellón....... 210

Figura 23. Primaria. Especialista en Educación Musical. 1992. Castellón. ... 210

Figura 24. Educación Primaria. 1993 y 2000. Valencia. 211

Figura 25. Educación Infantil. 1993 y 2000. Valencia. 211

Figura 26. Primaria. Especialista en L. Extranjeras. 1993 y 2000. Valencia.. 212

Figura 27. Primaria. Esp. en Ed. Física. 1993 y 2000. Valencia. 212

Figura 28. Primaria. Esp. en Ed. Musical. 1993 y 2000. Valencia. 213

Figura 29. Primaria. Esp. en Ed. Física. 1993 y 2000. Valencia. 213

Figura 30. Primaria. Esp. en Audición y Lenguaje. 1993 y 2000. Valencia. .. 214

Figura 31. Grado en Educación Infantil. Alicante. 217

Figura 32. Grado en Educación Primaria. Alicante. 218

Figura 33. Grado en Educación Infantil. Castellón. 219

Figura 34. Grado en Educación Primaria. Castellón. 220

Figura 35. Grado en Educación Infantil. Valencia. 221

Figura 36. Grado en Educación Primaria. Valencia. 222

Figura 37. Mínimo y Máximo asignaturas EA. 1992. Alicante. 223

Figura 38. Mínimo y Máximo asignaturas EA.1992. Castellón. 223 
Figura 39. Mínimo y Máximo asignaturas EA. 1992. Valencia. 223

Figura 40. Mínimo y Máximo asignaturas EA. 1992. C. Valenciana. 224

Figura 41. Mínimo y Máximo asignaturas EA. 1996. Alicante. 224

Figura 42. Mínimo y Máximo asignaturas EA. 2000. Alicante. 224

Figura 43. Mínimo y Máximo asignaturas EA. 2000. Valencia. 225

Figura 44. Mínimo y Máximo asignaturas EA. 2000. C. Valenciana 225

Figura 45. Mínimo y Máximo EA. Grado Infantil y Primaria. Alicante. 226

Figura 46. Mínimo y Máximo asignaturas EA. Grado Infantil. Castellón. 226

Figura 47. Mínimo y Máximo asignaturas EA. Grado Primaria. Castellón. .... 226

Figura 48. Mínimo y Máximo asignaturas EA. Grado Infantil. Valencia. 227

Figura 49. Mínimo y Máximo asignaturas EA. Grado Primaria. Valencia 227

Figura 50. Mínimo y Máximo de EA. Grado Infantil. C. Valenciana. 228

Figura 51. Mínimo y Máximo de EA. Grado Primaria. C. Valenciana. 229 
CAPÍTULO I. 
La Educación Artística en los planes de estudio de Magisterio de la Comunitat Valenciana. Visión para el siglo XXI.

\section{INTRODUCCIÓN}




\section{JUSTIFICACIÓN}

En todos los sistemas educativos, la formación del profesorado ${ }^{1}$ es una parte significativa. La forma en que se desarrollan y aplican los planes de estudio de cada momento no refleja solo un aspecto cualitativo o técnico, sino que pone de manifiesto, al mismo tiempo, factores propios del período histórico al que pertenecen.

Este estudio se inicia explorando la evolución de los modelos que fueron implantándose en nuestro país para la formación del docente. A medida que ha ido avanzando la investigación hemos pretendido evidenciar las modificaciones que se han incorporado y dando lugar a los planes vigentes en el momento presente. Se conservan los aspectos fundamentales que han permanecido en cada modelo, para ir destacando las modificaciones provocadas por variables sociales y culturales que intervienen en cada momento del desarrollo.

Muchos son los estudios que han insistido en la necesidad de una buena formación inicial del profesorado para mejorar la educación básica. Autores como Marín (1982) o Cuenca (1988), recuerdan la 35a Conferencia Internacional de Educación convocada por la UNESCO en Ginebra en 1975, que recoge como primer principio básico que debe configurar la política y la acción educativa es una rotunda afirmación del valor del profesor y de su necesaria preparación en toda mejora de la educación:

Cualesquiera que sean o vayan a ser los cambios del sistema de educación, las relaciones entre el personal docente y los educandos seguirán estando en el centro mismo del proceso de educación, y, por

${ }^{1}$ El uso obligado de términos para designar a las/os profesoras/es e intentar evitar una reiteración por el uso de uno sólo, obliga a diversificar la terminología. Sin embargo, debe entenderse que cuando se habla de profesorado, docentes, profesores, etc., queremos referirnos a los dos géneros. El uso indistinto de unos u otros obedece a cuestiones meramente literarias y no de prejuicios u olvidos sexistas. 
consiguiente, una mejor preparación del personal de educación constituye uno de los factores esenciales del desarrollo de la educación y una Importante condición para toda renovación de la educación.

El posterior informe de la UNESCO (1998, p. 63) lo apoya con manifestaciones como:

Aunque las condiciones de la enseñanza son importantes, el papel de los docentes es fundamental en lo que atañe a la calidad y la pertinencia de la educación. La manera en que se los educa y prepara para su trabajo constituye un indicador esencial del tipo de calidad y pertinencia de la enseñanza que se desea lograr.

Sin embargo, son escasos los estudios científicos e investigaciones centrados en concreto en la formación inicial en Educación Artística que recibe el alumnado de Magisterio. El concepto de Educación Artística ${ }^{2}$ abarca contenidos muy dispares, todos ellos con puntos en común pero que dificultan la acotación de la materia. Es por ello que en numerosas ocasiones resulta complejo abarcar y delimitar, de forma adecuada, a qué contenidos en concreto nos referimos. En el caso que nos ocupa trabajaremos concretamente sobre los denominados como Expresión Plástica y Visual.

Destacamos el valor educativo del área de EA pues ayuda a adquirir sensibilización y sentido estético. Su práctica proporciona imaginación, creatividad y estimula la integración social. Significamos pues la importancia de la formación inicial del profesorado en este ámbito, dado que los conocimientos y vivencias artísticas en general se reconocen como muy positivas para la formación de la persona, no sólo como mejora cultural, sino por todo aquello que genera para la propia formación integral. En nuestro mundo contemporáneo, consideramos imprescindible plantear acciones que mejoren esta preparación así como el aumento de la presencia de la EA en la educación.

\footnotetext{
${ }^{2}$ En adelante EA.
} 
Centramos el presente estudio en la necesidad de ofrecer una respuesta válida en cuanto a cómo se refleja en las sucesivas leyes educativas de nuestro país la formación inicial del alumnado de Magisterio, en concreto en el área de Educación Artística. Nuestro interés es hacer partícipe y, compartir los hallazgos con la comunidad educativa esperando que pueda tener continuidad en posteriores investigaciones sobre esta temática.

Un informe de la UNESCO (1999) insta a todos los órganos competentes en materia de enseñanza artística y cultural para que la EA adquiera un lugar destacado en la formación de cada persona, desde la Educación Infantil hasta el último año de Enseñanza Secundaria.

Para subrayar la importancia de la EA en la educación, nos remitimos también al informe emitido por la Comisión Europea en $2009^{3}$, elaborado por la Agencia Ejecutiva en el ámbito Educativo, Audiovisual y Cultural. En él se recogen las recomendaciones expresadas ya en el anterior informe de la UNESCO referenciado y menciona otras, numerosas, declaraciones que se han sucedido en Europa que apoyan estos planteamientos:

- 1995 - Proyecto Cultura, Creatividad y los Jóvenes, que examina la oferta de EA en los centros educativos de los Estados miembros, así como la participación de artistas profesionales y la disponibilidad de actividades extracurriculares.

- 1999 - Estudio sobre la EA en Europa ${ }^{4}$ y coloquio internacional.

- 2005 - Convenio marco sobre el valor del patrimonio cultural para la sociedad. En él se pone en valor la necesidad de que los países europeos preserven sus recursos culturales, promuevan la identidad cultural, respeten la diversidad y fomenten el diálogo intercultural. A la vez recomienda también que se establezcan vínculos entre materias impartidas en las diversas áreas de estudio.

\footnotetext{
${ }^{3}$ Disponible en:

http://eacea.ec.europa.eu/education/eurydice/documents/thematic reports/113ES.pdf

${ }^{4}$ Véase NACCCE. http://sirkenrobinson.com/pdf/allourfutures.pdf
} 
- 2006 - Conferencia Internacional sobre la Promoción de la Educación Cultural en Europa (Presidencia Austriaca de la UE).

Se celebra una Conferencia Mundial sobre la EA, en Lisboa, fruto de la colaboración internacional entre la UNESCO y los representantes del ámbito de la EA. Se refrendó la necesidad de incrementar la importancia que se le daba a la EA en la sociedad. A la vez, generó el impulso que permitió, por un lado la publicación de la obra de Bamford, el Factor Wow (2006) y, por la propia UNESCO, de la Hoja de Ruta para la Educación Artística (2006, p.7), que pretendía ser una guía de mejora de la EA. En él se afirma que la EA contribuye:

o A respetar el derecho humano a la educación y participación cultural.

- Al desarrollo de las capacidades individuales.

- A mejorar la calidad de la educación.

o A favorecer la expresión de la diversidad cultural.

- 2007 - Comunicación sobre una agenda europea para la cultura en un mundo en vías de globalización (Comisión Europea). Se recomienda fomentar la educación artística y la participación activa en actividades culturales para desarrollar la creatividad y la innovación.

- 2008 - Libro blanco sobre el diálogo intercultural ${ }^{5}$, ofrece un enfoque intercultural para gestionar la diversidad cultural. Se identifican las organizaciones educativas (incluidos museos, lugares de patrimonio, guarderías y centros educativos) que tienen potencial para respaldar el intercambio intercultural, el aprendizaje y el diálogo a través del arte y las actividades culturales. Se designa este año como Año Europeo del Diálogo Intercultural.

\footnotetext{
${ }^{5}$ Para más información: http://www.coe.int/t/dg4/intercultural/Source/Pub White Paper/WhitePaper ID SpanishVersio $\underline{\text { n.pdf }}$
} 
- 2009 - Se designa Año Europeo de la Creatividad y la Innovación. Se aprueba una resolución sobre Estudios Artísticos en la Unión Europea que recomienda:

- La EA debería ser obligatoria en todos los niveles educativos.

- La EA debe utilizar los recursos proporcionados por las nuevas tecnologías de la comunicación y de la información.

o La enseñanza de la Historia del Arte debe ir acompañada de encuentros con los artistas y de visitas a lugares emblemáticos relacionados con la cultura.

Además de estas consideraciones, estudiosos como Dewey (1896), Vigotsky (2003), o los más contemporáneos como Eisner (1995a), Gardner (1994), Jové (2001), entre otros, han incidido en la importancia de la inclusión del arte en el currículum. Consideran que si en la infancia existe un contacto con los procesos artísticos y con la cultura propia, se consigue:

- Desarrollar la imaginación.

- Mejorar la inteligencia emocional relacionada con la autoestima.

- Se adquiere autonomía así como libertad de acción y de pensamiento.

Todo ello conlleva:

- Una apreciación crítica y valoración estética.

- La comprensión y valoración del patrimonio cultural.

- Desarrollo de las competencias sociales y comunicativas a través del trabajo colaborativo en grupo.

- Aumenta, en conjunto, su sensibilidad para comprender y disfrutar de su entorno.

Recogiendo todo lo anteriormente planteado reflexionamos acerca de dos sectores que por lo tanto están íntimamente relacionados entre sí. Son la base educativa de la sociedad e implican un compromiso fundamental pues requieren evaluar qué margen de actuación tenemos en vistas a mejorar su desarrollo en el futuro, hablamos de: 
- La educación inicial en la infancia.

- La instrucción del profesorado, los profesionales encargados de llevar a cabo esta formación.

La formación en EA que recibe actualmente el alumnado en las universidades, determinará su futura capacidad para cumplir con la demanda social establecida legalmente para el futuro profesor de Educación Infantil y Primaria. La calidad de su formación previa y su interés por la formación continua, a lo largo de su vida laboral, integrarán su perfil profesional. Todos estos aspectos son necesarios e importantes. Le habilitarán para ser permeable a los cambios consecutivos y le animarán a introducir métodos innovadores que mejoren su docencia en la materia y, con ello, mejorar su potencial en la escuela.

Esta investigación es, además de una consideración teórica, el producto de una reflexión sobre mi propia dedicación docente en el Grado de Magisterio, concretamente en el área de Educación Artística. El interés surge a raíz de un fenómeno que observamos con asiduidad al inicio de cada curso, despertando la inquietud por profundizar en las causas que generan situaciones como:

- La formación previa en la materia con la que accede el alumnado de Magisterio

- La actitud que adoptan ante las materias de EA y sus expectativas con las mismas.

- Las competencias que adquieren durante sus estudios y como las aplican en la práctica.

El empeño es encontrar la manera de que, respondiendo a sus necesidades formativas, el alumnado de Magisterio se eduque adecuadamente en EA y aprenda a poner en valor unos conocimientos que inicialmente les resultan ajenos. Paralelamente pretendemos hacerles competentes para su futuro laboral en una educación de calidad y que sean capaces de aprender a comprender las necesidades de su futuro alumnado escolar. 
Partimos de una experiencia introspectiva que nos ayuda a evaluar la experiencia artística personal, durante la etapa formativa, y como es la enseñanza que se imparte en la actualidad. El propósito es, sobre todo, centrarlo en un alumnado que empleara estos conocimientos directamente como herramienta en su trabajo. Seguimos con una estrategia de reflexión sobre la propia práctica docente desarrollada durante estos años y, nos basamos en un proceso investigador en el que recabamos información del alumnado para ir orientando adecuadamente la práctica docente. La intención es conseguir unos resultados que ayuden a mejorar su formación como futuros profesionales del área de EA en Infantil y Primaria.

El contacto con otros niveles educativos ha sido de utilidad para observar aspectos diferentes que afectan a la didáctica de esta materia. Mi labor docente se inicia en el campo de la enseñanza del Dibujo Artístico aplicado al Diseño, en las Escuelas de Arte y Superiores de Diseño. Estas enseñanzas se enmarcan dentro de lo que hoy en día, en el marco de EEES, se denominan Enseñanzas Artísticas Superiores (Diseño, Cerámica, Música, Arte Dramático, Restauración).

Durante algunos años, esta ocupación fue paralela a la docencia como profesora asociada en los estudios de Magisterio en la Universidad Jaume I de Castellón. Estos dos ámbitos de trabajo, si bien los dos docentes, presentan diferencias notables:

1. En cuanto al tipo de enseñanzas que se imparten:

a. En el caso de las $\mathrm{EASD}^{6}$, las asignaturas son de contenidos puramente procedimentales y técnicos, con una proyección marcadamente profesionalizadora.

b. En el caso de la Diplomatura ${ }^{7}$ de Maestro/a, el trabajo se transformaba en formadora en Didáctica del Arte, impartiendo asignaturas de Didáctica de la Expresión Plástica además de

\footnotetext{
${ }^{6}$ Escuelas de Arte y Superiores de Diseño

${ }^{7}$ En ese momento todavía era Diplomatura.
} 
optativas, como Técnicas Tridimensionales o Técnicas Pictóricas y Gráficas.

2. En cuanto a los diferentes perfiles del estudiantado:

a. Una mayoría del alumnado de Diseño, en sus diferentes especialidades, se interesa por adquirir destrezas artísticas que les permitan desarrollar su actividad laboral futura. Están motivados por la materia y una gran parte tiene preparación previa al comienzo de sus estudios.

b. El alumnado de Magisterio, refiriéndonos al área de EA, percibe la materia como algo puntual en su curriculum y no relevante para su labor profesional futura. Su motivación hacia las asignaturas es escasa y no tienen formación didáctica previa en la materia.

Resultó sorprendente, como profesional de Artes Visuales, lo diferentes que parecían unos de otros:

1. La actitud del alumnado de Diseño era muy parecida al del estudiante de BBAA, mostrándose muy interesados por adquirir conocimientos artísticos.

2. En Magisterio, sin embargo, el enfoque era bien distinto. La EA representa una pequeña parte de la totalidad de los estudios. Consideran que los conocimientos artísticos tienen una relativa aplicación en la escuela y, por lo tanto, les despiertan poco interés. Un alto porcentaje del alumnado tiene una actitud expectante ante la materia pues desconoce los valores que les puede transmitir. No saben cómo integrar en su día a día los aspectos artísticos próximos de su entorno y solo conocen el concepto de Arte con mayúsculas. Ello parece proceder de creencias estereotipadas que no integran una concepción incluyente del arte que valora aspectos que podrían resultar cercanos a ellos mismos y a su profesión (patrimonio, cultura visual, expresión infantil, arte y genero, aproximación a la vertiente social...). A la hora de ejercer su profesión no se les pide conocimientos específicos 
en la materia pues no existe especialidad en la misma ni por lo tanto se requiere en las oposiciones para la escuela pública.

La sorpresa inicial ha dado paso a la búsqueda por averiguar el origen de esta situación. La actitud tan distinta del alumnado condiciona totalmente la forma de impartir la docencia, obviando la diferencia existente en los contenidos.

Consideramos interesante desarrollar en esta Tesis la vertiente investigadora de la EA. Se ha planteado en múltiples ocasiones la falta de esta condición cuando nos referimos al aporte teórico necesario para que la investigación en materia artística pueda ser considerada científica. Un importante porcentaje de estudiosos como Quilez (1990), Hernández (2000) o Marín (2005), han abogado por que se considere "investigación" a la realización de la propia práctica artística así como a otras vertientes artísticas. Por qué no tomar en cuenta, en el ámbito de la investigación artística, al "artista enseñante", de esta forma, el quehacer docente e investigador estaría permitiendo un mejor acceso al significado de la obra artística. Mediante un nuevo concepto de la docencia y una investigación al servicio de un mejor conocimiento del fenómeno artístico y sus derivaciones, la enseñanza artística superior ofrecería una respuesta válida a la comunidad a la que pertenece. Así, entre las múltiples opciones que se abren en este campo (Investigación en patrimonio, histórica de género, o diferentes metodologías, cuantitativas, cualitativas,....) hemos elegido centrarnos en los aspectos de la didáctica que contemplan las didácticas comparadas o las profesionales, Juanola (2011) y que cuestionan los actuales planteamientos institucionales o la separación de las diferentes didácticas atendiendo a la disciplina.

Es por ello que se ha hecho necesario, para iniciar adecuadamente la investigación, explorar y conocer más a fondo cuál ha sido el proceso de desarrollo e implantación de los estudios de Magisterio en España. Nos permitirá, más adelante, estudiar y analizar la situación en la que nos encontramos actualmente. Sin esta contextualización, nos resulta difícil interpretar, desde una perspectiva realista y fundamentada, cuál es el lugar que ha ocupado la EA en la historia y la evolución de estos estudios. 
Los límites cronológicos pueden parecer excesivamente amplios para un estudio de estas características pero la elección de fechas no es un hecho arbitrario. Responde al registro del inicio de una actividad, la creación de la primera Escuela Normal en Madrid, el 8 marzo de 1839 Olaya (1999), y que ha continuado sin interrupción hasta nuestros días.

Apreciamos en las sucesivas reformas educativas, qué significado e importancia otorga la Administración a la presencia de la EA en las enseñanzas de Infantil y Primaria y el hincapié que hace en la importancia de la docencia que se debe dar a esta área en el aula. Tomamos la referencia las dos últimas reformas educativas, $\operatorname{LOGSE}^{8}$ y $\operatorname{LOE}^{9}$, y de la que actualmente acaba de entrar en vigor $\operatorname{LOMCE}^{10}$ y veremos cómo tratan la idea de la importancia de la enseñanza del Arte en la educación.

\section{OBJETIVOS Y METODOLOGÍA}

A fin de facilitar la lectura de esta Tesis Doctoral expondremos el planeamiento general con los puntos principales abordados. Trataremos los objetivos fundamentales previstos que nos hemos propuesto realizar para la presente investigación y desarrollaremos la metodología empleada en el análisis del material empleado.

En la actualidad, la valoración de la calidad en los servicios es cada vez más importante. Se la considera un factor estratégico para conseguir que los egresados adquieran las competencias (conocimientos, habilidades y actitudes) que corresponden a su titulación y que éstas sean reconocidas por la sociedad en general.

${ }^{8}$ Ley 1/1990, de 3 de octubre, Orgánica de Ordenación General del Sistema Educativo. (BOE 4 octubre de 1990)

9 Ley Orgánica de Educación 2/2006, de 3 de mayo. (BOE 24 de mayo de 2006)

${ }^{10}$ Ley Orgánica 8/2013, de 9 de diciembre, para la mejora de la calidad educativa. (BOE 10 diciembre 2013) 
Los numerosos cambios legislativos que se han sucedido en la historia de la educación de España han afectado a la manera en que se ha formado a los estudiantes. Nuestro propósito es hacer una revisión panorámica general y ver qué cambios han afectado de forma fundamental a nuestra temática.

Contemplando nuestro trabajo de forma global queremos destacar el gran volumen de documentación existente relativa al asunto y la variedad temática que nos hemos vistos obligados a abordar. Ha sobrepasado con creces la visión inicial que presentaba al comienzo de la investigación. El punto de partida inicial no nos lo hacía prever. Trabajar sobre el tema de cómo se imparte la EA ha derivado en un cuestionamiento integral del sistema educativo en el que se entrecruzan numerosos problemas. No hemos podido ni querido abstraernos del aspecto evolutivo de la historia que implica inevitablemente aspectos sociales y políticos. Pero para poder pronunciarnos sobre ello hemos necesitado profundizar en el conocimiento de las realidades acontecidas en nuestro país. Esta experiencia nos ayuda a poder emitir un juicio crítico sobre la evolución y modificaciones legislativas realizadas en cada momento.

A pesar que nuestro campo de trabajo no es el histórico ha sido necesario recurrir a esa visión para contextualizar el estudio. Del mismo modo que también en la parte legislativa ha sido necesario consultar y aprender a manejarla con propiedad.

Una parte compleja de esta investigación ha sido hallar y desvelar esta diversidad de informaciones puesto que hemos necesitado realizar una interpretación de datos desincronizados que en ocasiones ofrecían una doble lectura. Es por ello que las ideas que pretendemos transmitir son producto de una integración personal, siempre, claro está con la intención de respetar el origen de los mismos.

Lo importante es llegar a comprobar y demostrar la gran distancia existente entre los planteamientos políticos de la Administración y la realidad de la posterior aplicación práctica del programa. Entre la formación universitaria y la aplicación en la práctica de la escuela. 
Este estudio, en la modalidad de investigación educativa, tiene como objetivos:

1. Situar las enseñanzas de $E A$ en el conjunto de materias que corresponden a la formación en Magisterio.

a. Contrastar los diferentes planes de estudio vigentes en las etapas históricas estudiadas.

b. Detallar la presencia de esta materia en cada período de los indicados.

c. Mencionar los cambios experimentados en cuanto a las diferentes estrategias didácticas.

2. Identificar los diferentes modelos de formación en EA establecidos

a. Describir las diferentes concepciones de la EA.

b. Especificar qué papel ha desarrollado la EA en los diferentes estudios: Magisterio, Escuela.

c. Analizar los diferentes perfiles de profesorado y de alumnado

3. Concretar las necesidades actuales reales en la formación inicial de los maestros en EA.

a. Justificar la necesidad de una mayor presencia de la EA en los estudios de Magisterio.

b. Ofrecer guías para poder cambiar y reflexionar acerca del problema histórico de la enseñanza de las asignaturas artísticas en nuestro país.

c. Determinar de qué forma podemos establecer orientaciones para mejorar la adquisición de las competencias profesionales necesarias, en particular en las asignaturas específicas del ámbito de la Educación Artística, para poder impartir a su vez esta asignatura en las aulas escolares.

Partimos del reflejo de un punto de vista, basado en la experiencia personal en la práctica, y pretendemos, desde el compromiso con la enseñanza de calidad en EA, contribuir a evidenciar las necesidades existentes en la mejora de la formación de estos profesionales en EA. Queremos sentar unas bases que ayuden a formar profesionales mejor preparados así como competentes en la materia. La finalidad es que, en el ejercicio de su profesión, atiendan a su 
futuro alumnado de la manera más integral posible conforme a las necesidades reales de la sociedad contemporánea.

El estudio requiere tener en cuenta los cambios socioculturales acaecidos en cada época histórica y valorar sus consecuencias en el concepto que se tiene de la educación. Nos preguntamos cómo han repercutido estas variaciones en la idoneidad y calidad de la formación inicial en vistas a su óptima incorporación al ámbito laboral escolar.

Para ello es importante ser capaces de revisar nuestros planteamientos docentes para intentar mejorar nuestra forma de trabajar. Necesitaremos evaluar la calidad de nuestro trabajo para poder proponer acciones de mejora. Estos planteamientos pueden servir para fundamentar estudios posteriores de mayor profundidad.

Debido a que la extensión temporal que abarca nuestro trabajo plantea una variada casuística ello aconsejó seguir las diferentes estrategias metodológicas que se detallan a continuación:

Pensamos que dada la complejidad del tema no se puede abordar desde un único punto de vista. Consideramos que la visión de conjunto requiere poder contemplar el problema desde diferentes perspectivas, lo cual enriquecerá el producto final. Según Andrews (2010), podemos abogar por una investigación integrada en la que los mixed methods combinan múltiples elementos, procedentes de métodos cuantitativos y cualitativos como ayuda a un conocimiento más profundo del tema. Los estudios en EA referidos a la educación requieren contemplar la situación con amplitud de miras:

1. En primer lugar, realizamos una búsqueda bibliográfica de datos, en diferentes tipos de fuentes. La investigación bibliográfica se orienta a la consulta de fuentes y fondos documentales diversos tanto en papel como de búsqueda en la web, pues numerosos estudios y, sobre todo los más recientes, son accesibles por este medio. Se recurre a bibliotecas y hemerotecas así como a los Archivos Universitarios e 
Instituciones de diversa índole como fuentes o instrumentos de información:

a. Los textos legislativos han sido inicialmente una parte fundamental. Con esta exploración conseguimos documentación sobre el diseño y desarrollo de los diferentes Planes de Estudio así como información legislativa acerca del tema en cada época estudiada. Todo este proceso nos ha permitido tomar de conciencia de la evolución histórica seguida por los planes de estudio de Magisterio en el entorno español, de cómo ha sido su formación desde que se les consideraba como "maestros instructores de leer y escribir" hasta el momento actual en el que son la base de la educación formativa del individuo. Destacamos en ellos la presencia de materias relacionadas con la EA, valorando inicialmente la presencia a nivel cuantitativo, atendiendo al papel que se les otorga en los planes de estudios vigentes de cada época. Solo aplicamos un análisis de evaluación cuantitativa a una mínima parte de la documentación y de los datos. Ello es debido a la complejidad y a las múltiples variantes que concurren en el tema analizado.

b. Por otro lado hemos realizado un estudio epistemológico en el que hemos revisado investigaciones anteriores a la nuestra que abordan parcelas que nos pueden resultar reveladoras. Provienen de variadas disciplinas y de especialistas reconocidos, tanto de ámbito nacional como internacional, en historia de la educación, investigación pedagógica, psicología, etc. lo cual aporta una visión más interdisciplinar al objeto de estudio.

2. En segundo lugar, hacemos una valoración cualitativa respecto a qué tipo de objetivos se pretendía conseguir con la materia según las creencias sociales vigentes en los diferentes periodos históricos. Nuestro estudio toma los datos de los diferentes integrantes que intervienen en el acto educativo: el profesorado, el alumnado universitario y la escuela. 
Las metodologías fueron incorporándose a medida que se presentaba la necesidad y a lo largo del conjunto de la investigación. Su aparición y aplicación cronológica se adapta atendiendo a las diferentes etapas:

- Las cualitativas de carácter histórico-pedagógico. En las etapas históricas de la investigación ha habido que realizar una selección del material localizado ya que la información era por un lado de difícil consulta y por otro excesivamente complejo para el motivo principal de nuestro estudio. El criterio seguido ha sido, fundamentalmente, incluir las iniciativas surgidas de la estructura orgánica oficial (ya sea nacional o autonómica).

- Metodología experimental ya que esta fase viene de la aplicación de la experiencia docente.

- Finalizando con métodos que denominaremos de análisis comparativo en la vertiente educativa.

Fundamentamos nuestro estudio con un tratamiento histórico cronológico de la evolución de los Planes de Estudio en nuestro país partiendo de finales del siglo XIX para llegar hasta el momento actual. Señalaremos en ellos la representación del área de EA. Situado el estudio a nivel general lo contextualizaremos en las Universidades Públicas de la Comunidad Valenciana:

- Universidad de Alicante

- Universidad Jaume I de Castellón

- Universitat de València

Completado el proceso anteriormente citado, abordamos un proceso de análisis de la información atendiendo a las distintas facetas que contemplamos en nuestro estudio. Las técnicas de análisis de datos empleadas en esta Tesis son las siguientes:

- Análisis de los datos de carácter histórico recogidos en libros, artículos, archivos y legislación. Se cotejan entre ellos, se evalúa su significación y relevancia para nuestro objeto de estudio. Se compendian las 
informaciones para elaborar una síntesis abarcable que nos permita exponerlos con claridad y más adelante extraer conclusiones.

- Análisis cuantitativo de la presencia de las asignaturas artísticas en cada uno de los planes de estudio presentes en las diferentes etapas históricas contempladas. Puntualizar que la forma en que estos datos cuantitativos han sido expuestos es personal y de elaboración propia, ya que en numerosas ocasiones no era posible realizar las comprobaciones oficiales pertinentes por carecer de los primeros planes de estudio.

- Análisis comparativo de las asignaturas artísticas ofertadas en los curriculums. Atendiendo especialmente a las que se ofertan al alumnado de Magisterio así como las presentes en los curriculums de Infantil y Primaria. El estudio se lleva a cabo en la legislación vigente en cada uno de los momentos históricos trabajados que exponemos a continuación. Extraemos datos que nos permiten posteriormente, indicar los encuentros y desencuentros importantes que apreciamos entre los diferentes niveles educativos que, a priori, deberían estar íntimamente relacionados.

- Síntesis crítica personalizada aplicada a cada una de las partes más significativas del estudio y así como una recapitulación comparativa entre los aspectos más relevantes de la investigación.

Identificamos 8 grandes etapas históricas que recogen unas características distintivas y unos hechos diferenciados en torno a nuestro motivo de estudio:

1. Comenzamos, cronológicamente, en la llustración en España, los antecedentes históricos en cuanto a la situación de la educación en la época.

2. El segundo período comienza en los finales del siglo XVIII y todo el XIX. Destacando en 1840 como fecha importante por la creación de la primera Escuela Normal y llegamos hasta 1900. Todo este tiempo es un periodo convulso política y socialmente y consigue sentar las bases educativas de lo que será la enseñanza en nuestro país. 
3. El tercer período abarca las tres primeras décadas del siglo XX (19001931). Es una etapa con aportaciones e iniciativas institucionales relevantes. Surgen propuestas educativas e ideológicas que marcarán una evolución interesante en los años siguientes.

4. La época de la Segunda República (1931 - 1939) supondrá un momento histórico único basado en las numerosas propuestas legislativas y prácticas que se llevaran a la práctica. Confluyen corrientes renovadoras que se han ido gestando desde épocas anteriores y que pondrán en práctica avances de gran importancia para nuestro objeto de estudio.

5. El siguiente apartado coincide con la guerra civil española y la primera etapa del franquismo, entre 1940 y 1960. Son momentos de una marcada ideología debido al reciente régimen establecido. Veremos cómo afecta y qué consecuencias tiene sobre la profesión.

6. A partir de 1960 se inicia una nueva etapa, que se prolongara aproximadamente hasta 1975. Surgen los tímidos primeros intentos de modernización escolar. La promulgación de la Ley General de Educación de 1970 inicia el camino hacia una nueva manera de entender el sistema educativo. Nuestro estudio, evoluciona junto a la instauración de la democracia en España de 1976 a 1984. Se asientan propuestas educativas y se incorporan nuevos planteamientos y metodologías en la formación del profesorado.

7. En los años 90 con la promulgación de la LOGSE, con la democracia plenamente asentada, se pretende que esta democracia se extienda al funcionamiento de los centros docentes. Fue la primera ley que estableció un sistema descentralizado de enseñanza en España. Se trabaja sobre la construcción del aprendizaje más que sobre la instrucción del conocimiento $\mathrm{Y}$ adopta básicamente el enfoque de la educación plástica y visual.

8. Con el inicio del proceso de Bolonia, en 1999, empieza a gestarse lo que será el Espacio Europeo de Educación Superior y se inicia la configuración de los nuevos grados, actualmente implantados. Se flexibiliza la organización de las enseñanzas universitarias y se fomenta 
la movilidad de los estudiantes. Se pretende impulsar un cambio en las metodologías docentes.

Pensamos que estos conocimientos nos ayudan a entender cómo han afectado los cambios al alumnado de Magisterio, y más concretamente, con respecto al área de EA. Se trata de comprender los diferentes planes de estudio que han regido en esta formación académica y su efecto en los curriculums escolares. Entre las numerosas asignaturas del curriculum de la educación nos cuestionamos:

- Cuál es el papel de la EA en Magisterio y en Educación Infantil y Primaria.

- Qué peso relativo tiene entre el conjunto de asignaturas.

- Cuáles son los contenidos que debe tratar.

- Si la formación del profesorado es adecuada y suficiente para abordar estos contenidos.

- Si están motivados los profesores hacia el área.

\section{ESTRUCTURA DEL TRABAJO}

Las diferentes partes en que se estructura el contenido de esta Tesis son las siguientes:

- En el Capítulo I, de Introducción, presentamos esta investigación enunciando su origen, los objetivos a alcanzar, la metodología empleada, así como, su estructura general.

- El Capítulo II, de Estado de la cuestión, recoge el marco histórico que nos ayuda a situar el trabajo. Sin un conocimiento adecuado de la forma en que se instruye a los maestros y del papel social que desarrollan, resulta a priori complejo ubicar el aspecto más específico que queremos abordar, el de la EA. Analizar la evolución de estas enseñanzas nos resulta valioso para evidenciar los cambios sufridos. 
- El Capítulo III, de Marco referencial, lo constituye el marco teórico en el que nos aproximamos más directamente al campo científico en que se centra el estudio y la temática concreta abordada. La exploración documental y bibliográfica nos proporciona referencias teóricas en las que fundamentar nuestros instrumentos de investigación además de corroborar los resultados y conclusiones obtenidas. Siguiendo el curso de la historia, exponemos cómo ha evolucionado el concepto de la EA hasta llegar a la actual situación de la posmodernidad, con consideraciones a nivel nacional e internacional. Cuál ha sido su significación, dependiendo del ámbito abordado, de las situaciones políticas, de las tendencias educativas y de las investigaciones relevantes de cada momento. En la parte final del capítulo abordamos más específicamente, la formación en EA en Magisterio. Para ello significamos los diferentes ámbitos en que analizaremos estos contenidos:

- Los planes de estudios de la universidad

- Los curriculums escolares

- Los sectores implicados: profesorado y alumnado.

- En el capítulo IV, de Resultados, revisamos el tema de forma general para abordar el proceso evolutivo seguido por la EA. Nos interesa sobre todo destacar las diferencias y similitudes que pueden llegar a existir entre el mundo cultural y el del arte contemporáneo así como entre el mundo académico y el de la enseñanza primaria. Ello nos servirá de plataforma para poder argumentar nuestro interés por mejorar la formación inicial que debe recibir, en nuestros días, el alumnado de Magisterio en EA.

El estudio desde un punto de vista histórico y educativo, nos ayudará a encauzar la búsqueda de una metodología que nos permita proporcionar al alumnado una educación holística. Aspiramos a generar cambios tanto en ellos como en su entorno. Que estos cambios les hagan cuestionarse sus relaciones con el mundo que les rodea para aprender a apreciarlo a través del hecho artístico. Para ello nos emplearemos a fondo en la tarea de modificar su sentido de la percepción y en trabajar su discurso como 
educadores para que a su vez sean capaces de transmitir ese sentir a los niños.

- El capitulo $V$ corresponde a la parte final de la investigación. En él recogemos las conclusiones así como planteamos unas propuestas futuras, a modo de prospectiva. Recopilamos las conclusiones parciales obtenidas en cada uno de los aspectos analizados a lo largo de nuestro estudio. Cada una de estas partes nos ayuda a extraer deducciones que nos permiten emitir recomendaciones educativas más completas y concluyentes en la parte final. Nos apoyamos sobre todo en el contraste entre la formación que reciben los futuros maestros y aquello que legalmente tienen que aplicar en el aula.

Así, analizando y sacando conclusiones de nuestra trayectoria histórica, así como de las necesidades y retos que nos plantea una sociedad en continua evolución, valoramos si son suficientemente competentes o necesitan mejoras en su formación.

Es nuestra intención promover una mejor formación artística para que la EA ocupe el lugar que consideramos que debe tener en la formación de las personas. Consideramos fundamental esta cuestión para el conocimiento y el disfrute general. 
CAPÍTULO II. 
La Educación Artística en los planes de estudio de Magisterio de la Comunitat Valenciana. Visión para el siglo XXI.

\section{ESTADO DE LA CUESTIÓN}




\section{INTRODUCCIÓN}

Este capítulo se estructura siguiendo un esquema evolutivo en el que comenzamos por situar los estudios en su contexto histórico y abordamos posteriormente la problemática conceptual de la Educación Artística. Este proceso nos llevará a determinar las conclusiones de la investigación y sus implicaciones en la mejora del ámbito docente.

Más adelante, concretaremos nuestro estudio en las universidades públicas de la Comunidad Valenciana, y analizaremos en particular, la docencia de la Educación Plástica en los actuales estudios de Magisterio.

Según Marín (2003, p. 467), el proceso de investigación en Historia de la Educación Artística consta normalmente de cinco fases:

- Elección y delimitación del tema.

- Reunión y catalogación de las fuentes.

- Establecer la cronología.

- Contextualizar.

- Clasificar y explicar.

Nuestra intención aquí es evidenciar las escasas horas dedicadas a la impartición de asignaturas de componente artístico dentro del conjunto del curriculum de formación de los estudios de Magisterio. Ello nos ayudará a interpretar adecuadamente algunos de los problemas y situaciones actuales. Dentro de lo que se consideran asignaturas artísticas, Música, Arte dramático y Expresión Plástica, particularizaremos nuestro estudio centrándonos en esta última.

\section{ESTUDIOS DE MAGISTERIO. LEGISLACIÓN Y PLANES DE ESTUDIO}

El sistema educativo no es un elemento aislado de su entorno, es el producto de un concepto social y transmite determinados valores según las diferentes épocas. La escuela, por lo tanto, es un reflejo de todos los contextos sociales 
que influyen en la educación. Cada momento histórico proyecta sus ideologías y valores culturales estableciendo una determinada filosofía que rige su sistema educativo. Este se diseña para lograr un determinado tipo de sociedad; el curriculum en vigor estará dotado de una organización y estructura generadas para aplicar y desarrollar un determinado modelo de individuo. "El sistema escolar siempre ha estado en función del tipo de organización de la vida social dominante" (Dewey, 1896, p. 285, citado en Westbrook, \& Teixeira (2010).

Las personas encargadas de transmitir los conocimientos, de llevar adelante y aplicar estos curriculums educativos son, en la enseñanza reglada contemporánea, los maestros, en lo que actualmente se denomina como Educación Infantil y Educación Primaria, y los profesores, en la Educación Secundaria.

En el ámbito que atañe a este estudio nos centraremos fundamentalmente en la manera en que se forma a los maestros que desarrollarán su profesión en las escuelas del país. Según Dewey, recogido por Westbrook (1993), la escuela, en la medida en que desempeña un papel decisivo en la formación del carácter de los alumnos, puede, si se la prepara para ello, transformar fundamentalmente esa sociedad.

2.1. Orígenes y evolución histórica de los estudios de Magisterio en el Estado Español. Historia de las Escuelas Normales.

La historia de la educación y de la formación de los maestros en España es relativamente compleja y convulsa. Atendiendo a diferentes momentos históricos y políticos, de los que hablaremos a continuación, ha atravesado por periodos políticamente diferenciados en los que han ido variando frecuentemente aspectos tan determinantes como:

- Las condiciones de acceso a los estudios.

- La estructura de las enseñanzas.

- La formación recibida. 
- La forma de acceder al ejercicio profesional.

Nos interesaría, a continuación, exponer estas diferentes etapas para conocer cómo evolucionan estas enseñanzas durante el largo periodo en el que no estaban contempladas dentro del rango de los estudios universitarios.

Los movimientos sociales que se fueron manifestando en la Europa del siglo XIX, con la llegada de la Ilustración y una incipiente Revolución Industrial, afectaron de forma sustancial a la manera en que se forma a los maestros. "En España, la Revolución Industrial, pujante en otros países de Europa como Inglaterra, Países Bajos, Alemania, etc., no arraiga; salvo en Cataluña y el País Vasco, y ello con matices" (Lorenzo, 1995 p. 211). La clase social burguesa tampoco consigue asentarse y desarrollarse con fuerza en España.

Son personas pertenecientes al sector del progresismo español de la primera mitad del siglo XIX y sus ideas liberales las que favorecerán las instituciones formadoras de maestros. La fundación de los centros específicos, denominados Escuelas Normales, es un hecho relevante y determinante. La creación de las Escuelas Normales hay que interpretarla como una conquista del pensamiento liberal español (Molero, 1994). Se deposita en los maestros la tarea de generalizar la alfabetización entre las clases populares mediante la educación primaria.

\subsubsection{La situación de la educación en la España llustrada.}

Durante el Antiguo Régimen no se había prestado atención a la creación de los más elementales mecanismos de financiación, información, gestión y control, necesarios para la configuración de un sistema educativo nacional. "A finales del siglo XVIII, en la España Ilustrada, con Carlos III y Carlos IV, la política de Estado fue muy exigua con respecto a los problemas de la educación y la enseñanza elemental, al igual que había sucedido anteriormente con Felipe $\mathrm{V}$ (1700-1746) y Fernando VI (1746 - 1759)" (Esteban, 1994 p. 386). 
En la época ilustrada, en España, la situación de la educación y la escuela primaria era muy precaria:

- La educación de las elites estaba en manos de las órdenes religiosas.

- La clase media y nobiliaria se educaba en las escuelas regidas por "maestros examinados".

- La instrucción de las clases populares era impartida por agrupaciones profesionalizadoras, evolucionadas de las asociaciones medievales de carácter gremial. La formación inicial de quienes debían llevar a cabo esta instrucción era muy básica. Las Academias de Maestros eran las encargadas de habilitar para el ejercicio de esta profesión y de difundir lo que podríamos llamar, "la ciencia pedagógica de la época". Se ingresaba trabajando de aprendiz, al lado de maestros en activo, para pasar luego a ser oficial y finalmente convertirse en maestros a su vez.

Existían unas "pruebas" que valoraban las "competencias" de los que querían dedicarse al oficio de Maestro de Instrucción Elemental. La situación de la formación de los maestros se caracterizaba por la escasa importancia social del mismo así como de la enseñanza primaria (Lorenzo, 1995). El primero que estableció unas pruebas reguladas fue Enrique II (Real Cedula de 1370). Se siguieron aplicando con los Reyes Católicos (1500), Carlos I (1540), Felipe II (1573), Felipe III (1610), Felipe IV (1642), Felipe V (1719) y Fernando VI (1758), (Román y Cano, 2008).

Desde 1642 se establecieron unos exámenes más complejos, diseñados por la Hermandad de San Casiano ${ }^{11}$. Eran los únicos que tenían la facultad de examinar a los maestros de toda España y de expedir títulos. Existían diferentes categorías acerca de los títulos de Maestro: Maestros Reales ${ }^{12}$,

${ }^{11}$ O Congregación de San Casiano: maestros de Madrid que se reúnen con ánimo de protegerse y mejorar la enseñanza, reciben, por parte del Consejo de Castilla, el privilegio de examinar a los demás maestros del Reino. Se forman Hermandades en diferentes ciudades como Toledo, Valencia, Zaragoza, Sevilla, Jerez de la Frontera, Granada y otras. Tienen derecho a examinar a los aspirantes y a nombras a aquellos "visitadores" que vigilaban las escuelas.

${ }^{12}$ Los más valorados. Debían justificar conocimientos de doctrina cristiana además de limpieza de sangre y vida ordenada. Se les examinaba de el arte de leer, escribir y contar.

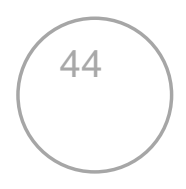


Leccionistas ${ }^{13}$ y Maestros de sólo leer ${ }^{14}$ (Román y Cano, 2008), dependiendo del trabajo que se les encomendaba realizar. Se controlaba más los intereses de los cofrades y el posible intrusismo que la calidad profesional (Lorenzo, 1995). Los requisitos eran más bien de carácter ideológico.

El nivel cultural y la preparación que se le exigía a un maestro se correspondía directamente con el trabajo que debía realizar: en general, atender a niños procedentes de zonas rurales o de familias obreras. La necesidad de formación de las clases populares era prácticamente nula pues normalmente los hijos continuaban con la actividad laboral de los padres, de tipo ganadero o agrícola. La mayoría de las veces, los alumnos venían poco motivados pues sus expectativas eran recibir una formación elemental que les permitiera acceder al mundo laboral, generalmente en el mismo lugar del que habían partido. La función del maestro era dotarlos de una formación elemental en conceptos y habilidades básicas, sobre todo en escritura y cálculo. Los comienzos de la industrialización y la necesidad de disponer de personas mejor formadas van a influir de forma decisiva en los cambios ${ }^{15}$.

2.1.2. Comienzos y asentamiento del sistema educativo nacional, finales del XVIII y siglo XIX.

La normativa que regulaba la actividad de los maestros era dispersa y complicada. En 1780, Carlos III suprime la Congregación de San Casiano y la sustituye por el Colegio Académico del Noble Arte de Primeras Letras. Pasará a llamarse Academia de Enseñanza Primaria en 1791 (Esteban, 1994). Se empieza a plantear la posibilidad de que la formación de un Maestro sea una profesión reglada y deje de considerarse como un oficio. Se regula el número

\footnotetext{
${ }^{13}$ Se dedicaban también a la enseñanza pero no tenían escuela abierta. El control sobre ellos era complicado.

${ }^{14}$ Maestros autorizados solo a enseñar a leer.

${ }^{15}$ Téngase en cuenta que el aspecto "artístico", que ni siquiera era considerado como tal, no era función del maestro sino que se dejaba para cuando entraban a trabajar como aprendices en talleres. Era una dedicación profesional y para artesanos.
} 
de escuelas y los exámenes de leccionistas y maestros: se les pide leer, escribir y contar.

En la Constitución de 1812 se incorpora en España la idea de la educación como un entramado en cuya organización, financiación y control debe intervenir el Estado. Se dedica un título en exclusiva a la instrucción pública donde se plantean renovadoras ideas en el campo educativo como la defensa de la universalidad de la Educación Primaria, la obligatoriedad para toda la población y la uniformidad de los planes de enseñanza para todo el Estado.

Entre 1814 y 1819, Fernando VII establece un conservadurismo educativo de neto influjo clerical que se verá abolido en la etapa liberal de 1820-23 con el restablecimiento de la Constitución. En 1821 se ordena la primera ley general de educación liberal: Reglamento General de Instrucción Pública. Regula una escuela pública y generalizada. La vuelta de Fernando VII al poder absolutista, en 1823, vuelve a las premisas anteriores a 1820. El llamado Plan Calomarde regula numerosos aspectos educativos aunque su aplicación solo se consiguió parcialmente.

Entre 1833 y 1843 se legisla abundantemente en el tema educativo (Esteban, 1994):

- Instrucción para el régimen y gobierno de las Escuelas de Primeras del Reino en 1834:

o Prevé, entre otras cuestiones, el diseño de una Escuela Normal.

- Plan de Instrucción Pública en 1836 llevado adelante por el Duque de Rivas. Según apunta Molero (1994), con este Plan se inicia la configuración de un nuevo modelo educativo. Es el nacimiento y principio del desarrollo de la educación pública y universal en España. Entendiendo por "escuela pública" la "institución docente pública, secular, dirigida y controlada por el Estado" (Molero, 1994, p. 13). La financiación unas veces aportada por ese Estado y otras mantenida por el Municipio o la Provincia, o incluso por alguna Fundación o entidad diferente, pero "siempre bajo la dirección de las autoridades administrativas" (Molero, 1994, p. 13): 
o Divide la enseñanza general entre Elemental y Superior.

- Crea escuelas acorde al censo de población.

- Separa la enseñanza de los niños y las niñas.

o Crea, a nivel nacional, unas escuelas modelo (las futuras Escuelas Normales) (Román y Cano, 2008) ${ }^{16}$. En ellas se formará a los maestros.

En 1838 se revisa el plan y se modifica mediante el Plan Provisional de Instrucción Primaria de 21 de julio de ese año. Lo fundamental es que:

- Exigirá la creación de una Escuela Normal Central para la formación de los maestros. En 1839, Pablo Montesino ${ }^{17}$ pone en marcha y dirige, esta primera Escuela Normal Central de Maestros de Madrid. Esta es, la primera a la que debe acudir cualquier aspirante a maestro. Nace con un carácter profesionalizador: mejorar el nivel educativo y cultural de las clases rurales.

En 1843, aparece el primer Reglamento Orgánico para las Escuelas Normales de Instrucción Pública del Reino, regirá hasta 1849. Con el nacimiento, impulso y desarrollo de las Escuelas Normales comienza una etapa con voluntad por el diseño institucional de la formación de Maestros con importantes innovaciones en el mapa educativo.

Las tasas de analfabetismo, así como el estado general de la enseñanza pública eran asiduamente denunciados por hombres ilustres como Macías Picavea $^{18}$ y el grupo de los llamados regeneracionistas, entre los que encontrábamos a Cossío ${ }^{19}$ o Giner de los Ríos ${ }^{20}$. En opinión de Molero (1994),

\footnotetext{
${ }^{16}$ Conviene aclarar que las Escuelas Normales nacen cuando el propio modelo de maestro todavía está sin definir.

${ }^{17}$ Político de ideas liberales e interés progresista.

${ }^{18}$ Escritor de ideas positivistas y regeneracionistas. En 1882 escribe Apuntes y estudios sobre la instrucción pública en España y sus reformas.

${ }_{19}$ Pedagogo krausista español e historiador del arte. Director del Museo Pedagógico Nacional y presidente de las Misiones Pedagógicas.

${ }_{20}$ Creador y director de la Institución Libre de Enseñanza (ILE).
} 
era muy complicado enderezar una situación problemática y un atraso crónico en el nivel formativo de los españoles.

Poco a poco se va perfilando un nuevo modelo educativo y la función exigible al maestro ya no será solo la de instruir, sino también la de educar, de ahí el carácter moral e incluso religioso que se va incorporando al perfil de estos profesionales (Molero, 1994). La institucionalización formativa del Maestro en centros específicos, creará suspicacias y un marco de relaciones encontradas entre el sector "gremialista" y los titulados en las Normales, que entendían su trabajo como una prueba de modernización y ajuste profesional, en consonancia con lo que estaba ocurriendo en otros países europeos.

A la primera Escuela Normal acudían, entre otros, dos alumnos por provincia. Se les formaba y tenían la misión de, al acabar su instrucción, abrir en sus lugares de origen nuevas Escuelas Normales Provinciales. En esta época estos nuevos centros establecen una competencia con los Institutos ${ }^{21}$, encargados de la formación cultural de las clases más instruidas. De forma paralela, se inicia la creación de la red escolar de España que establece las escuelas de párvulos y de adultos.

Entre 1845 y 1854 se entra en una época convulsa políticamente, van alternándose en el poder partidos progresistas y moderados. Es la llamada Década Moderada. Cada uno de ellos intentaba dejar su impronta atendiendo a su idea de qué entendía por educación, qué se debía de enseñar y de qué forma. Ello no impide que todos coincidieran en la necesidad de la reforma de la formación de los Maestros:

- Se sigue avanzando en establecer las normas básicas que regulan la carrera docente a la vez que trabajando en la reestructuración de la Enseñanza Superior.

\footnotetext{
${ }^{21}$ Provienen de las Facultades Menores creadas históricamente por la Universidad y que en el siglo XIX dieron origen a los Institutos de Segunda Enseñanza.
} 
Políticamente le sucede el Bienio Progresista entre 1854 y 1856 que llevará adelante en 1857, la Ley de Instrucción Pública o Ley Moyano ${ }^{22}$. Sobresale la regulación y unificación de la educación a nivel nacional pues uniformiza y centraliza el control de la enseñanza. Esta ley se mantendría casi inalterable hasta 1898, pero las múltiples reformas parciales supusieron una dispersión de criterios y esfuerzos para poder llevar adelante el Proyecto Educativo del sistema de Educación Nacional. Sin embargo, consigue mantenerse válida hasta mediados del siglo XX, pues no se volverá a dictar otra ley general completa hasta 1945. Destacar que:

- Recoge, por vez primera, la obligatoriedad de la enseñanza y la gratuidad de los puestos escolares.

- La importancia de que esta ley aconsejara la regularización, por primera vez, de la formación de las Maestras aunque, eso sí, estableciendo para ellas edificios independientes (que eran menos numerosos que los de formación de Maestros).

Se instaura definitivamente el funcionamiento de la Escuela Normal Central en Madrid y de las diferentes Escuelas Normales Provinciales. Cada Escuela Normal se dota con una escuela práctica aneja, en la que el alumnado realiza su periodo de Prácticas. Para el ingreso en las mismas se exige más de 17 años y menos de 25 .

Las Escuelas Normales, que formarán a Maestros e Inspectores de Primera Enseñanza, se subdividen en dos categorías (Esteban, 1994):

- La Elemental, de 2 años de formación. Para acceder a estos estudios se requiere tener Estudios Primarios.

- La Superior, de 2 años de formación, más las prácticas. Se requiere ser Maestro Elemental o tener el Bachillerato.

En el periodo de gobiernos liberales, entre 1858 y 1864, y el final del reinado de Isabel II, 1868, se publicaron nuevos reglamentos que afectaban tanto a la

22 Toma el nombre del ministro de Fomento, Claudio Moyano Samaniego. 
Enseñanza Primaria como a la formación de maestros. Señalar, entre todos ellos, la Reforma de las Escuelas Normales, publicada en 1866, que preparara el terreno del Proyecto de Ley de Primera Enseñanza de 1868, llamada Ley Catalina, de ideología ultramoderada y neocatólica (Esteban, 1994). Aquí, lo más destacable, además de la omnipresencia eclesiástica, es la supresión de las Escuelas Normales y el traslado de estos estudios a los Institutos.

Tras el destronamiento de Isabel II en septiembre de 1868, la Junta Superior Revolucionaria restaura la legislación anterior, y como consecuencia, las Escuelas Normales. La Constitución de 1869 proclamará la libertad de enseñanza.

Durante la época de la Restauración, entre 1874 y 1902, se instaura un régimen monárquico en el que se van alternando partidos conservadores y liberales. Ello conllevara frecuentes modificaciones legislativas, atendiendo a la ideología del partido gobernante, que afectarán tanto a la Escuela Primaria como a la organización de los estudios de maestros. En la década de 1880 a 1890 se introducen innovaciones educativas que se intentan poner en práctica en las Escuelas Normalistas femeninas. Se requiere un examen de ingreso y se acepta profesorado mixto. Se mejora además la dotación de los centros con material científico y pedagógico.

En 1877 surge la Institución Libre de Enseñanza ${ }^{23}$, de carácter privado y que tendrá un gran influjo en la vida y política educativa de nuestro país, que perdurará hasta 1936. Según Esteban (1994) sirvió de puente para la introducción de las doctrinas pedagógicas sustentadas por las principales corrientes filosóficas europeas: el positivismo comtiano, el krauso-positivismo así como las doctrinas de Pestalozzi y Froebel. Se siguió trabajando en la modernización y profesionalización de la formación de los Maestros. Se fueron mejorando sus condiciones laborales y económicas. En cuanto al bienestar profesional, a señalar que se instauró la celebración periódica de Congresos Pedagógicos, el primero de ellos en 1882, en los que se debatía sobre

\footnotetext{
${ }^{23}$ Creada por Salmerón, Fernando de Castro, Mesiá, Tapia, Canalejas, Giner de los Ríos.
} 
numerosos aspectos de las enseñanzas y más tarde la Asamblea General de Maestros de España, en 1891. También se celebraron numerosos Congresos Nacionales de Enseñanza.

Luzurriaga (2002) plantea que la problemática histórica de las Escuelas Normales ha sido la disyuntiva entre una "profesionalización" como educadores y maestros y una cultura general. Para él, el maestro debe poseer una base de conocimientos sobre la que se ha de fundamentar el estudio experimental y práctico de los métodos de enseñanza, o sea, la didáctica y la metodología aplicada.

Con el Real Decreto de 1898 se suprimió momentáneamente (se abolió a los dos años) la celebración de oposiciones y quedaba para el ministro de Fomento la decisión del número máximo de títulos que podía expedir cada Escuela Normal. Esta reforma, de 1898, representaba una regresión, sobre todo, respecto a la formación de maestros elementales. En 1900, pasa a dos años el período exigido para ser Maestro Elemental.

Debido a las dificultades económicas no se permitía reestructurar las instalaciones de las Escuelas Normales, entonces por el Real Decreto de 17 de agosto de $1901^{24}$, Romanones integra en los mismos centros a Escuelas Normales y a Institutos Generales y Técnicos de Segunda Enseñanza:

Estas reformas... como la reorganización de las Escuelas Normales de Maestros... con una cultura general como la que representan los tres cursos de estudios elementales y los dos cursos de estudios superiores, el Maestro español llegará a ser lo que han sido y son el Maestro alemán, el suizo, el sueco y el italiano: creadores de individualidades inteligentes y de nacionalidades respetables. Para lograr esto era necesario reorganizar las actuales enseñanzas de las Escuelas superiores de Maestros, conservando su carácter esencialmente pedagógico y de especialización, carácter que quizás no debiera perderse en los estudios elementales si las

24 Publicado en la Gaceta de Madrid el 19 de agosto de 1901. 
exigencias económicas, aparte de otras fundadas consideraciones, no hubieran aconsejado llevarlos a los Institutos.

La unificación supuso una pérdida de autonomía de las Normales y recortes en la formación de maestros, aunque se consiguió, en conjunto, una formación más uniforme. Se pretende, según el ministro, elevar el nivel intelectual, moral y social de los Maestros. La situación queda de la siguiente forma:

- Maestro Elemental:

- Pasaba de dos años a durar tres.

o Se solicita tener más de 16 años para el acceso.

o Había que realizar una prueba de ingreso.

o Superar el proceso docente.

o Realizar una reválida final.

- Maestros Superiores formados por este Plan:

o Era necesario cursar cinco cursos para obtener el título.

o Podían desempeñar Cátedras en Normales e Inspecciones de Primera Enseñanza (Esteban 1994).

Tras numerosas protestas en diferentes frentes, Congresos Pedagógicos de 1882 y 1888 así como en un Congreso de 1892, por parte del colectivo de profesores normalistas y de intelectuales de la época, los estudios volvieron a las Escuelas Normales en 1903, donde permanecerían en las mismas condiciones hasta 1914. En las capitales donde no existen Normales los estudios seguirán en los Institutos hasta la reforma de 1914. Este cambio supone una nueva reestructuración de los estudios ya que reduce su duración:

- Elementales, de nuevo, dos años. Se rebaja la edad de ingreso a los 16 años tras la superación de un examen.

- Superiores, dos años.

Se observa de todas formas que durante todos estos años los profesores de las Normales estaban muy poco especializados. Así los profesores de ciencias impartían enseñanzas de matemáticas y científicas en general y los de letras, 
materias como castellano, pedagogía, historia o dibujo. Con esta reforma sí que se refuerzan los estudios de carácter pedagógico.

2.1.3. Primer tercio del siglo XX. La Escuela Nueva y la estabilización de la formación del Magisterio.

Un paso decisivo en la educación española fue la introducción de las ideas de la Escuela Nueva (Román y Cano, 2008) ${ }^{25}$. Bajo este nombre se recoge la tendencia de la escuela europea de la primera mitad del siglo XX. Se rige por los principios pedagógicos del profesor Ferrière, fundador y director de la Oficina Internacional de Escuelas Nuevas (Oficina Internacional de Educación de Ginebra) y propagados por la Liga Internacional de Educación Nueva (Esteban, 1994). Las características principales son:

- La Escuela es un laboratorio de pedagogía práctica.

- Intenta demostrar en la práctica la eficacia de los métodos nuevos.

- Se basa en la psicología del niño y sus necesidades.

- Intenta llevar a cabo una educación que prepare para la vida real.

- Practica la coeducación.

- Los trabajos propuestos ponen al niño en contacto con su realidad cercana.

- Se trabaja la individualidad y los gustos personales.

- Los estudios no sobrecargan al estudiante y se intenta globalizar enseñanzas.

- Se promueve la creatividad y se evita la competitividad.

- Se valoran las enseñanzas artísticas como formadoras del individuo.

\footnotetext{
${ }^{25}$ Maestros e intelectuales de distintas orientaciones (liberales, izquierdistas, católicos -Ovide Decroly, María Montessori, Célestin Freinet, las Hermanas Agazzi, Andrés Manjón o Giner de los Ríos-) se plantearon la necesidad de reconsiderar los planteamientos educativos imperantes hasta ese momento, y se proponen revisar los principios que sustentan el acto educativo y las instituciones creadas para ello. Para ello buscaron una nueva educación que fuera activa, que preparara para la vida real y que partiera de los intereses reales que tenía el niño.
} 
En España, la evolución de la educación sigue muy mediatizada por la política. En numerosas ocasiones, además, las teorías que se manejan a nivel teórico no coinciden con la aplicación práctica en la escuela (sobre todo en la pública). Las propuestas de los sectores liberales y las de las conservadoras mantienen su dualidad. En la aplicación de las premisas de la Escuela Nueva coinciden en cierto modo ideas de la Institución Libre de Enseñanza ${ }^{26}$ con la escuela manjoniana, más conservadora.

En 1905, se producirá un intento de reformar los estudios de Maestro, pero no llegará a aplicarse. Se aprecia, una voluntad por unificar el título y los estudios, diferentes para maestros y maestras, así como a establecer en cuatro años la duración de éstos.

En $1909^{27}$ se crea definitivamente la que se llamará Escuela Superior del Magisterio ${ }^{28}$ que formará a Profesores de las Escuelas Normales y también a Inspectores. Atendiendo a las palabras de Cuenca (1989, p. 141):

Los antecedentes de esta Institución se encuentran en el artículo 70 de la Ley de 1857, en el que quedo dispuesto que "para ser Profesor de la Escuela Normal, además de estar en posesión de los grados Elemental y Superior del Magisterio, debería estudiarse otras disciplinas, un curso completo de Pedagogía y ampliación también, a las enseñanzas de ciegos y sordomudos junto a enseñanzas de Derecho Administrativo.

Con ello, se inicia una etapa en la que la colaboración laboral entre estos dos cuerpos fue fundamental para el progreso de la Escuela Pública. El inspector adopta el papel de órgano técnico, al servicio de la escuela, y guía del maestro, como orientador y asesor pedagógico, acompañándole en su perfeccionamiento durante el ejercicio de su profesión.

Todas estas novedades ayudaron a mejorar de forma notable la preparación que recibía el profesorado hasta ese momento. Se fueron afianzando nuevas

\footnotetext{
26 Las ideas de Giner de los Ríos y Bartolomé Cossío son fundamentales en este periodo.

27 Real Decreto del 3 de junio de 1909.

28 Se inspira en las innovaciones introducidas en Europa y América en materia de formación de los Profesores de las Escuelas Normales.
} 
bases pedagógicas que acabarían calando en los Maestros formados en esta época. Estas nuevas formas de entender la educación fueron el germen de las ideas que impulsaron las reformas que sentarían los principios que, según Román y Cano (2008, se mantuvieron vigentes hasta el final de la II República Española:

- La educación tiene al niño como centro del proceso educativo.

- Nuevas formas de entender la necesidad de la Didáctica.

- Contenidos teóricos académicos con apoyo práctico, relacionados con la realidad sociocultural.

Los requisitos para ser Profesor Normal siguieron perfilándose con ayuda de disposiciones posteriores para, según expresa la propia ley (Cuenca 1989, p. 143), "puedan los profesores formar maestros cultos y de vocación comprobada" y "no solo se den los medios de adquirir los modernos conocimientos científicos, poco atendidos hasta ahora en las Escuelas Normales, sino que se transforman y especializan los estudios pedagógicos".

En 1911, pasa a denominarse Escuela de Estudios Superiores del Magisterio, en 1930 vuelve a la denominación inicial de Escuela Superior del Magisterio.

En 1914, Bergamín ${ }^{29}$ promulga una profunda reforma ${ }^{30}$ que supone un cierto retroceso en la historia de la formación de los maestros:

- Reorganiza los estudios, se estructuran ahora en cuatro cursos.

- Elimina el grado Elemental y establece el titulo único de Maestro de Primera Enseñanza. Se tratará de superar una situación anacrónica, como era la de la existencia de dos tipos de maestros, de dos tipos de escuelas.

- Necesidad de realizar un examen de ingreso (las mujeres hacen además una prueba de Labores).

\footnotetext{
${ }^{29}$ Miembro del Partido Liberal-Conservador. Ministro de Instrucción Pública y Bellas Artes, de Gobernación, de Hacienda y de Estado durante el reinado de Alfonso XIII.

${ }^{30}$ Real Decreto de 30 de agosto de 1914.
} 
- Se vuelve a permitir el acceso con un nivel de instrucción muy elemental, la formación inicial requerida es la cultura básica primaria. Por lo tanto estos estudios funcionan apenas como un complemento de la instrucción recibida en la enseñanza primaria, dando lugar a unos maestros con una formación muy básica (González, 1994). Tiene una dimensión educadora, fundamentalmente.

- Predominaban los aspectos culturales sobre los profesionales pues al exigirse únicamente para el ingreso en las Escuelas Normales, la instrucción primaria, el bajo nivel de esta hacía preciso cursar materias de este tipo para luego poder enseñarlas.

- El titulo se obtiene al final de los estudios superando una reválida seguida de oposiciones para poder ejercer.

- Se realizan prácticas en las Escuelas Anejas en los dos últimos cursos.

Sin embargo, aspectos a destacar de la misma son:

- El énfasis que se ponía en el fomento de la vocación y aptitud pedagógicas, para "saber enseñar" y además "saber educar".

- Se proponía que las materias tuviesen siempre un carácter educativo que despertara la iniciativa del alumno y desarrollara su espíritu de observación.

- Se introdujeron innovaciones como la limitación de alumnado por clase y la recomendación de actividades extracurriculares.

En cuanto a las Normales de Maestras se concebían como instituciones para proporcionar a las mujeres, que quisieran adquirirla, una cultura superior a la impartida en la escuela primaria.

En 1917 se aprobó un primer Estatuto del Magisterio que intentaba recoger las disposiciones que afectaban a la actividad profesional de este cuerpo docente. Los aspectos más novedosos del plan se quedaron sin cumplir. Las nuevas disposiciones que se proponían supusieron un nuevo motivo de conflicto con la profesión pues era manifiesta la subestimación oficial de los estudios (González, 1994). "Una de las preocupaciones del colectivo de enseñantes 
eran los aspectos sociales y profesionales que habían dado lugar a un movimiento cuya aspiración común era la elevación del status social y profesional del maestro" (González, 1994 p. 111). Si atendemos a las palabras de Molero (1994, p. 181):

La difícil situación económica de los maestros, su retraso cultural, el hecho de que muchos de ellos sólo tuviesen un certificado de aptitud, su aislamiento en las zonas rurales y su falta de ambiciones profesionales eran factores que frenaban el despertar de cualquier ansia de superación y preparación.

El golpe de Estado dado por el general Primo de Rivera en 1923, no sirvió tampoco para beneficiar a los estudios de Magisterio. Se completaría y mejoraría el Estatuto anterior con otro en $1923^{31}$ en que se abordaban temas profesionales de los maestros y además aspectos que afectaban a la Escuela Primaria.

El Plan del 14 se mantendrá vigente hasta 1931. En este periodo se asumió plenamente la función formadora de las Escuelas Normales y se reconoció a estos centros como necesarios en la estructura de la enseñanza. Gracias al trabajo y esfuerzo desarrollado por el profesorado en ejercicio se consiguió mejorar ostensiblemente la calidad de la profesión tan desprestigiada hasta ese momento. Se empezó a trabajar a partir de entonces con otras ideas, apoyado por los intelectuales de pensamiento institucionista de la generación del $14^{32}$. No sin resistencias, se consiguió imponer un nuevo estilo en las instituciones normalistas y transmitir a sus alumnos las innovaciones didácticas de la Nueva Educación así como modernas técnicas apoyadas en un diagnóstico pedagógico (Molero, 1994). La consideración profesional que se tiene del maestro hasta ese momento va progresando y se introducen mejoras significativas:

${ }^{31}$ Real Decreto de 18 de mayo de 1923, aprobando el Estatuto General del Magisterio.

32 José Ortega y Gasset, Eugenio d'Ors, Manuel Azaña, Gregorio Marañón, Salvador de Madariaga, Claudio Sánchez Albornoz, Américo Castro, Manuel García Morente, Ramón de Basterra, y Pablo de Azcárate; los novelistas Gabriel Miró, Ramón Pérez de Ayala, Wenceslao Fernández Flórez; el dramaturgo Jacinto Grau; los poetas Juan Ramón Jiménez y Josep Carner; o el polifacético Ramón Gómez de la Serna. 
- Actividades de perfeccionamiento.

- Encuentros y publicaciones encaminadas a mejorar la preparación profesional e intercambiar experiencias y modelos de trabajos (como ocurría con el Boletín Escolar).

En estos años se oyen las primeras voces políticas que abogan porque el personal docente de todas las instituciones educativas se forme en la Universidad. Al aplicar este Plan (González, 1994, p. 111):

- Desaparece la diferenciación entre Elementales y Superiores

- Se concede un único Título de Maestro ${ }^{33}$.

- Se equiparan las Normales de Maestros y Maestras.

- Los estudios se estructuran ahora en cuatro cursos a los que se accede con una cultura básica primaria.

- Por primera vez se intenta introducir algunos profesores especialistas para impartir asignaturas específicas.

2.1.4. La II República y la universalidad de la enseñanza.

Ya en 1931, Marcelino Domingo, Ministro de Instrucción Pública, y Rodolfo Llopis, Director General de Enseñanza Primaria, diseñaron el Plan Profesional de $1931^{34}$, Decreto reorganizador de las Escuelas Normales, de gran trascendencia para los estudios de Maestros de Enseñanza Primaria y de las Escuelas Normales. El maestro es el eje fundamental de la reforma considerada necesaria de la Enseñanza Primaria en España. La consideración de la formación del Magisterio gana en consideración con el establecimiento del Plan Profesional que diferenciará tres niveles en la formación. La enseñanza primaria era prioritaria pero más prioritario era colocar al maestro en su papel social. Supone un acierto pleno ya que perfila claramente los ámbitos de la formación, muy por delante de la que en ese momento se impartía en otros países del entorno (Lorenzo, 1995):

\footnotetext{
${ }^{33}$ Real Decreto de 30 de agosto de 1914. Artículo 21.

${ }^{34}$ Decreto de 29 de septiembre de 1931.
} 
- Cultura general (Responsabilidad de Institutos de Segunda Enseñanza)

- Formación Profesional (Responsabilidad de las Escuelas Normales)

- Práctica docente (Responsabilidad de Institutos de las Escuelas Primarias Nacionales)

Según Román y Cano (2008) consiguen con él que los Maestros instruidos con este Plan sean los mejor formados académicamente de Europa y América. Francia e Italia no ofertaron esta formación hasta la década de los 50.

Se consideran unos estudios muy completos y por fin proporcionan al maestro una excelente formación profesional y un buen nivel pedagógico. La educación se convierte en una tarea científica y pretende transformar sus hábitos y modernizar sus técnicas pedagógicas y metodológicas.

Al exigir el requisito del título de Bachiller para el ingreso, pasaron a integrarse en la enseñanza superior. Por primera vez los estudios de Magisterio adquieren rango universitario (Lorenzo, 1995). Se vinculan a la Universidad por medio de la recién creada Sección de Pedagogía ${ }^{35}$, en la Facultad de Filosofía y Letras de la Universidad de Madrid, que vino a sustituir a la Escuela de Estudios Superiores del Magisterio ${ }^{36}$. Los aspectos más significativos son:

- Acceso con más de 16 años.

- Posesión del título de Bachiller o bien tener título de Maestro por el plan 1914 o bien haber realizado el Plan Cultural más las asignaturas de Pedagogía, $\mathrm{H}^{\mathrm{a}}$ de la Pedagogía, Legislación escolar y Prácticas de enseñanza.

- Superación de una prueba de ingreso dado que el número de plazas era limitado (art. $\left.4^{\circ}\right)$.

\footnotetext{
${ }^{35}$ Que preparara a los profesores de las Normales, Institutos, Inspectores de enseñanza y Directores de escuelas graduadas.

36 Decreto de 27 de enero de 1932.
} 
- Las prácticas se realizan cada curso a lo largo de dos meses.

- Al finalizar era necesario superar una reválida que determinaba el orden para acceder al periodo de un año de prácticas docentes tuteladas y remuneradas.

- Aquellos que, teniendo un buen expediente académico, superaban con éxito las prácticas eran propuestos con "acceso directo" al mundo laboral.

Entre los años 1900 y 1930 la profesión de maestro ha experimentado un cambio cualitativo importante (Molero, 1994):

- Se amplía su formación.

- Se consiguen mejoras económicas.

- Se logra elevar el status profesional y social.

- Se unifican las escuelas femeninas y masculinas.

- Se popularizan los cursos de perfeccionamiento así como las reuniones de intercambio de opiniones o conversas.

- Se visitan colegios modélicos y se asiste a lecciones de carácter metodológico ${ }^{37}$.

Entre los años 1931 y 1936, se alcanzó en el conjunto de España un buen nivel educativo con mejoras que aventajaban y que todavía no estaban incorporadas en otros países europeos o americanos. En palabras de Román $\left(2006\right.$, p. 96) ${ }^{38}$ : "Parece que, por fin, ha llegado el momento de pagar la "deuda histórica" que tenemos con el Magisterio. Deuda pendiente 1939. Si todo sale bien vamos a empezar a pagarla unos setenta años después".

37 Nos referiremos especialmente a la apertura de cauces de comunicación entre los maestros.

${ }^{38}$ Catedrático de Psicología Evolutiva de la Educación Departamento de Psicología. Universidad de Valladolid. Discurso de 2006 sobre la elaboración de los actuales Planes de Estudio. Es miembro de la Comisión de Expertos que ha elaborado el Proyecto de nuevos Grados de Magisterio, y de la Comisión de Coordinación de la Red de Magisterio/Red de Educación a la que la ANECA ha encomendado la elaboración del Mapa integrado de titulaciones de Educación (magisterio, pedagogía, educación social, psicopedagogía). 
Con la llegada de la II República el acceso a la educación se generaliza y adquiere una importancia de primer orden. Se considera el mejor medio para evitar las diferencias culturales entre los ciudadanos:

- Para los republicanos es evidente la falta de escuelas, textos, profesores, maestros, bibliotecas, etc. y dedican numerosos esfuerzos a cambiar esta situación. "La legislación republicana reguló la preparación de los maestros porque contribuiría al desarrollo de una España culta y próspera" (González, 1994, p. 113). Todo ello redundó en una Escuela Primaria de calidad. Se consiguió, entre otras cosas, dotar de profesorado a todos los pueblos de España, además de la creación de numerosas bibliotecas públicas. Esta labor fue desarrollada por las Misiones Pedagógicas bajo la influencia de la Institución Libre de Enseñanza.

- Mejora de las Escuelas Normales, uno de los primeros asuntos a considerar:

o Por primera vez se aplica una mejora a la deficiente formación de los maestros, sus escasas retribuciones y consideración social.

o Tienen una notable preocupación por la actualización de la formación de los Maestros y la función educadora de las Escuelas Normales.

- Cada Escuela Normal debía estar dotada con una biblioteca, laboratorios y un museo pedagógico ${ }^{39}$.

- Se encargaban de complementar la formación de los egresados mediante numerosas actividades tanto culturales como profesionales.

- Se estableció una política de becas que beneficiaba a los alumnos con menos recursos, así como residencias.

${ }^{39}$ Lo que hoy llamaríamos un centro de perfeccionamiento 
En numerosas publicaciones de la época queda patente, por primera vez, que sectores sociales muy diferentes (políticos, personas de la cultura y de la educación) reconocían el cambio sustancial, ambicionado desde hacía tiempo, que suponía esta última reforma:

- Modernizaba estructuras,

- Creaba numerosas escuelas,

- Mejoraba la preparación del profesorado y su situación económica y social.

A nivel europeo, 42 países de Europa, América y Asia, entre ellos España, discutían en Ginebra sobre los problemas de la formación profesional del Magisterio primario en el mundo. La IV Conferencia Internacional organizada por la Oficina Internacional de Educación de Suiza, presidida por el académico don Julio Casares, delegado del Gobierno español, celebró sus reuniones en la capital suiza en julio de 1935 . En sus recomendaciones expresan ${ }^{40}$ :

- La dificultad y complejidad del papel del maestro primario. La personalidad del maestro constituye un factor decisivo para la obra educativa. En casi todos los países es una de las preocupaciones primordiales de las autoridades escolares.

- Existe una corriente de opinión favorable a la preparación del Magisterio primario después de cursada la segunda enseñanza.

- Para la edad de ingreso en los centros de formación pedagógica se tenga en cuenta que el joven maestro haya alcanzado la suficiente madurez y valore la importancia de su misión.

- Que los estudios sean gratuitos o becados.

- La Conferencia estima que la preparación profesional y verdaderamente pedagógica debe constituir el complemento de una buena cultura general. Por lo tanto la duración de los estudios debe ser lo suficientemente larga.

\footnotetext{
${ }^{40}$ Para ampliar información, consúltese:

http://hemeroteca.lavanguardia.com/preview/1935/10/11/pagina-9/33144149/pdf.html
} 
2.1.5. La guerra civil y la dictadura franquista.

Durante la Guerra Civil (1936-1939) la política pedagógica y la formación del maestro tendrán continuidad aunque con los impedimentos propios de la situación bélica. El bando republicano mantiene la línea marcada por el Plan anteriormente expuesto y una ideología socialista. El bando nacional inicia diferentes actividades y cursos que formarán a los maestros en la línea del nacional catolicismo.

La guerra civil española supuso el final de los avances educativos y culturales, reconocidos y valorados en Europa como pioneros en muchos aspectos, e hizo retroceder el nivel cultural a las premisas instauradas muchos años antes. A partir de 1939:

- Se promulga una depuración de Maestros que aparta de las escuelas a todos aquellos que estaban en ejercicio y no se adaptaron a las nuevas consignas políticas del Movimiento Nacional.

- Se consideró que la formación que estaban impartiendo resultaba nociva y se emprendieron acciones encaminadas a anular el espíritu de esta reforma educativa. Fueron depuradas las personas más comprometidas y activas de la profesión mientras eran sustituidas por personas cuya preparación era manifiestamente deficiente.

- Se produjo una persecución, que castigaba por las ideas que se transmitían y no por la profesionalidad.

- Se utilizó la figura del maestro como señal de la destrucción de la cultura, se completó con la acción de la quema sistemática de los libros de las bibliotecas escolares.

- La defensa del modelo de escuela será la pelea fundamental, ya que representa la pieza clave en el asentamiento del orden político imperante.

- Las decisiones educativas, durante los numerosos años de la postguerra, funcionaran como reacción a la realidad republicana a la que había que combatir y destruir: "La escuela, el maestro, los contenidos escolares y toda la parafernalia escolar que va surgiendo día 
a día, sólo tiene un significado en estos iniciales del período bélico: la liquidación de la estructura educativa republicana" (Molero, 1994 p. 462).

Durante la época franquista, la profesión del Magisterio fue utilizada además como contenedor de afines al Régimen. Los aspirantes provenían de los más diversos sectores sociales y sin ningún tipo de competencia profesional, ni de preparación para ejercer este cometido. Las nuevas plantillas de profesorado primario comienzan a nutrirse con personal que ha pasado por los llamados "exámenes patrióticos", plazas de Maestros repartidas entre los antiguos combatientes que por una u otra causa, al dejar las armas, necesitaban un empleo (Molero, 1994, p. 463).

Se pone en funcionamiento el llamado Plan Bachiller ${ }^{41}$, en 1940, denominado así pues permite el acceso a los estudios a personas que únicamente tienen la titulación de Bachiller Elemental. Consiguen el título de Maestro realizando un curso intensivo con contenidos de Pedagogía, unas prácticas y realizando un examen libre. Acceden así a la profesión.

Cambian así, drásticamente, las premisas que hasta ese momento regían la profesión:

- Se admite el ingreso en las Escuelas de Magisterio a los 14 años.

- Se restablece la separación de hombres y mujeres.

- Se potencia la presencia de la Doctrina Cristiana.

Todo ello conllevará el desprestigio de una profesión considerada fundamental socialmente pero que con estas condiciones, pasa a convertirse poco menos que de segundo orden:

- Lo importante es el adoctrinamiento político más que las labores propiamente docentes.

\footnotetext{
${ }^{41}$ Decreto de 10 de febrero de 1940.
} 
- El aspecto religioso pasa a ser fundamental, no solo en cuanto a contenidos, sino como una práctica diaria.

- La escuela también se impregna, en su primera etapa, de la ideología falangista en cuestiones sociales y disciplinarias.

- La formación de las maestras está bajo el control de la Sección Femenina.

El Plan Provisional de 1942 establece las condiciones siguientes:

- Bachiller Elemental, con una edad mínima de 12 años.

- Realización de un examen de ingreso, ya fuera en enseñanza libre u oficial.

- Estudios de 3 años de formación Cultural más 1 de Profesional.

- Reválida final.

Hacia 1945 se da por terminada la depuración. Junto a la Ley de Educación Primaria se pone en marcha el Plan de $1945^{42}$, que se mantendrá vigente más de 20 años. En el prólogo de la ley, aparecen los párrafos siguientes:

La nueva Ley invoca, entre sus principios inspiradores, como el primero y más fundamental, el religioso... Se reconoce a la Iglesia el derecho a la creación de Escuelas primarias y de Escuelas de Magisterio con la facultad de expedir títulos académicos con validez en los centros por ella creados.

Según Molero (1994, p. 468), "La figura del maestro es apenas considerada como un agente mediador en los procesos ideologizantes que quieren introducir en las mentalidades de las nuevas generaciones, pero no se le ve como un profesional necesitado de una cobertura científica distinta".

En los nuevos estudios, que pasan a llamarse de Magisterio, se crearon también unos sistemas de convalidación que los hacen accesibles a cualquier titulado con unos mínimos requisitos académicos:

\footnotetext{
${ }^{42}$ Aparece junto con el Plan de Formación, el 17 de julio de 1945
} 
- El ingreso se hará con 14 años mediante un examen.

- Se requerirán los 4 cursos de bachiller elemental y tres de carrera que acabarán con una prueba final.

Ello devaluó el ya escaso prestigio institucional del maestro y su apreciación social.

Con condiciones semejantes al anterior, se presenta un nuevo Plan de Estudios en 1950, que establece:

- "La obligatoriedad de asistir a un Campamento o albergue, durante el verano, dirigido por el Frente de Juventudes, para maestros, y la Sección Femenina (para maestras)" (Román y Cano, 2008, p. 88). Sin este requisito es imposible ejercer al finalizar los estudios.

- El acceso a la profesión se sigue haciendo por oposición.

$\mathrm{Y}$, de la misma forma se requería, "atendiendo a la posibilidad de que existiera una malformación física que impidiera el desarrollo de la profesión" (Molero, 1994, p. 468).

En el certificado médico y de conformidad con lo dispuesto en el artículo 37 de la citada Ley $^{43}$, se expresará en forma determinada si el interesado realiza debidamente gimnasia, deportes y juegos, y en el del Claustro, además de estos extremos, se hará constar si ejecuta trabajos manuales, prácticas de taller, escritura, dibujo etc., y las alumnas, labores, y que el defecto que padece no se preste al ridículo.

El Plan permaneció vigente hasta el nuevo de 1967 y denotaba una fuerte orientación política nacional-católica. Destacar también que se mantenían las diferencias sexistas pues el alumnado tenia asignaturas diferentes, dependiendo de si eran hombres o mujeres.

${ }^{43}$ Decreto de 7 de julio de 1950 por el que se aprobó el Reglamento de las Escuelas del Magisterio. 
2.1.6. La época de apertura y la transición democrática.

Con el paso del tiempo el gobierno del país es consciente de que necesita cierta modernización y que demanda una mejor preparación académica. Se va renovando y transformando en consonancia con las necesidades socio culturales de la época histórica. Se intenta responder a las nuevas exigencias de los tiempos con una formación que integra las tendencias culturizadoras y profesionalizadoras. Las Escuelas de Magisterio vuelven a denominarse Escuelas Normales del Magisterio.

El Plan de estudios de $1967^{44}$, intenta recoger todas las modificaciones que han ido aplicándose a la Ley de Educación Primaria de 1945 estableciendo un nuevo panorama para la formación de los maestros:

- Genera, aunque no se desarrolla de forma paralela, la mejor capacitación de los maestros y las reformas de la escuela primaria que se traducen en la Reforma de la Educación Primaria ${ }^{45}$.

- El titulo que se obtiene es el de Maestro Generalista de Enseñanza Primaria que sirve para maestros y maestras pues las Normales masculinas y femeninas fueron unificadas unos años antes.

- Se tomará como referencia el Plan Profesional de 1931 estableciéndose algunas de las características siguientes:

- Eleva en dos años la edad mínima para acceder a los estudios de Magisterio. Establece la necesidad de poseer el Bachiller Superior, con lo cual se elimina el examen de acceso.

- Los estudios duran 2 años más un 1 año de prácticas (gratificadas) en los Colegios Nacionales, si se supera la reválida final.

- Se establece el acceso directo, sin paso por oposición, al Cuerpo del Magisterio Nacional para los mejores expedientes (30\% de las vacantes). Para el resto se mantiene la oposición.

\footnotetext{
${ }^{44}$ Ley de 21 de diciembre de 1965. Plan de estudios O.M. de 1 de junio de 1967.

${ }^{45}$ Decreto 193/1967, de 3 de febrero, se aprueba el texto refundido de la Ley de Enseñanza Primaria. BOE 13/2/1967.
} 
- Aunque no se recupera la consideración de estudios universitarios sí se requiere una mejor formación inicial.

- Mejoran los aspectos de formación didáctica pero, a pesar de todo, se seguirá manteniendo "los cursos de capacitación en las "actividades de tiempo libre" que habrán de realizar los alumnos para la obtención del título de maestro".

Queremos destacar la poca atención prestada al profesorado que imparte enseñanzas en las Normales:

En una gran mayoría era un profesorado envejecido que procedía de la antigua Escuela de Estudios Superiores del Magisterio ya que no había habido convocatorias para acceder a él. Su número permaneció invariable en el período 1960-1975, con 1.138 profesores para todo el país (Molero, 1994, p. 509).

En un ambiente de cambio político se suceden diferentes ministros en cuestiones educativas. A ello se añaden las nuevas posturas reivindicativas de alumnado y profesorado. Todo ello ira provocando cambios sucesivos en la educación del país.

Se promulga la Ley General de Educación de $1970^{46}$, llamada Ley Villar Palasí, que estará vigente durante más de una década. Es una de las leyes de mayor calado educativo por representar una reforma en profundidad del sistema en su conjunto desde la Ley Moyano. La Educación Primaria pasa a denominarse Educación General Básica (EGB). La publicación del Libro Blanco (La educación en España. Bases para una política educativa) por el propio ministerio en 1969 suscita un amplio debate social.

Esta ley da lugar a un nuevo Plan de Estudios en $1971^{47}$ y las Escuelas Normales se integran en la Universidad como Escuelas Universitarias de Formación del Profesorado en 1972. Este paso a la universidad se realizó con

\footnotetext{
46 Ley 14/1970, de 4 de agosto, General de Educación y Financiamiento de la Reforma Educativa (BOE de 6 de agosto de 1970).

${ }^{47}$ Orden de 13 de Junio de 1971 (BOE de 25 de Junio).
} 
pocos medios tanto materiales como docentes y todo ello dificultó la preparación del magisterio en buenas condiciones.

Se vuelve a conceder rango universitario a los estudios de Magisterio, de Diplomado Universitario:

- Para acceder se requiere el COU, suprimiendo el examen de ingreso.

- Los estudios duran 3 años. Cada uno de ellos se divide en dos cuatrimestres, cada cuatrimestre corresponde a un curso.

- Habrá que realizar dos cuatrimestres de prácticas en colegios nacionales.

- Los dos primeros cursos son comunes y el resto de especialización: Ciencias, Ciencias Humanas, Filología, Educación Especial y Preescolar (especialidades que establece la EGB).

- Los maestros obtendrán un titulo único y pasaran a denominarse Profesores de Educación General Básica.

Los profesores que ejerzan en dichas Escuelas han de ser Licenciados (Román y Cano, 2008). En algún caso podríamos plantearnos, a pesar de todos los avances experimentados en los estudios, la razón por la que los maestros deben seguir formándose en 3 años únicamente, si comparamos esta formación con los de otros estudios que alcanzan el rango de licenciatura. Por un lado parece que subsiste una menor consideración social y por otro, la formación que reciben puede considerarse que no cumple con lo considerado una enseñanza de calidad.

El paso a la universidad, perdido en 1936, no estuvo exento de tensiones pero proporcionó nuevas opciones a los maestros. Los estudios se integran de forma definitiva en la Universidad en 1983, tras la Ley de Reforma Universitaria, proceso que se completara con la Ley Orgánica de Ordenación General del Sistema Educativo en 1990 (LOGSE) ${ }^{48}$.

\footnotetext{
${ }^{48}$ Ley Orgánica de Ordenación General del Sistema Educativo 1/1990, de 3 de octubre (BOE 4 octubre de 1990).
} 


\subsubsection{La LOGSE y el nuevo concepto del Magisterio.}

Con la implantación del Plan de Estudios ${ }^{49}$ de 1990 nos encontramos ante un cambio muy importante. Si nos atenemos a lo que se expresa en la ley, el maestro adquiere un nuevo papel:

- Actuará de elemento mediador curricular entre las prescripciones normativas y su entorno escolar específico, aceptando los retos sociales que se le presenten sin prejuicios.

- Tendrá que saber adaptarse a trabajar en equipo, a relacionarse con los otros, atendiendo a las nuevas formas de trabajo cooperativo en los colegios, y ser flexible en la aplicación diaria de su docencia.

- Investigará sobre su práctica educativa en beneficio de su labor docente, como fuente de renovación.

- Como agente social, integrará en el aula el entorno diverso propio de una sociedad diferente trabajando las relaciones colaboradoras, de negociación e incluso, de mediación y de resolución de conflictos.

Las Escuelas Universitarias de Formación del Profesorado funcionaran bajo las premisas siguientes:

- Acceso tras la superación del Bachillerato Superior, de 2 años, más el curso de Orientación Universitaria, aunque sin necesidad de pasar por Selectividad.

- Estudios con una duración de 3 años.

- Se obtiene el Título de Diplomado en: Educación Infantil, Educación Primaria, Audición y Lenguaje, Educación Especial, Educación Musical, Educación Física y Lenguas Extranjeras.

- Cada Universidad determina autónomamente el 50\% del curriculum.

- Para el acceso a la profesión, en las etapas de Infantil y Primaria, se exige el nuevo título de Maestro, a diferencia de la situación

${ }^{49}$ BOE. 21-10-92. 
anterior en la que se podía acceder con cualquier título universitario de grado medio o superior. Se pretende garantizar una autentica formación pedagógica a los nuevos profesores.

\subsubsection{El Espacio Europeo de Educación Superior}

\subsubsection{El Plan Bolonia}

El llamado Plan Bolonia se inscribe dentro del concepto de ámbito general que se ha llamado Espacio Europeo de Educación Superior (EEES), recogido en la Declaración de La Sorbona (1998) ${ }^{50}$ en la que los ministros representantes de Francia, Alemania, Italia y Reino Unido acordaron extender el concepto de Unión a una Europa del Conocimiento. En ésta se señala que "La extensión y calidad de la Educación Superior son factores decisivos en el incremento de la calidad de vida de los ciudadanos" y se pretende "acabar con las fronteras y desarrollar un marco de enseñanza y aprendizaje", que permita movilidad y cooperación entre las instituciones universitarias. La clave para este intercambio vendrá definida por el Sistema de Europeo de Transferencia de Créditos (ECTS) ${ }^{51}$ que permitirá el reconocimiento de los estudios realizados en las diferentes Universidades europeas que lo componen.

En 1999, firman la Declaración de Bolonia 31 países europeos y se ratifican los acuerdos de la Declaración de La Sorbona además de establecer los objetivos para la creación y desarrollo armónico del Espacio Europeo de Educación Superior $^{52}$ antes de 2010. El proceso de integración en el EEES, es el marco de referencia actual básico para toda la universidad en el ámbito de la Unión Europea, y tiene como origen un importante cambio en la cultura universitaria que la lleva a impulsar el aprendizaje activo y comprometido del estudiante, a organizar la educación alrededor de las competencias que el estudiante debe alcanzar y, como fondo, a propiciar el desarrollo del pensamiento crítico que

\footnotetext{
${ }^{50}$ Para consultarla: http://wwwn.mec.es/univ/html/informes/EEES 2003/Declaracion Sorbona.pdf ${ }^{51}$ Cada crédito ECTS (European Credit Transfer System) corresponde a 25 horas de trabajo del alumnado.

${ }^{52}$ Se puede consultar la documentación en http://www.eees.es/es/documentacion
} 
es, frente a otras enseñanzas superiores enfocadas a la profesionalización, el gran valor añadido y el auténtico sello de identidad de la enseñanza universitaria. Además, destacar sobre todo la promoción de la movilidad entre personal de los diferentes países europeos con pretensión de cooperación y confianza mutua en la aceptación de los sistemas nacionales y la garantía de calidad. Así como la valoración del aprendizaje a lo largo de la vida como pieza clave en el EEES, dado que la futura Europa, se basa en la sociedad y economía del conocimiento. Se requiere para poder afrontar los retos de la competitividad y el uso de las TIC. EI EEES pretende unificar el estándar de calidad de todas las universidades de Europa.

En cuanto al concepto de créditos, los ECTS difieren de lo que se entendía en la Universidad española como tal según estaban definidos en la Ley de Reforma Universitaria. Esta última contabilizaba el crédito sobre las horas lectivas de clase, bien fueran teóricas o prácticas, el ECTS sin embargo basa el cálculo en el trabajo que debe realizar el estudiante para alcanzar los objetivos del aprendizaje en términos de conocimientos y de competencias.

La siguiente reforma, ya inmersos de lleno en el EEES, contemplará las nuevas titulaciones de Grado y posibles Másteres que podrían dar lugar a estudios de Doctorado. En esta década se creó un amplio número de nuevos títulos y se "renovaron" la totalidad de los planes de estudio de las titulaciones universitarias (Infante, 2010).

\subsubsection{La aplicación del Plan Bolonia en los estudios de Magisterio.}

En cuanto a su denominación los centros que imparten las enseñanzas de Magisterio, siguieron una evolución, llamándose inicialmente Escuelas Normales, para pasar con la Reforma de 1970 a Escuelas Universitarias de Formación del Profesorado de Enseñanza General Básica y transformándose más tarde, o siendo absorbidas, por Facultades de Educación. Por lo tanto ha continuado habiendo centros con diferentes denominaciones y con diferentes 
situaciones administrativas. Ello contribuye, a la confusión que se produce en ciertos lugares en la consideración de la titulación ${ }^{53}$.

Desde finales de los años 80, diversos agentes se movilizaron para conseguir que estos estudios se convirtieran en licenciatura. Tras muchos desencuentros, el Ministerio de Educación accedió a promover la elaboración del Libro Blanco de los Títulos de Magisterio, a través de la ANECA ${ }^{54}$.

En 2003 tuvo lugar, en la Escuela Universitaria de Formación del Profesorado de Ciudad Real, la I Asamblea de Decanos de Facultades y Directores de Centros $^{55}$ en los que se impartían las diferentes titulaciones de Educación, incluyendo las Diplomaturas de Maestro. Además asistieron las Facultades de Educación que, impartiendo estudios de Educación, no ofertaban enseñanzas de Diplomaturas de Maestro (Román, 2006). Entre estas Facultades se encontraba la de Valencia, que en principio no mostró excesivo interés en estas negociaciones.

En 2004, Antonio Maldonado ${ }^{56}$, entregó al Ministerio la propuesta de Títulos Maestro de Educación Infantil y Maestro de Educación Primaria. Se aspiraba a conseguir la Licenciatura para el Magisterio y para las demás titulaciones de Educación. Todo ello ayuda a sentar las bases definitivas para los Planes de Estudios de 2008, en los que se contempla los Grados, además de los posibles Másteres que abrirán el camino incluso a estudios de Doctorado. En la redacción de estos nuevos títulos se habla por primera vez de las Competencias (genéricas y específicas) que integraran el conjunto de capacidades a adquirir por los nuevos maestros.

\footnotetext{
${ }^{53}$ Existían, dentro de la misma Universidad o en diferentes Universidades, distintos centros: "Facultades de Educación con y sin pedagogía, Facultades de Ciencias Sociales y de la Educación, Escuelas de Educación sin Facultad, el estatus universitario de la formación de Maestros seguía siendo secundario.

${ }^{54}$ Agencia Nacional de Evaluación de la Calidad y Acreditación.

${ }^{55}$ Activistas del MAESLIC. CONFERENCIA DE DECANOS Y DIRECTORES CON TÍTULOS DE MAGISTERIO Y EDUCACIÓN.

${ }^{56}$ Presidente de la Conferencia de Decanos de Educación y Directores de Magisterio.
} 
En esta Conferencia de Decanos ${ }^{57}$, están representados la totalidad de los centros con titulaciones de Maestro, ya sean centros propios o adscritos de las Universidades Públicas, así como de las Universidades Privadas y de la Iglesia Católica.

Se creó un grupo de trabajo para la realización del Proyecto: Adecuación de las Titulaciones de Maestro al Espacio Europeo de Educación Superior. ${ }^{58}$ Pretenden lograr una agrupación de las titulaciones existentes ${ }^{59}$ en un número menor de ellas. Se trata de adecuarlos a la nueva Ley ${ }^{60}$ e intentar conseguir una mejor correspondencia con los títulos que se están impartiendo en el resto de Europa ya que persisten problemas de homologaciones con respecto a nuestros estudios de Maestros. También trabajan en el análisis de la definición de las competencias en función del borrador de R.D. de las titulaciones de Grado. En esta ley, LOCE, se insiste en la necesidad de incidir en la mejora de las competencias instrumentales generales (lectura, escritura, cálculo).

Ya en el curso 2009 - 10, se aplicaron los nuevos Grados adaptados a Bolonia en Educación en 28 Universidades. Paulatinamente se han ido implantando en el resto.

Por primera vez se habla, explícitamente, de "competencias" (genéricas y específicas), como conjunto integrado de conocimientos (procedimentales, conceptuales y valorativos) útiles para resolver los problemas profesionales,

\footnotetext{
${ }^{57}$ Desde sus inicios la Conferencia de Decanos ha centrado su trabajo en la realización de propuestas para lograr la plena homologación de las titulaciones de Maestro a los títulos correspondientes en la Unión Europea.

${ }^{58}$ Participan en este proyecto participan 40 de las 43 Universidades que imparten titulaciones de Magisterio. En total 47 Centros que imparten Magisterio y otros Títulos de Educación (35 Centros Propios de Universidades Públicas, 7 Centros adscritos, 5 Universidades Privadas) y 25 Centros que ofertan solo Magisterio (8 Centros propios de U. Públicas, 17 Centros Adscritos, ninguna Universidad Privada).

${ }^{59}$ Diplomado-Maestro en: Audición y Lenguaje, Ed. Especial, Ed. Física, Ed. Infantil, Ed. Musical, Ed. Primaria, Lengua Extranjera.

${ }^{60}$ Ley Orgánica 10/ 2002, de 23 de diciembre, de Calidad de la Educación (BOE 24 de diciembre de 2002) LOCE. complementa a la Ley Orgánica de Generalización del Sistema Educativo, LOGSE.
} 
que han de adquirir los futuros maestros. Las principales novedades en los estudios de Magisterio serán:

- Se completa el sistema de tres ciclos de estudios: Grado, Máster y Doctorado. El Grado constará de 240 créditos que capacita para el ejercicio profesional y el Máster, de 60 o 120 créditos, que da una formación especializada orientada al ámbito de la investigación o al mundo profesional. Y el Doctorado (3-4 años) tienen por objetivo proporcionar una formación avanzada en técnicas de investigación.

- Desaparecen los maestros especialistas y, por lo tanto, obtienen un título único, Graduado en Maestro de Infantil o bien de Primaria. Estos últimos pueden especializarse a través de itinerarios.

- Al ser un título único, se estipula que se pueden proponer menciones cualificadoras (entre 30 y 60 créditos) que se adecuen a los objetivos, ciclos y áreas de la Educación Primaria ${ }^{61}$. Pueden justificarse además si capacitan para desempeñar actividades asociadas a competencias educativas (biblioteca escolar, TICs, educación de adultos).

La Educación Primaria será impartida por maestros, que tendrán competencia en todas las áreas de este nivel. La enseñanza de la música, de la educación física, de los idiomas extranjeros o de aquellas otras enseñanzas que determine el Gobierno, previa consulta a las Comunidades Autónomas, será impartida por maestros con la especialización o cualificación correspondiente (Artículo 93 de la LOE).

- Adopción del Sistema Europeo de Créditos (ECTS) lo cual implicará un cambio metodológico pues se pasa de una enseñanza basada en la adquisición de conocimientos a una enfocada al aprendizaje de los estudiantes.

- Tendrán que realizar un Trabajo Fin de Grado.

${ }^{61}$ Según Ley Orgánica 2/2006 de 3 de mayo. 
- Se aumenta el requisito de competencia en idiomas extranjeros. En el caso del castellano se solicita un $\mathrm{C} 1$ al igual que en el caso de que exista la lengua específica de la Comunidad (como es nuestro caso) y un nivel B1 de una lengua extranjera atendiendo al Marco Común Europeo de Referencia para las Lenguas.

- Disminuye el número de asignaturas pues son todas cuatrimestrales de 9,6 y de 4,5 créditos.

Señalar a estas alturas del texto, los numerosos cambios sufridos por esta titulación que, a día de hoy está totalmente equiparada a cualquier otra universitaria tanto en requisitos como en formación. Tal y como demuestran las altas cifras de solicitudes de entrada a cursar estos estudios como la elevada puntuación en Bachillerato y PAU que se requiere para poder seguirlas. A pesar de ello todavía tenemos que avanzar mucho tanto en la consideración de la profesión como en la mejora de la formación de los maestros.

\subsubsection{Las competencias en el Grado de Infantil y Primaria.}

Según la Orden ECl/3854/2007 62 , de 27 de diciembre, por la que se establecen los requisitos para la verificación de los títulos universitarios oficiales que habiliten para el ejercicio de la profesión de Maestro en Educación Infantil, las Competencias propias del título de grado en educación infantil son:

- Conocer los objetivos, contenidos curriculares y criterios de evaluación de la Educación Infantil.

- Promover y facilitar los aprendizajes en la primera infancia, desde una perspectiva globalizadora e integradora de las diferentes dimensiones cognitiva, emocional, psicomotora y volitiva.

\footnotetext{
${ }^{62}$ BOE 29 de diciembre de 2007.
} 
- Diseñar y regular espacios de aprendizaje en contextos de diversidad que atiendan a las singulares necesidades educativas de los estudiantes, a la igualdad de género, a la equidad y al respeto a los derechos humanos.

- Fomentar la convivencia en el aula y fuera de ella y abordar la resolución pacífica de conflictos. Saber observar sistemáticamente contextos de aprendizaje y convivencia y saber reflexionar sobre ellos.

- Reflexionar en grupo sobre la aceptación de normas y el respeto a los demás. Promover la autonomía y la singularidad de cada estudiante como factores de educación de las emociones, los sentimientos y los valores en la primera infancia.

- Conocer la evolución del lenguaje en la primera infancia, saber identificar posibles disfunciones y velar por su correcta evolución. Abordar con eficiencia situaciones de aprendizaje de lenguas en contextos multiculturales y multilingües. Expresarse oralmente y por escrito y dominar el uso de diferentes técnicas de expresión.

- Conocer las implicaciones educativas de las tecnologías de la información y la comunicación y, en particular, de la televisión en la primera infancia.

- Conocer fundamentos de dietética e higiene infantiles. Conocer fundamentos de atención temprana y las bases y desarrollos que permiten comprender los procesos psicológicos, de aprendizaje y de construcción de la personalidad en la primera infancia.

- Conocer la organización de las escuelas de educación infantil y la diversidad de acciones que comprende su funcionamiento. Asumir que el ejercicio de la función docente ha de ir perfeccionándose y adaptándose a los cambios científicos, pedagógicos y sociales a lo largo de la vida.

- Actuar como orientador de padres y madres en relación con la educación familiar en el período $0-6$ años y dominar habilidades sociales en el trato y relación con la familia de cada estudiante y con el conjunto de las familias. 
- Reflexionar sobre las prácticas de aula para innovar y mejorar la labor docente. Adquirir hábitos y destrezas para el aprendizaje autónomo y cooperativo y promoverlo en los estudiantes.

- Comprender la función, las posibilidades y los límites de la educación en la sociedad actual y las competencias fundamentales que afectan a los colegios de educación infantil y a sus profesionales. Conocer modelos de mejora de la calidad con aplicación a los centros educativos.

Las competencias propias del título de grado en educación primaria son las que se aparecen en la Orden ECI/3857/2007 ${ }^{63}$, de 27 de diciembre, por la que se establecen los requisitos para la verificación de los títulos universitarios oficiales que habiliten para el ejercicio de la profesión de Maestro en Educación Primaria:

- Conocer las áreas curriculares de la Educación Primaria, la relación interdisciplinar entre ellas, los criterios de evaluación y el cuerpo de conocimientos didácticos en torno a los procedimientos de enseñanza y aprendizaje respectivos.

- Diseñar, planificar y evaluar procesos de enseñanza aprendizaje, tanto individualmente como en colaboración con otros docentes y profesionales del centro.

- Abordar con eficacia situaciones de aprendizaje de lenguas en contextos multiculturales y plurilingües. Fomentar la lectura y el comentario crítico de textos de los diversos dominios científicos y culturales contenidos en el currículo escolar.

- Diseñar y regular espacios de aprendizaje en contextos de diversidad y que atiendan a la igualdad de género, a la equidad y al respeto a los derechos humanos que conformen los valores de la formación ciudadana.

- Fomentar la convivencia en el aula y fuera de ella, resolver problemas de disciplina y contribuir a la resolución pacífica de conflictos. Estimular

${ }^{63}$ BOE 29 de diciembre de 2007. 
y valorar el esfuerzo, la constancia y la disciplina personal en los estudiantes.

- Conocer la organización de los colegios de educación primaria y la diversidad de acciones que comprende su funcionamiento. Desempeñar las funciones de tutoría y de orientación con los estudiantes y sus familias, atendiendo las singulares necesidades educativas de los estudiantes. Asumir que el ejercicio de la función docente ha de ir perfeccionándose y adaptándose a los cambios científicos, pedagógicos y sociales a lo largo de la vida.

- Colaborar con los distintos sectores de la comunidad educativa y del entorno social. Asumir la dimensión educadora de la función docente y fomentar la educación democrática para una ciudadanía activa.

- Mantener una relación crítica y autónoma respecto de los saberes, los valores y las instituciones sociales públicas y privadas.

- Valorar la responsabilidad individual y colectiva en la consecución de un futuro sostenible.

- Reflexionar sobre las prácticas de aula para innovar y mejorar la labor docente. Adquirir hábitos y destrezas para el aprendizaje autónomo y cooperativo y promoverlo entre los estudiantes.

- Conocer y aplicar en las aulas las tecnologías de la información y de la comunicación. Discernir selectivamente la información audiovisual que contribuya a los aprendizajes, a la formación cívica y a la riqueza cultural.

- Comprender la función, las posibilidades y los límites de la educación en la sociedad actual y las competencias fundamentales que afectan a los colegios de educación primaria y a sus profesionales. Conocer modelos de mejora de la calidad con aplicación a los centros educativos. 


\subsection{La formación de los maestros. Los Planes de Estudio.}

Según Marín (1980), los cuatro componentes clásicos en el contenido de la formación del profesorado han venido siendo: la formación cultural, la especializada, la pedagógica y las prácticas escolares. Numerosos trabajos de investigadores y comunicaciones en congresos así como de asociaciones profesionales, suscriben esta división. Lograr profesores eficientes depende del peso respectivo de esos bloques, así como de los conocimientos, hábitos y actitudes que se pretenda comunicar o suscitar en el alumno.

La existencia de una legislación que regule la formación escolar, en nuestro país, se remonta a finales del s. XVIII y principios del XIX. Los cambios políticos y la ausencia de una política educativa coherente y unificada, se traducen en tentativas para reformar y en cambios frecuentes en los programas y en la composición de las materias los estudios de maestros. La estructura de los planes estudios está condicionada por factores sociopolíticos, económicos y culturales.

Actualmente se considera que el Plan de Estudios es el que recoge el conjunto de asignaturas y enseñanzas que, organizadas por cada Universidad, conceden el título correspondiente. Lo aprueba la Universidad y lo homologa el Consejo de Coordinación Universitaria.

\subsubsection{La España llustrada y los comienzos del sistema educativo nacional.}

En el siglo XVI, la enseñanza, al igual que la cultura, estaba en manos de la Iglesia. La educación estaba muy diferenciada, escuelas al servicio de la Iglesia y de los nobles y otras para el pueblo. De la misma forma, se distinguía entre las escuelas de la ciudad y las rurales. Ello daba como resultado escuelas marcadamente distintas. Para ejercer de maestro la exigencia se limita al conocimiento de la lectura y escritura, reglas elementales de la 
Aritmética y Catecismo. Esta exigencia aun era menor en el caso de escuelas de ámbito rural. En muchos casos no poseían titulación alguna.

Más adelante, la Hermandad de San Casiano, en 1642, estableció unas pruebas algo más completas. En ellas se evaluaba:

- Lectura y escritura

- Aritmética

- Ortografía

- El arte de gobernar a los niños

- Doctrina cristiana

- $\quad H^{a}$ Sagrada y de España

Durante el Antiguo Régimen, la formación del profesorado no se ajustaba a planteamientos pedagógicos sino instructivos. Se valoraban los contenidos y las destrezas, "el qué", pero no, un procedimiento organizado de formación, "el por qué".

A partir de 1780, con el objetivo de profesionalizar al maestro, se decide institucionalizar y regularizar su formación. Se intenta, por primera vez, centralizar y controlar a nivel de Estado, a este conjunto de profesionales, hasta ahora dispersos y con formaciones de lo más diversas.

Hasta bien entrado el siglo XIX, en España, la formación era de tipo gremial y se alargaba en ocasiones durante 4 años después de los cuales, se les permitía crear su propia escuela tras la superación de unas determinadas pruebas habilitadoras. Estas, en general, versaban sobre saber leer y escribir todo tipo de documentos y más adelante se añadió Teoría y práctica de la lectura, reglas de aritmética y ortografía.

Aunque en $1814^{64}$ se exige a los maestros por ley un examen y, en $1825^{65}$, se insiste en su regularización con la edición del Método de Oposiciones y

\footnotetext{
64 Plan Quintana.

${ }^{65}$ Reglamento General de Primeras Letras.
} 
Exámenes para la provisión de todas las escuelas de primeras letras del Reyno (Esteban, 1994), hasta 1846 no se hace obligatorio asistir a las escuelas Normales para poder presentarse al examen.

Los centros específicos que se encargan de la formación reglada son las Escuelas Normales. La primera de ellas, como ya hemos indicado con anterioridad, se crea en 1839 y se denomina Escuela Normal Central de Maestros de Madrid. Hasta ese momento, las enseñanzas tenían muy poco componente teórico, se basaban en modelos prácticos casi exclusivamente. Se imparte:

- Lectura,

- Escritura,

- Cálculo y

- Caligrafía.

- Se intenta añadir un mayor componente teórico incorporando estudios de Fundamentos de Pedagogía y de Principios de Métodos Educativos.

En los Reglamentos de 1825 y 1839 se dan instrucciones de cómo deben ser los contenidos de los exámenes para maestros, seguiendo el programa de:

- Instrucción Moral y Religiosa

- Lectura

- Escritura Principios de Aritmética

- Elementos de Gramática Castellana

- Sistemas para la dirección, gobierno y enseñanza de las escuelas

- Métodos Especiales para enseñanza de lectura y escritura.

El 15 de octubre de 1843, se promulgó el Reglamento Orgánico para las Escuelas Normales de Instrucción Primaria del Reino. Recoge el currículo de los estudios de los futuros Maestros. En este, los conocimientos culturales seguirán primando sobre los conocimientos de métodos de enseñanza. Las "competencias" en las que se les forma son: 
- Saber. Componentes culturales: Lectura, Escritura, Lengua, Matemáticas, Historia Natural, Física, Geografía e Historia, Religión y Moral.

- Saber hacer. Conocimientos, destrezas y habilidades pedagógicas: Principios Generales de Educación Moral, Intelectual y Física; Métodos de Enseñanza y Pedagogía.

\subsubsection{La ley Moyano}

El 9 de septiembre de 1857 se publica la Ley de Instrucción Pública o Ley Moyano, que regula la educación a nivel nacional. Perdurará en el tiempo, incluso algunos de sus artículos, se mantienen parcialmente vigentes hasta su derogación en la década de los sesenta del siglo XX. Se introduce una reglamentación para la Enseñanza Primaria y se regula, por primera vez por ley, la formación de las Maestras, para las que se mantenía exigencias menores que para los Maestros y menor número de centros. Para el cumplimiento de esta ley se dictó el Programa General de Estudios en la Escuelas Normales de Primera Enseñanza (1858).

Contempla las Escuelas Normales como profesionales a la altura de las de otros estudios. Se establece una estructura con dos categorías o niveles de enseñanza: Elemental y Superior. Dicha estructura provocó desigualdad dentro de las escuelas normales así como en los títulos de Maestro de Instrucción Primaria. Se mantuvo vigente hasta 1914 , en que se estableció un titulo único de maestro.

El Plan de Estudios, el que presentamos recoge algunas modificaciones posteriores a 1858, queda establecido de la siguiente forma: 
Tabla 1. Plan de Estudios Nacional 1857

\begin{tabular}{|c|c|c|c|c|c|c|c|}
\hline \multicolumn{8}{|c|}{ Plan de estudios de $1857^{66}$} \\
\hline \multicolumn{4}{|c|}{ Maestro Elemental } & \multicolumn{4}{|c|}{ Maestro Superior } \\
\hline Primer curso & $\mathrm{H}$ & Segundo curso & $\mathrm{H}$ & Primer curso & $\mathrm{H}$ & Segundo curso & $\mathrm{H}$ \\
\hline $\begin{array}{l}\text { Religión e Historia } \\
\text { Sagrada }\end{array}$ & 3 & $\begin{array}{l}\text { Nociones } \\
\text { Agricultura }\end{array}$ & 3 & Religión y Moral & 3 & Francés & 3 \\
\hline $\begin{array}{l}\text { Gramática } \\
\text { Castellana }\end{array}$ & 6 & $\begin{array}{l}\text { Gramática } \\
\text { Castellana }\end{array}$ & 3 & $\begin{array}{l}\text { Lengua } \\
\text { castellana }\end{array}$ & 3 & Lengua castellana & 3 \\
\hline $\begin{array}{l}\text { Nociones } \\
\text { Pedagogía }\end{array}$ & 3 & Pedagogía & 3 & $\begin{array}{l}\text { Estudios } \\
\text { superiores } \\
\text { Pedagogía }\end{array}$ & 3 & $\begin{array}{l}\text { Historia de la } \\
\text { Pedagogía }\end{array}$ & 3 \\
\hline $\begin{array}{l}\text { Nociones } \\
\text { Aritmética- } \\
\text { Geometría }\end{array}$ & 3 & $\begin{array}{l}\text { Derecho usual y } \\
\text { Legislación } \\
\text { escolar }\end{array}$ & 3 & $\begin{array}{l}\text { Aritmética y } \\
\text { Algebra }\end{array}$ & 3 & $\begin{array}{l}\text { Aritmética y } \\
\text { Algebra }\end{array}$ & 3 \\
\hline $\begin{array}{l}\text { Nociones } \\
\text { Geografía-Historia }\end{array}$ & 3 & $\begin{array}{l}\text { Geografía e } \\
\text { Historia de } \\
\text { España }\end{array}$ & 3 & Francés & 3 & $\begin{array}{l}\text { Geografía e } \\
\text { Historia Universal }\end{array}$ & 3 \\
\hline Dibujo & 3 & $\begin{array}{l}\text { Ciencias físicas } \\
\text { y naturales } \\
\text { aplicación a } \\
\text { industria e } \\
\text { higiene }\end{array}$ & 3 & Geometría & 3 & $\begin{array}{l}\text { Ciencias físicas y } \\
\text { naturales } \\
\text { aplicación a } \\
\text { industria e higiene }\end{array}$ & 3 \\
\hline \multicolumn{2}{|l|}{ Prácticas Enseñanza } & \multicolumn{2}{|c|}{ Prácticas Enseñanza } & \multicolumn{2}{|c|}{ Prácticas Enseñanza } & \multicolumn{2}{|c|}{ Prácticas Enseñanza } \\
\hline \multicolumn{2}{|l|}{$\begin{array}{l}\text { Trabajos Manuales } \\
\text { (maestros) }\end{array}$} & \multicolumn{2}{|c|}{$\begin{array}{l}\text { Trabajos Manuales } \\
\text { (maestros) }\end{array}$} & Caligrafía & 3 & \multicolumn{2}{|l|}{$\begin{array}{l}\text { Dibujo de adorno y } \\
\text { de aplicación a } \\
\text { labores (maestras) }\end{array}$} \\
\hline \multicolumn{2}{|l|}{$\begin{array}{l}\text { Ejercicios corporales } \\
\text { (maestros) }\end{array}$} & \multicolumn{2}{|c|}{$\begin{array}{l}\text { Ejercicios corporales } \\
\text { (maestros) }\end{array}$} & Música & 3 & Música & 3 \\
\hline \multicolumn{2}{|l|}{ Labores (maestras) } & \multicolumn{2}{|c|}{ Labores (maestras) } & \multicolumn{2}{|c|}{ Labores (maestras) } & \multicolumn{2}{|l|}{ Labores (maestras) } \\
\hline
\end{tabular}

Fuente. Elaboración propia.

Román y Cano (2008) establecen una comparativa, basándose en los contenidos que se impartían al aplicar estas dos normativas, tal como presenta el esquema que aparece a continuación:

Tabla 2. Programas culturales de las Escuelas Normales Elementales

\begin{tabular}{|l|c|c|}
\hline \multicolumn{1}{|c|}{ Asignaturas } & Plan & Plan \\
& $\mathbf{1 8 4 3}$ & $\mathbf{1 8 5 8}$ \\
\hline Religión y Moral & $\mathrm{X}$ & -- \\
\hline Doctrina Cristiana e Historia Sagrada & -- & $\mathrm{X}$ \\
\hline
\end{tabular}

66 La Ley 1857 sufrió diversas y abundantes modificaciones, en cuanto a los estudios de Maestro. El Plan de estudios que se detalla es el aprobado por R.D. de 24 de septiembre de 1903, que estuvo vigente hasta 1914, año en el que se aprobó un nuevo plan de estudios.

NORMATIVA: Ley 9 de septiembre de 1857 (Ley Moyano) - R.D. de 23 de septiembre de 1898 - R.D. 6 de julio de 1900

R.D. 17 de agosto de 1901 - R.D. 21 de septiembre de 1902 - R.D. 24 de septiembre de 1903

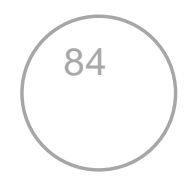




\begin{tabular}{|l|c|c|}
\hline Lectura y Escritura & X & -- \\
\hline Teoría y Práctica de la Lectura & -- & $\mathrm{X}$ \\
\hline Gramática de la Lengua Castellana & $\mathrm{X}$ & -- \\
\hline Lengua Castellana & -- & $\mathrm{X}$ \\
\hline Nociones de Retorica, Poética y Literatura Española & $\mathrm{X}$ & -- \\
\hline $\begin{array}{l}\text { Aritmética y sus aplicaciones. Principales pesos y medidas de } \\
\text { las diferentes provincias de España }\end{array}$ & $\mathrm{X}$ & -- \\
\hline Aritmética & -- & $\mathrm{X}$ \\
\hline $\begin{array}{l}\text { Principios de la Geometría con sus aplicaciones a los usos } \\
\text { comunes de la vida y a las artes industriales }\end{array}$ & $\mathrm{X}$ & -- \\
\hline Nociones de Geometría, Dibujo Lineal y Agrimensura & -- & $\mathrm{X}$ \\
\hline Dibujo Lineal & $\mathrm{X}$ & -- \\
\hline Elementos de Geografía e Historia de España & $\mathrm{X}$ & $\mathrm{X}$ \\
\hline $\begin{array}{l}\text { Nociones de Física y Química e Historia Natural aplicables a los } \\
\text { usos comunes de la vida }\end{array}$ & $\mathrm{X}$ & -- \\
\hline Agricultura & -- & $\mathrm{X}$ \\
\hline Principios de Educación y Métodos de Enseñanza & $\mathrm{X}$ & $\mathrm{X}$ \\
\hline Practica de la Enseñanza & $\mathrm{X}$ & $\mathrm{X}$ \\
\hline
\end{tabular}

Fuente. Melcón citado en Román y Cano, 2008, pp. 168-169.

Tabla 3. Programas culturales de las Escuelas Normales Superiores

\begin{tabular}{|c|c|c|}
\hline Asignaturas & $\begin{array}{l}\text { Plan } \\
1849\end{array}$ & $\begin{array}{l}\text { Plan } \\
1858\end{array}$ \\
\hline Religión y Moral & $\mathrm{X}$ & -- \\
\hline Doctrina Cristiana e Historia Sagrada & -- & $\mathrm{X}$ \\
\hline Lectura y Escritura & $\mathrm{X}$ & -- \\
\hline Teoría y Práctica de la Lectura & -- & $\mathrm{X}$ \\
\hline Teoría y Práctica de la Escritura & -- & $\mathrm{X}$ \\
\hline Gramática de la Lengua Castellana & $\mathrm{X}$ & -- \\
\hline Lengua Castellana & -- & $\mathrm{X}$ \\
\hline Retorica, Poética y Literatura Española & $\mathrm{X}$ & -- \\
\hline $\begin{array}{l}\text { Aritmética en toda su extensión con el sistema legal de pesos y } \\
\text { medidas }\end{array}$ & $\mathrm{X}$ & -- \\
\hline Aritmética & -- & $\mathrm{X}$ \\
\hline $\begin{array}{l}\text { Principios de la Geometría con sus aplicaciones a los usos } \\
\text { comunes de la vida y a las artes industriales y agrimensura }\end{array}$ & $\mathrm{X}$ & -- \\
\hline Nociones de Geometría, Dibujo Lineal y Agrimensura & -- & $\mathrm{X}$ \\
\hline Nociones Teóricas de Dibujo Lineal & $\mathrm{x}$ & -- \\
\hline Elementos de Geografía e Historia de España & $\mathrm{X}$ & $\mathrm{X}$ \\
\hline Nociones de Industria y Comercio & -- & $\mathrm{X}$ \\
\hline Nociones de Física aplicables a los usos de la vida & $\mathrm{X}$ & -- \\
\hline Nociones de Química aplicables a los usos de la vida & $\mathrm{X}$ & -- \\
\hline Conocimientos comunes de Ciencias Físicas y Naturales & -- & $\mathrm{X}$ \\
\hline Nociones de Agricultura & $\mathrm{X}$ & $\mathrm{X}$ \\
\hline Sistemas y Métodos de Enseñanza & $\mathrm{X}$ & -- \\
\hline Organización de las Escuelas & $\mathrm{X}$ & -- \\
\hline Principios generales de Educación & $\mathrm{X}$ & -- \\
\hline Principios de Educación y Métodos de Enseñanza & -- & $\mathrm{X}$ \\
\hline Pedagogía & -- & $\mathrm{X}$ \\
\hline Practica de la Enseñanza & $\mathrm{X}$ & $\mathrm{X}$ \\
\hline Caligrafía & $\mathrm{X}$ & -- \\
\hline
\end{tabular}

Fuente. Melcón citado en Román y Cano, 2008, pp. 168-169. 
En cuanto a los contenidos en la formación, en las de Maestros Elementales, en general, se aprecia cierto equilibrio, entre las enseñanzas científicas y literarias. Más adelante, se incrementa la ventaja de las letras a la vez que se introducen algunas materias de carácter pedagógico (Román y Cano, 2008). En lo sucesivo los Planes de Estudio seguirán manteniendo esta distribución, produciéndose cierta alternancia entre ciencias y letras, atendiendo al criterio político de cada momento.

En las enseñanzas Superiores, sin embargo, inicialmente había un mayor peso de las ciencias. Hacia 1900 se intenta repartir de forma más equilibrada y, en programas posteriores, las letras volverán a ganar terreno. La Pedagogía sigue relegada a algo testimonial.

Las disciplinas académicas de los estudios de Maestros Elementales y Superiores se intentaron equilibrar, aunque no siempre se consiguió. Se conjugó la dinámica cultural y la profesional. Estos tienen que dar respuesta a la falta de cultura de sus aspirantes por lo que los planes de estudios hacen énfasis en los contenidos y en las materias de carácter cultural buscando la instrucción en materias básicas y fundamentales para los futuros maestros.

Se pueden agrupar en cinco categorías (dentro de ellas las materias pueden variar de denominación):

- Ciencias

- Letras

- Pedagogía

- Prácticas

- Otras disciplinas ${ }^{67}$

En cuanto a lo que se refiere al tema que nos ocupa, veremos cómo, tanto en el nivel Elemental como en el Superior, no hay mención a materias artísticas ${ }^{68}$.

67 Aquí es donde se incluían asignaturas como Dibujo Lineal, Dibujo Artístico, Dibujo de Adorno y de aplicación a las Labores (Maestras), Trabajos Manuales (sistema Naas en madera, alambre y hierro forjado) Trabajos Manuales, Labores Artísticas y Corte. 
Puntualizaremos además que, si estaban presentes, muchas de ellas solo se impartían al alumnado femenino. Como nota señalar que, en cuanto a enseñanzas consideradas artísticas, destaca la creación de una cátedra de Música en las Escuelas Normales de Madrid. Se imparten materias de Música y Canto en el plan de estudios de la Normal Central de Maestras ${ }^{69}$.

Con el Real Decreto de 23 de septiembre de 1898 se pretende reorganizar los estudios. Se añaden disciplinas de carácter artístico y pedagógico, lo cual es muy valorable. Lo significativo y destacable para nosotros es que con este R.D. ya se integra al profesorado específico como especialista. Se denominan como tales a los de las materias de Dibujo y Caligrafía, Higiene y Gimnasia, Francés y Música y Canto.

Una circunstancia que se considera que pudo hacer fracasar este nuevo Plan, es precisamente la dificultad para encontrar especialistas que impartiesen las nuevas disciplinas pedagógicas y artísticas. Estas disciplinas, presentes en el programa escolar vigente y con pretensiones de "instrucción integral", no pasaban de estar únicamente en el papel pues la mayoría de los maestros no se sentían preparados para impartir los nuevos contenidos Dibujo, Canto, Trabajos Manuales y Ejercicios Corporales (Molero, 1994).

El Plan oficial de 1900 agrupa las materias en científicas, literarias y pedagógicas y establece una dedicación semanal de las asignaturas, tal como sigue:

Tabla 4. Plan de estudios de 1900

\begin{tabular}{|l|c|l|c|l|c|}
\hline \multicolumn{7}{|c|}{ Plan de estudios de 1900 - ELEMENTAL } \\
\hline Geografía e Historia & 3 & $\begin{array}{l}\text { Aritmética y } \\
\text { Geometría }\end{array}$ & 4,30 & Religión & 3 \\
\hline Derecho y Legislación & 1,30 & $\begin{array}{l}\text { Física, Química e Ha } \\
\text { Natural }\end{array}$ & 4,30 & Dibujo & $\mathbf{2}$ \\
\hline Lengua Castellana & 4,30 & Pedagogía & 3 & Labores (alumnas) & 6 \\
\hline
\end{tabular}

Fuente. Elaboración propia.

${ }^{68}$ Este estudio lo trataremos más adelante incluido en el apartado dedicado a la Educación Artística.

${ }^{69}$ Real Orden de 24 de agosto de 1878. 
Romanones, nombrado ministro de Instrucción Pública en 1901, modifica la estructura de los estudios de Magisterio al incorporarlos a los Institutos con el Real Decreto de 17 de agosto de 1901.

Se endurecieron ciertos requisitos en los estudios, como ya vimos en el apartado anterior. Señalar el aumento de la presencia de las materias de ciencias. La distribución de las materias queda de la forma siguiente:

Tabla 5. Plan de estudios de 1901. Elemental

\begin{tabular}{|l|l|l|}
\hline \multicolumn{2}{|c|}{ Plan de estudios de 1901 - ELEMENTAL } \\
\hline Primer curso & \multicolumn{1}{|c|}{ Segundo curso } & \multicolumn{1}{c|}{ Tercer curso } \\
\hline Lengua Castellana I & Lengua Castellana II & Historia Natural \\
\hline Pedagogía I & Pedagogía II & Pedagogía III \\
\hline Geografía General y de Europa & $\begin{array}{l}\text { Geografía especial de } \\
\text { España }\end{array}$ & $\begin{array}{l}\text { Agricultura y Técnica } \\
\text { Agrícola }\end{array}$ \\
\hline Aritmética & Algebra y Trigonometría & Física y Química aplicada \\
\hline Geometría & & Caligrafía \\
\hline Psicología y Lógica & Ética y Rudimentos del & $\begin{array}{l}\text { Derecho y Legislación } \\
\text { Escolar }\end{array}$ \\
\hline Religión e Historia Sagrada & Historia Universal & Historia de España \\
\hline Juegos Corporales & Ejercicios Corporales & Fisiología e Higiene \\
\hline Caligrafía I & Caligrafía II & Practicas de Escuela \\
\hline Dibujo & Dibujo & \\
\hline Trabajos Manuales & Trabajos Manuales & \\
\hline
\end{tabular}

Fuente. Elaboración propia.

Tabla 6. Plan de estudios de 1901. Superior

\begin{tabular}{|l|l|}
\hline \multicolumn{2}{|c|}{ Plan de estudios de 1901 - SUPERIOR } \\
\hline \multicolumn{1}{|c|}{ Primer curso } & \multicolumn{1}{c|}{ Segundo curso } \\
\hline Historia de la Pedagogía I & Historia de la Pedagogía II \\
\hline Estudios Superiores de Pedagogía I & Estudios Superiores de Pedagogía II \\
\hline Geografía Comercial y Estadística & $\begin{array}{l}\text { Estudios Superiores de Gramática } \\
\text { Castellana }\end{array}$ \\
\hline Ampliación de las Matemáticas & Ampliación de la Física \\
\hline Antropología y Principios de Psicogenesia & Técnica Industrial \\
\hline Instituciones extranjeras de Instrucción Primaria & Higiene Escolar y Profiláctica \\
\hline Francés & Francés \\
\hline
\end{tabular}




\begin{tabular}{|l|l|}
\hline Caligrafía Superior y Teoría de la Escritura I & $\begin{array}{l}\text { Caligrafía Superior y Teoría de la } \\
\text { Escritura II }\end{array}$ \\
\hline Dibujo & Dibujo \\
\hline & Practicas de Escuela \\
\hline
\end{tabular}

Fuente. Elaboración propia.

Se plantea una nueva reforma en $1903^{70}$, Plan de 1903 , que se mantendría vigente hasta 1914. Reduce los estudios Elementales en un año. Las disciplinas instrumentales y culturales ocupaban algo menos de la mitad del horario semanal debido a que era lo que necesitaban fundamentalmente en las escuelas primarias. No se aumentó la preparación profesionalizadora, si lo comparamos con el plan anterior.

Tabla 7. Plan de estudios de 1903

\begin{tabular}{|c|c|c|c|}
\hline \multicolumn{2}{|c|}{ Plan de estudios de 1903 ELEMENTAL } & \multicolumn{2}{|c|}{ Plan de estudios de 1903 SUPERIOR } \\
\hline Primer curso & Segundo curso & Primer curso & Segundo curso \\
\hline $\begin{array}{l}\text { Nociones de } \\
\text { Pedagogía }\end{array}$ & Pedagogía & Lengua Castellana I & Lengua Castellana II \\
\hline Gramática Castellana & $\begin{array}{l}\text { Gramática } \\
\text { Castellana }\end{array}$ & $\begin{array}{l}\text { Estudios Superiores } \\
\text { de Pedagogía }\end{array}$ & $\begin{array}{l}\text { Historia de la } \\
\text { Pedagogía }\end{array}$ \\
\hline $\begin{array}{l}\text { Nociones de } \\
\text { Geografía e Historia }\end{array}$ & $\begin{array}{l}\text { Geografía e } \\
\text { Historia de España }\end{array}$ & Religión y Moral & $\begin{array}{l}\text { Geografía e Historia } \\
\text { Universal }\end{array}$ \\
\hline $\begin{array}{l}\text { Nociones y } \\
\text { ejercicios de } \\
\text { Aritmética y } \\
\text { Geometría }\end{array}$ & $\begin{array}{l}\text { Ciencias Físicas y } \\
\text { Naturales con } \\
\text { aplicación a la } \\
\text { industria y a la } \\
\text { higiene }\end{array}$ & & $\begin{array}{l}\text { Ciencias Físicas y } \\
\text { Naturales }\end{array}$ \\
\hline $\begin{array}{l}\text { Ejercicios } \\
\text { Corporales(maestros) }\end{array}$ & $\begin{array}{l}\text { Ejercicios } \\
\text { Corporales } \\
\text { maestros }\end{array}$ & Aritmética y Algebra I & Aritmética y Algebra ॥ \\
\hline $\begin{array}{l}\text { Religión e Historia } \\
\text { Sagrada }\end{array}$ & $\begin{array}{l}\text { Derecho usual y } \\
\text { Legislación escolar }\end{array}$ & Geometría I & Geometría II \\
\hline $\begin{array}{l}\text { Practicas de } \\
\text { Enseñanza maestras }\end{array}$ & $\begin{array}{l}\text { Practicas de } \\
\text { Enseñanza } \\
\text { maestras }\end{array}$ & Francés I & Francés II \\
\hline $\begin{array}{l}\text { Trabajos Manuales } \\
\text { (maestros) }\end{array}$ & $\begin{array}{l}\text { Trabajos } \\
\text { Manuales } \\
\text { (maestros) }\end{array}$ & Música I & Música II \\
\hline Dibujo & $\begin{array}{l}\text { Nociones de } \\
\text { Agricultura }\end{array}$ & Caligrafía & $\begin{array}{l}\text { Dibujo de adorno y } \\
\text { de aplicación a } \\
\text { Labores (maestras) }\end{array}$ \\
\hline Labores (maestras) & Labores (maestras) & $\begin{array}{l}\text { Practicas de } \\
\text { Enseñanza y Labores } \\
\text { maestras }\end{array}$ & $\begin{array}{l}\text { Practicas de } \\
\text { Enseñanza y Labores } \\
\text { maestras }\end{array}$ \\
\hline
\end{tabular}

Fuente. Elaboración propia.

${ }^{70}$ Real Decreto de 24 de septiembre de 1903. 
La misma apreciación se repite en los Maestros Superiores aunque sí se potenciaron de forma notable, las asignaturas de ciencias.

La Escuela Superior del Magisterio, creada en 1909, pretendía tener unas enseñanzas de carácter práctico, educativo y de aplicación y que los profesores tuvieran conocimientos tanto técnicos como de cultura general. Así establece un plan de estudios de 4 años en el que divide los estudios entre: Comunes, y secciones de Letras, de Ciencias y de Labores.

\subsubsection{El siglo $X X$.}

El Real Decreto de 30 de agosto de 1914 desligó totalmente los Institutos Generales y Técnicos de las Escuelas Normales. El ministro Bergamín es el que impulsa esta nueva reforma y establece otro Plan de estudios, que se mantendrá vigente hasta 1931. En opinión de Molero (1994), supone de nuevo cierto retroceso en esta formación por:

- Favorecer los aspectos enciclopedistas y culturalistas frente a los profesionales, ya que el curriculum que se proponía para estas Escuelas Normales no era sino el propio de un Bachillerato Superior.

- El plan presentaba carencias en cuanto que no respondía de forma lo suficientemente profesional a las necesidades educativas que exigía el Gobierno del momento.

- La formación pedagógica apenas estaba presente aunque se mantienen como obligatorios los estudios de Pedagogía introducidos en 1903. Atiende más a los conocimientos instructivos en detrimento de los pedagógico-profesionales.

- En el Plan no figuraba ni una sola asignatura de metodología o didáctica.

Sin embargo, se sigue marcando una diferencia entre maestros y maestras a la hora del reparto de las asignaturas: 
- Se prescribe a los maestros la enseñanza de la Agricultura que en las maestras se reemplazaba por las Labores, Costura, Bordado y Economía Doméstica, a las cuales se destinaba una parte considerable del horario escolar.

- Destacar que se introduce la Educación Física en la formación de las maestras (González, 1994).

Se continúa nombrando profesores para contenidos homogéneos pero se intenta que haya profesorado especialista para impartir las siguientes materias: Religión y Moral, Educación Física, Dibujo, Música, Francés, Caligrafía, Fisiología e Higiene y Mecanografía (Botella, 2010). Se eleva a cátedra la disciplina de Pedagogía.

En el cuadro que sigue vemos la evolución de los contenidos por bloques de conocimiento y comprobamos cómo evoluciona la tendencia, iniciada a principios de siglo, de situar a las enseñanzas de Letras como núcleo fundamental de conocimientos (González, 1994).

Tabla 8. Evolución de los contenidos por bloques de conocimiento.

\begin{tabular}{|c|c|c|c|c|c|c|}
\hline AÑO & horas & PEDAGOGÍA & horas & LETRAS & horas & CIENCIAS \\
\hline 1900 & 9 & $18,55 \%$ & 13,5 & $27,83 \%$ & 15 & $30,92 \%$ \\
\hline 1901 & 18 & $13,33 \%$ & 36 & $26,66 \%$ & 45 & $33,33 \%$ \\
\hline 1903 & 13,5 & $19.56 \%$ & 22,5 & $32.60 \%$ & 9 & $13,04 \%$ \\
\hline 1914 & 18 & $11,65 \%$ & 54 & $34,95 \%$ & 31,5 & $20,38 \%$ \\
\hline
\end{tabular}

Fuente: González, 1994, p. 100

Hasta la reforma de las Escuelas Normales con un nuevo Plan de Estudios en 1931, estos estudios siguen sufriendo los avatares y veleidades políticas. Preocupaba sobre todo la consideración social y profesional de la figura del maestro. El Plan de Estudios queda estructurado como aparece reflejado en la siguiente tabla a continuación: 
Tabla 9. Plan de Estudios Nacional de las Escuelas Normales (1914).

\begin{tabular}{|c|c|c|c|c|c|c|c|}
\hline \multicolumn{8}{|c|}{ Plan de estudios de $1914^{\prime 1}$} \\
\hline Primer curso & $\mathrm{H} / \mathrm{s}$ & Segundo curso & $\mathrm{H} / \mathrm{s}$ & Tercer curso & $\mathrm{H} / \mathrm{s}$ & Cuarto curso & $\mathrm{H} / \mathrm{s}$ \\
\hline $\begin{array}{l}\text { Religión e } \\
\text { Historia } \\
\text { Sagrada }\end{array}$ & 4,30 & $\begin{array}{l}\text { Religión y } \\
\text { Moral }\end{array}$ & 4,30 & Historia Natural & 4,30 & Química & 4,30 \\
\hline $\begin{array}{l}\text { Teoría y } \\
\text { práctica de la } \\
\text { lectura }\end{array}$ & 4,30 & $\begin{array}{l}\text { Gramática } \\
\text { Castellana I }\end{array}$ & 4,30 & $\begin{array}{l}\text { Gramática } \\
\text { castellana }\end{array}$ & 4,30 & $\begin{array}{l}\text { Literatura } \\
\text { española }\end{array}$ & 3 \\
\hline Caligrafía & 4,30 & Caligrafía & 3 & & & $\begin{array}{l}\text { Fisiología e } \\
\text { Higiene }\end{array}$ & 4,30 \\
\hline $\begin{array}{l}\text { Nociones } \\
\text { Aritmética- } \\
\text { Geometría }\end{array}$ & 4,30 & $\begin{array}{l}\text { Aritmética y } \\
\text { Geometría }\end{array}$ & 4,30 & Algebra & 4,30 & $\begin{array}{l}\text { Rudimentos } \\
\text { derecho- } \\
\text { Legislación } \\
\text { escolar }\end{array}$ & 4,30 \\
\hline $\begin{array}{l}\text { Nociones } \\
\text { Geografía- } \\
\text { Geografía } \\
\text { Regional }\end{array}$ & 4,30 & $\begin{array}{l}\text { Geografía de } \\
\text { España }\end{array}$ & 4,30 & $\begin{array}{l}\text { Geografía } \\
\text { Universal }\end{array}$ & 4,30 & $\begin{array}{l}\text { Ampliación } \\
\text { Geografía de } \\
\text { España }\end{array}$ & 4,30 \\
\hline $\begin{array}{l}\text { Nociones } \\
\text { Historia - } \\
\text { Historia de la } \\
\text { Edad Antigua }\end{array}$ & 4,30 & $\begin{array}{l}\text { Historia de la } \\
\text { Edad Media }\end{array}$ & 4,30 & $\begin{array}{l}\text { Historia de la } \\
\text { Edad Moderna }\end{array}$ & 4,30 & $\begin{array}{l}\text { Historia } \\
\text { Contemporán } \\
\text { ea }\end{array}$ & 4,30 \\
\hline & & Pedagogía I & 4,30 & Pedagogía II & 4,30 & $\begin{array}{l}\text { Historia de la } \\
\text { Pedagogía }\end{array}$ & 4,30 \\
\hline Música & 3 & Música & 3 & Física & 4,30 & $\begin{array}{l}\text { Agricultura } \\
\text { (Maestros) }\end{array}$ & 4,30 \\
\hline Dibujo & 3 & Dibujo & 3 & Francés & 3 & Francés & 3 \\
\hline $\begin{array}{l}\text { Costura } \\
\text { (Maestras) }\end{array}$ & 6 & $\begin{array}{l}\text { Bordado y } \\
\text { Corte } \\
\text { (Maestras) }\end{array}$ & 6 & $\begin{array}{l}\text { Corte y } \\
\text { Labores } \\
\text { artísticas } \\
\text { (Maestras) }\end{array}$ & 6 & $\begin{array}{l}\text { Economía } \\
\text { domestica } \\
\text { (Maestras) }\end{array}$ & 4,30 \\
\hline $\begin{array}{l}\text { Educación } \\
\text { Física }\end{array}$ & 4,30 & $\begin{array}{l}\text { Educación } \\
\text { Física }\end{array}$ & 4,30 & Prácticas Ense & anza & Prácticas Ens & anza \\
\hline
\end{tabular}

Fuente. Elaboración propia.

Tabla 10. Asignaturas voluntarias para Maestras.

\begin{tabular}{|l|}
\hline \multicolumn{1}{|c|}{ VOLUNTARIAS PARA MAESTRAS } \\
\hline Mecanografía \\
\hline Taquigrafía \\
\hline Contabilidad mercantil \\
\hline
\end{tabular}

Fuente. Elaboración propia.

${ }^{71}$ NORMATIVA: Real Decreto de 30 de agosto de 1914 - Real Orden de 2 de junio de 1919 Orden Ministerial de 10 de octubre de 1932. 
2.2.4. El Plan Profesional de la II República.

Con la llegada de la II Republica se plantean numerosas reformas en la educación española y, entre ellas, un nuevo Plan para las escuelas Normales que mantiene una marcada orientación pedagógico profesional. Se subdivide en tres periodos:

- El Plan Cultural, que pretendía proporcionar una cultura general a alumnos que no poseían los estudios previos requeridos para acceder a la formación profesional específica. Se cursa en los Institutos Nacionales de Segunda Enseñanza.

- El denominado Plan Profesional de $1931^{72}$, para el que se requería haber completado el Bachillerato o el Plan Cultural, que representa un giro profesionalizador frente al carácter culturalista que había caracterizado los planes anteriores. Se cursa en las Escuelas Normales.

- La parte de práctica docente que se desarrolla en las Escuelas primarias nacionales (art. $\left.1^{\circ}\right)$.

Una de las medidas más importantes recogidas en el Decreto de 29 de septiembre de 1931, fue la unificación de las Escuelas Normales de maestras y maestros en una única. Se denominaron Escuelas Normales del Magisterio Primario $^{73}$. Se instaura la coeducación y el profesorado también es de ambos sexos (art. $2^{\circ}$ ).

Las prácticas se convirtieron en un componente básico dentro de la formación profesional del maestro, contrariamente a lo que sucedía en los planes anteriores.

Se trabaja la Educación Física, la formación en el conocimiento del Arte, la consideración de la realidad social próxima mediante visitas y excursiones y se utilizan los valores educativos del medio geográfico, etc. Se introducen las asignaturas de Psicología y Paidología, así como por primera vez las

${ }_{73}^{72}$ Decreto de 29 de septiembre de 1931.

${ }^{73}$ Todas las mejoras se recogen en el Reglamento de Escuelas Normales en la Orden Ministerial del 17 de abril de 1933. 
asignaturas optativas. Se organizan también tareas complementarias como cursillos, conferencias, reuniones culturales, debates, exposiciones...

Los planes quedan según se refleja en las tablas siguientes:

Tabla 11. Plan de estudios de 1931. Plan Cultural.

\begin{tabular}{|l|l|l|}
\hline \multicolumn{2}{|c|}{ Plan de estudios de 1931 Formación Inicial - Plan Cultural ${ }^{74}$} \\
\hline Primer curso & \multicolumn{1}{c|}{ Segundo curso } & \multicolumn{1}{c|}{ Tercer curso } \\
\hline Aritmética y Algebra & Geometría y Trigonometría & Historia Natural \\
\hline $\begin{array}{l}\text { Lengua Española Ejercicios } \\
\text { lectura y escritura }\end{array}$ & Lengua Española & Lengua y Literatura \\
\hline Francés I & Francés II & Derecho y Economía \\
\hline Dibujo I & Dibujo II & $\begin{array}{l}\text { Labores o Trabajos } \\
\text { Manuales }\end{array}$ \\
\hline Geografía I & Geografía II & Ejercicios físicos \\
\hline Historia I & Historia II & Música y Canto \\
\hline & Física & Fisiología e Higiene \\
\hline & Química & Agricultura \\
\hline
\end{tabular}

Fuente. Elaboración propia.

Tabla 12. Plan de estudios de 1931. Profesional.

\begin{tabular}{|c|c|c|c|c|c|c|}
\hline \multicolumn{7}{|c|}{ Plan de estudios de 1931 - Profesional } \\
\hline Primer curso & $\mathrm{H}$ & Segundo curso & $\mathrm{H}$ & Tercer curso & $\mathrm{H}$ & \\
\hline $\begin{array}{l}\text { Elementos de } \\
\text { Filosofía }\end{array}$ & 3 & Fisiología e Higiene & 3 & Paidología & 3 & \multirow{6}{*}{$\begin{array}{l}\text { Periodo de } \\
\text { Prácticas } \\
\text { docentes } \\
\text { remuneradas }\end{array}$} \\
\hline Psicología & 3 & Pedagogía & 3 & $\begin{array}{l}\text { Historia de la } \\
\text { Pedagogía }\end{array}$ & 3 & \\
\hline $\begin{array}{l}\text { Metodología de las } \\
\text { Matemáticas }\end{array}$ & 3 & $\begin{array}{l}\text { Metodología de la } \\
\text { Historia }\end{array}$ & 3 & Organización Escolar & 3 & \\
\hline $\begin{array}{l}\text { Metodología de la } \\
\text { Lengua y Literatura } \\
\text { españolas }\end{array}$ & 6 & $\begin{array}{l}\text { Metodología de la } \\
\text { Física y Química }\end{array}$ & 6 & $\begin{array}{l}\text { Cuestiones } \\
\text { económicas y } \\
\text { sociales }\end{array}$ & 3 & \\
\hline $\begin{array}{l}\text { Metodología de las } \\
\text { Ciencias Naturales y } \\
\text { de la Agricultura }\end{array}$ & 3 & $\begin{array}{l}\text { Metodología de la } \\
\text { Geografía }\end{array}$ & 3 & $\begin{array}{l}\text { Trabajos de } \\
\text { seminario }\end{array}$ & 3 & \\
\hline Música & 2 & Música & 2 & $\begin{array}{l}\text { Trabajos de } \\
\text { especialización }^{75}\end{array}$ & 3 & \\
\hline
\end{tabular}

${ }^{74}$ Los que hayan aprobado el ingreso en las Escuelas Normales, y no posean la titulación de Bachiller, tendrán que realizar los siguientes estudios de cultura general.

${ }^{75}$ Enseñanzas especiales para la educación de párvulos, retrasados, superdotados, sordos, ciegos, etc. 


\begin{tabular}{|c|c|c|c|c|c|}
\hline Dibujo & 2 & Dibujo & 2 & $\begin{array}{l}\text { Enseñanzas del } \\
\text { hogar (maestras) }\end{array}$ & 2 \\
\hline $\begin{array}{l}\text { Labores y Trabajos } \\
\text { manuales (maestras) }\end{array}$ & 3 & $\begin{array}{l}\text { Labores y Trabajos } \\
\text { manuales } \\
\text { (maestras) }\end{array}$ & 3 & Prácticas docentes & 6 \\
\hline $\begin{array}{l}\text { Trabajos manuales } \\
\text { (maestros) }\end{array}$ & 3 & $\begin{array}{l}\text { Trabajos manuales } \\
\text { (maestros) }\end{array}$ & 3 & & \\
\hline $\begin{array}{l}\text { Ampliación facultativa } \\
\text { de idiomas }\end{array}$ & 2 & $\begin{array}{l}\text { Ampliación } \\
\text { facultativa de } \\
\text { idiomas }\end{array}$ & 2 & & \\
\hline Prácticas docentes & 6 & Prácticas docentes & 6 & & \\
\hline
\end{tabular}

Fuente. Elaboración propia.

Delimita claramente en qué ámbitos se debe formar un maestro y representa una excelente formación, muy por delante de la que en ese momento se impartía en otros países del entorno. Los estudios se estructuraban en (art. $7^{\circ}$ ):

- Conocimientos filosóficos, pedagógicos y sociales

- Metodologías especiales

- Materias artísticas y prácticas

Ello no evitó críticas desde distintos sectores atribuibles, sobre todo, a la excesiva duración de los estudios para alumnos procedentes del ámbito rural y con pocos recursos. También provocó numerosos enfrentamientos la supresión de la asignatura de Religión (González, 1994) ${ }^{76}$.

Dada la importancia que se concedía a la formación de los maestros y por consiguiente a la Educación Primaria, este Plan permanece vigente durante toda la II República Española. Se ha considerado como los mejores estudios de carácter profesional y el mejor Plan que ha existido (Lorenzo, 2002).

${ }^{76}$ El Real decreto que dictó el gobierno el 12 de marzo de 1932, publicado en la Gaceta de Madrid el día 17 del mismo mes, decía: "En cumplimiento del artículo 48 de la Constitución ... queda suprimida la asignatura de Religión en todos los Centros docentes dependientes de este Ministerio". Esta disposición no contentó a todos los sectores sociales, hubo muchas presiones opositoras que provenían de los grupos conservadores y, sobre todo, de la Iglesia. Además en materia religiosa la Constitución de 1931 proclamaba la separación de la Iglesia y el Estado, disolvía la Compañía de Jesús, limitaba la actividad de las demás Órdenes religiosas y suprimía la asignación al clero y la enseñanza religiosa en las escuelas. El artículo 31 de la Constitución del 9 de diciembre de 1931 decía: "El Estado español no tiene religión oficial". Fue precisamente la cuestión religiosa la que produjo la crisis del gobierno provisional y los católicos se separaron desde el principio del nuevo régimen. Por esta causa, al discutirse en las Cortes los artículos que a ella se referían, los católicos Alcalá Zamora y Miguel Maura dimitieron de sus cargos. 
2.2.5. La dictadura franquista y el Plan Bachiller.

Tras la guerra civil se consideró que el concepto y desarrollo de la educación durante la II Republica era nocivo. Se inició una labor de aniquilación de todo aquello que estaba vigente hasta ese momento, sin tener en cuenta los aspectos positivos que se hubieran podido conseguir. A destacar la segregación sexista y la eliminación de la coeducación que permitió que aparecieran asignaturas que se impartían según el sexo al que iban dirigidas. En palabras de Araque (2009, p. 117):

Un modelo educativo basado en el nacionalcatolicismo, a través del cual se intentó construir una falsa identidad femenina al intentar transmitir una educación para las niñas basada en el estereotipo de buenas cristianas, patriotas, amas de casa, esposas y madres.

Con la instauración de la dictadura franquista se pone en marcha el Plan Bachiller $^{77}$. Provoca una vuelta atrás pues nos retrotraerá a la época del Plan de 1914, puesto que las asignaturas del Plan 1914 son convalidadas como Bachiller, acogido a los beneficios del Decreto 10 de febrero de 1940.

Tabla 13. Plan de estudios de 1940.

\begin{tabular}{|l|c|l|l|l|}
\hline \multicolumn{4}{|c|}{ Plan de estudios de $1 \mathbf{9 4 0}^{\mathbf{7 8}}$ - Bachiller } \\
\hline \multicolumn{1}{|c|}{ Curso único } \\
\hline Primer Cuatrimestre & H/s & \multicolumn{2}{c|}{ Segundo Cuatrimestre } & H/s \\
\hline Caligrafía & 6 & Religión y Moral & 6 \\
\hline Música & 3 & Caligrafía & 3 \\
\hline Pedagogía & 6 & Música & 6 \\
\hline $\begin{array}{l}\text { Costura, bordado en blanco y corte de } \\
\text { ropa blanca }\end{array}$ & 6 & Pedagogía & $\begin{array}{l}\text { Corte de vestidos, labores artísticas y } \\
\text { economía doméstica }\end{array}$ & 6 \\
\hline Prácticas de enseñanza & & Historia de la Pedagogía & 3 \\
\hline & & Prácticas de enseñanza & \\
\hline
\end{tabular}

Fuente. Elaboración propia.

\footnotetext{
77 Decreto de 10 de febrero de 1940.

78 Decreto 30 de agosto de 1914 - Decreto 10 de febrero de 1940 - O.M. del 28 de febrero de 1940 - Decreto 4 de octubre de 1940 - O.M. de 7 de octubre de 1947.
} 
Nuevos cambios se producirán con la puesta en marcha de un Plan Provisional en 1942 y el Plan de $1945^{79}$, que acompaña a la Ley de Educación Primaria.

Se establece de nuevo la vuelta al nombre de Escuelas de Magisterio, separándose las masculinas y las femeninas. Se contempla la creación de Escuelas de Magisterio de la Iglesia y privadas.

Tabla 14. Plan de estudios de 1942.

\begin{tabular}{|c|c|c|c|c|c|c|c|}
\hline \multicolumn{8}{|c|}{ Plan de estudios de $1942^{80}$ (revisado) } \\
\hline Primer curso & $\mathrm{H} / \mathrm{s}$ & Segundo curso & $\mathrm{H} / \mathrm{s}$ & Tercer curso & $\mathrm{H} / \mathrm{s}$ & Cuarto curso & $\mathrm{H} / \mathrm{s}$ \\
\hline Religión & 3 & Religión & 2 & Religión & 2 & $\begin{array}{l}\text { Religión y su } \\
\text { Metodología }\end{array}$ & 2 \\
\hline $\begin{array}{l}\text { Lengua } \\
\text { Española }\end{array}$ & 3 & $\begin{array}{l}\text { Lengua } \\
\text { Española }\end{array}$ & 2 & $\begin{array}{l}\text { Lengua } \\
\text { Española }\end{array}$ & 2 & $\begin{array}{l}\text { Psicología y } \\
\text { Lógica }\end{array}$ & 2 \\
\hline Caligrafía & 1 & Caligrafía & 1 & Música & 2 & $\begin{array}{l}\text { Fisiología e } \\
\text { Higiene }\end{array}$ & 2 \\
\hline Matemáticas & 3 & Matemáticas & 2 & $\begin{array}{l}\text { Aritmética y } \\
\text { elementos } \\
\text { Algebra }\end{array}$ & 2 & $\begin{array}{l}\text { Didáctica general } \\
\text { y especial y } \\
\text { Organización } \\
\text { Escolar }\end{array}$ & 2 \\
\hline Geografía & 2 & Geografía & 2 & Geografía & 2 & Pedagogía & 2 \\
\hline Historia & 2 & Música & 2 & $\begin{array}{l}\text { Historia } \\
\text { Universal }\end{array}$ & 2 & $\begin{array}{l}\text { Historia de la } \\
\text { Pedagogía }\end{array}$ & 2 \\
\hline $\begin{array}{l}\text { Ciencias de la } \\
\text { Naturaleza }\end{array}$ & 2 & $\begin{array}{l}\text { Ciencias de la } \\
\text { Naturaleza }\end{array}$ & 2 & $\begin{array}{l}\text { Elementos de } \\
\text { Física y } \\
\text { Química }\end{array}$ & 2 & \begin{tabular}{|l|} 
Labores artísticas \\
y Enseñanzas del \\
Hogar (maestras)
\end{tabular} & 2 \\
\hline $\begin{array}{l}\text { Lengua } \\
\text { Moderna }\end{array}$ & 2 & Francés & 2 & $\begin{array}{c}\text { Lengua } \\
\text { francesa }\end{array}$ & 2 & $\begin{array}{l}\text { Trabajos } \\
\text { Manuales } \\
\text { (Maestros) }\end{array}$ & 2 \\
\hline $\begin{array}{l}\text { Enseñanza } \\
\text { Patriótica }\end{array}$ & 2 & \begin{tabular}{|l|} 
Historia \\
Educación \\
Patriótica \\
\end{tabular} & 2 & $\begin{array}{l}\text { Trabajos } \\
\text { Manuales } \\
\text { (Maestros) }\end{array}$ & 2 & \multicolumn{2}{|c|}{ Prácticas Enseñanza } \\
\hline $\begin{array}{l}\text { Enseñanza } \\
\text { Artística } \\
\text { (dibujo y } \\
\text { modelado) } \\
\end{array}$ & 2 & Dibujo & 2 & Dibujo & 2 & & \\
\hline Gimnasia & 3 & $\begin{array}{l}\text { Gimnasia y } \\
\text { Recreos } \\
\text { dirigidos }\end{array}$ & 2 & $\begin{array}{l}\text { Labores } \\
\text { (maestras) }\end{array}$ & 2 & & \\
\hline $\begin{array}{l}\text { Recreos } \\
\text { Dirigidos } \\
\end{array}$ & 3 & Labores & 2 & & & & \\
\hline $\begin{array}{l}\text { Labores y } \\
\text { Enseñanzas de } \\
\text { Hogar (maestra }\end{array}$ & & $\begin{array}{l}\text { Enseñanzas del } \\
\text { Hogar } \\
\text { (maestras) }\end{array}$ & 1 & & & & \\
\hline
\end{tabular}

Fuente. Elaboración propia.

\footnotetext{
${ }^{79}$ Aparece junto con el Plan de Formación, el 17 de julio de 1945

${ }^{80}$ O.M. de 24 de septiembre de 1942 (BOE No273) - O. de 7 de octubre de 1942 - O.M. 27 noviembre de 1943 - O. 6 de diciembre de 1943 (B.O.E. del 10) - O.M. de 4 de octubre de 1944 - O. 16 de octubre de 1944 - O.M. de 22 de octubre de 1945 - O.M. de 15 de noviembre de 1945
} 
En 1950 se plantea un nuevo Plan de Estudios ${ }^{81}$ que contiene una fuerte carga política, impregnado de los principios del nacionalcatolicismo. Se mantienen los mismos requisitos de acceso y permanencia pero obliga a asistir a un campamento político social, del Frente de Juventudes o de la Sección Femenina, como condición para poder ejercer. Se mantendrá vigente unos 17 años.

En cuanto a las asignaturas o materias impartidas:

- Siguen predominando las materias de Ciencias y Letras puesto que lo que interesaba era que consiguieran conocimientos sólidos en ellas para luego enseñarlos en las Escuelas Primarias.

- Se cuida especialmente el desarrollo de las Prácticas, presentes en todos los cursos.

- Denota importantes carencias culturales y sobre todo profesionales, además de las diferencias sexistas de las asignaturas que se podían cursar.

- Señalar la influencia nacional-católica, atendiendo a comentarios de Araque (2009, p. 122):

La religiosidad se hizo efectiva en los maestros, programas y libros que quedaron impregnados del espíritu cristiano, según se observa en el Plan de Estudios de 1950, que incorporaba la asignatura de Religión en los tres cursos del Magisterio. Además, los profesores y cuestionarios debían proponerse por la jerarquía eclesiástica.

- Todos los maestros impartían metodología de la asignatura que tenían asignada. Será la primera vez que se menciona el concepto de Metodología del Dibujo.

${ }^{81}$ Decreto 7 de julio de 1950. BOE 219 de 7 de agosto de 1950 
Tabla 15. Plan de estudios de 1950.

\begin{tabular}{|c|c|c|c|c|c|}
\hline \multicolumn{6}{|c|}{ Plan de estudios de 1950} \\
\hline Primer curso & $\mathrm{H}$ & Segundo curso & $\mathrm{H}$ & Tercer curso & $\mathrm{H}$ \\
\hline $\begin{array}{l}\text { Religión y su } \\
\text { metodología }\end{array}$ & 2 & Religión y su metodología & 2 & $\begin{array}{l}\text { Religión y su } \\
\text { Metodología }\end{array}$ & 2 \\
\hline Matemáticas & 3 & Matemáticas & 2 & $\begin{array}{l}\mathrm{H}^{\mathrm{a}} \text { de la Literatura } \\
\text { Española, Metodología } \\
\text { de la Lengua }\end{array}$ & 3 \\
\hline Geografía e Historia & 3 & Física & 3 & $\mathrm{H}^{\mathrm{a}}$ Natural & 2 \\
\hline Fisiología e Higiene & 1 & Química & 3 & Francés & 2 \\
\hline \multirow{2}{*}{ Lengua Española } & 3 & Pedagogía & 3 & Pedagogía & 3 \\
\hline & & Música & 2 & Música & 2 \\
\hline $\begin{array}{l}\text { Labores y } \\
\text { Enseñanzas del } \\
\text { Hogar (maestras) }\end{array}$ & 2 & $\begin{array}{l}\text { Labores y Enseñanzas } \\
\text { del Hogar }\end{array}$ & 2 & $\begin{array}{l}\text { Agricultura e industrias } \\
\text { agrícolas }\end{array}$ & 2 \\
\hline Filosofía & 3 & Filosofía & 2 & Geografía e Historia & 3 \\
\hline Educación física & 3 & Educación física & 3 & Educación física & 3 \\
\hline $\begin{array}{l}\text { Formación político- } \\
\text { social }\end{array}$ & 2 & Formación político-social & 2 & $\begin{array}{l}\text { Formación político- } \\
\text { social }\end{array}$ & 1 \\
\hline $\begin{array}{l}\text { Practica de } \\
\text { enseñanza }\end{array}$ & 1 & Practica de enseñanza & 1 & Practica de enseñanza & 1 \\
\hline $\begin{array}{l}\text { Trabajos Manuales } \\
\text { (maestros) }\end{array}$ & 2 & Trabajos Manuales & $1 / 2$ & & \\
\hline \multirow{3}{*}{ Caligrafía } & 1 & Caligrafía & 1 & & \\
\hline & & Dibujo y su metodología & 1 & Dibujo del natural & 1 \\
\hline & & \begin{tabular}{|l|} 
Psicología \\
\end{tabular} & 1 & & \\
\hline
\end{tabular}

Fuente. Elaboración propia.

\subsubsection{El Plan del 67 y la Ley Palasí.}

La siguiente modificación la encontraremos con la Reforma de la Educación Primaria $^{82}$ y el consiguiente Plan de estudios de $1967^{83}$, que estará vigente en las Escuelas Normales durante dos años. Es el último plan no universitario. Se mejoran sensiblemente los contenidos y las enseñanzas. Las asignaturas teóricas, que se subdividen en cuatrimestres y anuales, ganan en contenidos pedagógicos, psicológicos y filosóficos.

${ }^{82}$ Ley de 21 de diciembre de 1965.

${ }^{83}$ Plan de Estudios de las Escuelas Normales (BOE 8/6/1967). 
Tabla 16. Plan de estudios de 1967.

\begin{tabular}{|c|c|c|c|c|c|c|}
\hline \multicolumn{7}{|c|}{ Plan de estudios de 1967} \\
\hline Primer curso & & & Segundo curso & & & Tercer curso \\
\hline $\begin{array}{l}\text { Pedagogía e Historia de la } \\
\text { Educación }\end{array}$ & 3 & 3 & $\begin{array}{l}\text { Filosofía y Sociología de } \\
\text { la Educación }\end{array}$ & 4 & 4 & \multirow{14}{*}{$\begin{array}{l}\text { CURSO DE } \\
\text { PRACTICAS }\end{array}$} \\
\hline $\begin{array}{l}\text { Psicología general y } \\
\text { evolutiva }\end{array}$ & 3 & 3 & $\begin{array}{l}\text { Didáctica y } \\
\text { Organización escolar }\end{array}$ & 6 & 6 & \\
\hline $\begin{array}{l}\text { Didáctica de las } \\
\text { Matemáticas }\end{array}$ & 3 & 3 & $\begin{array}{l}\text { Didáctica de las } \\
\text { Matemáticas }\end{array}$ & 3 & 0 & \\
\hline $\begin{array}{l}\text { Didáctica de la Lengua } \\
\text { Española y Literatura }\end{array}$ & 3 & 3 & $\begin{array}{l}\text { Didáctica de la Lengua } \\
\text { Española y Literatura }\end{array}$ & 2 & 2 & \\
\hline $\begin{array}{l}\text { Didáctica de la Geografía e } \\
\text { Historia }\end{array}$ & 2 & 2 & $\begin{array}{l}\text { Didáctica de la } \\
\text { Geografía e Historia }\end{array}$ & 0 & 3 & \\
\hline $\begin{array}{l}\text { Didáctica de las Ciencias } \\
\text { Naturales }\end{array}$ & 2 & 2 & $\begin{array}{l}\text { Didáctica de la Física y } \\
\text { la Química }\end{array}$ & 2 & 2 & \\
\hline $\begin{array}{l}\text { Idioma (inglés o francés) y } \\
\text { su didáctica }\end{array}$ & 2 & 2 & $\begin{array}{l}\text { Idioma (inglés o francés) } \\
\text { y su didáctica }\end{array}$ & 2 & 2 & \\
\hline Didáctica de la Religión & 2 & 2 & Didáctica de la Religión & 1 & 1 & \\
\hline $\begin{array}{l}\text { Didáctica de la Formación } \\
\text { del Espíritu Nacional }\end{array}$ & 1 & 1 & $\begin{array}{l}\text { Didáctica de la } \\
\text { Formación del Espíritu } \\
\text { Nacional }\end{array}$ & 1 & 1 & \\
\hline Educación Física & 3 & 3 & Educación Física & 3 & 3 & \\
\hline Música & 2 & 2 & Música & 2 & 2 & \\
\hline Practicas de Enseñanza & 2 & 2 & Practicas de Enseñanza & 2 & 2 & \\
\hline $\begin{array}{l}\text { Manualizaciones y } \\
\text { Enseñanzas del Hogar }\end{array}$ & 2 & 2 & $\begin{array}{l}\text { Manualizaciones y } \\
\text { Enseñanzas del Hogar }\end{array}$ & 2 & 2 & \\
\hline Dibujo & 2 & 2 & Dibujo & 2 & 2 & \\
\hline
\end{tabular}

Fuente. Elaboración propia.

En este Plan aparecen las asignaturas de Didácticas Específicas así como "Expresión Artística" que incorpora el dibujo, la música y las manualidades. Es el primer Plan que incorpora aspectos de la Didáctica y de la Metodología del Dibujo.

La Orden Ministerial de septiembre de 1969, declara extinto el Plan de Estudios de Magisterio aprobado en julio de 1950. La ley General de Educación de $1970^{84}$ o Ley Palasí ${ }^{85}$, cambia la denominación de la hasta

${ }^{84}$ Ley 14/1970, de 4 de agosto, General de Educación y Financiamiento de la Reforma Educativa (BOE de 6 de agosto de 1970). Refrendado por O. M. de 25 de Junio de 1977.

${ }^{85}$ Los títulos de Magisterio (con esa denominación desde 1991) que también actualizaron sus planes en el 2000, se consagraron como plenamente universitarios. Fue en 1971 cuando se habían incorporado a la Universidad, y en ese marco de reconocimiento, sobre todo desde

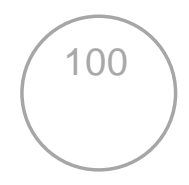


ahora Educación Primaria a Educación General Básica (EGB). Establece, paralelamente, planes experimentales en las Normales ${ }^{86}$, dando lugar al Plan Experimental de $1971^{87}$.

En esta ley se expresa que los planes de estudio de los Centros Universitarios, con asignaturas obligatorias y optativas, serán elaborados por las Universidades, bajo la supervisión del Ministerio de Educación y Ciencia. Con él se mejoran ligeramente los contenidos aunque siguen siendo insuficientes para responder de forma adecuada al reto profesionalizador. Aparecen, por primera vez los maestros especialistas (especialidades de Ciencias, Ciencias Humanas, Filología, Educación Especial y Preescolar). Además señalar que amplían su campo educativo en dos cursos, puesto que la EGB alarga en dos años la formación obligatoria.

En general cada Universidad adaptó los Planes Experimentales de forma diferente aunque siguiendo las pautas que marcaba la Ley de Educación. Ello provocó cierta dispersión en los programas y curriculums donde algunas asignaturas cambiaron de curso o se repartían de diferente forma (como de hecho ocurre en las de la Comunidad Valenciana). En Madrid, en el año 1974, una Comisión Nacional de Escuelas Universitarias de Profesorado de EGB intenta hacer una revisión de los Planes de Estudio (Cuenca, 1988) y consensuan que el Plan vigente no es adecuado para formar un verdadero profesional de la educación a nivel básico y aconsejando establecer un plan menos culturalista. A pesar de todo se sigue aplicando el Plan del 71, únicamente con algunos cambios en los horarios de las asignaturas.

Este plan de estudios permanecerá vigente durante 18 años aunque con sucesivas modificaciones. Se concretaran definitivamente en $1977^{88}$, cuando el

finales de los ochenta, las áreas de las didácticas específicas se desarrollaron de forma vertiginosa.

86 BOE 23/10/1971.

87 A partir de este Plan de estudios el número de asignaturas y especialidades aumenta considerablemente, ademas de que existen diferencias entre Universidades. Por lo tanto, resulta complejo seguir incluyéndolos en el texto. Por ello remitimos al lector a su consulta completa en Anexos.

88 Orden Ministerial de 13 de junio de 1977 (BOE 25/6/77). 
MEC establece nuevas directrices en la elaboración de los planes de estudio para homogeneizarlos. Se expresa que, más que definir materias, se proponen unas directrices sobre áreas de materias, lo cual pretende facilitar que el contenido interno pueda variar para facilitar convalidaciones y valoraciones globales de las áreas.

Se perfilan las especialidades de Preescolar, Educación Especial y Pedagogía Terapéutica, esta última solo en algunos centros. Se recomienda que los cursos no se repartan en cuatrimestres y que las prácticas en centros se realicen preferentemente en los cursos de $3^{\circ}$ y $4^{\circ}$. Se introduce la Educación Física en todas las especialidades. Se definen, de forma bastante general, las asignaturas consideradas como fundamentales.

Durante los años 80 se suceden seminarios y reuniones entre los directores de las Escuelas Universitarias de Magisterio para tratar las problemáticas de los estudios y los centros (Cuenca, 1988) como antecedentes de nuevas reformas.

2.2.7. La LOGSE. Ley Orgánica de Ordenación General del Sistema Educativo.

La Ley de Reforma Universitaria de 1983 inició el camino de la incorporación definitiva de estos estudios en la Universidad lo cual completó definitivamente la Ley Orgánica de Ordenación General del Sistema Educativo en 1990 (LOGSE) $^{89}$. Se establece el nuevo título universitario de Maestro, en sus diversas especialidades, Plan de Estudios en $1991^{90}$.

Las asignaturas se estructuran en créditos y existen de diferentes tipos:

- Troncales: que deben conformar al menos el 30\% del total de créditos del título y vienen fijadas por la administración.

\footnotetext{
${ }^{89}$ Ley Orgánica de Ordenación General del Sistema Educativo 1/1990, de 3 de octubre (BOE 4 octubre de 1990).

${ }^{90}$ Real Decreto 1440/1991, de 30 de agosto BOE. 11-10-91.
} 
- Determinadas por la Universidad: que suponen aproximadamente un $50 \%$ del total. Dentro de estas diferenciamos las Obligatorias (libremente establecidas por la Universidad ${ }^{91}$, las Optativas $^{92}$ y las llamadas de Libre Configuración ${ }^{93}$.

En alguna de las universidades que analizaremos más adelante con detalle, todavía se producen algunas modificaciones de planes de estudio en el $2000^{94}$. Realmente es una continuación del anterior puesto que mantiene las mismas especialidades pero lo que hace es modificar algunas dedicaciones horarias de las asignaturas. También se mantiene la separación en troncales, optativas y de libre elección.

\subsubsection{El EEES. Los nuevos Grados en Magisterio.}

El 21 de diciembre de 2001 se publica en el BOE la Ley Orgánica de Universidades $^{95}$, derogando la de Reforma Universitaria de 1983 que fue la primera ley que configura la estructura y el gobierno de las universidades españolas según los preceptos de la Constitución de 1978. Esta ley sería modificada más adelante por la Ley Orgánica 4/2007, de Universidades para adaptarse al proceso de Bolonia e iniciar el EEES.

El siguiente Plan de Estudios para Magisterio, de 2008, es producto de la aplicación de la LOCE (Ley Orgánica de Educación) aprobada en mayo de 2006. Tiene objetivo común de diseñar el mejor plan de formación para los estudiantes teniendo en cuenta las necesidades de la sociedad en la que han de ejercer; suele ser valorado con escepticismo como una propuesta ingenua.

\footnotetext{
${ }^{91}$ Fijan su contenido, el número de créditos, su distribución en teóricos y prácticos así como las áreas de conocimiento a las que se vinculan.

92 La Universidad fija igualmente el contenido, el número de créditos y las áreas a las que se vinculan atendiendo a criterios de disponibilidad docente, necesidades sociales o demanda de los estudiantes.

93 Que responden a una oferta institucional que permite cierta libertad personal a los estudiantes de flexibilizar la configuración de sus estudios.

${ }^{94}$ Resolución de 27 de julio de 2000. BOE (14/9/2000).

95 Ley orgánica 6/2001, de 21 de diciembre 2001
} 
La estructuración de los Grados de Magisterio se ha prolongado hasta el curso 2009-10. Posteriormente han realizado algunas adaptaciones para definir mejor la titulación.

Los nuevos Grados tienen 240 créditos ECTS, repartidos en 4 cursos. En el EEES la unidad de medida de las asignaturas ya no será el crédito antiguo (basado únicamente en las horas lectivas del profesor, por las que 10 horas de clase correspondían a un crédito), sino que será el crédito ECTS (sistema europeo de transferencia de créditos). En este sistema se valorarán las horas que el alumnado dedica a la actividad de estudio. En esta actividad, que será de entre 25 y 30 horas por crédito, se incluye el tiempo dedicado a las horas lectivas, horas de estudio, tutorías, seminarios, trabajos, prácticas o proyectos, así como las exigidas para la preparación y realización de exámenes y evaluaciones. La gran ventaja de los créditos ECTS es que es la unidad de medida igual en todas las universidades del nuevo espacio europeo.

En los planes de Bolonia no se pueden aplicar las especialidades y por lo tanto algunas universidades definen itinerarios o menciones dentro del título único, de Infantil y Primaria:

- Se equipara al resto de carreras universitarias, pues todas ellas van a durar 4 años.

- Se incrementan un año los estudios, muchos estudiantes europeos de Magisterio tenían formaciones que duraban más de los tres que se les dedicaba en España. Sobre todo se aumenta el número de horas de prácticas que llegaran, en algunos casos, a sumar los 60 créditos en el total de la carrera.

- Se intenta que los contenidos se equilibren entre formación psicopedagógica (30\%), la formación en las diferentes áreas de conocimiento (40\%) y la formación práctica (30\%).

La legislación que los rige es: 
- Real Decreto 1393/2007, de 29 de octubre, por el que se establece la ordenación de las enseñanzas universitarias oficiales (BOE, de 30 de octubre).

- Orden ECI/3854/2007, de 27 de diciembre, por la que se establecen los requisitos para la verificación de los títulos universitarios oficiales que habiliten para el ejercicio de la profesión de Maestro de Educación Infantil (BOE, 29 de diciembre).

- Orden ECI/3857/2007, de 27 de diciembre, por la que se establecen los requisitos para la verificación de los títulos universitarios oficiales que habiliten para el ejercicio de la profesión de Maestro de Educación Primaria (BOE, 29 de diciembre).

\subsection{Los estudios de Magisterio en la Comunitat Valenciana.}

Tras haber hecho un recorrido general y basado fundamentalmente en las actuaciones a nivel estatal, en este apartado querremos centrar nuestro interés en las tres universidades públicas que existen, a día de hoy, en la Comunitat Valenciana. Estas son, por orden alfabético, la Universidad de Alicante, la Jaume I de Castellón y la Universitat de València.

La más antigua de ellas es la de Valencia (1499) que se fundó con el privilegio real de Fernando II el Católico, concedido el 16 de febrero de 1502. Seguida de la de Alicante, creada en 1979 pero heredera de la Pontificia y Real Universidad de Orihuela. La de Castellón es de creación mucho más reciente.

Los estudios de Magisterio han seguido una legislación común a nivel nacional hasta que con la Ley de Reforma Universitaria de 1983 se dotó a las universidades de autonomía para organizar y definir sus estudios. Anteriormente, ya observábamos alguna diferencia entre los curriculums que se aplicaban en las diferentes universidades, pero no dejaban de ser cambios de alguna materia a cursos diferentes, desigual dedicación horaria o la introducción de materias "propias de la universidad". 
Hasta el Plan de estudios de 1971 los curriculums fueron muy semejantes y nos remitimos a los apartados anteriores. De aquí en adelante difieren según la universidad y ello es lo que queremos señalar. Veremos a partir de ahora los planes previos y la nueva organización de los estudios de Magisterio en el EEES, centrándonos en las Universidades de la Comunidad Valenciana: Alicante, Castellón y Valencia.

\subsubsection{La Universidad de Alicante y los estudios de Magisterio.}

Alicante está situada al sur de la Comunidad Valenciana. Es una ciudad con una población de unos 330.000 habitantes. La ciudad está a orillas del Mediterráneo en una provincia que se caracteriza por una gran planicie con algunas colinas y elevaciones. Destaca por ser una ciudad con un rico comercio, gracias a su puerto, y muy turística ya que cuenta con un rico patrimonio natural e histórico cultural. Es una ciudad que ha crecido mucho en numerosos aspectos desde la segunda mitad del siglo XX.

La Universidad de Alicante (UA) dejó de pertenecer a la Administración Central del Estado con el Real Decreto 2633/1985, de 20 de noviembre, de traspaso de servicios a la Generalitat Valenciana en materia de Universidades. Tiene su sede concretamente en San Vicente del Raspeig (Alicante). Fue creada en octubre de 1979 sobre la estructura del Centro de Estudios Universitarios (CEU) que empezó a funcionar en 1968 y como heredera de la Universidad de Orihuela $^{96}$.

Los estudios universitarios se reiniciaron en el curso 1968-69 con tan sólo 230 alumnos para pasar en la actualidad a una población estudiantil de casi 33.000 estudiantes, siendo la universidad con un mayor crecimiento proporcional de alumnado entre todas las del Estado español. Tiene un amplio campus y actualmente una cincuentena de titulaciones en Áreas de Ciencias Sociales y

96 Fundada 40 años después de la Universidad de Valencia, regida por la Orden de los Predicadores (Dominicos) y denominada Pontificia y Real Universidad de Orihuela. Fue suprimida en 1835. 
Jurídicas, Experimentales, Tecnológicas, Humanidades, Educación y Ciencias de la Salud. Se define como universidad innovadora, activa, dinámica y abierta al exterior con una prestigiosa actividad investigadora.

La Universidad de Alicante ofrece formación y servicios, así como actividades culturales en las diferentes comarcas de su entorno. Tiene diferentes sedes, que actúan como una extensión del campus, son la propia ciudad de Alicante, Benisa, Orihuela, Cocentaina, Biar, La Nucia, Jijona y Villena.

Las Diplomaturas de Maestro de EGB (1971) se e estructuran en tres cursos y las especialidades que se imparten son:

- Maestro Especialista en Filología.

- Maestro Especialista en Ciencias.

- Maestro Especialista en Ciencias Humanas.

- Maestro Especialista en Preescolar.

Los cursos están divididos en dos cuatrimestres, con asignaturas de 9 y 4,5 créditos, según sean anuales o cuatrimestrales. Cada crédito corresponde a 10 horas de enseñanzas teórica, práctica o equivalentes. Las asignaturas se dividen en Obligatorias y Optativas. Existen una serie de comunes para todos y en $2^{\circ}$ y $3^{\circ}$ se puede elegir un número determinado de optativas, que varían según el curso y la especialidad.

Las Diplomaturas de Maestro (1992) se estructuran también en tres cursos. Las especialidades que se imparten son:

- Maestro Especialista en Primaria.

- Maestro Especialista en Infantil.

- Maestro Especialista en Lengua Extranjera.

- Maestro Especialista en Educación Física.

- Maestro Especialista en Educación Musical.

Las asignaturas se dividen en Troncales, Obligatorias, Optativas y las de Libre Configuración Curricular. Estas se pueden elegir de entre todas las que se 
imparten en la Universidad. Existen una serie de comunes para todos y se puede elegir un número determinado de optativas, que varían según el curso y la especialidad.

Se realizan una serie de modificaciones en los años 1996 y 2000 sobre todo relativas al reparto de asignaturas y al creditaje de las mismas. El funcionamiento de la carrera es parecido en estos tres casos.

Las Diplomaturas de Maestro hasta ahora existentes se extinguen siguiendo el siguiente esquema:

Tabla 17. Extinción (D. Maestro) / implantación (Grado). Alicante.

\begin{tabular}{|l|c|c|c|c|c|}
\hline \multicolumn{7}{|c|}{ Planes de Estudio de Grado } \\
\hline \multicolumn{1}{|c|}{ Curso } & $\mathbf{2 0 0 9 - 1 0}$ & $\mathbf{2 0 1 0 - 1 1}$ & $\mathbf{2 0 1 1 - 1 2}$ & $\mathbf{2 0 1 2 - 1 3}$ & $\mathbf{2 0 1 3 - 1 4}$ \\
\hline MAESTRO & Docencia & $\begin{array}{c}\text { Docencia en } \\
2^{\circ} \text { y } 3^{\circ}\end{array}$ & Solo $3^{\circ}$ & Solo exámenes & Solo exámenes \\
\hline GRADO & & Inicio $1^{\circ}$ & $1^{\circ}$ y $2^{\circ}$ & $1^{\circ}, 2^{\circ}$ y $3^{\circ}$ & Todos los cursos \\
\hline
\end{tabular}

Fuente. Elaboración propia.

El Plan de Estudios de los Grados de Maestro en Educación Infantil ${ }^{97}$ y Educación Primaria ${ }^{98}$ se adscriben a la rama de las Ciencias Sociales y Jurídicas. La razón de ello son los créditos en materias básicas incluidas en esta rama. Las materias incluidas en el titulo se relacionan directamente con las competencias generales y específicas que se pretende alcance el alumnado.

\footnotetext{
${ }^{97}$ Basado en el R.D. 1393/2007, de 29 de octubre, por el que se establece la ordenación de las enseñanzas universitarias oficiales (art. 12.9), en la Resolución de 17 de diciembre de 2007 de la Secretaría de Universidades e Investigación, en la ORDEN ECI/3854/2007, de 27 de diciembre y en la Normativa para el Diseño, Elaboración y Aprobación de los Planes de Estudio de Grado de la Universidad de Alicante.

${ }^{98}$ Basado en el R.D. 1393/2007, de 29 de octubre, por el que se establece la ordenación de las enseñanzas universitarias oficiales (art. 12.9), en la Resolución de 17 de diciembre de 2007 de la Secretaría de Universidades e Investigación, en la ORDEN ECI/3857/2007, de 27 de diciembre y en la Normativa para el Diseño, Elaboración y Aprobación de los Planes de Estudio de Grado de la Universidad de Alicante.
} 
Tabla 18. Organización Planes de Estudio de Grado. Alicante.

\begin{tabular}{|l|c|c|c|c|c|}
\hline \multicolumn{7}{|c|}{ Planes de Estudio de Grado } \\
\hline $\begin{array}{c}\text { TOTAL cr. } \\
240\end{array}$ & $\begin{array}{c}\text { Formación } \\
\text { Básica }\end{array}$ & Obligatorias & Optativas & Practicas & $\begin{array}{c}\text { Trabajo Fin de } \\
\text { Grado }\end{array}$ \\
\hline & & & & & 6 \\
\hline PRIMARIA & 60 & 102 & 24 & 48 & 6 \\
\hline INFANTIL & 102 & 60 & 24 & 48 & \\
\hline
\end{tabular}

Fuente. Elaboración propia.

El reparto de asignaturas se realiza en asignaturas semestrales de 6 y 9 créditos ECTS. En cada semestre se cursan 30 créditos para realizar los 60 créditos por curso. Se ofrece la posibilidad de cursar los estudios a tiempo parcial cursando 30 ECTS por curso académico.

Las materias, según la definición de la propia Universidad, tienen un carácter interdisciplinar, se estructuran en este plan de estudios en función de los grandes bloques temáticos que constituyen el perfil generalista de la titulación de maestro. Se clasifican y distribuyen según la propuesta de clasificación por Módulos recogida en la Orden ECI/3857/2007.

En el apartado de Optatividad (a partir de tercer curso) tanto en Infantil como Primaria, se ofrece la posibilidad de realizar las Menciones en Lengua Extranjera: Inglés, Educación Física, Música o Educación Especial/Pedagogía, si se cursan los 24 créditos en las optativas vinculadas a dichas menciones. También se debe vincular el Practicum 3 y Trabajo Fin de Grado.

Cada curso se admiten 360 personas en Infantil y 440 en Primaria. Actualmente, los estudios se imparten en la Facultad de Educación y el área de Didáctica de la Expresión Plástica está ubicada en el Departamento de Didáctica General y Didácticas Especificas. 
Tabla 19. Organización del Plan de Estudios de Grado Infantil. Alicante.

\begin{tabular}{|c|c|c|c|c|c|}
\hline \multicolumn{7}{|c|}{ Plan de Estudios de Grado Infanti ${ }^{99}$} \\
\hline CURSO & $1^{\circ}$ & $2^{\circ}$ & $3^{\circ}$ & $4^{\circ}$ & TOTAL \\
\hline $\begin{array}{c}\text { FORMACION } \\
\text { BASICA }\end{array}$ & 36 & 42 & 18 & 6 & 102 \\
\hline OBLIGATORIAS & 24 & 18 & 12 & 6 & 60 \\
\hline OPTATIVAS & - & - & 12 & 12 & 24 \\
\hline PRACTICAS & - & - & 18 & 30 & 48 \\
\hline TFG & - & - & - & 6 & 6 \\
\hline TOTAL & 60 & 60 & 60 & 60 & 240 \\
\hline
\end{tabular}

Fuente. Elaboración propia.

Tabla 20. Organización del Plan de Estudios de Grado Primaria. Alicante.

\begin{tabular}{|c|c|c|c|c|c|}
\hline \multicolumn{7}{|c|}{ Plan de Estudios de Grado Primaria } \\
\hline CURSO & $1^{\circ}$ & $2^{\circ}$ & $3^{\circ}$ & $4^{\circ}$ & TOTAL \\
\hline $\begin{array}{c}\text { FORMACION } \\
\text { BASICA }\end{array}$ & 36 & 24 & - & - & 60 \\
\hline OBLIGATORIAS & 24 & 36 & 30 & 12 & 102 \\
\hline OPTATIVAS & - & - & 12 & 12 & 24 \\
\hline PRACTICAS & - & - & 18 & 30 & 48 \\
\hline TFG & - & - & - & 6 & 6 \\
\hline TOTAL & 60 & 60 & 60 & 60 & 240 \\
\hline
\end{tabular}

Fuente. Elaboración propia.

\subsubsection{La Universidad Jaume I de Castellón y los estudios de Magisterio.}

Castellón de la Plana está situada al norte de la Comunidad Valenciana, entre Valencia y Barcelona. Es una ciudad con una población de unos 180.000 habitantes. Es una provincia con marcadas diferencias entre la zona de costa y un interior muy montañoso. Destaca por su rico patrimonio cultural, histórico y paisajístico.

99 Grado de Maestro en Educación Infantil (Plan 2010, con Menciones). 
Castellón ha crecido mucho en los últimos años en muchos aspectos. Sin dejar de lado su tradición ha tenido un buen desarrollo económico y cultural tal y como demuestran la Universitat Jaume I, el Auditorio y Palacio de Congresos, el Museo de Bellas Artes, el puerto deportivo, etc.

La Universitat Jaume I nació como fruto de una unánime reivindicación social. El 27 de febrero de 1991 se publica la Ley 3/1991 de 19 de febrero de Creación de la Universitat Jaume I de Castellón por parte de las Cortes Valencianas. Esta circunstancia se vive como una oportunidad única para generar un instrumento de transformación social, para lo cual:

(...) es fundamental vincularla desde su origen a las demandas sociales, tanto en el perfil de formación de sus titulados, como en el liderazgo cultural que debe asumir, o en la respuesta que dé a las necesidades industriales y empresariales en proyectos conjuntos de investigación y desarrollo ${ }^{100}$.

La Universidad Jaume I de Castellón ofrece formación y servicios, así como actividades culturales en las diferentes comarcas de su entorno. Tiene diferentes sedes que actúan como una extensión del campus mediante el Programa Campus Obert. La UJI ofrece a las personas interesadas de las diferentes zonas el acceso a las actividades en las mismas condiciones que los de la ciudad. Estas sedes son: del Nord, dels Ports, del Interior, de la Ciudad, del Penyagolosa y del Camp de Morvedre ${ }^{101}$.

Su modelo educativo se basa en la formación a lo largo de la vida, la formación integral de la persona y la participación activa en el progreso social basado en una convivencia pacífica, justa, solidaria y respetuosa con el medio ambiente. Además la UJI tiene una marcada vocación de internacionalización de sus actividades surgida de la necesidad de apertura al mundo que caracteriza a las jóvenes universidades europeas y de las necesidades socioeconómicas del territorio valenciano.

100 Ley de creación de la Universitat JAUME I, de 13 de febrero de 1991, DOGV 27/2/1991.Preámbulo p. 1687.

${ }^{101}$ Página web de la Universidad: http://ujiapps.uji.es/institucional/uji/presentacio/. 
Nació en pleno proceso de consolidación de la "Sociedad de la información" y es por lo que sus pasos siempre han estado regidos por los avances en Tecnologías de la Información y la Comunicación.

En septiembre de 1993, el grupo formado por el profesor del Departamento de Educación, Jordi Adell, y por los miembros del Servicio de Informática de la Universidad, Antoni Carles Bellver, Enrique Navarro y Enrique Silvestre, informan a Tim Berners-Lee, creador de la WEB, que han instalado un servidor web experimental en la dirección .... Berners-Lee lo incluye en el listado de servidores mantenidos por el servidor de la Organización Europea de Investigación Nuclear (CERN) y nace así la primera web española.

En 1997 se publica en el Diari Oficial de la Generalitat Valenciana el Decreto $5 / 1997$, de 28 de enero, del Gobierno valenciano ${ }^{102}$, por el que se aprueban Ios Estatutos de la Universitat Jaume I de Castelló, con el lema Sapientia sola libertas est, regidos per ocho principios generales: libertad, democracia, justicia, igualdad, independencia, pluralidad, paz y solidaridad.

En diciembre de 2003 se aprueban definitivamente los nuevos Estatutos de la Universitat Jaume I, adaptados al EEES, mediante el Decreto 252/2003 ${ }^{103}$.

Fue reconocida en 2008 con el Sello de Oro de Excelencia Europea 500+ con la evaluación del Club de Excelencia en Gestión adaptado al modelo del European Foundation Quality Management (EFQM).

Volviendo un poco atrás quisiéramos hacer un poco de historia para conocer mejor los antecedentes de esta universidad que van ligados a la historia de los estudios de Magisterio.

La tradición educativa de Castellón había comenzado con los estudios de Magisterio, la Escuela de Formación del Profesorado fue fundada en 1901, y con el Colegio Universitario de Castellón (CUC) fundado en 1969.

\footnotetext{
102 DOCV núm. 2922 de 04.02.1997.

103 DOCV núm. 4658 de 26.12.2003
} 
En 1980, el presupuesto de la Diputación de Castellón, que era quien mantenía el CUC, era escaso, por eso se negoció la decisión de integrar el presupuesto del CUC en el de la Universidad de Valencia, financiada por el gobierno de España. Desde ese momento sus estudios pasan a formar parte de la organización departamental de la Universitat de Valencia donde permanecerían hasta la creación de la Jaume ${ }^{104}$. El Real Decreto 2633/1985, de 20 de noviembre, de traspaso de servicios de la Administración Central del Estado a la Generalitat Valenciana en materia de Universidades, recoge el traspaso de la Escuela Universitaria de Formación del Profesorado de Castellón junto a la de la Universidad de Valencia ${ }^{105}$.

En aquel momento se cursaban titulaciones de química, matemáticas, geografía e historia, filología, filosofía y educación. Los estudios de Maestro/a funcionaron a partir de 1960, sin interrupción, en la calle Herrero de Castellón. Cuando se creó la Universidad el número de estudiantes era de 4.847 y 16 titulaciones, 10 de las cuales eran nuevas y seis heredadas de la Universitat de València, que más tarde serían reconvertidas. Todas se agruparon en un campus universitario integrado con tres centros: la Facultad de Ciencias Jurídicas y Económicas (1996), la Escuela Superior de Tecnología y Ciencias Experimentales (1999, junto con la Biblioteca y el Rectorado) y la Facultad de Ciencias Humanas y Sociales (2002, junto con el Ágora, espacio que se concibe como centro neurálgico del campus universitario), Con la ocupación de este edificio la Universitat abandona definitivamente los edificios de la antigua Escuela de Magisterio y el antiguo Colegio Universitario de Castellón. Se concentra así toda su actividad en el campus del Riu Sec.

Con la ley de Creación de la Universitat JAUME $I^{106}$ la anterior Escuela Universitaria de Formación del Profesorado de EGB de Castellón deja de pertenecer a la Universidad de Valencia y estos estudios se integran en la Facultad de Ciencias Humanas y Sociales, en los que se obtiene la Diplomatura de Maestro. La preparación académica y profesional de los 
futuros docentes, constituirán un nuevo reto ante las nuevas reformas de la titulación según Real Decreto 1440/1991, de 30 de agosto. Al ampliarse las competencias de los maestros, se hace necesario adecuar los niveles de conocimientos y capacidades a lo que requiere la nueva legislación.

Antes de empezar el curso 1991/92, y según la Disposición Transitoria Sexta, el Consell aprueba el decreto ${ }^{107}$ en el que se regula la incorporación voluntaria a la Universitat Jaume I del personal docente e investigador de la Universitat de València, con docencia asignada en el centro de Castellón de la Plana.

Es este caso, las Diplomaturas de Maestro por lo tanto son iguales a las que se establecen en Valencia, hasta que se pone en marcha el Plan de 1992. A partir de entonces las clases de Magisterio en la UJI se imparten en la Facultad de Ciencias Humanas y Sociales. El área de Didáctica de la Expresión Plástica está ubicada en el Departamento de Educación.

Las asignaturas se dividen en Troncales, Obligatorias, Optativas y las de Libre Configuración. El estudiantado puede distribuirse libremente los créditos correspondientes a optativas y libre configuración a lo largo de los diferentes cursos. La única excepción es $1^{\circ}$, en el cual la matricula es de curso completo. Estos planes de estudio apenas sufren retoques hasta la llegada de los Grados.

Las Diplomaturas de Maestro (1992) se estructuran también en tres cursos. Las especialidades que se imparten son:

- Maestro Especialista en Primaria.

- Maestro Especialista en Infantil.

- Maestro Especialista en Educación Física.

- Maestro Especialista en Educación Musical.

Señalar, como particularidad, que dependiendo de las optativas que se elija cabe la posibilidad de realizar los itinerarios de:

${ }^{107}$ Decreto 66/1991, de 15 de abril. Disposición transitoria Sexta. C.C.E.C. (1991). 
- Teología y Pedagogía de la Religión y Moral Católicas.

- Valenciano (Capacitación o Diploma Maestro).

En el curso 2002-03 se ponen en práctica en la UJI los primeros estudios piloto, adaptados al Espacio Europeo de Enseñanza Superior. En el curso 2009-2010 comienzan los planes de estudio de grado, adaptados al Espacio Europeo de Enseñanza Superior en nueve titulaciones. El resto de ellas lo harán al curso siguiente.

Las Diplomaturas de Maestro hasta ahora existentes se extinguen siguiendo el siguiente esquema:

Tabla 21. Extinción (D. Maestro) / implantación (Grado). Castellón.

\begin{tabular}{|l|c|c|c|c|c|}
\hline \multicolumn{7}{|c|}{ Planes de Estudio de Grado } \\
\hline \multicolumn{1}{|c|}{ Curso } & $\mathbf{2 0 0 9 - 1 0}$ & $\mathbf{2 0 1 0 - 1 1}$ & $\mathbf{2 0 1 1 - 1 2}$ & $\mathbf{2 0 1 2 - 1 3}$ & $\mathbf{2 0 1 3 - 1 4}$ \\
\hline MAESTRO & Docencia & $\begin{array}{c}\text { Docencia en } \\
2^{\circ} \text { y } 3^{\circ}\end{array}$ & Solo $3^{\circ}$ & Solo exámenes & Solo exámenes \\
\hline GRADO & & Inicio $1^{\circ}$ & $1^{\circ}$ y $2^{\circ}$ & $1^{\circ}, 2^{\circ}$ y $3^{\circ}$ & Todos los cursos \\
\hline
\end{tabular}

Fuente. Elaboración propia.

Los estudios de Grado en Castellón quieren incorporar a su estilo propio, ya definido al crear la universidad, ciertos valores añadidos como son la responsabilidad social, el espíritu emprendedor, el compromiso social, la solidaridad, la igualdad de género, la no discriminación, el respeto a la diversidad y respeto al medio ambiente. Todo ello introducido de forma transversal en estos estudios.

Tanto en Infantil como en Primaria vemos que existen algunas optativas. En el caso de la Primaria, además, hay ciertas asignaturas que permiten obtener Menciones:

- Educación Física.

- Educación Musical.

Cada curso se ofertan 180 plazas para Infantil y 270 plazas para Primaria. 
Tabla 22. Organización Planes de Estudio de Grado. Castellón.

\begin{tabular}{|c|c|c|c|c|c|}
\hline \multicolumn{7}{|c|}{ Planes de Estudios de Grado } \\
\hline $\begin{array}{c}\text { TOTAL cr. } \\
240\end{array}$ & $\begin{array}{c}\text { Formación } \\
\text { Básica }\end{array}$ & Obligatorias & Optativas & Practicas & $\begin{array}{c}\text { Trabajo Fin de } \\
\text { Grado }\end{array}$ \\
\hline & & & & 44 & 6 \\
\hline PRIMARIA & 60 & 118 & 12 & 44 & 6 \\
\hline INFANTIL & 100 & 78 & 12 & & \\
\hline
\end{tabular}

Fuente. Elaboración propia.

Tabla 23. Organización del Plan de Estudios de Grado Infantil. Castellón.

\begin{tabular}{|c|c|c|c|c|c|}
\hline \multicolumn{7}{|c|}{ Plan de Estudios de Grado Infantil ${ }^{108}$} \\
\hline CURSO & $1^{0}$ & $2^{\circ}$ & $3^{\circ}$ & $4^{\circ}$ & TOTAL \\
\hline $\begin{array}{c}\text { FORMACION } \\
\text { BASICA }\end{array}$ & 48 & 22 & 12 & 18 & 100 \\
\hline OBLIGATORIAS & 12 & 38 & 22 & 6 & 78 \\
\hline OPTATIVAS & - & - & 6 & 6 & 42 \\
\hline PRACTICAS & - & - & 20 & 24 & 6 \\
\hline TFG & - & - & - & 6 & 240 \\
\hline TOTAL & 60 & 60 & 60 & 60 & 44 \\
\hline
\end{tabular}

Fuente. Elaboración propia.

Tabla 24. Organización del Plan de Estudios de Grado Primaria. Castellón.

\begin{tabular}{|c|c|c|c|c|c|}
\hline \multicolumn{7}{|c|}{ Plan de Estudios de Grado Primaria ${ }^{109}$} \\
\hline CURSO & $1^{0}$ & $2^{\circ}$ & $3^{\circ}$ & $4^{\circ}$ & TOTAL \\
\hline $\begin{array}{c}\text { FORMACION } \\
\text { BASICA }\end{array}$ & 30 & 30 & - & - & 60 \\
\hline OBLIGATORIAS & 30 & 30 & 36 & 22 & 118 \\
\hline OPTATIVAS & - & - & 6 & 6 & 12 \\
\hline PRACTICAS & - & - & 18 & 26 & 44 \\
\hline TFG & - & - & - & 6 & 240 \\
\hline TOTAL & 60 & 60 & 60 & 60 & 6 \\
\hline
\end{tabular}

Fuente. Elaboración propia.

108 Resolución de 27 de enero de 2011, de la Universidad Jaume I, BOE 9/2/2011.

109 Resolución de 6 de mayo de 2013, de la Universidad Jaume I, BOE 22/5/2013 


\subsubsection{La Universitat de València y los estudios de Magisterio.}

Valencia se sitúa entre las dos ciudades antes nombradas, en la costa mediterránea, justo en el centro del Golfo de Valencia. Es la capital de la Comunitat Valenciana y tiene una población de casi 800.000 habitantes, aunque si contamos su área metropolitana supera el millón y medio. Es una ciudad con un rico patrimonio histórico y monumental.

La Universitat de València se fundó con el nombre de Estudi General, con el esfuerzo de los Jurados de Valencia en su intento por reunir los estudios dispersos que se impartían en la ciudad. Los Fueros de Valencia otorgaban la libertad de educación para la ciudad más poblada de la Corona de Aragón, que permanecía sin universidad en la época del Siglo de Oro valenciano. Está orientada a la docencia e investigación de casi todos los ámbitos del saber (Ciencias Básicas y Experimentales, Ciencias de la Salud, Ingenierías, Humanidades, Ciencias de la Educación y Ciencias Sociales, Económicas y Jurídicas). Actualmente, en número de estudiantes supera los 55.000. Cuenta con tres campus principales en la ciudad (Blasco Ibáñez, Tarongers y Burjassot) y otro en Ontinyent, pero además cuenta con numerosas extensiones. Se define como una universidad moderna y global, comprometida con las nuevas tecnologías y conectada con las principales redes internacionales científicas y de docencia.

En esta Universidad coexisten la Facultad de Filosofía y Ciencias de la Educación con lo que era la Escuela de Formación del Profesorado "Ausias March" y que recientemente ha conseguido, tras un largo proceso, el estatus de Facultad de Magisterio.

La propia Web oficial de la misma ${ }^{110}$, nos presenta unas notas breves de historia.

El oficio de maestro en Valencia se puede documentar desde principios del siglo XIII. El número de maestros era ya grande en el siglo XVI. El

${ }^{110}$ http://www.uv.es/uvweb/magisterio/ca/facultat/coneix-nos/presentacio-1285848222201.html

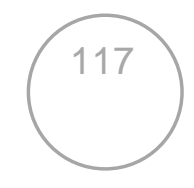


Consell de la Ciutat de València dictó el 28 de noviembre de 1625 unas Ordinacions dels Mestres de llegir i scriure, que dispusieron, entre otras cosas:

...lo saber be llegir i scriure es lo primer escalo i porta per a entrar en les demés facultats en lo temporal com en lo espiritual i lo primer que es deu procurar en una república i més en la present ciutat que los mestres que amostren al gichs sien hábils en dita art i virtuosos i de bones costums i no juradors i de males costums, i així los deixebles ysiran hábils en llegir i scriure i virtuosos tenint bons mestres...

Según consta en la declaración de principios de la propia Facultad:

La mejor descripción del propósito y las aspiraciones de las instituciones dedicadas a la preparación de maestros y profesores sigue siendo la que se puede leer en la declaración de principios de la primera de las Escuelas Normales Superiores de Francia, la Ecole Normale de l' an III, fundada en París el 20 de octubre de 1794 por la Convención de la Primera República Francesa:

Article 1er. II sera établi à Paris une École normale, où seront appelés, de toutes les parties de la République, des citoyens déjà instruits dans les sciences utiles, pour apprendre, sous les professeurs les plus habiles dans tous les genres, l'art d'enseigner ${ }^{111}$.

La revolución Francesa y su espíritu ilustrado hicieron de la educación y la instrucción el principal instrumento para favorecer el progreso y el bienestar de todos los miembros de la nueva sociedad. La moderna mentalidad laica, burguesa y utilitaria, dio lugar a la necesidad de abordar en las escuelas una educación cívica y una cultura técnica, así como a la de adoptar un modelo para la formación de maestros, cuyos antecedentes se pueden encontrar en la Volksschule prusiana.

${ }^{111}$ Se establecerá en París una Escuela Normal, a la cual serán llamados, desde todas las partes de la República, ciudadanos ya instruidos en las ciencias útiles, para aprender, bajo la tutela de los mejores profesores de todas las disciplinas, del arte de enseñar. 
La influencia de la Escuela normal francesa y su modelo de formación de maestros llegó a nuestro país con los ilustrados liberales en las primeras décadas del siglo XIX. Valencia inició la tradición normalista con su Escuela Normal de Maestros en 1845 y la de Maestras en 1867.

A lo largo de su dilatada historia, la primera Escuela Normal de Valencia hasta su conversión en la actual Facultat de Magisteri de la Universitat de València, ha ido pasando por numerosos emplazamientos. En 1982 la Universitat de València adquiere los edificios rehabilitados de Monteolivete donde permanecerá hasta que finalmente se construyen las actuales instalaciones que integran definitiva y plenamente en 2010 a la actual Facultat de Magisteri en el Campus dels Tarongers de la Universitat de València.

Esta larga trayectoria educativa, hace que en la Universitat de València se hayan ido implantando todos los planes de estudio que han ido estando vigentes en cada momento. Hemos atendido, como en el caso de las otras universidades, a aquellos más significativos, obteniendo los datos de fuentes legislativas y de la propia universidad, lo cual en algunos casos concretos ha sido complejo por estar incompleta. Los planes que hemos reflejado son los de 1857, 1914, 1931, los de 1940-42, 1950, 1967 y 1967 nocturno, 1971, 1993, 2000 y 2007 (Grados). Como hasta 1967 lo hemos comentado con anterioridad, para el conjunto de universidades, reflejaremos a continuación, de forma abreviada, el resto de planes.

Las Diplomaturas de Maestro de EGB (1971) se imparten a partir del curso 1972-73. Este plan sufre diversas reestructuraciones en los años 1982, 1984 y 1986. Se estructuran en tres cursos y las especialidades que se imparten son:

- Maestro Especialista en Lengua Española e Idioma Moderno.

- Maestro Especialista en Ciencias.

- Maestro Especialista en Ciencias Humanas.

- Maestro Especialista en Preescolar.

- Maestro Especialista en Educación Especial. 
Los cursos también están divididos en dos cuatrimestres, con asignaturas anuales y cuatrimestrales. Las asignaturas se dividen en Obligatorias y Optativas. Existen una serie de comunes para todos y en $2^{\circ}$ y $3^{\circ}$ se puede elegir un número determinado de optativas (anuales o cuatrimestrales), que varían según el curso y la especialidad.

Las Diplomaturas de Maestro (1993) se ponen en marcha en el curso 94-95. Se estructuran también en tres cursos. Las especialidades que se imparten son:

- Maestro Especialista en Primaria.

- Maestro Especialista en Infantil.

- Maestro Especialista en Lengua Extranjera.

- Maestro Especialista en Educación Física.

- Maestro Especialista en Educación Musical.

- Maestro Especialista en Educación Especial.

- Maestro Especialista en Audición y Lenguaje.

Las asignaturas se dividen entre Troncales, Troncales de Especialidad y Obligatorias de Universidad. Existen numerosas optativas que pueden elegirse y distribuirse a lo largo de los estudios. Todos los cursos cuentan con 20 Créditos de Libre Disposición que se pueden elegir entre todas las asignaturas que oferta la Universidad.

En la Universidad Laboral de Cheste $^{112}$ únicamente se imparten las especialidades de:

- Maestro Especialista en Primaria, con Inglés o Francés.

- Maestro Especialista en Preescolar.

- Maestro Especialista en Ciencias y Ciencias Humanas.

112 La Universitat de Valencia tiene adscrita la Escuela Universitaria de Profesorado de EGB del Centro de Orientación de Universidades Laborales de Cheste. BOE 19/10/1973. 
También con optativas en $2^{\circ}$ y $3^{\circ}$, aunque en número más reducido que en Valencia.

Se producen una serie de modificaciones en asignaturas y creditaje que configuraran el Plan del 2000. Las asignaturas son Troncales, Optativas y de Libre Configuración. No cambia ni se modifica el numero de especialidades. Sin embargo, en aplicación de este plan se instaura una extensión de la Universitat en Ontinyent, en la que se imparte la especialidad de Infantil.

Las Diplomaturas de Maestro hasta ahora existentes se extinguen siguiendo el siguiente esquema:

Tabla 25. Extinción (D. Maestro) / implantación (Grado). Valencia.

\begin{tabular}{|c|c|c|c|c|c|}
\hline \multicolumn{1}{|c|}{ Planes de Estudio de Grado } \\
\hline Curso & $\mathbf{2 0 0 9 - 1 0}$ & $\mathbf{2 0 1 0 - 1 1}$ & $\mathbf{2 0 1 1 - 1 2}$ & $\mathbf{2 0 1 2 - 1 3}$ & 2013-14 \\
\hline MAESTRO & $\begin{array}{c}\text { Docencia } \\
\text { en } 2^{\circ} \text { y } 3^{\circ}\end{array}$ & Solo $3^{\circ}$ & Solo exámenes & Solo exámenes & \\
\hline GRADO & Inicio $1^{\circ}$ & $1^{\circ}$ y $2^{\circ}$ & $1^{\circ}, 2^{\circ}$ y $3^{\circ}$ & Todos los cursos & \\
\hline
\end{tabular}

Fuente. Elaboración propia.

Los estudios de Grado en Valencia proporcionan al estudiante formación básica y especifica en todas las áreas y disciplinas establecidas en las etapas de Infantil y Primaria. Además recibe formación en principios organizativos y gestión de la escuela así como los procesos de desarrollo físico, emocional e intelectual de cada etapa. Las titulaciones tienen asignaturas compartidas que facilitan la obtención de los dos títulos.

Cada curso se ofertan 300 plazas para Infantil, más 50 en Ontinyent y 500 plazas para Primaria. 
Tabla 26. Organización Planes de Estudio de Grado en Valencia.

\begin{tabular}{|l|c|c|c|c|c|}
\hline \multicolumn{7}{|c|}{ Planes de Estudios de Grado } \\
\hline $\begin{array}{c}\text { TOTAL cr. } \\
240\end{array}$ & $\begin{array}{c}\text { Formación } \\
\text { Básica }\end{array}$ & Obligatorias & Optativas & Practicas & $\begin{array}{c}\text { Trabajo Fin de } \\
\text { Grado }\end{array}$ \\
\hline PRIMARIA & 60 & 99 & 30 & 45 & 6 \\
\hline INFANTIL & 103,5 & 73,5 & 12 & 45 & 6 \\
\hline
\end{tabular}

Fuente. Elaboración propia.

Tabla 27. Organización del Plan de Estudios de Grado Infantil. Valencia.

\begin{tabular}{|c|c|c|c|c|c|}
\hline \multicolumn{7}{|c|}{ Plan de Estudios de Grado Infantil } \\
\hline CURSO & $1^{\circ}$ & $2^{\circ}$ & $3^{\circ}$ & $4^{\circ}$ & TOTAL \\
\hline $\begin{array}{c}\text { FORMACION } \\
\text { BASICA }\end{array}$ & 46,5 & 37,5 & 15 & 4,5 & 103,5 \\
\hline OBLIGATORIAS & 6 & 22,5 & 22,5 & 22,5 & 73,5 \\
\hline OPTATIVAS & - & - & 6 & 6 & 12 \\
\hline PRACTICAS & 7,5 & - & 16,5 & 21 & 45 \\
\hline TFG & - & - & - & 6 & 6 \\
\hline TOTAL & 60 & 60 & 60 & 60 & 240 \\
\hline
\end{tabular}

Fuente. Elaboración propia.

En el apartado de Optatividad (a partir de tercer curso) en Primaria, se ofrece la posibilidad de realizar las Menciones en:

- Artes y Humanidades.

- Audición y Lenguaje.

- Ciencias y Matemáticas.

- Educación Física.

- Educación Musical.

- Lengua Extranjera (inglés o francés).

- Pedagogía Terapéutica.

- Tecnologías de la Información y la Comunicación. 
Tabla 28. Organización del Plan de Estudios de Grado Primaria. Valencia.

\begin{tabular}{|c|c|c|c|c|c|}
\hline \multicolumn{7}{|c|}{ Plan de Estudios de Grado Infantil } \\
\hline CURSO & $1^{\circ}$ & $2^{\circ}$ & $3^{\circ}$ & $4^{\circ}$ & TOTAL \\
\hline $\begin{array}{c}\text { FORMACION } \\
\text { BASICA }\end{array}$ & 42 & 18 & - & - & 60 \\
\hline OBLIGATORIAS & 12 & 42 & 25,5 & 19,5 & 99 \\
\hline OPTATIVAS & - & - & 18 & 12 & 30 \\
\hline PRACTICAS & 6 & - & 16,5 & 22,5 & 45 \\
\hline TFG & - & - & - & 6 & 6 \\
\hline TOTAL & 60 & 60 & 60 & 60 & 240 \\
\hline
\end{tabular}

Fuente. Elaboración propia.

En el siguiente cuadro resumen podemos contrastar las diferentes distribuciones de los Planes de Estudio en las Universidades de Alicante, Castellón y Valencia.

Tabla 29. Organización Planes de Estudio de Grado. C. Valenciana.

\begin{tabular}{|l|c|c|c|c|c|c|}
\hline & \multicolumn{2}{|c|}{$\begin{array}{c}\text { CREDITOS } \\
\text { UNIVERSIDAD } \\
\text { ALICANTE }\end{array}$} & \multicolumn{2}{c|}{$\begin{array}{c}\text { CREDITOS } \\
\text { UNIVERSIDAD } \\
\text { CASTELLON }\end{array}$} & \multicolumn{2}{c|}{$\begin{array}{c}\text { CREDITOS } \\
\text { UNIVERSIDAD } \\
\text { VALENCIA }\end{array}$} \\
\hline & INFANTIL & PRIMARIA & INFANTIL & PRIMARIA & INFANTIL & PRIMARIA \\
\hline $\begin{array}{l}\text { Formación } \\
\text { básica }\end{array}$ & 102 & 60 & 100 & 60 & 103,5 & 60 \\
\hline Obligatorias & 60 & 102 & 78 & 118 & 73,5 & 99 \\
\hline Optativas & 24 & 24 & 12 & 12 & 12 & 30 \\
\hline Practicas & 48 & 48 & 44 & 44 & 45 & 45 \\
\hline TFG & 6 & 6 & 6 & 6 & 6 & 6 \\
\hline TOTAL & 240 & 240 & 240 & 240 & 240 & 240 \\
\hline
\end{tabular}

Fuente. Elaboración propia.

\section{CONCLUSIONES}

En el recorrido histórico sobre el nacimiento de las instituciones que forman a los maestros hemos apreciado el balance entre la ideología liberal y conservadora. En la época de la Restauración, así como más adelante en el conservadurismo de principios de siglo, los ideales laicos y proletarios de la II 
Republica y el ideario nacional-católico del Franquismo. A partir de mitad de los 70 asistimos a los primeros intentos de modernización escolar con la presencia de un nuevo sistema educativo. En el periodo de la consolidación democrática asistimos de nuevo a unos planteamientos progresistas que plantean nuevas metodologías. De nuevo se vieron modificados por las leyes impulsadas por el partido conservador del gobierno. Entrados ya en la época actual hemos asistido a una profunda modificación de los estudios:

No militar en lo ideales y objetivos del régimen en el poder, o haber militado en otro distinto, supone, las más de las veces, la depuración y separación del cuerpo del Magisterio. Política y pedagogía, en verdad, van paralelas cuando no se identifican. Fiel reflejo de lo anotado es la serie de disposiciones de Órdenes y Decretos de la legislación escolar correspondiente, así como la ideología (de cada Régimen en su caso), expresada de "modo tácito y expreso" en los libros escolares y de texto (Esteban, 1994, p. 529).

Una vez realizada la implementación de la investigación sobre la trayectoria histórica de los estudios de formación de los Maestros, podremos revisar y destacar dentro de ellos, cual ha sido la presencia de las asignaturas de Educación Artística. Esto nos permitirá constatar la carga lectiva que supone esta disciplina dentro del conjunto del Currículum Académico de futuros graduados en Magisterio. Pretendemos llegar a exponer la evolución de esta área, siguiéndola a través de los diferentes planes de estudio, intentando comprender la situación de la Educación Artística y definiendo lo que realmente queremos que sea en el futuro.

La contextualización del tema nos ha permitido evidenciar qué elementos filosóficos o teorías provocan los cambios en el concepto o forma de valorar la materia. Tal como expresa Eisner (1995a), el papel del llamado "dibujo" o similar, considerado como un instrumento en función de una profesión más que como expresión, en la sociedad de la Revolución Industrial. Las posteriores teorías de Piaget y sus coetáneos que colocaron en primer plano la expresión artística como valor en sí misma. Seguido del replanteamiento de la misma con la toma de conciencia de la importancia del medio social en el 
aprendizaje señalada por Vigotsky (2003). Para finalmente, tal y como reivindican en su libro, Efland, Freedman y Stuhr (2003), la necesidad y urgencia de repensar los discursos educativos desde el universo de las artes. Teniendo en cuenta las condiciones sociales y culturales, por ejemplo de grupos marginados, la multiculturalidad, etc., revalorizando así nuevas formas artísticas y culturales hasta entonces infravaloradas y desterradas. 
La Educación Artística en los planes de estudio de Magisterio de la Comunitat Valenciana. Visión para el siglo XXI.

CAPÍTULO III. 
MARCO REFERENCIAL 


\section{INTRODUCCIÓN}

La cuestión de cuál debería ser la formación en materia de artes plásticas que reciban las personas durante su escolarización, es una preocupación que viene de lejos. Todavía no ha recibido una respuesta suficientemente satisfactoria a pesar de que lo que se consigue es una sociedad más culta, equilibrada y mejor formada en general. Históricamente, la formación intelectual, y mucho más la artística, ha estado reservada a un sector reducido de la sociedad, muy alejado del ideal de una formación universal y completa.

Según hemos visto en el capítulo anterior, las cuestiones sociales y filosóficas han influido decisivamente en el campo de la educación. Tal y como plantean sociólogos educativos como Bourdieu (2002) ${ }^{113}$ no podemos desligar la historia de la Educación de su entorno y desarrollo dentro de una sociedad concreta que es la que organiza y pone en práctica las teorías educativas que defiende dicha sociedad.
El habitus ${ }^{114}$ no es el destino, como se lo interpreta a veces. Siendo producto de la historia, es un sistema abierto de disposiciones que se confronta permanentemente con experiencias nuevas y, por lo mismo, es afectado también permanentemente por ellas. Es duradera, pero no inmutable.

La Historia de la Educación está inmersa, y se debe contextualizar, dentro de la historia total. La afirmación de que la vida política implica completamente a la institución educativa y al educador podría ser puesta en duda hace unos años pero hoy en día está plenamente aceptado y confirmado. Actualmente se intenta tener una visión global de la Educación en la que, para poder hacer un análisis de los fenómenos educativos, se puedan tomar en cuenta estructuras

\footnotetext{
113 Que habla de que en la escuela es "donde se fabrican las personas, donde estructuran su manera de pensar" en simbiosis con la familia. La escuela es un lugar donde se reproduce la estructura social.

${ }^{114}$ El habitus tenderá a ser cada vez más "una creatividad gobernada por reglas", una competencia capaz de engendrar una infinidad de respuestas a partir de un número reducido de principios.
} 
demográficas, economía, organización social, mentalidades, ordenamiento político. La educación es, en su significado más general, la manera en que se forma o instruye a los individuos de una determinada sociedad. Por ello es fundamental saber entender cómo funcionan las organizaciones influyentes y qué sistemas utilizan para estructurar la vida social y cultural.

Siguiendo el sistema de pensamiento de este sociólogo, en nuestro estudio no pretendemos hablar de "que está mal y que está bien", sino considerar la posibilidad de un enfoque educativo diferente que hipotéticamente favorecería la estructura cognitiva. La entenderíamos bajo unas premisas menos encorsetadas a priori, para contemplar aspectos más lúdicos y creativos que favorecerían la adquisición de los conocimientos estipulados pero desde un sistema de coordenadas diferente.

Refiriéndonos al campo artístico, Bourdieu (2002), considera que el arte ofrece una experiencia estética imbricada en una atmosfera filosófica. Posibilita la apreciación y comprensión de la obra artística relacionándola con la sociedad y la época histórica en la que se ha gestado. También nos habla de los creadores, sus razones, sus motivaciones y pensamientos. De esta forma se toma conciencia de ellos como individuos inmersos en una determinada sociedad y época histórica. Considera que el creador y su obra se ven constantemente afectados por el sistema de las relaciones sociales. Se presupone una preparación intelectual de clase que ayuda a poder disfrutar de la cultura.

Dada esta interrelación de lo artístico con lo social y con la educación, nuestra intención en este capítulo es:

- Tratar las diferentes denominaciones que se le aplican.

- Exponer diferentes corrientes e interpretaciones de lo que se considera EA.

- Ver como están las enseñanzas artísticas en el momento.

- Centrarnos luego en ver qué papel ha tenido en los estudios de Magisterio y en la escuela para intentar establecer una relación. 


\section{DEFINICIÓN DE LA EDUCACIÓN ARTÍSTICA}

Existe una dificultad manifiesta en poder establecer una definición única, concreta y válida de lo que consideramos Educación Artística, si lo que se pretende es encontrar una denominación que recoja todos los cambios habidos, y los que puedan producirse.

Acotar el campo que engloba el término de EA es una cuestión compleja por el carácter cambiante de su denominación. La multiplicidad de aspectos que se aprecian en nuestra disciplina se mueven en una continua indefinición por una manifiesta falta de unificación de criterios epistemológicos, metodológicos y organizativos.

En ocasiones, se ha intentado paliarlo intentando organizar la EA como a las disciplinas técnicas pero no era adecuado y no suponía ninguna ventaja. La postura de la filosofía positivista ante el conocimiento es una actitud cientificista. Fomentó la idea de que el único conocimiento válido era el que podía obtenerse a través de las ciencias. Esta visión relegó materias de índole humanista que no podían seguir los estándares científicos de control:

A lo largo de la historia de la educación en estos siglos, las artes visuales eran vistas como una ocupación demasiado baja, como para ser digna de las personas socialmente prominentes, o bien como una actividad ociosa a la que solo los ricos podían dedicarse (Efland, 2002, pp. 79-80).

En otros intentos, se le ha atribuido un conjunto heterogéneo de conocimientos que no hacen más que reforzar su ambigüedad. El no tener un espacio propio, claramente diferenciado del resto, no ha permitido poder precisar de forma objetiva los contenidos y materias que le son propios y que ayudarían a acotar su ámbito de influencia. Sin embargo es cierto que podemos abordar la EA desde diferentes campos de conocimiento y perspectivas. Los diferentes profesionales que lo trabajan y utilizan, en alguna parcela de sus disciplinas, son numerosos y diversos. En cada caso, dependiendo de qué aspectos interesa más destacar, se aproximan a alguno de los elementos heterogéneos que abarca la materia (ejecución manual y técnica, bidimensionalidad, 
tridimensionalidad, fundamentos teóricos, aspectos éticos,...). Se toman en consideración distintos aprendizajes perceptivos (vista, oído, gusto, tacto y olfato). Abrimos así la puerta al trabajo multidisciplinar en el que podemos abordar un determinado tema integrando diferentes aprendizajes perceptivos. También podemos disfrutar de que el contenido de varias disciplinas conformen una única experiencia artística. Favorecemos la idea de la EA como elemento contenedor que permite un disfrute holístico del hecho artístico.

\subsection{El término Educación Artística.}

Por las razones anteriormente expuestas, y por la dificultad manifiesta de que un término abarque todo lo que implica al área, conceptos y temas básicos, obviaremos el carácter discutible del término EA, para utilizarlo de forma general, por ser el más internacionalmente y ampliamente aceptado. Con ello no estamos descartando las nuevas denominaciones actuales tal vez mucho más ajustadas. Numerosos investigadores a lo largo del tiempo, han abordado la problemática de la denominación. Autores como Aguirre (2005), Barragán (2005) y Hernández (2002) son de los más destacados.

Para aclarar, además, otros aspectos importantes que pueden afectarnos en la realización nuestro estudio, consideramos necesario exponer algunas consideraciones de interés relativas a los términos que estamos utilizando:

- Plantear qué se entiende por Arte, en el contexto de nuestra sociedad actual.

- Qué papel desempeña este en la cultura contemporánea.

- Intentar definir, un poco más adecuadamente, de qué hablamos cuando utilizamos el término de Educación Artística.

Según Aguirre (2005) uno de los primeros aspectos a considerar cuando queremos hablar de EA es conocer cuál es el valor concedido al arte y la relación con la realidad cultural en la comunidad en la que estamos tratando. 
Remontándonos a la obra El arte y el Hombre de René Huyghe (1977), obtenemos una definición del alcance e importancia de este aspecto para las personas:

El arte y el hombre son indisociables. No hay arte sin hombre, pero quizá tampoco hombre sin arte. Pero con éste, el mundo, se hace más inteligible, más accesible y más familiar. Es el medio de un perpetuo intercambio con lo que nos rodea, una especie de respiración del alma, bastante parecida a la física, sin la que no puede pasar nuestro cuerpo. El ser aislado o la civilización que no llegan al arte están amenazados por una secreta asfixia espiritual, por una turbación moral.

En el caso de Eisner (1995), establece diferencias entre la utilización de los términos Arte (para designar las artes plásticas) y Artes (para cuando habla del conjunto de todas las Artes). Formula que muchas veces solo distinguiremos su significado por el contexto pues en la mayoría de ocasiones es confuso. Para él, la función del Arte estaría orientada a la "apropiación" de los hábitos de percepción y de comportamiento para transformarlos en posibilidades y opciones de vida. Distingue diferencias entre los expertos en educación y aprendizaje de las artes: los esencialistas y los contextualistas:

- Los esencialistas consideran que el arte aporta un tipo de experiencia peculiar vinculada a la expresión. Promueve en el individuo emociones y experiencias que otras áreas de conocimiento no generan. Aquello que se aprende a través de la EA no se adquiere con otras disciplinas. Es el conocimiento del arte en sí mismo.

- los contextualistas atienden a todo aquello que se puede aprender y lo que puede construir el aprendizaje a través del arte. Se empleará de distinta forma según las necesidades del colectivo que quiera atender (otras materias, aprendizaje para el mundo laboral, otras finalidades educativas y de integración sociocultural).

Este mismo autor, introduce en 2004, la definición del término cultura en cuanto a lo que se refiere a la educación, bajo dos vertientes: una es antropológica y la otra es de carácter biológico: 
- En el sentido antropológico, una cultura es una manera de vivir compartida.

- En el sentido biológico, en lugar del término cultura se emplea su sinónimo cultivo.

Para él las escuelas funcionan en los dos sentidos como cultura y como cultivo.

Arañó (1989), a su vez, concibe el Arte como un fenómeno de carácter universal que afecta a todas las personas, grupos sociales y culturas. Se encuentra inmerso en la cultura, de esta forma puede ser un medio de expresión, un lenguaje o un medio de comunicación. Asimismo, define la cultura como: "conjunto de diferencias que delimitan a los distintos grupos sociales. Es la forma genuina de búsqueda de soluciones a los problemas específicos comunes. Estas soluciones dependerán de determinados factores ambientales y de relación con otros grupos sociales" (Arañó, 1989, p. 28).

\subsection{La Educación Artística y el curriculum.}

Las manifestaciones anteriores nos derivan a considerar otros aspectos relacionados con el arte: la cultura y la sociedad en la que se desarrolla. No podemos pues dejar de abordar el tema de la educación y aquello que tiene que ver con el diseño curricular, concebido como algo más que limitarse a legislar lo que se debe realizar y poner en práctica en los centros de enseñanza.

Aguirre (2005), abordando el tema del diseño curricular, nos hace reflexionar acerca de las dificultades especiales con las que se encuentra la EA en la trayectoria de la implantación en el sistema escolar, la función y consideración social que merece o la reflexión sobre sus contenidos esenciales:

No cabe duda que si concebimos el curriculum como algo más que un documento lleno de objetivos e instrucciones para la práctica didáctica, es decir como el reflejo en la educación en los valores sociales, (Efland, 
1990) culturales e ideológicos (Arañó, 1989) de una comunidad, estamos abocados a reflexionar sobre el papel que el arte y la educación artística cumple en nuestra sociedad (Aguirre, 2005, p. 52).

Para Hernández (2000), en el curriculum escolar, figuran campos disciplinares de reconocida presencia, útiles para conformar los elementos ideológicos a los que la escuela contribuye. Esta presencia se cuestiona con las materias artísticas que siempre deben argumentar su inclusión ya que su utilidad se pone en duda.

La evolución seguida por el área de Educación Artística, siguiendo las premisas educativas posmodernas, todavía vigentes en estos momentos, nos plantea la cuestión de porqué, siendo un área que puede aportar tanto al desarrollo del individuo, se la ha cuestionado tan a menudo. Nos encontramos ante una especie de "asignatura sin voz ", relegada durante gran parte de la historia educativa, a la que continuamente estamos intentando dar visibilidad, apoyándonos en el concepto de la reafirmación de lo subjetivo y emocional. En numerosas ocasiones se la toma como un espacio dedicado al entretenimiento, a la libre expresión de emociones y sensaciones, a funciones de naturaleza terapéutica o bien como apoyo de asignaturas "relevantes". Sin embargo en palabras de (Goodman, 1995, p. 226):

El desarrollo de la discriminación sensorial es algo tan cognitivo como inventar conceptos numéricos complejos, o probar teoremas. Llegar a entender una pintura o una sinfonía realizadas en un estilo desconocido, llegar a reconocer la obra de un artista o de una escuela, llegar a ver o a oír de un modo nuevo, es una hazaña tan cognitiva como aprender a leer, a escribir o a sumar.

Comprobamos con esta muestra de ello que, a pesar de las numerosas investigaciones nacionales e internacionales que avalan su importancia en cuanto a la formación integral de la persona y su valor en la educación, todavía tenemos que estar justificando continuamente y en numerosos ámbitos, el porqué de su presencia o la necesidad de aumentar su peso en el curriculum. 
Autores como Eisner (1995a), Arnheim (1980), Gardner (1994) y Arañó (1989) han abogado por abordar esta necesidad cultural.

Sin embargo el hecho de querer conceder mayor valor a estas asignaturas no quiere decir que nuestra intención es que todas las personas deban alcanzar un grado optimo de dominio artístico sino más bien como expresa Read ${ }^{115}$, no el hacer de todos los individuos artistas, sino acercarles los lenguajes de las disciplinas artísticas que les permitan nuevos y distintos modos de comunicación y expresión, desarrollando las competencias individuales interrelacionadas con lo social, a través de la sensibilización, la experimentación, la imaginación, y la creatividad: "Cómo se pueden comprender y crear obras de arte, y a través de ellas nuestros mundos, debe ser parte de la educación básica de millones de los que nunca seremos artistas" (Goodman, 1995, p. 229).

Es cierto que, como veremos más adelante, existe en la práctica docente una diferencia significativa entre los profesionales que se dedican a la formación de artistas, o profesionales de las Artes Visuales, tal y como indica Eisner, y aquellos que forman a los educadores en Didáctica de la EA, que forman a pedagogos y maestros cuya finalidad principal no es formar artistas sino impartir técnicas adecuadas para que cualquier persona pueda expresarse plásticamente.

Pero, a nuestro modo de ver, es una diferencia que se produce por la meta profesional del alumnado al que se dirigen más que porque se diferencien en sus conocimientos. Claro que los objetivos y los contenidos trabajados difieren pero hablamos de formarse en una disciplina aunque luego la aplicación sea en ámbitos profesionales diferentes.

\footnotetext{
${ }^{115}$ Poeta inglés, considerado como una autoridad en materia de Historia y Filosofía del Arte, ha derivado sus estudios hacia otros campos como el de la Educación, la Sociología, y la Historia de la Cultura. En su libro "Arte y Educación" (1991) su tesis se basa en la formulada por primera vez por Platón que promueve la idea de que el arte debe ser la base de toda forma de educación natural y enaltecedora. Para ello se dedica a aclarar conceptos fundamentales: Educación y Arte y la relación de ambos con la formación durante todas las etapas evolutivas del hombre.
} 
Es por ello que cuestionamos más adelante el porqué el aspecto didáctico ha sido denostado en los estudios profesionales artísticos cuando, realmente lo que interesa socialmente y culturalmente es que haya artistas, que generan productos, y que exista un espectador formado que pueda sentir e interpretar sus obras. De esta manera se alcanzaría una normalización artística en la que la escuela seria más creativa y dinámica. Se formaría un público educado y culto que sabría valorar y disfrutar con el trabajo de los artistas a la vez que estos ampliarían sus experiencias.

Basándonos en investigaciones anteriores, y en la propia personal, podemos afirmar que la consideración que la EA tiene en los diferentes planes de estudio actuales es bastante baja todavía en la sociedad española (Arañó, 1989). La razón es que la EA, en concreto en España, todavía se considera como una asignatura de segundo orden en cualquiera de los planes de estudios del sistema educativo reglado. También señalar los tópicos que se siguen manejando alrededor de la idea de lo que se entiende que desarrolla la materia, tales como las manualidades, la libre expresión o la idea de poseer un "don especial para dibujar". A ello podríamos añadir tal vez el reconocimiento que recibe el aprendizaje del Dibujo Técnico por su utilidad como herramienta profesional.

Queremos recoger a continuación en una visión general, cada uno de los nombres que han sido utilizados en los diferentes curriculums así como sus ventajas y desventajas. Siguiendo un orden cronológico, podríamos resumir las propuestas en:

- ENSEÑANZA DEL DIBUJO Y TRABAJOS MANUALES - Denominación histórica que se otorgaba a la parte didáctica del área. Es la que, durante mucho tiempo y hasta principios y mediados del siglo $X X$, la que incluía cualquier enseñanza artística. Utilizar el término Enseñanza, nos parece que abarca un ámbito algo reducido pues consideramos que aparenta que limitarse a una pura transmisión de conocimiento que no implica reflexión posterior sobre los resultados obtenidos. 
- EXPRESIÓN PLÁSTICA - Término que aparece con la ley educativa de 1970. Se consideraba que era un término más amplio que los anteriores porque podía incluir a otras materias o manifestaciones que pudieran considerarse Arte. Se buscaba fomentar y dejar fluir la propia expresión del alumno como medio para manifestar sus gustos y aptitudes. Se inspira en las teorías de Lowenfeld y Read.

- EDUCACIÓN VISUAL Y EDUCACIÓN ARTística - Aparece con la LOGSE en 1990. El término Educación nos remite a contenidos más completos de transmisión de saberes. Incorpora nuevas consideraciones al Arte (mass media). Pero se puede considerar que el término visual es muy restrictivo, pues puede dar la sensación de que únicamente se abordan aspectos visuales sin tener en cuenta otras posibilidades artísticas, aunque esto no tiene porque ser así.

- EDUCACIÓN DE LAS ARTES VISUALES - Se adecua a lo planteado pero sigue restringiendo a lo visual y no concreta el nivel en el que utilizamos el término educación.

- DIDÁCTICA DE LAS ARTES VISUALES - Introduce a las didácticas especificas. Parece que el término Didáctica implica un interés por investigar sobre el propio trabajo y la forma de realizarlo. Sigue excluyendo modalidades no visuales (body-art, las performance, los happening). Se incluyen en las perspectivas amplias de la educación escolar.

- DIDÁCTICA DE LA EXPRESIÓN PLÁSTICA - Introduce también las didácticas especificas. Demasiado ligada al concepto del Currículo. El concepto Expresión solo se aplica al hacer y limita la pluralidad de registros artísticos actuales.

- EDUCACIÓN ESTÉTICA - Relación con la inmediatez de la experiencia y la proximidad de la experiencia artística con la experiencia vital. Se relaciona excesivamente con la rama de la semiótica, antropología, filosofía o historia del arte.

- EDUCACIÓN ARTÍSTICA - Aparece con la LOCE. Es una definición muy general y que pretende recoger la gran amplitud de modalidades tanto para el disfrute como en su práctica. Parece dar a entender que 
recoge el conjunto de las Artes. A tener en cuenta que abarca contenidos de otras disciplinas (música, teatro, cine). No tiene un sentido discriminatorio y permite que se tomen en consideración otros aprendizajes perceptivos (vista, oído, gusto, tacto y olfato) que supongan según la idea expresada anteriormente un disfrute sensible y global del hecho artístico.

\section{NUEVAS CONSIDERACIONES FORMALES SOBRE EDUCACIÓN ARTÍSTICA}

Actualmente, a nivel curricular, observamos que siguen coexistiendo diferentes formas de plantear e impartir la disciplina. Las políticas educativas, con su falta de rigor en la materia, permiten persistir a modelos procedentes del siglo XIX con planteamientos y métodos del siglo XXI. Los contenidos van desde la utilización del dibujo en sí mismo, al aprendizaje del manejo de diferentes técnicas (ya sea bi o tridimensionales) para reflejar habilidades expresivas, y relacionándose a la vez con planteamientos más actuales que abordan el aspecto teórico del arte en sus vertientes históricas o éticas atendiendo al estudio de la cultura del momento. Esta situación no hace más que contribuir a la constante indefinición y desconocimiento de esta área.

Resulta complejo manejar y organizar los nuevos términos artísticos que se van incorporando. En otros estudios no se produce este fenómeno, pues el concepto global incluye a los más específicos surgidos con posterioridad. Recoger tanto lo apreciado históricamente como lo que se concibe actualmente dificulta una denominación que satisfaga al conjunto. La verdad es que no existe una razón clara que lo justifique; tal vez intereses políticos o sociales del momento o bien un interés profesional por acotar el ámbito de trabajo y defenderlo de intrusismos.

Retomando la idea anterior, referida a la heterogeneidad que se presenta en la EA en la actualidad, observamos la aparición de nuevos conceptos tales como cultura visual, consideración del arte popular, los productos artísticos y 
estéticos o bien los objetos culturales. Asumimos que nos encontramos ante nuevos paradigmas que podemos considerar como pedagogías artísticas emergentes:

Los artistas posmodernos tienden a usar una belleza disonante o una armonía inarmónica, rechazando las ideas modernas sobre composición. Reinterpretan la tradición. El estilo posmoderno es ecléctico, reflejo de la pluralidad de las fuentes culturales y políticas de origen de la obra...Los soportes son diversos, hacen uso de objetos e imágenes variadas, reciclándolas y re-contextualizándolas mediante instalaciones o a través del uso de nuevas tecnologías de la información e informática (Efland, y otros. 2003, p.65-66).

Aguirre (2005) realiza una profunda revisión de los términos utilizados históricamente y establece una clasificación progresiva a través de las numerosas denominaciones que llegan a afectar a esta disciplina sobre la que trabajamos:

- En la era decimonónica, su utilización para designar a los objetos propios de las Bellas Artes.

- En la Modernidad, la designación de cualquier objeto, imagen o actividad valorada como Arte en el seno de la cultura. Se aborda la obra de arte centrando el interés en los contenidos artísticos, trabajados desde cuatro aspectos: la creatividad, la estética, la crítica y la historia del arte.

- En la era Posmoderna, la utilización con un carácter más versátil, aplicándose a diferentes y nuevas incorporaciones en las manifestaciones artísticas:

o La cultura visual: mass media. Todo lo que sea principalmente visual, cultural y con valores y actitudes. Los objetos producidos por nuestra cultura.

o El Arte popular: productos estéticos de culturas distintas a la occidental, productos de consumo y de la realidad cotidiana (Reconstruccionismo). 
o Los productos artísticos y estéticos: cuanto produzca experiencia estética por la intención, forma y sentido que el receptor da a su relación con el concepto o el evento (Pragmatismo).

o Los objetos con poder performativo de biografías o de cultura (en cualquier momento o lugar, en constante elaboración) que puede proporcionar identidad y sensibilizar (Experiencia estética contingente).

\subsection{La EA y el desarrollo humano.}

A partir de planteamientos de Ernst Cassirer $^{116}$, Claude Levy-Strauss ${ }^{117}$, Suzanne Langer ${ }^{118}$ y otros, Nelson Goodman ${ }^{119}$ impulsó en Harvard la investigación para entender y mejorar la educación, la enseñanza, el pensamiento y la creatividad en las artes: en el conocido Proyecto Zero ${ }^{120}$ sobre la EA y el desarrollo humano (1967). Para Goodman (1995, p. 239) el arte no debe tomarse menos en serio que las ciencias en cuanto a forma de descubrimiento, de creación y de ampliación del conocer:

\section{(...) La comprensión y la creación en las artes, al igual que toda especie de conocimiento y de descubrimiento, desde la percepción más simple hasta el patrón de descubrimiento más sutil y la}

\footnotetext{
116 Filósofo prusiano que vivió en la primera mitad del S.XX y cuyo trabajo versa sobre la filosofía de la cultura, estudiando cómo afecta la cultura al individuo. Los estudios culturales contemporáneos son herederos de este campo de estudio, y han ayudado a introducir términos como el de interculturalidad, que se fija ya no en la relación entre un único sujeto y su cultura sino entre diversos patrones culturales, entendiendo que en un mundo globalizado ya no se suele tener una sola cultura.

117 Antropólogo francés que vivió durante todo el siglo $X X$, que estudia la importancia del objeto artístico para los estudios culturales. Estudios etnográficos basados en la observación directa de culturas diversas. Para él, el arte tiene una dimensión comunitaria y no individual.

${ }^{118}$ Filosofa norteamericana que vivió durante el siglo XX. Su investigación filosófica se centra en los símbolos y su utilización en el arte, entre otras materias.

${ }^{119}$ Filósofo estadounidense del S. XX. Seguidor de las teorías de Cassirer respecto a la función constructiva de los símbolos pero él considera que los mundos no se construyen desde la nada, sino siempre a partir de mundos preexistentes. Construimos versiones/mundos a partir de otros preexistentes.

${ }^{120}$ Para un conocimiento más amplio del tema se remite al lector a la web: http://www.pz.harvard.edu/
} 
clarificación conceptual más compleja, no son cuestiones ni de contemplación pasiva ni de pura inspiración, sino que implican procesos activos, constructivos, de discriminación, interrelación y organización. De acuerdo con esto, ni la sensación esta tan aislada del pensamiento, ni lo están los diversos sentidos entre sí, ni las artes de las ciencias.

En este proyecto se integran figuras de la talla de Howard Gardner ${ }^{121}$ quien durante el proceso desarrolla ideas tan influyentes en el campo de la educación como la Teoría de las Inteligencias Múltiples $(1998,2003)^{122}$. Según esta, cada individuo posee siete inteligencias independientes, que combinadas nos permiten resolver problemas con distintos niveles de habilidad. Estas inteligencias son:

- Lingüística (capacidad de utilizar el lenguaje).

- Lógica-matemática (capacidad de resolver problemas mediante el razonamiento lógico).

- Musical (capacidad de percibir melodías, ritmos, tonos, armonía).

- Espacial (capacidad de pensar en tres dimensiones).

- Corporal (capacidad de utilizar el cuerpo y sus movimientos).

- Interpersonal (capacidad de comprender e interactuar con los demás).

- Intrapersonal (capacidad de un sujeto de conocerse a sí mismo).

- Gardner añadió una octava inteligencia: naturalista (capacidad de comunicación con la naturaleza).

Cada persona desarrolla unas más que otras. Diferentes culturas y segmentos de la sociedad ponen diferentes énfasis en ellas. Según él:

Concentrarse de forma exclusiva en las capacidades lingüísticas y lógicas durante la escolaridad formal puede suponer una estafa para los individuos que tienen capacidad en otras inteligencias. Un repaso de los

${ }^{121}$ Concentra sus estudios en la creatividad y en los procesos cognitivos del arte, con la pretensión de crear modelos de mentes creativas.

${ }^{122} \mathrm{Se}$ basa en la variedad de respuestas del ser humano a los problemas. Incluye el estudio de la personalidad, las emociones y el contexto cultural en el que se desenvuelven.

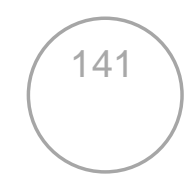


roles adultos, incluso en la sociedad occidental dominada por el lenguaje, muestra que las capacidades especial, interpersonal o cinético corporal, a menudo, desempeñan un papel fundamental (Gardner, 1998, p. 47).

Aboga por la idea de trabajar interrelacionando diferentes materias sin limitarse al estándar del dibujo. Quiere transmitir que la experiencia artística es un concepto más amplio, que es importante para el desarrollo individual y social, pues ayuda a relacionar aspectos culturales, con la enseñanza artística y la evaluación de las artes. Introduce diferentes elementos artísticos y, a la vez, separa la enseñanza artística de la práctica del arte. Habla no de enseñar a dibujar sino de dar herramientas para desarrollar aspectos creativos asequibles. Dando lugar a individuos capaces de ser críticos a la hora de abordar una obra de arte.

En EA, más que en generar productos, se debería trabajar más en la construcción de un pensamiento crítico y creativo que se pudiera aplicar a diversos productos, no necesariamente artísticos.

\subsection{Planteamientos curriculares.}

Los planteamientos curriculares de Formación Docente se han visto fuertemente influenciados por una línea de pensamiento que asocia las ideas de Dewey (1995), sobre el valor de la experiencia adquirida, la perspectiva disciplinar de Bruner (1999) y los análisis sobre la percepción visual y los estudios de la forma de Arnheim (1980).

Bruner (1999), entre otras premisas, aboga por el aprendizaje por descubrimiento en el que el instructor debe motivar a los estudiantes a que ellos mismos descubran relaciones entre conceptos y construyan a partir de ellos. La representación por la imagen, o representación icónica constituye un nivel mayor de autonomía del pensamiento. Las imágenes se convierten en grandes resúmenes de la acción, en las que el interés está centrado en la forma el tamaño y el color. La representación icónica se rige principalmente por principios de organización perceptiva. 
Introducido el término de la percepción, Arheim (1980) aduce la imposibilidad de la inteligencia sin esta, pues según él, percepción y pensamiento actúan recíprocamente. Son, a la vez, causa y efecto de una acción continua: la actividad perceptiva. Es por ello que considera fundamental la educación sensorial.

Figuras de la talla de Efland (2002) y Eisner (1995a) se vincularon a estas ideas y proponen, entre otras cosas, la ampliación de los dominios de la EA puesto que se quieren tener en cuenta todos los ámbitos de las artes visuales, considerándola una necesidad curricular por su interés para la formación personal y social. Entienden por un lado, que se debe planificar y tener una secuenciación clara de los contenidos para evitar errores como los de la época expresionista y que además a la habitual tarea de producción (trabajo de taller) se le debe sumar la de la comprensión del arte (la estética), el análisis del arte (la crítica) y el saber del arte (dominio cultural e historia del arte). Abre así la puerta a una interpretación simbólica del pensamiento artístico. El movimiento, dio origen a diversas iniciativas, entre las más conocidas el Proyecto DBAE (Discipline-based Art Education, estudios promovidos por el Getty Center) ${ }^{123}$ en EEUU, en la que se planteaba la importancia de enseñar la EA desde aspectos como la imaginación, la sensibilidad o la destreza técnica. Todo ello contextualizado en la cultura en la que se trabaja. De esta forma el alumnado va progresando en la tarea de comprender el arte en toda su dimensión.

\subsection{El arte como lenguaje.}

Existe una perspectiva que concibe la disciplina y el arte como un lenguaje. Como tal requiere la necesidad de desarrollar competencias propias de la alfabetización, en este caso la visual. La expansión de los medios audiovisuales y de las Nuevas Tecnologías orientan hacia los aspectos comunicativos de las imágenes influido por el desarrollo de la semiótica y la aplicación a la imagen visual de los planteamientos lingüísticos. Se 
contemplaba como una necesidad educativa el comprender los diversos lenguajes. Los contenidos se organizan en torno a la imagen y la comunicación visual. Predomina el mundo de la publicidad, el diseño, la fotografía y los audiovisuales. Se trabajan los elementos formales (línea, punto, textura, plano, color, luz...) basados en la teoría de la percepción, las leyes de la Gestalt y los elementos básicos del lenguaje plástico y visual. A nuestro entender también, lo que ocurre es que, en muchos casos, la alfabetización visual explica los elementos de la imagen pero no su significado por lo que debemos añadir un componente de interpretación por parte del sujeto.

En cuanto a alfabetización visual, Dondis (1976) diseñadora estadounidense, a mediados del siglo $X X$, ya defiende la importancia de la educación visual basándose en el auge de la cultura visual y en el potencial de la comunicación visual. Pone la alfabetización visual al mismo nivel que tenemos la escritura. Expone que debemos de saber utilizarla a nivel simple, correcto y claro. Al igual que cualquier persona puede escribir, y no por ello es un literato, cualquier persona ha de poder expresarse por un medio de representación visual aunque no alcance el nivel de un artista. El nivel de complejidad del lenguaje vendrá dado por el nivel de profesionalidad. Este mismo argumento podemos utilizarlo nosotros para plantear la necesidad de formarse y saber expresarse con él:

La fuerza cultural y planetaria del cine, la fotografía y la televisión en la confirmación de la imagen que el hombre tiene de si mismo, define la urgencia de la enseñanza de la alfabetidad visual tanto para los comunicadores como para los comunicados. En 1935, Moholy-Nagy, el brillante profesor de la Bauhaus, dijo que "los iletrados del futuro ignoraran tanto el uso de la pluma como el arte de la cámara". Aquel futuro es ahora el presente. El potencial espectacular en la comunicación universal, implícita en la alfabetización visual, está esperando un desarrollo amplio y articulado (Dondis 1976, p. 12). 
Bamford (2004) $)^{124}$ es una de las principales autoridades reconocidas en investigación sobre la alfabetización visual a nivel internacional. Para ella (Bamford, 2004), el concepto de comunicación visual es un proceso en el que se emiten y reciben mensajes utilizando imágenes. Durante este proceso el lector debe ser capaz de decodificar, analizar y reflexionar sobre lo que está viendo para construir el significado.

El concepto de alfabetización visual o visual literacy (Bamford, 2004) es un concepto acuñado desde hace bastantes años. Según Bamford (2004) es la habilidad que permite construir significado a partir de imágenes visuales. Esta capacidad permitirá interpretar y construir imágenes creando productos visuales capaces de comunicar mensajes. Para Bamford (2004) la alfabetización visual debe incluir no solo conocimiento sino también capacidad crítica.

Siguiendo con esta misma autora el trabajo con imágenes abarca numerosos campos profesionales muy distintos entre sí. Señalar la Medicina en la que la interpretación de los diagnósticos por imagen es cada día más frecuente, las Ciencias o la Arquitectura e Ingeniería. Es por ello que si nos remontamos en la historia vemos como las disciplinas en las que la alfabetización visual es importante son numerosas: Artes Visuales, Historia del Arte, Estética, Lingüística, Literatura, Filosofía, Psicología de la Percepción, Semiótica o diferentes campos del Diseño (Bamford, 2004).

Según Zanin (citada en March, 2010), bibliotecaria referencista sobre Artes Visuales de la Western Carolina University, la diversidad de definiciones de la alfabetización visual se debe a su interdisciplinaridad. Define el término como la habilidad para interpretar, reconocer, crear o manipular imágenes.

El grado de alfabetización visual "adecuado" es, para Bamford (2004), el que una persona sea capaz de leer y escribir con este lenguaje y transmitir su

\footnotetext{
${ }^{124}$ Profesora y reconocida investigadora especializada en educación artística, alfabetización emergente y comunicación visual. Colabora como especialista con la UNESCO dirigiendo y evaluando numerosos estudios para gobiernos de Dinamarca, Holanda, Bélgica, Islandia, Hong Kong y Australia.
} 
mensaje con eficacia. En nuestra cultura actual estamos rodeados por imágenes provenientes de diferentes fuentes, en todo momento. Nuestra formación, a nivel visual, determinara en qué medida seremos capaces de interactuar con esta información; de interpretarla y analizarla para ser críticos con ella. A la vez, insiste, en que nos da la capacidad de comunicarnos de forma efectiva y de crear imágenes que comuniquen de forma eficiente (Bamford, 2004). De la misma manera nos permitirá hacer frente al incremento en el uso de los mensajes visuales utilizados en nuestra cultura debido a su eficacia e inmediatez.

Duncum (2004) ${ }^{125}$ esgrime otro argumento a favor de la alfabetización visual al hablar de la capacidad de manipulación audiovisual. Para este autor, los nuevos medios audiovisuales tienen la capacidad de combinar imágenes, palabras y sonido para producir experiencias seductoras que no siempre se utilizan en interés del público. Alerta pues sobre la fuerza de los mensajes multicanal. Así, aboga por una sociedad que pueda estar preparada ante estos medios interactivos y va más allá acuñando un nuevo término que denomina, multiliteracy, multialfabetización (Duncum, 2004) para poder analizar y entender correctamente los mensajes multicanal que recibimos. Así pues nos explica como este concepto nos amplia el de la EA tradicional que basaba sus conocimientos únicamente en los aspectos visuales. Contempla algunas ideas de Arnheim y de otros investigadores como Debes o Paivio. Se trabaja sobre los conceptos de imagen mental, procesamiento dual del pensamiento, lateralidad, inteligencia visual, aprendizaje visual, mensaje visual, codificación y decodificación. Oholer, en esta línea de trabajo, subraya la importancia de la alfabetización visual en el contexto de lo multimedia y digital.

\footnotetext{
125 Paul Duncum, es Doctor en Bellas Artes por la Flinders University of South Australia. Fundador del Art Education Australia. Profesor de Educación Artística de la Escuela de Arte y Diseño de la Universidad de Illinois en Urbana Champaign, EUA. Anteriormente fue docente en las Universidades Central de Queenland y de Tasmania en Australia. Es un autor reconocido a nivel internacional especializado en cultura visual y educación en arte. Ha publicado internacionalmente numerosos artículos sobre problemas teóricos, estéticos y críticos de la cultura visual, especialmente la popular, y de la educación artística, en particular de la niñez. De 1982 a 1987 editó The Journal of the Institute of Art Education (ahora Australian Art Education), y, en fecha más reciente, La cultura visual en la clase de arte: Estudios de casos (2006). Fue distinguido con la condición de Miembro Vitalicio del Instituto Australiano de Educación Artística y el Premio Manual Barkan Memorial.
} 


\subsection{La Educación para la Comprensión de la Cultura.}

Hemos ido viendo como la necesidad de ampliar el ámbito de lo que tradicionalmente se concebía como Arte, ha ido dando lugar a nuevas posturas. Los artistas de finales del siglo XIX valoraron las aportaciones de otras culturas y podríamos considerarlos como los primeros que plantearon un posible multiculturalismo, aunque lo hicieron desde sus propias premisas. Más adelante, en el siglo XX, los movimientos políticos y sociales liberalizadores favorecieron la relevancia de todo tipo de culturas y sus valores propios. Se reivindica una identidad cultural dinámica que se enriquece con los intercambios entre las diferentes culturas. La conformidad con la diversidad cultural permite la práctica de una ecología cultural, en la que la interculturalidad, o interacción entre las diferentes culturas, favorece el conocimiento de la cultura local, las culturas integrantes de una comunidad y las variadas culturas globales. Pues solo si se interiorizan los códigos culturales propios se puede relacionar con "el otro".

A través del arte se conoce la simbología de una sociedad o grupo social. No se conoce completamente la cultura si no se conoce su arte pues este refleja su historia. El arte visual refleja los valores sociales y favorece la identificación cultural y el desarrollo pues la percepción sensorial, ayuda a entender la realidad circundante de forma crítica. Actualmente nos encontramos con variadas propuestas para una nueva visión sobre la EA. No se trata únicamente de incluir el arte en el curriculum sino que se ha de cuidar lo que se enseña y la forma en que se enseña. Si el arte no se trata como un conocimiento y solo plantea una liberación de emociones, no se ofrece una verdadera EA.

Las propuestas tienen semejanzas pero también diferencias significativas que marcaran diferentes enfoques en el estudio. La multiplicidad de perspectivas ha generado propuestas curriculares eclécticas que se enriquecen integrando y asumiendo aspectos significativos de cada una de ellas. El hecho de exponerlas por separado solo obedece a un intento clasificador de las mismas. 


\subsubsection{Estudios de la Cultura Visual.}

El pensamiento posmoderno criticó la visión individualista, etnocéntrica y elitista del arte de pensadores anteriores. Es un campo complejo pues abarca multitud de disciplinas que van a influir en el estudio de lo considerado como cultura visual. Se promueve la idea de dejar de centrar los aprendizajes en tomo al Arte, considerado un fenómeno ligado a un tipo privilegiado de producción cultural considerado de Alta cultura y centrarse más en la producción de cualquier individuo o grupo (producciones culturales), esto es la cultura popular y la cultura visual en sentido amplio. Los estudios parten inicialmente de la parte literaria para extenderse a estudios de sociología, sobre medios de comunicación e historia del arte. Sus referencias son los objetos visuales y nuestra forma de mirarlos. Tratan el significado de la imagen en el cine, la fotografía, la televisión, la publicidad o la pintura. Se busca cómo las connotaciones sociales y el lugar o espacio desde el que se ve, influyen en la mirada. Se establecen relaciones entre el sujeto (que mira) y el objeto (que es visto).

La idea de cultura visual implica centrarse en cualquier elemento que cumpla las condiciones de ser prioritariamente visual (aunque muchas veces las imágenes se presentan unidas a elementos sonoros, verbales, gestos y lenguajes corporales, etc.) y, que sea integrante de valores y creencias, por tanto, de contenido cultural. Es un campo de estudio que ha ido emergiendo desde la confluencia de diferentes disciplinas, en particular desde la Sociología, la Semiótica, los Estudios culturales y feministas y la Historia cultural del arte, y que dibuja diferentes perspectivas teóricas y metodológicas.

Aunque estamos siempre rodeados de imágenes, no es lo mismo reflexionar sobre lo que vemos que analizar la procedencia o intención de dichas imágenes en relación con el contexto real. Por eso es necesaria una educación que trate directamente las imágenes que constituyen el mundo del espectador así como que le guie en la labor de la interpretación de su significado. Utilizar la EA para ejercicios de libre expresión o coloreado, no es cultura visual, no es 
lo mismo creatividad que improvisación. Conocer el arte visual implica experimentarlo, decodificarlo y poder producirlo.

Ejemplos de investigadores que han explorado la cultura visual desde la perspectiva de los Estudios Culturales son Green (1997) sobre programas de televisión infantiles, Stuhr y Ballangee-Morris (2001) sobre la violencia en los medios de comunicación, Duncum sobre las imágenes de niños en los medios (2000), Garber (2002) sobre los estereotipos raciales en los cómics populares, Jagodzinski $(1995,1996)$ sobre la violencia en las películas para adolescentes.

Mirzoerf (2005, p. 3) cuando intenta definir lo que entiende por cultura visual nos indica que:

Visual culture is concerned with visual events in which information, meaning or pleasure is sought by the consumer in an interface with visual technology. By visual technology, I mean any form of apparatus designed either to be looked at or to enhance natural vision, from oil painting to television and the Internet ${ }^{126}$.

Las visiones de Duncum (2004) y Mirzoerf (2005) difieren en que mientras para el primero el término cultura visual sí recoge el concepto de cultura en su sentido amplio, en el segundo el término otorga excesivo protagonismo a la parte visual dejando en segundo lugar las otras fuentes de información.

Duncum (2004) destaca la predominancia del discurso escrito en el que, aunque hubiera imágenes, siempre aparecían como ilustración pues el discurso escrito o leído era lo que las explicaba. Actualmente existen corrientes que, ante un cambio de actitud por parte del lenguaje escrito, abogan por un disfrute más global de la experiencia cultural, se acercan al campo de la cultura visual en pro de generar un conocimiento más completo y más adaptado a tal y como se entiende la cultura en la actualidad. Lo mismo

\footnotetext{
${ }^{126}$ La cultura visual tiene que ver con los acontecimientos visuales en los cuales el consumidor busca información, significado o placer en una interfaz con tecnología visual. Por tecnología visual, me refiero a cualquier tipo de aparato diseñado ya sea para ser visto o para mejorar la visión natural, desde la pintura al óleo a la televisión e Internet.
} 
ocurre cuando nos asomamos a elementos multicanal como la televisión, videojuegos, páginas de internet, etc. no evaluamos por separado cada uno de los campos perceptivos (imagen, música, mensaje o texto) sino que los interpretamos como un conjunto indisociable.

La EA, y lo que en otros momentos ha significado, ha ido paralelo a los valores que se le adjudicaban y a la forma en que se interpretaba la obra de arte. El componente sociológico y cultural ha envuelto el ámbito artístico en todo su desarrollo histórico. Implica una interdisciplinaridad propia de una sociedad diversa. La sociedad actual cada vez busca más sus creencias en los ámbitos de la cultura global en vez de en otros ámbitos más tradicionales (familia, religión...). Este planteamiento requiere un nuevo posicionamiento de la EA e ir en esa dirección aunque atendiendo a la posible incomprensión ante los temas abordados, pueden dar la sensación que no hablamos de elementos propiamente artísticos (representaciones de la mujer, los roles sociales, los estereotipos, el multiculturalismo, los fenómenos de la globalización vinculados a las TIC, etc.).

\subsubsection{Estudios de Cultura Material.}

Los estudios de Cultura Visual, para determinados autores, dejan de lado aspectos considerados importantes y referidos a lo más cercano y cotidiano. Al abordar el tema de lo que llaman Cultura Material pretenden referirse a experiencias mucho más amplias, considerando que hasta los objetos más insignificantes pueden funcionar como símbolos (cualquier elemento es digno de estudio ya que contiene en sí mismo el mensaje de la cultura que lo produce). En la sociedad actual el producto de consumo acumula valores y creencias sociales. Los aprendizajes en EA abarcaran temáticas tan dispares como el arte de la calle, mobiliario urbano, la moda, la decoración, la iconografía de las revistas infantiles y juveniles, etc. La cultura material (el significado cultural de los objetos para un grupo), deben ser interpretados y comprendidos en sus contextos históricos, sociales y políticos. 
Ejemplos de estudios de EA en los que han influido los estudios de Cultura Material encontramos el estudio de Wagner-Ott (2002) sobre las muñecas Barbie y los personajes de acción, el estudio de Pistolesi (2002) sobre la iconografía de Elvis y el estudio de Stokrocki (1997) sobre los disfraces, las calabazas y las decoraciones de Halloween. Klein y Agostinone-Wilson instan a los educadores de arte a que se conviertan en turistas críticos, analizando los objetos recogidos en un viaje ya que constituyen la narrativa del lugar que hemos visitado.

Al considerar que todos los objetos son susceptibles de apropiación para generar significado en ocasiones se puede argumentar que está poco relacionada con el mundo artístico.

Ambas aproximaciones rechazan la consideración de que la cultura únicamente atienda a obras con una sensibilidad determinada, al estimar que estas solo representan una parte muy selectiva de lo que es la cultura. Su concepto de la cultura recoge lo cercano que incluye las relaciones sociales y el sistema de valores y creencias.

Para el educador de arte es interesante poder trabajar combinando ambos aspectos. Se pueden utilizar todo tipo de objetos (bi o tridimensionales), tanto los considerados como simbólicos y como los diseñados para la comunicación. Además trabajar acerca del material en que están fabricados y añadiendo las circunstancias en las que los vivimos. En este campo incluiríamos los propios objetos, su procedencia e historia, el lugar donde los vemos o se exhiben, que función tienen....

Tenemos unos ejemplos interesantes en el número de otoño de 2002 de Visual Arts Research que contenía 11 artículos que trataban el ámbito de la cultura, visual-cum-material.

- Referidos al campo de la cultura visual, encontramos los trabajos de Tavin que trabaja sobre la publicidad en las revistas, de Freedman acercándose al tema de la televisión y Krun abordando el terreno de los medios de comunicación electrónicos, como Internet. 
- En el campo referido a la cultura material señalamos a Congdon que trata ampliamente el diseño de las tablas de surf.

- Finalmente encontramos a los que mezclan las dos tendencias, Stanley que escribe sobre los parques temáticos, Webb sobre los enclaves turísticos y su promoción, Smith-Shank sobre las celebraciones sociales y Stokrocki sobre las galerías comerciales.

\subsubsection{Práctica del Arte Contemporáneo.}

Abordar esta premisa supone tener que estar al corriente de los nuevos procesos evolutivos dentro del mundo artístico contemporáneo para afrontarlo tanto desde su práctica como desde su crítica.

Actualmente existe un camino de ida y vuelta entre el mundo artístico y la cultura popular. El mundo artístico asume signos propios de los medios de comunicación y, a su vez, la cultura popular adopta elementos considerados del dominio del mundo artístico. El arte contemporáneo se involucra cada vez más en los sucesos de la cultura de masas global, en el campo de lo ideológico y político. Ejerce un papel de crítica y reflexión sobre todo aquello que lo rodea. Se trabaja más sobre investigaciones intelectuales y críticas que sobre lo puramente formalista.

Por lo tanto a la hora de hablar de EA se podría trabajar sobre el producto pero también sobre la forma en que se produce. El artista siempre ha utilizado la representación de objetos para hablar de aquello que le rodea. Por lo tanto, para generar nuestros nuevos objetos artísticos, podemos utilizar todo aquello que aparece en los medios de comunicación y es propio de nuestra cultura. De este modo podemos abordar cuestiones éticas, culturales e interdisciplinares que conecten al alumnado con su realidad social y contextual.

En este caso el arte se viviría como una experiencia artística que busca recursos para abordar un mensaje que no puede transmitir por medio del 
lenguaje discursivo o el científico pero si mediante la colaboración entre las diferentes áreas de conocimiento y lenguajes para fomentar aprendizajes ricos y diversificados. Otro aspecto destacable seria la posibilidad de intervención socioeducativa por medio del arte potenciando las experiencias artísticas que permitan crear y a la vez apreciar tanto las creaciones individuales como las del grupo o comunitarias. Se fomenta la participación en la comunidad, la relación con el otro, la colaboración, la mediación y resolución de conflictos. El aprendizaje artístico favorece la escucha de opiniones diversas y la aceptación e integración de lo diferente tanto de creación como de apreciación y dirigidas al desarrollo de la subjetividad del individuo, así como a la identidad grupal y comunitaria. Acción social desde la conciencia de la diversidad cultural y que promueve la participación del individuo en la comunidad.

\subsubsection{La visión global del hecho artístico.}

Una forma global de abordar esta temática es la de los autores que han trabajado tratando de unir todos los aspectos: el mundo artístico pasado y presente, con la cultura visual contemporánea y la cultura material.

Explicaremos esta opción con un ejemplo práctico. Duncum (2004) nos demuestra con uno de sus trabajos que podemos abordar cualquier tema del curriculum. El punto de partida es una pregunta: ¿La masculinidad tiene que suponer bravuconería y violencia?

Para contextualizarla toma como referencia los espectáculos de lucha en televisión. Además toma referencia en la historia del arte para trabajar con los inmensos lienzos de los siglos XVII y XIX, que representan luchas de hombres musculosos. Se remonta a los gladiadores romanos y lo relaciona con los actuales macro espectáculos deportivos. Utiliza todas estas imágenes como referentes para analizar los múltiples aspectos que podemos encontrar en ellas. Un tema general y actual es el punto de arranque para investigar en imágenes de la historia del arte y la búsqueda de sus creencias y costumbres. 
Además de Duncum (2004), otros investigadores como Hernández (2000), Freedman $(2002,2006)$ y Aguirre (2000) trabajan sobre, lo que este último ha venido a llamar, la significación de los "artefactos visuales", entendiéndolos como discursos de prácticas sociales y de relaciones de poder. El interés prioritario no está tanto en esos artefactos visuales por sí mismos, sino en su condición de mediadores de valores culturales.

En nuestro país resaltamos algunos ejemplos relativamente recientes que se acercan al hecho artístico de forma global:

La principal finalidad de la educación artística en el contexto postmoderno es la construcción de la realidad, función del arte común a la Historia de la humanidad. Gran parte de la realidad es pura construcción social y, en este sentido, los artistas acaparan una porción importante del discurso contemporáneo de nuestra realidad. Por este motivo, el principal objetivo de la enseñanza del arte es que los alumnos lleguen a entender los mundos sociales y culturales en los que viven (Calaf y Fontal, 2010, p. 142)

Vallés (2005) en su tesis doctoral ${ }^{127}$, considera que en el momento actual el arte fusiona disciplinas múltiples y ya no se puede pretender que las distintas manifestaciones artísticas permanezcan en departamentos estancos. Lo define una forma abierta que incluye variadas formas de expresión artística.

Abad (2009, p. 20) no contempla las producciones culturales como un privilegio y sostiene que:

Decididamente, en este panorama de la experiencia humana no podríamos definir en la actualidad unas funciones universales de las artes, sino más bien una serie de estrategias de cómo cada persona o colectivo las aplica y contextualiza en su propio proyecto de "construcción de la realidad" (el arte, como mediador de

127 Competencia multicultural en educación artística. Contextos y perspectivas de futuro en la formación de maestras y maestros. 
significados, se produce en un contexto de relación y estos significados se construyen de acuerdo con esta necesidad de interpretar la realidad). Estrategias que no solo sirven para descubrir nuevas oportunidades, sino como una manera de concretar elecciones y asumir compromisos. Cuando las artes desempeñan esta función contextualizada en cada situación de realidad, otorgan a lo individual una forma pública en la cual pueden participar otros como manifestación e invitación a una construcción colectiva de los significados.

Además, (Abad, 2009, p. 6):

Desde este punto de vista de integración del arte en la educación, se pueden empezar a plantear supuestos diferentes que afectan a los diferentes sujetos, a sus relaciones, sus representaciones culturales y sus conocimientos entendidos no solo como una situación de intercambio en los procesos de enseñanza y aprendizaje, sino como una práctica de política comunitaria para el desarrollo humano.

Por último, nos parece que la siguiente cita resume los conceptos que hemos querido plasmar aquí, ya que plantea un nuevo paradigma para la EA:

El eclecticismo postmoderno implica asumir la interdisciplinariedad y la multidisciplinariedad para poder adaptarse al acelerado ritmo del presente (...) se están aproximando al entramado sociocultural fragmentado, diversificado, multigenérico, intercultural, desclasificado y multidireccional, bajo la óptica específica de la educación artística. En este sentido la cultura visual es, el mejor aglutinante, que permite comprender precisamente el entramado en el que nos hallamos inmersos (Escaño, 2003, p.427) ${ }^{128}$.

El contexto cultural ha cambiado radicalmente en las últimas décadas del siglo $\mathrm{XX}$ y lo que llevamos del siglo XXI. Algunas corrientes pedagógicas intentan

\footnotetext{
${ }^{128}$ Escaño, J. C. Lágrimas en la lluvia. Debate sobre la educación artística y la posmodernidad, vol. I, en Marín, R. (2003). Didáctica de la educación artística para Primaria. Madrid. Pearson Educación.
} 
proporcionar capacidades a los agentes sociales y educativos para comprender mejor estos cambios. Los artefactos culturales ayudan al individuo o al grupo a pensar sobre su identidad. Las finalidades educativas se organizan en tomo a la idea de ayudar a comprender la realidad:

(...) a proseguir el proceso de examinar los fenómenos que nos rodean de una manera cuestionadora y construir "visiones" y "versiones" alternativas no sólo ante las experiencias cotidianas, sino ante otros problemas y realidades alejados en el espacio y en el tiempo del nuestro (el de los adultos y el de los niños, las niñas y los adolescentes (Hernández, 2000, p. 22).

\subsection{La Creatividad y la Educación Artística.}

Enunciar la creatividad como un principio fundamental de la educación contemporánea es un acierto especial del profesor Ricardo Marín Ibáñez ${ }^{129}$, pionero en la pedagogía de la creatividad y la innovación. Define los productos creativos como la conjunción de lo nuevo con lo valioso y la formación de personas creativas con la multiplicidad subjetiva de respuestas libres.

La actividad creadora no es considerada habitualmente en nuestro sistema educativo como una actividad apropiada para el desarrollo de los aprendizajes en el aula. La creencia se basa que mayoría de las personas consideran que la creatividad o la creación es un "don" privativo de algunos elegidos (artistas, talentos, descubridores, genios, etc.). Sin embargo pensamos que una persona que realiza actividades creativas es aquella que no se limita a la mimesis sino que continuamente reelabora la experiencia para crear una nueva. En palabras de Vigotsky (1997, p. 9):

Se puede llamar actividad creadora a toda realización humana creadora de algo nuevo, ya se trate de reflejos de algún objeto del mundo exterior,

\footnotetext{
${ }^{129}$ Fundador del Instituto de la Creatividad de la Universidad de Valencia. Catedrático de Pedagogía de la Facultad de Educación de la UNED, miembro de número de la Real Academia de Doctores y Titular de la Cátedra UNESCO de Educación a Distancia de la UNED.
}

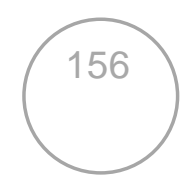


ya de determinadas construcciones del cerebro o del sentimiento que viven y se manifiestan sólo en el propio ser humano.

Toda actividad humana que no se limite a reproducir hechos 0 impresiones vividas, sino que cree nuevas imágenes, nuevas acciones, pertenece a la función creadora o combinadora. El cerebro no se limita a ser un órgano capaz de conservar o reproducir nuestras pasadas experiencias, es también un órgano combinador, creador....Es la actividad creadora del hombre la que hace de él un ser proyectado hacia el futuro, un ser que contribuye a crear y que modifica su presente.

La combinación creadora no se da natural ni repentinamente, se ha de educar y cultivar porque nace y crece con la experiencia. Combinar lo antiguo con lo nuevo, sienta las bases de la creación. Para poder expresarse adecuadamente es necesario educar, cultivar los sentidos y saber evaluar la calidad de las imágenes que se nos presentan. De esta forma conseguiremos favorecer la fluidez, la flexibilidad y la originalidad. Solo con un grado alto de comprensión por parte del público, la producción artística podrá ser entendida en su totalidad. Por lo tanto es necesaria la intervención del docente como agente colaborador y facilitador de los medios para potenciar las experiencias y que generen nuevas creaciones. La competencia cultural y artística es transversal y óptima para todos los alumnos, puesto que se vincula con todas las áreas y es clave en el desarrollo de la creatividad.

Nos interesaría destacar en este apartado, la figura de Robinson ${ }^{130}$, educador, escritor y conferencista británico. Experto en asuntos relacionados con la creatividad, la calidad de la enseñanza, la innovación, los recursos humanos y la importancia de la gestión emocional que son las bases en las que asienta sus publicaciones y apariciones públicas en congresos. Es asesor de de sistemas educativos a nivel mundial y promulga especialmente la necesidad de incorporar clases de arte al currículum escolar. Entre 1985 y 1989 fue el director del proyecto The Arts in Schools Project, iniciativa que pretendían

\footnotetext{
${ }^{130}$ http://www.ted.com/talks/ken robinson says schools kill creativity http://www.ted.com/talks/sir ken robinson bring on the revolution
} 
mejorar la enseñanza y el aprendizaje de las artes en las escuelas británicas. Desde 1989 hasta 2001 fue profesor de Educación Artística en la Universidad de Warwick. En 1998, Blunkett, Ministro de Educación y Empleo británico, lo puso al frente del comité consultivo nacional sobre educación creativa y cultura $\left(N A C C C E^{131}\right)$. Comité que, posiblemente, realizó la mayor investigación nacional sobre la importancia de la creatividad en la educación y la economía del Reino Unido. Fruto del trabajo en dicho comité, se publicó en 1999, el llamado Informe Robinson cuyo título formal, traducido, es: Todos nuestros futuros: creatividad, cultura y educación. El informe tuvo un gran impacto pues ponía de relieve el escaso papel que hasta entonces había recibido la creatividad y la importancia que sobre ella recaía el futuro. Dictaminó que el dicho currículo no sólo no educaba la creatividad, sino que la anulaba ${ }^{132}$.

La sociedad contemporánea necesita y busca personas emprendedoras y creativas. La creatividad, por defecto, siempre se ha relacionado a la EA pero sin embargo se puede aplicar a diferentes ámbitos de la vida y del saber, añadiendo la importancia que tiene la inteligencia emocional.

Robinson (2009), Roeser et al., (1996), Darling-Hammond y Muñoz (2001), Goleman (2009), hablan sobre ello en medios de comunicación de masas, como la televisión, acercando este pensamiento al debate ciudadano e introduciéndolo en las redes sociales. Este debate se acentúa a partir de 2008, que es cuando comienzan a aparecer más ponencias en los medios y congresos relacionadas con todo ello, como las del TED ${ }^{133}$.

En uno de sus libros, titulado The Element, Robinson (2009) expresa la necesidad de que todas las personas, para realizarse en la vida, encuentren su "elemento" o talento personal, aquel con el que son felices. Aporta la idea de fomentar estas prácticas de búsqueda del propio talento desde la escuela. Estas prácticas íntimamente relacionadas con las enseñanzas artísticas.

\footnotetext{
${ }^{131}$ National Advisor Committee on Creative and Cultural Education.

132 Consultar completo en: http://sirkenrobinson.com/pdf/allourfutures.pdf

${ }^{133}$ Technology, Entertainment, Design.
} 
Una de las primeras consecuencias debería ser el cese de la estigmatización de estas enseñanzas para pasar a promover las prácticas artísticas y los intereses artísticos de sus alumnos. Evitar colocarlos en el plano más inferior en prioridad de enseñanza en la jerarquización actual de las materias académicas:

Una de las características de la enseñanza es que hay una jerarquía de asignaturas en las escuelas. En la mayoría de sistemas tenemos, arriba de todo de la jerarquía, la lengua, las matemáticas y las ciencias; un poquito más abajo están las humanidades, como la geografía y los estudios sociales, o la filosofía (cuando se enseña)...y debajo de todo están las disciplinas artísticas (Robinson, 2011, p. 4).

Dondis (1976), que ya hemos tratado anteriormente, considera que la EA es útil en la educación de todo tipo de personas pues desarrolla cualidades como la agudeza visual y la capacidad expresiva mejorando la creatividad. Aboga por la formación en alfabetización visual para que esta formación no se dirija exclusivamente a profesionales de ámbito artístico. Según expresa:

Por ello constituye una de las preocupaciones prácticas del educador. Una mayor inteligencia visual implica una comprensión más fácil de todos los significados que asumen las formas visuales...La inteligencia visual incrementa el efecto de la inteligencia humana, ensancha el espíritu creativo (Dondis, 1976, p. 208).

Ese desarrollo de la creatividad visual resultará muy útil por facilitar el acceso al conocimiento de este lenguaje. Tiene dos vertientes, por un lado mejora la interpretación de los mensajes que se reciben pero por otro lado, y tal vez tan importante si cabe, permite aprender a utilizarlo para la creación y mejora de los que se emiten. La utilización de las herramientas tecnológicas, que nos facilitan el uso de la imagen, necesita de una formación para saber aplicar los distintos lenguajes implicados en la generación de mensajes visuales.

Para Bamford (2012), firme defensora de utilizar el potencial creativo en todos los agentes implicados en la escuela y la educación, nos proporciona las siguientes definiciones: 
La creatividad consiste en conseguir que los alumnos desarrollen comportamientos y pensamientos originales e innovadores a través de un extenso y nutrido curriculum. Ésta florece cuando constituye una parte esencial del aprendizaje y la docencia, tanto en el curriculum oficial como en todo el entorno escolar (...)

Una clase creativa comienza con la pasión y el entusiasmo del profesor, que

tiene que «cuestionar»y «retar»a su alumnado. El profesor tiene que sentirse

capaz de asumir riesgos. Todas y cada una de las lecciones deben planificarse

para que resulten interesantes y estimulantes. Un aula creativa tiende a florecer cuando se realizan una planificación rigurosa y secuencias de aprendizaje, al mismo tiempo que se establecen tareas abiertas y se reta a los alumnos. Unos programas de aprendizaje, planes de estudios y libros de texto excesivamente restrictivos pueden limitar la enseñanza creativa si se convierten en recursos demasiado autocráticos y no permiten que los profesores hagan uso de su propia pasión e iniciativa (Bamford, 2012, p. $57)$.

Kenneth Bain, catedrático de Historia y Educación en Columbia (EUA), fue investido doctor 'honoris causa' por la Universitat de València en noviembre de 2014. Queremos señalarlo en este apartado porque en su discurso de investidura ha señalado:

En una concepción nueva, una educación debería tener como objetivo principal el desarrollo del pensamiento curioso, creativo y crítico en personas humanitarias. Debería centrarse en ayudar a todos y cada uno de los estudiantes a desarrollar el poder creativo y dinámico de sus mentes. Eso requeriría que ayudáramos a los estudiantes a concienciarse de su singularidad... Una parte importante del proceso creativo se convierte en la capacidad de reconocer las buenas ideas cuando me las 
encuentro, y de incorporarlas, contrastarlas e integrarlas con las mías $\operatorname{propias}^{134}$.

Existen, en los últimos tiempos, numerosas instituciones comprometidas con el fomento de la EA involucrándose en la revalorización de la misma y trabajando en temas como la creatividad o la innovación, para construir un futuro ciudadano más creativo. Algunos ejemplos de ello son:

- NAEA (National Art Education Association)

- INSEA (International Society for Education Through Art)

- PDEA (Plataforma por la Defensa de las Enseñanzas Artísticas)

- EACEA (Agencia Ejecutiva en el Ámbito educativo, Audiovisual y Cultura)

- NSEAD (National Society for Education in Art \& Design)

- CAA (California Arts Advocates)

- Universidades como las de Yale, Oxford o Harvard, que han acogido con interés los estudios en arte fomentando de este modo el estatus de esta disciplina.

Retomamos pues la idea expresada anteriormente sobre la EA como elemento contenedor que permite un disfrute holístico del hecho artístico. Abrimos así la puerta al trabajo multidisciplinar en el que podemos abordar un tema determinado integrando diferentes aprendizajes perceptivos y también podemos disfrutar de que el contenido de varias disciplinas conformen una única experiencia artística. 


\section{LA ENSEÑANZA ARTÍSTICA Y LA EDUCACION PARA LAS ARTES.}

Arañó (1989) expresa su idea de que el pensamiento académico marca la ideología cultural en nuestro país. Considera que el pensamiento académico ejerce una actitud proteccionista y conservadora sobre valores y creencias que afectan a las actividades artísticas. Se erige en juez de aquello que tiene que ver con el Arte. Mantiene que:

La legislación reguladora de las Escuelas de Bellas Artes y la literatura académica mantienen una estructura y contenido invariable y homogéneo durante el último siglo y medio de su historia. Se han constituido como formas institucionalizadas de un determinado modo de pensar sobre arte o cultura artística. Los elementos básicos de esta cultura se han relacionado generando creencias, valores y normas pretendiendo representar las soluciones que la sociedad española por medio de sus Academias daba a su realidad social artística o a sus problemas relacionados con el Arte (Arañó, 1989, p. 29).

El empeño en diferenciar entre cuales han de ser los modelos de actividad artística y cual la forma de enseñarlos, ha determinado completamente la dirección a seguir. Bebemos de una historia en la que los artistas eran "esclavos" calificados, hábiles con las manos. Así que Araño comenta que desde los más remotos orígenes el arte ha sido considerado como una de las actividades humanas menos relacionadas con la inteligencia, fruto de ella pero que no fomenta actividad inteligente. Por deducción las enseñanzas artísticas siempre se han tenido en cuenta como una parte de la instrucción manual.

El concepto que se tiene, en muchos casos de que está reservado a personas especialmente dotadas o bien que se trata de labores manuales o de expresión libre, lastran el que se tenga un mejor concepto en cuanto a su inclusión en la planificación curricular. Podríamos añadir, que también nos pesa el concepto educativo de preparar a las personas para la realización de una labor profesional en las que poca importancia se concede a priori a la preparación artística. 
En nuestro país es bastante complejo, al parecer, plantear estas cuestiones en ámbitos educativos y administrativos. Coincidimos con lo que defiende Fernando Hernández (2000) al plantear que podríamos encontrar varios argumentos que justificarían el escaso interés que despierta este tema en la sociedad española:

1. Socialmente está aceptado que el "artista" es un ser que ha nacido con una predisposición especial, que únicamente se puede mejorar en estas personas "excepcionales". Tiene pues muy poca repercusión entre la gente corriente. Esto no ocurre con otras cualidades que a priori no se cuestionan como escribir, cantar... En el caso del artista y de la sociedad también nos encontramos con la errónea separación de alta cultura y cultura popular.

2. No se considera que saber dibujar o pintar sea algo útil, se queda en el ámbito de lo lúdico o de lo relajante. No tiene un valor cognitivo para realizar otras tareas que se puedan considerar necesarias. Solo es importante aquello que permite el acceso al sistema productivo. También se considera que no contribuye al desarrollo de la inteligencia y no se percibe como un proceso de aprendizaje o generador de conocimiento. Esto se ve trasladado con frecuencia todavía de forma muy habitual en las mismas escuelas. Se reserva el trabajo de plástica para rellenar momentos en los que otros ya han acabado las tareas o se coloca en huecos de horarios. Ello no quiere decir que se produzca en todos los casos pero si de forma habitual. Cada vez más profesorado se preocupa de cómo incluir estos aspectos en su práctica diaria pero a veces carecen de la información o formación suficiente. Esto es lo que queremos plantear en este trabajo. Qué formación reciben y como pueden aplicarlo en la escuela.

3. Por último, y como adelantábamos en el punto anterior, el tercer elemento importante es la propia formación del profesorado: si el profesorado está mal formado no dará la importancia debida a la materia. Con ello, los alumnos tampoco tendrán la formación adecuada y no valoraran los aspectos educativos artísticos con la consiguiente minusvaloración. Socialmente no tendrá repercusión y por lo tanto 
tendrá poco peso en el curriculum. Se convierte en un círculo que se va retroalimentando.

Podríamos distinguir diferentes formas de abordar la presencia del arte en la enseñanza, dependiendo de la finalidad que se pretenda: bien proporcionar conocimientos artísticos en la etapa escolar al conjunto de individuos (en este caso se trata el arte como contenido pues se abordan aspectos históricos y técnicos) o bien llevar a cabo una enseñanza especializada y progresiva dirigida a profesionales de Facultades de Bellas Artes o Escuelas de Arte que utilizarán estos conocimientos como medio para elaborar su discurso personal. Por último, y obedeciendo a nuevas tendencias educativas que hemos comentado anteriormente, podríamos utilizar los recursos artísticos como un medio para abordar diferentes estrategias educativas. De esta manera se pueden establecer asociaciones con factores artísticos y culturales que contribuirán a enriquecer el método de aprendizaje y la enseñanza e introducir factores emocionales y relacionales que posibilitarán una educación más creativa y significativa.

\section{LAS ENSEÑANZAS ARTÍSTICAS EN ESPAÑA.}

El concepto de Educación Artística en España ha seguido una evolución histórica diferente a como lo hizo en el resto de Europa. En el siglo XIX la necesidad de la producción industrial ejerció una importante presión social sobre la actividad artística. En Europa rivalizaban los productos industriales en cuanto a su calidad y diseño. Según plantea Arañó (1989) fue necesario establecer una coordinación y organización entre las escuelas de arte y el artesanado, pues planteaban dos formas diferentes de abordar los "temas artísticos". Las Academias debían mediar entre las necesidades que demandaba la sociedad del momento y los artistas, encargados en un primer momento de educar a los artesanos. En algunos momentos, debido a la evolución social de finales del XIX, se diluyó un poco esta pugna entre los dos conceptos de las artes. Socialmente perdía peso el gusto cortesano para crecer el gusto de los habitantes de las ciudades y el mercado industrializado. 
En Europa la coordinación entre las escuelas de arte y los artesanos se resolvió a mitad de siglo, no así en España. Aquí se acrecentaron las diferencias entre quienes abogaban por unas artes liberales o por aquellas que estaban enfocadas a labores de reproducción más mecánica. Se resolvió creando unas escuelas de Artes y Oficios Artísticos que permitían seguir manteniendo a salvo una supuesta pureza artística en las Escuelas de Bellas Artes. De esta forma lo que en el resto de Europa sirvió para abordar un planteamiento innovador artístico más profesional, en España provocó un nuevo cisma.

Las enseñanzas artísticas en nuestro país nacieron paralelas a la aparición de las Academias, fruto de la renovación artística de los siglos XVIII y XIX y junto a las ideas de la llustración que aportaron nuevas propuestas en filosofía, literatura, política, etc. El origen concreto es impreciso debido a que existía cierta confusión por la intervención de los gremios artesanales decimonónicos y los talleres privados de artistas.

Se plantea, con cierta complejidad, definir qué se entiende por Enseñanzas Artísticas. Nos encontramos con la eterna dicotomía de la diferenciación entre las llamadas "enseñanzas de primer orden", dirigidas a la formación de profesionales y expertos en arte, y aquellas planteadas como una enseñanza artística dirigida al conjunto de la población o bien impartidas para ser aplicadas de forma aparentemente mecánica o para la producción industrial. Lo curioso es que tal y como destaca Arañó (1989) "las metodologías didácticas" son las mismas, aún en niveles muy diferentes de enseñanza.

Este autor mantiene que, el hecho de intentar englobar numerosas y diversas disciplinas, ha provocado una confusión conceptual. Ello se ha trasladado al sentir general de la sociedad y ha provocado la infravalorando de la presencia de dichas enseñanzas. Se da la situación de "enseñanza del dibujo, educación estética, expresión plástica y otras muchas expresiones con las que habitualmente se las ha denominado, llegando a producir concretas y sorprendentes paradojas como la división de áreas de conocimiento universitarias" (Arañó, 1989, p. 11). 
La falta de respaldo teórico en la metodología didáctica, depositando el peso del aprendizaje en un aspecto de destreza manual también ha contribuido al desprestigio de estas enseñanzas. Esta situación se ve agravada por la falta de tradición investigadora, de innovación y de desarrollo que ha padecido a lo largo de la historia.

El primer texto que regula la enseñanza de las Bellas Artes es el Real Decreto de 24 de septiembre de 1844 (Arañó, 1989).

Las enseñanzas artísticas que se impartían se repartían entre las Academias de Bellas Artes y el Dibujo de los Institutos de Bachillerato. En las Escuelas Superiores se establecían estudios Elementales, para los cuales no se necesitaban requisitos especiales y los Superiores dirigidos a personas con cualidades artísticas demostradas.

El mantenimiento económico de estas Escuelas también era bastante ambiguo, en ocasiones las mantenían las Diputaciones provinciales, con pocos recursos habitualmente, o bien incluso algunos Ayuntamientos. En 1869, los numerosos problemas financieros del gobierno justificaron el cierre de estas Escuelas salvo la de San Fernando de Madrid, puesto que las consideraba poco rentables y no se entendía muy bien cuál era su función. En la Ley Moyano, a pesar de considerar la enseñanza de las Bellas Artes como estudios superiores, equiparaba a su profesorado a los de Segunda Enseñanza. Debido al empeño del profesorado, dos años después, se restauró el funcionamiento de las Escuelas.

El modelo didáctico de estas Escuelas y sus planes de estudios resultaban bastante confusos y poco definidos. Los propios académicos y pintores se negaban a concretarlos aduciendo su competencia exclusiva a la hora de formar a los futuros artistas. Era un sistema de enseñanza planteada sobre todo en el juicio crítico personal. Se funciona como en un taller renacentista en el que un maestro instruye a sus discípulos y en el que la habilidad manual lograda tras un largo periodo de aprendizaje prima sobre la intelectual. 
Hubo un intento de reorganización de las enseñanzas artísticas pero rechazado por el profesorado. En 1881, aprovechando la reforma de la Instrucción Pública, hubo un nuevo intento también rechazado. Al igual que en 1892 en que el ministerio pretendía organizar las enseñanzas a la imagen de las otras enseñanzas superiores y ello chocaba frontalmente con el carácter que los académicos imprimían a sus enseñanzas (artistas que enseñaban a otros artistas). A principios del XX se crean las Escuelas de Artes e Industrias sobre la base de las Escuelas de Bellas Artes de provincias.

En 1912 (Cuenca, 1988), ya aparecía presupuestada la figura del profesor de Dibujo entre los profesores de Institutos generales y técnicos (solo se imparte Dibujo como materia artística). Pero aparece por primera vez en el Real Decreto que se publica el 21 de abril de 1922 publicado el que la Escuela tiene la función de preparar a los artistas para la enseñanza del dibujo. Además de las tres secciones existentes Pintura, Escultura y Grabado se crea, por primera vez en esta escuela una sección dedicada a la formación inicial de los profesores de Dibujo. "Estudios de los métodos y procedimientos de la enseñanza del Dibujo y del Arte en los Centros de enseñanza primaria y secundaria del extranjero"(Prat, 2012), impartida por Víctor Masriera. Esta materia daría lugar a una de las primeras cátedras de Pedagogía del Dibujo en los estudios de las entonces denominadas Escuelas Superiores de Bellas Artes.

A principios del siglo $X X$ el nivel cultural de la población española es muy bajo y con un alto índice de analfabetismo. Los intentos de organización y estructuración de la Instrucción Pública por parte de los poderes políticos tropiezan cuando se trata de enseñanzas artísticas sobre todo porque no está definido el perfil del profesional que obtiene el título de Bellas Artes ni la preparación que ofrecen dichos estudios. Ello se evidenció con el intento de la reorganización del procedimiento de provisión de profesores para los Institutos, Escuelas de Formación de profesores, Cátedras de Dibujo y la organización de la Segunda Enseñanza. Se pretendía, sin llegar a conseguirlo, valorizar el título de Profesor de Dibujo al mismo nivel que las licenciaturas de Ciencias o Letras. Se sigue manteniendo el interés por diferenciar la formación de los 
especialistas de actividad artística de la de la formación de los otros profesionales. Para ello, en Madrid, se añade una nueva sección en estos estudios "Estudios de los métodos y procedimientos de la enseñanza del Dibujo y del Arte en los Centros de enseñanza primaria y secundaria del extranjero" (Cuenca, 1988).

Toda esta situación de continuas pugnas entre el academicismo y los partidarios de una apertura a nuevos planteamientos artísticos provocó que el sentir social siguiera considerando a las Bellas Artes como algo ineficaz. El desprestigio se aprecia en este párrafo de Arañó en el que vemos que el valor legal que se les daba a los estudios no tenía nada que ver con cualquier otra titulación:

\begin{abstract}
Según los datos del Decreto de 3 de agosto de 1867 que regulaba las tasas para la matrícula en los Centros docentes y expedición de títulos, las tasas de menor cuantía las suponían las de la Escuela de Pintura y Escultura (San Fernando de Madrid) y los Conservatorios de Música. La matrícula del curso completo costaba 6 escudos, la misma cantidad que una sola asignatura de una Facultad universitaria (Arañó, 1989, p. 22).
\end{abstract}

Se siguió planteando la vieja polémica de la función educativa de las Escuelas y el debate sobre el concepto de Enseñanzas Artísticas. Una parte social muy activa fue el alumnado de estos estudios que reivindicó durante largos años que:

- La enseñanza del Dibujo fuera obligatoria en la Segunda Enseñanza.

- El reconocimiento administrativo real del título de Profesor de Dibujo y su equiparación al resto de títulos universitarios tanto para la enseñanza pública como para la privada.

La reforma más profunda que la enseñanza de las Bellas Artes españolas ha conocido se produce con el Decreto de Bases de 22 de marzo de 1934. Organiza los estudios de la Escuela en tres secciones:

- “Enseñanzas de índole cultural artística. 
- Enseñanzas prácticas generales.

- Enseñanzas profesionales (Estudios-taller dirigidos por artistas de reconocida fama (Araño 1989, p. 25)".

Además introduce la necesidad de conocimiento de un idioma extranjero y también, aunque no se pudo llevar adelante a causa de la guerra civil, planteo los estudios de Técnica Cinematográfica. Todo esto, por lo tanto introduce innovaciones importantes, la presencia de profesorado externo y nuevas metodologías artísticas, que contrastan con las tendencias tradicionales.

Tras la guerra se frenaron las innovaciones y se volvió a los planteamientos tradicionales y académicos. Cambiaron los contenidos impartidos y también se reunifican las Academias. Se vuelve a las premisas del Decreto de 1922. Sin embargo, sí se consigue definir definitivamente la figura del Profesor de Dibujo que va afianzando su situación profesional.

Con la Ley General de Educación de 1970 se adscriben a la Universidad las Escuelas de Bellas Artes. Fue un largo proceso que duró en su conjunto unos 11 años. Hubo enormes dificultades pues estas enseñanzas se estructuraban de forma muy diferente al resto de estudios superiores y sus peculiaridades a nivel académico e investigador preocupaban a la Universidad y Ministerio. Esos momentos tampoco se aprovecharon para resolver los importantes problemas curriculares que planteaban estas enseñanzas.

Con la LOE (2006) queremos destacar que hace especial mención a las enseñanzas artísticas que tienen como finalidad proporcionar a los alumnos una formación artística de calidad y cuya ordenación no había sido revisada desde 1990. Regula las enseñanzas artísticas profesionales.

Actualmente los estudios artísticos siguen manteniendo notables diferencias y no se ha resuelto la dicotomía de las enseñanzas artísticas. Existen diferentes tipos de centros en los que se obtiene este tipo de conocimientos:

- Por una parte las facultades de Bellas Artes, totalmente integradas en las Universidades, que imparten un curriculum de contenido técnico 
dirigido fundamentalmente a la formación de profesionales artistas. Los estudios están estructurados en Grados, Máster y Doctorado.

Sus egresados, sin embargo, ocupan puestos profesionales de lo más diversos. Entre estas dedicaciones encontramos la de Profesorado de Secundaria, que son los encargados de impartir las asignaturas artísticas en este nivel educativo. Quisiéramos señalar que, en casos como la facultad de Bellas Artes de Valencia, no se imparte ninguna asignatura de carácter didáctico. En otras facultades del Estado sí que se contempla el Área Didáctica dentro de las facultades de Bellas Artes.

- Por otro lado, las antiguas Escuelas de Artes y Oficios que se han reconvertido en las actuales Escuelas de Arte y Superiores de Diseño. En ellas se imparte un curriculum de contenido más profesionalizador. Estas Escuelas, sin embargo, no han conseguido el status universitario a pesar de sus largas reivindicaciones. Su profesorado todavía está considerado como no universitario, aunque imparten enseñanzas denominadas "superiores" y algunas de sus titulaciones son "equivalentes" a los grados universitarios. En la Comunidad Valenciana están agrupadas en un organismo llamado Instituto Superior de Enseñanzas Artísticas, que recoge los estudios de Diseño, Cerámica, Danza, Arte Dramático, Conservatorio Superior de Música y Restauración de Bienes Culturales.

- Citaremos también a facultades de Filosofía y Letras que forman a historiadores y filósofos.

- Finalmente, nos encontramos con los estudios de magisterio cuyo enfoque se dirige a la educación en general. Son los más dependientes en cuanto a que están sometidos a las políticas educativas que son las que marcan los planes de estudios y sus aplicaciones. 


\section{LA PRESENCIA DE LA EDUCACIÓN ARTÍSTICA EN LOS ESTUDIOS DE MAGISTERIO.}

Las diferentes denominaciones que han atravesado estos estudios de Magisterio y los diferentes criterios pedagógicos y filosofías o políticas educativas han afectado a esta área. Desde la creación de la Escuela Normal de Maestros en 1839 hasta la actualidad, el concepto que se tiene de las asignaturas, las diferentes materias, los contenidos y objetivos han ido evolucionando junto con el concepto del currículo educativo.

A lo largo de la historia vemos que las diferentes denominaciones obedecen a contenidos concretos y programaciones definidas. Ello obedece a distintos criterios pedagógicos y a la idea que se tiene de la materia. Algunas han desaparecido de los planes de estudio, otras, por el contrario, han ido surgiendo paulatinamente.

En este apartado nuestra intención es destacar la consideración y carga lectiva de las materias artísticas, en su apartado visual. Evidentemente lo que ocurre en el apartado de los estudios de Magisterio está íntimamente relacionado con lo que ocurre de forma paralela en la escuela primaria. Es por ello que todo lo que afecte a uno de estos factores repercutirá en el otro. Para realizar ese paralelismo habrá que tener presente los materiales procedentes de ambos ámbitos. Ello nos permitirá establecer criterios pedagógicos en general y de la pedagogía de nuestra área en particular. No nos es posible entrar en total profundidad en cada uno de los momentos que tratamos pues sería excesivo pero si atenderemos a las épocas más cercanas.

De esta forma atenderemos en un apartado especial la formación que han recibido y reciben, los futuros maestros en el área que nos ocupa. 
6.1. Educación artística y planes de estudio de Magisterio.

Atendiendo a las directrices nacionales de la época, en la legislación que rige durante sus primeros años de existencia, la formación de los maestros, apenas apreciamos la presencia y mención de las enseñanzas artísticas. La enseñanza de materias de EA era testimonial pues no prestaba atención a este tipo de contenidos. La educación básica de la época priorizaba un tipo de formación de contenidos culturizadores debido al escaso nivel cultural de los aspirantes al Centro. En los casos en que aparecen, siempre se cursaban con una aplicación práctica y profesionalizadora. Nos referimos a aquellas materias que pudieran tener alguna relación con el Área Artística, como el Dibujo Lineal o las Labores Artísticas.

En las tablas siguientes destacamos la presencia de este tipo de asignaturas en los planes de 1843-49 y en los de 1858. Tanto en Elementales como en Superiores, nos encontramos con Principios de la Geometría, con sus aplicaciones a los usos comunes de la vida y a las artes industriales, y el Dibujo Lineal, en el Plan de 1843-49. Estas materias no se rescatan en el de 1858, quedando una única denominada Nociones de Geometría, Dibujo Lineal y Agrimensura (de contenidos sobre todo profesionalizadores).

Tabla 30. La Plástica en las Esc. Normales Elementales.

\begin{tabular}{|l|c|c|}
\hline \multicolumn{1}{|c|}{ Asignaturas } & $\begin{array}{c}\text { Plan } \\
\mathbf{1 8 4 3}\end{array}$ & $\begin{array}{c}\text { Plan } \\
\mathbf{1 8 5 8}\end{array}$ \\
\hline $\begin{array}{l}\text { Principios de la Geometría con sus aplicaciones a los } \\
\text { usos comunes de la vida y a las artes industriales }\end{array}$ & $\mathrm{X}$ & -- \\
\hline Nociones de Geometría, Dibujo Lineal y Agrimensura & -- & $\mathrm{X}$ \\
\hline Dibujo Lineal & $\mathrm{X}$ & -- \\
\hline
\end{tabular}

Fuente. Elaboración propia. 
Tabla 31. La Plástica en las Esc. Normales Superiores.

\begin{tabular}{|l|c|c|}
\hline \multicolumn{1}{|c|}{ Asignaturas } & $\begin{array}{c}\text { Plan } \\
\mathbf{1 8 4 9}\end{array}$ & $\begin{array}{c}\text { Plan } \\
\mathbf{1 8 5 8}\end{array}$ \\
\hline $\begin{array}{l}\text { Principios de la Geometría con sus aplicaciones a los } \\
\text { usos comunes de la vida y a las artes industriales y } \\
\text { agrimensura }\end{array}$ & $\mathrm{X}$ & -- \\
\hline Nociones de Geometría, Dibujo Lineal y Agrimensura & -- & $\mathrm{X}$ \\
\hline Nociones Teóricas de Dibujo Lineal & $\mathrm{X}$ & -- \\
\hline
\end{tabular}

Fuente. Elaboración propia.

Testimonialmente aparecerá, en alguna modificación posterior de los Planes, el concepto de Dibujo (con esta denominación explicita). También nos encontramos con la de Trabajos Manuales. cursada, eso si esta ultima por el alumnado masculino, y con un carácter de "aprender a hacer". En el caso femenino, señalaremos la presencia de una asignatura de Labores. Esta asignatura que, inicialmente podríamos pensar también que tiene cierto componente creador, en la realidad era tan mecánica como la de Trabajos Manuales solo que con distinta orientación.

En ocasiones las materias artísticas aparecerán englobadas en el apartado: Otras disciplinas ${ }^{135}$. La dedicación horaria en estos casos se repartía también entre los dos cursos de la titulación. En los estudios de Maestro Superior, desaparecerá esta dedicación horaria y únicamente se conservara, para segundo curso, la asignatura de Dibujo de adorno y de aplicación a Labores. Recordaremos que en estos estudios se priorizan los contenidos de materias de ciencias o letras y por lo tanto no se concede importancia al artístico. Son las únicas asignaturas relacionadas, pero como vemos, con un enfoque bastante diferente a lo que consideraríamos actualmente como adecuado.

\footnotetext{
135 Otras disciplinas: Nociones de Agricultura, Práctica de la Agricultura, Agricultura y técnica Agrícola, Religión y Moral, Catecismo, Doctrina Cristiana, Historia Sagrada, Dibujo Lineal, Dibujo Artístico, Dibujo de Adorno y de Aplicación a las Labores (Maestras), Trabajo Manual por el Sistema Naäs (objetos y trabajos en madera, alambre y hierro forjado), Trabajos Manuales, Nociones de Industria y Comercio, Labores y Corte de prendas usuales (Maestras), Corte y Labores (Maestras), Labores(Maestras), Costura (Maestras), Bordado en blanco y Corte de ropa blanca (Maestras), Corte de vestidos y Labores artísticas (Maestras), Música, Música y Canto, Ejercicios Corporales, Educación Física.
} 
En la siguiente gráfica podemos apreciar el porcentaje de EA en el conjunto de los estudios (Elementales y Superiores):

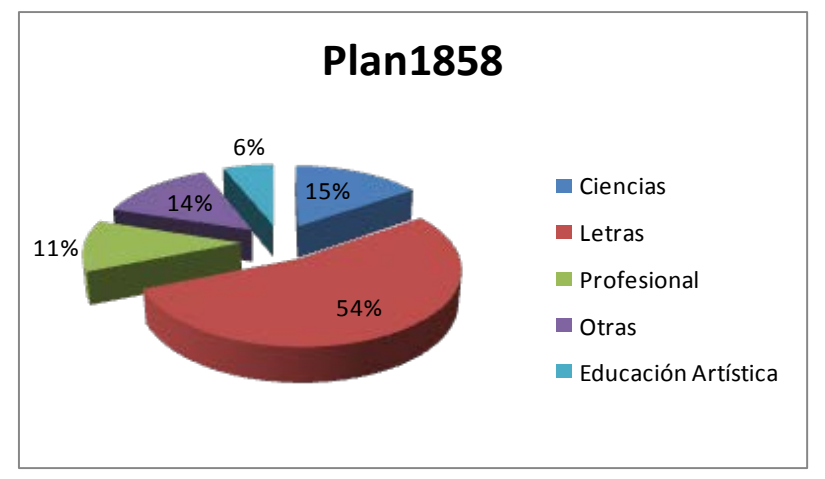

Figura 1. Plan de 1858.

En 1871, Cossío, propone un Plan de Estudios para las Escuelas Normales de Maestros y Maestras en las que tenemos:

$\begin{array}{lll}\text { Maestros } & \text { Elemental - } 1 \text { y } 2^{\circ} \text { curso: } & \text { Dibujo Lineal } \\ & \text { Superior - } 1 \text { y } 2^{\circ} \text { curso: } & \text { Dibujo Lineal } \\ & \text { Elemental - } 1 \text { y } 2^{\circ} \text { curso: } & \text { Dibujo Lineal }\end{array}$

Maestras

Superior - 1 y $2^{\circ}$ curso: $\quad$ Trabajos Manuales, Dibujo Artístico y Caligrafía

Los planes son muy parecidos aunque en el caso de las maestras se especifica un dibujo de carácter artístico, señalando un dibujo para utilidad "al adorno, manualidades y trabajos de aplicación". En los maestros únicamente hay Dibujo Lineal. También apreciamos la aparición de la Caligrafía, que no es explícitamente de carácter artístico pero en algunos casos se podía considerar como tal. Se complementaban estas formaciones culturales con visitas a monumentos.

Comparándolo con el anterior, plan del 58, en este se profundiza en los conocimientos. En el caso que nos ocupa, el Dibujo era impartido por el 
profesorado de letras, lo cual indicaba que no se consideraba necesario que tuvieran una formación cualificada para ello.

En este Plan, el Dibujo Lineal y el Artístico se tratan desligados de la Geometría y la Agrimensura, como figuraba en planes anteriores. Aunque poco después (programas de 1883) se volverá a unir a la Geometría, con la idea de servir de práctica aplicada de la misma: se cursaba en 2 horas semanales en las que la primera hora se explicaba el problema geométrico y en la segunda se dibujaba. El poco tiempo dedicado a ello plantea la poca profundidad con que se trataba la materia. Cuenca (1988) rescata algunos textos de la época en los que se aprecia como los contenidos de la asignatura de Dibujo son problemas de trazados lineales y figuras geométricas. En la asignatura de Agrimensura, los futuros maestros aprendían a resolver problemas prácticos de medición de terrenos, cuestiones que se les podía plantear en el momento de su ejercicio.

En el caso de las maestras hay una consideración menos utilitaria que la Agrimensura, en la que Cossío había planteado una enseñanza del Dibujo basado en la representación del natural. Esta circunstancia era difícil de cumplir ya que el profesorado que la impartía no estaba formado en la materia. En el trabajo de Cuenca (1988) se nos facilita el programa de estas enseñanzas, indicando los contenidos según el curso. En ellos vemos como para las maestras sí se hace una clara diferenciación entre los contenidos de Geometría de los del Dibujo, ya que este tiene un alto componente artístico orientado a la realización de las Labores, con contenidos que trabajan la composición, el color, perspectivas, etc.

Los trabajos elaborados por las maestras, bordados fundamentalmente, se considera que reflejan mejor cierta sensibilidad femenina. En el caso de los maestros sus productos se inclinan más por trabajos en madera y cartón (Manualidades).

En estos programas del 1883, para las Escuelas Centrales de Maestras y Maestros, en los contenidos para las maestras se abordan las materias de Literatura y Bellas Artes, que no se encuentran en las enseñanzas para los 
maestros. En ellas se adquieren conocimientos elementales de Historia del Arte y se profundiza en conocimientos artísticos. Son programas bastante completos que se complementan con visitas a museos. Este reparto de materias apenas tenía reflejo en las Escuelas de Provincias, con muchos menos recursos materiales y de personal. Por otra parte, se consideraba que no resultaba muy útil para aplicarlo luego en la escuela.

En su libro sobre el Dibujo en las Escuelas de Magisterio (1988, p. 95-135), Cuenca nos presenta detallado, en su segundo capítulo, el contenido de un libro publicado en 1899, La enseñanza del Dibujo en las Escuelas Primarias y Escuelas Normales de España, de Adsuar y Moreno, J. Refiere que este libro fue muy utilizado en las Escuelas Normales del momento, alcanzando numerosas reediciones. Destacaremos, a continuación, las ideas fundamentales que consideramos de interés:

- La primera mención de Dibujo, como parte de la instrucción primaria, es en el Plan de 21 de julio de 1838.

- Con el Decreto Orgánico de 1849, se crearon once Escuelas Elementales de Bellas Artes. Que servían para preparar a aquellos que querían cursar estudios superiores de Bellas Artes pero también para "dar educación artística e industrial a los artesanos". Valora además las iniciativas privadas a favor de la divulgación de las artes.

- Señala que, en 1895, se presentó una solicitud para que en las Escuelas Normales se separara la asignatura de Dibujo de la de Geometría y Agrimensura, por considerar que el Dibujo debía de estar de forma obligatoria en toda la carrera. Se queja, ya entonces, de la poca importancia que se le concede, del poco tiempo real que se le dedica y de las nulas condiciones en que se encuentran las aulas. Las compara con las enseñanzas de Artes y Oficios, donde el nivel obtenido es mayor, y con las de Maestras, donde se imparte en mejores condiciones que en las de Maestro. Alude al decreto próximo a publicar, Real Decreto de 23 de septiembre de 1898. 
o En este Decreto, hay un amplio desarrollo de cómo se deben impartir las asignaturas de Dibujo Lineal, de Dibujo Artístico, de Caligrafía y de Trabajos Manuales. Expresa que el profesorado debe ser específico.

- Se resalta la importancia del Profesorado Especial de Dibujo de las Escuelas Normales Centrales, profesoras especialistas formadas mayoritariamente en la institución privada de "Asociación para la Enseñanza de la Mujer". Este personal enseñaba en las escuelas primarias, daba clases particulares e incluso trabajaba en la Escuela Normal Central de Maestras. Todo lo contrario de lo que ocurría en el resto de Escuelas Normales y en la instrucción pública.

o Es la primera vez que se acuña el termino Dibujo Artístico, especificándose sus contenidos artísticos. Divide su aprendizaje entre lo concreto, en primer lugar, ya que educa el sentido de la vista y lo abstracto posteriormente, "que cultiva la facultad superior del entendimiento". Divide pedagógicamente la asignatura en: Dibujo de imitación, Croquis y Dibujos de Composición.

- En su libro expone un detallado plan para la enseñanza del Dibujo en los estudios de Magisterio. Es muy de apreciar su voluntad metodológica y didáctica. Explica asimismo sus propuestas de reforma para la enseñanza del Dibujo tanto en las Escuelas Normales como en la escuela primaria.

- Valora muy positivamente la obligatoriedad de cursar Dibujo, señalando que solo había opción a hacerlo en la Central y en alguna otra. Pero se queja de que no esté presente en las pruebas de acceso así como de las escasas horas que se le dedican en los planes de estudio.

- Considera que si no se forma correctamente a los formadores estos no podrán ejercer correctamente. Las indicaciones que se estipulan en el decreto son excesivamente simples y no favorecen un buen desarrollo 
de la materia. Al no detallar los programas, cada profesor lo impartirá ajustado a su cultura y formación en Dibujo.

- Reclama la necesidad de que los profesores de Dibujo de las Escuelas Normales sean especialistas con conocimientos adecuados a lo que tienen que enseñar ${ }^{136}$.

En 1891, bajo el impulso del Fomento de las Artes, se constituye la Asamblea General de Maestros de España, asociación que aglutina a maestros, artistas, artesanos, etc...que establecen clases prácticas y conferencias de carácter artístico y científico. Ello suponía iniciar un camino hacia una enseñanza más profesionalizada. Fue importante para cimentar las materias artísticas en la escuela (Cuenca, 1988).

En el Plan de estudios de 1901, se especifica que:

En términos porcentuales, las ciencias superarían el 33\% del tiempo empleado en las enseñanzas teóricas. Los Trabajos Manuales era una materia a cursar en los dos primeros años de la carrera y en su denominación se incluía el tipo de trabajos a realizar y los materiales a emplear. Con respecto a esta asignatura en el primer curso especificaba: Trabajo manual por el sistema Naas; objetos y trabajos en cartón, papel, barro y yeso. Esta enseñanza no se exigirá hasta que haya en España suficiente número de maestros que la hayan aprendido. Para el segundo año decía: Trabajo manual por el sistema Naas, objetos y trabajos en madera, alambre y hierro forjado (González, 1994, p. 83).

Al hilo de esta reforma curricular de 1901, bastantes maestros se interesaron por perfeccionarse en los contenidos del nuevo plan de estudios, especialmente en la asignatura de Trabajos Manuales. Entre 1903 y 1912, en Cataluña se impartieron unos once cursillos de esta materia. En Gijón se celebró en agosto de 1907 otro sobre el mismo tema, y también se realizaron actividades similares en Valladolid, Santander, Santiago de Compostela y

\footnotetext{
${ }^{136}$ En numerosas ocasiones, caso de haberlos, los exámenes de Dibujo que se les hace a los aspirantes a maestros son mas propios de Escuelas de Artes y Oficios que de personas que luego tienen que enseñar el Dibujo en la escuela.
} 
Madrid. En los Congresos provinciales de Valencia (1902) y Albacete (1903) fue objeto de ponencias. Durante la época entre 1912 y 1921, así como en la década de los veinte, disminuyó el interés por los Trabajos Manuales y, por el contrario, creció la preocupación por otras experiencias y los nuevos contenidos curriculares de Educación Física, Dibujo o Música. Estos cursos, el $22 ' 72 \%$ del total impartido, eran indicativos del comienzo de una preocupación que se manifestaría con mucha más claridad en los años 1922-1930, cuando aumentó el porcentaje a un 28'96\% del total entre los de Dibujo, Música y Gimnasia. Si a ello añadimos los dedicados a la formación profesional agrícola, un $11^{\prime} 72 \%$, y el $8 ' 27 \%$ de Labores, Costura y Bordado a máquina, se puede afirmar que un 49\% de las actividades de reciclaje realizadas entre 1922 y 1930 se enfocaron hacia la especialización en aquellas asignaturas más novedosas incluidas del plan de 1901, y que esta fue uno de los sucesos más característicos de la segunda década del siglo XX (Molero, 1994).

Tabla 32. Cursos de perfeccionamiento en España (1912-1930).

\begin{tabular}{||l|r|r|r|r|r||}
\hline \multirow{2}{*}{ TEMATICA } & \multicolumn{2}{|c|}{$1912-1921$} & \multicolumn{2}{|c|}{$1922-1930$} & \multirow{2}{*}{ Total } \\
\cline { 2 - 6 } & Abs. & $\%$ & Abs. & $\%$ & \\
\hline \hline $\begin{array}{l}\text { Pedagogía, Métodos y Didácticas } \\
\text { especiales }\end{array}$ & 27 & $40^{\prime} 90$ & 23 & $15^{\prime} 86$ & 49 \\
\hline Cultura general y profesional & 17 & $25^{\prime} 00$ & 23 & $15^{\prime} 86$ & 40 \\
\hline Educación Física, Musical y Artística & 14 & $22^{\prime} 72$ & 42 & $28^{\prime} 96$ & 56 \\
\hline Psicometría y Educación Especial & 5 & $7^{\prime} 81$ & 16 & $11^{\prime} 03$ & 21 \\
\hline Formación profesional agrícola & - & - & 17 & $11^{\prime} 72$ & 17 \\
\hline Costura y bordado a máquina & 1 & $1^{\prime} 56$ & 12 & $8^{\prime} 27$ & 13 \\
\hline Selección para ensayos pedagógicos & 1 & $1^{\prime} 56$ & 5 & $3^{\prime} 44$ & 6 \\
\hline Mutualidad escolar & 1 & $1^{\prime} 56$ & 1 & $0^{\prime} 68$ & 2 \\
\hline Enseñanzas de Orientación marítima & - & - & 2 & $1^{\prime} 37$ & 2 \\
\hline Esperanto & - & - & 2 & $1^{\prime} 37$ & 2 \\
\hline Puericultura & - & - & 1 & $0^{\prime} 68$ & 1 \\
\hline Orientación Profesional & - & - & 1 & $0^{\prime} 68$ & 1 \\
\hline \hline TOTAL & 66 & $100 \%$ & 145 & $100^{\prime} \%$ & 211 \\
\hline \hline
\end{tabular}

Fuente. (Molero, 1994).

La Administración central, ante la incorporación de estas "materias especiales" en el Plan de Estudios de 1901 (Dibujo, Canto y Ejercicios corporales) no 
había optado por la incorporación de especialidades en las Escuelas Normales, como hubiera sido lógico, sino que fomentó estos cursillos de perfeccionamiento para crear maestros especialistas en los nuevos contenidos curriculares. En ocasiones, se enviaba al extranjero a docentes dispuestos a especializarse en una determinada metodología o en una técnica específica, que aprenderían con los mejores profesores europeos, y después volverían a España y se dedicarían a enseñarla a otros maestros, extendiendo así los nuevos métodos.

Esta estrategia se llevó a cabo, por primera vez en el caso del Dibujo, en 1911. Víctor Masriera recibió una beca para estudiar, en Francia y Bélgica, la didáctica de esta asignatura en la escuela primaria. A su vuelta se le encargó, mediante la R.O. de 27 de junio de 1912, la formación de los docentes de Primaria en el área de Dibujo, y, específicamente, la preparación de "Maestros especiales" de Dibujo destinados a los colegios públicos de la capital. Los cursos, el primero destinado a maestros, sobre la enseñanza elemental del Dibujo pretendía ser muy aplicable: "en el cual pueden adquirir algún conocimiento técnico de Dibujo, utilizable en la labor diaria, iniciarse en el estudio psicológico del niño, con relación a su aptitud para el dibujo, como fundamento de la Metodología de éste"; el otro, dirigido a docentes con una base previa de dominio del Dibujo, y que aspirasen a conocer sus aplicaciones didácticas: "con objeto de prepararse como Maestros especiales de Dibujo en las Escuelas primarias".

Acabados esos dos primeros cursos, la actividad adquirió rango anual y permanente, mediante la Orden de 23 de junio de 1913. Cada año se realizaba un curso en Madrid, que duraba de octubre a junio, y al final del cual los participantes recibían un "certificado de aptitud pedagógica". Participaron en esta experiencia los maestros madrileños más brillantes. Por Real Orden de 13 de noviembre de 1913, se adscribió dicho Curso Permanente de Dibujo a la Escuela de Estudios Superiores del Magisterio. A partir de aquel momento el alumnado que asiste pertenece a ese centro y a las Escuelas Normales de 
Maestros y Maestras de Madrid. Se equipara su función a la de los Cursos Normales de Dibujo existentes en Suiza y en otras naciones europeas ${ }^{137}$.

Con una nueva reforma, en el Plan de 1903, las materias de Trabajos Manuales y Ejercicios Corporales aparecen unidas. Se hizo para poder intercalar la distribución horaria entre alumnas y alumnos; mientras ellas cursaban Labores, ellos las otras materias.

En la Escuela Superior del Magisterio, creada en 1909, se requiere a los estudiantes una prueba de Dibujo en el examen de ingreso. Dependiendo de la sección elegida (ciencias, letras o labores) el ejercicio cambia de contenidos para adaptarse a la especialidad. El profesor encargado de esta materia es Víctor Masriera. Sus numerosas publicaciones así como artículos en la revista de la Institución Libre de Enseñanza y revistas de las Escuelas Normales, permiten difundir sus conocimientos sobre la enseñanza del Dibujo tanto en Escuelas Normales como en la Enseñanza Primaria. Introduce conclusiones metodológicas que ya se están aplicando en países europeos y aboga por la necesidad de "crear la ciencia de la Pedagogía del Dibujo". Fruto de su labor divulgadora nace en 1915 La Liga para la Divulgación de la Pedagogía del Dibujo, con más de 189 personajes adheridos. Su obra La ciencia del arte, publicada el 1913 fue declarada de utilidad pública en 1916, así como el publicado en 1917, Manual de pedagogía del dibujo, que también fue declarado de utilidad pública para las Escuelas Normales y las bibliotecas pedagógicas por la Real Orden de 25 de abril de 1918. El Ministerio de Instrucción Pública y Bellas Artes le ofrece la posibilitad de impartir un curso de dibujo en Barcelona para maestros de primera enseñanza, con el Patronato del Rector de la Universitat de Barcelona. Este, se convertiría en el Curso Permanente de Dibujo, adscrito desde sus inicios en 1912 a la Dirección General de Primera Enseñanza y, desde 1922, a la Escuela Superior del Magisterio. Más tarde en 1935 se adscribiría a la Escuela Superior de Pintura, Escultura y Grabado de Madrid.

137 Sobre estos Cursos Normales, véase: Masriera, V. (1926). Pedagogía del Dibujo (Impresiones de viaje). Revista de Pedagogía, 57, 391-398. 
En el Plan de 1914, el número de materias es elevado y probablemente la profundidad de los contenidos se resiente.

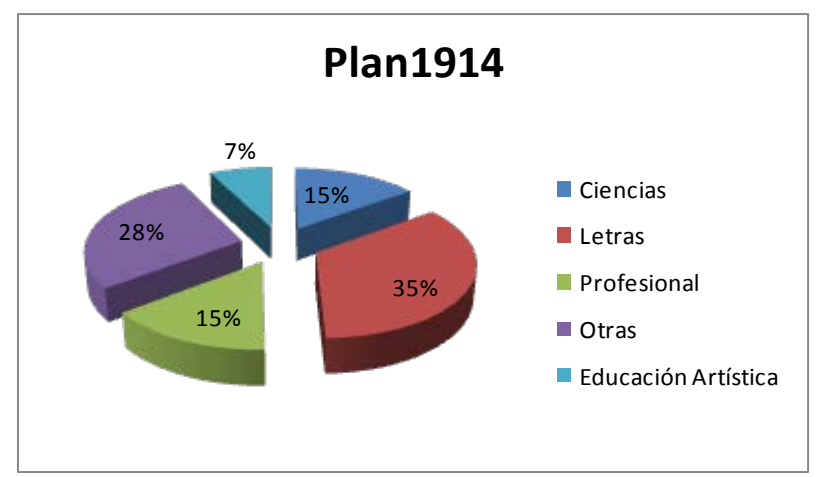

Figura 2. Plan de 1914.

Se contemplaba la posibilidad de introducir profesorado especialista para materias específicas, entre las que se encontraba el Dibujo. Apreciamos que aparece la denominación de Dibujo propiamente dicha, sin que se especifique en absoluto nada sobre su contenido, y separadamente, la Caligrafía y la Geometría (junto a la Aritmética). En planes anteriores, aparecía con otras denominaciones que fijaban mejor cuáles eran sus contenidos:

- 1839: "Dibujo Lineal"

- 1858: "Nociones de Geometría, Dibujo Lineal y Agrimensura"

- 1871: "Dibujo Lineal"

- 1898: "Dibujo y Caligrafía", "Dibujo como aplicación al corte de prendas usuales", "Dibujo artístico".

En el currículo de este Plan la presencia del Dibujo disminuye, pues aparece junto a Aritmética y Geometría, en los dos primeros cursos, correspondientes al Ciclo Elemental, se imparten 3 horas semanales. 

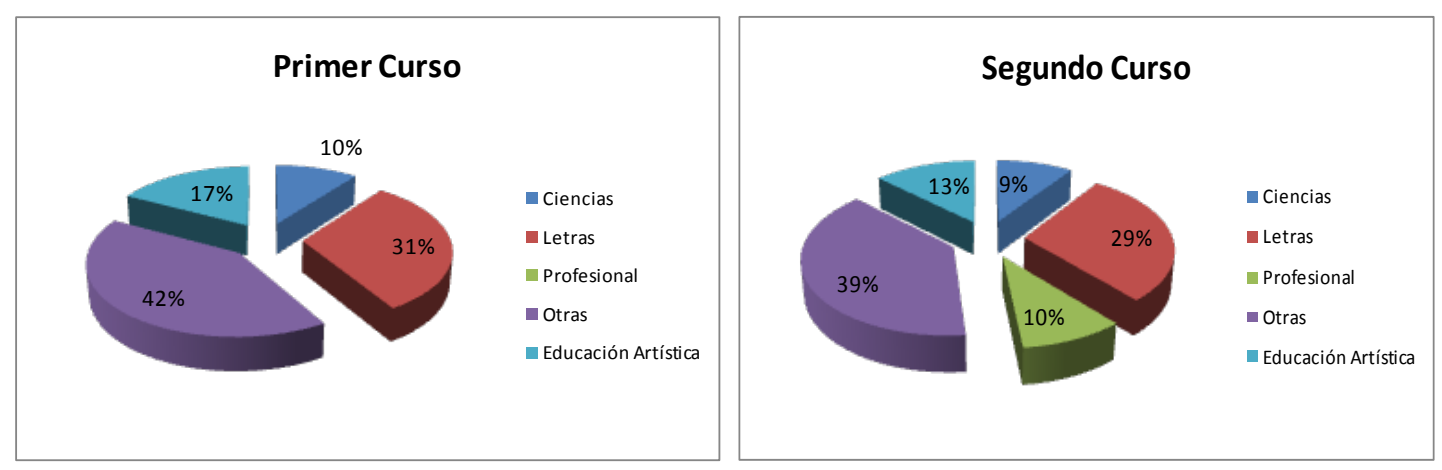

Figura 3. $1^{\circ}$ y $2^{\circ}$ de Plan de 1914.

Desaparece en el Ciclo Superior siendo que anteriormente se impartía en los cuatro cursos. Figura también una asignatura dirigida al alumnado femenino, denominada Corte y Labores Artísticas, diferenciadas de otras dos de costura. No se hace mención de asignaturas de carácter artístico entre aquellas "voluntarias para maestras".
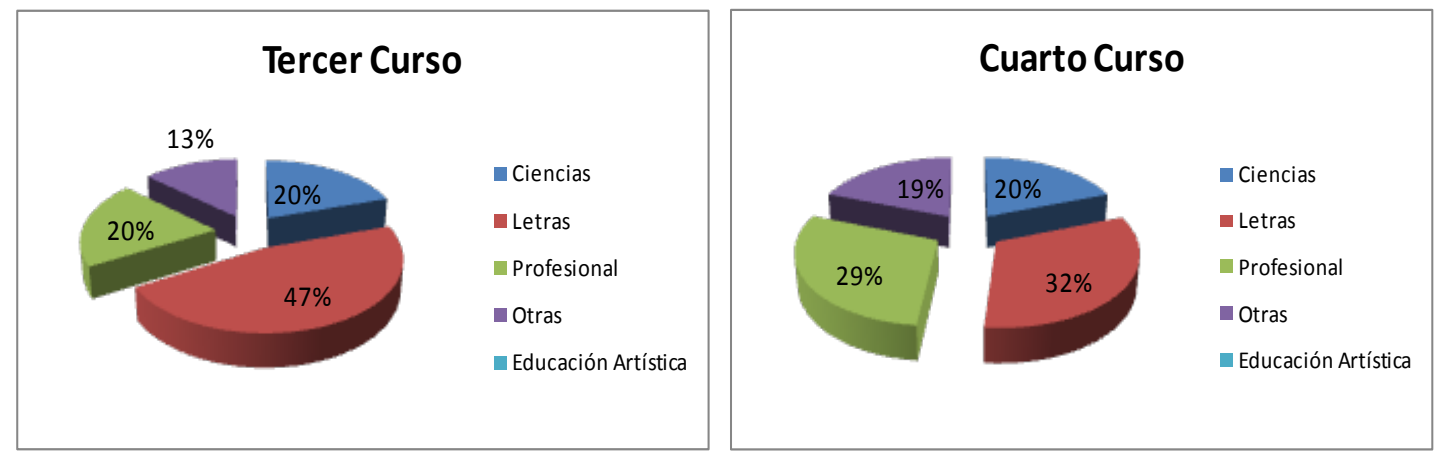

Figura 4. $3^{\circ}$ y $4^{\circ}$ de Plan de 1914.

Debemos señalar también las notables diferencias materiales y dotacionales entre las Escuelas Normales de Madrid con respecto a las de provincias, incluyendo la presencia de profesorado especialista y la preparación del mismo. Lo mismo ocurría con el acceso a recursos culturales. Por esta razón, para cubrir la carencia de profesorado especialista, se recurre a personas escasamente cualificadas o bien a artesanos con conocimientos de Dibujo o, en último caso, a los profesores "de letras" (Cuenca, 1989). En numerosos casos se recurre al Dibujo Lineal y Técnico que requiere menos habilidades. 
En 1915, Masriera junto con profesorado de las Escuelas Normales, constituye una sociedad denominada Liga para la divulgación de la pedagogía del dibujo, cuyo aspecto destacable dentro de nuestro estudio es la elaboración de un programa integral de metodología de enseñanza del dibujo a lo largo de toda la educación inicial, parvulario y primaria. En ese manual se incluye un capítulo que trata "La enseñanza del dibujo en las Escuelas Normales" (Cuenca, 1989, p. 170) donde trata la relación directa de la enseñanza del dibujo a los maestros con la del dibujo en la escuela primaria. Critica ácidamente la forma en que se recluta al profesorado que lo imparte y la forma en que se enseña el dibujo. Para Masriera, el dibujo en las Escuelas Normales debe formar a los futuros maestros en la importancia social y escolar que tiene, en la capacidad de adquirir un lenguaje gráfico fundamental para la aplicación práctica en su trabajo y en orientarles en el conocimiento psicológico del niño respecto al dibujo.

Encontramos una referencia a la Revista de Escuelas Normales ${ }^{138}$, en el libro de Cuenca (1989), sobre un plan de estudios del año 1929. Consultada esta publicación apreciamos que aunque está desarrollado con detalle no deja de ser una propuesta de organización que legalmente no se llegó a aplicar. Es por esta razón que, aunque se plantean cuestiones interesantes, no lo reflejamos aquí. Señalar que en cuanto a la materia de Dibujo no se aprecian variaciones respecto al plan de 1914. También se nos referencia el libro de José Junquera El Museo Pedagógico y su contribución a la formación del Maestro donde se elabora un listado de publicaciones para la formación de los maestros sobre la disciplina del dibujo.

Los Cursos Internacionales María Montessori, en los que ella misma explicaba la metodología que ponía en práctica en las "Case dei bambini", se consideraban de gran interés para la formación de los maestros pues suponían

138 (1922-1936), fue dirigida por intelectuales españoles muy activos políticamente y que defendieron enérgicamente la importancia de la educación pública, así como la calidad de la formación del profesorado. Escribieron en ella autores de renombre internacional, como Llopis, Cossío o Lombardo Radice. Después de la dictadura se reeditó, ya en formato digital hacia 1997, como "Revista Electrónica Interuniversitaria de Formación del Profesorado (REIFOP)". 
una renovación pedagógica importante. El primero de ellos se había celebrado en Roma en 1914 con la asistencia de docentes catalanes becados por las instituciones para aprender el método y poderlo aplicar en las escuelas catalanas. El interés manifestado por los docentes de Cataluña hizo que entre febrero y mayo de 1916 se celebrara en Barcelona el III Curso Internacional María Montessori ${ }^{139}$.

En el Plan de 1931, en el de formación inicial, o Cultural, se sigue impartiendo la materia de Dibujo paralelamente a la de Trabajos Manuales y la de Labores. Se añade a estas la Geometría y Trigonometría, que consideramos tendría una inclinación científica más que artística.

Ello se mantiene al pasar al Plan Profesionalizador concediendo una presencia significativa a las materias de índole artística. Comparándolo con el anterior de 1914, sigue en las mismas condiciones. En un plan que tiene una duración de 4 años, se repite la asignatura de Dibujo en los dos primeros años, con una dedicación de 2 horas semanales. También encontramos la asignatura de Labores y trabajos manuales para las maestras y de solo Trabajos manuales para los maestros. Cada una de las asignaturas tiene una dedicación de 3 horas semanales. Esto sumaba 5 horas a la semana de preparación.
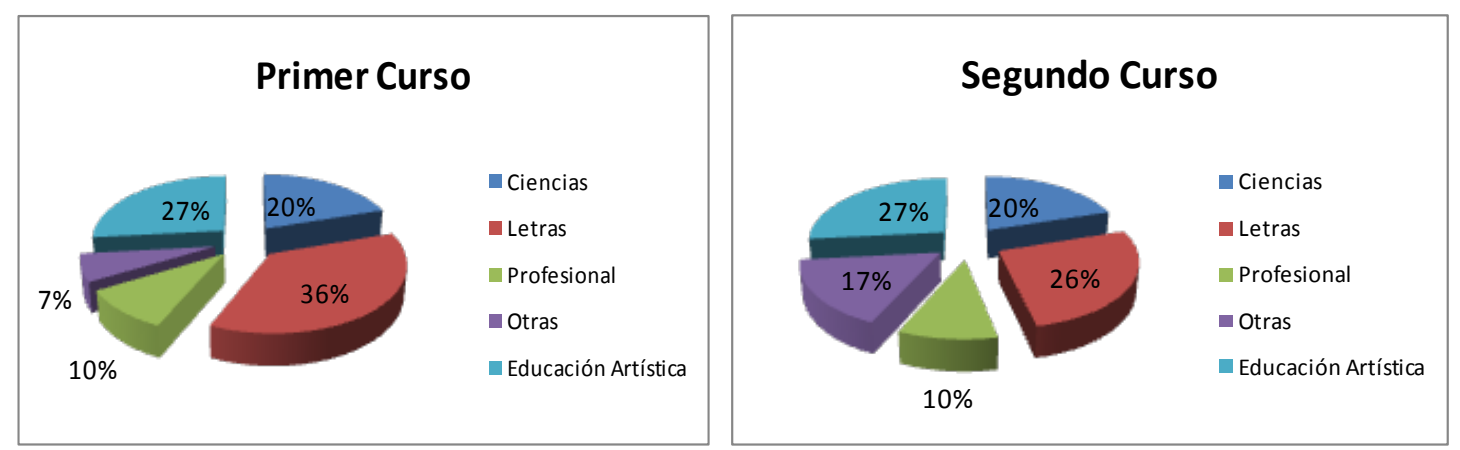

Figura 5. $1^{\circ}$ y $2^{\circ}$ de Plan de 1931.

\footnotetext{
139 Un resumen de este curso puede consultarse en ROSA Y ALBERTI, R.: "El Curso Internacional de Pedagogía científica de la Doctora Montessori", Boletín de la Institución Libre de Enseñanza, 710 (31 de mayo de 1919), pp. 129-140; y 711 (30 de junio de 1919), pp. 177181. 490 "El 'Consell de Pedagogía' de Barcelona", El Sol, 288.
}

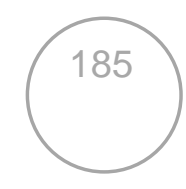


Aún así en los planes de estudio sigue sin constar mayor información sobre las características de la asignatura.

A su vez, el conjunto de materias Artísticas y Prácticas en las que destacaban los Trabajos de Especialización y de Seminario suponían un $25 \%$ del horario, completando los contenidos teóricos del currículum permitiendo al maestro en formación ampliar sus horizontes e inquietudes a la vez que le ponían en contacto con las enseñanzas especiales (González, 1994, p.125).

Los profesores que impartían dichas asignaturas estaban denominados como Profesores Especiales, junto a los de Música y Francés. Para Cuenca (1989), existía cierto malestar entre este tipo de profesorado ya que solicitaba no hubiera intrusismo en sus materias y que quienes las impartieran fueran especialistas. Además solicitaban que sus condiciones de trabajo y sueldo se equipararan a las del resto de profesores de las Normales para poder desarrollar su labor en buenas condiciones pues sus asignaturas son consideradas en muchas ocasiones "de adorno" o "de menor rango". Sin embargo en las consideraciones preliminares del Plan de estudios de 1931 si que figura que son materias "esenciales, sustantivas, necesarias y obligatorias". "En las Escuelas Normales eran escasos los Profesores de Dibujo con una titulación adecuada, es decir, la de Profesores de Dibujo por la Escuela Superior de Bellas Artes" (Cuenca 1989, p. 220).

En esta época asistimos a la aparición de nuevos campos de interés en los Congresos del quinquenio 1925-1930 entre ellas la pedagogía del Dibujo ${ }^{140}$.

\footnotetext{
140 Jornadas pedagógicas en Castellón. Organizadas por la Federación de Maestros de Levante. Participó la Inspección Profesional y otras instituciones. Asistieron a las Jornadas más de quinientos Maestros. Entre los conferenciantes figuraron el profesor Trillo Torija quien habló sobre la didáctica del dibujo; el Inspector provincial señor Artigas quien desarrolló el tema la fe profesional así como otros Maestros de la región. Se realizaron paralelamente excursiones a centros educativos de la zona. Al finalizar sus trabajos, los jornadistas reclamaron la presencia en los actos de clausura del ya Ministro de Agricultura, Marcelino Domingo quien aceptó la invitación que tuvo lugar el 31 de diciembre de 1932.
} 
En la seva obra pedagògica es podrien plantejar tres grans blocs: l'Educació Infantil, l'ensenyament del dibuix a l'escola primària i els manuals adreçats als mestres i professors de dibuix.

Seguint en part els ideals imperants de l'època, Víctor Masriera no solament concebia l'ensenyament del dibuix com una activat artística, sinó com un veritable element educador de la persona, un llenguatge gràfic que li servís per tot, tant si es decantava cap al camp intel-lectual, artístic, com cap el camp professional i tècnic del món del treball. En sintonia amb el que succeïa en la resta de països avançats, a través de l'ensenyament del dibuix no pretenia solament que la societat el conegués, l'utilitzés, l'apliqués o gaudís en la seves vides laborals o privades, sinó que la seva tasca anava més enllà, amb la intenció de formar unes noves generacions, més cultes, més hàbils, més sensibles; en definitiva, elevar el nivell intel-lectual, cultural i, per tant, de benestar de la societat (Prat 2012, p. 160).

Hoy en día puede sonar bastante normal esta manera de plantear la enseñanza pero en aquellos años resultaba extraño a los sectores conservadores. Rechazaba realizar copias de láminas y de dibujos del maestro en la pizarra para favorecer el estudio riguroso del modelo natural. Sin embargo en las clases de Metodología del Dibujo, en las Escuelas Normales se acostumbraba a realizar dibujos en la pizarra para que el alumnado aprendiera y supiera realizarlo posteriormente en sus aulas (Cuenca, 1989).

Podemos tomar como referencia los diversos autores que nos cita este autor que, con sus publicaciones en la materia, nos transmiten sus visones sobre la enseñanza del Dibujo en esos años. Según él mismo manifiesta, son un reflejo de la enseñanza en las Normales. Para un conocimiento mayor de los mismos nos remitiremos a dicha publicación. Únicamente los nombraremos y destacaremos alguna idea señalada de los mismos: 
- En 1934, Lorenzo Gascón Portero publica, en Madrid, el libro Como enseñar el Dibujo y las Bellas Artes en la escuela ${ }^{141}$. Es profesor de la Escuela Normal de Madrid y discípulo de Masriera. Destacar su defensa del dibujo como disfrute y adiestramiento de la inteligencia y su respeto por el proceso de aprendizaje de cada persona. Lo incluye en el aprendizaje de todas las materias.

- En 1933, se publica la traducción por Masriera de la obra de L. Artus Perrelet, El Dibujo al servicio de la Educación ${ }^{142}$. La autora es seguidora de Froebel y Montessori y dedica la obra a los fundamentos de la geometría, el color, el claroscuro y la composición. Establece una visión global de las enseñanzas, uniendo Dibujo con Música y Ritmo. Estas indicaciones tan avanzadas pueden ser muy útiles en manos de personas que sepan aplicarlas aunque sin la formación adecuada se pueden quedar en otra receta más.

- Otro libro muy conocido en la época y utilizado como libro de texto en las escuelas, según Cuenca, es el de Trillo Torija, Dibujo Lenguaje ${ }^{143}$. El autor es maestro y por lo tanto su obra está muy aplicada a la escuela y es práctica para el profesorado.

- Los libros de Ezequiel Solana, Dibujo Lineal aplica a las Artes, El Dibujo en el encerado, Dibujo de cosas, también son muy bien acogidos por los maestros.

- Abel Chancel publica El libro del Maestro para la enseñanza del Dibujo $^{144}$, está basado en los programas oficiales de enseñanza del dibujo de Francia en los años 30. Los aspectos más destacables son la educación de la vista y del tacto junto a ejercicios gráficos prácticos. Se separa claramente el concepto de forma del de color.

- Elisa López Velasco ofrece un sencillo pero profundo estudio metodológico y didáctico de la enseñanza del Dibujo en la escuela

141 Gascón Portero, Lorenzo. (1934). Como enseñar el Dibujo y las Bellas Artes en la escuela. Madrid.

142 Perrelet, L. Artus (1933). El Dibujo al servicio de la Educación. Madrid.

143 Torija, Trillo (1935). Dibujo Lenguaje. Madrid. Magisterio Español.

${ }^{144}$ Chancel, Abel (1934). El libro del Maestro para la enseñanza del Dibujo. Barcelona.

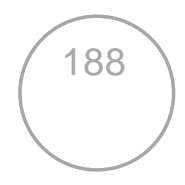


primaria y que resulta muy útil para los docentes, La práctica del Dibujo en la Escuela Primaria ${ }^{145}$. Aboga en él por una "escuela activa" que "respete la personalidad del niño". Considera al Dibujo como materia fundamental de la escuela criticando la diferenciación del aprendizaje según el sexo. Para ella el dibujo en la escuela no es para hacer artistas sino que se debe emplear con un enfoque educativo y formativo.

La materia desaparece totalmente en el Plan de 1940. Sin embargo en el del 42 aparece 2 horas de Enseñanza Artística en $1^{\circ}, 2$ horas de Dibujo en $3^{\circ}$ y $4^{\circ}$, además de 2 horas más de Trabajos Manuales en $3^{\circ}$ y $4^{\circ}$ y 2 horas de Labores Artísticas en $4^{\circ}$. Las horas de Dibujo quedan reducidas al mínimo, con contenidos meramente instrumentales y sin orientación metodológica ni didáctica. El Dibujo es sobre todo de carácter Técnico y Geométrico.

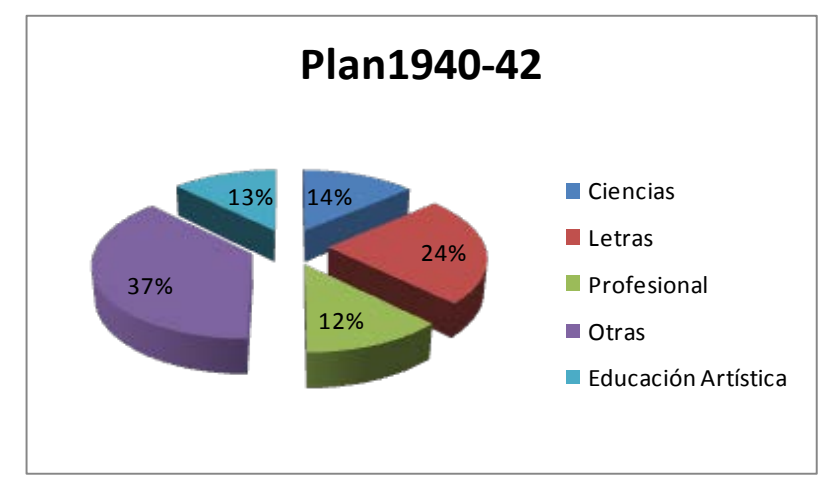

Figura 6. Plan de 1942.

En el Plan del 45 se establecen cursos de Cultura General y otros de Profesional, el Dibujo se imparte únicamente en la etapa Cultural y, se acentúa en todo el recorrido, los Trabajos Manuales y las Labores. Reaparece la asignatura de Caligrafía a la que se considera con "cierta inclinación artística".

145 López Velasco, Elisa (1933). La práctica del Dibujo en la Escuela Primaria. Madrid. Espasa Calpe. 


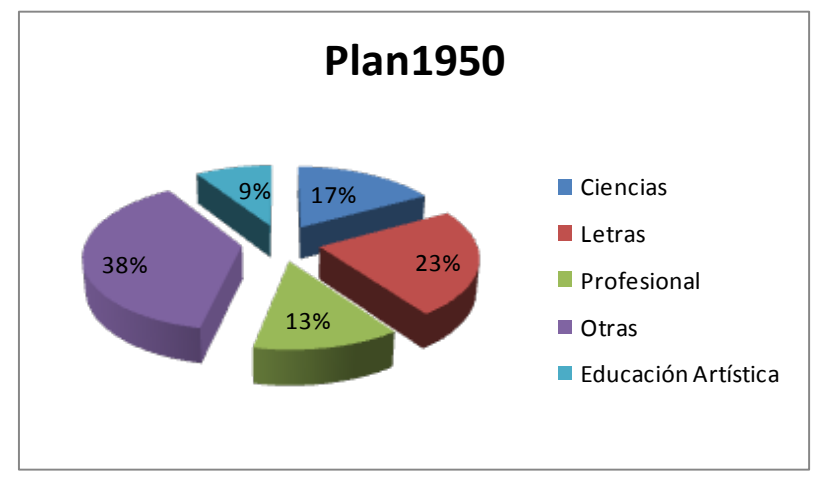

Figura 7. Plan de 1950.

Como ya hemos visto reflejado, en el Plan de 1950, el Dibujo solo aparece en dos de los tres cursos de los estudios y la dedicación horaria es de una hora semanal en cada curso. Este Plan es el primero que normaliza los libros de texto de las Escuelas Normales, especificando los Programas de las materias. En el análisis y critica pormenorizada que realiza Cuenca (1989) de los mismos en su libro llega a demostrar su escasa coherencia. Sin embargo, aparece como positivo el concepto de Metodología del Dibujo. Se impartían estudios sobre las etapas de evolución infantil, además de los procedimentales. Se utilizaban estos conocimientos como lenguaje complementario y aplicado a otras disciplinas (ciencias y letras) lo cual es valorable positivamente. Se favoreció el dibujo artístico sobre el técnico pero valorándose la copia fiel de originales (prácticamente nunca del natural). El aspecto creativo no se contemplaba. Atendiendo a los programas que se exponen en el tratado, se aprecia como en la asignatura de Dibujo se desarrollaban exclusivamente trabajos bidimensionales dejándose para las de Trabajos Manuales la aplicación de la tridimensionalidad. La diferenciación entre asignaturas obedecía a los objetivos propuestos.

Es curioso destacar cómo se nombraba y colocaban los horarios de las asignaturas artísticas tal y como se cita en el BOE ${ }^{146}$ correspondiente: "Por la tarde, la primera sesión de una hora se dedicaba a disciplinas que no exigían

${ }^{146}$ Decreto de 7-7-1950. BOE, no 219, 7-8-1950, pp. 3468-3478. 
demasiada tensión psico -física, tales como: Música, Caligrafía y Trabajos Manuales" (Araque, 2009, p. 121).

El profesorado de Dibujo era denominado como Profesores Especiales y, para poder acceder a dar clases en las Escuelas Normales, deben ser Maestros y titulados por la Escuela Superior de Bellas Artes (Cuenca, 1989).

En este periodo señalaremos otros libros que nos referencia Cuenca que se publican sobre la materia:

- El Dibujo y su Metodología, de Francisco Pérez Lozao, que intenta adecuarse al programa oficial establecido así como a las horas establecidas en el curriculum. Dedicación totalmente insuficiente, según manifiesta para poder abordar dignamente y en profundidad los contenidos necesarios (en Cuenca, 1989 p. 337). Las materias que para él vertebran el Dibujo son: el color, los dibujos a yeso y la metodología propiamente dicha. El libro, a su parecer, queda únicamente como unas pocas recetas aplicadas.

- Orientaciones y Cuestionarios Oficiales para la Enseñanza Primaria, que publica en 1953, el Ministerio de Educación Nacional. Su interés para la educación primaria lleva asociado lo importante que puede ser para la formación de los maestros en las Escuelas de Magisterio del momento. Estos cuestionarios recogen recomendaciones más avanzadas y adecuadas al estudio de la materia; aparecen por primera vez reflejados los términos de motricidad, observación, acercamiento a la naturaleza y manifestación libre de la actividad. El problema surge cuando en las Escuelas de Magisterio o en las escuelas quienes lo tienen que impartir no han tenido formación para ello. Para poder llevar a cabo nuevos enfoques en la escuela se ha de formar correctamente al maestro. Las recomendaciones oficiales, como ocurre en numerosas ocasiones llegando incluso a nuestros días, son excesivamente teóricas y poco aplicables.

- Se cita un artículo de Carlos Garrido Rujula, al que aludimos por ser el exponente del concepto de la enseñanza del dibujo de esos tiempos. 
Basa sus enseñanzas en la "corrección de los errores" de los niños al dibujar y como el adulto reorienta sus percepciones.

- Otra obra señalada, esta vez de mayor interés, es la de Josefina Rodríguez, El arte del niño. Es el fruto de su investigación sobre la Psicología, el Arte y la Pedagogía de la Plástica. Su aportación más significativa, desde nuestro punto de vista, es la forma de plantear como deben ser enseñadas las actividades artísticas y creadoras en la escuela.

- Por último denotaremos una propuesta de plan de estudios para la Escuela Nocturna y Experimental del Magisterio, creada en Madrid en 1959. Nuestro interés no es reseñar este plan de estudios sino resaltar conceptos nuevos que en él aparecen y que se utilizaran, años más tarde:

o Crítica los anteriores planes de Magisterio por no responder a las necesidades profesionales de las personas que allí se forman.

o Aboga por elaborar una distribución horaria más racional y que contempla la formación mediante actividades culturales fuera del aula.

o Propone que las prácticas desarrolladas en las Escuelas Anejas sean con supervisión de especialistas.

o Valora una "educación estética" para la formación del maestro a cargo de profesores especializados.

o Sugiere una reorganización de las asignaturas consideradas "artísticas", bajo la denominación de Artes Plásticas. El término abarca un espectro mayor de materias y unifica el estudio de la metodología y de las técnicas.

El Plan de 1967 basado en nuevas perspectivas docentes requiere profesionales mejor preparados para las asignaturas específicas de lo que hasta ahora se había tenido. Esta cuestión plantea problemas en la materia de Dibujo pues con las incorporaciones de la Didáctica o Pedagogía del dibujo los profesores que ejercen en ese momento no están preparados. Se suma a ello 
la poca formación en la materia que arrastra también el alumnado que accede a estos estudios.

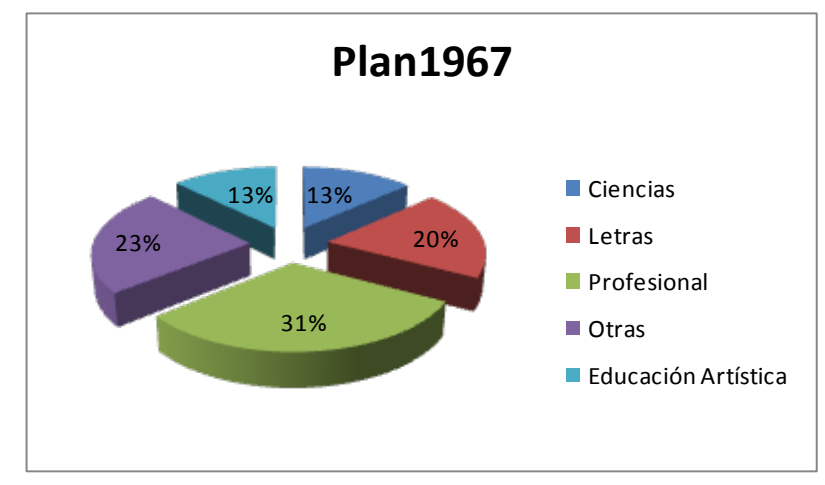

Figura 8. Plan de 1967.

El Dibujo se imparte en $1^{\circ}$ y $2^{\circ}$ curso. En cuanto a contenidos, aborda temas fundamentales del Lenguaje de la Plástica. Gana terreno la valoración del Dibujo del natural con conceptos de Percepción, de claroscuro y de Perspectiva. Advertimos que desaparecen los Trabajos Manuales, probablemente porque los contenidos se incluyen en esta asignatura. Tanto en primero como en segundo el temario es muy amplio, tal vez excesivo para tratarlo en profundidad en la dedicación horaria de 2 horas a la semana. A pesar de todo, es de valorar la mejora cualitativa con respecto a planes y concepciones anteriores.

Referenciamos dos obras importantes que funcionaron como libros de texto en las Escuelas Normales. Consideramos de interés, al menos nombrarlas:

- Dibujo y su Metodología I y II $^{147}$, de Francisco Pérez Lozao.

- Dibujo I y Dibujo II. Magisterio ${ }^{148}$, de Manuel Clemente Ochoa

Ambas parten de una concepción del Dibujo en que dejan poco espacio a la iniciativa del alumnado. 
Los planes de estudio de las Escuelas Normales, al igual que ocurrió durante la época de la Republica, están directamente relacionados con la escuela primaria, incluso a veces coinciden los nombres de las materias. Para el alumnado de las Escuelas Normales resultaba complejo poder adquirir todos los conocimientos que se exponen en los cuestionarios a lo largo de sus estudios. Hubieran necesitado mejores preparadores y mayor dedicación horaria ya que su función era luego adaptarlo a las características de su escuela, cuestión para la que se encontraban muy poco capacitados.

El relevo lo tomaron las editoriales de la época que, con la excusa de acercar y facilitar el trabajo a los maestros, editaron unos textos en los que el maestro solo necesitaba seguir paso a paso para elaborar su clase sin tenerse que preocupar de las secuencias didácticas. Ello, en un principio, pareció suplir las carencias en conceptos, técnicas y metodologías que arrastraban los maestros de las Escuelas Normales.

Hasta el Plan experimental del 71, los planes de estudio y programaciones del Dibujo en las Escuelas Normales han sido a nivel nacional. A partir de este, cada centro desarrolla sus programas de manera autónoma lo cual genera diversidad de planteamientos. A la hora de hacer un seguimiento, es complejo. Son bastante diferentes las programaciones de los 70 de las que se ponen en marcha en los 80.

En la Enseñanza Primaria de la Reforma de 1970 y en los Programas Renovados de 1981, entonces EGB, la asignatura pasa a denominarse Expresión Plástica. El interés que prevalecía en aquel momento era salir de la situación de aislamiento existente e intentar adecuarse al marco internacional. Ello requería una organización del Sistema Educativo que favoreciera el enfoque tecnológico vigente en ese momento. Se utilizaron para ello modelos europeos y norteamericanos. Los planteamientos dominantes para esta área son los que intentan satisfacer "la necesidad de expresión del niño" y estimular "la espontaneidad creativa" además de "fomentar la originalidad y la creatividad". También se pretende "introducir a la comprensión de las obras artísticas de todos los tiempos" y a la "cultura visual". 
Todos estos nuevos enfoques requieren un replanteamiento del trabajo del maestro y por lo tanto de la manera en que se le debe formar pues, según la nueva ordenación de la EGB, "todo futuro profesor debe estar capacitado para el desempeño de la enseñanza para la primera etapa de la educación general, así como una de las áreas de especialización de la segunda etapa." ${ }^{149}$. En esta década de los 70 y en los años 80 , el concepto de la creatividad en la educación española tuvo su momento culminante. Afirmamos esta cuestión atendiendo al número creciente de artículos publicados en las revistas de educación en esos años. El concepto de creatividad que más se utiliza es la consideración de la misma como "lo nuevo y lo valioso" o como "resolución novedosa y valida de los problemas y las necesidades".

En el curriculum de EGB, se delimitan dos aéreas fundamentales, las de la Experiencia y las de la Expresión. La Educación Plástica está en la de Expresión, se denomina Expresión Plástica, junto a otras materias como Lengua, Matemáticas y Pretecnología. Ello provocó que las dos primeras prevalecieran y que la Plástica se quedara relegada. Aun así, en los planes de estudio de Magisterio figura como materia común en las Especialidades de Ciencias, Filología y Ciencias Humanas, y como materias de especialidad en segundo curso en Preescolar y en Especial. En el Plan siguiente, aunque mejora, sigue formando parte de un bloque, lo cual no ayuda a identificarla como área importante (Hernández, 1995, p. 28): "La implantación de estas materias requiere un tratamiento diferencial, para que puedan hacerse de un espacio curricular propio, en una cultura educativa que las acepta pero que no las integra".

Las materias especificas en la EGB determinarán las diferentes especialidades en cuanto a la formación de los maestros. En los planes de estudio, las asignaturas que aparecen son comunes, de especialidad y optativas. Hay ciertas diferencias de entre el de Valencia y Castellón con el de Alicante. En Alicante las especialidades son: Preescolar, Filología, Ciencias y Ciencias 
Humanas. En todas ellas se impartía 9 créditos de Dibujo en $1^{0}$ y otra asignatura denominada Manualizaciones que se impartía a razón de 9 créditos tanto en $2^{\circ}$ como en $3^{\circ}$. La especialidad de Ciencias Humanas incorporaba en tercer curso 9 créditos de $\mathrm{H}^{\mathrm{a}}$ del Arte, no es una asignatura propiamente de Educación Plástica pero sí que garantiza una mejor preparación en aspectos artísticos. En cuanto a otras asignaturas de EA que se pudieran cursar, únicamente en Preescolar tienen la opción de coger una optativa cuatrimestral denominada Expresión Plástica y Pretecnología.

En Castellón, los profesores de EA formaban parte de una sección departamental del Departamento de Didáctica de la Expresión Musical, Plástica y Corporal de la Universitat de Valencia.

En Valencia las especialidades son: Lengua Española e Idioma Moderno, Ciencias, Ciencias Humanas, Preescolar y Educación Especial. En todas ellas se impartía 3 horas semanales de Dibujo en $1^{0}$ y la otra denominada Manualizaciones que se impartía a razón de 2 horas semanales tanto en $2^{\circ}$ como en $3^{\circ}$. La especialidad de Ciencias Humanas también incorporaba, igual que Alicante, en tercer curso 3 horas semanales de $\mathrm{H}^{\mathrm{a}}$ del Arte. En la de Preescolar se añade otra asignatura de Educación Plástica en $2^{\circ}$ con una dedicación de 3 horas semanales, así como en Educación Especial que tiene 3 horas de Expresión Plástica en tercero y Ergoterapia y Terapia Ocupacional, con 3 horas también semanales.

En el cuadro de optativas cuatrimestrales no figura ninguna asignatura de carácter artístico, aunque sí que aparecen, en las optativas anuales de segundo curso, la opción de elegir Técnicas de Manualizaciones o Técnicas y Tecnología de la Imagen, ambas con 3 horas semanales dedicación.

Señalar que se sigue priorizando en muchos casos el Dibujo Técnico y los Sistemas de Representación sobre el Dibujo Artístico. Además como se trataba de un Plan de Estudios Experimental cada Escuela tenia autonomía en su aplicación. De la misma forma se aprecia diferencias en la aplicación de los programas, que al no tener directrices concretas favorecen diferentes formas 
de aplicarlos según las tendencias del profesorado que lo gestiona. En general lo que sí coinciden los distintos programas es en el exceso de contenidos a impartir para el tiempo que dura la materia.

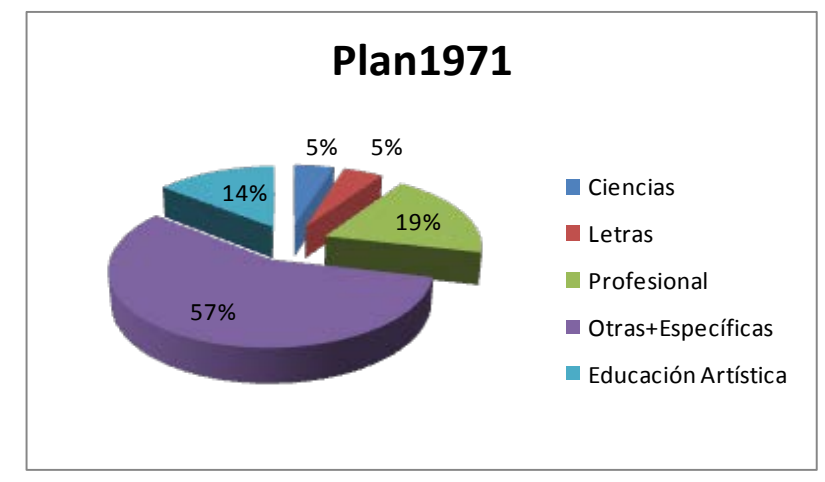

Figura 9. Plan de 1971.

Un dato curioso es que los profesores de las Escuelas Universitarias eran a su vez profesores de Institutos de Bachillerato, lo cual llevaba en ocasiones a que en las Escuelas se realizaran ejercicios más propios de los bachilleres que de lo que debía de saber un maestro (Cuenca, 1989). Ocurría que los programas de Bachillerato estaban muy bien definidos y había numerosos textos que la desarrollaban, en consecuencia se utilizaron frecuentemente estos textos para consulta. En el aspecto didáctico las teorías de Lowenfeld (1972) son las que se impusieron en muchos casos como referencia pues se defendía un aprendizaje por medio de los sentidos basándose en la propia experiencia y descubrimiento, donde el docente únicamente actúa de guía sin imponer su visión.

Se producía la circunstancia, como en Alicante, de que se estaban utilizando a la vez textos que correspondían al plan de 1967 junto a otros que abordaban la Expresión Plástica. La indefinición de los criterios a seguir para impartir la materia y la falta de de fundamentos teóricos sobre la misma, impedía la especialización en la materia que necesitaban los futuros maestros para poder impartirla con propiedad. Posteriormente se trabaja en ello para concretarse, años más tarde, en los Programas Renovados de EGB. 
La ampliación de las plantillas de profesorado mejoró la enseñanza de la Expresión Plástica, y se adecuó mejor a los contenidos que necesitaban en Magisterio al introducir nuevos planteamientos y unificar criterios. A pesar de todo, a criterio de Cuenca (1989), permanece cierta dispersión de contenidos, al establecer comparativa entre las programaciones de diferentes Escuelas y comprobar la mezcla que se realizaba entre consideraciones didácticas y técnicas plásticas, así como la ausencia de bibliografías concretas y de trabajos a realizar. En estos tiempos, también señala que la masificación de los centros va en detrimento de la realización de trabajos prácticos favoreciendo las clases de teoría.

Las asignaturas de la diplomatura ${ }^{150}$ se agrupaban en torno a tres áreas generales, tal y como se recomendaba en los medios internacionales:

- Formación psicopedagógica e instrumental. En ellas se incluye Dominio de la Expresión Plástica por medio del Dibujo y Manualizaciones en sus diversos tipos.

- Áreas culturales y especializaciones profesionales. En ellas expresa "expresión plástica y manual-conocimiento de sus técnicas. Conocimiento de las técnicas de globalización y de las formas de lograr un clima de libertad y espontaneidad del niño como base de la creatividad". Concretando en lo referente a la Educación Especial "adquisición de técnicas de expresión, así como terapias lúdicas y ocupaciones".

- Practicas docentes.

Estudios realizados en los años 80 coinciden en tratar como asignaturas opcionales entre otras, a las materias de Dibujo, Medios Audiovisuales y Manualizaciones. Para ilustrar estas, Cuenca (1988) recurre a la cita y exposición del libro La Formación del Profesorado de EGB. Análisis de la 
situación española ${ }^{151}$ del que resalta el apartado referido al "Área de Educación Artística Plástica". De las apreciaciones que expresa deducimos la falta de preparación que manifiesta el alumnado en la materia. Además expresa la falta de preparación previa que traen de los estudios anteriores y la poca adecuación de las enseñanzas que reciben en relación a lo que van a necesitar para ejercer en la escuela lo cual se manifiesta que debería estar interrelacionado. Por lo tanto la necesidad que tienen de formación en el área es totalmente imprescindible.

Con todos estos condicionantes, se entiende la predominancia de la enseñanza del dibujo geométrico pues permite una asimilación más fácil siguiendo las pautas adecuadas y se puede aplicar para clases con gran número de alumnos.

En otro par de capítulos Cuenca expone diferentes programas de Escuelas Universitarias de Profesorado de EGB, para que sirvan de referencia de lo que se impartía en esos momentos tanto para EGB como para Preescolar y Educación Especial. Salvo su mención de la Escuela de Alicante para el curso 1979-80 y el ejemplo de la de Valencia para Preescolar, el resto no corresponde al objeto de este estudio pues se centra sobre todo en Cataluña y Madrid, por lo tanto solo apuntaremos las ideas más importantes de las mismas:

- En cuanto a EGB, referencia las dos asignaturas que coinciden en todas los especialidades que son Expresión Plástica-Dibujo y Manualidades. La segunda en muchos casos está relacionada con la primera, y aunque mantiene contenidos diferenciados, actúa como refuerzo de esta. Pero en otras ocasiones se mimetiza y sus contenidos específicos se diluyen. Cuenca valora como positivos los contenidos y valores culturales que transmite la asignatura de Manualidades abogando por actualizar sus contenidos y conservarla. 
- En las especialidades de Preescolar y Educación Especial resaltar que aumentan las horas dedicadas a la materia. Mantienen el curso común de $1^{\circ}$ pero, según escuelas, añaden la materia artística en $2^{\circ}$ e incluso en $3^{\circ}$.

Atendiendo a las diferentes Escuelas referenciadas, en algunas de ellas, destacar que los programas se adecuan al nivel y especialidad tratada, pero en otras no. Señalar, en estos casos, la inclusión del estudio de lo tridimensional, la voluntad de globalización de las enseñanzas, la interdisciplinaridad y el trabajo conjunto de diferentes áreas. En algunos casos pasa ya a denominarse Educación Artística, término más amplio pues parece querer abarcar mayor numero de aspectos educativos. En estos niveles cobra importancia y fomenta el inicio de numerosas investigaciones.

En el estudio que realiza manifiesta que los contenidos de las asignaturas no están especificados, ni muy detallados, con lo que es difícil saber qué contenidos se impartían. Aunque la exposición de los programas nos indica la dirección educativa que tenia cada una de las escuelas estudiadas. Señalaremos algunos aspectos generales que nos ayudaran a fijar los conceptos en que se trabajaba:

- En general se pretende dotar a los alumnos de un máximo de información y de mecanismos que les enseñen a generar recursos propios para facilitarle el desarrollo su función docente. Se enseñan las técnicas plásticas necesarias para la escuela y el proceso evolutivo del niño.

- Los contenidos que se imparten difieren según las universidades y apreciamos que, en algunas, una importante parte del temario se dedica al dibujo lineal; tal vez por resultar menos comprometido de impartir. Consideramos que para el nivel al que va dirigido se deben obtener previamente conceptos más generales sobre el conjunto del lenguaje grafico-plástico antes de abordar estos aspectos que solo cubren una parte de los conocimientos necesarios. Otras por el contrario, como por ejemplo la Escuela María Giménez de Madrid en su completo programa 
del curso 84-85, pretende favorecer múltiples y ricas experiencias artísticas que más adelante se pudieran adaptar a los diferentes Ciclos en las escuelas. En la Primaria se deben contemplar criterios plásticos de forma más general así como centrarse en el desarrollo de la sensibilización de capacidades que permitan más adelante integrarse en sus conocimientos. Aun así, no apreciamos contenidos que trabajen a favor de un mayor desarrollo perceptivo, que aumenten la capacidad creativa y sensibilicen al alumnado hacia la producción artística.

- Por otra parte, el conocimiento del desarrollo del niño se revela como necesario para poder en un futuro plantear las actividades adecuadas a cada edad. Aquí entramos de lleno en la didáctica aplicada.

- En cuanto a la metodología, en algunas Escuelas se inclinan por la interiorización de los conceptos y contenidos plásticos mediante la práctica y posterior análisis de lo realizado. Se plantea la voluntad de realizar experiencias fuera de las aulas así como abogar por un horario flexible en una nueva "aula taller" que funcione como un lugar de encuentro y experimentación. En la evaluación se incluyen valoraciones de capacidad y actitud mediante autoevaluaciones y criterios valorativos de la clase. Con todo ello se favorece por un lado el trabajo personal y a la vez las tareas comunes y en grupo.

En resumen, con respecto a los planteamientos de los años 70, observamos un intento de precisión en los programas en los que se detalla mejor cuales son los objetivos, actividades, metodología y evaluación. Se observa una mayor creatividad en los proyectos docentes y mayor definición en las asignaturas.

En cuanto a las asignaturas optativas, las que se ofrecen de EA, suelen tener muy buena acogida por parte del alumnado. Generalmente son de tipo taller con enseñanzas principalmente prácticas. En estos años, se palia la deficiencia de enseñanzas artísticas en el Plan, con este tipo de asignaturas.

Con la Ley Orgánica General del Sistema Educativo (LOGSE), de 1990, se intenta conjugar la obligación del Gobierno de establecer un curriculum 
obligatorio y la autonomía del profesorado, mediante la noción de curriculum abierto y del Proyecto Curricular de Centro. Se definirán los objetivos y contenidos en términos de conceptos, procedimientos y actitudes que se han de aprender en la materia. Los contenidos especificados se han de enseñar en todas las escuelas. Los Gobiernos Autónomos y el Proyecto Curricular de Centro los adaptaran a las peculiaridades de cada Centro. Esta es una labor compleja que en la realidad se enfrentó a numerosos problemas de aplicación.

Cambia la denominación del área y pasa a llamarse Educación Artística. El nuevo curriculum intenta ofrecer un acercamiento al mundo del arte pues la integra como materia en toda la enseñanza obligatoria. Trata de hacerlo adaptándose a los cambios que se producen en una sociedad cada vez más dominada por la imagen. Esa es la razón del cambio en el nombre de la materia y también en cuanto a los objetivos que persigue.

El nuevo planteamiento pretende "educar para saber mirar, analizar y comprender la imagen" así como "potenciar la percepción de representaciones plásticas y de la expresión de sentimientos e ideas". También se da importancia a introducir "el análisis y reflexión acerca de la producción artística para descubrir valores de belleza en un objeto". Lo que podemos extraer de esta modificación es la importancia que se pretende conceder a la cultura de la imagen.

El alumno establece una comunicación con el mundo que le rodea mejorando su interpretación del mismo. En el Plan anterior la atención se fijaba sobre todo en las técnicas que aprende y las actividades que realiza. Tenemos el arte como expresión frente al arte como lenguaje.

El área comprende la Educación Artística, la Musical y la Dramatización, entendida como "una disciplina perceptiva, expresiva y comunicativa interpersonal e interdisciplinar, bajo los parámetros de: percepción, lenguaje y técnicas"

Las premisas que plantea esta reforma requieren un cambio importante en el profesorado. No ya porque deba cambiar el planteamiento de la asignatura

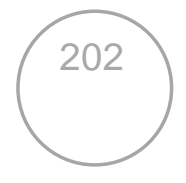


sino porque necesitará cambiar su formación para adecuarse a las nuevas demandas educativas. Se retoman aquí planteamientos antes mencionados de Prrelt en la Republica.

En el siguiente Plan de Estudios ${ }^{152}$ (Plan del 93) para las enseñanzas de los maestros se introduce el concepto de crédito como unidad de valoración de la docencia. Un crédito corresponde a 10 horas de docencia. Para obtener el título se ha de cursar 198 créditos, con diferente distribución dependiendo de la especialidad cursada. También se vuelven a introducir los estudios por cuatrimestres. Esta transformación cambia sustancialmente los estudios de Magisterio: desaparecen las especialidades de Ciencias y de Humanas, Preescolar pasa a denominarse Educación Infantil, se crean las especialidades de Primaria, Lenguas Extranjeras, Educación Física, Educación Musical, Audición y Lenguaje y Educación Especial (aunque no todas se cursan en todas las universidades). Se pierde la oportunidad de crear una especialidad de Educación Artística.

Con el Real Decreto 779/1998, de 30 de abril ${ }^{153}$ se realizan una serie de modificaciones, sobre otras anteriores ya aplicadas. Fundamentalmente se reasigna la excesiva carga horaria inicial de ciertas asignaturas. En el año 2000 se hicieron algunos retoques en los Planes de Estudio de Alicante y Valencia. El de Castellón se mantuvo hasta la llegada de los Grados.

Las asignaturas artísticas quedaran de la diferente forma, según las universidades y especialidades.

En Alicante:

- Primaria - Atendiendo a las asignaturas Troncales u Obligatorias, tenemos Educación Artística y su Didáctica, con 4 créditos de dedicación $\left(2^{\circ}\right)$ y Educación en las Artes Plásticas con 6 créditos $\left(3^{\circ}\right)$.

\footnotetext{
152 R.D.1440/1991, de 30 de agosto [Directrices generales propias de los planes de estudios del título universitario oficial de Maestro en sus diversas especialidades]

153 Publicado en el BOE de 14 de diciembre de 1998.
} 
Como Optativas (4 cr.) tenemos las posibilidades de Historia General del Arte $\left(1^{\circ}\right)$ y Técnicas y Procedimientos Artísticos $\left(2^{\circ}\right)$.

- En la modificación que se hace en el plan de estudios en el 96, las asignaturas que quedan son Expresión Plástica de 4,5 créditos (10) y Educación Artística y su Didáctica de 4,5 créditos $\left(2^{\circ}\right)$. Sin opción de Optativas aunque tienen 21 créditos de Libre Configuración.

- En el 2000, Educación Artística y su Didáctica de 4,5 créditos $\left(2^{\circ}\right)$ se mantiene y se añade Expresión Plástica de 4,5 créditos $\left(2^{\circ}\right)$. Sin Optativas y se mantienen los 21 créditos de Libre Configuración.
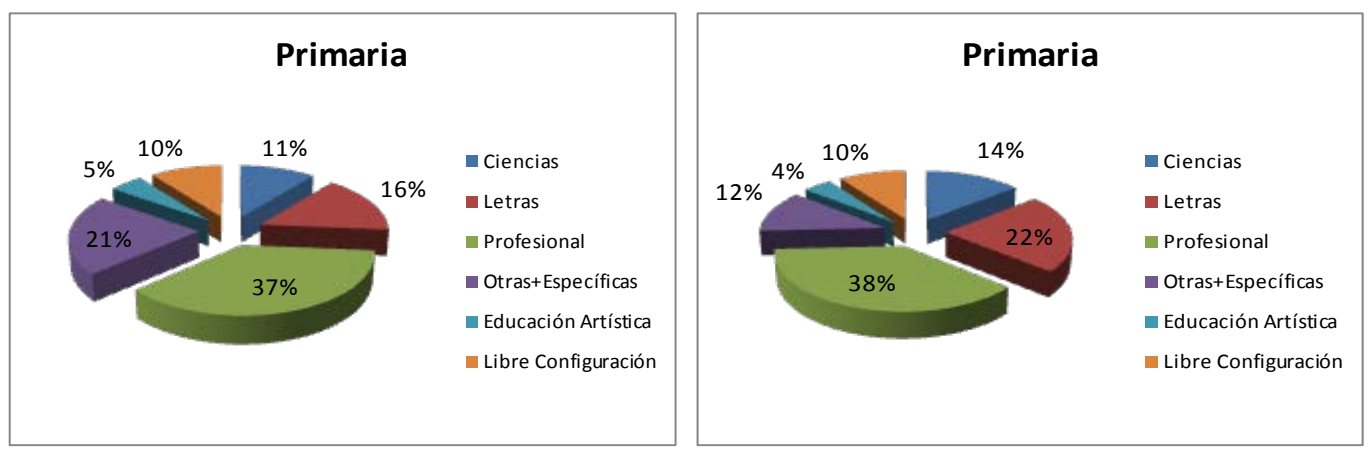

Figura 10. Educación Primaria. 1992 y 1996. Alicante.

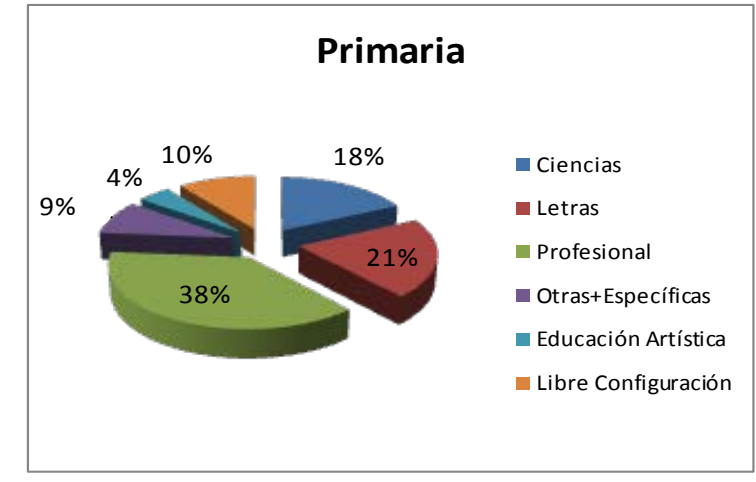

Figura 11. Educación Primaria. 2000. Alicante.

- Infantil - Atendiendo a las asignaturas Troncales u Obligatorias, tenemos Desarrollo de la Expresión Plástica y su Didáctica, con 6 créditos de dedicación $\left(1^{\circ}\right)$. Como Optativas $(4 \mathrm{cr}$.) tenemos las posibilidades de Historia General del Arte $\left(1^{\circ}\right)$, Técnicas y 
Procedimientos Artísticos $\left(2^{\circ}\right)$ y Análisis de la Forma Bi y Tridimensional $\left(3^{\circ}\right)$.

- En la modificación que se hace en el plan de estudios en el 96, se mantiene Desarrollo de la Expresión Plástica y su Didáctica, con 6 créditos $\left(1^{\circ}\right)$ y se añade Expresión Plástica de 4,5 créditos $\left(2^{\circ}\right)$. Sin opción de Optativas aunque tienen 21 créditos de Libre Configuración.

- En el 2000, Desarrollo de la Expresión Plástica y su Didáctica, con 6 créditos de dedicación $\left(1^{\circ}\right)$ se mantiene y se añade Expresión Plástica de 4,5 créditos $\left(3^{\circ}\right)$. Sin Optativas y se mantienen los 21 créditos de Libre Configuración.
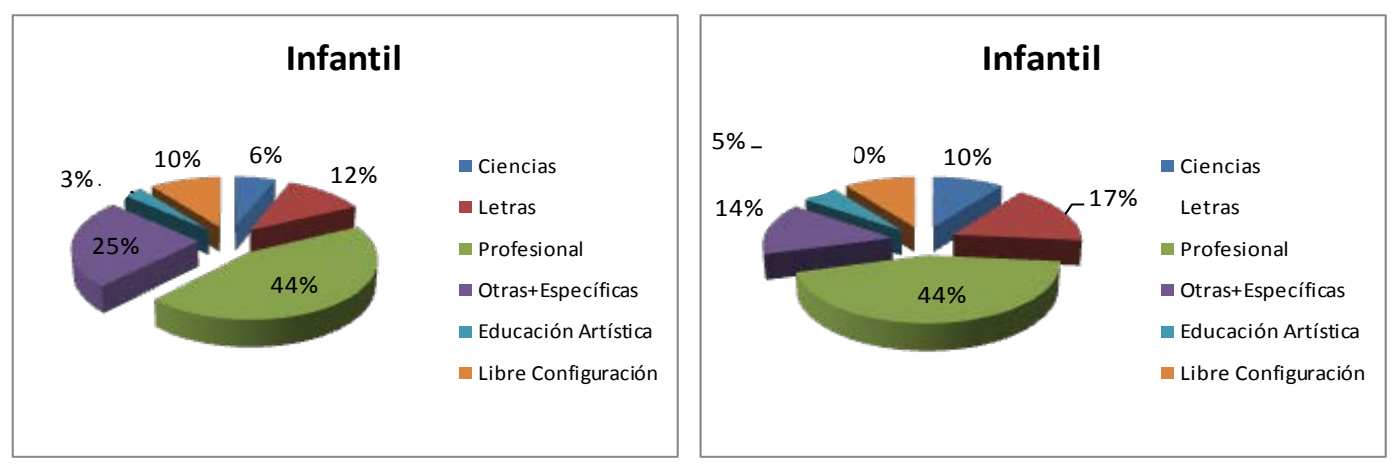

Figura 12. Educación Infantil. 1992 y 1996. Alicante.

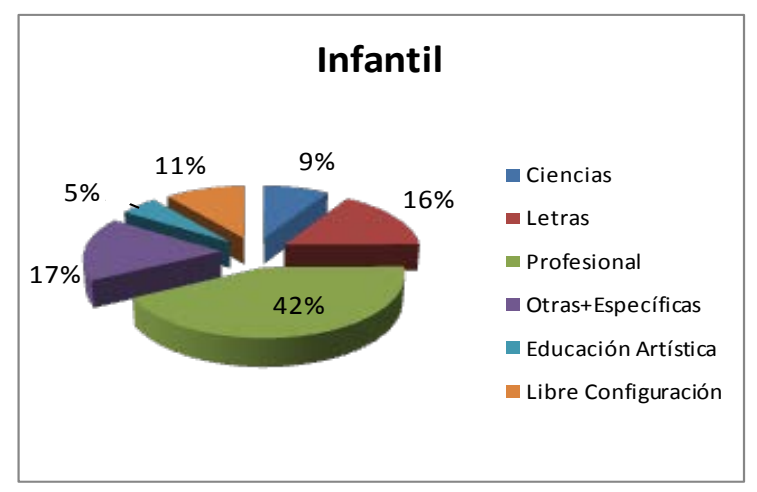

Figura 13. Educación Infantil. 2000. Alicante.

- Lengua extranjera - Atendiendo a las asignaturas Troncales u Obligatorias, encontramos de nuevo la asignatura de Educación Artística y su Didáctica con 4 créditos de dedicación $\left(2^{\circ}\right)$. Como Optativas ( $4 \mathrm{cr}$.) tenemos las posibilidades de Historia General del Arte 
$\left(1^{\circ}\right)$, Técnicas y Procedimientos Artísticos $\left(2^{\circ}\right)$ y La Creatividad Plástica en la Didáctica de la Lengua Extranjera( $\left.3^{\circ}\right)$.

- En la modificación que se hace en el plan de estudios en el 96, se mantiene Educación Artística y su Didáctica de 4,5 créditos $\left(2^{\circ}\right)$ y se añade Didáctica de la Expresión Plástica y Visual con 6 créditos $\left(1^{\circ}\right)$. Se mantiene la Didáctica de la Imagen de 4,5 créditos $\left(2^{\circ}\right)$ como optativa y tienen 21 créditos de Libre Configuración.

- En el 2000, Didáctica de la Expresión Plástica y Visual con 6 créditos, con 6 créditos de dedicación $\left(2^{\circ}\right)$ se mantiene aunque cambia de curso y al igual que Educación Artística y su Didáctica de 4,5 créditos $\left(3^{\circ}\right)$. Como Optativas $\left(4,5 \mathrm{cr}\right.$.) tenemos Didáctica de la Imagen $\left(3^{\circ}\right)$ y se mantienen los 21 créditos de Libre Configuración.
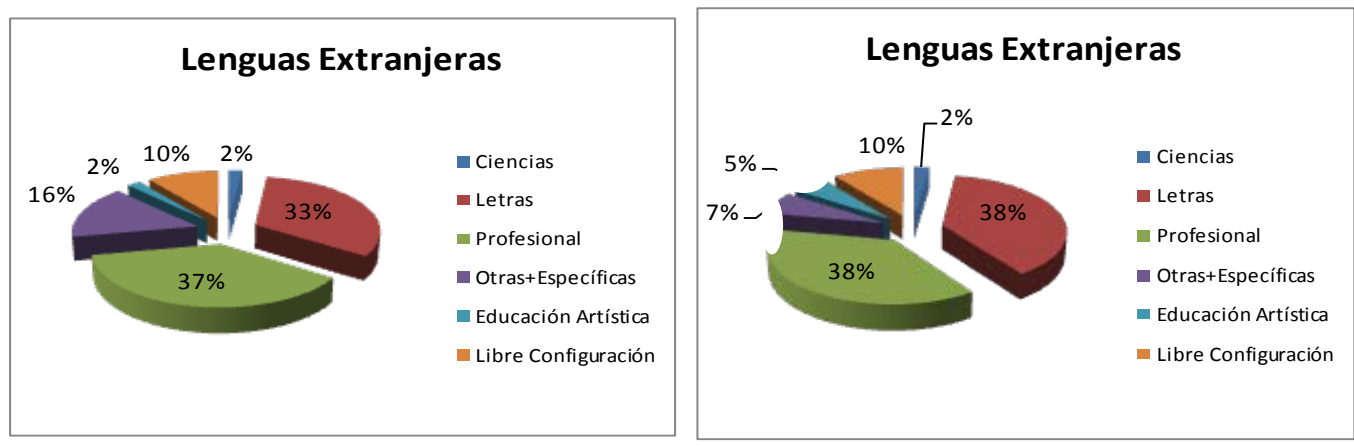

Figura 14. Primaria. Especialista en L. Extranjeras. 1992 y 1996. Alicante.

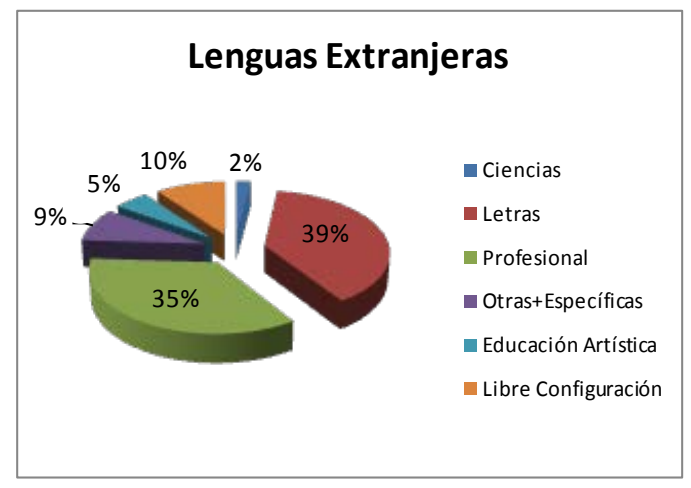

Figura 15. Primaria. Especialista en L. Extranjeras. 2000. Alicante.

- Educación Física - Atendiendo a las asignaturas Troncales u Obligatorias, tenemos Educación Artística y su Didáctica, de 4 créditos de dedicación $\left(2^{\circ}\right)$. Como Optativas $(4 \mathrm{cr}$.) tenemos las posibilidades de

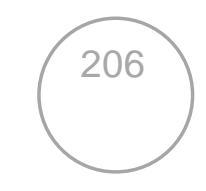


Historia General del Arte $\left(1^{\circ}\right)$ y Técnicas y Procedimientos Artísticos $\left(2^{\circ}\right)$.

- En la modificación que se hace en el plan de estudios en el 96, se mantiene Educación Artística y su Didáctica, de 4,5 créditos $\left(2^{\circ}\right)$ y se añade Educación Plástica con 4,5 créditos $\left(1^{\circ}\right)$. Sin opción de Optativas aunque tienen 21 créditos de Libre Configuración.

- En el 2000, Educación Plástica con 4,5 créditos (1º) se mantiene y al igual que Educación Artística y su Didáctica de 4,5 créditos ( $\left.3^{\circ}\right)$ aunque cambia de curso. No tiene Optativas y se mantienen los 21 créditos de Libre Configuración.
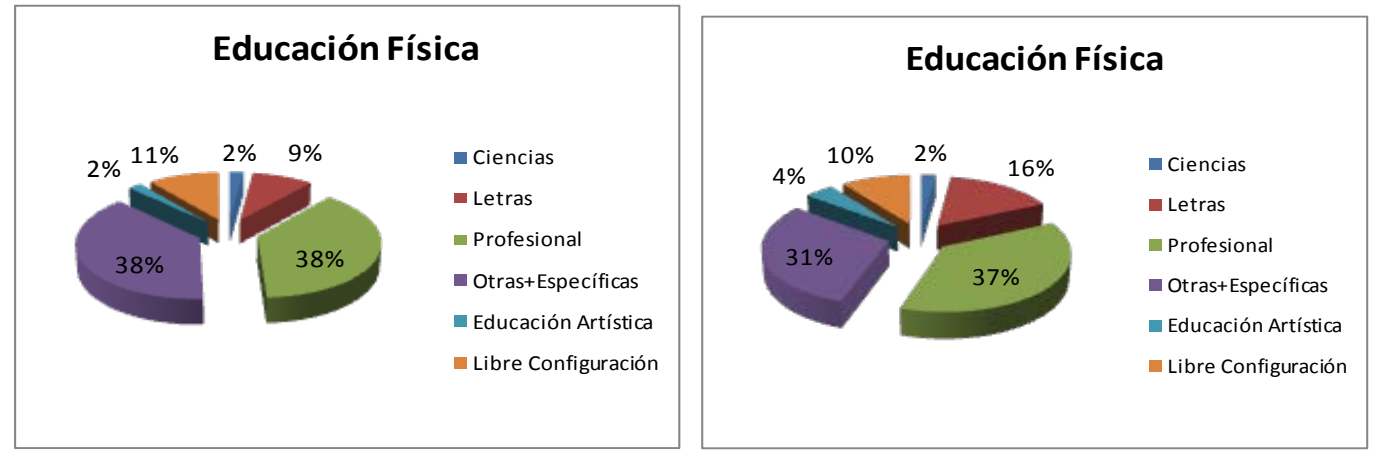

Figura 16. Primaria. Especialista en E. Física 1992 y 1996. Alicante.

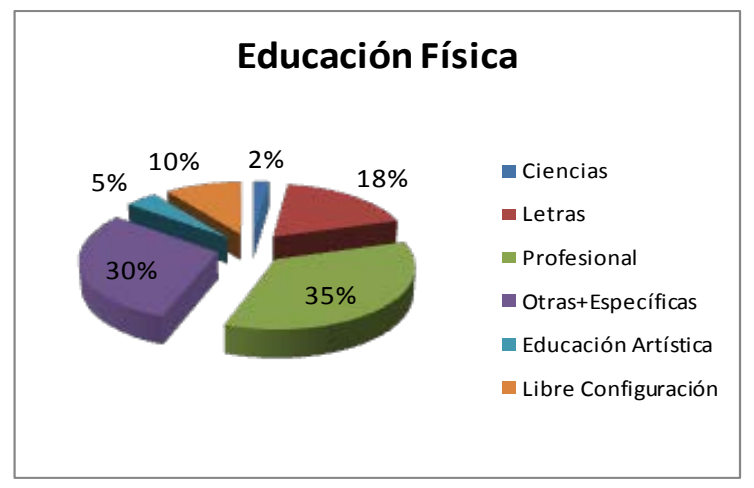

Figura 17. Primaria. Especialista en E. Física. 2000. Alicante.

- Educación Musical - Sin ninguna asignatura de nuestra área. Aunque con la posibilidad de las Optativas (4 cr.) tenemos las posibilidades de Historia General del Arte $\left(1^{\circ}\right)$, Técnicas y Procedimientos Artísticos $\left(2^{\circ}\right)$ y La Creatividad Plástica en la Didáctica de la Lengua Extranjera $\left(3^{\circ}\right)$. 
- En la modificación que se hace en el plan de estudios en el 96, se introduce Didáctica de la Expresión Plástica y Visual, de 6 créditos (10) y se añade Historia del Arte con 6 créditos (3०). Se añade Técnicas y Procedimientos Artísticos de 4,5 créditos ( $\left.3^{\circ}\right)$ como optativa y tienen 21 créditos de Libre Configuración.

- En el 2000, Didáctica de la Expresión Plástica y Visual, de 6 créditos $\left(1^{\circ}\right)$ se mantiene y al igual que Historia del Arte con 6 créditos $\left(3^{\circ}\right)$. Se mantiene también como Optativa Técnicas y Procedimientos Artísticos de 4,5 créditos $\left(3^{\circ}\right)$ y se mantienen los 21 créditos de Libre Configuración.
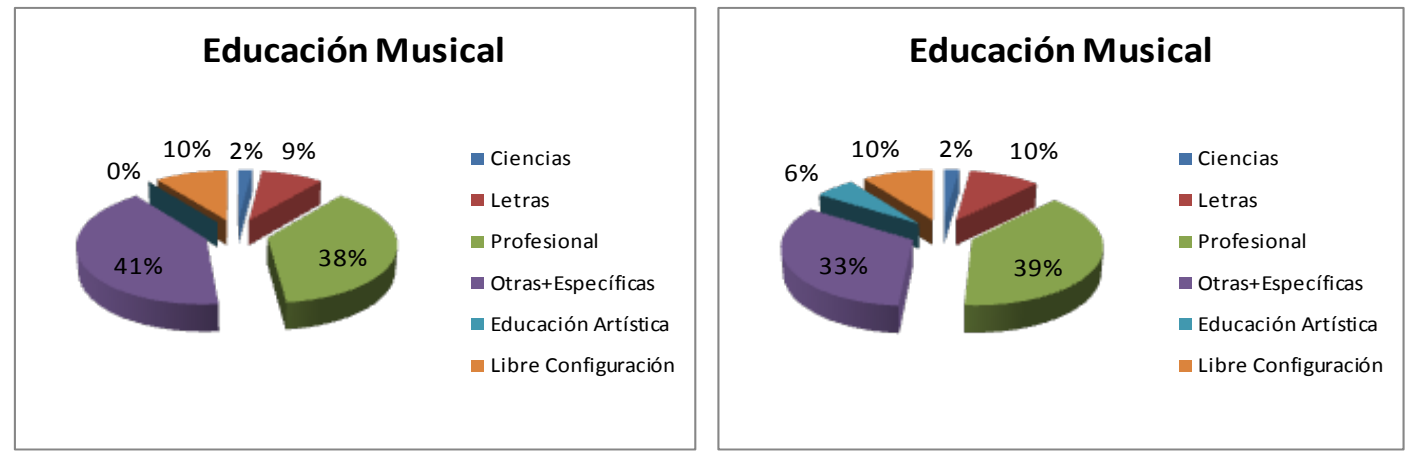

Figura 18. Primaria. Especialista en E. Musical. 1992 y 1996. Alicante.

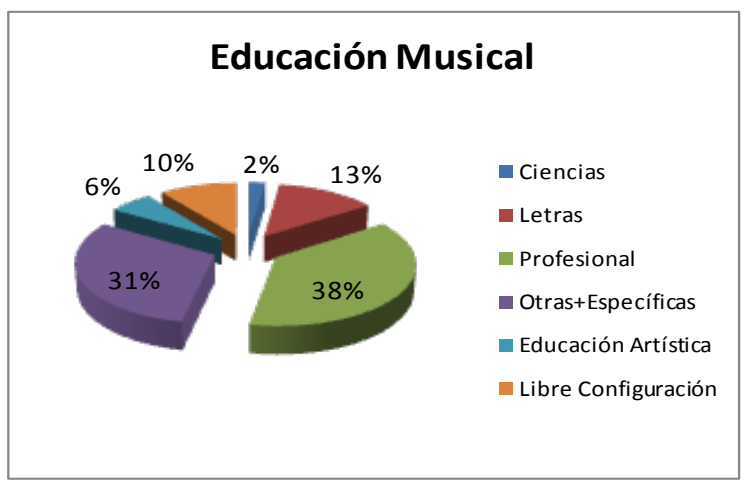

Figura 19. Primaria. Especialista en E. Musical. 2000. Alicante.

En Castellón la carga docente del área de Didáctica de la Expresión Plástica escasa pese a la importancia que le da la LOGSE. Aun así, todas las especialidades tienen asignatura de Plástica que además pueden ampliar con 
la oferta de Optativas y de Libre Disposición. Tenemos cuatro especialidades en las que la EA se distribuye de la siguiente forma:

- Primaria - Atendiendo a las asignaturas Troncales y Obligatorias, tenemos Desarrollo de la Expresión Plástica y su Didáctica, con 4 créditos de dedicación (10) y Las Técnicas Plásticas en la Ed. Primaria, también de 4 créditos $\left(3^{\circ}\right)$.

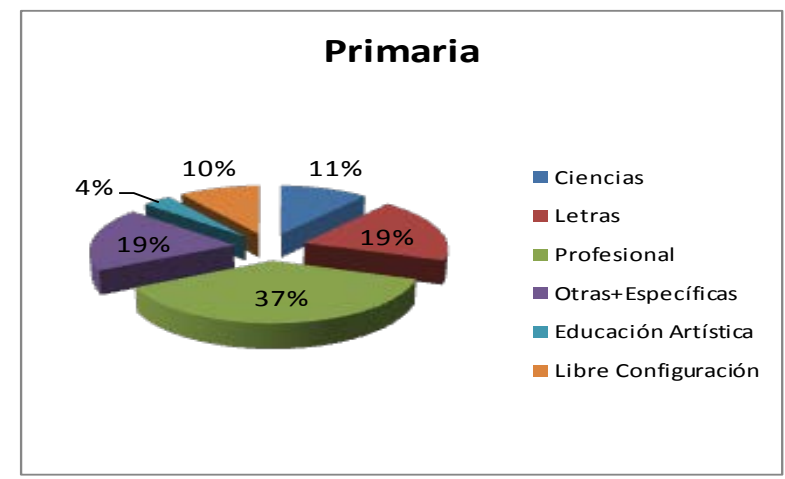

Figura 20. Educación Primaria. 1992. Castellón.

- Infantil - Atendiendo a las asignaturas Troncales u Obligatorias, tenemos Desarrollo de la Expresión Plástica y su Didáctica, con 6 créditos de dedicación $\left(1^{\circ}\right)$ y Las Técnicas Plásticas en la Ed. Infantil, de 4 créditos $\left(3^{\circ}\right)$.

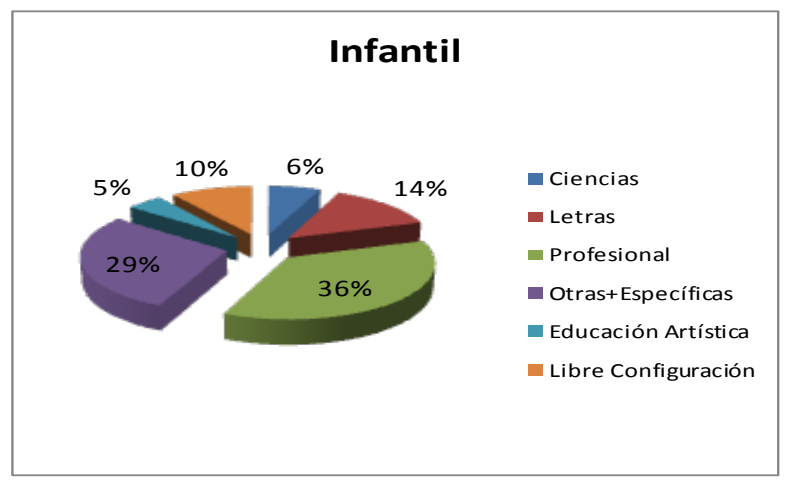

Figura 21. Educación Infantil. 1992. Castellón.

- Educación Física - Atendiendo a las asignaturas Troncales u Obligatorias, tenemos Desarrollo de la Expresión Plástica y su Didáctica, de 4 créditos de dedicación ( $\left.3^{\circ}\right)$. 


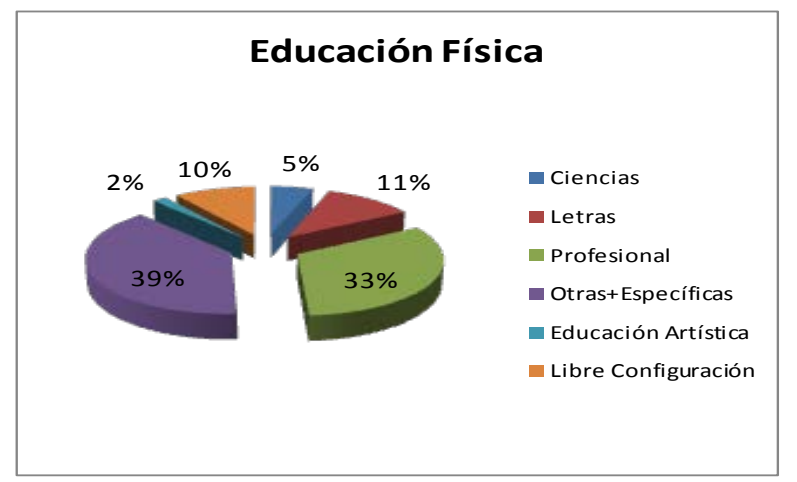

Figura 22. Primaria. Especialista en Educación Física. 1992. Castellón.

- Educación Musical - Atendiendo a las asignaturas Troncales u Obligatorias, tenemos Desarrollo de la Expresión Plástica y su Didáctica, de 4 créditos de dedicación $\left(3^{\circ}\right)$.

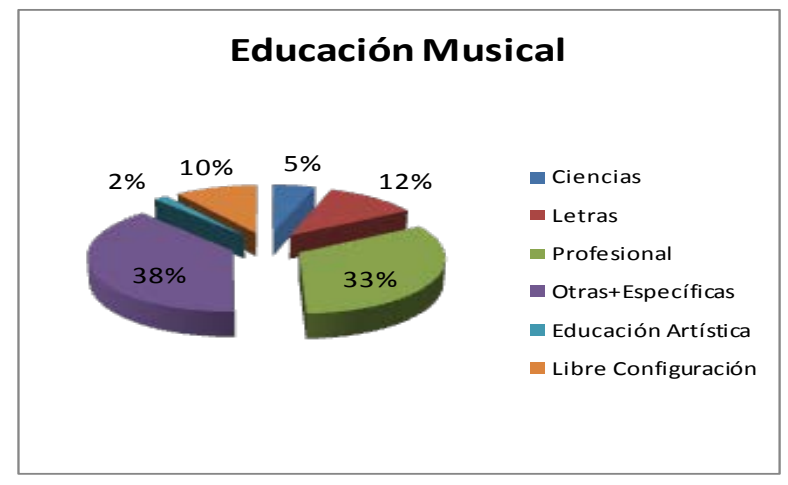

Figura 23. Primaria. Especialista en Educación Musical. 1992. Castellón.

- Optativas - Entre las que puede elegir el alumnado para completar los créditos necesarios encontramos las siguientes asignaturas de nuestra área: Taller de Técnicas Pictóricas y Gráficas, Taller de Recursos Materiales en la Expresión Plástica y Taller de Técnicas Tridimensionales. Todas ellas son de 4 créditos.

En la Universitat de València:

- Primaria - Atendiendo a las asignaturas Troncales u Obligatorias en el Plan de 93 , tenemos Educación Artística y su Didáctica I y II, con 4 créditos de dedicación cada una. 
- En la modificación que se hace en el plan de estudios en el 2000 , se queda Educación Plástica y su Didáctica con 4,5 créditos.
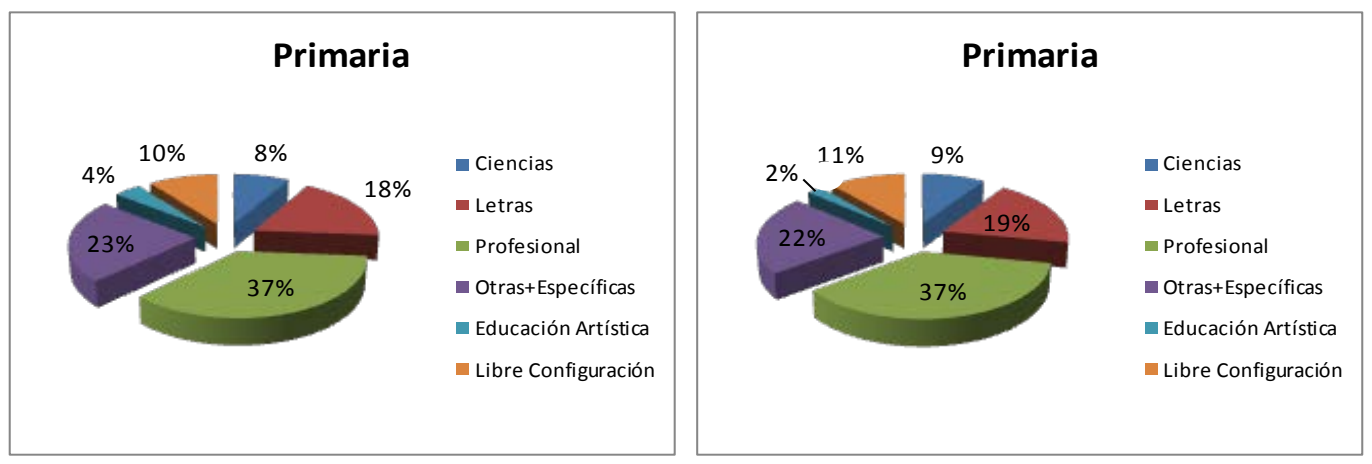

Figura 24. Educación Primaria. 1993 y 2000. Valencia.

- Infantil - Atendiendo a las asignaturas Troncales u Obligatorias en el Plan de 93, tenemos Expresión Plástica en la Educación Infantil, con 6 créditos de dedicación.

- En la modificación que se hace en el plan de estudios en el 2000, tenemos Desarrollo de la Educación Plástica y su Didáctica con 6 créditos.
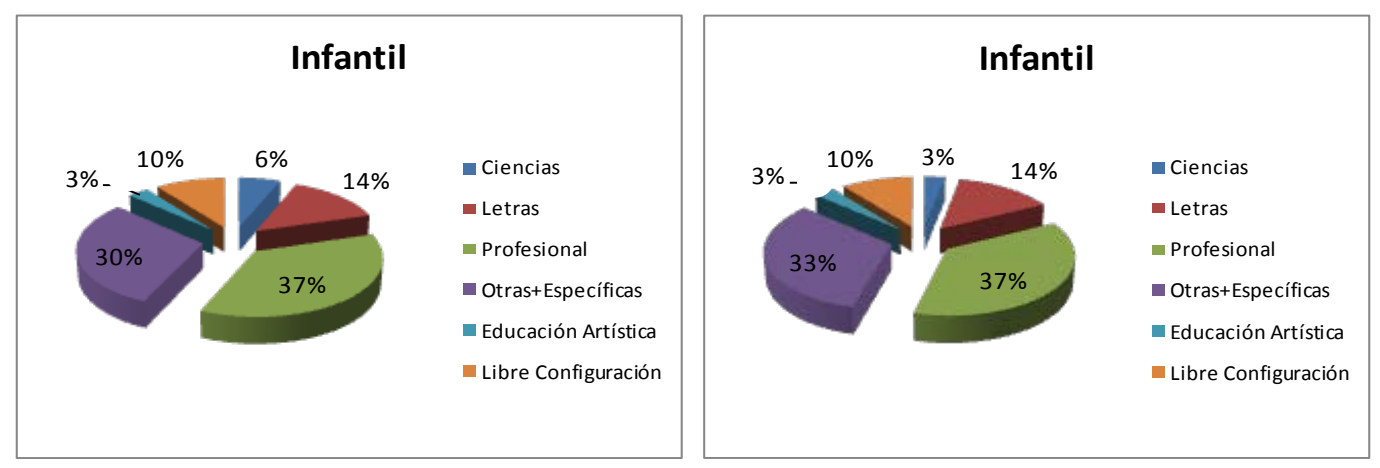

Figura 25. Educación Infantil. 1993 y 2000. Valencia.

- Lenguas extranjeras - Atendiendo a las asignaturas Troncales u Obligatorias en el Plan de 93, encontramos de nuevo la asignatura de Educación Artística y su Didáctica con 2 créditos de dedicación.

- En la modificación que se hace en el plan de estudios en el 2000, encontramos de nuevo Educación Artística y su Didáctica pero con 4,5 créditos. 

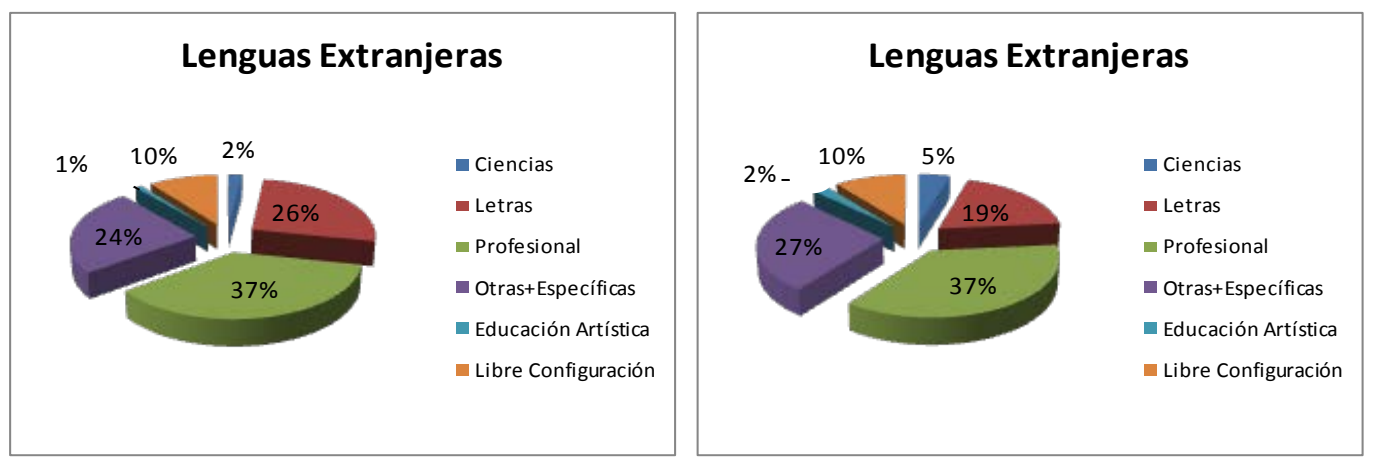

Figura 26. Primaria. Especialista en L. Extranjeras. 1993 y 2000. Valencia.

- Educación Física - Atendiendo a las asignaturas Troncales u Obligatorias en el Plan de 93, tenemos Educación Artística y su Didáctica, de 2 créditos de dedicación.

- En la modificación que se hace en el plan de estudios en el 2000, encontramos de nuevo Educación Artística y su Didáctica pero con 4,5 créditos.
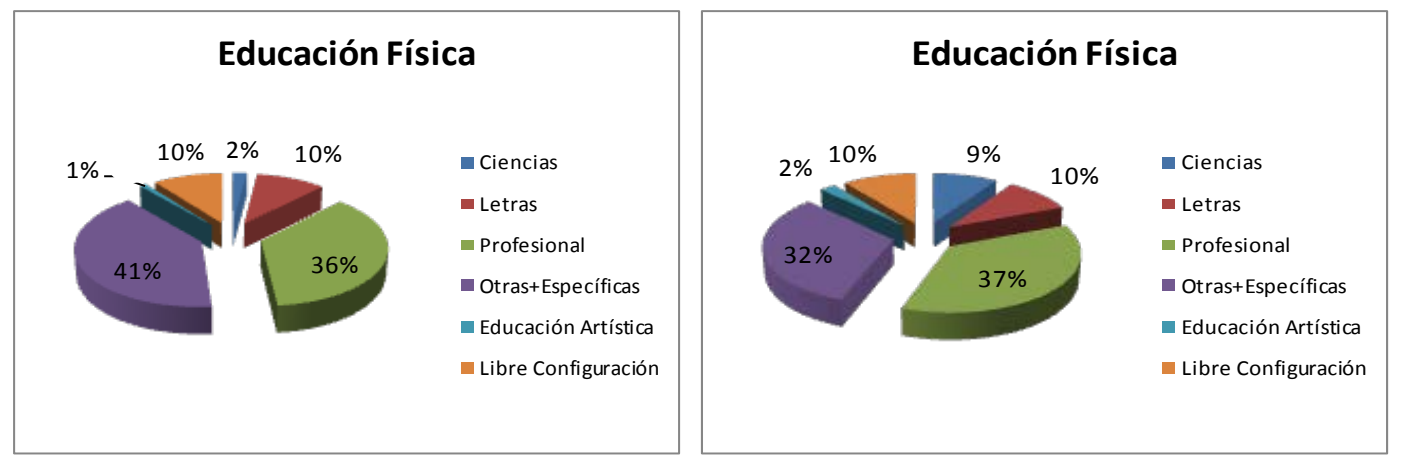

Figura 27. Primaria. Esp. en Ed. Física. 1993 y 2000. Valencia.

- Educación Musical - Sin ninguna asignatura de nuestra área en el Plan de 93.

- En la modificación que se hace en el plan de estudios en el 2000, sigue sin ninguna asignatura de nuestra área. 

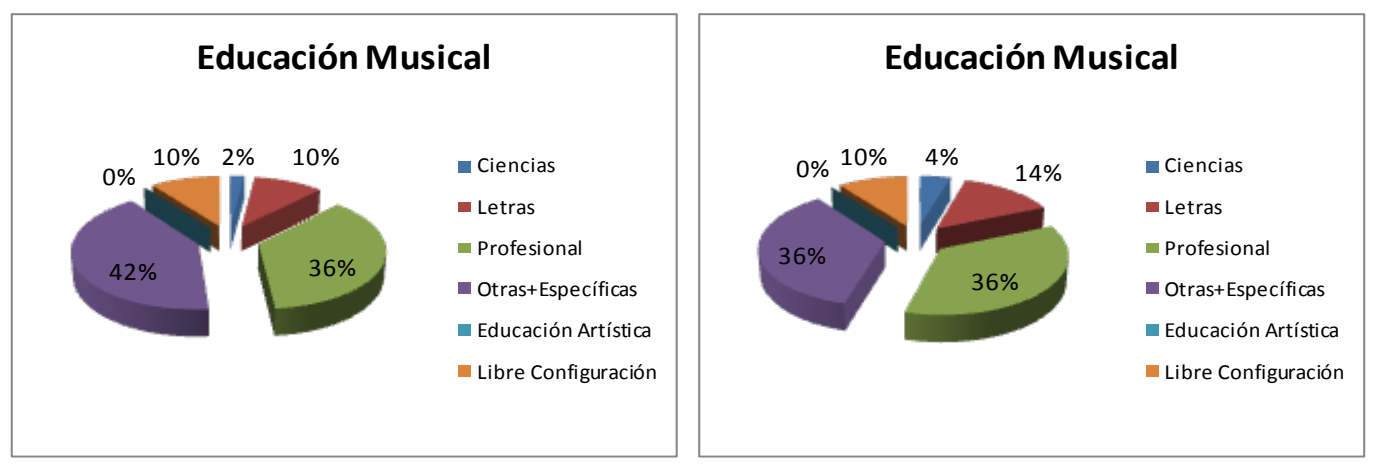

Figura 28. Primaria. Esp. en Ed. Musical. 1993 y 2000. Valencia.

- Educación Especial - Atendiendo a las asignaturas Troncales u Obligatorias en el Plan de 93, tenemos Expresión Plástica en Educación Especial con 2 créditos.

- En la modificación que se hace en el plan de estudios en el 2000, tenemos Educación Artística y su Didáctica con 4,5 créditos.
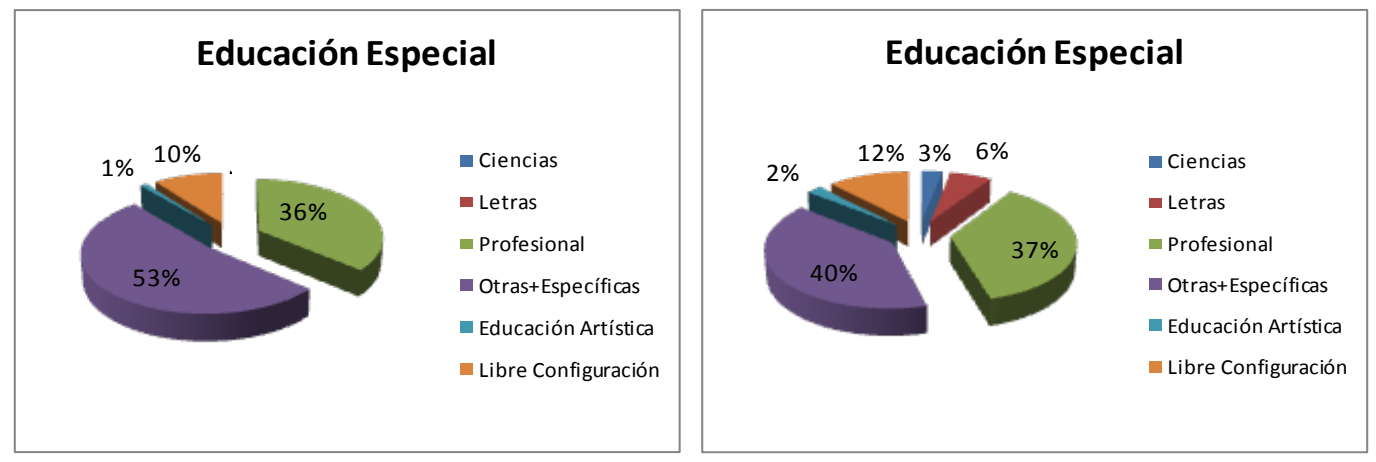

Figura 29. Primaria. Esp. en Ed. Física. 1993 y 2000. Valencia.

- Audición y Lenguaje - Sin ninguna asignatura de nuestra área en el Plan de 93.

- En la modificación que se hace en el plan de estudios en el 2000, tenemos Educación Artística y su Didáctica con 4,5 créditos. 

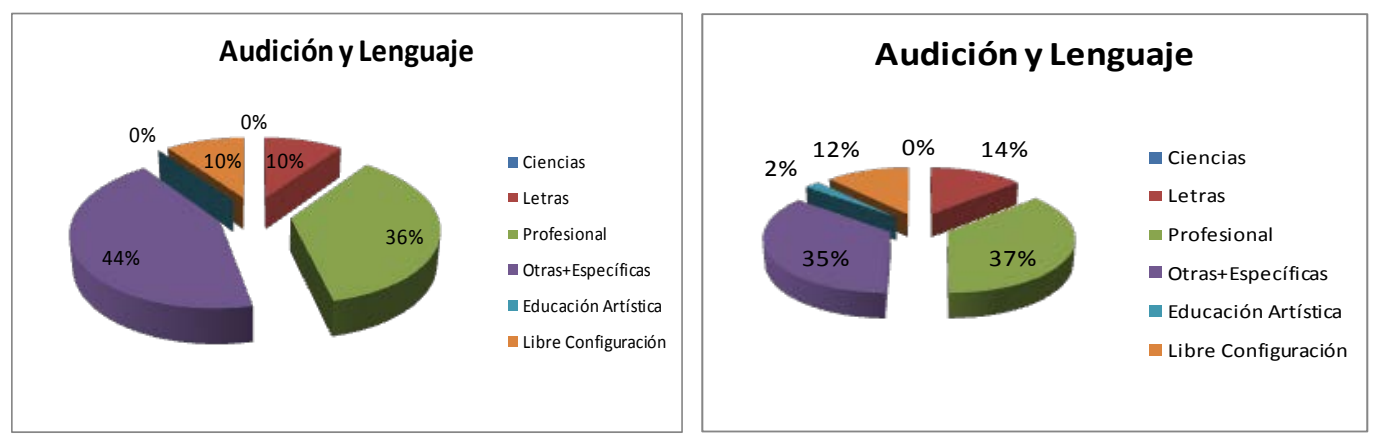

Figura 30. Primaria. Esp. en Audición y Lenguaje. 1993 y 2000. Valencia.

- Optativas 1993 - Entre las que puede elegir el alumnado para completar los créditos necesarios encontramos las siguientes asignaturas de nuestra área: Percepción y Análisis de la Imagen y su Didáctica, Profundización en Expresión Plástica en Educación Infantil, Proyecto y elaboración de materiales didácticos en expresión plástica, Técnicas Audiovisuales y su Didáctica y Técnicas Plásticas en el Marco Escolar. Todas ellas son de 4 créditos. Además tienen los 20 créditos de Libre Disposición.

- Las Optativas del Plan del 2000 son de 6 créditos y pueden escoger del área Percepción y Análisis de la imagen, Técnicas Audiovisuales y Técnicas Plásticas en el Marco Escolar. A ello añadiríamos las llamadas de Libre Elección en las que el alumnado podía escoger entre asignaturas ofertadas para toda la Universidad. Podía así completar su formación adecuándola a sus gustos o perfil personal.

En la Universitat de València nos encontramos con el caso especial de la Escuela Universitaria de Profesorado de EGB de Cheste. En la que difieren ligeramente los planes de estudio. Según especialidades:

- Filología - Se cursan 3 horas de Dibujo en $1^{\circ}$ y 2 horas semanales de Manualizaciones en $2^{\circ}$ y $3^{\circ}$.

- Ciencias y Humanas - Se repite lo anterior pero añadiendo 4 horas de $\mathrm{H}^{\mathrm{a}}$ del Arte en $3^{\circ}$.

- Preescolar - Tenemos 4 horas semanales de Dibujo en $1^{\circ}, 4$ horas en $2^{\circ}$ de Educación Plástica y 4 horas en $3^{\circ}$ de Manualizaciones.

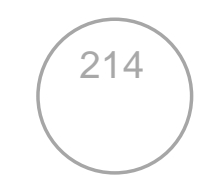


- Optativas - Disponen de la de Tecnología de la imagen I y II, ya sea en $2^{\circ}$ o en $3^{\circ}$

En la Ley Orgánica de Calidad de la Educación (LOCE) se insiste en la necesidad de incidir en la mejora de las competencias instrumentales generales (lectura, escritura, cálculo). Esta ley no llegó a aplicarse. Fue derogada en mayo de 2006 por la Ley Orgánica 2/2006, de3 de mayo, de Educación, dando continuidad al sistema anterior.

Ley Orgánica 2/2006, de 3 de mayo. LOE ${ }^{154}$. El sistema educativo tiene como principio básico propiciar la educación permanente. Quiere formar, tanto en materias de conocimientos concretos, como en conocimientos sociales y culturales. La LOE propone un conocimiento más competitivo y dinámico, pero siempre pensando en los valores sociales de la comunidad. Desarrollar habilidades comunicativas en diferentes lenguajes y formas de expresión. Los métodos de trabajo se basarán en las experiencias, las actividades y el juego y se aplicarán en un ambiente de afecto y confianza, para potenciar su autoestima e integración social. Conocer y valorar su entorno natural, social y cultural, así como las posibilidades de acción y cuidado del mismo. Iniciarse en la utilización, para el aprendizaje, de las tecnologías de la información y la comunicación desarrollando un espíritu crítico ante los mensajes que reciben y elaboran. Utilizar diferentes representaciones y expresiones artísticas e iniciarse en la construcción de propuestas visuales.

En marzo de 2006 se publica un documento ${ }^{155}$, por parte del área de Didáctica de la Expresión Plástica de las Facultades y Escuelas Universitarias $^{156}$, en el que se hacen y solicitan recomendaciones importantes

\footnotetext{
${ }^{154}$ Ley orgánica de Educación 2/2006, de 3 de mayo (BOE 24 de mayo de 2006)

155 Consideraciones, enmiendas y sugerencias sobre los títulos universitarios de Grado en Magisterio, que ocupa 18 páginas.

156 De las Universidades de: Alcalá, Rovira i Virgili (Tarragona), Autónoma de Madrid, Barcelona, Burgos, Complutense de Madrid, Girona, Granada, Huelva, Jaén, Málaga, Pública de Navarra, Santiago de Compostela, La Laguna, País Vasco, Sevilla, Valencia, Valladolid y Vigo.
} 
de mejora. La forma en que se recogen, y que presenta ese mismo año ${ }^{157}$, la Conferencia de Decanos y Directores de Magisterio y Educación, no podemos más que señalar lo cortas que se quedan frente a los argumentos y solicitudes esgrimidos en el citado texto. Queda del siguiente modo:

- Para Educación Primaria, se solicita que la materia Enseñanza y aprendizaje en los ámbitos musical, plástico y visual, se desglose en dos:

o Enseñanza y aprendizaje de la música.

o Enseñanza y aprendizaje de la expresión plástica y visual.

- Para Educación Infantil, se solicita un incremento de créditos a 18 para la materia de Enseñanza y aprendizaje de la expresión musical, plástica y corporal.

Con la nueva reforma educativa actual ha vuelto a aparecer la discusión sobre la necesidad o no de que se establezcan un curriculum estatal que unifique el contenido de lo que se ha de enseñar en las escuelas, establecer los diferentes criterios de evaluación y marcar cuando y como deben de impartirse las enseñanzas. También es fundamental seleccionar los contenidos curriculares que han de impartirse según la importancia que se les conceda. En España, con el sistema de autonomías el proceso se hace un poco más complejo.

El siguiente Plan de Estudios para Magisterio, de 2008, da lugar a los Grados. Con ellos desaparecen las especialidades y se obtiene el título de Graduado en Maestro en Educación Infantil ${ }^{158}$ y el de Graduado en Maestro en Educación Primaria ${ }^{159}$. En principio se pretende que haya una mayor unificación pero como comprobaremos a continuación esto no es una realidad.

\footnotetext{
${ }^{157}$ En las Enmiendas a las fichas técnicas de los títulos de Grado de Magisterio de Educación Primaria y Magisterio de Educación Infantil que se elevan al Ministerio.

158 Orden ECI/3854/2007, de 27 de diciembre.

159 Orden ECI/3857/2007, de 27 de diciembre.
} 
En el caso de la Universidad de Alicante, existen Menciones tanto en la titulación de Infantil como en la de Primaria. Estas son para las dos titulaciones, Lengua Extranjera, Educación Física, Educación Musical y Educación Especial (o Pedagogía Terapéutica). Del total de los 240 Créditos que completan el titulo, únicamente 6 créditos son de EA, con la asignatura denominada Didáctica de la Expresión Plástica, situada en los dos casos en el cuarto curso. No existe ninguna Optativa de EA posible. La proporción que guarda con respecto a las otras materias la veremos en los siguientes esquemas.
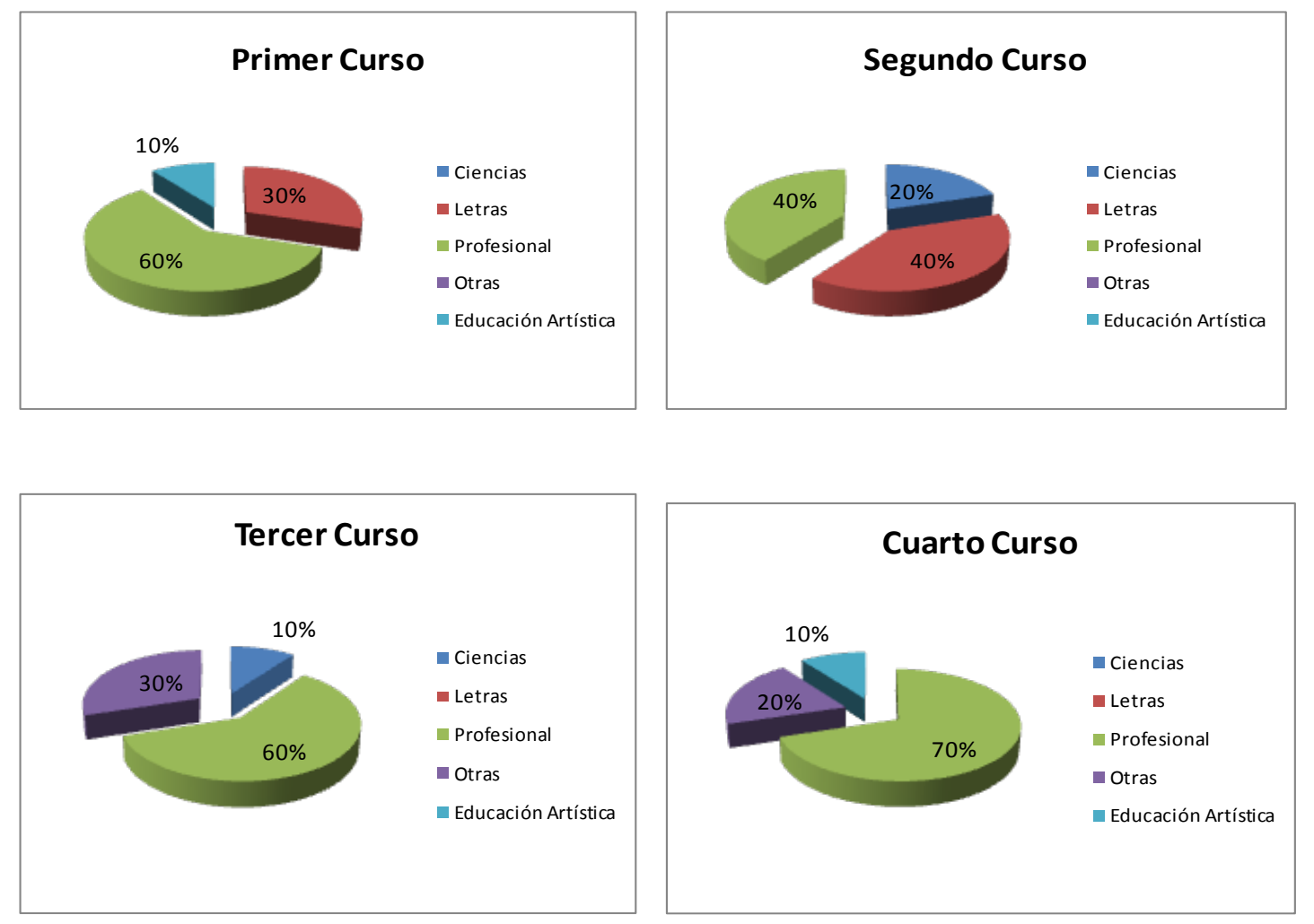

Figura 31. Grado en Educación Infantil. Alicante. 

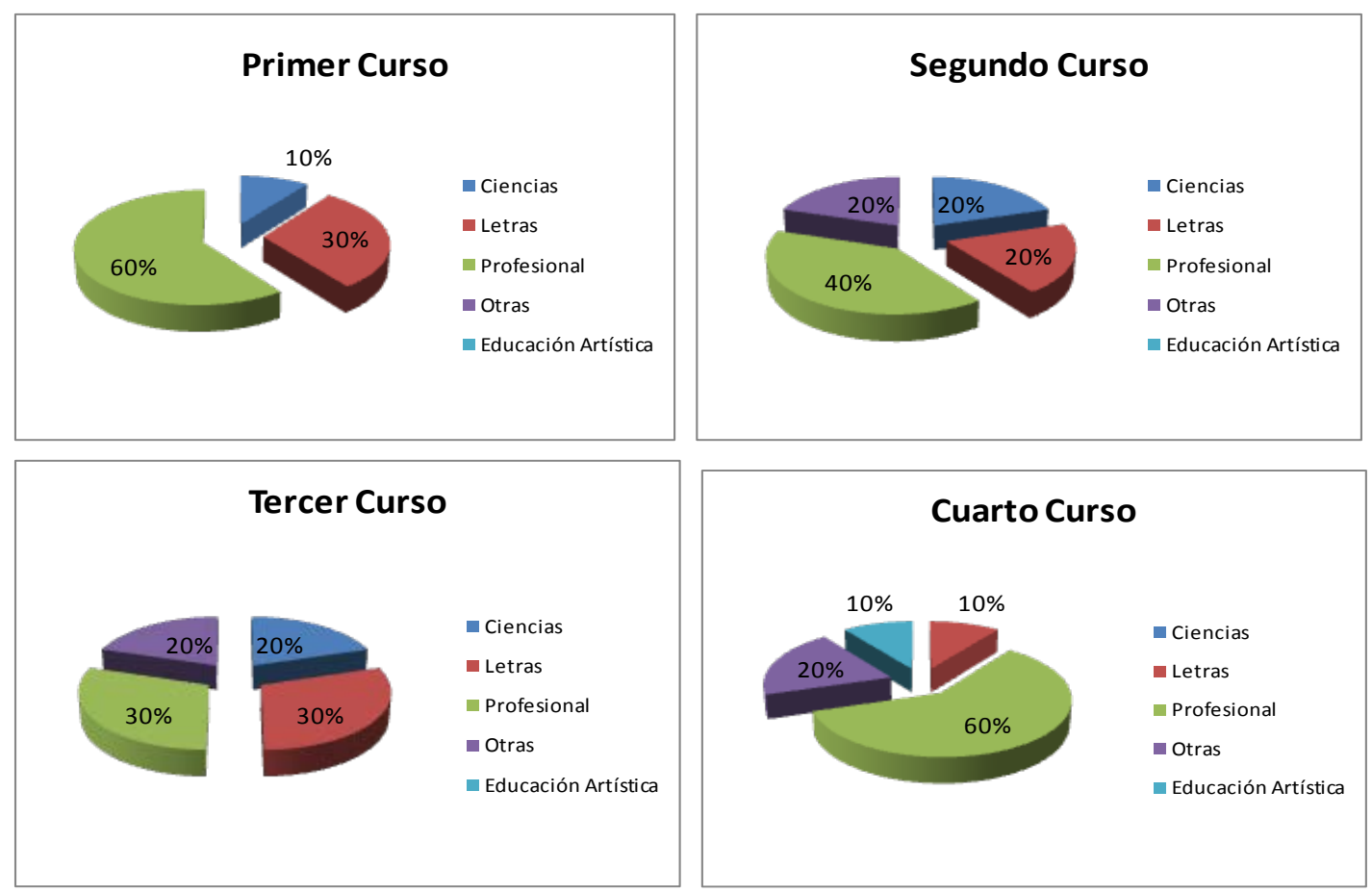

Figura 32. Grado en Educación Primaria. Alicante.

En el caso de la Universidad de Castellón, existen Menciones en la titulación de Primaria, únicamente.

En Infantil, del total de los 240 Créditos que completan el titulo, 8 créditos son de EA, con la asignatura denominada Didáctica de la Percepción y de la Expresión Plástica $\left(3^{\circ}\right)$. Como Optativa se puede elegir Didáctica del Modelado y la Construcción de 6 créditos ( $3^{\circ}$ ó $4^{\circ}$ ). 

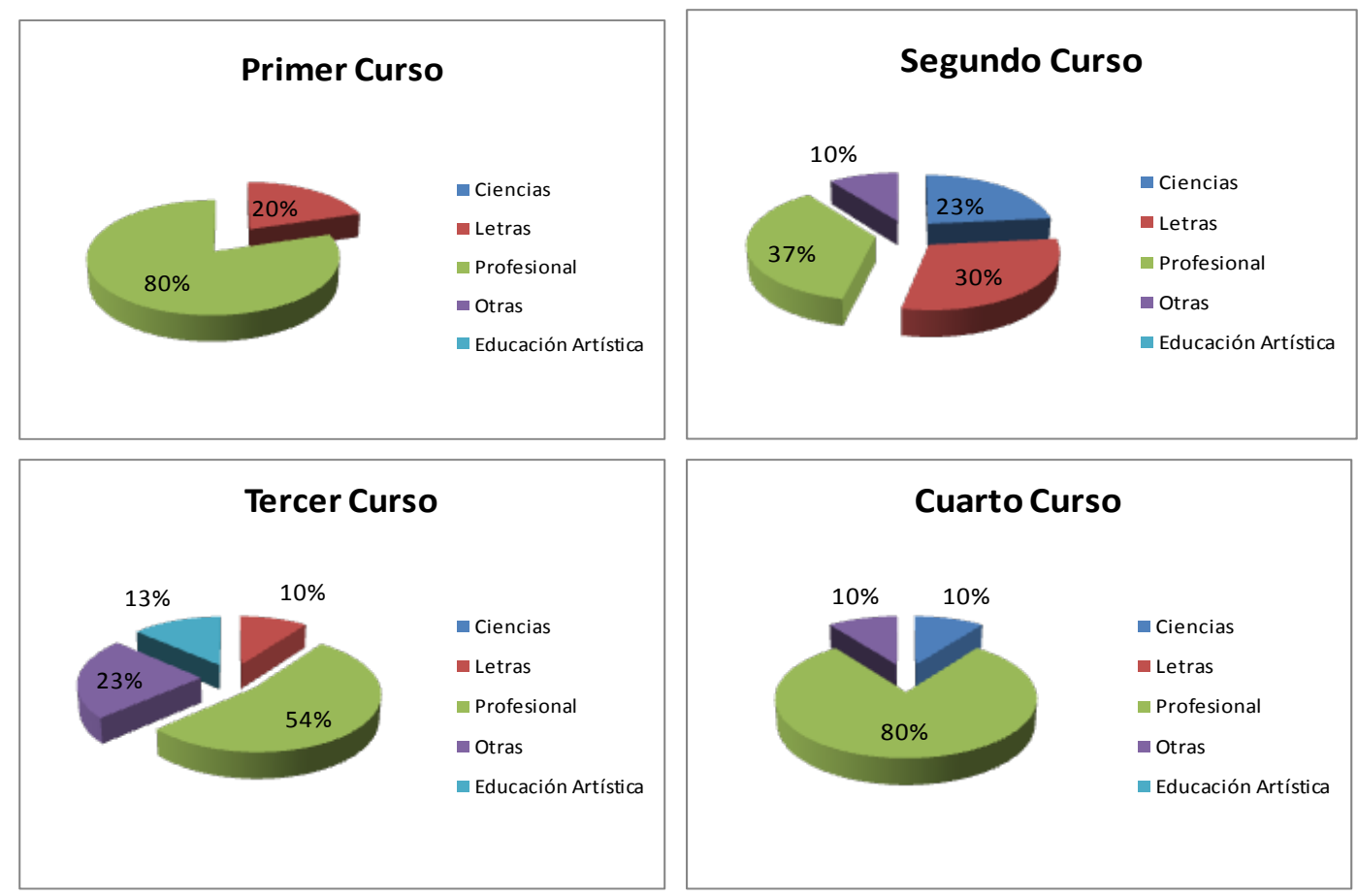

Figura 33. Grado en Educación Infantil. Castellón.

En Primaria, las Menciones son Educación Física, Educación Musical. Del total de los 240 Créditos que completan el titulo, 14 créditos Obligatorios son de EA, con las asignaturas denominadas Didáctica de las Artes Plásticas I de 6 créditos $\left(3^{\circ}\right)$ y Didáctica de las Artes Plásticas II de 8 créditos $\left(4^{\circ}\right)$. Como Optativa se puede elegir Didáctica del Modelado y la Construcción de 6 créditos $\left(3^{\circ}\right.$ ó $\left.4^{\circ}\right)$. 

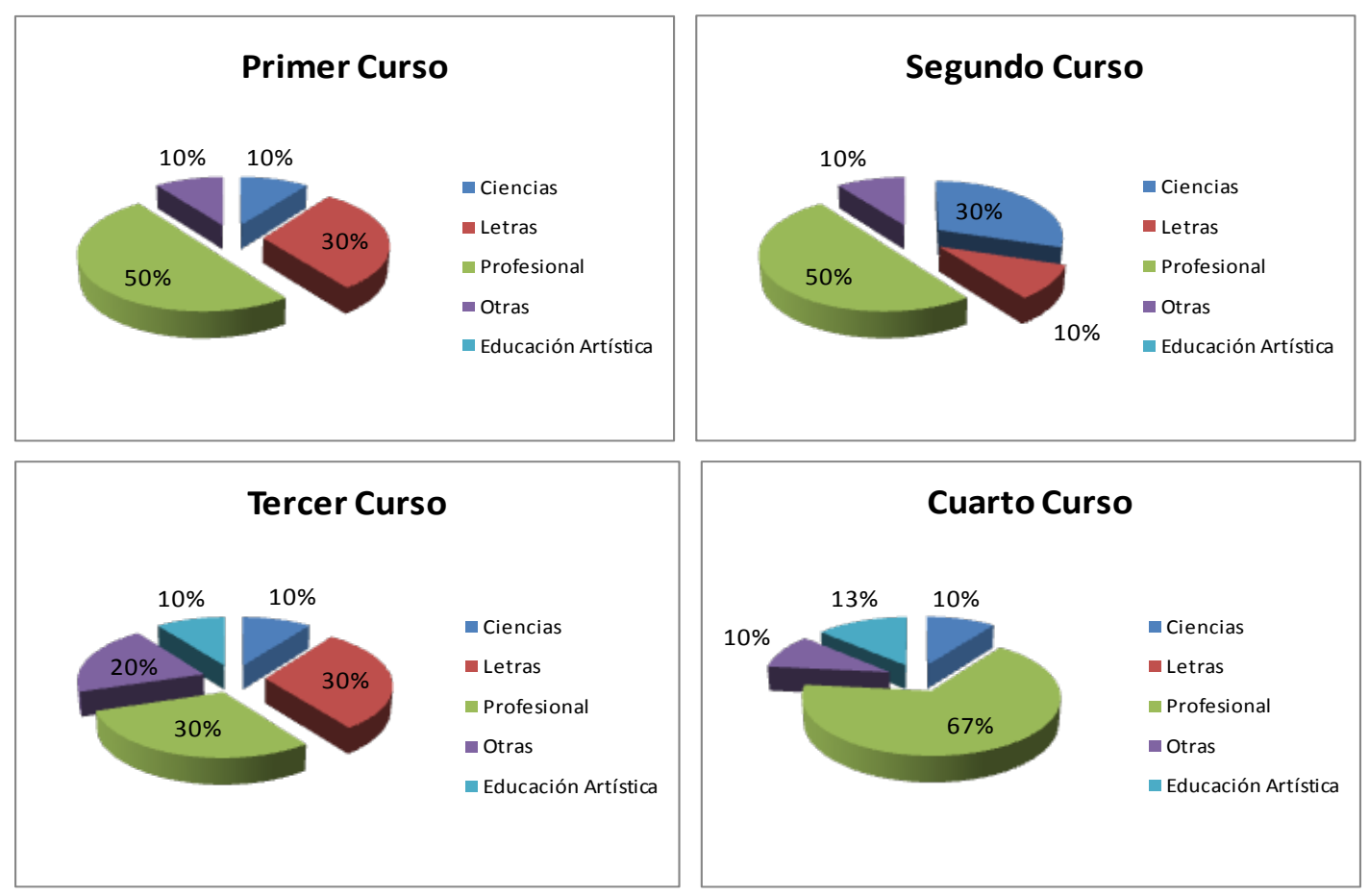

Figura 34. Grado en Educación Primaria. Castellón.

En el caso de la Universidad de Valencia, existen también Menciones en la titulación Primaria.

En Infantil, del total de los 240 Créditos que completan el titulo, 8 créditos son de EA, con la asignatura denominada Didáctica de la Educación Plástica y Visual en la Ed. Infantil (30) y como única Optativa de $3^{\circ}$ se tiene Taller Multidisciplinar de Proyectos de Expresión Musical, Plástica y Corporal de la que Plástica imparte 2 créditos. En $4^{\circ}$ se tiene como Optativa Taller multidisciplinar del área de los Lenguajes: Comunicación y Representación, de la que también se imparte 2 créditos. 

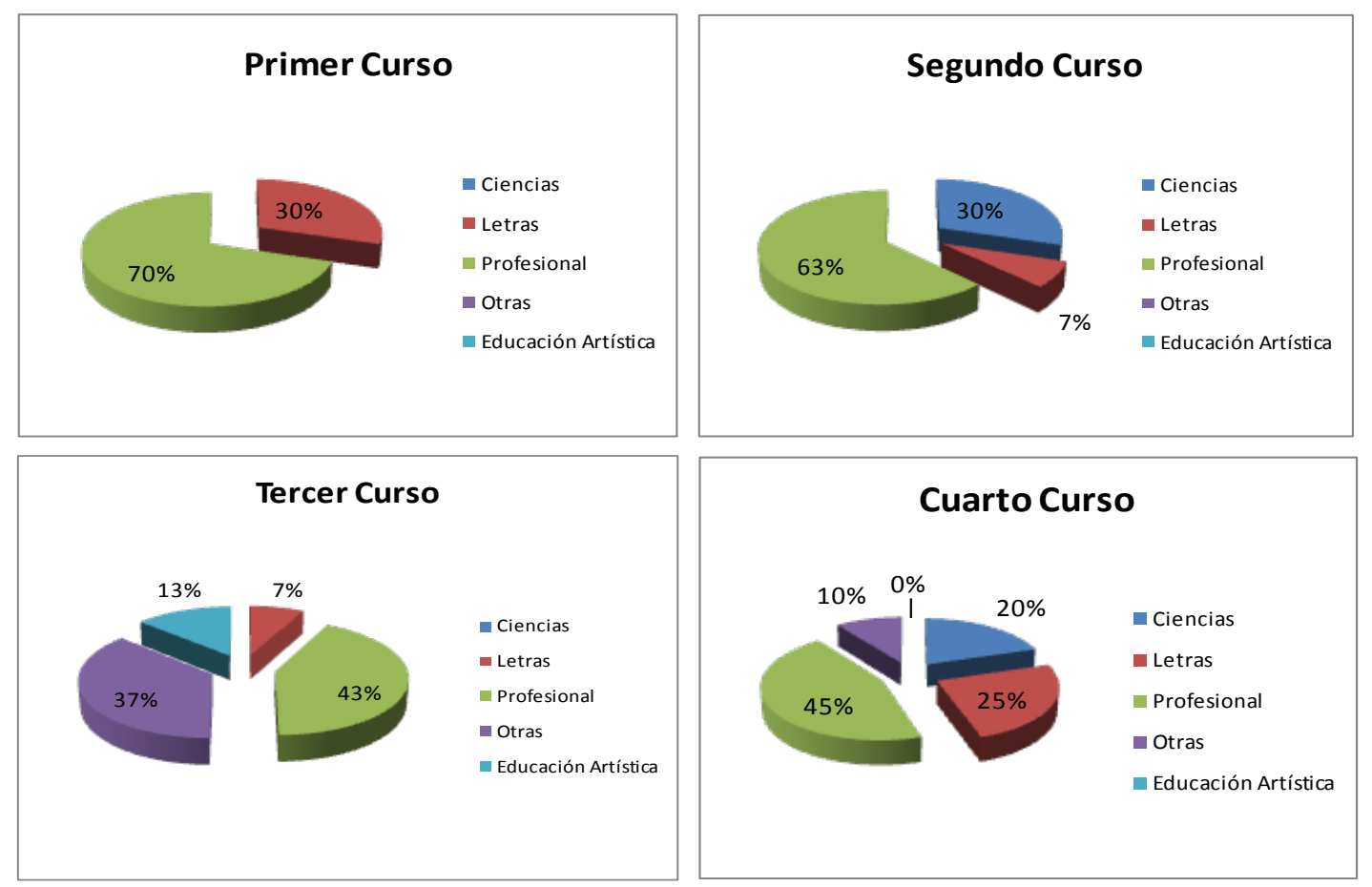

Figura 35. Grado en Educación Infantil. Valencia.

En Primaria, del total de los 240 Créditos que completan el titulo, 6 créditos son de EA, con la asignatura denominada Didáctica de la Educación Plástica y Visual en la Ed. Primaria $\left(2^{\circ}\right)$.

Las Menciones son Artes y Humanidades, Audición y Lenguaje, Ciencias y Matemáticas, Educación Física, Educación Musical, Lengua Extranjera, Pedagogía Terapéutica y Tecnologías de la Información y la Comunicación. De las menciones, tienen asignaturas de EA:

- Artes y Humanidades: Propuestas Didácticas en Educación Artística de 6 créditos y TIC como recurso Didáctico en Artes y Humanidades de 6 créditos.

- Tecnologías de la Información y la Comunicación: Programación y Maquina en Contextos Educativos y Educación y TIC, de 6 créditos cada una aunque no siempre las imparte profesorado de EA. 

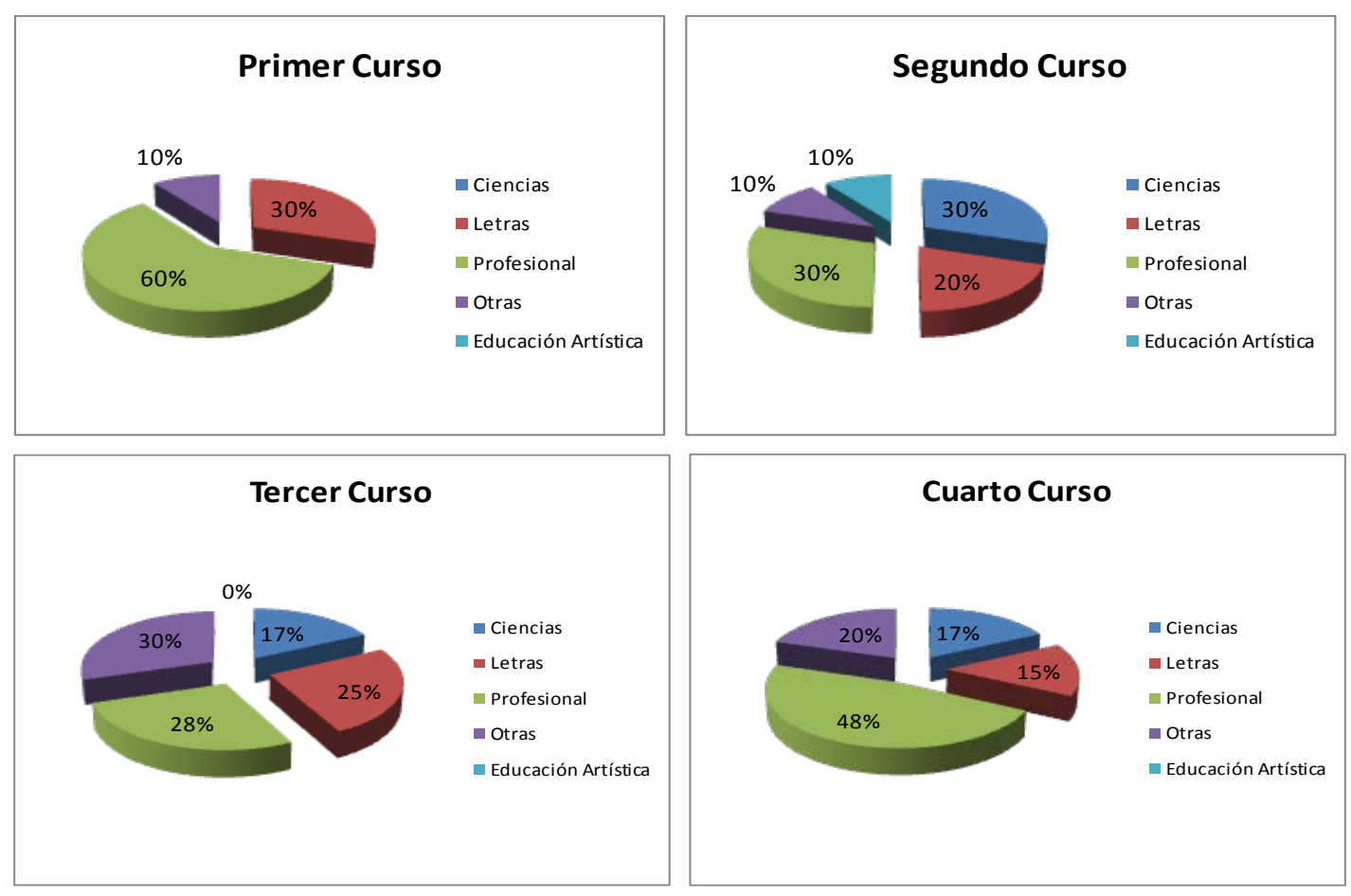

Figura 36. Grado en Educación Primaria. Valencia.

En resumen veremos el proceso seguido en EA según las tres universidades, desde el Plan del 92 para ver que estudios mínimos realizarían los estudiantes que únicamente cursaran las asignaturas obligatorias y máximos que se pueden cursar si se eligen el máximo de optativas permitidas en los estudios. 

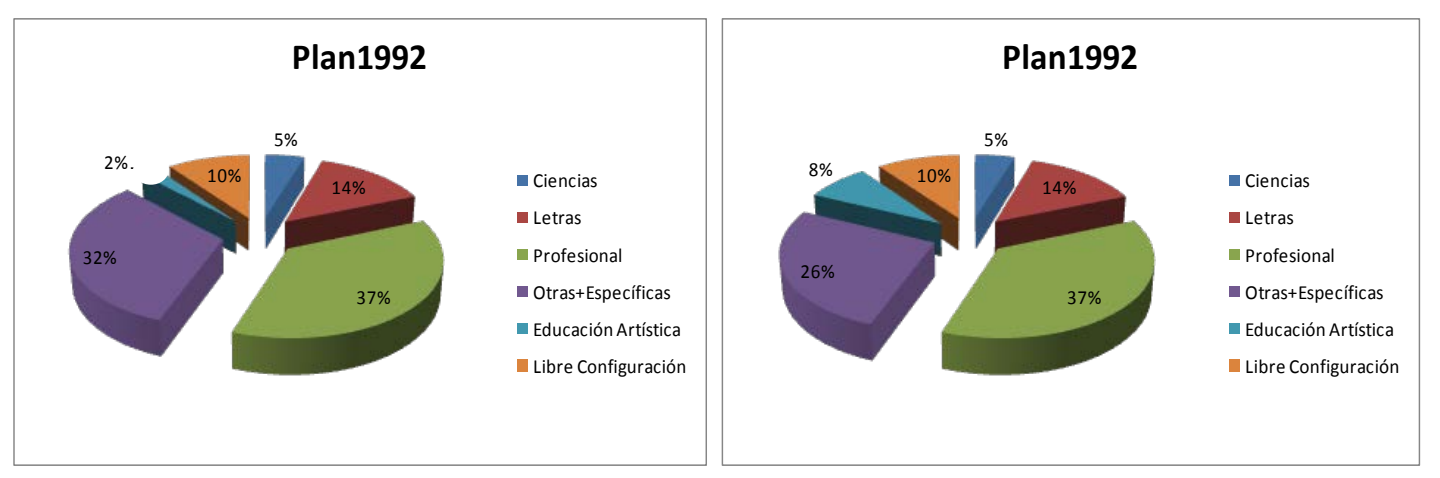

Figura 37. Mínimo y Máximo asignaturas EA. 1992. Alicante.
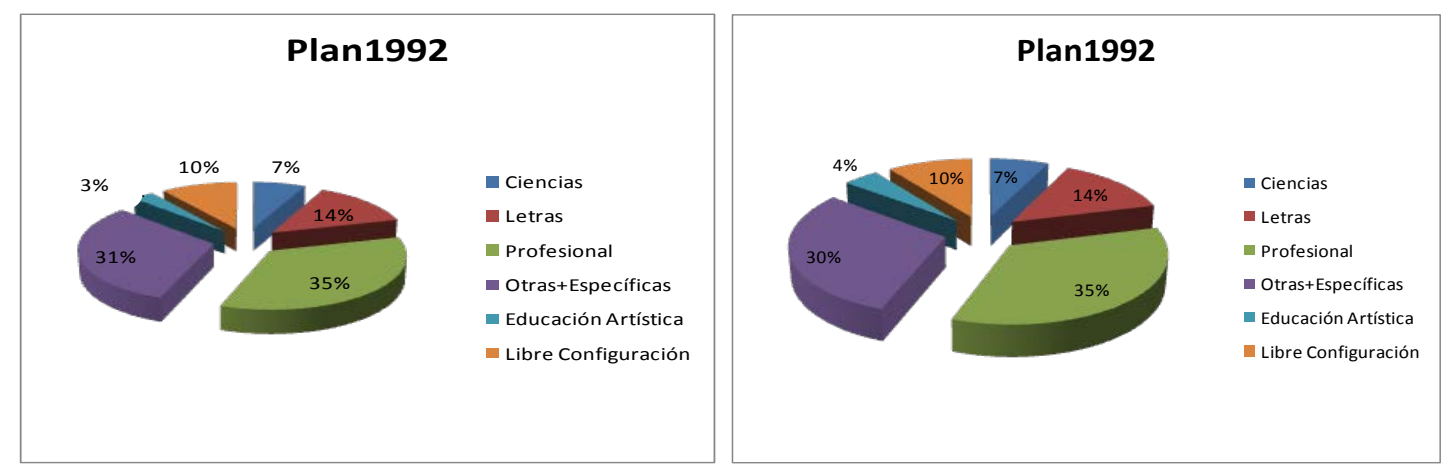

Figura 38. Mínimo y Máximo asignaturas EA.1992. Castellón.
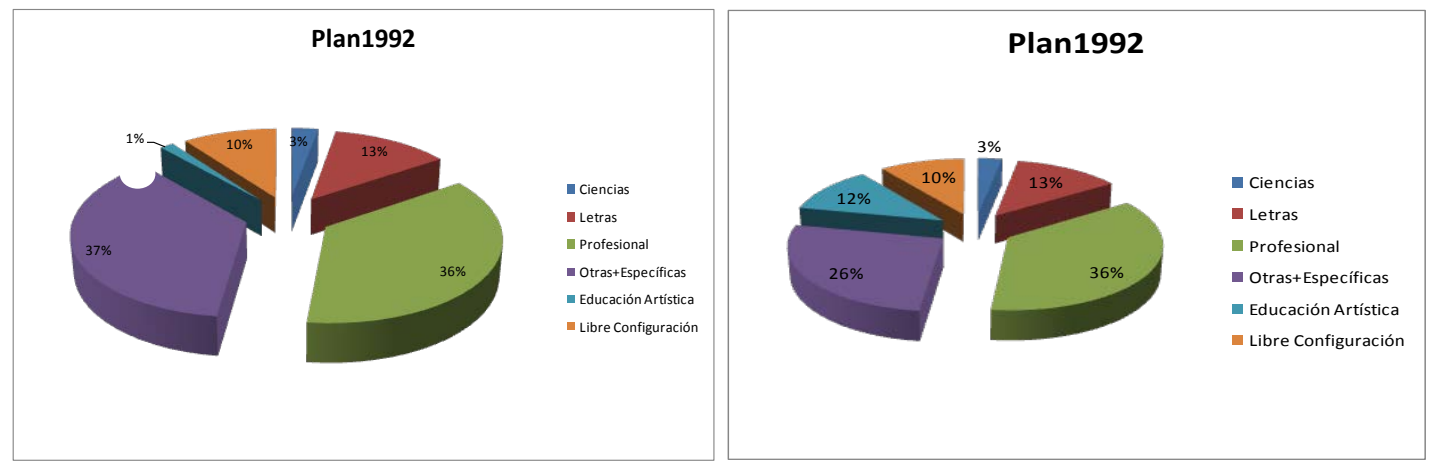

Figura 39. Mínimo y Máximo asignaturas EA. 1992. Valencia.
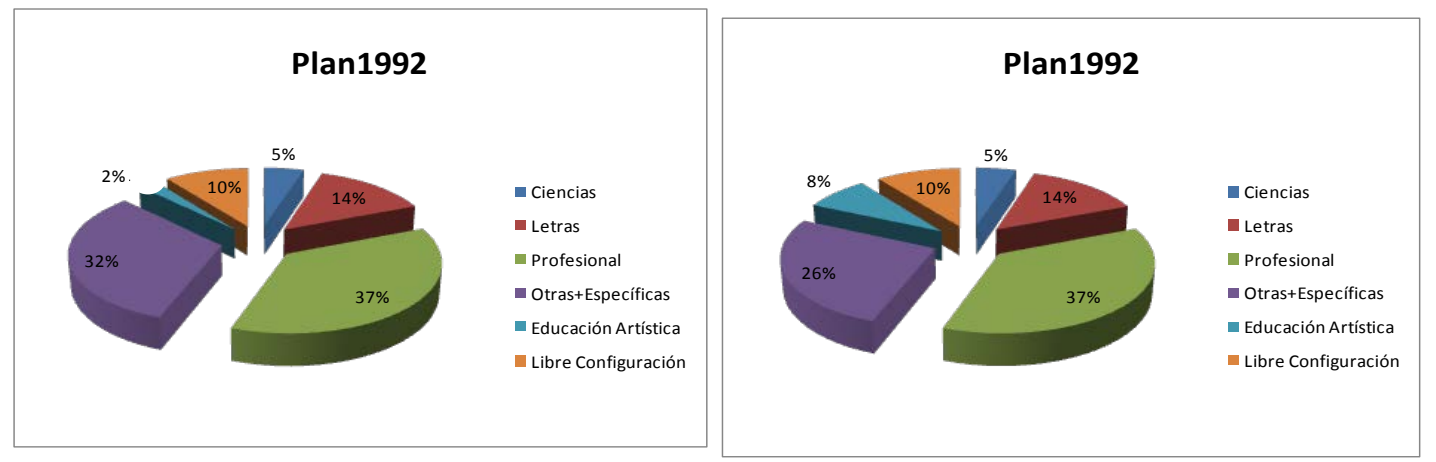

Figura 40. Mínimo y Máximo asignaturas EA. 1992. C. Valenciana.

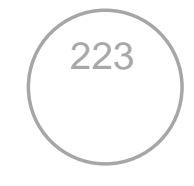


Vemos como en el Plan del 92, en Alicante los estudios de EA oscilan entre un 2 y un $8 \%$ del total de horas impartidas. Que en el caso de Castellón, oscilan entre un 3 y un $4 \%$ del total de horas impartidas y en Valencia oscila entre un 1 y un $12 \%$ del total de horas impartidas. El nivel medio de la Comunidad oscilan entre un 2 y un $8 \%$ del total de horas.
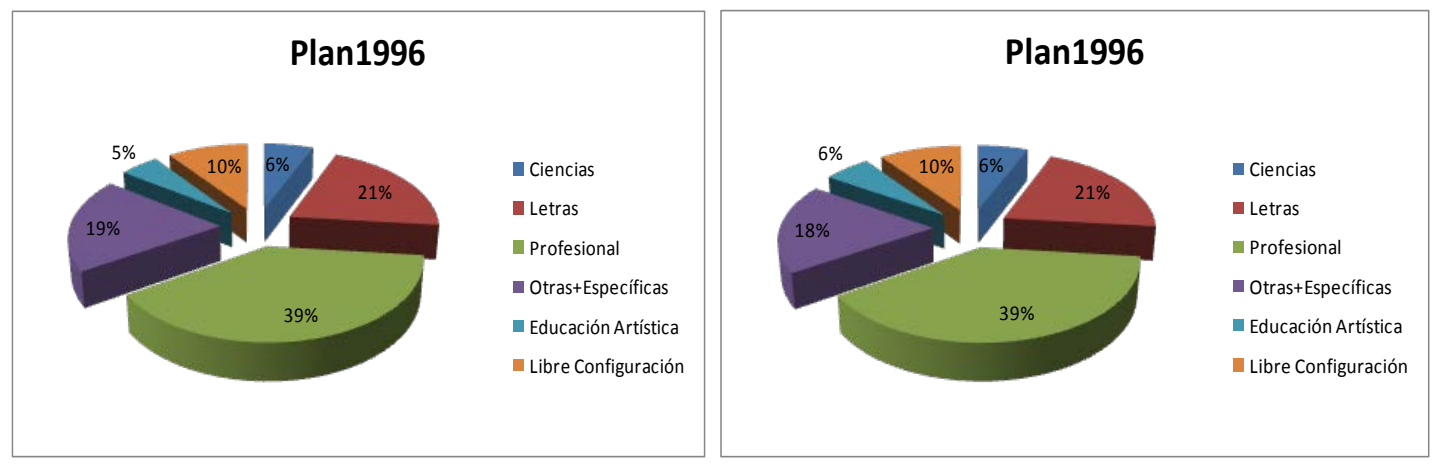

Figura 41. Mínimo y Máximo asignaturas EA. 1996. Alicante.

En el año 96 únicamente se revisan los de Alicante y pasan a tener entre un 5 como mínimo a un 6\%. Con ello suben los créditos obligatorios pero la totalidad apenas mejora.
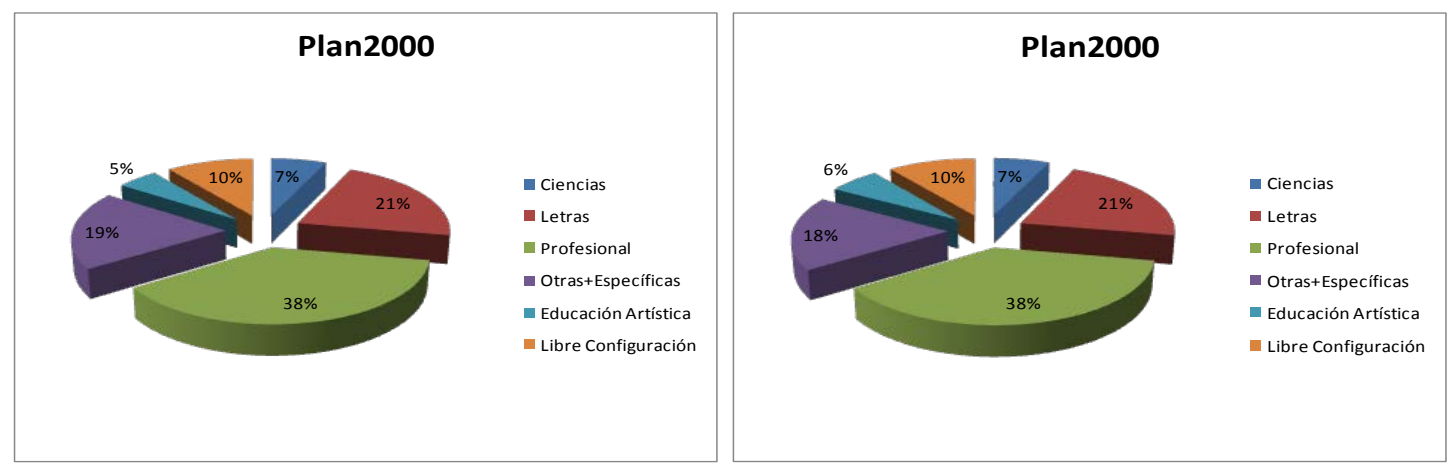

Figura 42. Mínimo y Máximo asignaturas EA. 2000. Alicante. 

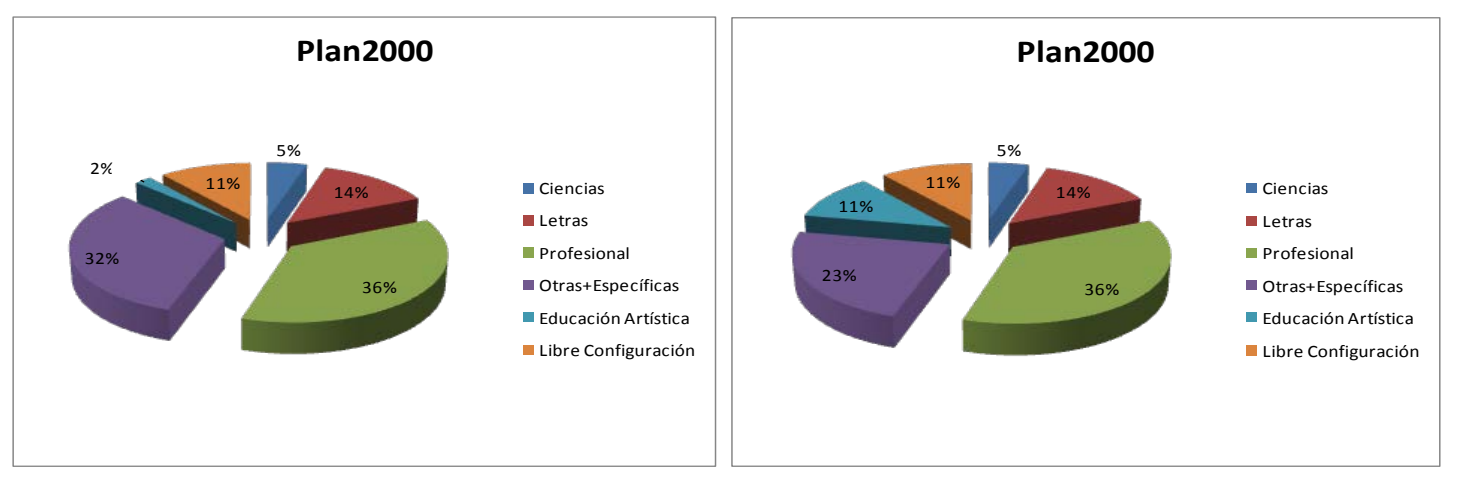

Figura 43. Mínimo y Máximo asignaturas EA. 2000. Valencia.

En el 2000, quienes revisan sus planes son Alicante, de nuevo, y Valencia. En Alicante no varía el porcentaje con respecto al total pero en Valencia se modifica un poco a la baja pues el mínimo se mantiene en un 2\% y el máximo pasa del 12 al 11\%.
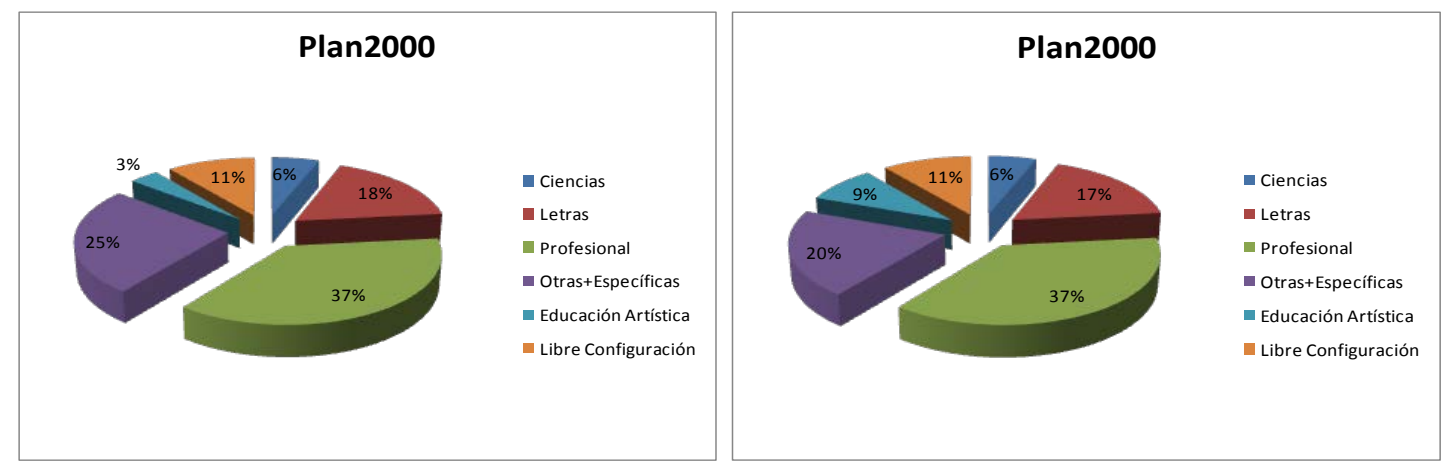

Figura 44. Mínimo y Máximo asignaturas EA. 2000. C. Valenciana.

El nivel medio de la Comunidad mejora un poco con este plan del 2000, pasando de un 2 y un $8 \%$ del total de horas a un 3 de mínimo y $9 \%$ de máximo de horas. 
La situación actual, con los Grados, es la siguiente:
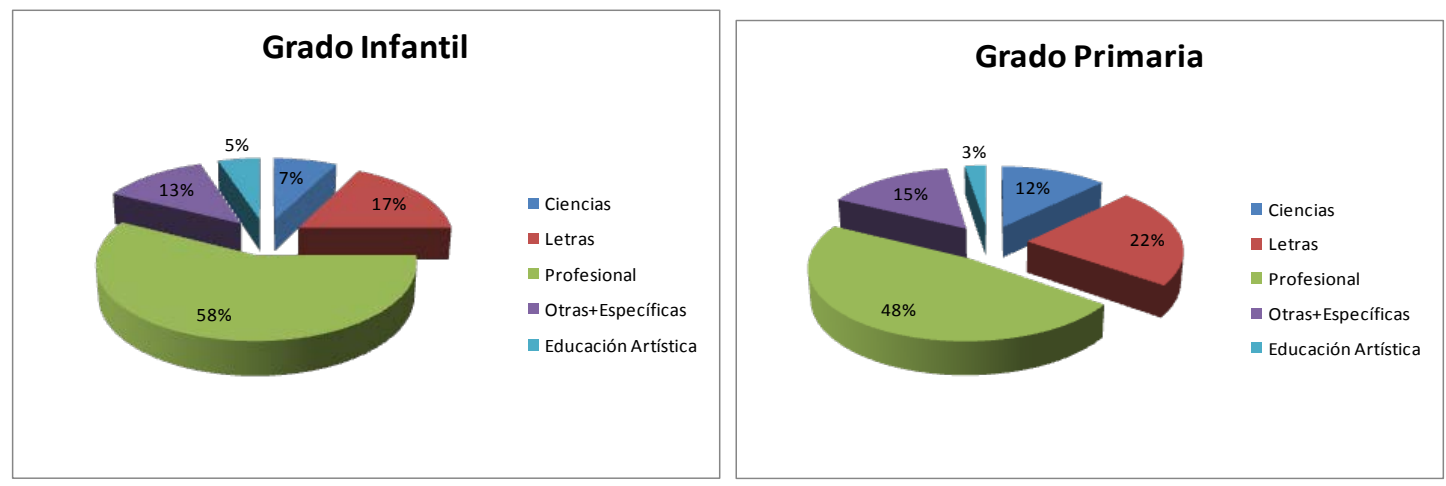

Figura 45. Mínimo y Máximo EA. Grado Infantil y Primaria. Alicante.

En el caso de Alicante, no hay mínimos y máximos pues independientemente de lo que cursen, siempre tienen la misma carga horaria. Con respecto al total de créditos impartidos tenemos un porcentaje del 5\% en los estudios de Infantil y un $3 \%$ en los estudios de Primaria.
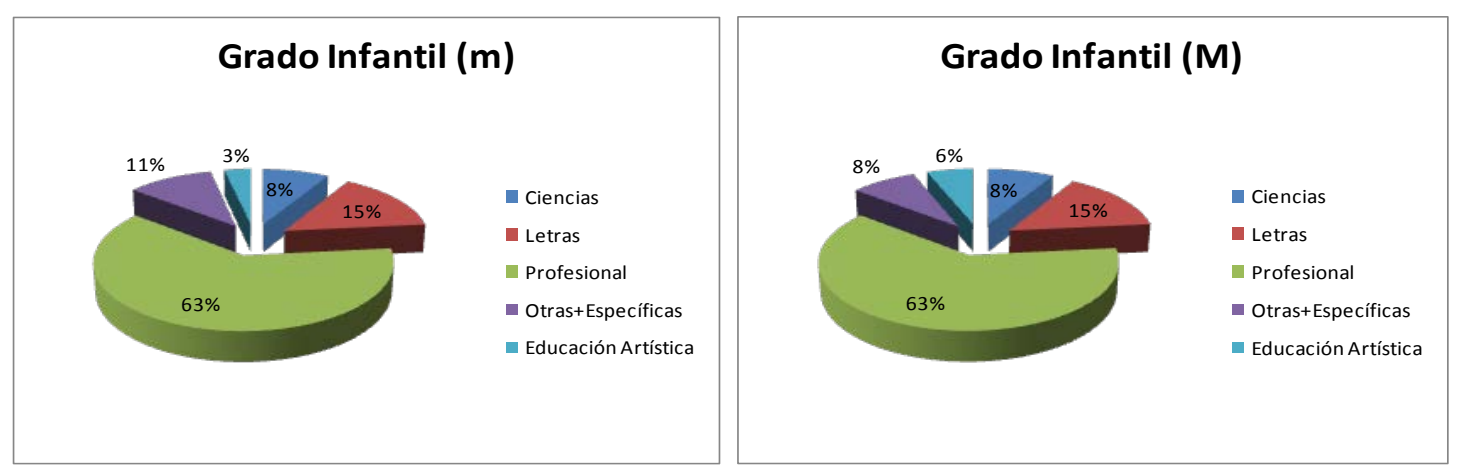

Figura 46. Mínimo y Máximo asignaturas EA. Grado Infantil. Castellón.
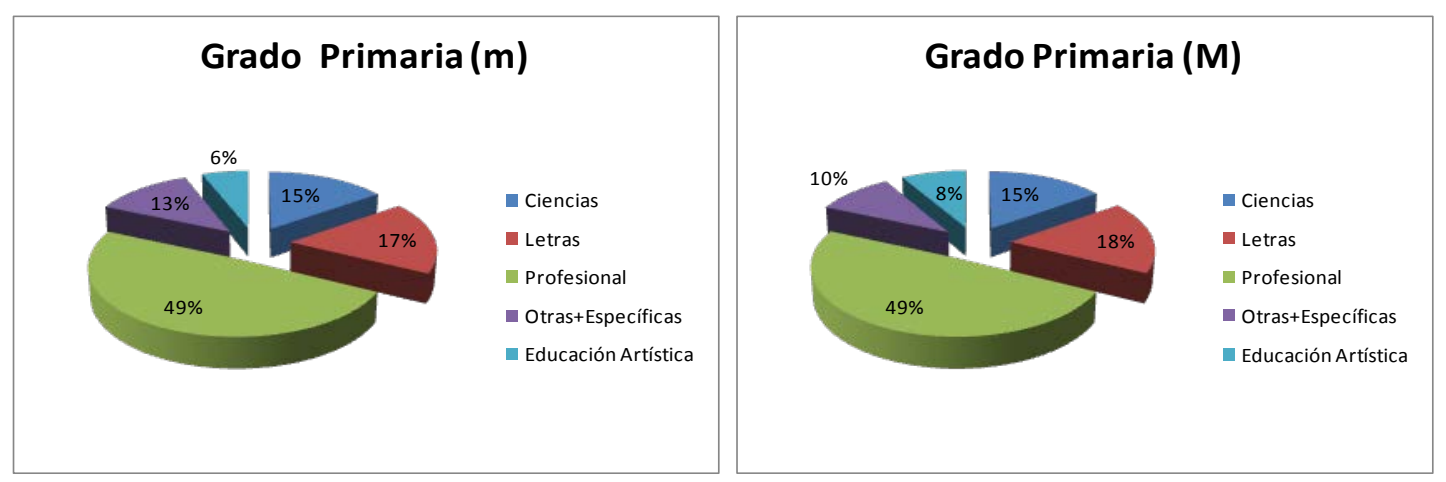

Figura 47. Mínimo y Máximo asignaturas EA. Grado Primaria. Castellón.

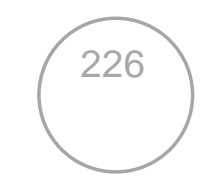


En el caso de Castellón tenemos, con respecto al total de créditos impartidos:

- Infantil, oscila entre un 3 y un 6\%.

- Primaria, oscila entre un 6 y un $8 \%$.
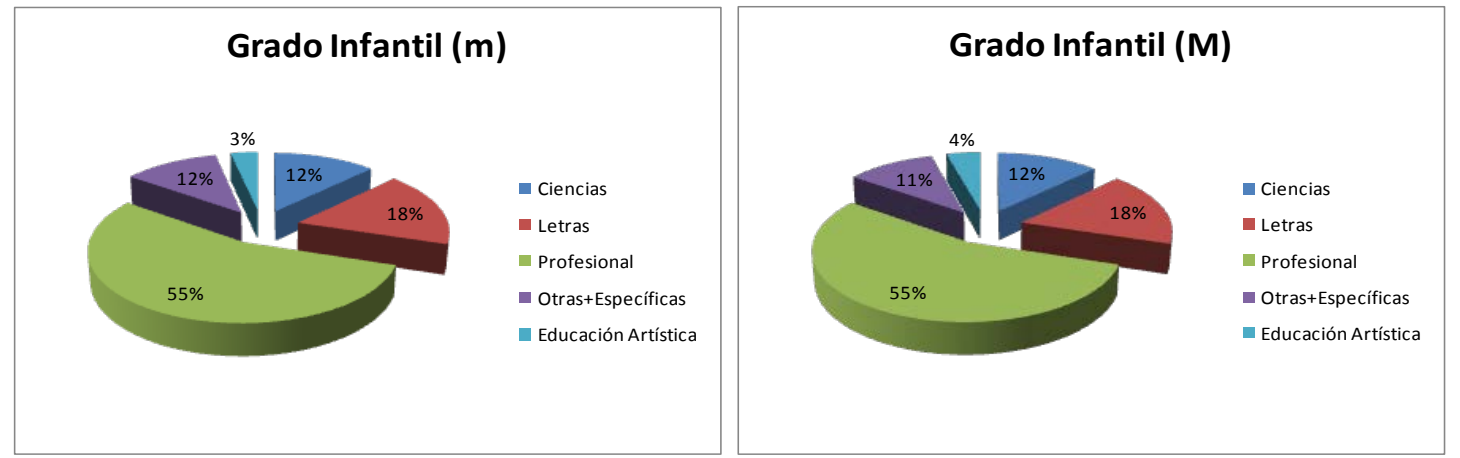

Figura 48. Mínimo y Máximo asignaturas EA. Grado Infantil. Valencia.
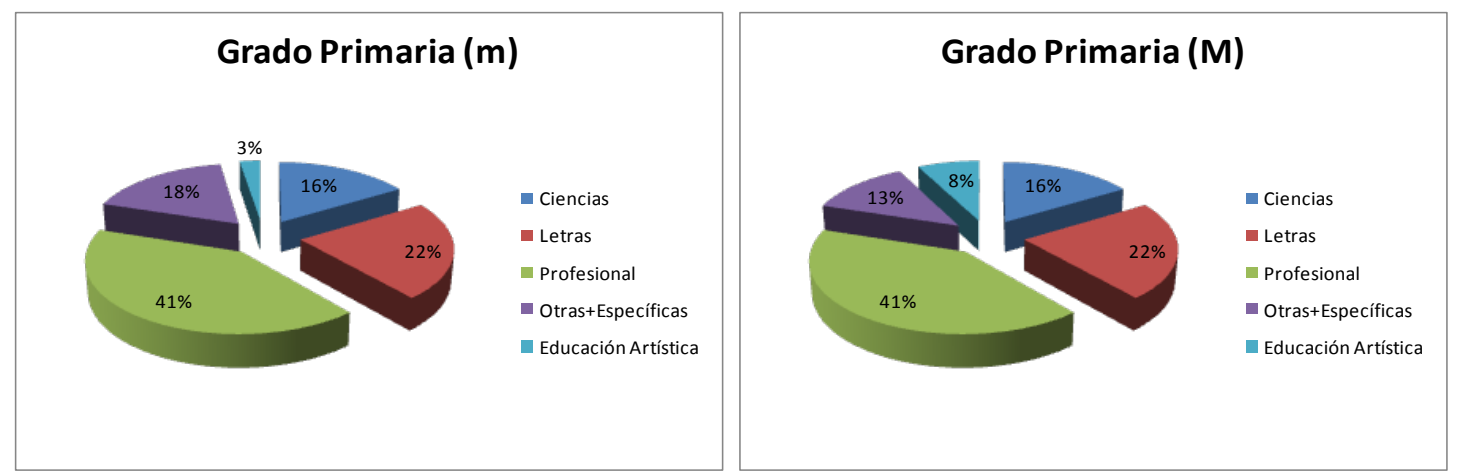

Figura 49. Mínimo y Máximo asignaturas EA. Grado Primaria. Valencia.

En el caso de Valencia tenemos, con respecto al total de créditos impartidos:

- Infantil oscila entre un 3 y un $4 \%$.

- Primaria oscila entre un 3 y un $8 \%$.

En resumen, según las distintas universidades, con los Grados actuales, observamos que pese a que existe una carga lectiva de horas de EA bastante elevada en alguna de ellas, cuando lo comparamos con el total los porcentajes no son tan diferentes. Hemos comprobado que en diferentes Universidades no coinciden, ni en la nomenclatura de las asignaturas ni en el número de asignaturas especializadas en EA que existen. 
Tabla 33. Porcentajes mínimos y máximos de EA / Universidades.

\begin{tabular}{|c|c|c|c|c|c|c|}
\hline & \multicolumn{2}{|c|}{$\begin{array}{c}\text { UNIVERSIDAD } \\
\text { ALICANTE }\end{array}$} & \multicolumn{2}{c|}{$\begin{array}{c}\text { UNIVERSIDAD } \\
\text { CASTELLON }\end{array}$} & \multicolumn{2}{c|}{$\begin{array}{c}\text { UNIVERSIDAD } \\
\text { VALENCIA }\end{array}$} \\
\hline & mínimo & máximo & mínimo & máximo & mínimo & máximo \\
\hline Infantil & $5 \%$ & $3 \%$ & $3 \%$ & $6 \%$ & $3 \%$ & $4 \%$ \\
\hline Primaria & $5 \%$ & $3 \%$ & $6 \%$ & $8 \%$ & $3 \%$ & $8 \%$ \\
\hline
\end{tabular}

Fuente. Elaboración propia.

Como conclusión a este apartado referido al grado de Magisterio en el EEES en resumen y con los Grados actuales el nivel de la Comunidad empeora con respecto a los planes anteriores pues los porcentajes \% de créditos que quedan son los siguientes:

- Infantil oscila entre un 4\% de mínimo y un 5\% de máximo.

- Primaria oscila entre un 4\% de mínimo y un 6\% de máximo.
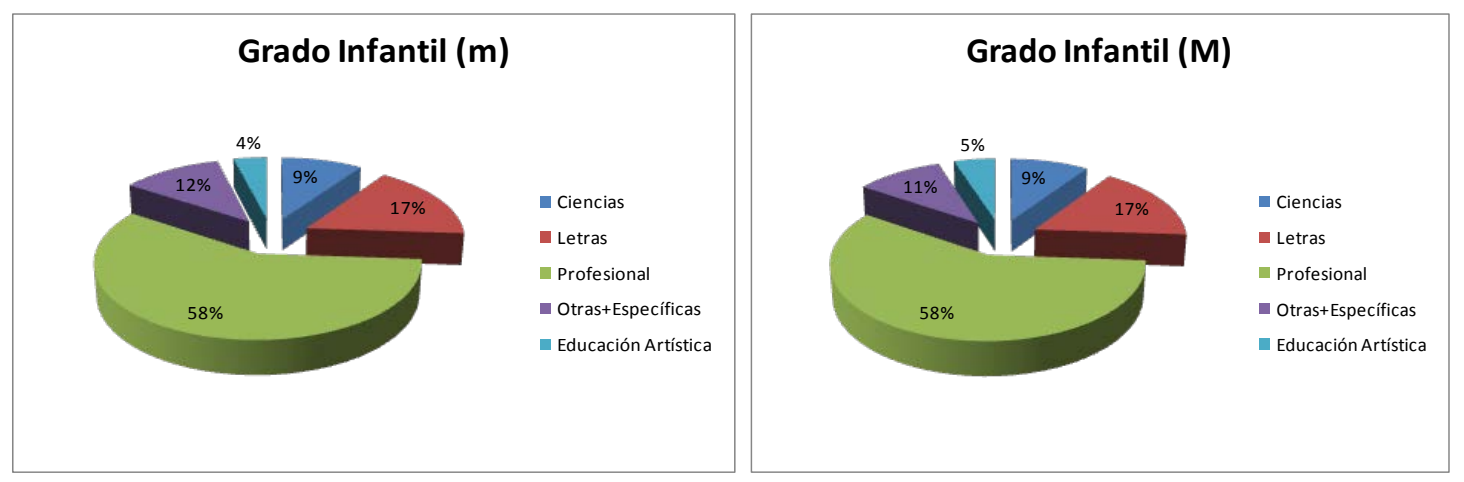

Figura 50. Mínimo y Máximo de EA. Grado Infantil. C. Valenciana.
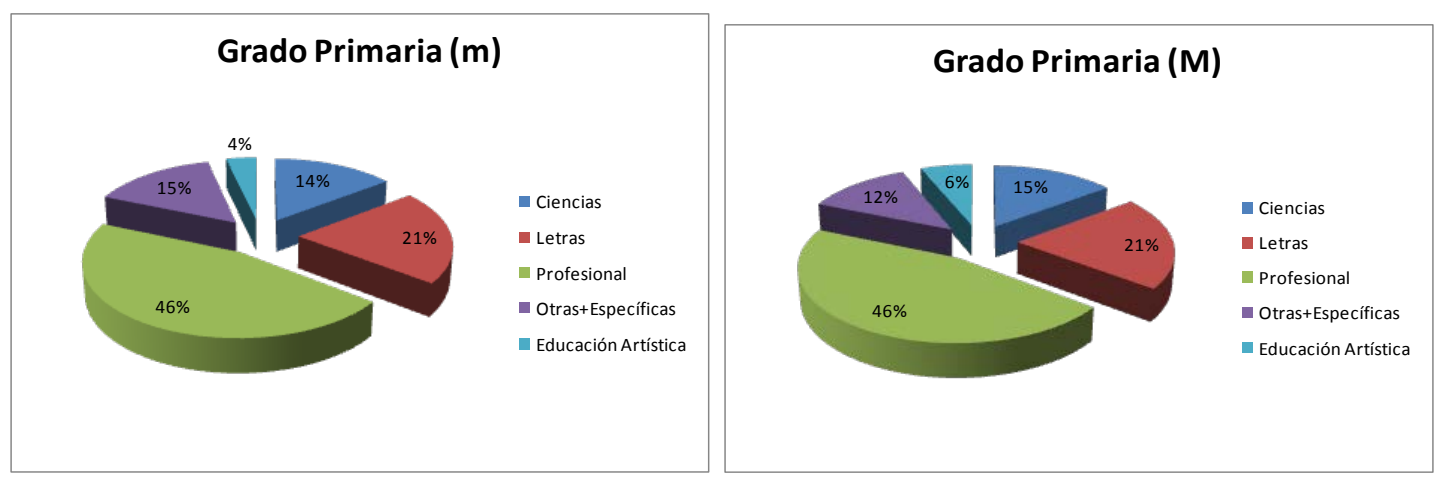

Figura 51. Mínimo y Máximo de EA. Grado Primaria. C. Valenciana. 
De todo esto podemos deducir que la formación de los maestros en Educación Artística es totalmente insuficiente si queremos conseguir que transmitan una enseñanza y unos contenidos de calidad. En otros momentos los alumnos completaban su formación artística, si estaban interesados en la materia, mediante optativas o asignaturas de libre configuración pero los actuales planes de grados no ofrecen esta posibilidad.

\subsection{Curriculum de Educación Artística en la escuela Infantil y Primaria.}

En el apartado anterior hemos tratado de situar qué formación han recibido los futuros maestros en sus estudios superiores y cuál ha sido el desarrollo de la EA en los planes de estudio de Magisterio. En este apartado queremos destacar la incidencia que ha tenido esta formación en el sistema educativo general ya que ambos fenómenos están estrechamente vinculados. Pretendemos relacionar así diferentes aspectos como son la evolución histórica, legislativa, sociológica y curricular.

En las primeras etapas de la educación los procesos formativos se deben fundamentar en la realización de experiencias personales así como en vivencias lúdicas y gratificantes, con el fin de despertar el interés y desarrollar la imaginación creadora de los escolares. Se trata, por lo tanto, de motivar a los alumnos con el fin de crear aptitudes y actitudes, aunque el objetivo de la educación general no es formar artistas sino el abrir las posibilidades expresivas que en algunos casos les llevarán a una meta profesional artística (Oriol de Alarcón, 2012).

Tomando como base la Constitución de 1812 que otorga al Estado la responsabilidad de la enseñanza y establece el derecho a la educación pública, hacia 1833 se reconoce, de un lado, la universalidad educativa pero a la vez se valora la libertad individual que proviene de las ideas del liberalismo político del momento. Estos dos aspectos se aunaron estableciendo una educación que el Estado controlaba pero que también reconocía la libertad de 
ejercer o dedicarse a la enseñanza, o de elegir el centro docente más conveniente para la educación de los hijos.

Enumeramos a continuación únicamente las Leyes Generales de Educación puesto que son las que mayor repercusión tienen en los cambios educativos. Obviaremos pues otros cambios o modificaciones aplicados, que provienen de Decretos, Órdenes y Resoluciones diversas:

- Ley de Instrucción Pública de 9 de septiembre de 1857. Ley Moyano.

- Ley General de Educación y Financiamiento de la Reforma Educativa de 4 de agosto de 1970. Ley Villar.

- Ley Orgánica de Ordenación General del Sistema Educativo de 3 de octubre de 1990. (LOGSE).

- Ley Orgánica de Calidad de la Educación de 23 de diciembre de 2002 (LOCE).

- Ley Orgánica de Educación de 3 de mayo de 2006 (LOE).

- Ley Orgánica 8/2013, de 9 de diciembre, para la mejora de la calidad educativa (LOMCE).

En ellas intentaremos señalar el espacio ocupado en el curriculum escolar por la EA y las variaciones experimentadas por sus objetivos y contenidos atendiendo a las diferentes reformas.

6.2.1. De la Ley de Instrucción Pública de 1857 al año 1939.

En el Plan General de Instrucción Pública de $1836^{160}$, promulgado por el Duque de Rivas, abarca toda la problemática de la educación en España y es destacable por sus aportaciones sobre la ordenación educativa. Plantea como una de las materias a impartir en la primaria superior ${ }^{161}$, el Dibujo.

\footnotetext{
160 Real Decreto de 4 de agosto de 1836.

${ }^{161}$ La enseñanza primaria está dividida en Elemental y Superior.
} 
Anteriormente esta materia no había aparecido con esta denominación como tal.

En 1858, cuando se promulga la Ley Moyano, España se encuentra en un periodo histórico difícil, y las políticas educativas se dirigían fundamentalmente a la escolarización y alfabetización. Las mejoras en la instrucción pública desde entonces hasta principios del siglo $X X$ habían sido escasas. El funcionamiento de la enseñanza primaria, económicamente a cargo de los ayuntamientos, era complicado y apenas cambió en ese tiempo.

En esta ley, la primera enseñanza sigue dividida en elemental y superior. La enseñanza superior amplia las materias cursadas en la elemental, en las que no existía ninguna artística, y hace referencia, en la educación primaria superior, en la Sección Primera: De los estudios. Título Primero: De la primera enseñanza; en su Artículo 4\%: principio del Dibujo lineal, englobándolo con Geometría y Agrimensura. Y en el Artículo 50, haciendo referencia a la educación de las niñas, se expone la materia de: Elementos de dibujo aplicado a las labores del hogar.

Nombraremos en este caso, por considerarlo adecuado dada la edad en que se admitía a los alumnos (9 y 10 años respectivamente), la segunda enseñanza:

- En los Estudios Generales se admitía a los niños a los 9 años. Se dividía en dos periodos uno que duraba 2 años y contenía la asignatura que se denominaba Ejercicios de Lectura, Escritura, Aritmética y Dibujo. Y otro que duraba 4 años de y contenía la asignatura que se denominaba Elementos de Aritmética, Álgebra y Geometría.

- En los Estudios de aplicación a las profesiones industriales se admitía a los niños a los 10 años. Estaban considerados Estudios de aplicación: Dibujo lineal y de figura, Nociones de Agricultura y Aritmética mercantil, podrán recibir un certificado de peritos en la carrera a que especialmente se hayan dedicado. Cada uno de ellos habilita para la profesión correspondiente. La superación de los estudios generales de segunda enseñanza permitirá a los alumnos ser admitidos al examen 
del grado de Bachiller en Artes, necesario para matricularse en las facultades.

A partir de $1902^{162}$, con el Decreto de Romanones, el Ministerio de Instrucción Pública y Bellas Artes se hizo cargo del personal y material de las Escuelas públicas de primera enseñanza. La enseñanza primaria se divide en: de párvulos, elemental y superior. Las asignaturas a señalar son: Nociones de Geometría, Dibujo y Trabajos Manuales (Labores). Estas asignaturas se correspondían con los contenidos que se explicaban en los estudios de Magisterio y se intentaba dar al alumnado unas nociones de Dibujo que les resultaran útiles en su futuro laboral.

En el año 1876 la fundación de la Institución Libre de Enseñanza por un grupo de catedráticos, entre los que se encontraban Francisco Giner de los Ríos, Gumersindo Azcárate y Nicolás Salmerón, supone un gran influjo en la vida y política educativa de nuestro país. La educación adopta aires innovadores con influencias pedagógicas europeas. En su Boletín aparece reflejada la materia de una forma más completa:

Todas las enseñanzas que constituyen la base de la cultura general de nuestro tiempo: así, la lengua materna y las vivas, las ciencias matemáticas, fisicoquímicas y naturales, las sociales, las filosóficas, la historia de la civilización, la geografía, lo literatura, la teoría y la historia del arte, el dibujo y el modelado, la música y el canto, el trabajo manual en diversas aplicaciones... (BILE, 1934, pp. 87- 94).

En consecuencia, la aparición de la enseñanza de lo que consideraríamos EA en la educación general se remonta a principios del siglo XX. Los motivos hay que buscarlos en los principios de la Escuela Nueva, por el belga Ovidio Decroly $^{163}$ y la italiana María Montessori ${ }^{164}$ que valora lenguajes más activos, creativos y participativos. Se trabajan globalmente los diferentes lenguajes

\footnotetext{
${ }^{162}$ Real Decreto de 26 de octubre de 1901.

163 Decroly, Ovidio (1871-1932). Médico y neurólogo que trabajo sobre teorías y prácticas sobre los centros de interés.

${ }^{164}$ Montessori, María (1869-1952). Pedagoga italiana.
} 
artísticos para cultivar el sentimiento artístico de los alumnos sobre todo la música, las creaciones literarias, las representaciones teatrales y las artes plásticas (Luzuriaga, 2002).

Entre 1914 y 1931 algunas instituciones y docentes se preocuparon por recoger los nuevos movimientos sobre el arte, herederos de la labor iniciada por la Institución Libre de Enseñanza. Se plantea un Proyecto de Primera Enseñanza en 1924 y la política educativa republicana la encontramos enmarcada en el Anteproyecto de Ley de Instrucción Pública (1931). Los principales principios que definen la educación republicana son la función del Estado, laica, gratuita, social, coeducación y la escuela única. (donde conviven todas las confesiones y religiones). Se potencia la participación social en la escuela colaborando con diferentes colectivos profesionales, culturales 0 artistas de forma que enriquezcan la educación de los niños y a la vez transmitan cultura al entorno. Hubo un último Plan de Estudios Primarios en 1937.

En un artículo publicado en 2009 por Cuenca, queremos rescatar algunos pasajes que manifiestan las inquietudes, los criterios y concepciones, que sobre la materia de Dibujo se exponían en aquellos momentos. Nos refiere a Elisa López Velasco, maestra del Grupo Escolar Cervantes de Madrid y que publica en Madrid en el año 1933: La práctica del dibujo en la escuela primaria. Aprecia de forma prioritaria el trato de los niños y aboga por respetar siempre su personalidad e iniciativas, valora el entusiasmo que el niño, de un modo natural, manifiesta por el dibujo y anima a "respetar éste y encauzarlo para que llegue a interés múltiple creador es, principalmente, la obra de la escuela" (Cuenca, 2009, p. 345). Con su libro pretende abordar y orientar el trabajo diario de la Escuela:

Está pensado como guía práctica del hacer en dibujo, para el gran número de maestros de buena voluntad que tienen dificultades de orientación en el cómo puede enseñarse una disciplina esencialmente práctica, que apenas practicaron en la Normal...Es conveniente ser dibujante para enseñar dibujo, es cierto, pero se puede enseñar bien sin ser dibujante. Basta para ello con respetar siempre la personalidad del niño; sostener su interés, 
graduar los modelos en orden a su dificultad, ponerlos ante la naturaleza y el arte como sugeridores de trabajo y dejar hacer.... (Cuenca, 2009, p. 339).

Expresa sobre su defensa del Dibujo, considerándolo de una importancia capital y argumenta:

Como toda disciplina, tiene en la formación humana un amplio margen de posibilidades. Es técnica de un hacer manual, pero es antes y sobre todo el cultivo de la emoción personal, del fino y trascendental sentir estético; es acción y sentimiento.

Tiene el dibujo un gran poder de formación; los sentidos más ricos encuentran en su ejercicio el más acertado desenvolvimiento. Las facultades intelectuales, en el amplio campo de las sensaciones, percepciones y conceptos, ejercitan, cuando la orientación es acertada, el rico tesoro del juicio y del raciocinio (..) Hoy el dibujo es una disciplina escolar como la Geografía, la Aritmética o el Lenguaje; a nadie se le ocurre pensar que aquéllos y los demás contenidos escolares que integran la primera enseñanza han de darse de modo distinto en ambas escuelas, porque siendo formativas sus finalidades últimas en cada enseñanza, es antes la función educadora que realizan que la cultural, aunque vayan íntimamente unidas. Del mismo modo en Dibujo su metodología es una porque uno es su fin educativo, y solo cuando buscan aplicaciones prácticas en los últimos grados de ambas escuelas, se diferencian en los temas de trabajo (Cuenca, 2009, p. 341).

Introduciéndose en los conceptos de la Escuela Nueva y de la Escuela Activa, a las que considera "avanzadas pedagógicas, no tanto por su contenido como por su método", expresa en cuanto a la materia:

Para esta nueva dirección, el dibujo en la escuela es antes que la escritura o simultáneo con ella, es decir ayuda a la escritura y la prepara, es además lenguaje"... "Del mismo modo el color interesa al niño antes que la forma. De ello deriva una corriente pedagógica de actualidad que intenta partir en dibujo del color y, así, dan lápices de colores para llenar formas; tal es uno de los ejercicios montessorianos". 
El dibujo es subjetivo primero en cuanto al color y a él se entregan desde los primeros grados. Es lenguaje siempre, cuando el niño expresa libremente sus conceptos y estados emocionales; y tercero puede llegar a una capacitación técnica, y en tal sentido lo toma la escuela en los grados complementarios y de preaprendizaje.

Este método es intuitivo en las primeras edades, es gradual cuando toma la Naturaleza para interpretarla objetivamente, es intuitivo creador en el dibujo decorativo, es matemático-natural cuando se aplica al dibujo geométrico, y es activo siempre porque se funda en el hacer libremente dentro de un círculo obligado de modelos. Es libre en el procedimiento (Cuenca, 2009, p. 343).

Masriera (1933), pedagogo, dibujante y experto en la Enseñanza del Dibujo, en uno de sus trabajos expresa:

El estudio de las relaciones de las diversas enseñanzas para emprender una labor de sintetización de la Escuela... sean Ciencias y Artes los principales sostenes de la Escuela... Sólo así llegaremos a una Escuela rica, compleja y sencilla como la vida misma (Cuenca, 2009, p. 346).

En su obra de 1911, El Dibujo para todos, nos comenta su interés por "relacionar el Dibujo con la Vida, con la realidad que nos rodea":

Se cree equivocadamente que el aprender a dibujar entraña la pretensión única de ser artista y llegar a sus altos vuelos, como si el aprender gramática, aprender a leer y a escribir significase la pretensión de ser literatos. ¡Ah, si nos interesáramos de veras por la cultura de nuestro pueblo! Entonces tomaría el dibujo el lugar importante que le corresponde en la enseñanza general, por ser una manifestación muy honda del espíritu y al mismo tiempo el mejor camino para llegar al conocimiento de lo que nos rodea (Cuenca, 2009, p. 347).

Lorenzo Gascón Portero es también maestro y profesor de Dibujo con una sólida formación artística. En el año 1934, escribió un libro titulado Cómo se enseña el Dibujo y las Bellas Artes en la Escuela. Recogemos a continuación algunas de sus manifestaciones: 
La enseñanza del Dibujo es hoy de una importancia grande en la Escuela. No es ya un auxiliar, ni solamente un lujo, sino una base para la expresión de todas las demás materias, y de desarrollo de los sentidos. El diagrama, esquema, el mapa, la ilustración de trabajos de clase, etc., son una necesidad... La enseñanza del dibujo no es tampoco sólo un problema de educación manual y de los sentidos corporales, sino también de la inteligencia. El disfrute que proporciona el dibujo, la combinación de crear formas, la improvisación de motivos, la apreciación de proporciones, el buen gusto y el acertado juicio sobre lo que se ve, son cosas que, adquiridas por adiestramiento de la inteligencia, juntamente con los sentidos, producen bienestar y mejoramiento en el individuo, placer y elevación. El hecho de saber ver, integrado por una parte mecánica, acaso inconsciente, la reproducción de la imagen en la retina, y por otra más importante, la de calcular, medir, combinar, y esforzarse en retener a nuestra disposición lo visto e interpretar, es esencial en el niño (Cuenca, 2009, p. 348).

Con estas valoraciones, ilustramos un poco mejor las visiones particulares de la época que abogaban por una valoración intelectual del hecho de dibujar, que proporciona sentido crítico y que ayuda a entender el entorno.

Otro ejemplo de publicaciones para mejora de la práctica docente del momento es el Boletín Escolar que entre otras cosas, reproducía dibujos de alumnos respondiendo a un interés expresado por varios maestros de tener modelos y sugerencias para encauzar esa asignatura en sus respectivos colegios (Molero, 1994).

En la etapa republicana, en el Plan de Estudios para la Escuela Primaria, se introducen las "Actividades Creadoras" que vienen a sustituir a los anteriores Trabajos Manuales (Cuenca, 1989). Se introducen como elemento fundamental en todas las materias y tienen una gran presencia horaria. 
Según se aprecia en el texto ${ }^{165}$...el Ministerio está dispuesto a emprender una reactivación de las enseñanzas artísticas poniendo todos sus recursos a su alcance para lograrlo, e instruyendo a los maestros e inspectores de enseñanza primaria para que tales criterios se lleven a buen término (Cuenca 1989, p. 268).

\subsubsection{De 1939 a 1975. Dictadura del General Franco.}

El nuevo gobierno instaurado por la dictadura franquista dictó una Ley de Reforma de la Enseñanza Primaria el 17 de julio de 1945. Surge una pugna entre la Iglesia y el monopolio falangista de la educación. En la nueva Ley estaban contemplados todos los temas relativos al nacional-catolicismo (Oriol de Alarcón, 2012).

Las asignaturas estaban agrupadas en Instrumentales consideradas "de hábitos indispensables en el estudio de las diversas materias de enseñanza y para la práctica de ejercicios educativos" (en la que estaba incluida Dibujo dentro del apartado de Expresión Gráfica), Formativas y las Complementarias consideradas para complementar " la cultura mínima primaria", entre las que se incluía las Ciencias Artísticas (Dibujo), y las asignaturas de carácter utilitario: Trabajos Manuales y de Taller y Labores femeninas. La enseñanza artística quedaba supeditada a la buena voluntad o afición del maestro pues no había unas reglas metodológicas especificas. La jornada escolar, que se estipulaba debía ser de cinco horas "sin incluir las complementarias". En las Enciclopedias, que se utilizaban de vehículo de aprendizaje, lo que figuraba era la Geometría y los Trabajos Manuales.

En el año 1964 se dictó una nueva Ley sobre la ampliación de la escolaridad obligatoria hasta los 14 años. Esta Ley se complementa con otra posterior del año 1965, sobre reforma de la Enseñanza Primaria. En la Enseñanza Primaria

\footnotetext{
165 Plan y Ordenamiento de la Escuela Primaria. Gaceta de Madrid, 17 de noviembre de 1937. Dirección General de Primera Enseñanza.
} 
se distinguen únicamente dos periodos: preescolar y de escolaridad obligatoria, dividido en 8 cursos. Las Órdenes Ministeriales de julio y octubre del año 1965 normalizan los textos escolares y, en 1967, se publican los cuestionarios para cada materia y cursos de Primaria en un Decreto que refunde la Ley de Enseñanza Primaria ${ }^{166}$. Estos cuestionarios tienen la función de indicar los objetivos a los que tienen que aspirar los maestros en cada nivel. "Por primera vez se solicita colaboración de especialistas en Expresión Plástica para la confección de los Cuestionarios Nacionales" (Cuenca 1989, p. 442). En el caso de la EA se nombran como: Técnicas de Expresión Artística (Dibujo, Música y Manualizaciones) sobre cuya base puede el escolar primario contemplar y crear los valores estéticos y artísticos y adquirir las destrezas operativas.

En la EA es la primera vez que aparece el término "Expresión Artística", que engloba el Dibujo, la Música y las Manualizaciones. Este último término, atendiendo al desarrollo de los cuestionarios abarca contenidos de iniciación profesional que por los valores que aportan encajan en esta materia (hoy en día corresponderían a conceptos de Diseño o de dibujo aplicado a materias como geografía o ciencias).

6.2.3. De 1970 a 1990. Ley General de Educación y Financiamiento de la Reforma Educativa.

La Ley General de Educación, aprobada el 4 de agosto de $1970^{167}$, supuso una reforma integral y había sido debatida ampliamente con anterioridad ${ }^{168}$. Fue innovadora en su momento y supuso un estimulo para el profesorado. Se

\footnotetext{
166 Decreto 193/1967, de 3 de febrero, se aprueba el texto refundido de la Ley de Enseñanza Primaria. BOE 13/2/1967.

167 Ley 14/1970, de 4 de agosto, General de Educación y Financiamiento de la Reforma Educativa (BOE de 6 de agosto de 1970).

${ }^{168}$ Se publicó en febrero de 1969 el estudio «La educación en España: bases para una política educativa» (Libro blanco»). En él se habla de la necesidad de un amplio consenso social ante la reforma educativa recordando la ineficacia de anteriores leyes.
} 
aplicaron planteamientos de calidad e innovación educativa y se fomentó la formación permanente del profesorado ${ }^{169}$. La ley se define como:

Establecer un sistema educativo que se caracterice por su unidad, flexibilidad e interrelaciones al tiempo que se facilita una amplia gama de posibilidades de educación permanente y una estrecha relación con las necesidades, que plantea la dinámica de la evolución económica y social del país. Se trata, en última instancia, de construir un sistema educativo permanente no concebido como criba selectiva de los alumnos sino capaz de desarrollar hasta el máximo la capacidad de todos y cada uno de los españoles (BOE 187, p. 12526).

La ley define unas intenciones renovadoras y con idea de perdurabilidad:

Intensificar la eficacia del sistema educativo la presente Ley atiende a la revisión del contenido de la educación, orientándolo más hacia los aspectos formativos y al adiestramiento del alumno para aprender por sí mismo, que a la erudición memorística a establecer una adecuación más estrecha entre las materias de los planes de estudio y las exigencias que plantea el mundo moderno evitando, al propio tiempo, la ampliación creciente de los programas y previendo la introducción ponderada de nuevos métodos y técnicas de enseñanza (BOE 187, p. 12526).

Los llamados "Programas Renovados" se establecen con diferentes leyes que los van regulando ${ }^{170}$.

La enseñanza de Párvulos se denomina Educación Preescolar y no hace diferencias entre ese nivel y el Ciclo Inicial de EGB, en cuanto a lo que se refiere a orientaciones pedagógicas, pues establece una estrecha relación entre ambos.

\footnotetext{
${ }^{169}$ Se nombra los Institutos de Ciencias de la Educación.

170 Orden Ministerial de 2 de diciembre 1970 que publica las Orientaciones Pedagógicas para EGB. BOE 8/12/1970.

Real Decreto 69/1981 de 9 enero de Ordenación de la EGB y fijación Enseñanzas Mínimas del Ciclo Inicial. BOE 17/1/1981.

Real Decreto 710/1982 de 12 febrero fijación Enseñanzas Mínimas del Ciclo Medio. BOE $15 / 4 / 1982$.

Orden Ministerial de 6 de mayo 1982, regula Enseñanzas Mínimas del Ciclo Medio. BOE $14 / 5 / 1982$.
} 
La enseñanza Primaria se transforma en EGB ampliándose la duración anterior en dos años. Se estructura en dos partes diferenciadas. La que va de $1^{\circ}$ a $5^{\circ}$ curso con una enseñanza globalizada y la que va de $6^{\circ}$ a $8^{\circ}$ en que se estipula una "moderada diversificación de la enseñanzas por áreas de conocimiento" que intentan preparar para el estudio o el trabajo. Los objetivos generales y el contenido cultural y científico se estructuran en dos grandes áreas de aprendizaje: Áreas de Expresión y Áreas de Experiencia. Cada área se organiza en Bloques Temáticos que integran los Temas de Trabajo. Es el propio profesor el que tiene que elaborar las unidades con la ayuda de las Niveles Básicos de Referencia estipulados.

Las áreas de Expresión se centran en las posibles formas de lenguaje (lengua española, lengua extranjera, matemáticas, plástica y dinámica) y las áreas de Experiencia abarcan las realidades y experiencias concretas del medio en el que viven los alumnos, junto con las materias científicas y técnicas (social y cultural, ciencias de la naturaleza y formación religiosa).

Posteriormente ${ }^{171}$ se estructuraría en Ciclo inicial $1^{\circ}$ y $2^{\circ}$, Ciclo Medio $3^{\circ}, 4^{\circ}$ y $5^{\circ}$, y Ciclo Superior $6^{\circ}, 7^{\circ}$ y $8^{\circ}$. La EGB, subsistirá hasta el curso 1997-98.

Es una de las primeras leyes que, en lo sucesivo y con diferente intensidad, se preocupa de cómo proporcionar a la persona, desde los primeros niveles de su educación, contacto con las artes. En el artículo 18 de la ley se expresa que:

Los métodos didácticos en la EGB habrán de fomentar la originalidad y la creatividad de los escolares, así como el desarrollo de aptitudes y hábitos de cooperación, mediante el trabajo en equipo de profesores y alumnos. Se utilizaran ampliamente las técnicas audiovisuales (LGE, 1970) ${ }^{172}$.

Se hace referencia a la Expresión Artística y Estética, así como al fomento de la creatividad y la originalidad de los estudiantes.

\footnotetext{
${ }^{171}$ Real Decreto 69/1981 de 9 enero de Ordenación de la EGB y fijación Enseñanzas Mínimas del Ciclo Inicial. BOE 17/1/1981.

${ }^{172}$ Sección segunda. Educación General Básica, Artículo dieciocho.
} 
En la Educación General Básica, la formación se orientará a la adquisición, desarrollo y utilización funcional de los hábitos y de las técnicas instrumentales de aprendizaje, al ejercicio de las capacidades de imaginación, observación y reflexión...a la iniciación en la apreciación y expresión estética y artística... (LGE, 1970) ${ }^{173}$.

Se atendió por primera vez la incorporación de la EA en la enseñanza general, por lo menos en cuanto a intenciones de innovación pedagógica traducida en un desarrollo de objetivos, contenidos, evaluación y horarios de EA, para aplicar en la escuela. Se indica en la propia ley que "la expresión plástica no debe ser entendida únicamente como educación o actividad artística, sino más ampliamente como acto de expresión, conocimiento y cultura" y que es "un medio educativo de gran valor psicológico y social".

Se propone una metodología en base a la globalización y las unidades didácticas. En el artículo 14, donde trata la Educación Preescolar, comprende entre las demás disciplinas la expresión rítmica y plástica. Indica que los métodos serán predominantemente activos para lograr el desarrollo de la espontaneidad, la creatividad y la responsabilidad.

Como hemos visto, una de las 6 grandes áreas que se establecen es la de Educación Artística. La filosofía del área indicaba la necesidad de ser una iniciación en la apreciación y expresión estética y artística. Forma parte del área de Expresión Plástica, englobando conocimientos de Dibujo, Manualizaciones y Labores. En el Ciclo Superior la dedicación es de 3 horas semanales.

En el año 1981 se acometió, por parte del Ministerio de Educación y Ciencia (M.E.C.), una remodelación de la Educación Primaria, que afectaba principalmente a los programas educativos, en ellos se especificaba los objetivos y qué tipo de actividades se realizarían ${ }^{174}$ así como la forma de evaluar los conocimientos. También se modificó la distribución del tiempo y los

\footnotetext{
173 Sección segunda. Educación General Básica, Artículo dieciséis.

174 Objetivos en cada uno de los Ciclos (Ministerio de Educación y Ciencia, 1984)
} 
horarios escolares. Variaba el criterio según las diferentes Comunidades Autónomas. En EGB, para la EA se determinaban 5 horas semanales en el Primer Ciclo; 2 horas en el Segundo Ciclo y 2 horas en el Tercer Ciclo. La EA comprendía: La Educación Plástica, la Educación Musical y la Dramatización (Oriol de Alarcón, 2012).

Sin embargo el avance legislativo sobre los objetivos y contenidos en este nivel educativo, nunca se correspondió con la asignación de un profesorado específico en la Enseñanza General Básica. Se buscaba "Ofrecer un conocimiento general de las artes, educando el sentimiento artístico para hacer posible la apreciación del arte". Pero se seguía contando con la buena voluntad del maestro para impartir esta asignatura lo que provocó niveles muy desiguales.

Tanto en la educación Infantil/Preescolar como en EGB, lo legislado en estos años no ha dejado de ser poco más que una declaración de intenciones y principios, incumplidos generalmente en la realidad. Ello es debido fundamentalmente a:

- Escasa formación inicial del profesorado de EGB en el llamado campo de "la plástica", dramatización o lo musical.

- Escasa motivación, por parte del profesorado, para incluir en sus programas las enseñanzas artísticas. Todavía se sigue considerando a estas asignaturas como "marías". Se encarga la tarea de atender estas asignaturas a profesorado menos preparado para otros menesteres, desconocen totalmente el lenguaje específico y la realidad del campo artístico. Los materiales que se utilizan no son específicos y son poco adecuados.

- Escasa demanda social. En los centros educativos, en general, los padres de alumnos, no suelen protestar cuando lo artístico no se realiza y sí que lo hacen, cuando hay deficiencias en el campo de la matemática o lenguaje. 
Si debemos señalar, sin embargo que existe una parte del profesorado que se preocupa de actualizarse y reciclarse. Mediante seminarios o cursos de perfeccionamiento, actualizan sus enfoques metodológicos y sus procedimientos didácticos, aunque de forma voluntaria y a cargo de su tiempo libre.

6.2.4. LOGSE, 1990. Ley Orgánica de Ordenación General del Sistema Educativo.

Con anterioridad a esta ley, se promulga la $\operatorname{LODE}^{175}$, que es una modificación de la ley anterior, es fundamentalmente una ley de programación de la enseñanza y de regulación de los centros escolares y su funcionamiento.

Nombra el aspecto artístico de forma superficial, "La adquisición de hábitos intelectuales y técnicas de trabajo, así como de conocimientos científicos, técnicos, humanísticos, históricos y estéticos. La preparación para participar activamente en la vida social y cultural" ${ }^{176}$.

La Ley General de Ordenación del Sistema Educativo del año $1990^{177}$, reformó de forma integral el sistema educativo y amplía la enseñanza básica obligatoria a los 16 años. Se fue aplicando paulatinamente, con sucesivas reformas.

En 1989, Solana ${ }^{178}$ publica el Libro Blanco para la Reforma del Sistema Educativo. Esta nueva ley se debatió ampliamente antes de su aplicación pues es muy ambiciosa. Pretende ser innovadora pues aspira a una reforma amplia y compleja que esté a la altura de la educación de otros países europeos y que asuma un modelo más acorde a los nuevos cambios tecnológicos surgidos en

${ }^{175}$ Ley Orgánica 8/1985 de 3 de julio Reguladora del Derecho a la Educación. BOE de 4/7/1985.

${ }^{176}$ Título Preliminar, artículo segundo, puntos c y f.

177 Ley Orgánica 1/1990, de 3 de octubre de 1990, de Ordenación General del Sistema Educativo. BOE 4/10/1990.

178 Javier Solana, ministro de Cultura (1982-1988) y de Educación y Ciencia (1988-1992). 
educación. Se opta por potenciar un sistema de enseñanza constructivista, donde aprender consiste en construir significados y atribuir sentido a aquello que se aprende mediante la experiencia personal partiendo de una base real y de los conocimientos previos del alumno; con un modelo de currículum abierto y flexible que favorece los valores democráticos.

Debido a la aparición de las comunidades autónomas, se intenta conjugar la unidad estatal con la descentralización.

- Define los factores que contribuyen a la mejora de la calidad de la enseñanza.

- El decreto determina los aspectos básicos del currículo, común para todo el territorio estatal (objetivos, contenidos, metodología y criterios de evaluación), así como la distribución horaria, que responde al 55\% del total.

- Competencias por parte de las Comunidades Autónomas, reforzando la diversidad e identidad cultural, lingüística y educativa (oportunidad al bilingüismo y a la inclusión de materias propias de la cultura de cada territorio).

La enseñanza Primaria está concebida con un carácter global e integrador. Comprende 6 cursos académicos abarcando desde los 6 a los 12 años. Se organiza en tres ciclos, de dos cursos cada uno. Cada ciclo constituye una unidad temporal en la que se organizan las actividades de enseñanza y aprendizaje, de evaluación y de recuperación, con objeto de asegurar la coherencia metodológica y la adecuación a las particularidades de aprendizaje del alumnado.

La finalidad de esta etapa educativa es:

Proporcionar a todos los niños una educación común que haga posible la adquisición de los elementos básicos culturales, los aprendizajes relativos a la expresión oral, a la lectura, a la escritura 
y al cálculo aritmético, así como una progresiva autonomía de acción en su medio ${ }^{179}$. (p. 28931)

Entre los objetivos que se definen, queremos entresacar:

- Se pretende que el alumno al finalizar la etapa sea capaz de comunicarse a través de medios de expresión verbal, corporal, visual, plástica, musical y matemática.

- Las enseñanzas mínimas deben responder a las demandas de la sociedad y a la cultura de nuestro tiempo y su aprendizaje contribuir, entre otras, al aprecio del patrimonio cultural de la sociedad a la que pertenecen $^{180}$. Se debe procurar que los alumnos conozcan el patrimonio cultural y participen en su conservación y mejora...

- Que aprendan como realizar obras artísticas y visuales a través de procesos de representación y mediante estrategias técnicas y expresivas.

Respecto a la metodología, se indica que ha de orientarse al desarrollo general del alumno, integrando sus distintas experiencias y aprendizajes. La enseñanza debe tener un carácter personal y adaptarse a los distintos ritmos de aprendizaje de los alumnos. El principio básico que rige esta ley es "Aprender a aprender". La evaluación debe ser global, continua y formativa. Los centros se encargaran de desarrollar todo esto elaborando proyectos curriculares y programaciones de aula. En Educación Infantil se indica que la actividad lúdica es un recurso especialmente adecuado y que el alumnado puede relacionarse con los demás a través de las distintas formas de expresión y de comunicación. En Primaria contribuirá a desarrollar en los niños la capacidad de conocer las características fundamentales de su medio físico, social y cultural así como las posibilidades de acción en el mismo.

Desde la promulgación de la LOGSE, se inicia un proceso de defensa del arte y la cultura popular. La enseñanza de la EA en el régimen general se

\footnotetext{
179 BOE 4/10/1990.

180 Real Decreto 1006/1991 (BOE 14 junio 1991).
} 
contempló en la Educación Infantil dentro del área de Comunicación y Representación, y en la Educación Primaria formó parte de las Enseñanzas Artísticas junto con la música y la dramatización. La ampliación de los contenidos y de los aspectos que engloban esta materia pretenden reflejarse con este cambio de denominación de la anterior de Expresión Plástica. Los decretos sucesivos que la desarrollaron cuidaron la inclusión de la protección del patrimonio cultural.

En el listado de capacidades que la LOGSE pretende contribuir a desarrollar está "Utilizar los diferentes medios de representación y expresión artística"(art.13). Organiza la enseñanza en seis áreas de conocimiento obligatorias. Todas ellas han de entrelazarse, complementarse y reforzarse mutuamente dentro de un planteamiento integrador y una metodología globalizada e interdisciplinar. Una de estas áreas es la de "Educación Artística"(p. 1447). En ella "están comprendidas diversas formas de expresión y representación, plástica, musical y dramática, mediante las cuales se aprehenden, expresan y comunican diversos aspectos tanto de la realidad exterior como del mundo interior de los niños"181. El horario correspondiente en el área de EA, en la Comunidad Valenciana es de 3 horas semanales en el primer ciclo, otras 3 en segundo ciclo y 2 en el tercero.

La formación inicial que requiere el docente es la que le proporciona el título de Maestro, que le capacita para la Educación Infantil o bien para la Primaria en sus diferentes especialidades. Existen además maestros especializados (música, educación física, idioma). Consideramos que en este momento se pierde una gran oportunidad que es la creación dentro de la plantilla de los colegios públicos del Maestro especialista en EA. Ello deriva de la modificación en 1971 del plan de estudios de Magisterio en el que sí se crean las especialidades de Educación Infantil, Educación Primaria, Lengua Extranjera, Educación Física, Audición y Lenguaje y Educación Especial pero ninguna de Educación Artística. currículo de la Educación Primaria en la Comunidad Valenciana. DOCV 20/0271992. 
6.2.5. LOCE, 2002. Ley Orgánica de Calidad de la Educación.

La Ley Orgánica de Calidad de la Educación (LOCE) se aprueba el 23 de Diciembre del $2002^{182}$. Modifica en ciertos aspectos a la Ley Orgánica de Ordenación General del Sistema Educativo (LOGSE) sobre todo en aquello que se refiere a estimular el esfuerzo en cuanto a exigencias académicas. Se pretende sustituir de nuevo el sistema curricular por los programas escolares estipulados en los años 70. En el nivel Infantil, aunque contempla las enseñanzas artísticas, fue criticada por la reducción de contenidos y de horario que planteaba. En cuanto a Primaria, sigue manteniendo la misma denominación que en la ley anterior, Educación Artística, pero retira de la misma la dramatización quedándose únicamente la música y la plástica. Finalmente no fue puesta en marcha, siendo reemplazada por la LOE.

\subsubsection{LOE, 2006. Ley Orgánica de Educación.}

La LOE fue aprobada el 3 de mayo de $2006^{183}$. Entra en vigencia en el curso 2006/07. Pretende proporcionar una educación de calidad a todos los ciudadanos en todos los niveles del sistema educativo y fomentar el aprendizaje a lo largo de la vida. Impulsa un planteamiento participativo de la comunidad en la organización y funcionamiento de los centros. Expresa un compromiso firme con los objetivos educativos planteados por la Unión Europea en cuanto a la mejora de la calidad y la eficacia de los sistemas de educación y formación. Así como una apertura a la cooperación e intercambio del mundo educativo con el resto de la sociedad.

Manifiesta también su interés por simplificar la reglamentación educativa pero sin pretender cambiar todo el sistema educativo, construyendo sobre la experiencia adquirida en pro de la mejora continua y progresiva de la educación.

\footnotetext{
182 BOE de 24 de diciembre de 2002.

183 Ley Orgánica 2/2006 de Educación, de 3 de mayo. BOE 4 del 5 de 2006.

Real Decreto 806/2006, de 30 de junio, por el que se establece el calendario de aplicación de la nueva ordenación del sistema educativo.
} 
En el Preámbulo de esta Ley (p. 17158 - 17164), es donde se expone "los principios y fines de la educación, que constituyen los elementos centrales en torno a los cuales debe organizarse el conjunto del sistema educativo":

- Para la sociedad, la educación es el medio de transmitir y, al mismo tiempo, de renovar la cultura y el acervo de conocimientos y valores que la sustentan.

- Se insiste en la importancia de la preparación del alumnado para el ejercicio de la ciudadanía y para la participación en la vida económica, social y cultural, con actitud crítica y responsable.

- Se pretende, desarrollar las aptitudes necesarias para la sociedad del conocimiento, garantizar el acceso de todos a las tecnologías de la información y la comunicación, aumentar la matriculación en los estudios científicos, técnicos y artísticos y aprovechar al máximo los recursos disponibles, aumentando la inversión en recursos humanos.

Con todo ello vemos la relevancia que se intenta dar al arte y cultura de una nación, comunidad autónoma o región, conservándolo, desarrollándolo y difundiéndolo.

La etapa de Educación Infantil tiene identidad propia, no es obligatoria y va desde el nacimiento a los 6 años. En el Real Decreto 1630/2006, donde se establecen las enseñanzas mínimas para esta etapa, dice que "se sientan las bases para el desarrollo personal y social, y se integran aprendizajes que están en la base del posterior desarrollo de competencias que se consideran básicas para todo el alumnado".

Entre los objetivos que se marcan destacamos:

- Desarrollar habilidades comunicativas en diferentes lenguajes y formas de expresión.

- Iniciarse en las habilidades lógico-matemáticas, en la lecto-escritura y en el movimiento, el gesto y el ritmo.

Los contenidos educativos se organizan en áreas que corresponden a ámbitos propios de la experiencia y del desarrollo infantil, fundamentalmente con el 
área de Lenguajes: Comunicación y Representación. Se abordan por medio de actividades globalizadas con interés y significado para los niños. Entre todas, destacamos la aproximación a la expresión visual. Se trabajan de forma lúdica y en un ambiente que fomenta la autoconfianza.

La etapa de Educación Primaria abarca de los 6 a los 12 años, es obligatoria y gratuita. En el Capítulo II, Principios generales, Artículo 16, expone que: "La finalidad de la educación primaria es proporcionar a todos los niños y niñas una educación que permita...adquirir las habilidades culturales básicas...el sentido artístico, la creatividad y la afectividad".

Entre los objetivos destacaremos:

- d) Conocer, comprender y respetar las diferentes culturas...

- h) Conocer y valorar su entorno natural, social y cultural...

- j) Utilizar diferentes representaciones y expresiones artísticas e iniciarse en la construcción de propuestas visuales.

El artículo 18 señala que la organización es en tres ciclos de dos años académicos cada uno. Se organiza en áreas, que tendrán un carácter global e integrador:

- Conocimiento del medio natural, social y cultural

o Educación artística

o Educación física

- Lengua castellana y literatura y, en su caso, lengua y literatura cooficial.

- Lengua extranjera

o Matemáticas

Cada una de las áreas contribuye al desarrollo de diferentes competencias y, a su vez, cada una de las competencias básicas se alcanzará como consecuencia del trabajo en varias áreas o materias.

La evaluación de los procesos de aprendizaje será continua y global y tendrá en cuenta su progreso en el conjunto de las áreas. 
El Real Decreto 1513/2006, de 7 de diciembre ${ }^{184}$, determina los aspectos básicos del currículo, común para todo el territorio estatal (objetivos, competencias básicas, contenidos, métodos pedagógicos y criterios de evaluación), así como la distribución horaria, que responde al 55\% del total, en el caso de la Comunidad Valenciana. Las enseñanzas mínimas que establece el Ministerio definen las competencias básicas que el alumnado deberá desarrollar. A notar la aparición del concepto de competencias que:

Permiten identificar aquellos aprendizajes que se consideran
imprescindibles desde un planteamiento integrador y orientado a la
aplicación de los saberes adquiridos. Su logro deberá capacitar a los
alumnos y alumnas para su realización personal, el ejercicio de la
ciudadanía activa, la incorporación a la vida adulta de manera satisfactoria
y el desarrollo de un aprendizaje permanente a lo largo de la vida.

Al identificar las competencias básicas para Primaria se manifiesta la intención de integración los conocimientos artísticos en igualdad de condiciones:

- Competencia en comunicación lingüística.

- Competencia matemática.

- Competencia en el conocimiento y la interacción con el mundo físico.

- Tratamiento de la información y competencia digital.

- Competencia social y ciudadana.

- Competencia Cultural y Artística.

- Competencia para aprender a aprender.

- Autonomía e iniciativa personal.

Reproducimos lo que integra la competencia Cultural y Artística (BOE 293, p. 43062):

Esta competencia supone conocer, comprender, apreciar y valorar críticamente diferentes manifestaciones culturales y artísticas, utilizarlas

${ }^{184}$ BOE de 8/12/2006. 
como fuente de enriquecimiento y disfrute y considerarlas como parte del patrimonio de los pueblos.

Apreciar el hecho cultural en general, y el hecho artístico en particular, lleva implícito disponer de aquellas habilidades y actitudes que permiten acceder a sus distintas manifestaciones, así como habilidades de pensamiento, perceptivas y comunicativas, sensibilidad y sentido estético para poder comprenderlas, valorarlas, emocionarse y disfrutarlas.

Esta competencia implica poner en juego habilidades de pensamiento divergente y convergente, puesto que comporta reelaborar ideas $y$ sentimientos propios y ajenos; encontrar fuentes, formas y cauces de comprensión y expresión; planificar, evaluar y ajustar los procesos necesarios para alcanzar unos resultados, ya sea en el ámbito personal o académico. Se trata, por tanto, de una competencia que facilita tanto expresarse y comunicarse como percibir, comprender y enriquecerse con diferentes realidades y producciones del mundo del arte y de la cultura.

Requiere poner en funcionamiento la iniciativa, la imaginación y la creatividad para expresarse mediante códigos artísticos y, en la medida en que las actividades culturales y artísticas suponen en muchas ocasiones un trabajo colectivo, es preciso disponer de habilidades de cooperación para contribuir a la consecución de un resultado final, y tener conciencia de la importancia de apoyar y apreciar las iniciativas y contribuciones ajenas.

La competencia artística incorpora asimismo el conocimiento básico de las principales técnicas, recursos y convenciones de los diferentes lenguajes artísticos, así como de las obras y manifestaciones más destacadas del patrimonio cultural. Además supone identificar las relaciones existentes entre esas manifestaciones y la sociedad -la mentalidad y las posibilidades técnicas de la época en que se crean-, o con la persona o colectividad que las crea. Esto significa también tener conciencia de la evolución del pensamiento, de las corrientes estéticas, las modas y los gustos, así como de la importancia representativa, expresiva y comunicativa que los factores estéticos han desempeñado y desempeñan en la vida cotidiana de la persona y de las sociedades. 
Supone igualmente una actitud de aprecio de la creatividad implícita en la expresión de ideas, experiencias o sentimientos a través de diferentes medios artísticos, como la música, la literatura, las artes visuales y escénicas, o de las diferentes formas que adquieren las llamadas artes populares. Exige asimismo valorar la libertad de expresión, el derecho a la diversidad cultural, la importancia del diálogo intercultural y la realización de experiencias artísticas compartidas.

En síntesis, el conjunto de destrezas que configuran esta competencia se refiere tanto a la habilidad para apreciar y disfrutar con el arte y otras manifestaciones culturales, como a aquellas relacionadas con el empleo de algunos recursos de la expresión artística para realizar creaciones propias; implica un conocimiento básico de las distintas manifestaciones culturales y artísticas, la aplicación de habilidades de pensamiento divergente y de trabajo colaborativo, una actitud abierta, respetuosa y crítica hacia la diversidad de expresiones artísticas y culturales, el deseo y voluntad de cultivar la propia capacidad estética y creadora, y un interés por participar en la vida cultural y por contribuir a la conservación del patrimonio cultural y artístico, tanto de la propia comunidad, como de otras comunidades.

En cuanto a los contenidos del área de EA:

Se establece un debate acerca de lo que en realidad las numerosas las leyes por las que ha pasado el país, han aportado a la educación artística. La asignatura como tal aparece por primera vez con la LOGSE alcanzando su punto álgido para, después, ir perdiendo protagonismo en las reformas sucesivas a base de reducción horaria y de un planteamiento de objetivos más pobre. La LOE actualiza los contenidos y los acerca más a la realidad social actual, en la que la presencia de la imagen es muy importante, pero no hay horas suficientes para enseñar esos contenidos.

Las diferentes manifestaciones artísticas tienen una presencia constante en el entorno y en la vida de las personas. Desde esta perspectiva, el área de Educación Artística tiene el propósito de favorecer la percepción y la expresión 
estética del alumnado y de posibilitar la apropiación de contenidos imprescindibles para su formación general y cultural.

La Educación Artística involucra lo sensorial, lo intelectual, lo social, lo emocional, lo afectivo y lo estético, desencadenando mecanismos que permiten desarrollar distintas y complejas capacidades con una proyección educativa que influye directamente en la formación integral del alumnado, ya que favorece el desarrollo de la atención, estimula la percepción, la inteligencia y la memoria a corto y largo plazo, potencia la imaginación y la creatividad y es una vía para desarrollar el sentido del orden, la participación, la cooperación y la comunicación.

El área está integrada por dos lenguajes: plástico y musical. Ambos se articulan a su vez en dos ejes, Percepción y Expresión. El primero incluye todos aquellos aspectos relacionados con el desarrollo de capacidades de reconocimiento sensorial, visual, auditivo y corporal, que ayudan a entender las distintas manifestaciones artísticas, así como el conocimiento y disfrute de producciones plásticas y musicales de diferentes características. El segundo se refiere a la expresión de ideas y sentimientos mediante el conocimiento y la utilización de distintos códigos y técnicas artísticas.

En el área, la Percepción se refiere a la observación de los elementos plásticos y a la audición musical. La observación debe centrarse en la interpretación, indagación y análisis del entorno natural y de la actividad y creación humanas, entendida esta última como generadora de objetos y elementos presentes en lo cotidiano y de representación puramente artística. Por su parte, la audición se centra en el desarrollo de capacidades de discriminación auditiva y de audición comprensiva, durante los procesos de interpretación y creación musical así como en los de audición de piezas musicales grabadas o en vivo.

La Expresión remite a la exploración de los elementos propios del lenguaje plástico y visual, al tratamiento de los materiales y a las diversas posibilidades de expresar lo percibido y sentido, ajustándose a una planificación en el proceso de elaboración. También alude a la interpretación musical desarrollando habilidades técnicas y capacidades vinculadas con la 
interpretación vocal e instrumental y con la expresión corporal y la danza. A través de uno u otro lenguaje se estimula la invención y la creación de distintas producciones plásticas o musicales.

Tanto el lenguaje plástico como el musical constituyen ámbitos artísticos específicos con características propias, sin embargo, dado que la producción y la comprensión en ambos tienen aspectos comunes, en esta etapa quedan incluidos en una sola área para posibilitar un enfoque globalizado que contemple las estrechas conexiones entre los distintos modos de expresión y representación artística. Por esta misma razón, y a pesar de la especial mención de la música y la expresión plástica, dentro del área se incorporan también contenidos de la danza y el teatro.

A partir de los dos grandes ejes en que se articula el área, Percepción y Expresión, se han distribuido los contenidos en cuatro bloques. El bloque 1, Observación plástica y el Bloque 3, Escucha integran los relativos a la percepción para los lenguajes plástico y musical respectivamente. El bloque 2 , Expresión y creación plástica y el bloque 4, Interpretación y creación musical incluye los contenidos relacionados con la expresión en ambos lenguajes ${ }^{185}$.

El horario escolar, expresado en horas, correspondiente a los contenidos básicos de las enseñanzas mínimas de EA para la Educación Primaria es:

- Primer ciclo: 105 horas/1085 horas totales.

- Segundo ciclo: 105 horas/1120 horas totales.

- Tercer ciclo: 105 horas/1100 horas totales.

Del total de horas se puede disponer de un $10 \%$ para la enseñanza del valenciano, no pudiendo detraer de un área una cifra superior a 35 horas ${ }^{186}$. 
Apreciamos con el análisis del curriculum oficial como le legislación española respalda la valoración de la utilización el arte en la escuela.

\subsubsection{LOMCE, 2013. Ley Orgánica de Mejora de la Calidad en Educación.}

La LOMCE ${ }^{187}$, actualmente en proceso de aplicación, plantea la situación de que esta asignatura sea de libre configuración autonómica, tal y como puede comprobarse en el Capítulo III Currículo y distribución de competencias, Artículo 6 bis. Distribución de competencias ${ }^{188}$. Además disminuye el número de horas que corresponden con la anterior ley, en Primaria. A continuación recogemos algunos aspectos referentes a la EA dentro de lo que se establece para el curriculum básico ${ }^{189}$ de Primaria:

El área de Educación Artística se ha dividido en dos partes: la Educación Plástica, y la Educación Musical, atendiendo al estudio de los dos lenguajes mencionados anteriormente. A su vez, cada una de estas partes se subdivide en tres bloques, que aun estando relacionados entre sí mantienen ciertas diferencias con el resto. No obstante, en su desarrollo metodológico el docente podrá abordar de manera conjunta los diferentes bloques.

El primero de los bloques de la Educación Plástica, Educación Audiovisual, está referido al estudio de la imagen en todas sus manifestaciones, tanto visual como audiovisual, en el que cobran una gran relevancia las aportaciones que las Tecnologías de la Información y la Comunicación realizan al mundo de la imagen. El segundo bloque denominado Educación Artística hace referencia al conjunto de conceptos y procedimientos que tradicionalmente han estado asociados al área. El último bloque incluye el desarrollo desde el punto de vista gráfico de los

\footnotetext{
187 Ley Orgánica 8/2013, de 9 de diciembre, para la Mejora de la Calidad Educativa. BOE $10 / 12 / 2013$

${ }^{188}$ BOE de 10/12/2013, Sec. I. Pág. 97868.

189 Real Decreto 126/2014, de 28 de febrero.
} 
saberes adquiridos desde el área de matemáticas en el apartado de geometría.

Vemos, de nuevo, relegada esta asignatura que pasa a un segundo plano al no considerarse materia obligatoria. Pierde el poco espacio que había logrado ganarse en años anteriores. Todo ello obedece a un concepto educativo, ya visto en ocasiones anteriores, en las que se considera que las materias instructivas son las únicas validas para la educación.

\section{LOS AGENTES EN LA EDUCACIÓN ARTÍSTICA EN MAGISTERIO: PROFESORADO / ALUMNADO.}

Procuraremos exponer qué acontecimientos y en qué manera han afectado a la evolución de la formación del profesorado de EA, tratando de relacionar las leyes más significativas que han configurado el sistema educativo con los acontecimientos políticos y sociales en España en el siglo XIX, XX y XXI.

La investigación en Ciencias de la Educación tiene un largo recorrido. Sin embargo, consideramos que hasta hace muy poco, no se ha dedicado un interés suficiente a las didácticas de determinados campos del conocimiento disciplinar o curricular en el aula. La investigación y generación de conocimiento sobre la manera de añadir valor didáctico a los conocimientos científicos es fundamental. La disciplina sola, sin la parte de didáctica aplicable, no es suficiente en el aula. Los elementos fundamentales que podríamos definir sobre lo que consideramos didáctica propia de un área es:

- Contenidos de conocimiento.

- Características del alumnado.

- Acción del profesor.

Cada campo científico tiene características propias y por lo tanto necesita una didáctica particular y específica, que se adapte a la forma de aprender los conocimientos. El contenido, de cada rama de conocimiento, se estructura y presenta de forma diferente; se estudia de forma diferente. Cada materia 
necesita de su lenguaje y forma organizativa particular. Los problemas que se plantean en ella necesitan una respuesta específica adaptada a su realidad para que el efecto sobre el intelecto y la abstracción de ideas genere un proceso educativo eficaz. Por lo tanto, se generan contextos con contenidos propios e implicación social. La respuesta de cada alumno será diferente, responderá arreglo a sus capacidades y conocimientos previos con las creencias e imaginarios personales que posea.

De todo ello deducimos que tampoco los procesos de aprendizaje son los mismos en unos campos u otros. Diferirá la aproximación a los problemas, el seguimiento de los mismos así como las soluciones.

Lo que se ha venido a llamar Didáctica Específica no es únicamente la enseñanza de una determinada materia sino que debemos prestar especial atención al modo más adecuado de hacerlo.

Un profesor puede tener grandes conocimientos en una determinada disciplina pero carecer de bagaje didáctico. Un alto nivel de cualificación no garantiza un profesor eficaz. Hablar de investigación no es lo mismo que hablar de docencia, tener una alta cualificación puede preparar para investigar pero para la docencia se han de tener en cuenta, además, otros factores. En este caso, en la mayoría de las ocasiones, el docente tenderá a repetir la forma en cómo se le ha enseñado. Es muy posible que el alumnado no responda a sus expectativas de aprendizaje y que los responsabilice de ello. No valora que su papel es el de decodificar la materia con la que está trabajando para luego ser capaz de presentarla ante el alumnado con una nueva apariencia que ellos sean capaces de entender, aprender y reutilizar.

La investigación en la didáctica de nuestra área no es demasiado habitual pues históricamente no se ha considerado que pudiera ser objeto de investigación. La bibliografía todavía es relativamente escasa y la metodología para abordarlo no está claramente definida. Se va construyendo paulatinamente conforme crece el número de profesores universitarios, especialistas en la disciplina y que les preocupa la forma en que pueden 
comunicar sus conocimientos día a día tanto al alumnado en particular como al resto de la sociedad. Es interesante pues trabajar en esta labor científica para contribuir a construir ese respaldo teórico tan necesario que ayude a justificarlo con una metodología que lo valide, frente a opiniones o prejuicios infundados.

El profesor que pretenda concebir su acción didáctica como una investigación necesita una teoría potente y una metodología validadora que le conduzca al examen crítico y sistemático de su acción docente para evaluarlo y averiguar qué debe hacer para enseñar bien mediante la experimentación (González, 2002).

González (2002, p.25) define que "los saberes educativos como objeto de una rama especializada de la ciencia: una especialización de las ciencias de la educación (la didáctica disciplinar) y una especialización de cualquier ciencia (su propia didáctica)". Por lo tanto, la didáctica de área seria la construcción de un sistema de comunicación adecuado a los sujetos con los que trabajamos. Para seguir con una definición, en sus propias palabras:

La didáctica de un área de conocimiento podría ser definida así: Una ciencia que estudia la fenomenología suscitada por las acciones que se aplican para la comunicación educativa o social, a partir de un campo determinado de conocimientos... constituyen una especialidad propia de cada campo científico, en tanto en cuanto esta especialidad didáctica se preocupa por los problemas que surgen ante la transmisión de sus contenidos, la transposición de su estructura lógica y los procesos de comunicación a los que da origen...

Podemos deducir de estas palabras que nuestro trabajo en el aula no puede fijarse de antemano de forma rígida sino que la actitud debe estar abierta a los estímulos que se produzcan e ir adaptando nuestras respuestas y las actividades a las necesidades. El bagaje profesional nos permitirá saber cómo utilizar los recursos al alcance en cada momento atendiendo a los diferentes contenidos que se pretenda enseñar. Procurará aplicar la didáctica de forma efectiva para que sea lo más significativa posible para el alumnado. Incluso 
recurrirá a contenidos de otras disciplinas, trabajando de forma interdisciplinar, si ello redunda en una mejora de la acción educativa.

En numerosas ocasiones en nuestra área se ha desatendido la vertiente didáctica, o se ha visto como un conocimiento menor, por el hecho de no considerar que sea un saber especializado. Los profesionales de las Bellas Artes, al menos en la Comunidad Valenciana, han desdeñado de diversas formas, su implicación y dedicación a la didáctica de esta área. Este hecho se ve reflejado en el hecho de que en las facultades de BBAA actuales no existe ninguna asignatura de didáctica enfocada a la enseñanza. Se puede hablar de que se ha trivializado el conocimiento para poder negar una didáctica de ese conocimiento por no ser lo suficientemente científico o artístico.

Esta situación tiene diferentes consecuencias que afectan a:

- La pérdida del número de profesores de EA y su escasa presencia en la enseñanza. Esta cuestión la hemos tratado en otro capítulo anterior.

- Las deficiencias didácticas que presentan las personas que llegan a la enseñanza y, dependiendo de si hablamos de maestros, profesores de secundaria o de universidad, se encuentran con problemáticas diferentes.

Pero lo que sí ocurre en todos los casos, es que se provoca la sensación de una falta de definición que genera desconocimiento $y$, por lo tanto, minusvaloración de dichas materias. El hecho es que el definir de forma inadecuada este campo de conocimiento da lugar a una negación del mismo, quedando relegado al ámbito de lo anecdótico y de ocio.

Si lo que queremos es establecer un método didáctico no trataremos de simplificar la materia ni trivializarla para que sea más asequible. De lo que se trata es de poder establecer la forma de poder transmitir este conocimiento, adaptando y estructurándolo al alumnado al que va dirigido para construir significados que den respuesta a los problemas que se les plantean. De esta forma hacerlos capaces de dar respuestas propias y diversas, construidas a partir de los conocimientos globales de su entorno y los nuevos adquiridos. 
Pues la EA nos permitirá desarrollar determinados hábitos mentales propios del área y que no se desarrollan de la misma forma sin ella o con otras áreas (se educan en la paciencia, en aceptar sus fracasos, mirando de otra manera el significado del error mediante la continua corrección de sus trabajos). Debemos de ser capaces de ver como enseñamos nuestra área a nuestros alumnos universitarios y que ellos a su vez entiendan de qué manera se deben de enfrentar a la enseñanza de estos conocimientos. Se trata de aprender una forma de hacer, no solo los contenidos propios. No aprende de la misma forma un estudiante universitario que un niño de Infantil o Primaria pero hemos de encontrar cual es la ruta más adecuada para aprender a poder transmitirlo y que no repitan las viejas formulas como:

- Enseñar a los niños como si fueran adultos, cuando todavía no tienen los conocimientos suficientes.

- Seguir instrucciones, que no entienden, de libros de texto o les hagan rellenar dibujos ya resueltos en los que el niño no tiene nada personal o creativo que aportar.

- Dar instrucciones precisas de cómo se ha de realizar una tarea sin dejar margen a la iniciativa y creatividad personal.

- Proporcionarles modelos estereotipados que les llevaran a no poder crear el suyo propio.

Cabe ahora citar el libro de Morin (1999) sobre sus siete propuestas educativas que se deberían tener en cuenta:

- Enseñanza del conocimiento. Permanecemos ajenos a ciertos conocimientos por no tenerlos en cuenta a la hora de aprender los hechos en su conjunto. Debemos a abrir el conocimiento de forma global, todo cabe para poder entender el problema. Integrar todo tipo de conocimientos, interdisciplinaridad.

- Enseñanza del Conocimiento pertinente. El conocimiento fragmentado de la realidad no contribuye positivamente a la idea global del conocimiento. El alumnado debe tener a su alcance cualquier medio que le permita entender y resolver el problema planteado. Cada cual 
puede poder escoger que se adapta más a su forma de entender la realidad. Aprender usar el conocimiento de forma multidimensional, a percibir e integrar las partes en un conjunto.

- Enseñanza de la identidad humana. Comprender que el ser humano es a la vez físico, biológico, psíquico, cultural, social e histórico. Todas estas características deben poder tenerse en cuenta a la hora de entender los intereses personales en el aprendizaje.

- Enseñanza de la identidad mundial. En un mundo cada vez más globalizado cualquier tema abordado tiene una dimensión global además de la individual afectando al conjunto humano y formando parte de su naturaleza.

- Enseñanza frente a las incertidumbres. Los conocimientos actuales no se asientan sobre verdades inamovibles. En el mundo actual cambiante e imprevisible hemos de tener una concepción abierta y critica para poder ofrecer soluciones diversas a problemas inesperados.

- Enseñanza de la comprensión. El conocimiento debe servir para favorecer la solidaridad y la comprensión de nuestra identidad entre las identidades de los demás. Es la base de la educación para la paz.

- La enseñanza de la ética. La ética debe estar presente en todos los actos educativos como parte de nuestra individualidad, nuestra sociedad y nuestra especie.

Si retrocedemos y realizamos una visión histórica del área de conocimiento en la que valoramos como se aplicaba la didáctica antes de crearse realmente el área, confirmaríamos la existencia de elementos teóricos así como actividades y procesos que nos confirmarían dichas teorías. Con estas condiciones consideramos que sí que es una ciencia que puede ser objeto de investigación y teorización, aunque es aplicada. Sobre todo, e importante destacar que, nos movemos dentro de un conjunto de relaciones que parten de la disciplina propia pero que llega a tener implicaciones interdisciplinares, y relaciones con aspectos psicopedagógicos y comunicativos. 
El papel del profesor del área artística debe tomar conciencia e investigar sobre cuál es su labor a desarrollar. No enseñamos a artistas ni a ser artistas. Partimos de un alumnado totalmente distinto, al que nuestros conocimientos artísticos les son muy lejanos pues su formación inicial es muy deficitaria con lo que en muchas ocasiones nos vemos explicando conceptos excesivamente simples a nuestro parecer. Ese es el problema en muchas ocasiones porque no hay una verdadera formación de docentes que aborde en profundidad la complejidad que esto entraña, abriendo un campo científico serio al respecto, la didáctica del área. Es importante que las personas con experiencia docente y con ideas renovadoras se ocupen de formar a futuros profesores a la vez que continúan con la investigación educativa en torno a su área de conocimiento. Dando prioridad al aspecto educativo sobre el de la ciencia referencial para que esté como prioritario al menos. Una misma persona formada al más alto nivel puede ser o un profesional de la materia o bien un profesor de dicha materia, sus trabajos y las herramientas que emplean en ellos son diferentes. No se le ha enseñado como debe educar con ese conocimiento, con qué trabajar, como seleccionarlo, como impartirlo con respecto a otros saberes, de qué forma transmitirlo.

En el caso de nuestro alumnado que sí recibe formación general sobre didáctica, lo que falta es trabajar sobre la didáctica específica que es la que permitirá a ellos en primer lugar y por extensión a sus futuros alumnos a "ayudar a alguien a que aprenda algo".

No podemos evitar tener como referencia nuestra vida de estudiante y como nos han enseñado, normalmente con clases meramente expositivas y que nos hablaba de los saberes como algo inamovible. No se trabajaba sobre como despertar el gusto por aprender y el saber.

Para averiguar esto no basta la intuición sino que debemos investigar de forma seria y científica para poder encontrar respuesta a los problemas y que sirva como apoyo de la formación de los profesores. Esa investigación no se puede desligar de la actividad en el aula pues necesitamos la respuesta crítica a nuestra actividad para poder mejorarla. Ello implica un cambio de rutina en el 
profesor y en la forma de trabajar de los educadores para poder generar nuevos modelos de Formación Inicial.

7.1. Perfil del profesorado de EA en los estudios de Maestro.

Si consideramos como punto de partida la situación del profesorado que había en los años 70 y 80 se produce una inflexión debido a la creciente demanda de los mismos provocado por el aumento del alumnado que accede a los estudios en esos años. También resalta dentro del profesorado que los porcentajes de presencia de la mujer es mayor que el de los hombres. Y la ratio también es mayor que en otros estudios.

El profesorado pues, en las áreas de EA, tiene un exceso de alumnado lo que dificulta la realización de las imprescindibles prácticas de forma adecuada. A ello no ayudan frecuentemente ni el mobiliario inadecuado que evita grandes mesas ni las condiciones de espacio.

Los profesores que imparten su docencia en esta área son Licenciados o Doctores universitarios, que es lo que se requiere actualmente para ejercer en la universidad. En un futuro lo podrán hacer los graduados. Tienen una procedencia muy diversa, aunque proceden mayoritariamente de las facultades de Bellas Artes. Los estudiantes de Magisterio, durante muchos años, no han tenido posibilidad de ello pues su diplomatura no les daba acceso a estudios de tercer ciclo ni a realizar tesis doctorales. Esto ha cambiado con los Grados.

Además de la titulación en Bellas Artes, muchos tienen formación en otras áreas, que completan sus conocimientos en la materia. Como ya indicábamos en un capitulo anterior numerosas disciplinas pueden desarrollar contenidos artísticos. La variedad de contenidos que puede abarcar el concepto de "artístico" permite que se vayan incorporando profesionales de ámbitos muy dispares. La amplitud, o indeterminación, del término permite su inclusión. Por lo tanto los profesores que pueden impartir docencia de EA, en diferentes 
ámbitos, tienen una procedencia de lo más heterogénea. De este personal formado en distintas facultades sale el profesorado que podría impartir docencia en los Grados de Maestro.

En el Catálogo de Áreas de Conocimiento del Consejo de Universidades existen variadas áreas de conocimiento que aglutinan al profesorado que dedica su docencia a las Artes $^{190}$. Para ilustrar esta idea nos gustaría exponer las más relevantes. Estas son:

- 185 DIBUJO

- 260 ESCULTURA

- 270 estética y teoría de LAS ARTES

- 690 PINTURA

- 465 HISTORIA DEL ARTE

A continuación enumeramos las diferentes titulaciones incluidas en estas áreas con las asignaturas que cursan y sus contenidos. Ello nos dará una idea de la diversidad de campos y profesionales que se acercan a contenidos artísticos y que se puede plantear:

- Ingeniero Técnico en Diseño Industrial:

o Estética y Diseño Industrial: Ideas estéticas y su evolución. Estética y funcionalidad. Historia del diseño.

o Expresión Artística: Composición y análisis de formas. Forma y color.

o Metodología del Diseño: Sistemas de análisis y síntesis de diseño. Modelos y prototipos.

- Licenciado en Bellas Artes

o Dibujo: Representación objetiva y descriptiva de la figura humana, del mundo objetual, animal y natural. La estructuración de la forma en el espacio topológico y proyectual. La proyección 
de la línea como medio de reflexión de los factores variantes de la composición plástica y el perfeccionamiento del gesto gráfico.

o Idea, Concepto y Proceso en la Creación Artística: Investigación de los lenguajes estéticos en general $y$, en especial, a nivel compositivo. La adecuación de los medios técnicos y materiales plásticos a los fines estéticos planteados.

o Metodología, Lenguajes y Técnicas en la Creación: Los puntos de partida de la creación artística varían según las necesidades e intereses, del mismo modo que los de la Obra Artística y en su Conservación medios de expresión artística y la forma de abordarlos configuran resultados diversos que inciden directamente en la conservación y posible restauración de los mismos. Así pues, atendiendo a las posibilidades de especialización es este campo, así como a su carácter abierto a los distintos procesos de creación, en este segundo ciclo habrá de profundizarse en los proyectos y sus métodos procesuales y tecnológicos, permitiéndose así particularizar un lenguaje apropiado en cada caso.

o Sistema de Análisis de la Forma y la Representación: Modelos de la configuración visual propia de los lenguajes del arte.

o Volumen: La configuración tridimensional de la forma (espacio y volumen). Tratamiento de las distintas propiedades de los materiales. Proceso y proyectos escultóricos.

o Color: Sistemas de formación y leyes de la percepción del color. Organizaciones y divisiones cromáticas. Dimensiones, simultaneidad, proporciones, dinámica, psicología y métrica cromática. Simbología y práctica del color.

o Teoría e Historia del Arte: Teorías y fundamentos de las Artes. El Arte a través de la Historia.

- Licenciado en Historia del Arte:

o Técnicas Artísticas y Conservación de Bienes Culturales: Introducción al conocimiento de los procesos materiales y los 
procedimientos técnicos de creación y conservación de las obras de arte.

o Historia de las Ideas Estéticas: Estudio de la historia del pensamiento estéticos y las ideas artísticas. Definición y estudio de las diversas metodologías.

o Teoría del Arte: Conocimientos básicos de los procesos materiales y los procedimientos técnicos de creación y conservación de las obras de arte.

o Fuentes de la Historia del Arte: Estudio de las obras de arte a través de los documentos relacionados con su creación, de la literatura artística de la época y otros textos coetáneos.

o Historia del Arte Antiguo, Historia del Arte Contemporáneo, Historia del Arte en la Edad Moderna, Historia del Arte Medieval.

o Historia del Cine y de otros Medios Audiovisuales: Estudio general de la historia del cine; de la fotografía y de los modernos medios de producción de imágenes artísticas.

- Licenciado en Humanidades:

o Historia del Arte: Estudio de las principales manifestaciones artísticas a lo largo de la Historia que se relacionan más directamente con nuestro presente.

Tal como vemos la formación de estos profesionales provee de amplios y muy diversos conocimientos artísticos pero su formación didáctica, durante sus estudios universitarios, es muy escasa o nula. Anotar que hoy en día está plenamente incorporada la idea de la necesidad de una formación continua de los profesionales de cualquier ámbito pero habría que plantearse de forma seria cual ha de ser la formación didáctica que ha de recibir un profesional que se quiera dedicar a la docencia.

Los grandes cambios que se han producido en la Educación Superior en los últimos tiempos requieren tal vez una revisión de la situación del profesorado. Estos profesionales docentes, formados en los contenidos propios de su área y con alta cualificación y con trayectoria investigadora, que trabajan en 
instituciones de formación superior en muchos casos no han recibido ningún tipo de formación pedagógica, ya que mayoritariamente no han sentido esta necesidad formativa, ni la institución les ha exigido ninguna formación pedagógica previa al desarrollo de dicha función docente. Es por ello que en numerosas universidades se desarrollan planes de formación para el profesorado a ella vinculado, aunque se discute sobre cuáles deben ser sus contenidos, estructura, etc.

En el caso concreto de la EA, reconocemos que en muchas ocasiones no somos capaces de orientar con eficacia a nuestros alumnos, dotándoles de los conocimientos y recursos que van a necesitar con posterioridad. Es cierto también que estamos limitados por unas directrices oficiales que mediatizan las posibilidades de actuación real. Los planes de estudio determinan cual es nuestra presencia en las titulaciones de los graduados en Magisterio. Los escasos créditos existentes a lo largo de los estudios limitan mucho la capacidad de formación adecuada en la materia. Se podría plantear que implicación o responsabilidad tienen los propios docentes de esta situación. En numerosas ocasiones la escasez de créditos se ha intentado suplir con la incorporación de materias optativas y de libre elección. Lo cual puede que mejore de alguna forma la formación de una parte de los estudiantes pero globalmente solo sirve para mejorar muy parcialmente el nivel de adquisición de contenidos de aquellos que tienen algún interés previo especial en la materia. Para el resto del alumnado no tienen relevancia. Influye de forma notoria también en cuanto a la concepción global que se tiene de la disciplina.

La solución a esta situación no se presenta fácil pues están implicados múltiples factores, entre ellos las autoridades educativas. En cualquier caso, el profesorado de EA somos los más interesados en poner en valor nuestra área y debemos estar al tanto en todo momento para poder hacer valer nuestras opiniones cuando el momento lo requiera.

Es por ello que planteamos una necesidad de definición de nuestro entorno de trabajo con unos contenidos bien concretos, así como una revisión de conjunto incluyendo el propio nombre del área. Asimismo incorporar todos aquellos 
avances tecnológicos que nos permitan aplicar nuevas metodologías en el aula. Sin resolver estas cuestiones es complejo pretender estar presentes de forma visible en una sociedad cada vez más compleja y tecnificada.

Podemos aprovechar las nuevas investigaciones que se están planteando en este momento, fundamentadas en prácticas de comprobada eficacia en diversos ámbitos: académicos, museos, talleres sociales, ámbitos de la salud, educación no formal para respaldar la importancia social que tiene la EA. De la misma forma es importante generar una teoría seria que evite considerar la EA de forma frívola o únicamente como ocio y entretenimiento para que no se utilice de forma errónea. El problema es que en ocasiones, personal no preparado o no formado lo utiliza de forma incorrecta, colaborando en una idea inadecuada de la misma. La mediación entre el arte y el público debe ser de calidad y el papel de los educadores es el de favorecer el conocimiento a todo tipo de público.

\subsection{Perfil del estudiante de Grado de Magisterio.}

Hemos comentado con anterioridad de la masificación de alumnado que sufren estos estudios con las reformas de los estudios de Magisterio en los años 70 y 80. Ello provoca principalmente un empeoramiento de la formación y un excedente de titulados. Numerosos autores consideran que todo ello redunda evidentemente de forma negativa sobre la profesión y su consideración social. Se aprovecha para insistir en enumerar algunas de las características del alumnado refiriéndose a su bajo estrato social, a la absoluta predominancia de mujeres y a la masificación de las aulas. Con todo ello contribuye a perpetuar la consideración de estos estudios como de menor cualidad o como puente a otros estudios. El currículo, muy atomizado, adolece de exceso de asignaturas, la mayoría de carácter teórico. La enseñanza que se practica se adecua a esta situación lo cual es totalmente contradictorio en el caso de la EA que requiere una atención más personalizada y una evaluación diferente. Es una enseñanza mayoritariamente basada en clases magistrales que no favorecen la autonomía y creatividad del alumnado. Ello puede dar a entender 
que las asignaturas que se plantean de otra forma se interpretan como que son menos serias.

En aquel momento, el alumnado ya comienza a mostrarse más inclinado ante las asignaturas más practicas y existe una demanda favorable a que los aprendizajes estén más enfocados a la realidad escolar. Incluso se comenta la necesidad de una pedagogía más cooperativa. Podríamos entenderlo como que se muestran más inclinados hacia la metodología que se utiliza habitualmente en las asignaturas artísticas e incluso interesados por los contenidos que estas les aportan.

Además de lo que ya hemos puesto en relieve en los planes de estudio, también queremos llamar la atención sobre las características del alumnado que accede a Magisterio y su postura referente a la disciplina.

Nos interesaran sus motivaciones para elegir esos estudios y cuáles son sus expectativas futuras, profesionalmente hablando. Al igual que cuál es su procedencia tanto a nivel cultural como socioeconómico. Estos condicionantes nos determinaran de forma significativa en la forma en que debemos abordar la materia.

El alumnado procedente del Bachillerato apenas tiene conocimientos plásticos. Normalmente proceden de menciones en las que, caso de cursarlo, se ha priorizado los contenidos de Dibujo Técnico. Tienen un escaso bagaje cultural y apenas conocimientos de conceptos y elementos grafico plásticos. Por ello se enfrentan a un lenguaje que es prácticamente nuevo y desconocido para ellos.

Tras años de docencia hemos ido comprobando que una serie características se repiten. Para conocer a las personas con las que íbamos a trabajar e ir orientando las enseñanzas, hemos ido recogiendo las opiniones del alumnado de estos estudios durante el desarrollo del curso y también al finalizar este. Ello nos ha permitido también ir viendo como evolucionaban sus expectativas y qué efectos producía nuestra formación sobre su forma de trabajar y su forma de enfocar su futura docencia en la materia. 
Año tras año comprobamos que la actitud del estudiante ante nuestra materia es de duda y prevención. En primer lugar porque no sabe cómo abordar estos contenidos con claridad sino que tiene ideas preconcebidas sobre el papel que desarrolla esta asignatura en la formación. (ya sea lo que se le va a impartir como lo que va a tener que impartir después. A añadir sus experiencias generalmente negativas con la materia en su educación).

Los motivos podrían ser:

- La escasa información con la que acceden. El alumnado llega al aula sin conocimiento de qué va a aprender ni en qué consisten las asignaturas. Su concepto previo de la asignatura está lleno de tópicos y bastantes prejuicios. Su idea de cómo enseñar se remite a la forma en que le puedan haber enseñado.

- Siguiendo la trayectoria educativa que se deriva de la Administración el alumnado llega al aula con unos escasos conocimientos en Arte (en esta denominación incluimos tanto aspectos teóricos como prácticos). En su trayectoria educativa, desde su paso por Infantil, Primaria, Secundaria y hasta Bachillerato, su contacto con la EA habrá sido bastante escaso, en general. Únicamente en algunos casos de colegios o profesores concretos o habiendo estudiado el Bachillerato de la modalidad de Artes tendrá una formación algo más completa. La tónica general es de la realización de múltiples experiencias prácticas que percibe en la mayoría de casos como inconexas y faltas de significado. En numerosas ocasiones con motivo de alguna celebración social o cultural. En la realización, se quejan de los criterios arbitrarios de evaluación y en la monotonía de las propuestas. También referencian lo anecdótico y falto de significación que les ha resultado para su formación y lo frustrante en la mayoría de ocasiones. Todo ello conlleva a esa predisposición inicial ante la materia que les plantea unos contenidos difíciles de asimilar frente a otras áreas curriculares que sí dominan y a las que dotan de una importancia académica relevante.

- Su falta de conciencia ante su papel como futuros docentes. Durante sus años de estudio, el alumnado debe empezar a formar su idea de

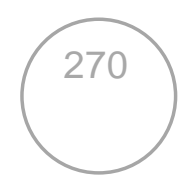


que su futura labor como docente es extremadamente importante porque de ella van a depender los conocimientos de sus propios alumnos e intentar transmitirles el aprecio por la misma. Por lo tanto si no aprecia lo suficiente el valor educativo de nuestra materia, no le concederá tampoco en un futuro su valor en el curriculum escolar. Precisamente de lo que ellos se quejan de que siempre está situada en horas finales de la jornada o de la semana y que en numerosas ocasiones se utiliza el horario para adelantar otras materias. Esa idea de qué es la asignatura y de cómo se enseña tiene un componente importante de lo que piensa generalmente la sociedad sobre el tema.

Las carencias más destacables podrían ser:

- Su falta de conocimientos prácticos y teóricos previos, por lo que en muchas ocasiones "hay que partir de cero".

- Desconocimiento de la Historia del Arte y preparación para abordar el Arte circundante.

- Prejuicios e ideas erróneas.

- Poco interés por ampliar sus conocimientos de la materia, que luego tendrán que impartir.

Si consideramos acertadas estas observaciones no podemos menos que determinar la enorme importancia que tiene el no haber disfrutado de una evaluación educativa formativa y formadora, que les orientara a la comprensión de lo que estudiaban. Constatamos lo decisivo de ello en la formación de este alumnado y, como consecuencia, las estructuras de los planes de estudios que se apliquen.

Podemos adjudicar la importancia que les corresponde a los planes de estudio que han formado parte de la educación del alumnado que recibimos, para seguir con la importancia de la efectividad de las enseñanzas que impartamos y no perder de vista los planes de estudios que estos alumnos han de cumplir cuando se dediquen a su labor docente. 
La cuestión fundamental es que al no existir como especialidad, no se forma especialistas de EA y no existen maestros lo suficientemente formados en la materia para abordarla con eficacia. Formamos maestros generalistas que, con su escasa formación, adquirida en sus estudios de Grado con pocas horas presentes en sus curriculums, tendrán la responsabilidad de la formación artística de su futuro alumnado.

En el caso de la especialidad de Infantil, en que las enseñanzas son globalizadas el impacto puede que sea menor pero, en Primaria, la Expresión Plástica se comparte el área con la Expresión musical y, en la mayoría de los casos, acaba con una presencia puramente anecdótica. Incluso siendo dos áreas artísticas es complicado plantearnos hacer una comparativa pues las situaciones difieren mucho. El área de música ha tenido una especialidad diferenciada desde los planes de estudios del 71. Ello quiere decir que, aunque actualmente el titulo sea generalista, ha formado especialistas durante una larga temporada y se ha reconocido su especificidad. En los planes actuales ha desaparecido como especialidad pero sigue conservando una mención propia en los estudios de Magisterio (al menos en la Universitat de Valencia) y sigue formando sus propios maestros especialistas. Ellos son los que imparten música en los colegios. En el área de EA nunca ha existido la especialidad en los estudios de Magisterio y por lo tanto nunca la ha impartido un especialista en los colegios.

Otra diferencia importante, que se deriva de la anterior, es que para acceder a la mención de música se requieren unos conocimientos y formación previa sobre contenidos musicales para después continuar con unos estudios específicos. Por lo tanto, cuando los estudiantes la eligen y acceden a ella, además de interés tienen formación previa que garantiza ciertos conocimientos básicos. En el caso de la EA, no tiene mención propia, y únicamente tiene una o dos asignaturas en la de Artes y Humanidades (al menos en la Universitat de València). Evidentemente la situación y preparación del alumnado que accede a esta mención no tiene las mismas motivaciones ni preparación que en el caso de la música. Podemos añadir a ello que el alumnado manifiesta que la elección de este itinerario frecuentemente no figura entre sus primeras 
opciones y acceden a él por no poder optar al de su primera elección. De nuevo otras opciones educativas son más valoradas que las Humanidades y por supuesto que la EA cuya presencia, a nuestra forma de ver, es anecdótica.

En muchos casos escuchamos y leemos sobre el agravio comparativo que sufre la música en cuanto a la forma en que se estudia esta especialidad. Y, efectivamente queremos señalar que existen diferencias que consideramos importantes. Sin embargo, a juicio de los expertos en materia musical, se considera que la formación que van a recibir no les resultara suficiente y que deberían continuar aprendido música por su cuenta o en conservatorios para afrontar con solidez su labor educativa. Entienden que la formación que van a recibir no les aportara unos cimientos sólidos de música y cultura musical sino que les servirá únicamente para dar una educación musical general y básica en la escuela.

Como último punto en este apartado no quisiéramos dejarnos el tema de la necesidad de la educación permanente del profesorado pues, el alumnado cualquiera que sea su formación, tiene que ser consciente la importancia de ello.

El profesorado, una vez finalizada su carrera, no puede conformarse con la Formación Inicial recibida. En su profesión el docente necesita adecuarse a un mundo en constante evolución. Para que el sistema educativo pueda seguir en paralelo a las novedades sociales, económicas y culturales, debe estar continuamente perfeccionándose. Por lo tanto, precisará revisar sus métodos pedagógicos y aprender a integrar nuevos. Durante la puesta en práctica profesional el docente necesita buscar soluciones creativas a los retos que se le presentan, en un proceso de reflexión integrara sus conocimientos con las actividades que desarrolle en el aula. Por lo tanto la práctica docente debe servir de llevar a término, reflexionar y modificar, si fuera necesario, su actividad en el aula y su actitud en la misma. La formación permanente debería apoyar este hábito. 
Este aspecto siempre ha sido importante. Los primeros intentos fueron con los Congresos pedagógicos en 1882, 1888, 1892 con los que se iniciaron los encuentros profesionales con el apoyo económico de la administración correspondiente. En estos encuentros se promocionaba el intercambio de experiencias educativas así como de métodos y técnicas para aplicar en la escuela. No fueron actividades constantes y se desarrollaron sobre todo en la época de la Institución Libre de Enseñanza. Se celebraron sobre todo en Cataluña donde se inició el movimiento de las Escoles d' Estiu así como otras numerosas actividades culturales que pretendían fomentar la formación y perfeccionamiento de los maestros.

Tello y Aguaded (2009) sostienen que una de las principales razones de la necesidad de la Formación Permanente del Profesorado es la continua evolución de la sociedad y que los métodos de enseñanza y educativos se adapten y respondan a las necesidades de la misma. Creen que la profesión del docente requiere una continua revisión para poder seguir dando una respuesta adecuada a su trabajo de enseñanza-aprendizaje y que conlleva involucrarse en actividades de actualización docente.

Por esta razón, consideramos que el papel de los profesores es fundamental para el buen funcionamiento del sistema educativo. Es el motor que generará una mejora en la calidad educativa, y por lo tanto, se le debe motivar a participar en actividades formativas.

El trabajo del profesor requiere estar continuamente actualizando sus conocimientos científicos, valorando el contexto sociocultural en el que trabaja, evaluando el aprendizaje de sus alumnos y adaptando a ellos sus métodos educativos. La complejidad habitual de su trabajo se complica cuando se plantea una reforma educativa y debe adaptarse a nuevos conceptos y técnicas y a nuevas prácticas pedagógicas demandadas por la sociedad.

El sistema educativo y principalmente la escuela, no puede quedarse al margen de los cambios sociales, sino que debe adaptarse a ellos, tal y como expresan Tello y Aguaded (2009). Por lo tanto, y no solo eso sino que, debería 
incluso adelantarse, puesto que debería ser el motor social y fomentar el cambio que formara nuevos ciudadanos más cultos y comprometidos.

No se necesitan numerosos medios ni recursos en el aula para desarrollar actividades innovadoras de aprendizaje. La aplicación de sencillos pero efectivos métodos didácticos conseguirán resultados asombrosos. Estos se pueden ir adquiriendo en la Formación Inicial y seguir perfeccionándose con la Formación Permanente. No tienen por qué ser elementos separados sino que una es la continuidad de la otra a lo largo de la carrera profesional. Hoy en día, tanto en el aula como fuera de ella, las nuevas tecnologías permiten el acceso a numerosa y valiosa información. Ello revertirá en una mejora formativa que adquirirán también los estudiantes para saber buscar cualquier información necesaria, procesándola después y utilizándola para su trabajo de forma que lo enriquezcan dando lugar a nuevas soluciones.

Por lo tanto, y concretando en el terreno artístico, el profesorado que necesitamos es un docente bien preparado en la materia, y que se siga formando, que sepa ser eficaz en su puesta en práctica en el aula, que reflexione sobre su práctica y tenga interés en reconducirla en pro de la mejora de su ejercicio en el contexto educativo.

\section{CONCLUSIONES}

La EA, en el sistema educativo general, no tiene el papel de formar artistas sino que debe facilitar una formación visual y cultural que junto al conocimiento y manejo de técnicas y materiales, pueda poner a disposición de la sociedad los recursos artísticos necesarios que amplíen la posibilidad de expresión y de comunicación.

Como ya hemos visto, obviando el carácter discutible del término EA, lo utilizamos, comúnmente, por ser el más internacionalmente y ampliamente aceptado. Aunque respaldamos la necesidad de establecer una denominación actual más ajustada al ámbito de trabajo e investigación que se lleva a cabo. 
Esta disciplina requiere una puesta a punto y una actualización que permita incluir y considerar aspectos que todavía pueden resultarnos novedosos (apreciación crítica, reflexión estética). Es sobre todo necesario aumentar y mejorar el campo de la investigación lo cual permitirá cohesionar y fundamentar el área de trabajo.

Los elementos del curriculum no son únicamente una cuestión meramente académica sino que reflejan un sentir social pues los estudios se estructuran a semejanza de las cuestiones más o menos valoradas ideológicamente.

Aquí es donde el curriculum artístico encuentra las mayores dificultades. Una notabilidad de aspectos creativos y críticos es mal aceptada por quienes ven la educación como un medio para alcanzar un estatus productivo. El hecho de que en parte exista una inclinación hacia la realización de actividades manuales parece que desprestigia las mismas frente a unas posturas más intelectuales. De hecho, en el estudio que realizamos comprobamos como efectivamente hay un componente ideológico que determina la prioridad de contenidos del curriculum.

En el área de EA hemos ido viendo como su presencia en la formación de maestros ha sido siempre insuficiente para enfrentarse de forma competente a su aplicación correcta en el aula.

En los primeros cincuenta años, desde la creación de las Escuelas normales, 1839, hasta los primeros planes de 1900, la materia que se impartía era fundamentalmente Dibujo Geométrico, Lineal y Agrimensura. En algunos planes se presentaba la asignatura unificada y en otros el Dibujo se separaba de la Geometría. La Agrimensura tenía una aplicación práctica profesional clara. Señalar la opción de Dibujo Artístico en los estudios para maestras en aplicación de labores femeninas y bordados. A partir de 1898 se establece el Dibujo, denominado como tal, en las Escuelas Normales de ambos sexos, aunque sigue estando poco adecuado a los contenidos que necesita aprender un maestro. 
En un segundo periodo, que establecemos desde el Plan de 1903 hasta el Plan Profesional de la época republicana, 1931, se introduce la Metodología del Dibujo y hay un intento por introducir un dibujo más artístico, acorde con las tendencias pedagógicas europeas. Los programas se adecuan más a la práctica escolar y el dibujo tiene un carácter formador dentro del curriculum.

Tras la guerra civil se inicia un periodo de retroceso en la profesionalización del Magisterio, volviendo a los conceptos de principio de siglo. Los conocimientos se centran en el Dibujo Geométrico y Lineal ( planes de los años 1940, 1942 y 1945). Con el Plan del 50 y el posterior de 1967, se inicia una época de mayor aperturismo y se establece la materia como Metodología y Didáctica del Dibujo. Se introducen algunas nociones de educación estética , aunque se sigue concibiendo como una herramienta para las otras disciplinas escolares. Las asignaturas de Manualidades y Labores, recogen muchos contenidos del ámbito del Dibujo, lo que los diferencia son los objetivos con los que se plantea.

A partir de la reforma de 1970, aparece el término de Expresión Plástica para incluir la Música, el Dibujo y las Manualidades, en unos estudios que pretenden ser diferentes a todo lo anterior. Se determinan las especialidades y se cursan materias comunes, de especialización y optativas. Se implantan de diferente forma según las universidades pues tienen criterios diversos, predominando el Dibujo Técnico sobre el Artístico y, en general, con déficit de planteamientos teóricos.

En los años posteriores y durante la década de los 80, va ganando terreno la introducción de objetivos para dotar al maestro de conocimientos para que pueda aplicarlos a los programas y contenidos de su futura aula. Se potencia el aprendizaje del lenguaje expresivo y la práctica como método de aprendizaje, además del aspecto didáctico. Se amplían en muchos casos las horas lectivas, sobre todo en especialidades como la de Preescolar. Se organizan clases como talleres, sobre todo en las materias optativas. Se mejora cualitativamente la impartición de las asignaturas artísticas. 
Podemos apreciar claramente el retroceso paulatino de horas lectivas sufrido posteriormente, según los diferentes Planes de Estudio. En los últimos tiempos hemos visto como al recorte sufrido en el 91, va sucediendo otro mayor pues se rebajaron todavía más los créditos adjudicados. Al llegar a los Grados, en el momento actual, podemos asegurar que en nuestra Comunidad tienen una presencia testimonial. Referente a la Educación Artística exponemos el creditaje de las diferentes asignaturas artísticas que tanto la Universidad de Alicante como la de Castellón o la de Valencia incorporan en sus dos itinerarios (Educación Primaria y Educación infantil) y a lo largo de los cuatro años de carrera:

Tabla 34. Créditos mínimos y máximos de EA / Universidades.

\begin{tabular}{|c|c|c|c|c|c|c|c|c|c|c|}
\hline \multirow[b]{2}{*}{ CURSO } & \multicolumn{2}{|c|}{$\begin{array}{l}\text { CREDITOS } \\
\text { UNIVERSIDAD } \\
\text { ALICANTE }\end{array}$} & \multicolumn{4}{|c|}{$\begin{array}{l}\text { CREDITOS } \\
\text { UNIVERSIDAD } \\
\text { CASTELLON }\end{array}$} & \multicolumn{4}{|c|}{$\begin{array}{l}\text { CREDITOS } \\
\text { UNIVERSIDAD } \\
\text { VALENCIA }\end{array}$} \\
\hline & INFANTIL & PRIMARIA & \multicolumn{2}{|c|}{ INFANTIL } & \multicolumn{2}{|c|}{ PRIMARIA } & \multicolumn{2}{|c|}{ INFANTIL } & \multicolumn{2}{|c|}{ PRIMARIA } \\
\hline $1^{0}$ & 0 & 0 & \multicolumn{2}{|c|}{0} & \multicolumn{2}{|c|}{0} & \multicolumn{2}{|c|}{0} & \multicolumn{2}{|c|}{0} \\
\hline $2^{\circ}$ & 0 & 0 & \multicolumn{2}{|c|}{0} & \multicolumn{2}{|c|}{0} & & & \multicolumn{2}{|c|}{6} \\
\hline $3^{\circ}$ & 0 & 0 & \multicolumn{2}{|c|}{8} & \multicolumn{2}{|c|}{6} & \multicolumn{2}{|c|}{6} & 0 & 6 \\
\hline $4^{\circ}$ & 6 & 6 & 0 & 6 & 8 & 12 & 2 & 4 & 0 & 6 \\
\hline TOTAL & 6 & 6 & 8 & 14 & 14 & 18 & 8 & 10 & 6 & 12 \\
\hline
\end{tabular}

Fuente. Elaboración propia.

Comprobamos como lo máximo que se ha conseguido en esta reforma es, referente a nuestra área, mantener unos niveles parecidos de formación que se quedan por debajo de lo que sería deseable, todo ello derivado de la adaptación de los nuevos planes a las viejas estructuras, cuando tendríamos que estar adaptando las viejas estructuras a las nuevas necesidades formativas. Si a ello añadimos la necesaria formación didáctica del profesorado universitario por una parte, y, por otra, los conocimientos y actitudes de los estudiantes de Magisterio, denotamos la poca preparación en la materia con la que se preparan los futuros maestros. 
En estas condiciones resulta muy complejo poder responder profesionalmente a los requerimientos legales que se hacen en las diferentes reformas educativas. Aunque, si abordamos sobre todo las ultimas, observamos que, tras la importancia que concedía la LOGSE a la formación artística, con las sucesivas reformas (LOCE y LOMCE) las enseñanzas artísticas van sufriendo un retroceso en beneficio de las enseñanzas instrumentales y de idiomas. Mientras aquí se está denostando la educación artística, no ocurre igual en otros países con sistemas educativos considerados de calidad.

Necesitamos un concepto nuevo de maestro que consiga transmitir los valores artísticos a sus alumnos. Pero para ello, además de tener la formación adecuada, debe poder disponer de los medios y espacios necesarios para poder hacerlo en las mejores condiciones posibles, tal y como se le requiere sobre el papel. El lenguaje del arte facilita el acceso y el disfrute de la cultura y sus variadas manifestaciones mediante el aprendizaje de lenguajes alternativos. Ello implicará, para el profesorado y el alumnado, la necesidad de familiarizarse con competencias complejas que favorecerán un pensamiento abstracto y crítico tanto a la hora de enfrentarse con obras ajenas como con las propias.

Las nuevas capacidades de lenguaje y comunicación facilitan el intercambio e interacción social y, por tanto, derivan de ella, ya que no sólo el lenguaje, sino la representación misma de la realidad, puede ser considerado un producto social. En la infancia, la relación entre iguales, y no sólo con los adultos, es una importante fuente de desarrollo y un estímulo para el aprendizaje. A través de las relaciones que viven en la escuela, los alumnos asimilan sistemas de valores y creencias, y desarrollan determinadas actitudes. Eso les permite progresar en la construcción de un juicio y de una posición moral autónoma, elaborando criterios propios que regirán su comportamiento.

Por todo ello, el papel del profesorado en los estudios de Magisterio es sumamente importante pues si consigue generar en el aula un clima de interacción social, desarrollará valores como la autonomía, la cooperación, la solidaridad, el respeto a lo plural y la conciencia crítica. Con su enseñanza 
está centrada en los estudiantes, podrá desarrollar su pensamiento divergente y su creatividad, corrigiendo la visión sesgada que estos vienen arrastrando y que, si no les hacemos reconsiderar sus planteamientos, perpetuarán cuando lleguen a las escuelas. 
CAPÍTULO IV. 
CONSIDERACIONES FINALES 


\section{INTRODUCCIÓN}

Dado el avance de los elementos multimedia y de comunicación hoy en día, recibimos continuamente estímulos que involucran lo artístico. Algunos son mensajes fáciles de descifrar pero otros contienen elementos de difusa lectura que los hacen dificultosos a la hora de interpretar su significado. Contienen elementos ideológicos complejos adheridos a valores culturales que no siempre conseguimos identificar. Podemos considerarlo un medio de conocimiento, que nos permite analizar e interpretar, mensajes de producciones estéticas mediante diferentes lenguajes simbólicos (corporales, sonoros, visuales, orales, escritos), es aquí, por lo tanto, donde toman protagonismo los procesos de enseñanza-aprendizaje.

Vigotsky (2003) considera que el individuo, mediante la acción del lenguaje, puede interactuar con la realidad. El contacto con el pensamiento de los demás, con la cultura, es lo que lo convierte en un ser social. El lenguaje regula el pensamiento y la acción, cuando es un instrumento de comunicación. Cuanto mayor sea esta actividad social, mayores son las posibilidades de aprendizaje. Si el arte es considerado como un lenguaje (musical, corporal, plástico-visual, oral y escrito) su carácter social mejorará el aprendizaje además de ayudar al individuo a interiorizar la cultura de su entorno.

El arte no es sólo una forma de expresión, constituye también una forma de conocimiento. Aprovechar su ejercicio (incluida la aceptación de prácticas tradicionales como la pintura, escultura o el dibujo) puede ser un medio capital para el desarrollo de la capacidad perceptiva, la interpretación del entorno y la comprensión, de los distintos lenguajes artísticos.

\section{LA IMPORTANCIA DE LA EDUCACIÓN ARTÍSTICA EN EL S. XXI.}

Podríamos distinguir diferentes formas de abordar la presencia del arte en la enseñanza:

- Educar en el arte: trata de enseñar al alumnado a conocer los 
fundamentos históricos del arte, sus escuelas, movimientos, autores, etc. Conocer el arte se convierte en el contenido de la educación.

- Educar para el arte: se pretende enseñar para formar en la competencia técnica de las diversas presentaciones artísticas. El lugar en el que se forma en estos campos son las Facultades de Bellas Artes, las Escuelas de Arte y otras instituciones de carácter no formal. La finalidad de estas enseñanzas es formar a un especialista en las disciplinas que constituyen el currículo y que las utilice en su propuesta de actividades. El aprendizaje es progresivo pues cada conocimiento adquirido permite el acceso a otro posterior de mayor complejidad.

- Educar a través del arte: se utilizan los recursos artísticos en las propias estrategias educativas. No solo es el objeto de estudio sino que funciona como mediador de los contenidos actitudinales que se quieren transmitir. Se trata lograr una mejora de ámbito general en el conjunto de la formación. Introduciendo estos contenidos en el modelo educativo se pretende incluir aspectos que todavía hoy no se revelan presentes en el curriculum y que ayudan a aprender a trabajar en objetivos comunes en los que se consigue introducir valores, actitudes, percepciones y sentimientos. A tener distintos puntos de vista sobre una misma realidad. Educar a través de recursos estéticos permite captar la riqueza del mundo emocional y relacional del individuo, proceso esencial para cualquier cambio o movilidad en el ser humano, como bien vislumbraba Vygotsky (1986). Así como Read (1996) para quien esta propuesta no tiene como fin hacer de todos los individuos artistas, sino acercarles por medio de recursos artísticos a otros lenguajes o a otras formas de acceder al conocimiento, que les permitan nuevos y distintos modos de comunicación y expresión, desarrollando las competencias individuales interrelacionadas con lo social, a través de la sensibilización, la experimentación, la imaginación y la creatividad.

Además podemos constatar que si bien antes la publicidad o los mensajes se transmitían más por el texto o las palabras, comprobaremos que culturalmente hoy en día nos comunicamos sobre todo por imágenes. Aquí es donde entra 
con toda su fuerza la necesidad de la educación artística actual. Nos afecta especialmente en nuestro entorno de formación en las aulas en las que, independientemente de que nos basemos en aspectos culturales, materiales o de arte contemporáneo, la EA puede beneficiarse de todos ellos. Lo que importa es que los estudiantes puedan trabajar sobre su propia realidad cultural y sus intereses, utilizando, eso sí, la EA. De esta forma además de adquirir conocimientos más profundos sobre lo que les rodea pueden expresar su propio punto de vista sumándole un nuevo lenguaje.

La educación artística tiene como objetivo transmitir la relación cultural a los jóvenes y prepararlos para que puedan generar su propio lenguaje artístico y contribuir así a su formación global (emocional y cognitiva). Por tanto, la educación artística implica al niño y a la niña tanto en el plano académico como en el personal. Son dos los enfoques que pueden adaptarse en la educación artística: la educación en el arte supone transmitir a los alumnos las prácticas y los principios de diferentes disciplinas artísticas, con la idea de estimular su conciencia crítica y su sensibilidad y permitirles construir identidades culturales. En cambio, la educación a través del arte implica considerar el arte como vehículo de aprendizaje de otras materias y como medio para alcanzar resultados educativos más generales (Bamford, 2009, p. 24).

En este punto es en el que queremos incidir desde este trabajo, intentando, tras analizar la cuestión de cómo está estructurada la formación de los maestros y el curriculum, intentar romper la dinámica de ese círculo vicioso.

En EEUU el informe Tough Choices or Tough Times (National Center on Education and the Economy, 2006) pedía cambios en el currículo, afirmando que es necesario integrar el pensamiento crítico y la creatividad en el mismo currículo.

Hernández (2008) partiendo de una metodología predominantemente cualitativa, utiliza procedimientos artísticos (literarios, visuales y performativos) en los que tantos los diferentes sujetos (investigador, lector, colaborador) como las interpretaciones sobre sus experiencias, develan aspectos que no se hacen 
visibles en otro tipo de investigación. Pretende considerar otras maneras de ver los fenómenos a los que se dirija el interés del estudio.

Cada uno de los investigadores presenta ejemplos de sus intentos de dar significado a cuestiones que son importantes a través de una indagación artística. Todos están implicados en sus procesos creativos. Algunos exploran temas en torno al yo y la identidad. Otros afrontan la cuestión del cambio en los sistemas terapéuticos y educacionales o en las relaciones cliente/estudiante. En cada uno de estos campos el compromiso del autor se vincula a una forma particular de arte que le sirve como medio-guía para la indagación y como vehículo a través del cual emerge la investigación (Hernández, 2008, p. 91).

Hemos argumentado en apartados anteriores como, históricamente, seguimos manteniendo estructuras educativas basadas en la era industrial. Ello está generando un sistema educativo anacrónico que no responde a las necesidades de los estudiantes y del ciudadano de hoy en día (Robinson, 2011). Es evidente que han surgido propuestas que intentan marcar otras líneas de pensamiento como son las referidas a la importancia de la educación emocional (Goleman, 2009), de la educación por competencias (LOE, 2006) y no por objetivos, acerca de la necesidad del aprendizaje durante toda la vida (Gómez, 2007). Pero se han mostrado insuficientes para responder a la demanda social de la era digital.

La sociedad contemporánea requiere un replanteamiento de las habilidades necesarias para responder a los nuevos trabajos, pues los requisitos han cambiado pero las personas no han recibido una educación adecuada. En la entrevista realizada a Ken Robinson en el Institute for the Future for the University of Phoenix Research Institute, expresa:

Uno de los motivos por los que defiendo con tanta pasión que hay que modificar la educación y replantearse la creatividad es porque me parece que, a no ser que cambiemos nuestra manera de pensar en nosotros mismos, no estaremos a la altura de los desafíos a los que nos enfrentamos ahora (Robinson, 2011: final entrevista) 
Robinson, experto en creatividad e innovación, ha comentado:

(..) la mayor parte de nuestros sistemas educativos están desfasados. Son anacrónicos. Se crearon en el pasado, en una época distinta, para responder a retos diferentes.(...), en la mayoría de sistemas, se insiste mucho en elevar los estándares de matemáticas y de lengua, que por supuesto son muy importantes, ipero no son lo único que cuenta en la educación! Las disciplinas artísticas cuentan, las humanidades cuentan, la educación física también... (Robinson, 2011, p. 1).

Para Robinson (2009, contraportada): "El mundo cambia a una velocidad vertiginosa. Es imposible adivinar cómo viviremos en el futuro. Lo único que sabemos es que hará falta mucha imaginación y creatividad para transformarnos y afrontar los nuevos retos."

Si atendemos en primer lugar a lo expresado en la XXX Sesión de la Conferencia General de las Naciones Unidas de París en el año 1999 por Federico Mayor Zaragoza, presidente de la Fundación Cultura para la Paz, a favor de la promoción de la Educación Artística y de la creatividad en la escuela:

En un mundo en el que las estructuras familiares y sociales se transforman a causa de unos impactos, a menudo negativos, sobre los niños y los adolescentes, la escuela del siglo XXI debe ser capaz de anticiparse a las nuevas exigencias, concediendo un lugar privilegiado a la enseñanza de unos valores y unas materias artísticas que favorezcan la creatividad. Ha llegado el momento de permitir que los niños que acuden a la escuela se beneficien de esta enseñanza.

Según los términos del Acta fundacional de la UNESCO la dignidad del hombre exige la difusión de la cultura y la educación en pro de la justicia, la libertad y la paz. En consecuencia, en nombre de la Organización de las Naciones Unidas para la educación, la ciencia y la cultura hago una solemne llamada a los estados miembros de la UNESCO para que tomen las medidas administrativas, financieras y jurídicas adecuadas a fin de que la enseñanza de las artes, que incluyen materias tales como la poesía, las artes plásticas, la música, el teatro, la danza o el cine, tengan carácter 
obligatorio a lo largo del ciclo escolar, es decir, desde la escuela infantil hasta el último año de la enseñanza obligatoria. ${ }^{191}$

Araño (1989) nos habla de que se necesitan contribuciones teóricas y prácticas que permitan superar el desinterés por la EA que manifiesta la sociedad española.

Olaiz (2010) entiende el arte como una construcción cultural y cambiante, punto de confluencia de valores, ideas y símbolos culturales diversos. Coincidimos con esta visión que está además recogida como una de las claves del concepto de competencias básicas otorgado por nuestra legislación como punto de distinción con otras legislaciones europeas, la interdisciplinariedad.

Organismos como la UNESCO, investigadores reconocidos internacionalmente, así como en los propios informes y declaraciones elaborados por el Ministerio de Educación y Ciencia, se resalta la importancia de la alfabetización visual. En un mundo donde las imágenes cada vez están más presentes, tanto los creadores como los espectadores deben disponer de unos conocimientos de lenguaje visual que les permitan valorar tanto el mensaje como la calidad de los productos audiovisuales que crean o que les rodean. Según estos numerosos informes y autores, promocionar la alfabetización visual en un mundo dominado por lo visual permitirá entre otros, hacer más efectiva la comunicación, fomentar la creatividad, la individualidad, la observación critica y el disfrute visual. Los avances tecnológicos actuales han puesto al alcance de muchas personas herramientas tecnológicas que se utilizan en la mayoría de los casos sin formación previa sobre lenguaje visual.

Según diversas investigaciones realizadas, la educación en y a través de las artes estimula el desarrollo cognitivo y fortalece el pensamiento divergente. Enseña a los alumnos a tomar y valorar las decisiones basadas en sus percepciones, evaluándolas y rectificando las veces necesarias hasta alcanzar una decisión final. Esta transformación, que se fortalece con las artes, es la

191 Organización de las Naciones Unidas Para la Educación, la Ciencia y la Cultura. Actas de la Conferencia General, vol. 1, Resoluciones, 74-75. 
que llamamos frecuentemente "creación" o proceso creativo. En el mundo en que nos desenvolvemos es muy importante saber generar ideas creativas en cualquier ámbito.

De la misma forma la EA sirve para comunicarse, relacionarse, expresarse, aprender, sentir y tender puentes cuando no se dominan suficientemente otros lenguajes. Hablamos aquí de su poder y utilidad en la integración de la diversidad y de la interculturalidad.

En 2006, Organizada por la UNESCO y el Gobierno de Portugal, se celebra la Primera Conferencia Mundial sobre Educación Artística, en Lisboa, Portugal ${ }^{192}$. Es la culminación de un proceso de colaboración iniciado cinco años antes entre la UNESCO y las ONG especializadas, asociadas al programa de la Educación Artística. La Conferencia reunió a más de 1200 participantes, de 97 Estados Miembros.

Fueron discutidos los siguientes temas:

- Promoción y políticas de introducción de la Educación Artística. En este punto se debate el papel fundamental que ha adquirido el concepto de creatividad con respecto al arte y la educación dentro de la sociedad postindustrial. También se aborda el nuevo papel del arte y el aprendizaje mediante este para intentar acercarlo al ámbito escolar. El objetivo es utilizar la EA como herramienta pedagógica para que el niño pueda identificar su cultura y sentirse parte de ella a la vez que dentro de un mundo globalizado.

- Impacto de la Educación Artística en las esferas sociales, culturales y académicas. Se abordara partiendo de investigaciones que justifiquen y demuestren que la introducción de la EA ha tenido un papel decisivo a la hora de abordar temáticas variadas sobre cohesión social, no- 
violencia, patrimonio, la mejora de la capacidad de aprendizaje, resolución de conflictos, trabajo en equipo y creatividad.

- Educación de calidad en relación a la formación de docentes y a métodos pedagógicos. Se resalta la necesidad de dotar a los docentes de competencias especificas en EA así como la posibilidad de integrar a los artistas en los procesos educativos. Es pues de vital importancia la formación inicial y continua del profesorado en las disciplinas artísticas para que adquieran métodos pedagógicos que se basen en la creatividad.

- Promoción de Consorcios para la introducción de programas de Educación Artística.

Siguiendo esta pauta en 2010 se lleva a cabo una Segunda Conferencia Mundial sobre Educación Artística, esta vez en Seúl ${ }^{193}$. Se organiza también en colaboración de la UNESCO y toma como partida lo que se trabajó en la anterior de Lisboa.

Numerosos expertos internacionales debatieron sobre la forma de poner en valor el papel de la EA y su promoción en la comunidad internacional. La UNESCO integra esta cuestión en su programa sobre la educación de calidad para todos. En esta Conferencia se trabaja sobre los resultados obtenidos en un cuestionario que la UNESCO remitió a los miembros para evaluar la Hoja de Ruta ${ }^{194}$ marcada anteriormente. Los resultados se presentarán en esta Segunda Conferencia y reflejan la gran diversidad de acciones diferentes que se llevan a cabo dentro de este campo según las distintas culturas y países.

Dada esta situación se potencia la capacidad que tiene la EA para crear cohesión social y cultural sin desatender la diversidad propia de cada forma de gestionar la educación. Se evalúan los diferentes contextos educativos tanto a

${ }^{193}$ Para mayor información consultar la web de la misma:

http://www.unesco.org/new/fr/culture/themes/creativity/arts-education/worldconferences/2010-seoul/

194 Hoja de Ruta para la Educación Artística, Conferencia Mundial sobre la Educación Artística: construir capacidades creativas para el siglo XXI (Lisboa). 
nivel formal como no formal y se fomenta la visión interdisciplinar que permite la EA.

Otro tema importante abordado en esta Conferencia es la necesidad de llevar a cabo una investigación de calidad sobre el impacto de la EA para ofrecer datos significativos así como asegurar que tengan una difusión suficiente. Se alienta la generación de redes y cooperaciones para llevar adelante estos trabajos de cooperación (planes de la UNESCO, la red de observatorios de Asia y el Pacífico, el proyecto piloto de la realización de un glosario, etc.)

Considerando estas Conferencias y todo lo que de ellas deriva creemos que sirve de respaldo a nuestra afirmación sobre la importancia de la EA en educación y al beneficio de la vida de las personas.

Nos gustaría destacar un caso en el que se ha llegado a poner en práctica a nivel institucional la integración de la EA en el sistema educativo. Irène Sénécal, es conocida por sus innovaciones en el terreno de la EA en Quebec (Canadá) entre las décadas de 1930 a 1960. Impartió docencia en diferentes niveles educativos e investigó sobre innovaciones educativas en ámbitos formales y no formales. Su trabajo fue tan importante y valorado que estableció una nueva forma de abordar la enseñanzas artísticas en el sistema educativo de Quebec. Plantea aspectos teóricos y prácticos sobre la EA basándose en las innovadoras tendencias metodológicas a nivel internacional para paliar la poca calidad del método tradicional de enseñanza del dibujo en las escuelas. Aborda todo el espectro de factores educativos y llega a establecer recomendaciones institucionales sobre cuál ha de ser el papel del Estado en el desarrollo de las artes, como ha de formarse al profesorado especialista y el reconocimiento y lugar que ha de ocupar la EA para sustituir a los tradicionales cursos de dibujo. Dedicó mucho trabajo a formar al profesorado que más adelante daría continuidad a sus métodos e innovaciones educativas. Por otra parte, entre 1965 y 1968, el recién creado Ministerio de Educación asumió muchas de sus propuestas. Desde 2006 el Ministerio de Educación, Ocio y Deportes (MELS) introdujo una reforma educativa en la que las artes forman parte del curriculum del alumnado ya que son materias obligatorias en toda la primaria. Se abordan dos materias 
artísticas entre danza, música, arte dramático y artes plásticas. Desde 2010 es reconocido como uno de los cinco campos de conocimiento y se introducen también en secundaria, siendo una materia a superar para poder obtener el diploma de estudios secundarios. En este sistema educativo el arte y la cultura forman parte importante de la formación de los jóvenes pues consideran que "contribuyen al desarrollo integral del joven, a su interacción con su entorno y comunidad y a ampliar sus conocimientos culturales".

Hoy en día, notar la existencia de la AQESAP ${ }^{195}$, producto de la unión de varias asociaciones que agrupa personas implicadas tanto en la organización y como en la enseñanza de las artes plásticas en todo el sistema educativo de Quebec. Realiza numerosas actividades encaminadas a promover y defender la calidad de enseñanza de las artes, estimular la investigación, compartir, por diferentes medios, experiencias docentes. Además de todo tipo de acciones que permitan desarrollar estas premisas. Entre otras favorecen la relación entre medios culturales y escolares, lo cual se traduce, entre otros ejemplos en el acceso gratuito a la mayoría de los museos.

Abordamos a continuación el caso de nuestro entorno más cercano para recoger lo visto con anterioridad de forma pormenorizada.

Desde su creación en el siglo XIX, los centros de formación de maestros, con sus distintas denominaciones, han desarrollado su labor educativa. Actualmente se encuentran totalmente integrados en la Universidad aunque bajo diferentes denominaciones, según estén integrados en las facultades de Educación o de otra forma.

Lo que hoy en día entendemos por EA ha estado presente en los diferentes planes de estudio, que como se ha expuesto, han ido cambiando a través de los diversos acontecimientos políticos y sociales. Según las épocas su denominación ha ido variando para ajustarse a los contenidos que en cada momento se impartían.

195 Association Québécoise des éducatrices et éducateurs spécialisés en arts plastiques. 
Junto al desarrollo en las Escuelas de Magisterio, han ido en paralelo los currículos de la Educación Infantil y Primaria. A partir de la década de los años sesenta es cuando se empieza a conceder en nuestro país cierta importancia a la Educación Artística, con más de cincuenta años de retraso con muchos países del resto de Europa.

Desde el año 1970, con la Ley General de Educación, se va desarrollando en nuestra sociedad un cambio en el currículo que configura la EA en la Educación Básica. La EA alcanza cierta consolidación con la LOGSE en el año 1990. A pesar de ese evolución, en lo que debe ser el proceso educativo, la EA sigue sin ocupar un lugar propio dentro del currículo del sistema educativo de la enseñanza general con el consiguiente déficit en EA en nuestro país. No se ha conseguido obtener la presencia de profesores especialistas en la materia ni una presencia significativa en la escuela. Ello ha influido por lo tanto, o al revés, en que en la Universidad tampoco se haya potenciado la formación de estos profesores especialistas.

Según el Real Decreto 1888/1984 de 26 de septiembre ${ }^{196}$, se crea el Catálogo de Áreas de Conocimiento para las materias impartidas en la Universidad. La denominación inicial de esta área fue la de «Didáctica de la Expresión Musical, Plástica y Corporal», quedando englobado en ella el profesorado de Dibujo, Educación Física, Expresión Plástica y Música de las Escuelas Universitarias de EGB y de Pedagogía del Dibujo de la Facultad de Bellas Artes. A petición de la comunidad universitaria, el Consejo de Universidades en $1987^{197}$ modificó el Catálogo de Áreas de Conocimiento en vigor suprimiendo la de Didáctica de la Expresión Musical, Plástica y Corporal y creando tres nuevas áreas de conocimiento: Didáctica de la Expresión Plástica (193); Didáctica de la Expresión Corporal (195); Didáctica de la Expresión Musical (189).

En el área de Didáctica de la Expresión Plástica (193), en 2004, tenemos el siguiente listado de materias troncales clasificadas por área de conocimiento y titulación: 
Tabla 35. Denominación Troncales del área de Did. de la Exp. Plástica.

\begin{tabular}{|c|c|c|c|}
\hline $\begin{array}{l}\text { TITULACION } \\
\text { MAESTRO }\end{array}$ & DENOMINACION & CONTENIDOS & CREDITOS \\
\hline Educación Especial & $\begin{array}{l}\text { Expresión Plástica y } \\
\text { Musical }\end{array}$ & $\begin{array}{l}\text { Aproximación al } \\
\text { fenómeno artístico. La } \\
\text { expresión plástica y } \\
\text { musical. El mundo } \\
\text { creativo y expresivo del } \\
\text { niño. } \\
\text { Contenidos, recursos y } \\
\text { materiales para la } \\
\text { educación artística. } \\
\text { Aspectos terapéuticos } \\
\text { y de diagnóstico en la } \\
\text { educación. }\end{array}$ & $4 \mathrm{Cr}$ \\
\hline Educación Física & $\begin{array}{l}\text { Educación Artística y } \\
\text { su Didáctica }\end{array}$ & $\begin{array}{l}\text { Aproximación al } \\
\text { fenómeno artístico. La } \\
\text { expresión plástica y } \\
\text { musical. El mundo } \\
\text { creativo del niño. } \\
\text { Contenidos, recursos y } \\
\text { materiales para la } \\
\text { educación artística. }\end{array}$ & $4 \mathrm{Cr}$ \\
\hline Educación Infantil & $\begin{array}{l}\text { Desarrollo de la } \\
\text { Expresión Plástica y } \\
\text { su Didáctica }\end{array}$ & $\begin{array}{l}\text { El lenguaje visual en la } \\
\text { educación infantil. } \\
\text { Valores educativos y } \\
\text { elementos de la } \\
\text { expresión plástica. La } \\
\text { globalización en la } \\
\text { expresión plástica. } \\
\text { Recursos didácticos y } \\
\text { materiales en la } \\
\text { expresión plástica. }\end{array}$ & $6 \mathrm{Cr}$ \\
\hline Educación Primaria & $\begin{array}{l}\text { Educación Artística y } \\
\text { su Didáctica }\end{array}$ & $\begin{array}{l}\text { Aproximación al } \\
\text { fenómeno artístico. La } \\
\text { expresión plástica y } \\
\text { musical. El mundo } \\
\text { creativo y expresivo del } \\
\text { niño. Contenidos, } \\
\text { recursos didácticos y } \\
\text { materiales para } \\
\text { educación artística. }\end{array}$ & $4 \mathrm{Cr}$ \\
\hline Lengua Extranjera & $\begin{array}{l}\text { Educación Artística y } \\
\text { su Didáctica }\end{array}$ & $\begin{array}{l}\text { Aproximación al } \\
\text { fenómeno artístico. La } \\
\text { expresión plástica y } \\
\text { musical. El mundo } \\
\text { creativo del niño. } \\
\text { Contenidos, recursos y } \\
\text { materiales para la } \\
\text { educación artística }\end{array}$ & $4 \mathrm{Cr}$ \\
\hline
\end{tabular}

Fuente: Elaboración propia.

Remarcamos la escasa dedicación horaria y lo ambiguo de sus contenidos, que apenas difieren aparentemente de unas especialidades a otras. Para los 
docentes, el plan de estudios se presenta, normalmente saturado de contenidos. Intentarán multiplicar sus esfuerzos para conseguir alcanzar el estándar que se les pide. Pero el profesorado de EA encuentra dificultades en obtener resultados cuantificables, en la forma en que se exigen en otras asignaturas. Las peculiaridades de la disciplina artística no se ajustan al modelo uniforme que se quiere implantar. En la Educación Artística, el docente tiene poco margen para propiciar en el alumnado la experimentación y el descubrimiento. Las pocas horas semanales y el numeroso alumnado por clase le inclinan hacia prácticas que le resultan asequibles en tiempo y resultados.

Todo ello, evidentemente repercute en la calidad de la formación de los maestros que no conseguirán alcanzar unas competencias suficientes para poder impartir la asignatura con suficiencia.

Podríamos aventurarnos en el apunte para una Propuesta Metodológica para la optimización de la EA, el diseño de una herramienta de trabajo para la mejora de la didáctica de la EA en el entorno académico, adaptada a las necesidades de los alumnos de grado. Con esta herramienta lo que pretenderíamos sería plantear una innovación docente que fomente la educación visual del alumno de grado en nuestro entorno universitario.

Este planteamiento, que excede del ámbito de este trabajo, podría realizarse tras la recogida de datos observacional que nos permitiera elaborar unas pautas de metodología docente innovadora en la que implementáramos unas unidades didácticas con ejercicios determinados para el aula que como resultado obtuviéramos una mejora en la alfabetización visual del alumnado de Grado de Maestro. Revisando y cuestionándonos nuestros planteamientos conseguiríamos mejorar nuestro trabajo proponiendo acciones de mejora que consiguieran hacerles más competentes.

Para ello podríamos relacionarlo con la antes nombrada "enseñanza para la comprensión", de la que hablaba Morín (1999), que nos servirá para identificar nuestra identidad entre las identidades de los demás. El modelo de la escuela inteligente, un conjunto de siete directrices para una buena educación basado 
en dos pautas: el aprendizaje es la consecuencia de pensar y todos los estudiantes pueden aprender a pensar bien. El aprendizaje debe incluir una comprensión profunda, que involucra el uso flexible, y activo del conocimiento. Perkins y Blythe (2005) dicen que esta comprensión “...es poder realizar una gama de actividades que requiere el pensamiento en cuanto a un tema...explicarlo, generalizarlo, aplicarlo, presentar analogías y representaciones de una manera nueva." Este enfoque didáctico es desarrollado en el proyecto Zero de de la Escuela de Educación de la Universidad de Harvard, liderado por David Perkins. La Enseñanza para la Comprensión está ligada a la acción, es decir a la capacidad que tiene un individuo de dominar los conocimientos y aplicarlos a otras situaciones.

El primer elemento a tener en cuenta, en este caso, es como se produce la transmisión de los conocimientos. Se pretende conseguir del alumnado que en el área artística tenga capacidad intelectual y emocional para entender los significados de los productos artísticos de su tiempo y posteriormente, ser capaz de repetirlo y explicarlo. Una vez cumplido este paso, el alumnado debe, aprovechando las experiencias anteriores, saber poner en práctica sus habilidades, ejecutando y aplicando lo que ha aprendido. El punto definitivo sería cuando, fuera capaz de interpretar de forma crítica y producir elementos culturales. Está preparado para comprender: pensar y actuar de forma creativa e innovadora. De esta forma recoge datos e información (visual y verbal), los elabora de forma diferente para explicarlos y presentarlos de manera personal. Realiza un trabajo de exploración, sigue con un proceso de investigación guiada para poder llegar a un desarrollo final sintético. Esta actividad la realiza no solo sobre imágenes ajenas sino que también puede actuar con las suyas propias o las de compañeros, de forma que no permanezca en estado de aislamiento ante las necesidades del mundo real.

En este proceso interviene tanto la actitud del profesor como la del alumnado. Las dos deben ser activas. La labor del profesor será:

- Coordinar, crear ambientes de trabajo y tutorizarlos y guiarlos. 
- Explicar los aspectos fundamentales necesarios para que se pueda desarrollar los temas.

El trabajo del alumnado consistirá en:

- Entender y saber utilizar la información que se le proporcione.

- Plantear la propuesta de trabajo a realizar. Organizarlo y seguir su desarrollo.

o Definir el motivo de trabajo que conecte todos los contenidos.

o Concretar cronología y desarrollo del mismo.

o Proponer las actividades a realizar y las técnicas/procedimientos a utilizar.

o Hacer una presentación pública del mismo, una vez llevado a término.

Esta forma de trabajar implica tanto al profesorado como al alumnado. El profesor es como un asistente ambulante, que va respondiendo a las necesidades, escuchando las preguntas, dudas y confusiones. Está atento a los progresos y a reconducir los procesos. Genera debates abiertos en clase en los que escucha los razonamientos y las preguntas, que de esta forma sirven para el conjunto del alumnado. En muchas ocasiones deberá relativizar los criterios artísticos y estéticos atendiendo a la diversidad cultural con la que trate. Solicita al alumnado que escriba sus reflexiones ya que le servirán para elaborar el producto final.

En el apartado de la evaluación también hay una intervención conjunta. Una vez explicados y compartidos los elementos de evaluación, el alumnado se evalúa entre sí. Esto fomentara la reflexión y producirá una retroalimentación. Los criterios deben ser claros y explícitos, en el inicio de la actividad, pertinentes a la actividad que se está realizando y públicos, todos los de la clase los saben y los comprenden.

Esta retroalimentación debe proporcionarse con frecuencia, en distintos momentos y desde diferentes fuentes. En el inicio y durante todo el desarrollo del trabajo, ya sea de forma planeada, en las que se le pide que opine sobre 
alguna actividad, o bien espontanea, cuando surja en cualquier conversación de clase. Conforme va avanzando el trabajo también se puede ir dando valoraciones que permitan mejorar lo que se realice con posterioridad. la evaluación no es algo aislado en el proceso de enseñanza sino que forma parte del proceso de aprendizaje. También esta herramienta permite valorar y respetar las diferencias individuales, porque se tiene en cuenta el desempeño de cada alumno y cómo este muestra su comprensión.

La temporalización de las actividades debe estar clara y disponible. Las valoraciones del producto final vendrán así de las reflexiones que haga, las actitudes y decisiones que adopte tras estas reflexiones, las valoraciones de sus compañeros y finalmente del docente.

Esta valoración constante no suele ser fácil para el alumnado si no tiene unos criterios claros y aprende a aplicarlos. Para que se familiaricen con ello deben ir practicando y tener el tiempo suficiente para asumirlo. Ello lo conseguiremos proporcionando oportunidades diferentes a lo largo del proceso para que puedan ir ejercitándose en la autoevaluación, la evaluación por parte de sus compañeros y la del docente. Es mucho mejor que si solo se hace al final.

Se les puede implicar también en la determinación de factores de evaluación, valorar el efecto que les produce la opinión de externos, o pueden elaborar portafolios o cuadernos de reflexión ya que les ayudará a aprender de forma progresiva.

Otras actuaciones que favorecerán este tipo de enseñanza es:

- Relacionar la instrucción en clase con las tareas y experiencias que los estudiantes encontrarán fuera de la escuela y particularmente en el mundo del trabajo.

- Contar con los variados esfuerzos de instituciones culturales para enriquecer la educación en las artes con el diseño de juegos, exhibiciones interactivas y otras actividades que fomentan una variedad de estilos de aprendizaje y atraen nuevos públicos a los museos. 
- Llevar artistas a las escuelas como mentores, interpretes, o para perfeccionamiento de profesores.

- Utilizar métodos de evaluación innovadores que evalúan las diferentes formas en que el aprendiz piensa, y no solo habilidades lingüísticas y matemáticas, métodos que incluyen proyectos, portafolios, portafolios en video, que consideran las habilidades que los estudiantes tienen para usar la información en forma flexible y apropiada en situaciones de la vida real.

Al docente todas estas actividades no le servirán solo para evaluar el trabajo del alumnado sino que podrá valorar su propio trabajo y el curriculum , ayudándole así a mejorar su práctica pedagógica. Adoptará una actitud crítica y reflexiva que le permitirá evaluar sus estrategias de enseñanza para lograr, mediante un proceso de innovación continua, sus propósitos educativos. El profesor asumirá un papel de investigador en el aula que, a la vez que mejora su experiencia, le permite elaborar su teoría profesional.

La enseñanza de las artes requeriría un replanteamiento desde la base: qué nivel de flexibilidad existe en cuanto a la forma de abordar el curriculum, en cuanto a la metodología a emplear o incluso a las horas de dedicación que necesita y a los docentes que implica. Lo idóneo sería poderse alejar del concepto científico de la educación para acercarse a la práctica de la educación artística de forma que adoptemos una metodología más acorde a sus necesidades.

\section{COMPETENCIAS ARTÍSTICAS DE FUTUROS MAESTROS DE PRIMARIA} E INFANTIL.

La noción de competencia se define como la capacidad de acción eficaz frente a un conjunto de situaciones que se logran dominar porque se dispone de los conocimientos necesarios y de la capacidad para movilizarlos a la vez, en el momento oportuno, a fin de identificar y resolver los problemas (Perenoud, 1999). 
Intentaremos recoger algunos de los puntos clave de lo que se considera el origen del enfoque por "competencias" en la formación, el acceso y la acreditación profesional (Bunk, 1994). Progresivamente se han ido adoptando en los sistemas educativos y de empleo a nivel internacional.

- Adopción del principio de "aprendizaje a lo largo de toda la vida" por parte de los sistemas educativos.

- La velocidad a la que cambian los requisitos de las profesiones requiere tener adquiridas las competencias específicas de la profesión pero sin olvidar competencias generales como:

o Comprender lo que se hace en el lugar de trabajo.

o Conocer el papel a desarrollar por el profesional en su lugar de trabajo.

o Tener capacidad de aprender de las acciones y saber cambiar.

En definitiva, a la capacidad de movilizar conocimientos para resolver problemas de forma autónoma, creativa y adaptada al contexto y a los problemas (Manzanares, 2004).

La Comisión Europea ha definido como competencia a una "combinación de destrezas, conocimientos, aptitudes y actitudes adecuadas al contexto, incluyendo la disposición para aprender, y el saber cómo" (CE, 2004, pp. 4 y $7)^{198}$. Se identifican cuatro elementos de la competencia profesional:

Competencia cognitiva: empleo de teorías y conceptos, así como del conocimiento tácito e informal adquirido por experiencia.

Competencia funcional (habilidades y saber hacer): lo que una persona debería ser capaz de hacer bien cuando desempeña una determinada ocupación.

198 La Ley 5/2002 de las Cualificaciones y de la Formación Profesional definió la competencia como "el conjunto de conocimientos y capacidades que permiten el ejercicio de la actividad profesional conforme a las exigencias de la producción y del empleo". 
Competencia personal: saber comportarse en un rol o situación profesional determinada.

Competencia ética: implica un comportamiento coherente con un conjunto de valores personales y profesionales.

Coll y Martín (2006) profundizan en esta perspectiva, identificando una serie de componentes esenciales en las competencias:

- Movilización de los conocimientos, posibilidad real de activar y utilizar ante un problema el conocimiento que se posee.

- Integración de los distintos tipos de conocimientos conceptuales, de las habilidades, los valores y actitudes, para comprender la realidad y actuar sobre ella de acuerdo con las metas que uno se propone.

- Transferencia de lo aprendido en una situación o contexto concreto, a otros diferentes.

- Capacidades metacognitivas (de toma de conciencia y autorregulación) que posibilitan un aprendizaje autónomo para seguir aprendiendo a lo largo de la vida.

Según estas premisas una persona competente sabe gestionar su aprehensión del conocimiento y lo utiliza ajustándose a los problemas que le plantea su entorno. Podríamos decir que sabe, sabe aplicarlo de diferentes formas adecuándose al entorno laboral, utiliza sus conocimientos para seguir adquiriendo otros nuevos y hace un uso ético de todo ello.

El alumnado en la Universidad adquiere unos conocimientos que deben serle útiles para tomar conciencia de los problemas de la sociedad en la que viven y ser capaces de resolverlos de forma eficiente y apropiada. Los conocimientos que recibe deben servirle para su formación holística tanto a nivel personal como profesional. No debe ser un cúmulo de informaciones y datos. El alumnado debe aprender a identificar los problemas, analizarlos y darles una solución adecuada. No sirven las recetas sino que su respuesta ha de ser meditada y útil. 
En definitiva un alumnado, que partiendo de un compromiso previo, favorezca mediante el intercambio de ideas la construcción del conocimiento en el aula, que sepa resolver los problemas que le surjan y que tome decisiones resolutivas tal y como ocurre con las competencias de cualquier formación, que el trabajo cooperativo sea lo habitual, que evalúe lo que estudia y que sepa aprovechar el error como oportunidad para aprender.

Hemos visto ya con anterioridad la implicación de la escuela en la realidad social, económica, política y cultural de un país. Forma parte de ese conjunto $y$, por ello, la labor del profesional de Magisterio formado en nuestras facultades tendrá que implicarse en los nuevos entornos sociales y adaptarse a las nuevas demandas, lo mismo que ocurre en otros campos profesionales . La formación que deben recibir tiene que tener en cuenta estos nuevos factores para que pueda desarrollarla adecuadamente. Entramos pues a afirmar que:

Posee competencia profesional quien dispone de los conocimientos, destrezas y actitudes necesarias para ejercer una profesión, puede resolver problemas profesionales de forma autónoma y flexible y está capacitado para colaborar en su entorno profesional y en la organización del trabajo (Bunk, 1994, p. 9).

En otros apartados hemos señalado lo importante que era para los profesionales de la enseñanza tener un espacio profesional propio reconocido socialmente. Se fue logrando con manifiestas dificultades y muy lentamente, pero a partir de la segunda mitad del siglo $X X$ se ha ido definiendo mejor qué conocimientos que se debían adquirir para poder ejercer la profesión con propiedad. Se ha ido evidenciando cada vez más la importancia que tiene una buena formación inicial y la necesidad de seguir formándose de forma permanente. Todo ello para conseguir ser un buen profesional. 
En la LOE ${ }^{199}$, en el Capítulo III que se refiere a la Formación del profesorado, el artículo 100 trata la Formación inicial, en el punto 1 dice:

La formación inicial del profesorado se ajustará a las necesidades de titulación y de cualificación requeridas por la ordenación general del sistema educativo. Su contenido garantizará la capacitación adecuada para afrontar los retos del sistema educativo y adaptar las enseñanzas a las nuevas necesidades formativas.

Y en el 102, que trata la Formación Permanente, expresa:

La formación permanente constituye un derecho y una obligación de todo el profesorado y una responsabilidad de las Administraciones educativas y de los propios centros.

Los programas de formación permanente, deberán contemplar la adecuación de los conocimientos y métodos a la evolución de las ciencias y de las didácticas específicas(...)encaminados a mejorar la calidad de la enseñanza(...)

El perfil de los profesionales de la educación se ha diversificado mucho en los últimos años: maestro, profesor de secundaria, educador social, pedagogo y psicopedagogo. La universidad forma diferentes tipos de profesionales, todos ellos dentro del ámbito educativo pero orientados hacia tareas distintas, aunque en ocasiones resulta difícil diferenciarlas. La titulación que reciben los estudiantes actuales de Magisterio son: generalista de Educación Primaria y de Educación Infantil.

Nos enfrentamos a una nueva forma de plantearse los modos de aprendizaje pues ya no se trata de enseñar contenidos sino cambiar la forma de utilizar estos para mejorar la educación. Las instituciones vinculadas al arte, la literatura o la tecnología son claves en la tarea de formación docente. En las facultades de Educación se debería invitar a colaborar de forma habitual a todo tipo de profesionales que ayudaran en la formación de los nuevos maestros,

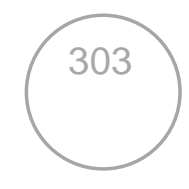


científicos, intelectuales, artistas, músicos, actores. De la misma forma podrían estar presentes en la escuela y participar de bibliotecas, museos, galerías de arte, talleres de expresión artística, etc. De esta forma estarían presentes en su formación inicial pero también en su formación posterior a lo largo de su ejercicio profesional y a lo largo de su propia practica.

Los aspectos elementales en los que se basa la formación son la forma en que el profesor transmite sus conocimientos y en cómo el estudiante aprende. En EA es importante tener un conocimiento suficiente del manejo de técnicas y materiales pero no es lo único. Existen otros contenidos artísticos importantes en el aprendizaje del alumnado. Se debe trabajar en el aula aunando la puesta en práctica y el aprendizaje de las herramientas. En las clases es importante que aprendan los contenidos artísticos a la vez que los ponen en práctica. Ello redundará en abordar la materia introduciendo modos creativos de utilizar el arte.

En muchos casos si nos dejamos llevar por lo que expone el curriculum oficial podríamos pensar que el profesor es el transmisor y poseedor de conocimientos, y que el alumno es un elemento receptor pasivo. Esto es lo primero que hay que empezar a cambiar en nuestras clases y posteriormente en la escuela.

Los docentes necesitamos trabajar de una forma diferente y cambiar la forma de impartir los conocimientos pues lo que se aprenda en EA no solo es cuestión de lo que se enseñe, sino como se enseñe. La clase magistral, debe sustituirse por métodos más activos en los que el alumnado se sienta totalmente implicado (clases prácticas, conferencias y demostraciones, investigación) y pueda poner en práctica sus conocimientos previos para adquirir otros nuevos. En este caso cualquier conocimiento previo, el uso adecuado de las nuevas tecnologías y la motivación incitaran al alumnado a buscar soluciones creativas. 
En cuanto a la forma de transmisión de conocimientos tenemos un amplio abanico de posibilidades que podemos utilizar según interese en cada momento y dependiendo de los aspectos que queramos evaluar:

- Lección Magistral. Expositivo, pues solo se transmite la información. Se produce poca interactuación con el alumno pues el profesor solo expone los contenidos. Se puede plantear al inicio de la asignatura 0 cuando tengamos que explicar algunos contenidos imprescindibles para el trabajo.

- Seminario. Permite mas interacción al utilizar una metodología más participativa.

- Trabajo en Grupo. El alumnado trabaja de forma cooperativa bajo la supervisión y orientación del profesor. Su aprendizaje es más autónomo.

- Discusión. Utilizado cuando queramos recabar opiniones sobre un contenido concreto y someterlo con las ideas personales a la valoración conjunta.

- Prácticas. Se pretende llevar a cabo situaciones reales que permitan la utilización de los medios disponibles y llegar a la solución de los problemas planteados.

- Tutorías. Sesiones utilizadas para comprobación de la marcha del trabajo y cambio de impresiones con el profesor.

Si planteamos cambios en el sistema tradicional de enseñanza, introduciendo una nueva metodología, debemos tener en cuenta que hemos de buscar la forma de valorarlo (evaluarlo) también de forma distinta. La forma de evaluar el trabajo realizado, determina totalmente la manera en que va a plantear su aprendizaje el alumnado. Si mediante pruebas o exámenes se valoran los conocimientos adquiridos el alumnado trabaja para lograr llegar a unos objetivos predeterminados al final de la etapa. Se está evaluando una suma de conocimientos pero no el aprendizaje interiorizado. No reflejaran la realidad del aula los exámenes de tipo memorístico y acumulativos sino que deberemos introducir nuevos métodos de evaluación del aprendizaje. En vez de realizar una prueba final podemos realizar pruebas puntuales a lo largo del proceso de 
aprendizaje que nos permitirán evaluar la adquisición gradual de determinadas competencias, nos dará una visión de conjunto sobre el trabajo del alumnado permitiéndonos valorar actitudes y habilidades y el conjunto de su evolución. Este seguimiento progresivo nos permitirá tener una visión integral de cual y como ha sido su aprendizaje y si este ha sido significativo. Valoraremos las capacidades del alumnado para abordar situaciones laborales futuras (practicas, estudios de casos). Por lo tanto una evaluación continua se presenta como la más ajustada a esta forma de trabajar.

Por otra parte, esta forma de evaluar resulta mucho más asequible tanto para el alumnado como para el profesorado. Por un lado se obtiene mayor número de calificaciones correspondientes al progreso de aprendizaje de los conocimientos, no se vuelcan todos al final. Esto favorece la adquisición progresiva de conocimientos. Por otra parte van viendo también progresivamente la respuesta a sus trabajos con lo que van ajustando y perfeccionando su trabajo a lo demandado. Por último recibe información sobre su propio ritmo de aprendizaje y puede ir rectificándolo, de esta manera es parte activa de su aprendizaje pues lo va construyendo conforme avanza el tiempo. Todo ello conseguirá que al final el trabajo global sea de mayor calidad y el aprendizaje mas integral. En todo momento y para que tenga su valor educativo, el alumnado debe estar informado de los métodos de evaluación y de su progresión y que insista en las ventajas que va a reportarles el seguimiento de este sistema educativo (Calderón y Escalera, 2008).

Para que la evaluación continua cumpla su misión evaluadora, Cabrera (2003) señala tres elementos clave:

- Adecuada planificación. "la evaluación no se puede identificar con un único acto (pasar un cuestionario o pasar una prueba de rendimiento), sino con un proceso, o mejor dicho, con un conjunto de procesos no improvisados ni espontáneos". Lo fundamental es definir de forma exhaustiva los objetivos que pretendemos conseguir adecuándonos a la asignatura de que se trate. En función de estos prepararemos las actividades a desarrollar, su temporalización y su evaluación. Todo ellos 
para conseguir un logro positivo. En esta preparación del proceso de desarrollo de las actividades se tendrán en cuenta factores como la temporalización y créditos disponibles de la asignatura, facilidad de acceso a la información, proporcionar el material didáctico necesario. El volumen de trabajo del estudiante y su esfuerzo es lo que nos determinara la organización definitiva de nuestra actividad docente. Es uno de los elementos que mas en cuenta tiene la contabilización de las créditos europeos. Toda esta forma de trabajar aumentara el nivel de dedicación del alumnado pero también del profesorado ya que el hacer un seguimiento concienzudo de todas las actividades para realizar una correcta evaluación exige mayor número de horas de trabajo.

- Información al estudiante. Es fundamental para favorecer su motivación y para permitirle además que pueda conocer cuál va a ser su aprendizaje y sepa como planificar se para poder llegar a las metas requeridas.

- Actividades concretas de evaluación. Evidentemente deben ser coherentes con la forma de trabajo y metodología llevada a cabo en el aula y fuera de ella. La motivación del estudiante es interesante para que participe y se implique en su propio aprendizaje.

Si nuestra intención es obtener al final del curso una valoración global del trabajo realizado, bien es verdad que un examen o una prueba final nos lo proporcionaría pero si hemos empleado una metodología de evaluación continua, tendremos numerosos datos sobre la evolución del alumnado. Lo recomendable sería realizar una exposición pública oral del trabajo realizado que nos serviría también para valorar competencias de comunicación y expresión.

A ello añadiríamos un portfolio, en el que al alumnado hiciera una reflexión personal sobre su proceso de aprendizaje y los resultados obtenidos. Con todo ello tendríamos datos suficientes como para realizar una evaluación completa del alumnado valorando su progreso en el trabajo y apreciando las diferentes facetas en las que se ha tenido que desenvolver hasta llegar al resultado final. 
Tal y como señala Zabala (1995), la evaluación no es el punto final del proceso, sino al contrario, la evaluación del aprendizaje debe concebirse como el punto de partida de un proceso de "retroalimentación" del que se derivan un conjunto de decisiones que afectarán a la planificación del curso siguiente.

El papel del profesor es el de dinamizador así como facilitador del aprendizaje. Adopta un papel real educativo pues lo que hace es guiarles en su proceso. De esta forma el alumnado aprende a decidir hacia donde y como quiere dirigir su aprendizaje. El alumnado aprende por sí mismo y lo que importa es más el proceso que el producto.

El aprendizaje, de esta forma, es más significativo pues se mueve por sus propios intereses. La gestión de la información obtenida ayudándose de las nuevas tecnologías posibilitan un conocimiento más abierto y flexible. Esto se traduce en colaboración y cooperación entre el alumnado de los hallazgos y resultados que va obteniendo e interactuación entre compañeros y con el profesor.

El cambio de papel del profesor que pasa de fuente del saber a orientador y asesor le proporciona la posibilidad de hacer una reflexión sobre su propia práctica docente a la vez que valorar y validar sus propias metodologías y actividades, lo cual consideramos de gran importancia.

Tabla 36. El cambio del modelo de profesorado.

\begin{tabular}{|l|l|}
\hline \multicolumn{1}{|c|}{ Modelo Tradicional } & \multicolumn{1}{c|}{ Modelo Propuesto } \\
\hline $\begin{array}{l}\text { Profesor como único responsable de su } \\
\text { trabajo }\end{array}$ & $\begin{array}{l}\text { Profesor que forma parte de un equipo } \\
\text { docente }\end{array}$ \\
\hline $\begin{array}{l}\text { Profesor como instructor y transmisor de } \\
\text { conocimientos }\end{array}$ & $\begin{array}{l}\text { Profesor como mediador y facilitador } \\
\text { cultural }\end{array}$ \\
\hline Aplica la normativa incondicionalmente & $\begin{array}{l}\text { Adapta las normativas al contexto escolar } \\
\text { específico }\end{array}$ \\
\hline $\begin{array}{l}\text { No afronta las situaciones sociales } \\
\text { conflictivas. Su enseñanza es uniforme. }\end{array}$ & $\begin{array}{l}\text { Interpreta y asume el modelo social de } \\
\text { nuestro tiempo. Respeta las diferencias } \\
\text { individuales. }\end{array}$ \\
\hline Mayor importancia de lo que se enseña & $\begin{array}{l}\text { Mayor importancia el proceso de } \\
\text { aprendizaje }\end{array}$ \\
\hline Utiliza recursos & Diseña y gestiona sus propios recursos \\
\hline
\end{tabular}




\begin{tabular}{|l|l|}
\hline $\begin{array}{l}\text { La información sigue una única dirección: } \\
\text { de profesor a alumnado. Expositivo }\end{array}$ & $\begin{array}{l}\text { El aprendizaje es mutuo y bidireccional. } \\
\text { Se busca el conocimiento conjuntamente }\end{array}$ \\
\hline $\begin{array}{l}\text { Los resultados de aprendizaje son acierto } \\
\text { y no acierto }\end{array}$ & $\begin{array}{l}\text { No hay un conocimiento definido como } \\
\text { cierto. Existen diversas soluciones para } \\
\text { un mismo problema. }\end{array}$ \\
\hline $\begin{array}{l}\text { El alumnado necesita del profesor para } \\
\text { trabajar }\end{array}$ & $\begin{array}{l}\text { El alumnado gestiona su aprendizaje de } \\
\text { forma autónoma }\end{array}$ \\
\hline $\begin{array}{l}\text { No se contempla especialmente el uso de } \\
\text { las TICs }\end{array}$ & $\begin{array}{l}\text { Las TIC están presentes como una } \\
\text { herramienta mas }\end{array}$ \\
\hline
\end{tabular}

Fuente: Elaboración propia.

La formación del profesorado y el curriculum de las enseñanzas deberían por lo tanto tener muy en cuenta la experiencia y reflexión de los docentes. Una buena formación debería contar con:

- Formación técnica, correspondiente a las materias que han de impartir.

- Formación pedagógica, didáctica, de tecnología, organización escolar, psicología, filosofía y de sociología de la educación. Proporcionarían al profesor en formación la base necesaria para conseguir "saber enseñar".

- Formación práctica en la que adquiriría destrezas, técnicas, procedimientos que podría aplicar en su futura labor docente.

- Formación actitudinal que haría que el futuro profesor valorara su profesión.

Si consideramos que la formación general de los maestros es mejorable, cuando hablamos del área de EA, que no ha tenido nunca especialidad ni en la formación ni en la escuela, deberíamos reflexionar acerca de cuál es el nivel que consideramos que tiene realmente nuestro alumnado para impartir la materia.

La formación del maestro de EA debería tener unos conocimientos científicos y culturales amplios vinculados a los contenidos que conforman en curriculum de Educación Primaria junto a contenidos propios del área artística para garantizarles una formación de calidad que les permitiera ser competentes en la materia. El futuro profesor debe adquirir una formación no como artista plástico, sino como orientador didáctico, por lo que ha de tener conocimientos 
técnicos para poder desarrollar las materias artísticas y desenvolverse en los distintos lenguajes gráficos. Una buena formación previa es imprescindible para poder enseñar convenientemente después y promover el disfrute del mundo artístico al alumnado.

Es importante considerar las asignaturas de EA como fundamentales en los estudios conducentes a la formación del profesor de éste área de conocimiento. Para todo aquel que aspire a ser un profesional de la EA también es fundamental la didáctica del área y la metodología que emplea en las clases. A esto habría que añadir la voluntad por una Formación Permanente para que tras finalizar sus estudios pueda seguir ampliando sus conocimientos y seguir mejorando en su labor docente. Recordamos el informe de la UNESCO redactado por Delors (1996) que reflejaba la necesidad de esta formación pues manifestaba que "La educación debería desarrollarse a lo largo de toda la vida, como acceso al siglo XXI". Esta formación podría buscarse en numerosos ámbitos ya sean cursos reglados, de enseñanza no formal u otro tipo de instituciones.

El problema más grave que se debería resolver, para conseguir una buena educación plástica, refiriéndonos al profesorado, sería convencer a este de la validez y de la transcendencia de esta materia, o mejor aún, de la ausencia de esta materia en la formación de los alumnos de la escuela primaria. (Moreno, 2001).

Si obviamos la enseñanza Infantil ya que trata los contenidos de forma globalizada y centramos nuestra mirada en la formación de los maestros de Primaria hemos observado la escasa Formación Inicial que les proporciona el curriculum universitario. Los contenidos se centran casi exclusivamente en los recursos didácticos. En el curriculum escolar, el área de Educación Artística está integrada por la música y la plástica. Sin embargo no es habitual que se trabaje conjuntamente, se realizan las actividades por separado de Música (canciones, danzas) y trabajos de plástica por otro. Ello viene sobre todo condicionado porque quienes las imparten son profesores diferentes, el de música es un especialista y la plástica la imparte el maestro generalista. Lo 
interesante seria que pudieran recibir una formación integrada con una metodología globalizadora en la que recibieran formación sobre aspectos creativos para que pudieran aprovechar el potencial que les ofrece el área. Estas estrategias metodológicas permitirían integrar las dos disciplinas pero sin que ninguna de ellas predominara sobre la otra sino que formaran parte de un trabajo globalizado a partir del área de Educación Artística. Nos permitiría utilizar lenguajes alternativos al verbal para poder explorar otras formas de comunicación.

No queremos finalizar este apartado sobre los maestros en la escuela sin citar las opiniones recogidas por Cuenca (2009) de un profesor de la Escuela Normal de Maestros de Guadalajara, en los primeros años del siglo veinte, Alberto Blanco Roldán. Este profesor publica en 1919, una monografía titulada "El dibujo libre y espontáneo de los niños y su relación con la inteligencia". Nos gustaría compartir alguna de sus interesantes opiniones sobre los maestros y la EA:

El profesor especial que no se haya preocupado de conocer al niño y la Escuela primaria, lo que es preciso, no desempeñará bien su función de contribución a la formación de los maestros, puesto que la metodología de la enseñanza, y el enseñar a enseñar, lo hará deficientemente. Concretándonos al dibujo, diremos que esta es la causa de que, en general, los maestros no enseñan dibujo en las escuelas, y si lo enseñan, hagan antipático el aprendizaje de éste, a pesar de ser unos de los entretenimientos a que con más placer se dedican los niños, a la vez que un medio educativo incomparable (Cuenca 2009, p. 338).

Plantea a continuación otra cuestión, que en este estudio hemos expuesto, que es la utilidad de la EA para abordar otros campos de conocimiento e integrarse en diferentes ramas del saber.

De lo que debe tratarse al enseñar el Dibujo a los niños en las escuelas primarias, es de proporcionarles una nueva y utilísima forma de expresión, que ha de servirles para los estudios de Historia Natural, Física, Geometría, Fisiología, Geografía, etc.. y en general, para todas las ramas de saber, en que sea aplicable. 
El método que se siga deberá tener como principal objeto enseñar a ver la naturaleza y educar, desarrollar la observación, para que llegue a ser lo más precisa posible, facilitando la expresión gráfica, de manera que llegue a ser reveladora fiel de nuestros pensamientos y de las cosas observadas.

Se deberá enseñar dibujo útil, no ese dibujo con pretensiones que trata de hacer de cada niño un artista, sino ese otro que tienda a dar a cada hombre un medio de expresión bella y elegantemente por medio de la escritura, de manera que a todos emocione estéticamente; es don de privilegiados; pero el exponer con claridad y fielmente los pensamientos debe ser un don de todos los inteligentes (Cuenca 2009, p. 338).

No debemos ofrecer al niño unas pautas concretas para resolver la imagen de un objeto pues al hacerlo, limitamos sus posibilidades ya que imitará ese modelo y no creará uno propio.

\section{CONCLUSIONES}

El currículo en el último termino es el resultado de un reparto de poder entre los distintos departamentos didácticos responsables de las asignaturas (Hargreaves, 1996). En la concreción que se produce en el currículo oficial de las áreas influyen muchas veces estos sesgos corporativistas en detrimento de argumentos realmente pedagógicos.

La relación de las artes con el proceso de aprendizaje es cada vez más tenida en cuenta científicamente. Tener en cuenta el aspecto emocional a la hora de obtener un mejor aprendizaje es cada vez más evidente pues el contexto influye decisivamente en la forma en que se adquieren los aprendizajes. Puesto que el objeto artístico cada vez tiene unas características menos definidas cada vez más profesionales trabajan de forma interdisciplinar. $Y$ también diferentes profesionales se interesan por el objeto artístico.

Al aplicar estos conocimientos a la práctica educativa sobre la cultura visual estamos poniendo en valor la multiplicidad de aspectos que rodean el hecho 
artístico. El alumnado valorara la posibilidad de representación e interpretación del entorno al entenderlo como un todo en el que intervienen diferentes puntos de vista. La manera en que se enfrentan a los trabajos conlleva una actitud diferente. Por otra parte su capacidad de investigación y la cantidad de información a la que tiene acceso se ve favorecida por la utilización de las TIC.

De las posibles actuaciones didácticas que dentro del aula se pueden realizar en el área de la Educación Artística, una de ellas es el enfoque investigador. Es un medio para la adquisición de conocimientos mediante la resolución de problemas que se va perfeccionando con la misma práctica. Cuanto mayor sea nuestra capacidad perceptiva mejor analizaremos nuestro entorno y ello crecerá en la medida en que practiquemos en la resolución de problemas que se nos planteen. Así pues si abordamos la búsqueda de soluciones desde un enfoque polifacético y dejándonos guiar por nuestra curiosidad estaremos utilizando una aproximación investigadora que nos proporcionará un mayor y más diverso numero de soluciones. Esta forma de acercarse al conocimiento a base de resolver problemas que se plantean en el aula se acerca bastante a la forma en la que aprendemos de los sucesos diarios para lo que utilizamos nuestro conocimiento del entorno y su exploración. Por lo tanto resulta una manera de acercarse a la producción artística muy parecida a como nos relacionamos con el medio que nos rodea. Esta manera de aprender trabajando, y construir el conocimiento sobre lo que vamos encontrando, servirá a la vez para establecer una guía de actuación a los profesores en formación.

En este papel de profesor investigador, el papel que adoptamos es el de evaluar constantemente nuestras actuaciones pues las conclusiones y conocimiento provendrán de la reflexión sobre la nuestra práctica docente. Es cierto que no podremos controlar todo aquello que ocurre en el aula y por lo tanto deberemos decidir en qué aspectos queremos basar nuestra investigación y asumir esas limitaciones.

El alumnado, por su parte, verá la posibilidad de aprender de una forma práctica que se acerca bastante a aquello con lo que se puede encontrar en su 
futuro profesional y por lo tanto relacionara positivamente su aprendizaje formativo con el aula.

Los contenidos trabajados se estructuraran en el curriculum de forma que respondan a la voluntad investigadora y para favorecer la misma.

Esta investigación sobre la práctica educativa y didáctica obedece a un interés por aunar la experimentación práctica al desarrollo profesional ya que los hallazgos repercutirán a su vez en nuestra práctica diaria. Esta retroalimentación proporcionara fundamentación a la materia pues contará con el respaldo investigador.

El plantear esta forma de trabajar no es que se pueda considerar una cuestión novedosa pero si responde a una manera de acercarse al entorno que es habitual para el artista plástico. El hecho de darle una estructura más científica proponiendo la investigación como modelo didáctico para la EA obedece a la necesidad de dotar de un contenido teórico a aquello que se ha llevado a cabo en la práctica en esta materia de forma habitual.

Hemos constatado que históricamente se ha considerado que la EA carecía de rigor frente a otras materias y era un producto espontaneo y casual. El proponer y sistematizar esta metodología servirá para establecer una estructura didáctica que ayudara a investigar como aprendemos y a valorar la enseñanza recibida. Esta manera de plantearlo como investigación didáctica es a la vez directamente aplicable al trabajo de formación de docentes.

Los procesos de enseñanza-aprendizaje cuando se realiza de una forma activa y por voluntad del individuo tienen mayor significación y se aprehenden como propios. La EA es una materia que se adapta perfectamente a esta forma de experiencia.

Por lo tanto consideramos que esta forma de impartir la docencia de EA que implica una investigación, observación y acción participativa del alumnado se adapta perfectamente a los contenidos estructurales de la EA. Se manifiesta 
válida por lo tanto, y sobre todo, para la formación de profesionales de la enseñanza.

El alumnado es un elemento activo en su propio aprendizaje y los conocimientos que se busca que adquiera para que más tarde sea capaz de aplicarlos en su propia aula los va a ir construyendo mientras los pone en práctica consigo mismo. Experimentará situaciones que le proporcionaran pautas futuras.

El profesor aportará su conocimiento científico que guiara al alumnado en la utilización y transformación de su conocimiento mediante un medio heurístico y abierto que le proporcionara conocimientos:

- Productivos, pues adquiere habilidades técnicas.

- Creativos, pues desarrolla la creatividad.

- Emotivos, pues implica la sensibilidad.

- De pensamiento lógico, pues necesita resolver los problemas que se le planteen.

- Sociales, pues necesita interactuar y aprende a relacionarse en el grupo.

- Personales, pues refuerza su autoestima y su formación.

- Culturales, pues conoce su entorno artístico.

- Comunicativos, pues el arte es un lenguaje que comunica (el mensaje) en un canal determinado (la estructura técnica).

- Críticos, pues necesita analizar y comprender para poder elaborar su propio discurso.

- Didácticos, pues aprende a enseñar, basándose en su propia experiencia y reflexión sobre su aprendizaje.

Las enseñanzas se basaran en la realización de un proyecto real que se diseñara desde el principio hasta el producto final terminado y listo para presentar al resto de alumnado. Se utilizará todo en lo que pueda intervenir la EA, apoyándose en otros contenidos y conocimientos, para conseguir un producto final completo. Para llevar a cabo todo ello necesitara además 
programar, planificar y realizar todo el proceso. Esta práctica proporcionara conocimientos y experiencias que pretenden que sepa abordar la enseñanza de la EA. Si estos profesores no salen lo suficientemente preparados, difícilmente podrán a su vez motivar y educar a los niños en el ámbito de las artes.

En la preparación del alumnado deberíamos favorecer su creatividad personal tal y como nos recomienda Bain (2014) para acrecentar su interés por acercarse a tareas de mayor envergadura, que trascendieran el concepto de asignatura o disciplina, en las que tuvieran que emplear su potencial creativo y en las que el trabajo cooperativo fuera algo habitual. En el aula no podemos limitarnos a transmitirles información sino que tienen que servirles para adquirir capacidades que les proporcionen la sensación de que dirigen su experiencia de aprendizaje. Para ello necesitarán experimentar, cometer errores, someterse a la crítica y rectificar antes de proceder a su evaluación. Deberán cambiar su idea de lo que significa aprender y de cómo conseguirlo pues cambia la forma de adquirir el conocimiento. Cualquier trabajo al que se enfrenten deberíamos incidir en despertar su curiosidad y estimular su imaginación, sin darles soluciones previas, haciendo que vayan construyendo su conocimiento. 
CAPÍTULO V. 
La Educación Artística en los planes de estudio de Magisterio de la Comunitat Valenciana. Visión para el siglo XXI.

\section{CONCLUSIONES Y PROPUESTAS \\ DE MEJORA}




\section{CONCLUSIONES}

Llegados al punto final de esta Tesis, podemos confirmar la hipótesis inicial de que la investigación histórica realizada nos ha servido para tener un conocimiento en profundidad de los estudios de EA y demostrar que en la gran mayoría de los planes de estudio esta materia ha sido desatendida. Los objetivos y la metodología propuestos, planteados al principio, han sido suficientes para llegar a la meta planteada en la hipótesis inicial.

Este trabajo ha pretendido ser un inicio de referencia aplicable, ya que se trata de una investigación de carácter teórico que no incluye aplicaciones prácticas concretas. Consideramos que incluso puede resultar de lectura árida al tratarse de una búsqueda meramente cronológica pero, como ya indicábamos en la justificación del tema, nuestra intención ha sido documentarnos para una acción futura. No hemos llegado a ninguna afirmación innovadora, pero creemos, eso sí, que hemos sido rigurosos en la búsqueda de material de referencia para desarrollar nuestro objetivo. Tenemos también la certeza de que será de gran ayuda a otros posibles investigadores en estos aspectos.

Hemos intentado alcanzar un conocimiento teórico justificado en la investigación-acción y la experiencia que nos permitiera el desarrollo coherente de prácticas educativas adecuadas a los nuevos entornos, materiales y formatos. A la vez que intentar integrar los conocimientos artísticos en el proceso de Enseñanza- Aprendizaje con el resto de conocimientos para evidenciar la posibilidad de abordar el conocimiento desde un punto de vista cultural y creativo. Con ello incidimos en nuestra idea de que educación y arte se relacionan estrechamente pues no podemos entender una sin la otra y en la importancia de que una rica formación docente lo haga posible.

Por tanto, la práctica educativa, implica necesariamente una integración curricular que ha de llevarse a cabo desde tres perspectivas distintas:

1. La consideración del conjunto de destrezas y competencias que suponen la EA para profesores y alumnos. 
2. El potente recurso que supone, en manos del profesor, como medio eficaz y motivador de tratamiento de la información orientado a fomentar procesos de generación de conocimiento del mundo que tiene el alumno.

3. Actuar como agente de cambio, por lo que supone respecto a otros modos de acceder a los procesos de Enseñanza-Aprendizaje, potenciando una observación consciente del mundo.

Esta práctica comportará actuaciones docentes diferentes pero no excluyentes, todo lo contrario. Comienzan con la elaboración de materiales curriculares para continuar con la aplicación práctica, su consiguiente evaluación y su posterior puesta en funcionamiento. Este proceso requiere planificación y deliberación. Se diseñan propuestas de aprendizaje concretas y en ellas intervienen como parte del proceso: el diseño, el análisis, la selección, aplicación y evaluación de los recursos focalizados en el aprendizaje. La EA permite la adopción de nuevas metodologías que potencian un desarrollo holístico de la Educación gracias a las posibilidades que ofrecen el diseño y el desarrollo de las propuestas de Enseñanza-Aprendizaje que buscan potenciar el conjunto de las capacidades del alumnado.

La figura del docente es primordial en este proceso pues es quien debe administrar los distintos recursos para lograr unos objetivos formativos determinados y que se integren respetando el contexto social. Su adecuada formación en la materia es primordial para que sepa qué diseño didáctico se corresponde mejor con las peculiaridades de sus estudiantes. Enseñar y aprender con la EA y el éxito del proceso de Enseñanza-Aprendizaje, es uno de los desafíos a los que deben hacer frente los docentes porque no conseguiremos el pretendido aprendizaje significativo en el alumnado únicamente con la introducción de la EA en el contexto educativo.

Sin embargo no debemos pensar que a priori suponga necesariamente que la práctica pedagógica de los docentes en el aula sufra una modificación importante del modelo de que utiliza habitualmente pues la forma en que se 
transmite la información no supone necesariamente una alteración o innovación significativa del modelo de enseñanza.

Nos planteamos qué mejoras se podrían introducir para que aquellas personas implicadas pudieran trabajar en una misma dirección y poner en valor el área de EA. Detectados los múltiples problemas que se plantean en cuanto a criterios epistemológicos, metodológicos u organizativos. Estas podrían ser:

- Definir el campo de estudio de forma que abarque un amplio espectro de contenidos. De esta forma podrá implicarse en ámbitos en los que a veces, por desconocimiento, se le niega la participación.

- Fomentar el entendimiento entre las diferentes disciplinas relacionadas poniendo en valor las aportaciones de la EA a la formación del individuo.

- Establecer una diferenciación clara y sin competencia entre las diferentes formas de impartir la materia dependiendo de los ámbitos a los que vaya dirigida.

- Aceptar la evolución de la materia desde los inicios puramente espontáneos, seguidos por los modelos academicistas, pasando por los expresionistas para llegar a los actualmente válidos.

- Abrir otras posibilidades de trabajo compartido y en igualdad de condiciones para favorecer el trabajo interdisciplinar y la transversalidad.

- Consensuar la utilización de una denominación adecuada atendiendo a las terminologías internacionales y que refleje ámbitos de trabajo actualizados.

- Establecer unos mínimos curriculares adecuados a la importancia del área en la enseñanza obligatoria y hacer cumplir su aplicación de forma correcta, sin que sea menos valorada frente a otras materias.

- Reivindicar el papel fundamental de la EA en una educación holística.

- Formar adecuadamente a los futuros maestros y actualizar a los que ejercen para poder impartir la materia de forma idónea: dinámica y de interrelación. 
- Consolidar el valor del campo de estudio mediante aportaciones de investigación teórica y práctica por parte de los profesionales del área.

- Valorar a nivel social y político la relevancia del planteamiento de los planes de estudio, así como su ejecución y revisión adecuada al momento histórico.

- Integrar la materia en los diferentes estudios universitarios atendiendo a las necesidades sociales actuales y futuras, permitiendo la apertura a nuevos campos laborales y de estudio, para que satisfaga aspiraciones, en conexión con los intereses reales.

Todas estas acciones podrían llevarse a cabo siempre que el diverso colectivo que abarca, trabajara el unísono. Para ello, se requeriría una mayor complicidad de los diferentes sectores profesionales implicados para poder reivindicar, desde diferentes foros, sociales, administrativos o profesionales, la presencia de la EA. Como ejemplos, proporcionar mayor visibilidad a personajes representativos mediante actos sociales o académicos de forma que las nuevas generaciones los valoren adecuadamente o que tengan más presencia activa en la vida cívica, social, educativa y política.

Tal vez fruto o reminiscencia del individualismo artístico del siglo XIX, la realidad es que tras numerosos años de propuestas y de gestiones a favor de esta mejora, lo cierto es que no acaba de funcionar. Es deseable que ante los numerosos cambios a los que nos enfrentamos y las nuevas estructuras sociales actuales, los actuales representantes de la EA, demostraran mayor flexibilidad para romper con las ideas caducas y aprender a compartir y generar nuevas experiencias.

Por lo tanto, es significativamente importante lograr una denominación unificadora que ayude a denotar su importancia en cualquier ámbito abordado. No debemos pues considerar la EA como un espacio contenedor de cosas diversas e inconexas sino más bien al revés, un área de conocimiento válida para adoptar una visión diferente y acercarse casi a cualquier ámbito de la sociedad. 
Nos resulta indicado considerar el concepto de curriculum con una idea menos restrictiva que limitarse únicamente a un plan de objetivos, áreas y contenidos. Para ello lo contemplaríamos como el conjunto de experiencias que viven los alumnos, dentro y fuera del aula. El currículum ensalza unas cosas y silencia otras y, por ello, podría considerarse como la propuesta cultural que un centro educativo ofrece a su comunidad.

Desde este punto de vista, reivindicamos un enfoque educativo en el que las artes y la cultura estén presentes y colaboren en el crecimiento vital del alumnado. Concebimos la escuela como un espacio de cultura que educa a una sociedad en los valores artísticos necesarios para el entendimiento de su realidad social y cultural. Que les permita conocer su entorno, interpretarlo y disfrutarlo estableciendo la doble referencia cultural de ida y vuelta que requiere cualquier proceso de aprendizaje.

El papel de la EA en el currículum debería consistir en establecer el marco de actuación que haga posible el proceso de conocimiento y disfrute del pensamiento artístico. Se necesita aportar conocimientos y herramientas y poder compartirlo en espacios comunes. Sin dar lugar a que enseña uno y aprenden los otros, sino que debe ser un proceso en el que se aprende enseñando.

El término transversal en Educación ha dado lugar a frecuente controversia. Admite, desde luego, diversas interpretaciones y, como es sabido, produjo (especialmente con la implantación de la LOGSE) grandes debates y propuestas variadas. Entenderemos aquí transversal con un concepto amplio: hablaremos de contenidos transversales a aquellos que se integren en el currículum de manera vertical y horizontal, los que aparecen de manera recurrente en las diferentes etapas educativas y en las diversas áreas de aprendizaje. Estos contenidos además llevan implícitos la educación en valores y un importante factor actitudinal.

Uno de los aspectos relevantes, y que queremos destacar, es que históricamente y probablemente debido a la ambigua naturaleza de la materia, la EA ha padecido el desconocimiento de lo que realmente supone para el ser 
humano. Por ello, lo que hoy en día hemos venido a denominar Educación Artística, ha ido variando de designación:

a) Así nos hemos encontrado con la denominación de "Dibujo" que deriva de una visión romántica del papel del artista. Incorpora una especial atención a la enseñanza del dibujo (disciplina de la representación gráfica del mundo visible y como instrumento gráfico de proyección) y a las diversas técnicas y procedimientos artísticos. En plena Revolución Industrial, la materia que se imparte en las escuelas centra su contenido sobre todo en el Dibujo Lineal y Técnico, que permitirá a los alumnos poder integrarse en los centros de producción. Se complementa frecuentemente con el estudio de la historia del arte (recopilación de los movimientos y artistas).

b) En nuestro país, las primeras décadas del siglo $X X$ y sobre todo en la época de la República, los aspectos culturales entraron a formar parte de la formación del individuo. Sin embargo, durante la Depresión Mundial de los años 30, nuestra guerra civil en España y los conflictos mundiales, se produjo un retroceso absoluto en el campo de la educación y por supuesto en el campo artístico. La recuperación económica traerá consigo la aparición de las teorías de la Bauhaus que propiciarán el interés por la alfabetización visual. Se generalizaran planteamientos teóricos críticos y movimientos sociales.

c) En las décadas de los 60 y 70, de amplias reformas tecnológicas, primarán los conocimientos de contenidos instrumentales sobre los artísticos. Posteriormente parecen recuperarse e incrementarse los valores propios de la EA. La denominación evolucionará a la de "Expresión Plástica”, al relacionarse con las teorías cognitivas del arte de Piaget y Vigotsky, correspondiéndose con una visión sociológica favorecedora de la libre expresión autoexpresión y la creatividad a través del arte. Influyen movimientos de renovación pedagógica (Montessori, Ferriere, Lowenfeld), los avances en el conocimiento de la conducta humana (Freud) y los movimientos artísticos vinculados a la expresión del individuo. Se recupera la subjetividad, el mundo emocional y la identidad grupal y comunitaria del sujeto. Esta corriente también dio lugar a la utilización terapéutica del arte. Propone la educación estética para todos los 
individuos sin excepción, ya que ayuda a desarrollar distintos aspectos como la autoexpresión, la creatividad, la percepción, la personalidad, etc. Es el medio de comunicación de sus necesidades y su comunicación con el entorno. Sigue confundiéndose con conceptos como "manualidades" o "trabajos manuales" que lamentablemente aún siguen usándose.

d) En los últimos años del siglo pasado comienzan a tomarse nuevos rumbos en cuanto a lo que se entiende como perteneciente al ámbito de la EA. Se amplían sus espacios de actuación que lo consiguen integrar en el terreno cultural y social. Las nuevas tendencias producen diferentes cambios en facetas que afectan ya al concepto, como explica Acaso (2009), y a la profesionalización, fruto de la institucionalización de los centros de formación integrados en la Universidad. En cuanto al aspecto formativo de los maestros nace una inquietud por profesionalizar la práctica y la formación de estos, en particular en lo que respecta a la Didáctica. Nace también un nuevo papel del profesor que desbordará las fronteras del aula en lugar y tiempo. Se convierte en un mediador social que va a interactuar entre los proyectos sociales, los políticos, los programas educativos y los propios sucesos del aula. Este nuevo papel le lleva también a considerar su posición como investigador y agente principal de su formación.

Otro de los aspectos es la contextualización actual, con referencia a los nuevos estudios de Grado de Maestro. En nuestra opinión, se ha desaprovechado la ocasión para dar la visibilidad y entidad que le corresponde a la materia, aspecto que se denota en los pocos y dispersos créditos docentes que se nos adjudican. En definitiva, supone rebajar la importancia de la EA en el currículum de formación del Maestro. $Y$ no nos equivoquemos, para nuestros alumnos, desconocedores en profundidad de lo que es la EA, una materia de pocos créditos es sinónimo de menor importancia.

Podríamos aprovechar para incorporar nuevas formas de entender el papel del maestro. Este ya no es el transmisor absoluto de un conocimiento, que cambia muy rápidamente, su papel debe adecuarse a las nuevas necesidades sociales y tener en cuenta competencias basadas en las experiencias personales. Por lo tanto, la formación de este maestro también necesita de otro tipo de 
aprendizajes que puedan garantizar a sus alumnos la adquisición de la competencia de aprender a aprender, a ser críticos y poder generar conocimientos creativos producto de las iniciativas personales o cooperativas, basadas en la investigación personal y de grupo.

Queremos, pues, reivindicar el papel de la presencia de la EA como parte fundamental de la formación de las competencias y capacidades de estos nuevos maestros. Para ello, la formación previa que reciban debe ser de calidad y orientada hacia este nuevo papel activo que les demanda su profesión. Ello redundará en la mejora de su calidad educativa en la materia artística, así como en la futura consideración de estas enseñanzas.

En 2010, la Sociedad para las Competencias del Siglo XXI publicaba su Mapa para las Artes $^{200}$ con el que se ponía de manifiesto que:

El papel fundamental que las artes desempeñan en la adquisición de hábitos de trabajo, promoviendo al mismo tiempo la curiosidad, la imaginación y la creatividad; la tolerancia ante la ambigüedad y la incertidumbre; la expresión de ideas y sentimientos, y la comprensión de distintas realidades $y$ perspectivas que contribuyen a adquirir una conciencia global, colaborativa $y$, en definitiva, una ciudadanía responsable (...) se sugiere que las comunicaciones en nuestro mundo interconectado se basan cada vez más en mensajes multimedia que los estudiantes deben aprender a interpretar críticamente, al tiempo que expresan sus propias ideas a través de los distintos lenguajes artísticos. Muchos de los ejemplos del documento apuntan a la importancia de incorporar las artes y las tecnologías en el desarrollo de todas las competencias básicas (Giráldez 2012, p.131).

Siguiendo el sistema de pensamiento de Acaso (2009), en este estudio no pretendemos hablar de "que está mal y que está bien", sino considerar la posibilidad de un enfoque educativo diferente que hipotéticamente favorecería la estructura cognitiva. La entenderíamos bajo unas premisas menos 
encorsetadas a priori, para contemplar aspectos más lúdicos y creativos que favorecerían la adquisición de los conocimientos estipulados pero desde un sistema de coordenadas diferente.

Según la visión de la escuela democrática de Dewey ${ }^{201}$ (1987b) los maestros tienen que crear un entorno social en el que los niños asuman por sí mismos las responsabilidades de una vida moral democrática. Su convicción de que la escuela, tal como la concibe, inculcar en el niño un carácter democrático se basa menos en la confianza en las "capacidades espontáneas y primitivas del niño" que en la aptitud de los maestros para crear en clase un entorno adecuado "para convertirlas en hábitos sociales, fruto de una comprensión inteligente de su responsabilidad" (pp. 94 y 95).

En la medida en que la escuela desempeña un papel decisivo en la formación del carácter de los niños de una sociedad, puede, si se la prepara para ello, transformar fundamentalmente esa sociedad. Si los maestros desempeñan bien su papel de orientador del aula, comprometido con el respeto y la defesa de los valores, podría ser el germen de una comunidad auténticamente democrática y cooperativa.

En el núcleo del programa de estudios de la escuela de Dewey figuraba lo que éste denominaba "ocupación", es decir, "un modo de actividad por parte del niño que reproduce un tipo de trabajo realizado en la vida social o es paralelo a él" (Dewey, 1899, p. 92).

Por otra parte, en palabras de Aguilar (2005, p. 201): "en un nuevo enfoque de la EA creativa, por tanto, será primordial una atención especial a la diversificación y enriquecimiento de la experiencia tanto personal como colectiva de los alumnos". Cada alumno tiene sus tareas asignadas y su papel pero no podrá evitar estar pendiente de desarrollar correctamente el rol que se le ha asignado. Ello favorece que cada uno aprenda desde su propia manera

\footnotetext{
${ }^{201}$ Las obras completas de John Dewey se han publicado en treinta y siete volúmenes con el título de Collected works of John Dewey (Carbondale, Southern Illinois Universiry Press, 19671992). Esta compilación consta de tres series: The early works of John Dewev. 1882-1898: The middle works of John Dewey. 1899-1924: y The later works of John Dewey. 1925-1953.
} 
de entender la actividad y la forma de trabajar. Cada uno trabaja desde sus posibilidades y habilidades personales lo cual repercute de forma muy positiva en el aprendizaje.

Para Gros (2004, p. 3):

Probablemente uno de los problemas más importantes de la educación y la formación en la actualidad es que la mayoría de los enfoques educativos utilizados no están en consonancia con las necesidades de los niños y jóvenes actuales no con el tipo de sociedad en que estamos viviendo.

La perspectiva histórica de la formación de los maestros comprendida entre 1730 y 1990 nos puede llevar a la consideración de la distinción de tres etapas bien diferenciadas:

a) La primera la podríamos establecer en los tiempos que preceden a 1780 en los que se da una ausencia total de formación teórica, la profesión se adquiere con una formación de carácter gremial y se basa, principalmente, en la práctica como ayudante junto a un maestro en una escuela y en la posterior superación de un examen. Se produce un control personal, dadas las condiciones exigidas, y poco reconocimiento social.

b) La segunda etapa podríamos establecerla entre 1780 y 1838 , en que Montesinos crea la primera Escuela Normal. Se produce un intento de romper el carácter gremial que hasta entonces tenía; las nuevas ideas de la llustración traen consigo una mayor preocupación de la sociedad por la educación y se producen algunos intentos de elevar el nivel formativo y social de los maestros.

c) Una tercera etapa, que establecemos entre 1839 y 1990 comienza la etapa en que las Escuelas Normales, con sus vaivenes correspondientes, se encargan de la formación de los maestros llegando con el tiempo a su integración en la Universidad. 
Hay que considerar la formación de los maestros no solo desde el punto de vista de los periodos acaecidos o en las diferentes etapas y cambios, sino que debemos atender a otros factores que han influido directamente en este análisis. Estos factores son la evolución paralela de la educación primaria y la consideración social de la figura del maestro. En cuanto a consideración social establecemos los parámetros que marcaran las exigencias de formación y condiciones de acceso que se solicitaran para ser admitidos a los estudios en cada etapa histórica y la remuneración que reciben por su trabajo. Por tanto, aspectos a tener en cuenta a la hora de analizar la perspectiva histórica de la formación de los maestros son, al menos, los requisitos que se le piden en cada periodo o etapa, qué tipo de formación reciben o no, en cada caso, las instituciones en que dicha formación se imparte y la forma de acceso a la actividad profesional.

Varios autores han denominado a las escuelas normales como las "Universidades de los Pobres". En efecto, a estos centros solía acceder aquel alumnado que carecía de medios económicos como para costearse otra clase de estudios e, incluso, quienes habían fracasado en otras carreras más exigentes. El prestigio de los estudios de Magisterio se correspondía con el origen humilde de los alumnos normalistas, con los bajos salarios percibidos por los maestros y con la escasa consideración social del cuerpo.

La formación del maestro debería abarcar conocimientos científicos y culturales amplios y además contenidos propios del área artística. Todos ellos vinculados a los contenidos que conforman el currículum de Educación Infantil y Primaria para que hubiera una relación directa entre los conocimientos que adquieren los estudiantes en sus estudios y su aplicación en su futura labor profesional. En muchas ocasiones excusan su poca dedicación a las materias artísticas por la mala formación recibida en la materia. Su falta de formación en EA como alumnado provoca lagunas en su labor docente.

Abogamos por una mayor oferta de créditos en asignaturas específicas y especializadas aunque normalmente lo que apreciamos es una ampliación de asignaturas de contenidos psicopedagógicos en detrimento de otros. La formación del maestro debería tener unas solidas bases epistemológicas, 
psicopedagógicas y didácticas que le permitieran ser realmente competente en el aula en un futuro.

La elevada atomización de la enseñanza universitaria no beneficia a la adquisición de conocimiento. Su fragmentación y el elevado número de asignaturas no benefician a que el alumno reciba una enseñanza que perciba como coherente. Se presentan dificultades para cuadrar horarios, aulas... incluso asignaturas que solapan contenidos. Sobre todo se plantean unas expectativas de aprendizaje que solo son reales sobre el papel pues no se llevan a la práctica por imposibilidad material de horas de dedicación. Tal vez una mayor globalización del conocimiento a adquirir ayudaría a su mejor asimilación.

El que las asignaturas de EA se impartan de forma estanca y con tan poca presencia curricular no ayuda a que esté integrada en la formación inicial y a que adquiera la consideración adecuada en la enseñanza obligatoria. Se la percibe como una asignatura descontextualizada y ello no favorece la transversalidad de los contenidos. Sería deseable una mayor incidencia en la presencia de ésta en la formación de los maestros para garantizar una mayor integración curricular en la EA que consideramos básica. Que empezara a formar parte también del ideario colectivo. Puesto que es una labor conjunta, no solo sirve modificar planes de estudios o asignaturas sino también la percepción y utilización social de esos conceptos en la escuela así como también en la presencia en la vida diaria de las personas. Aumentar el uso y presencia de la cultura para su disfrute general.

No menos importante es trabajar con los profesionales que están en ejercicio así como con la formación postgraduada. El despertar en ellos el interés por la materia implicará que consideren importante seguir formándose para poder aplicarla adecuadamente a sus aulas. Si para ellos no es relevante, ni siquiera se lo plantearan. De hecho muchos de estos maestros manifiestan su interés por seguir formándose en la materia. 
Se debe potenciar en nuestros alumnos el deseo de experimentar las diferentes posibilidades de trabajo e ir orientándoles en los usos aplicados en el aula. Necesitamos que se interesen en adquirir estas competencias artísticas que los capacitaran para aplicar la didáctica a sus conocimientos y herramientas convirtiéndolas en un recurso más dentro de su aula. O sea, que la formación artística en la educación inicial de los maestros, debe incidir principalmente en las enseñanzas que se les imparte en la facultad pero se debe continuar fuera de ella, cuando ya se han graduado. Esa formación debe ser de calidad, integrando la teoría y la práctica, estar presente en los proyectos de innovación y de desarrollo del currículo escolar y por fin integrarse completamente en la vida del aula. Con esto conseguiremos, si bien parcialmente, paliar la escasa presencia curricular pero eso sí, que esté presente en la educación.

Estas enseñanzas pues deben trascender a la transmisión únicamente de conocimientos teóricos y prácticos de índole técnica, se deben centrar en aspectos que aborden cuestiones de enseñanza y aprendizaje. Con una formación globalizada y atenta a lo conceptual aprenderán a aplicar los recursos adquiridos en cualquier ámbito que aborden. Serán capaces de integrar lo aprendido a esquemas conceptuales más amplios y cualquiera que sea su práctica profesional. La formación artística no debe ser algo aislado ni en el tiempo ni en el espacio sino que su presencia debe ser progresiva y mantenerse presente en los procesos para abordar y apoyar cualquier aspecto que se le presente al profesor. Este necesita de la libertad suficiente para poder aplicar en su aula aquello que considere más adecuado y adaptado a sus propias posibilidades e intereses. El profesorado de los niveles de Infantil y Primaria no busca crear artistas sino que debe tratar de disfrutar de las posibilidades que brinda el área y los elementos artísticos como una herramienta más para su actividad profesional. Conseguirá abrir caminos diferentes y construir escenarios nuevos para el aprendizaje de sus alumnos. Con esto último queremos manifestar no solo la voluntad de emplear herramientas e instrumentos diferentes a los adoptados actualmente sino un cambio real de la manera de plantear el aprendizaje. 
Al presentar enfoques diferentes creamos entornos más ricos, interactivos y variados, en los que el alumnado podrá generar y crear su propio conocimiento. Cuestionamos pues la forma de trabajar la EA en la educación española, salvo honrosas excepciones, y contrastando con el camino emprendido por otros países europeos, de Norteamérica o australianos en los que ha cobrado un protagonismo mayor. La introducción de la EA en nuestro sistema educativo nos permitiría mejorar, para ganar en calidad.

\section{PROPUESTAS DE MEJORA Y PROSPECTIVA}

Enumeramos a continuación diferentes propuestas de mejora que convendría tener en cuenta:

- En primer lugar, se propone la modificación de la Ordenación General del Sistema y las enseñanzas comunes de la Educación Secundaria Obligatoria con el fin de realizar una ordenación rigurosa, coherente y completa a fin de "garantizar una formación común a todos los alumnos" ( LOCE, art. 8. 2).

- La revisión y reforma del desarrollo curricular del área y asignatura de EA con el fin de perfilar su organización en pro de un aprendizaje significativo que abarque todos los aspectos (comprensivo, expresivo, analítico, crítico y sensitivo) específicos de la EA y su relación con la historia y la sociedad. La presencia de la EA en todos los niveles del sistema educativo, con un horario suficiente para realizar un trabajo serio destinado a desarrollar un gran número de capacidades de modo global, con el fin de coadyuvar a la formación integral de calidad en nuestro alumnado.

- Para lo cual se estima necesario la siguiente ordenación del sistema educativo:

- En Educación Infantil, deben incluirse las dimensiones estéticas, creativas, de conocimiento y desarrollo de la EA ya que siempre ha sido una herramienta fundamental de

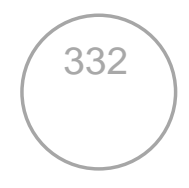


conocimiento y relación en esas edades. De hecho, consideramos la EA un instrumento imprescindible para la consecución de objetivos propios de Educación Infantil, con los cuales está estrechamente relacionada dado su carácter globalizador.

o En Educación Primaria, el área denominada de Educación Artística, engloba los contenidos de "Plástica" y la Música. Las asignaturas, que nosotros denominamos de EA, no figuran en el currículo de Primaria de forma diferenciada. Este hecho en sí le hace perder relevancia, puesto que en el Boletín de Notas del alumnado la nota no figura con entidad propia sino globalizada con la asignatura de Música en el concepto de Educación Artística. Esta presencia camuflada revierte en que el alumnado la considere como una "maría" que se aprueba sin ningún esfuerzo. Por lo tanto, deberían debe desglosarse por ley estas áreas especificas sobre todo dado que la Música ya tiene su profesorado específico.

- En Educación Primaria, la Educación Artística debería aumentar el número de horas lectivas de que dispone. Es una etapa fundamental para asentar las bases de la EA, y para la detección tanto de talentos como de dificultades de aprendizaje. Atender a que todos los colegios estén dotados de un espacio adecuado en cuanto a dimensiones y ubicación, al igual que de unos medios materiales en la cantidad y con la calidad idónea. Tenemos que ser conscientes de que si queremos compararnos con sistemas educativos más avanzados en el tema y recuperar nuestro prestigio debemos empezar por primar la cultura.

- En la ESO deben mantenerse las condiciones expresadas para la Primaria en cuanto a dotación material y horaria. La ventaja es que en este nivel, así como en bachillerato, el profesorado sí es especialista en la materia. 
o En Bachillerato se propone ofertar, con carácter optativo y para todas las modalidades, la EA en dos niveles, correspondientes a $1^{\circ}$ y a $2^{\circ}$, lo que permitiría una preparación adecuada para vertientes profesionales relacionadas con los contenidos artísticos.

- Respecto a la Formación Inicial del Profesorado:

o Establecer un programa de Formación Inicial que ayude a consolidar una preparación adecuada en EA. Que el alumnado consiga un nivel de competencias profesionales sólido que les permita cumplir con las exigencias de su profesión. A resaltar el papel que desempeñan los tutores de las practicas de docentes en formación.

o Es necesario un cambio de actitud general hacia la EA y hacia el papel que debe desempeñar en la sociedad y en el sistema educativo. La integración de la EA en todos los aspectos de la docencia resulta fundamental y en los estudios de Magisterio resulta imprescindible.

o Que en la Formación Inicial se incluyan métodos de trabajo globalizados que aborden la transversalidad de contenidos de manera que los futuros profesionales interioricen esta forma de trabajar y la integren de forma natural en su aula.

o Que la Formación Inicial del Profesorado se base en el trabajo sobre actitudes y habilidades, de forma que se ayude al futuro docente a ser flexible ante la realidad social con la que se encuentre. Generando un profesional creativo y que a la vez favorezca esta cualidad en su alumnado.

o Que la Formación Inicial incluya elementos metodológicos para la Educación en valores, el esfuerzo, el compañerismo y la convivencia ya que los consideramos 
como aspectos primordiales para su integración social y cultural. El objetivo es generar una identidad profesional bien definida.

- En cuanto a la Formación Permanente del Profesorado:

- Los cursos ofertados deben resultar útiles para el desarrollo del trabajo que el currículo exige. Deben ayudar a la mejora de las competencias adquiridas durante los estudios reglados y permitir la actualización de contenidos a los profesionales que ya están en ejercicio.

o No todo son los contenidos de las materias, se debe promover que el profesorado desarrolle proyectos de innovación que permitan avanzar en el conocimiento y los métodos que emplean en su práctica docente. Facilitar, por supuesto, la difusión de los hallazgos y puesta en común en encuentros profesionales que sirvan de reflexión y aprendizaje .

o También muy importante estimular los intercambios culturales creando relaciones de cooperación y entendimiento artístico entre comunidades escolares de los países que forman el Espacio Europeo.

o Que la Formación Permanente del Profesorado acompañe al profesional en la adaptabilidad a nuevos conocimientos, fomentando actitudes y habilidades ante los cambios y avances de la sociedad.

o Concebir esa Formación Permanente como un derecho y un deber de todo el profesorado. En este sentido hay que ayudar a los profesores a desarrollar entornos compartidos de reflexión y práctica para que se estimule la puesta en común de estrategias de aprendizaje para optimizar la práctica docente. 
Sería fundamental que, por parte de los políticos con competencia en materia educativa, se empezara por dar ejemplo de ello desde la propia normativa modificando e introduciendo cambios legislativos que nos parecen urgentes. Entre ello destacar los siguientes:

- El sistema educativo español tiene que dar el mismo tratamiento dentro del currículum de Educación Primaria al área de EA que al resto de asignaturas específicas.

- Existe una infravaloración con respecto al resto de áreas que también requieren tener una especialización para poder impartirlas.

- Dotar al área de Plástica, dentro del currículo de Educación Primaria, de la misma carga lectiva que el resto de asignaturas específicas como es el caso de Educación Física o Religión.

- Incluir el área de EA en el currículum de Educación Infantil, puesto que las horas lectivas no figuran como tal sino como apoyos a Infantil, puesto que legislativamente no figura de forma explícita dicha área dentro del currículo de Infantil.

- Definir el perfil del especialista en EA para que esta asignatura tenga independencia dentro del currículo al igual que en su momento se hizo con la creación de la especialización en Lengua Extranjera, Educación Física y Música.

- Propuesta de modificación para incorporar en los Planes de Estudio de la formación del Maestro el especialista en EA. Disminución del número de créditos asignados a las disciplinas generales y aumento en el número de créditos de asignaturas específicas, con especial énfasis, una mayor oferta de créditos de asignaturas específicas de Didáctica de la Expresión Plástica consolidándose como asignaturas obligatorias, en lugar de optativas.

- Disminución del número de asignaturas, para paliar los problemas de organización del Plan de estudios de maestro.

- Redefinición de los contenidos y objetivos formativos propuestos en las asignaturas del plan, evitando el solapamiento de contenidos y la falta de concreción de los objetivos. 
- Redistribución en la oferta de las asignaturas optativas, manteniendo globalmente una proporción entre las distintas categorías de asignaturas, facilitando de esta manera que el alumnado defina su perfil curricular.

- Revisión de la denominación adecuándola a los nuevos contenidos y a las premisas de tiempos actuales. Favoreciendo los estudios e investigaciones en la materia y dotándola de entidad propia.

Se debe trabajar en la búsqueda de soluciones con el fin de potenciar la enseñanza de la EA y garantizar para esta área niveles de exigencia semejantes a los que se tienen en las demás áreas. Es un reto nuevo, que le planteamos al profesor en el desarrollo curricular, el llegar a saber integrar la EA en él. Proporcionar a esta sociedad de la información y del conocimiento los nuevos perfiles personales más creativos que demanda. En manos del profesor queda reflexionar acerca de los medios más adecuados que le permiten liberarse de la rutina establecida hasta el momento y que le posibiliten iniciar procesos de mejora de la propia práctica docente y por tanto de innovación.

Nos postulamos frente a un modelo educativo que se inclina por una educación cada vez menos crítica y que pretende crear personas conformistas, con escaso nivel cultural pero rápidamente adaptables a los cambios económicos y sociales que se produzcan. La educación superior debe reivindicar los aspectos formativos creativos y críticos para configurarse como elemento integrador de una sociedad y de una cultura. En el modelo Educar a través del arte, nos encontramos con la posibilidad ideal de transversalizar la experiencia estética en la Educación Superior. Estamos convencidos de que este tipo de conocimiento contribuirá a alcanzar competencias complejas relacionadas al desarrollo de la capacidad de abstracción, a la construcción de un pensamiento crítico y divergente y a la apropiación de valores culturales. Se debe respetar el equilibrio relación entre el hacer y el ver, fundamental entre el aprendizaje en y a través de las artes visuales. Cuando los procesos entre el arte y la educación se encuentran en un terreno común, pierde importancia los agentes que lo promueven: 
[...] ...el saber ya no está solo en la escuela sino que puede estar en la calle o en la gente del entorno; los alumnos no son solo receptores de ese saber sino que lo co-construyen; educadores, artistas, intelectuales, trabajadores culturales, etc. trabajan desde posiciones distintas, pero no jerárquicas a la manera convencional, para elaborar al tiempo que transitan un campo de saber no preexistente a la acción colectiva, poniendo en juego sus saberes y habilidades junto con los de otros para generar situaciones y procesos de fin no siempre previsible. Esta circulación de saberes no solo es imprescindible sino que constituye la misma razón de ser del proceso de aprendizaje (Sánchez de Serdio, 2010, p. 54).

Una nueva perspectiva sobre la EA significa plantear los aprendizajes curriculares siguiendo un proceso creativo en el que los estudiantes desarrollan sus propuestas con la supervisión de los educadores que actúan como orientadores-guía.

Es fundamental apoyar el proceso del estudiante cuando interviene en la generación de su propia planificación y posterior puesta en práctica de sus proyectos artísticos. Más adelante habrá que acompañarlo para que sepa reflejar sus hallazgos a través de objetos artísticos en los que su identidad se vea reforzada y afianzada. Aprenderá a expresar y vivir sus inquietudes sobre el mundo que lo rodea llevando a cabo acciones mediante las diversas formas que le ofrecen las artes visuales. Tendrá a su alcance desde lo más local y cercano hasta lo más lejano e internacional. No hay una separación entre lo considerado tradicional y popular y las artes más elitistas. La sociedad de la información parece permitir el acceso a todo tipo de contenidos.

Pensamos en una meta, seguramente todavía lejana, en la que aspiraríamos a conseguir un nuevo profesor formado en un adecuado plan de estudios, que pudiera ser tutorizado en la fase de prácticas de forma eficaz y que realizara un buen desempeño del puesto de trabajo posterior. Esta meta es un objetivo viable si se analizan adecuadamente los factores y se obtiene una colaboración efectiva entre los distintos agentes implicados. Si fuese posible, esta es la manera de aprender que me gustaría proponer a mi alumnado. 
Nos reafirmamos en la idea de que debería existir una especialidad de EA en los estudios de Magisterio.

Dado que las legislaciones que se han venido sucediendo no lo han considerado necesario no demuestra más que la poca importancia y valoración que recibe esta área. Podríamos plantearnos si el futuro docente recibe la formación necesaria para poder llevar a cabo esta materia con la importancia y eficacia que se merece. Los docentes que han recibido una enseñanza especializada han recibido formación específica sobre su área para tener un conocimiento más amplio y especializado sobre su materia. Nos encontramos sin embargo, que la EA, la imparte el maestro generalista.

El no ser una especialidad, el no tener profesores formados en el aula, el reducido horario impuesto por el currículum, la ausencia de un aula taller propia en la que trabajar esta asignatura... todas estas barreras, son la respuesta de por qué no se valora esta materia.

La enseñanza de la EA solo se practica formalmente, es decir, en su estructura y organización, pero esto está vacío de contenido, por varias razones:

- Por parte de la administración:

- La falta de estimulación y la escasa formación del profesorado.

- El rechazo, la minusvaloración y la supuesta poca utilidad que se le atribuye a la EA.

- Por parte de los centros y los profesores:

o La mala organización.

- La escasa tradición en el trabajo en equipo y lo que ello conlleva en relación a la discusión, al acuerdo y al compromiso para llevar adelante una formación transdisciplinar.

o Las carencias en la formación del profesorado adecuadas a las necesidades

- La escasa y en casos, inadecuada información sobre los beneficios de la EA. La dificultad y el compromiso que entraña implicarse en la educación global del niño (preocuparse por sus 
necesidades educativas, por su contexto familiar, por crear vínculos de cooperación entre padres y docentes, etc.) desarrollar en los niños un espíritu crítico propiciar que los niños sean partícipes de su propia educación.

- Por parte de los alumnos:

o Los comportamientos reacios hacía ella.

- Por parte de los padres:

o La poca valoración del trabajo y de la utilidad de la EA en la educación de sus hijos. La ley, aunque acorde con el continuo cambio de la sociedad, no es aún tangible en su práctica educativa. Es difícil seguir la evolución social, pero a veces la educación es la que debe empezar a enseñar el camino.

No cabe duda que supondría un avance importante ofrecer una EA para todos: este cambio es importante académicamente, pero, sobre todo, que ésta sea realmente una educación y que no se quede en una sensibilización, que abrace todos los campos recogidos por el diseño curricular y que se pueda hacer con el máximo rigor y calidad. Se reconoce que la enseñanza y aprendizaje de la EA en nuestro país no se ha visto favorecida por estudios teóricos profundos. En este aspecto, han abundado más las aproximaciones pedagógicas en un marco educativo. Y las necesidades de investigación son grandes.

Por último, señalar que consideramos que esta investigación, puede actuar como punto de partida de otras que profundicen en aspectos tal vez no suficientemente desarrollados en ella. Por sus características y debido a la amplitud tanto temporal como conceptual que abarca no pretendemos haber llegado al fondo de las diferentes cuestiones tratadas. Pero sí, en todo caso, haber iniciado un camino que puede ser completado con otras investigaciones que permitan mejorar tanto la formación holística del alumnado de nuestras Facultades de Magisterio como del futuro alumnado con el que desarrollen su función formadora. 
CAPÍTULO VI. 
La Educación Artística en los planes de estudio de Magisterio de la Comunitat Valenciana. Visión para el siglo XXI.

REFERENCIAS BIBLIOGRÁFICAS 


\section{FUENTES DOCUMENTALES}

Acaso, M. (2009). La educación artística no son manualidades: nuevas prácticas en la enseñanza de las artes y la cultura visual. Madrid: La Catarata

Abad, J. (2009). Iniciativas de educación artística a través del arte contemporáneo para la escuela Infantil. Tesis doctoral. Madrid. UCM.

Abad, J. (2009). Usos y funciones de las artes en la educación y el desarrollo humano. En: Jiménez, Lucina, et al. Educación artística, cultura y ciudadanía (pp. 17-23). Colección Metas Educativas 2021, Madrid: OEl-Fundación Santillana.

Aguirre, I. (2000) Teorías y prácticas en educación artística. Pamplona: Universidad Pública de Navarra.

Alonso, A. (2012). La formación del alumnado de magisterio en Educación artística. Un estudio de caso a partir de las historias de vida de futuros docentes de la Universidad de Alicante. Tesis Doctoral. UV. Valencia

Anguita, R. (1997). Algunas claves de la historia de la Formación del Profesorado en España para comprender el presente. Revista Interuniversitaria de Formación del Profesorado, 30, 97-109.

Alsina, P. y Giráldez, A. (2012) (Coord.) La competencia cultural y artística. Barcelona: Grao.

Aguayo, M. C. (2004). (Coord.). Las artes plásticas como fundamento de la educación artística. Madrid: MEC

Andrews, B. W. (2010): Seeking Harmony: Teachers' Perspectives on Learning to Teach in and through the Arts. Encounters on Education, 11, 81-98.

Anguita, R. (1997). Algunas claves de la historia de la Formación del Profesorado en España para comprender el presente. Revista Interuniversitaria de Formación del Profesorado, 30, 97 - 109. 
Araño, J. C. (1989). La enseñanza de las Bellas Artes como forma de ideología cultural. Arte, individuo y sociedad, 2, 9-30. Disponible en: http://www.arteindividuoysociedad.es/articles/N2/Juan Arano.pdf

Araque, N. (2009). La formación de las maestras durante la primera etapa del franquismo. Tendencias Pedagógicas 14. Universidad Autónoma de Madrid. Disponible en: http://dialnet.unirioja.es/servlet/articulo?codigo=3002734

Arnheim, R. (1980). Arte y Percepción Visual. Madrid: Alianza

Arnheim, R. (1993). Consideraciones sobre educación artística. Barcelona: Paidós Estética.

Ávila, A. y Holgado, J. (2008). Formación del Magisterio e España. La legislación normalista como instrumento de poder y control (1834-2007). Madrid: MEPSYD.

Bain, K. (2007). Lo que hacen los mejores profesores universitarios. Valencia: Universitat de València.

Bain, K. (2014). Lo que hacen los mejores estudiantes de universidad. Valencia: Universitat de València.

Bamford, A. (2004). The Visual Literacy White Paper. Disponible en: http://wwwimages.adobe.com/content/dam/Adobe/en/education/pdfs/visualliteracy-wp.pdf

Bamford, A. (2009). El Factor Wow. El papel de las artes en la educación. Barcelona. Octaedro.

Bamford, A. (2012). Buenos días creatividad. Hacia una educación que despierte la capacidad de crear. En Informe Fundación Botín 2012. Santander. Fundación Botín.

Bartolomé, D., Pascual, M. Á. y Sevillano, Ma . L. (dir). (2007). Investigar para innovar en enseñanza. Madrid: Pearson Prentice Hall. 
Bartolomeis, F. (2001). El color de los pensamientos y de los sentimientos. Barcelona: Octaedro.

Barragán, J. M. (2005). Educación artística, perspectivas críticas y práctica educativa. Investigación en educación artística: temas, métodos y técnicas de indagación sobre el aprendizaje y la enseñanza de las artes y culturas visuales. Ricardo Marín Viadel (coord.). Universidad de Granada.

Benarroch, A. et al. (2010). Las didácticas específicas en el plan de estudio del Grado de Magisterio de Educación Primaria. Un estudio empírico sobre la opinión de los maestros, estudiantes y profesores de Facultad. I Congreso Internacional de Didáctica, Universidad de Granada (en prensa).

Berrocal, M. (2005). Menús de educación visual y plástica. Siete propuestas para desarrollar en el aula. Barcelona: Grao

Botella, A. (2010). La Enseñanza de la música en la Escuela de Magisterio de Oviedo. MAGISTER. Revista Miscelánea de Investigación. 23, 79-90. Disponible en: http://dialnet.unirioja.es/descarga/articulo/3405897.pdf

Bourdieu, P. (2002). Campo de poder, campo intelectual. Itinerario de un concepto. Buenos Aires: Montressor.

Bunk, G. P. (1994). La transmisión de las competencias en la formación y perfeccionamiento profesionales en la R.F.A. Revista Europea de Formación Profesional, (1), 8-14. Disponible en:

http://dialnet.unirioja.es/descarga/articulo/131116.pdf

Bruner, J. (1999). La educación, puerta de la cultura. Madrid: Visor.

Cabrera, A. (2003). Evaluación de la formación. Madrid: Síntesis.

Caja, J. (2001). (coord.). La educación plástica y visual hoy. Barcelona: Grao.

Calaf, R. y Fontal, O. (2010). Cómo enseñar arte en la escuela. Madrid. Síntesis 
Calderón, C. y Escalera, G. (2008). La evaluación de la docencia ante el reto del Espacio Europeo de Educación Superior (EEES). Educación XX1. 11. Facultad de Educación. UNED.

Charest, D. (2007). (coord.). Vie des Arts à l'école québécoise. Vie des Arts. 50, 205, 30. Disponible en: http://id.erudit.org/iderudit/52509ac

Coll. C. y Martín. E (2006). Vigencia del debate curricular. Aprendizajes básicos, competencias y estándares. PRELAC, 3 (3), 6-27.

Cuenca, M. (1988). La enseñanza del dibujo en las escuelas de magisterio (1839-1986). Madrid: Universidad Complutense.

Cuenca, M. (2009). El dibujo en la escuela una revisión histórica de sus primeros tratadistas. Tendencias pedagógicas. 14, 335-351.

Darling-Hammond, L., y Muñoz, J. M. E. (2001). El derecho de aprender: Crear buenas escuelas para todos. Ariel.

Delors, J. et al. (1996). La educación encierra un tesoro. Informe a la UNESCO de la Comisión Internacional sobre la Educación para el siglo XXI. Madrid: Santillana-Ediciones UNESCO.

Dewey, J. (1897). "My pedagogic creed". En Early works of John Dewey. Carbondale, Southern Illinois University Press, 1972, Vol. 5, pp. 84-95.

Dewey, J. (1899). "The school and society". En Middle works of John Dewey. Carbondale, Southern Illinois Universiry Press, 1976, Vol. 1, pp. 1-109.

Dewey, J. (1995). Democracia y educación: una introducción a la filosofía de la educación. Madrid: Ediciones Morata.

Dondis, A. (1976). La sintaxis de la imagen. Introducción al alfabeto visual. Barcelona: GG. 
Duncum, P. (2004). Visual cultura isn't just visual: Multiliteracy, Multimodality and meaning. Studies in Art Education. 45 (3), 252-264. Disponible en: http://vassarliteracy.pbworks.com/f/Duncum visual cultural.pdf

Efland, A. (1990). La Educación Artística en los Estados Unidos desde la Segunda Guerra Mundial hasta nuestros días, Luego, 25, 1.

Efland, A. (2002). Una historia de la educación artística. Tendencias intelectuales y sociales en la enseñanza de las artes visuales. Barcelona: Paidós.

Efland, A., Freedman, K., y Stuhr, P. (2003). La educación en el arte posmoderno. Barcelona: Paidós

Eisner, E. (1995a). Educar la visión artística. Barcelona: Paidós

Eisner, E. (1995b). What artistically crafted research can help us to understand about schools. Educational Theory, 45 (1), 1-13.

Esquivel, N. (2009). Escuela Orff: Un acercamiento a una visión holística dela educación y al lenguaje de la creatividad artística. Revista La Retreta , II (2 ), $1-6$.

Esteban, L. y López, L. (1994). Historia de la enseñanza y de la escuela. València: Tirant lo Blanch.

Freedman, K. (2002). Cultura visual e identidad. Cuadernos de pedagogía, 312, 59-61.

Freedman, K. (2006). Enseñar la Cultura Visual. Currículum, estética y la vida social del arte. Barcelona: Octaedro.

Gardner, H. (1994). Educación artística y desarrollo humano. Barcelona: Paidós.

Gardner, H. (1998). Inteligencias múltiples. La teoría en la práctica. Barcelona: Paidós. 
Gardner, H. (2003). La inteligencia reformulada. Las inteligencias múltiples en el siglo XXI. Barcelona: Paidós.

Giráldez, A. (2007). Competencia cultural y artística. Madrid: Alianza

Giráldez, A. (2012). La competencia cultural y artística es imprescindible en un mundo digital, en Alsina, P. y Giráldez, A. (coord.): Siete ideas clave. La competencia cultural y artística, Barcelona, Gráo. pp. 127-140.

Goleman, D. (2009). Inteligencia Emocional. Barcelona: Kairos.

Gómez, L. (2007). El aprendizaje a lo largo de toda la vida. CEE Participación Educativa, 6 (noviembre, 2007) 7-13. Disponible en:

http://www.educacion.gob.es/revista-cee/pdf/n9- gomez-Ilorente.pdf

González, I. (2002). Las didácticas de área: un reciente campo científico.

Revista de Educación. 328. 11-33. Madrid. Disponible en:

http://www.mecd.gob.es/dctm/revista-de-

educacion/articulosre228/re3280210861.pdf?documentld=0901e72b81259624

González, T. (1994). Las escuelas de Magisterio en el primer tercio del siglo XX. La formación de maestros en La Laguna. Tesis dirigida por Martin Hernández, Ulises. Universidad de la Laguna

González, A. P. \& Sánchez, P. (2005). ¿Qué sabemos de cómo aprenden nuestros alumnos en la Universidad?, en Chamorro Plaza, M. C. y Sánchez Delgado, P., Iniciación a la docencia universitaria. Manual de ayuda. Madrid: Instituto de Ciencias de la Educación, Universidad Complutense, 11-44.

Goodman, N. (1995). De la mente y otras materias. Madrid. Antonio Machado.

Gros, B. (2004). De cómo la tecnología no logra integrarse en la escuela a menos que ...cambie la escuela, Jornada Espiral, 1-9.

Hargreaves, A. (1996). Profesorado, cultura y postmodernidad. Madrid: Morata. Hargreaves, D. J. (1997). Infancia y Educación artística. Madrid: Morata. 
Hernández, F., Jodar, A, y Marín, R., (1991). ¿Qué es la Educación artística? Barcelona: Sendai Ed.

Hernández, F. (1995). El diseño curricular de educación visual y plástica: un análisis crítico. Revista Interuniversitaria de Formación del Profesorado. 24 Disponible en: http://dialnet.unirioja.es/servlet/articulo?codigo=117877

Hernández, F. (2000). Educación y cultura visual. Barcelona: Octaedro

Hernández, F. (2002). El Área de «Didáctica de la Expresión Plástica»: entre búsqueda de reconocimiento, la diversidad de intereses y la necesidad de afrontar nuevos desafíos. Revista de Educación. 328. 111-136. Disponible en: http://www.mecd.gob.es/dctm/revista-de-

educacion/articulosre228/re3280710861.pdf?documentld=0901e72b81259407

Hernández, F. (2007). Espigador@s de la cultura visual. Otra narrativa para la educación de las artes visuales. Barcelona: Octaedro.

Hernández, F. (2008). La investigación basada en las artes. Propuestas para repensar la investigación en educación. Educatio Siglo XXI, 26, 85-118.

Huerta, R. (2002). Els valors de l'art a l'ensenyament. Valencia. Universitat de València.

Huyghe, R. (1977). El arte y el hombre. Barcelona: Planeta.

Imbernon, F. (1994). La formación y el desarrollo profesional del profesorado. Hacia una nueva cultura profesional. Barcelona: Grao.

Infante, J. La reforma de los planes de estudio universitarios de la España democrática (1977-2000). Revista de Educación, 351, 259-282. Disponible en: http://www.educacion.gob.es/dctm/revista-de-

educacion/articulosre351/re35111.pdf?documentld=0901e72b81234601

Johnson, R. y Onwuegbuzie, A. (2004). Mixed Methods Research: A Research Paradigm Whose Time Has Come. Educational Researcher, 33 (7), 14-23. 
Jové, J.J. (2001). Iniciación al arte: propuesta de un modelo didáctico centrado en los procesos de producción. Madrid: Machado Libros.

Jové, J. J. (2008). Art i Educació. Lleida: Universitat de Lleida.

Juanola, R. (2011). Hacia una definición de las didácticas comparadas (..) en L'activitat docent: intervenció, innovació, investigación de Valles, J., Álvarez, D., Rickenmann, R. Girona: Documenta Universitaria.

Juanola, R. (2011). La investigación didáctica: hacia la interdisciplinariedad y la cooperación. Educatio Siglo XXI, 29-1, 233-262.

López-Barajas, E. y Ruíz, M. (Coord.). (2000). Derechos Humanos y Educación. Madrid: UNED.

López, J. L. (1999). Didáctica especifica de la expresión plástica. Oviedo: Universidad Oviedo.

López, M. (2001). La evaluación del aprendizaje en el aula. Madrid: Edelvives.

Lorenzo Vicente, J. A. (1995). "Perspectiva histórica de la formación de los maestros en España (1370-1990)". Revista Complutense de Educación, 6, (2), 203-234.

Disponible

en:

http://dialnet.unirioja.es/servlet/articulo?codigo $=150170$

Lorenzo, J. A. (2002). Hacia la profesionalización y modernización del Magisterio (1898-1936). Revista Complutense de Educación, 13 (1), 107-139.

Lowenfeld, V. y Brittain, W. L. (1972). Desarrollo de la capacidad creadora. Buenos Aires: Kapelusz.

Luengo, J. (1993). Educación artística-plástica. Revista Aula de Innovación Educativa, 15, 1-8. Disponible en: http://aula.grao.com/revistas/aula/015sentido-y-funcion-de-la-educacion-visual-plastica--gestion-y-planificacion-decentros/educacion-artistica-plastica

Luzuriaga, L. (2002). La Escuela Nueva pública. Madrid: Losada.

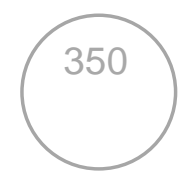


Magisnet (2008). Profesores de Plástica, obligados a pintar poco. Política educativa. Disponible en:

http://www.magisnet.com/noticia/3349/INFORMACION/.html29/04/2008

Manzanares, A. (2004). Competencias del psicopedagogo: una visión integradora de los espacios de actuación en la familia profesional de educación. Bordón. Revista de pedagogía. 56 (2), 289-303.

March, E. (2010). Lenguaje Visual y animación 3D. Propuesta educativa de desarrollo de la alfabetización visual para el disfrute del producto 3D. Tesis doctoral. Valencia. UPV. Disponible en:

http://riunet.upv.es/bitstream/handle/10251/10742/tesisUPV3502.pdf?sequence $\equiv 1$

Marín, R. (1982). Principios de la educación contemporánea. Madrid: RIALP.

Marín, R. (1982). Tendencias actuales en la formación del profesorado. En Revista de Educación, 269, 101-119.

Marín, R. (1998). Los valores del siglo XXI. Discurso pronunciado en la toma de posesión como académico de número el día 27 de mayo en la Real Academia de Doctores de Madrid.

Marín, R. (2003). Didáctica de la Educación Artística para Primaria. Madrid: Pearson

Marín, R. (2005). La Investigación Educativa Basada en las Artes Visuales o Arteinvestigación educativa en Marín. R. (Ed.) Investigación en Educación Artística (pp. 223-274). Granada: Universidad de Granada.

Marín, R. (2011). La investigación en educación artística. Educatio Siglo XXI, 29 (1), 211-230.

Martínez, A. (2007). Nuevos títulos. Revista Comunidad Escolar (Tribuna Libre), XXV, 822. Madrid: MEC. Disponible en: http://comunidadescolar.pntic.mec.es/822/tribucar.html 
Masriera, V. (1926). Pedagogía del Dibujo (Impresiones de viaje). Revista de Pedagogía, 57, 391-398.

Mirzoerf, N. (2005). An Introduction to Visual Culture. New York: Taylor \& Francis Group.

Molero, A. (1994). Ciento cincuenta años de perfeccionamiento del magisterio en España. (Desde las academias de profesores a la creación de los CEPS. 1840-1984). ICE Universidad de Alcalá de Henares.

Morales, J.J. (2001). La evaluación en el área de educación visual y plástica en la educación secundaria obligatoria. Barcelona. UAB. Tesis Doctoral: http://hdl.handle.net/10803/5036

Morin, E. (1999). Los siete saberes necesarios para la educación del futuro. París: UNESCO.

Munari, B. (1985). Diseño y comunicación visual. Barcelona: Gustavo Gili.

NAEA. (2008). Creating a Visual Arts Education Research Agenda for the 21st Century, Arteducators. Disponible en:

http://www.arteducators.org/research/NAEA Research Agenda 12-08.pdf

Ohler, J. (2003). Arte: La Cuarta Competencia Básica en esta Era Digital. Education Leadreship. EDUTEKA, 16. Disponible en: http://www.eduteka.org/Profesor16.php

Olaiz, I. (2010). Subjetividad en las prácticas de interpretación del arte. Revista Iberoamericana de Educación. 52/3. Disponible en:

http://www.rieoei.org/expe/35770laiz.pdf

Olaya, D. (1999). La formación inicial y permanente del profesorado de educación primaria y secundaria en España. Revista Ensayos, 14, 189-198).

Disponible en:

http://www.uclm.es/ab/educacion/ensayos/pdf/revista14/14 13.pdf 
Oriol de Alarcón, N. (2012). Contribución de la Enseñanza Musical, en los Estudios de Magisterio en España, a la conservación del Arte y la Cultura popular. DEDICA. REVISTA DE EDUCAÇÃO E HUMANIDADES, 3, 13-42.

Palacios, F. (1999). Educación artística y cultural. Un proyecto de didáctica de la expresión plástica en la formación inicial del profesorado. Arte, Individuo y Sociedad, 11, 147-161.

Perenoud, P. (1999). Construire des compétences, tout un programme! Revue Vie Pédagogique, 112, 16-20.

Perkins, D. y Blythe, T. (2005). Ante todo, la comprensión. Revista Magisterio Educación y Pedagogía, 14, 19-24. Bogotá.

Piña, R. (2013). El uso de las TIC en el aprendizaje de la música en estudiantes de educación primaria. Estudio de caso. Propuesta de mejora. Madrid. UNED. Disponible en:

http://e-acio.uned.es/fez/eserv.php?pid=tesisuned:EducacionRpina\&dsID=Documento.pdf

Prat Paz, E. (2012). "Víctor Masriera Vila (1875-1938). Pedagog de l'art, mestre en la didàctica del dibuix. El seu pas per Sabadell." Arraona: revista d'història [en línia], Núm. 33 , p. 146-171. http://www.raco.cat/index.php/Arraona/article/view/260469/347628

Quilez i Bach, M. (1990). La enseñanza del arte y la Universidad. Arte, Individuo y Sociedad, 3, 185-189.

Read, H. (1970). Arte y Sociedad. Barcelona: Península.

Read, H. (1973). El significado del Arte. Madrid: NyC.

Read, H. (1982). Educación por el arte. Barcelona: Paidós Ibérica.

Robinson, K. (1999). All Our Futures: Creativity, Culture and Education. Disponible en: http://sirkenrobinson.com/pdf/allourfutures.pdf 
Robinson, K. (2000). Une politique gouvernementale en faveur de la culture, de la créativité et des jeunes. Editions du Conseil de l'Europe. Disponible en: http://128.121.10.98/coe/pdfopener?smd=1\&md=1\&did=565939

Robinson, K. (2009). The Element. Barcelona: Grijalbo.

Robinson, K. (2011). Redes. El blog de Eduard Punset. Disponible en: http://www.redesparalaciencia.com/wpcontent/uploads/2011/03/entrev87.pdf

Rodríguez, R. (2004). ¿Kant o Nietzsche? ¡Dewey! El idealismo naturalista y democrático de El arte como experiencia. Fedro, Revista de estética y teoría de las artes, 2, 51-69.

Roeser, R. W., Midgley, C., y Urdan, T. C. (1996). Perceptions of the school psychological environment and early adolescents' psychological and behavioral functioning in school: The mediating role of goals and belonging. Journal of Educational Psychology, 88 (3), 408.

Roldán, J. y Marín, R. (2012). Metodologías artísticas de investigación en educación. Málaga: Aljibe.

Román, J. M. (2006). Los nuevos Grados de Magisterio: El pago de una "deuda histórica". Disponible en: http://www.uned.es/decanoseducacion

Román, J. M., y Cano, R. (2012). La formación de maestros en España (18382008): necesidades sociales, competencias y planes de estudio. Educación XXI, 11, 73-101. Disponible en: http://www.uned.es/educacionXX1/200811.htm

Rosales, C. (2006). En torno a la formación permanente del profesor, motivos y procesos. Comunicación y pedagogía: Nuevas tecnologías y recursos didácticos, № 212, págs. 26-29.

Rousseau, J. (1981). El Emilio de la educación. Madrid: Biblioteca EDAF. 
Sainz, A. (2002). Teorías sobre el arte Infantil: una mirada a la obra de G.H. Luquet. Revista Arte, Individuo y Sociedad. Universidad Complutense de Madrid. Disponible en:

http://revistas.ucm.es/bba/11315598/articulos/ARIS0202110173A.PDF.

Sánchez, P. (2005). Estrategias de motivación del alumno en la universidad, en Chamorro Plaza, M. C. y Sánchez Delgado, P. (Coord.). Iniciación a la docencia universitaria. Manual de ayuda. Madrid: Instituto de Ciencias de la Educación, Universidad Complutense, 105-134.

Sánchez, P. (2011). Metodologías docentes en el EEES: de la clase magistral al portafolio. Tendencias pedagógicas, 17, 83-103.

Sánchez de Serdio, A. (2010). Arte y Educación: Diálogos y Antagonismos. Revista Iberoamericana de Educación, 25, 43-60.

Sanchidrian, C. y Ruiz, J. (2010) (coord.). Historia y perspectiva actual de la educación infantil. Barcelona: Graó.

Sevillano, Mª L. (coord.) (2007). Investigar para innovar enenseñanza. Madrid: Pearson Prentice Hall.

Tello, J. y Aguaded, J.I. (2009). "Desarrollo profesional docente ante los nuevos retos de las tecnologías de la información y comunicación en los centros docentes educativos". Pixel-Bit. Revista de Medios y Educación. № 34, enero, pág. 31-47. Sevilla. U. de Sevilla.

Torres, M. y Juanola, R. (1998a). Dibuixar. Mirar i pensar. Barcelona: Rosa Sensat

Torres, M. y Juanola, R. (1998b). Una manera d'ensenyar arts plastiques a l'escola. Barcelona. Rosa Sensat

Valles, J., Álvarez, D., y Rickenmann, R. (2011). L'activitat docent: intervenció, innovació, investigació. Girona: Documenta Universitaria. 
Vallès, J. (2005). Competencia multicultural en educación artística. Contextos y perspectivas de futuro en la formación de maestras y maestros. Tesis doctoral, Universidad de Gerona. Disponible en: http://hdl.handle.net/10803/7666

Vallvé, LI. (2009). Ha de ploure cap amunt. Reflexions d'un mestre de plástica. Barcelona: Rosa Sensat.

Vásquez, R. (2011). Enseñanza para la comprensión: el caso de la Escuela Rural de Bolonia (Cádiz, España). Revista Iberoamericana de Educación, 57, 183-202.

Wenham, M. (2003). Entender el arte. Una guía para el profesorado. Barcelona: Grao.

Westbrook, R. (1993). John Dewey. Perspectivas: revista trimestral de educación comparada. XXIII (1-2), 289-305.

Westbrook, R. B., y Teixeira, A. (2010). John Dewey. Fundação Joaquim Nabuco.

Vygotsky, L. S. (1979). El desarrollo de los procesos psicológicos superiores. Disponible en: http://www.slideshare.net/DamarisJB11c/ensayo-de-la-teoradelev-vigotsky 12509992\#

Vigotsky. L. S. (2003). Imaginación y el arte en la Infancia. Madrid: AKAL.

V. AA. (2006). Bases para un debate sobre investigación artística. Colección Conocimiento educativo. Didáctica. Madrid: MEC.

Zabala, A. (1995). La práctica educativa. Cómo enseñar. Barcelona: Graó.

Zabalza, M. A. (2003). Competencias docentes del profesorado universitario. Calidad y desarrollo profesional. Madrid: Narcea.

Zarlenga, M. (2012). Sociología de la cultura y educación artística. Un análisis de propuestas pedagógicas en cultura visual. Instrumento. Revista de Estudo e Pesquisa em Educação, 14 (2). 


\section{REFERENCIAS LEGISLATIVAS}

ANECA (2004a). Libro blanco del Título de Grado en Magisterio. Vols. 1 y 2. Madrid.

ANECA (2004b) Sistema europeo de transferencia de créditos (ECTS). UniónEuropea y países de próxima adhesión. (Consulta mayo, 2014). Disponible en: http://www.upv.es/upl/U0135170.pdf

ANECA (2005). Libro blanco del Título de Grado en Magisterio. Madrid.

ANECA - VERIFICA (2010). Ordenación de las enseñanzas universitarias oficiales (grado y máster): Programa Verifica. Disponible en: (http://www.aneca.es/Programas/VERIFICA).

Comisión de las Comunidades Europeas (1999). The Bologna Declaration of 19 June 1999. Joint declaration of the European Ministers of Education. The European Higher Education Area. Disponible en: http://www.mec.es/universidades/eees/files/Declaracion Bolonia.pdf

Comisión Europea (1996). Libro blanco sobre educación y formación. Enseñar y aprender. Hacia la sociedad del conocimiento. Bruselas

Comisión Europea (2009). Educación artística y cultural en el contexto escolar en Europa, Eurydice, EACEA (Agencia Ejecutiva en el ámbito Educativo, audiovisual y Cultural). (Consulta mayo, 2014). Disponible en: http://eacea.ec.europa.eu/education/eurydice/documents/thematic reports/113 EN.pdf>

Decreto 56/2005, de 21 de enero, por el que se regulan los estudios universitarios oficiales de posgrado. Disponible en: http://www.boe.es/boe/dias/2005/12/20/pdfs/A41455-41457.pdf

DECLARACIÓN DE LA SORBONA (1998). Disponible en: http://wwwn.mec.es/univ/html/informes/EEES 2003/Declaracion Sorbona.pdf 
DECLARACIÓN DE BOLONIA (1999). (Consulta mayo, 2014). Disponible en: http://wwwn.mec.es/univ/html/informes/EEES_2003/Declaracion_Bolonia.pdf y en http://www.eees.es/es/documentacion

INCUAL/MEC: Catálogo Nacional de Cualificaciones Profesionales (CNCP). Disponible en: http://www.mec.es/educa/incual/ice catalogoweb.html

Ley General de Educación Primaria y Fuero de los Españoles, de 17 de julio 1945 (BOE 18 de julio de 1945).

Ley 14/1970, de 4 de agosto, General de Educación y Financiamiento de la Reforma Educativa (BOE de 6 de agosto de 1970). Corrección de errores en BOE de 7 de agosto de 1970 y de 10 de mayo de 1974, y modificación en BOE de 3 de agosto de 1976.

Ley 1/1990, de 3 de octubre, Orgánica de Ordenación General del Sistema Educativo (BOE 4 octubre de 1990) LOGSE.

Ley Orgánica de Reforma Universitaria 11/1983, de 25 de agosto (BOE 1 septiembre de 1983).

Ley Orgánica reguladora del derecho a la educación 8/1985, de 3 de julio (BOE 4 de julio de 1985).

Ley orgánica de Universidades 6/2001, de 21 de diciembre (BOE 24 de diciembre de 2001).

Ley Orgánica 10/ 2002, de 23 de diciembre, de Calidad de la Educación (BOE 24 de diciembre de 2002) LOCE.

Ley Orgánica de Educación 2/2006, de 3 de mayo (BOE 24 de mayo de 2006).

Ley Orgánica 4/2007, de 12 de abril, por la que se modifica la Ley Orgánica 6/2001, de 21 de diciembre, de Universidades. Disponible en: http://www.boe.es/boe/dias/2007/04/13/pdfs/A16241-16260.pdf 
Ley Moyano. Disponible en:

http://elgranerocomun.net/IMG/pdf/Ley Moyano de Instruccion Publica 1857 .pdf

El Sistema Universitario Español y el Espacio Europeo de Educación Superior. (s. f). http://www.upv.es/upl/U0135170.pdf

M. E. C. (2011). Real Decreto 1594/2011, de 4 de noviembre (BOE de 9-112011), por el que se establecen las especialidades docentes del Cuerpo de Maestros que desempeñan sus funciones en las etapas de Educación Infantil y de Educación Primaria reguladas en la Ley orgánica de educación 2/2006, de 3 de mayo (L.O.E.).

M. E. C. (2007a). Real Decreto 1393/2007, de 29 de octubre (BOE de 30-102007) por el que se establece la ordenación de las enseñanzas universitarias oficiales.

M. E. C. (2007b). Orden ECI/3857/2007, de 27 de diciembre (BOE de 29-122007), por la que se establecen los requisitos para la verificación de los títulos universitarios oficiales que habiliten para el ejercicio de la profesión de Maestro en Educación Primaria.

M. E. C. (2003c). Real Decreto 829/2003, de 27 de junio (BOE de 1-07-2003) por el que se establecen las enseñanzas comunes de la Educación Infantil.

M. E. C. (2003d). Real Decreto 830/2003, de 27 de junio (BOE de 2-07-2003), por el que se establecen las enseñanzas comunes de la Educación Primaria.

M. E. C. (2003e). La integración del sistema universitario español en el espacio europeo de enseñanza superior. Documento Marco.

M. E. C. (2003f). Real Decreto 1044/2003, de 1 de agosto (BOE de 11-9-03), por el que se establece el procedimiento para la expedición por las universidades del Suplemento Europeo al Título.

M. E. C. (2003g). Real Decreto 1125/2003, de 5 de septiembre (BOE de 18-903), por el que se establece el sistema europeo de créditos y calificaciones en 
las titulaciones universitarias de carácter oficial y validez en todo el territorio nacional.

MECD (2003). La integración del sistema universitario español en el Espacio Europeo de Enseñanza Superior. Documento Marco. Disponible en: http://www.mec.es/universidades/eees/files/Documento Marco.pdf

Modificació Pla d'estudis de graduat Mestre o Graduada Mestra en Educació Primària (BOE $\mathrm{n}^{0} 286,25$ de noviembre de 2012)

Modificació Pla d'estudis de graduat Mestre o Graduada Mestra en Educació Infantil (BOE $\mathrm{n}^{\circ} 286,25$ de noviembre de 2012)

Plan Profesional del Magisterio. Decreto de 29 de septiembre de 1931 (publicado al día siguiente. Gazeta de Madrid (1931).

Pla d'estudis de graduat Mestre o Graduada Mestra en Educació Primària (BOE $n^{\circ}$ 11, 13 de enero de 2012).

Pla d'estudis de graduat Mestre o Graduada Mestra en Educació Primària (DOCV nº 6694, 18 de enero de 2012).

Pla d'estudis de graduat Mestre o Graduada Mestra en Educació Infantil (BOE $n^{\circ}$ 11, 13 de enero de 2012).

Pla d'estudis de graduat Mestre o Graduada Mestra en Educació Infantil (DOCV nº 6694, 18 de enero de 2012).

Real Decreto 1497/1987 de 27 de noviembre, con posteriores modificaciones en el RD 1267/1994 de 10 de junio, en el RD 2347/1996 de 8 de noviembre, en el RD 614/1997 de 25 abril y en el RD 779/1998 de 30 abril.

Real Decreto 1006/1991, de 14 de junio, por el que se establecen las enseñanzas mínimas correspondientes a la Educación Primaria. (Vigente hasta el 9 de diciembre de 2006). 
Real Decreto 1440/1991, de 30 de agosto, por el que se establece el título universitario oficial de Maestro, en sus diferentes especialidades, y directrices generales propias de los planes de estudios (BOE 11 octubre 1991).

Real Decreto 830/2003, de 27 de junio (BOE 2 de julio de 2003) por el que se establecen las enseñanzas comunes de la Educación Primaria.

Real decreto 1318/2004, de 28 de mayo, por el que se modifica el RD 827/2003, de 27 de junio, por el que se establece el calendario de aplicación de la nueva ordenación del sistema educativo, establecido pos la ley Orgánica 10/2002, de 23 de diciembre de calidad de la Educación.

Real Decreto 1509/2005, de 16 de diciembre, por el que se modifican el Real Decreto 55/2005, de 21 de enero, por el que se establece la estructura de las enseñanzas universitarias y se regulan los estudios universitarios oficiales de grado.

Real Decreto de 4 de agosto de 1836, Plan General de Instrucción Pública, promulgado por el Duque de Rivas. Disponible en: http://www.filosofia.org/mfa/fae836a.htm

UNESCO (1998). La educación superior en el siglo XXI. Visión y acción. Conferencia Mundial sobre la Educación Superior.

UNESCO (2006). Hoja de ruta para la Educación Artística.

http://www.unesco.org/new/fileadmin/MULTIMEDIA/HQ/CLT/CLT/pdf/Arts Edu RoadMap es.pdf

VV. AA. (2005). El Espacio Europeo de Educación Superior-Alcanzando las metas. Comunicado de la Conferencia de Ministros Europeos responsables de Educación Superior. Bergen, 19-20 de Mayo de 2005.

VV. AA. (2006). El marco europeo de cualificaciones: una nueva herramienta para entender las cualificaciones en toda Europa. 
VV. AA. (2006). Aplicación del Programa comunitario de Lisboa. Recomendación del Parlamento Europeo y del Consejo relativa a la creación del Marco Europeo de Cualificaciones para el aprendizaje permanente Bruselas, 5.9.2006. Disponible en:

http://ec.europa.eu/education/policies/educ/egf/com_2006 0479 es.pdf 
CAPÍTULO VII. 
La Educación Artística en los planes de estudio de Magisterio de la Comunitat Valenciana. Visión para el siglo XXI.

ANEXOS 
ANEXO I

Tabla 37. DECRETO 111/2007, de 20 de julio, del Consell, por el que se establece el currículo de la Educación Primaria en la Comunitat Valenciana. [2007/9730).

EDUCACIÓN ARTÍSTICA 30296>>30307

\begin{tabular}{|c|c|c|c|}
\hline CONTENIDOS & PRIMER CICLO & SEGUNDO CICLO & TERCER CICLO \\
\hline \multirow{11}{*}{$\begin{array}{l}\text { Bloque } 1 . \\
\text { OBSERVACIÓN } \\
\text { PLÁSTICA }\end{array}$} & $\begin{array}{l}\text { Observación y exploración sensorial de los } \\
\text { elementos presentes en el entorno natural, } \\
\text { artificial y artístico. }\end{array}$ & $\begin{array}{l}\text { Clasificación de texturas y tonalidades y apreciación de } \\
\text { formas naturales y artificiales exploradas desde } \\
\text { diferentes ángulos y posiciones. }\end{array}$ & $\begin{array}{l}\text { Indagación sobre las posibilidades plásticas y expresivas de } \\
\text { elementos naturales y de las estructuras geométricas. }\end{array}$ \\
\hline & $\begin{array}{l}\text { Descripción verbal de sensaciones y } \\
\text { observaciones. }\end{array}$ & $\begin{array}{l}\text { Establecimiento de un orden o pauta para seguir el } \\
\text { procedimiento de observación. }\end{array}$ & $\begin{array}{l}\text { Elaboración y seguimiento de protocolos de forma oral y } \\
\text { escrita para la observación de aspectos, cualidades y } \\
\text { características notorias y sutiles de elementos naturales y } \\
\text { artificiales. }\end{array}$ \\
\hline & $\begin{array}{l}\text { Comentario de obras plásticas y visuales } \\
\text { presentes en el entorno y en exposiciones o } \\
\text { museos. }\end{array}$ & $\begin{array}{l}\text { Observación de los materiales empleados en las obras } \\
\text { plásticas. }\end{array}$ & $\begin{array}{l}\text { Exploración de las características, elementos, técnicas y } \\
\text { materiales que las obras artísticas ofrecen y sugieren para la } \\
\text { recreación de las mismas y creación de obras nuevas. }\end{array}$ \\
\hline & $\begin{array}{l}\text { Curiosidad por descubrir las posibilidades } \\
\text { artísticas que ofrece el entorno. }\end{array}$ & $\begin{array}{l}\text { Respeto y cuidado del entorno, de las obras que } \\
\text { constituyen el patrimonio cultural, de las producciones } \\
\text { propias y de las de los demás. }\end{array}$ & $\begin{array}{l}\text { Documentación, registro y valoración de formas artísticas y } \\
\text { artesanales representativas de la expresión cultural de las } \\
\text { sociedades. }\end{array}$ \\
\hline & $\begin{array}{l}\text { Conocimiento y observancia de las normas de } \\
\text { comportamiento en exposiciones. }\end{array}$ & $\begin{array}{l}\text { Interés por buscar información sobre producciones } \\
\text { artísticas y por comentarlas. }\end{array}$ & $\begin{array}{l}\text { Valoración y apreciación de la obra artística como } \\
\text { instrumento de comunicación personal y de transmisión de } \\
\text { valores culturales. }\end{array}$ \\
\hline & $\begin{array}{l}\text { Descripción de imágenes presentes en contextos } \\
\text { próximos: historietas, cómics, ilustraciones, } \\
\text { fotografías, etiquetas, cromos, carteles, adhesivos, } \\
\text { dibujos animados, marcas, propaganda, cine. }\end{array}$ & $\begin{array}{l}\text { Interpretación y valoración de la información que } \\
\text { proporcionan las imágenes en el contexto social y } \\
\text { comunicación de las apreciaciones obtenidas. }\end{array}$ & $\begin{array}{l}\text { Análisis y valoración de la intención comunicativa de las } \\
\text { imágenes en los medios y tecnologías de la información y } \\
\text { comunicación. }\end{array}$ \\
\hline & $\begin{array}{l}\text { Exploración de distancias, recorridos y situaciones } \\
\text { de objetos y personas en relación con el espacio. } \\
\text { Observación de diferentes maneras de presentar } \\
\text { el espacio. }\end{array}$ & $\begin{array}{l}\text { Observación de elementos del entorno para el estudio } \\
\text { de las escalas y proporciones entre los objetos. } \\
\text { Indagación sobre diferentes maneras de representar el } \\
\text { espacio. }\end{array}$ & $\begin{array}{l}\text { Análisis de las formas de representación de volúmenes en el } \\
\text { plano según el punto de vista o la situación en el espacio. } \\
\text { Comparación entre las formas que la representación del } \\
\text { espacio adopta en diferentes áreas o ámbitos. }\end{array}$ \\
\hline & Percepción visual y táctil del volumen. & & \\
\hline & $\begin{array}{l}\text { Introducción al mundo artístico mediante la } \\
\text { observación y lectura de obras de arte. }\end{array}$ & & \\
\hline & $\begin{array}{l}\text { Autonomía en la observación, la distinción, la } \\
\text { selección y la interpretación de aquello que es } \\
\text { percibido. }\end{array}$ & $\begin{array}{l}\text { Valoración de la importancia de la comunicación y de la } \\
\text { expresión plástica en el contexto de las relaciones } \\
\text { interpersonales. }\end{array}$ & \\
\hline & $\begin{array}{l}\text { Valoración estética del entorno natural y urbano. } \\
\text { Tradiciones populares de la Comunitat } \\
\text { Valenciana. }\end{array}$ & & \\
\hline
\end{tabular}

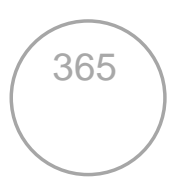




\begin{tabular}{|c|c|c|c|}
\hline CONTENIDOS & PRIMER CICLO & SEGUNDO CICLO & TERCER CICLO \\
\hline \multirow{8}{*}{$\begin{array}{l}\text { Bloque } 2 . \\
\text { EXPRESIÓN Y CREACIÓN } \\
\text { PLÁSTICA }\end{array}$} & $\begin{array}{l}\text { Experimentación de las posibilidades expresivas } \\
\text { del trazo espontáneo y con intencionalidad, de las } \\
\text { líneas que delimitan contornos y del espacio que } \\
\text { define la forma. }\end{array}$ & $\begin{array}{l}\text { Experimentación con líneas diversas y formas en } \\
\text { diferentes posiciones. } \\
\text { Representación de repertorios formales sencillos. }\end{array}$ & $\begin{array}{l}\text { Experimentación de formas abiertas y cerradas y de líneas } \\
\text { según su forma, dirección y situación espacial. } \\
\text { Representación de repertorios formales complejos. }\end{array}$ \\
\hline & $\begin{array}{l}\text { Experimentación de mezclas y manchas de color } \\
\text { con diferentes tipos de pintura y sobre soportes } \\
\text { diversos. }\end{array}$ & $\begin{array}{l}\text { Búsqueda de las posibilidades del color en contrastes, } \\
\text { variaciones y combinaciones, mezclando diversas } \\
\text { clases de pintura y apreciando los resultados sobre } \\
\text { diferentes soportes. } \\
\text { Manipulación de los colores primarios para crear otros } \\
\text { diferentes. } \\
\text { Selección y utilización de diversas mezclas de colores. }\end{array}$ & $\begin{array}{l}\text { Aplicación de colores complementarios, opuestos y } \\
\text { tonalidades de forma intencionada. }\end{array}$ \\
\hline & $\begin{array}{l}\text { Búsqueda sensorial de texturas naturales y } \\
\text { artificiales y de las cualidades y posibilidades de } \\
\text { materiales orgánicos e inorgánicos. }\end{array}$ & $\begin{array}{l}\text { Indagación sobre las cualidades de los materiales, } \\
\text { tratamientos no convencionales de los mismos y uso } \\
\text { que puede hacerse de las texturas en la representación. }\end{array}$ & $\begin{array}{l}\text { Manipulación de materiales para concretar su adecuación al } \\
\text { contenido e interés por aplicar a las representaciones } \\
\text { plásticas los hallazgos obtenidos. }\end{array}$ \\
\hline & $\begin{array}{l}\text { Elaboración de dibujos, pinturas, collages, } \\
\text { estampaciones, ilustraciones, volúmenes, } \\
\text { modelado y plegado de formas. }\end{array}$ & $\begin{array}{l}\text { Elaboración de imágenes usando manchas cromáticas, } \\
\text { tonalidades y gamas en cómics, historietas, carteles, } \\
\text { murales, mosaicos, tapices e impresiones. }\end{array}$ & $\begin{array}{l}\text { Uso de texturas para caracterizar objetos e imágenes. } \\
\text { Elaboración de obras a través de técnicas mixtas. }\end{array}$ \\
\hline & $\begin{array}{l}\text { Manipulación y transformación de objetos para su } \\
\text { uso en representaciones teatrales. }\end{array}$ & $\begin{array}{l}\text { Construcción de decorados y máscaras y elaboración de } \\
\text { maquillajes para la representación teatral. }\end{array}$ & $\begin{array}{l}\text { Creación de ambientes para la representación teatral. } \\
\text { Exploración e investigación de los cambios que experimentan } \\
\text { los volúmenes y espacios por la incidencia de la luz: sombras } \\
\text { chinas, teatro negro. }\end{array}$ \\
\hline & Composiciones plásticas a través de fotografías. & Realización de fotografías: enfoque y planos. & \\
\hline & $\begin{array}{l}\text { Disfrute en la manipulación y exploración de } \\
\text { materiales. }\end{array}$ & $\begin{array}{l}\text { Construcción de móviles, estructuras, maquetas, } \\
\text { juguetes, volúmenes exentos o en relieve. }\end{array}$ & $\begin{array}{l}\text { Construcción de estructuras y transformación de espacios } \\
\text { por medio de nociones métricas y de perspectiva visual. } \\
\text { Representación directa de la realidad. }\end{array}$ \\
\hline & $\begin{array}{l}\text { Uso progresivo y adecuado de términos referidos } \\
\text { a materiales, instrumentos o aspectos de la } \\
\text { composición artística. } \\
\text { Inicio en la utilización de un vocabulario } \\
\text { específico. }\end{array}$ & & \\
\hline
\end{tabular}

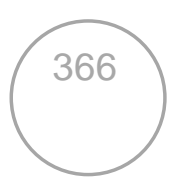




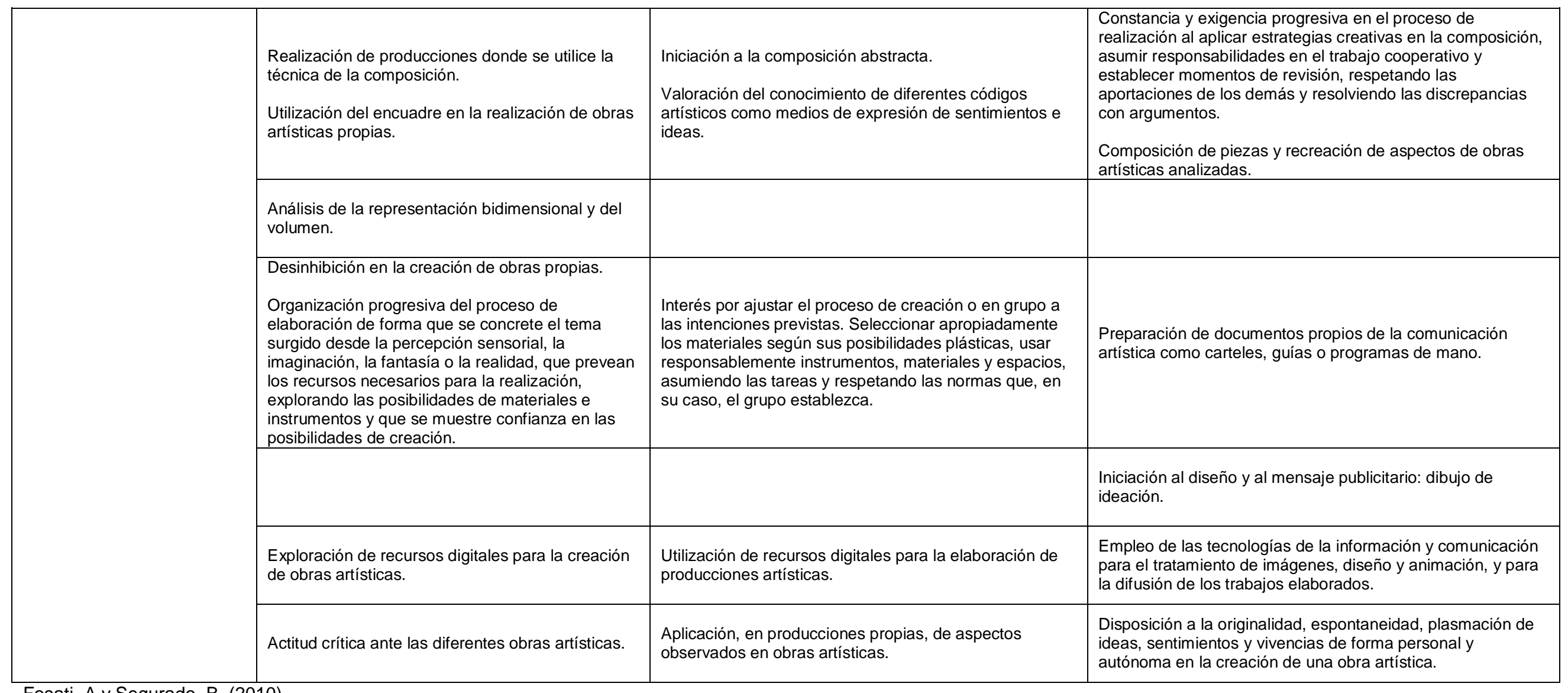




\section{ANEXO II}

Real Decreto 2633/1985, de 20 de noviembre, de traspaso de servicios de la Administración Central del Estado a la Generalitat Valenciana en materia de Universidades, recoge el traspaso de la Escuela Universitaria de Formación del Profesorado de Castellón junto a la de la Universidad de Valencia.

\begin{tabular}{|c|c|c|c|c|c|}
\hline VALENCLA - UNIVER SIDAC & DLITERARIA & 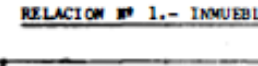 & & & \\
\hline Nonter y uno & Locollitod & Otracelón & $\begin{array}{l}\text { Situocíón } \\
\text { terfdco }\end{array}$ & sumpeleme. & Coserwociones \\
\hline Comos Deporten Universitor to & $\begin{array}{l}\text { VALENACIA } \\
\text { VALENCIA } \\
\text { VALENCIA }\end{array}$ & 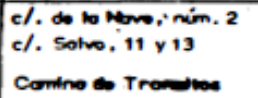 & $\begin{array}{l}\text { Estovol } \\
\text { Estotol }\end{array}$ & $\begin{array}{r}4.112 .- \\
254.50\end{array}$ & 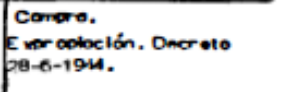 \\
\hline Foculatod do Clonelos Económicas y & VAL ENCIA & 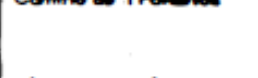 & Estotol & $20.990 .-1$ & $\begin{array}{l}\text { Exproptoción. Dosorto } \\
1237 / 01 . \text { in } 22 \text { do junto. }\end{array}$ \\
\hline $\begin{array}{l}\text { Foculad do Clonelos Eeconómleas y } \\
\text { Emprosor lobs }\end{array}$ & VALENCLA & 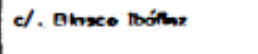 & & & \\
\hline Foculad do Dor action & VALENCIA & & & & \\
\hline Focutiod do Formoclo & VALENCIA & c/. Bloxe noilmz, " & & & \\
\hline Focultod de F llolooro & VALENCLA & 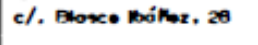 & & & \\
\hline $\begin{array}{l}\text { Focul tod do Fillosot lo y Clonclos } \\
\text { ot lo Educoclón }\end{array}$ & VALENCIA & d. Blosen nodinz, zt & & & \\
\hline Focution don Modtelino & VALENCIA & & & . & \\
\hline 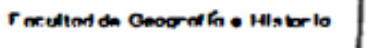 & VALENCIA & 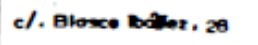 & & & \\
\hline Focullod do Psicoloaro & VAL ENCIA & c/. Aloxe boritury & & . & \\
\hline Focutiod de Babloofa & EURJASOT & cl. Deckor Momerer & & & \\
\hline rocultod do Fiskica & DUPJASOT & 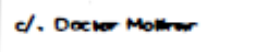 & & & \\
\hline Focut tod do Mot amóltcas & PURJA SOT & c/. Docher Molnor & & & \\
\hline Focut tod do Oufmico & FURJASOT & c/. Doche Maluer & & & \\
\hline mattituto do Clanctos do lo Educnelif & VALENCIA & c/. Mantinkium & & $7.500,--$ & $\begin{array}{l}\text { Expropoloc lón, Decrato } \\
132 / 73, \text { do } 7 \text { in knilo. }\end{array}$ \\
\hline E.U. do Entermertó & VAL ENCIA & c/. betm Rota. , s/n. & & - & \\
\hline E.U. do Estuat os Emar osarlalas & VAL ENCIA & De de Vertencla of Mor & Estotal & 0.000 & Danoción. Esc.4-1a-1914 \\
\hline $\begin{array}{l}\text { E.U. de Formoclón del Frotesorg } \\
\text { do do E.G.B. }\end{array}$ & VALENCIA & & Eslotol & 20.810.-- & $\begin{array}{l}\text { Exorootoctón. Docrato } \\
11-11-1959\end{array}$ \\
\hline $\begin{array}{l}\text { E.U. do F ormoción dol Prot nsorng } \\
\text { do de E.Q.B. }\end{array}$ & CASTELLON & c/. Horrero. a/n. & Estotol & 0.751 & Danoctón. - Ex. 31-3-1050 \\
\hline $\begin{array}{l}\text { Coledo Movor "Luls vives" y Com } \\
\text { do do doportos }\end{array}$ & VALENCIA & Porthoo Sen Estuban & Estotod & $\begin{array}{l}10.785 \\
12.000\end{array}$ & Dansción.- Exc. 20-1043 \\
\hline
\end{tabular}




\section{ANEXO III}

En este anexo presentamos los sucesivos Planes de Estudio que se han ido implantando desde 1857. Mostramos los Planes Generales, basados en la legislación general de cada momento. En ocasiones, se introduce en una misma tabla alguna modificación posterior al Plan original. En la mayoría de ocasiones se expresan las horas/semana de dedicación o los créditos. Cuando no figura es porque no ha sido posible su comprobación. El orden que se sigue es:

- Planes Nacionales desde 1857 hasta 1967.

- Planes Autonómicos, con las diferencias entre universidades: Alicante (1971, 1992, 1996, 2000 y Grado), Castellón (1992 y Grado) y Valencia (Nocturno 1967, 1971, 1993, variante Cheste 1993, 2000 y Grado).

\begin{tabular}{|c|c|c|c|c|c|c|c|}
\hline \multicolumn{8}{|c|}{ Plan de estudios de 1857} \\
\hline \multicolumn{4}{|c|}{ MAESTRO ELEMENTAL } & \multicolumn{4}{|c|}{ MAESTRO SUPERIOR } \\
\hline Primer curso & H & Segundo curso & $\mathbf{H}$ & Tercer curso & H & Cuarto curso & H \\
\hline Religión e Historia Sagrada & 3 & Nociones Agricultura & 3 & Francés I & 3 & Francés II & 3 \\
\hline Gramática Castellana & 6 & Gramática Castellana & 3 & Lengua Castellana I & 3 & Lengua Castellana II & 3 \\
\hline Nociones Pedagogía & 3 & Pedagogía & 3 & Estudios superiores Pedagogía & 3 & Historia de la Pedagogía & 3 \\
\hline Nociones Aritmética-Geometría & 3 & Derecho usual y Legislación escolar & 3 & Aritmética y Algebra I & 3 & Aritmética y Algebra II & 3 \\
\hline Nociones Geografía-Historia & 3 & Geografía e Historia de España & 3 & Religión y Moral & 3 & Geografía e Historia Universal & 3 \\
\hline Labores (M) & & Labores (M) & & Labores (M) & & Labores (M) & \\
\hline Ejercicios corporales $(\mathrm{H})$ & & Ejercicios corporales $(\mathrm{H})$ & & Música I & 3 & Música II & 3 \\
\hline Practica de enseñanza & & Practica de enseñanza & & Practica de enseñanza & & Practica de enseñanza & \\
\hline Trabajos Manuales (H) & & Trabajos Manuales (H) & & Caligrafía & 3 & Dibujo de adorno y de aplicación a labores (M) & \\
\hline Dibujo & 3 & $\begin{array}{l}\text { Ciencias físicas y naturales aplicación a } \\
\text { industria e higiene }\end{array}$ & 3 & Geometría I & 3 & Geometría II & 3 \\
\hline & & & & & & $\begin{array}{l}\text { Ciencias físicas y naturales aplicación a industria } \\
\text { e higiene }\end{array}$ & 3 \\
\hline
\end{tabular}




\begin{tabular}{|c|c|c|c|c|c|c|c|}
\hline \multicolumn{8}{|c|}{ Plan de estudios de 1914} \\
\hline Primer curso & $\mathbf{H}$ & Segundo curso & H & Tercer curso & H & Cuarto curso & $\mathbf{H}$ \\
\hline Religión e Historia Sagrada & 4,5 & Religión y Moral & 4,5 & Historia Natural & 4,5 & Agricultura $(\mathrm{H})$ & 4,5 \\
\hline Teoría y práctica de la lectura & 4,5 & Gramática Castellana I & 4,5 & Gramática Castellana II & 4,5 & Literatura española & 3 \\
\hline Nociones Aritmética-Geometría & 4,5 & Aritmética y Geometría & 4,5 & Algebra & 4,5 & Rudimentos Derecho-Legislación escolar & 4,5 \\
\hline Nociones Geografía-Geografía Regional & 4,5 & Geografía de España & 4,5 & Geografía Universal & 4,5 & Geografía de España & 4,5 \\
\hline $\begin{array}{l}\text { Nociones Historia -Historia de la Edad } \\
\text { Antigua }\end{array}$ & 4,5 & Historia de la Edad Media & 4,5 & Historia de la Edad Moderna & 4,5 & Historia Contemporánea & 4,5 \\
\hline Música I & 3 & Música II & 3 & Francés I & 3 & Francés II & 3 \\
\hline Educación física & 4,5 & Educación física & 4,5 & Física & 4,5 & Fisiología e Higiene & 4,5 \\
\hline Costura & 6 & Bordado y Corte & 6 & Corte y labores artísticas (M) & 6 & Economía domestica (M) & 4,5 \\
\hline Caligrafía & 4,5 & Caligrafía II & 3 & & & Química & 4,5 \\
\hline Dibujo I & 3 & Dibujo II & 3 & \multicolumn{2}{|l|}{ Practica de enseñanza } & \multicolumn{2}{|l|}{ Practica de enseñanza } \\
\hline & & Pedagogía I & 4,5 & Pedagogía II & 4,5 & Historia de la Pedagogía & 4,5 \\
\hline
\end{tabular}

\begin{tabular}{|c|}
\hline VOLUNTARIAS PARA MAESTRAS \\
\hline Mecanografía \\
\hline Taquigrafía \\
\hline Contabilidad mercantil \\
\hline
\end{tabular}




\begin{tabular}{|c|c|c|c|c|c|c|}
\hline \multicolumn{6}{|c|}{ Plan de estudios de 1931} & \\
\hline \multicolumn{6}{|c|}{ Formación Inicial - Plan Cultural } & \\
\hline \multicolumn{2}{|l|}{ Primer curso } & \multicolumn{2}{|l|}{ Segundo curso } & \multicolumn{2}{|l|}{ Tercer curso } & \\
\hline \multicolumn{2}{|l|}{ Aritmética y Algebra } & \multicolumn{2}{|l|}{ Geometría y Trigonometría } & \multicolumn{2}{|l|}{ Historia Natural } & \\
\hline \multicolumn{2}{|l|}{ Ejercicios lectura y escritura } & \multicolumn{2}{|l|}{ Lengua Española } & \multicolumn{2}{|l|}{ Lengua y Literatura } & \\
\hline \multicolumn{2}{|l|}{ Geografía I } & \multicolumn{2}{|l|}{ Geografía II } & \multicolumn{2}{|l|}{ Derecho y Economía } & \\
\hline \multicolumn{2}{|l|}{ Historia I } & \multicolumn{2}{|l|}{ Historia II } & \multicolumn{2}{|l|}{ Fisiología e Higiene } & \\
\hline \multicolumn{2}{|l|}{ Francés I } & \multicolumn{2}{|l|}{ Francés II } & \multicolumn{2}{|l|}{ Música y Canto } & \\
\hline \multicolumn{2}{|l|}{ Dibujo I } & \multicolumn{2}{|l|}{ Dibujo II } & \multicolumn{2}{|l|}{ Labores o Trabajos Manuales } & \\
\hline & & \multicolumn{2}{|l|}{ Física } & \multicolumn{2}{|l|}{ Agricultura } & \\
\hline & & \multicolumn{2}{|l|}{ Química } & \multicolumn{2}{|l|}{ Ejercicios físicos } & \\
\hline \multicolumn{7}{|c|}{ Plan de estudios de 1931} \\
\hline \multicolumn{7}{|c|}{ Formación - Plan Profesional } \\
\hline Primer curso & $H / s$ & Segundo curso & $H / s$ & Tercer curso & $H / s$ & Cuarto curso \\
\hline Elementos de Filosofía & 3 & Fisiología e Higiene & 3 & Paidología & 3 & Periodo de Prácticas docentes \\
\hline \begin{tabular}{|l} 
Psicología \\
\end{tabular} & 3 & Pedagogía & 3 & Historia de la Pedagogía & 3 & \\
\hline Metodología de las Matemáticas & 3 & Metodología de la Historia & 3 & Organización Escolar & 3 & \\
\hline Metodología de la Lengua y Literatura españolas & 6 & Metodología de la Física y Química & 6 & Cuestiones económicas y sociales & 3 & \\
\hline Metodología de las Ciencias Naturales y de la Agricultura & 3 & Metodología de la Geografía & 3 & Trabajos de seminario & & \\
\hline Música & 2 & Música & 2 & Trabajos de especialización & & \\
\hline Ampliación facultativa de idiomas & 2 & Ampliación facultativa de idiomas & 2 & Enseñanzas del hogar & 2 & \\
\hline Dibujo & 2 & Dibujo & 2 & & & \\
\hline Labores y Trabajos Manuales (M) & 3 & Labores y Trabajos Manuales (M) & 3 & & & \\
\hline Trabajos Manuales (H) & 3 & Trabajos Manuales $(\mathrm{H})$ & 3 & & & \\
\hline
\end{tabular}


Plan de estudios de 1940

\begin{tabular}{|l|r|l|l|}
\hline \multicolumn{3}{|c|}{ Plan de estudios de 1940 } \\
\hline \multicolumn{3}{|c|}{ Plan BACHILLE - Curso único } \\
\hline \multicolumn{1}{|c|}{ Primer cuatrimestre } & H & \multicolumn{1}{|c|}{ Segundo cuatrimestre } & H \\
\hline Religión e Historia Sagrada & $\mathbf{6}$ & Religión y Moral & $\mathbf{6}$ \\
\hline Pedagogía & $\mathbf{6}$ & Pedagogía & $\mathbf{6}$ \\
\hline Música & $\mathbf{6}$ & Música & $\mathbf{6}$ \\
\hline $\begin{array}{l}\text { Costura, bordado en blanco y corte de } \\
\text { ropa blanca }\end{array}$ & $\mathbf{6}$ & $\begin{array}{l}\text { Corte de vestidos, labores artísticas y } \\
\text { economía doméstica }\end{array}$ & $\mathbf{6}$ \\
\hline Caligrafía & $\mathbf{3}$ & Caligrafía & $\mathbf{3}$ \\
\hline Practica de enseñanza & & Practica de enseñanza & $\mathbf{3}$ \\
\hline & & Historia de la Pedagogía & \\
\hline
\end{tabular}

\begin{tabular}{|c|c|c|c|c|c|c|c|}
\hline \multicolumn{8}{|c|}{ Plan de estudios de 1942} \\
\hline Primer curso & $H / s$ & Segundo curso & $H / s$ & Tercer curso & $\mathrm{H} / \mathrm{s}$ & Cuarto curso & $\mathrm{H} / \mathrm{s}$ \\
\hline Religión & 3 & Religión & 2 & Religión & 2 & Religión y su Metodología & 2 \\
\hline Lengua Española & 3 & Lengua Española & 2 & Lengua Española & 2 & Psicología y Lógica & 2 \\
\hline Matemáticas & 3 & Matemáticas & 2 & Aritmética y elementos Algebra & 2 & Didáctica general y especial y Organización Escolar & 2 \\
\hline Caligrafía & 1 & Caligrafía & 1 & Música & 2 & Fisiología e Higiene & 2 \\
\hline Geografía & 2 & Geografía & 2 & Geografía & 2 & Pedagogía & 2 \\
\hline Historia & 2 & Música & 2 & Historia Universal & 2 & Historia de la Pedagogía & 2 \\
\hline Ciencias de la Naturaleza & 2 & Ciencias de la Naturaleza & 2 & Elementos de Física y Química & 2 & Labores artísticas y Enseñanzas del Hogar & 2 \\
\hline Lengua Moderna & 2 & Francés & 2 & Lengua Francesa & 2 & Trabajos Manuales & 2 \\
\hline Enseñanza Patriótica & 2 & Historia Educación Patriótica & 2 & Labores & 2 & \multicolumn{2}{|l|}{ Practica de enseñanza } \\
\hline Gimnasia & 3 & Gimnasia y recreos dirigidos & 2 & Trabajos Manuales & 2 & & \\
\hline Recreos dirigidos & 3 & Labores & 2 & Dibujo & 2 & & \\
\hline \multicolumn{2}{|c|}{ Labores y Enseñanzas del Hogar } & Enseñanzas del Hogar & 1 & & & & \\
\hline Enseñanza Artística & 2 & Dibujo & 2 & & & & \\
\hline
\end{tabular}




\begin{tabular}{|c|c|c|c|c|c|}
\hline \multicolumn{6}{|c|}{ Plan de estudios de 1950} \\
\hline Primer curso & $\mathbf{H}$ & Segundo curso & $\mathbf{H}$ & Tercer curso & H \\
\hline Religión y su metodología & 2 & Religión y su metodología & 2 & Religión y su Metodología & 2 \\
\hline Matemáticas & 3 & Matemáticas & 2 & $\mathrm{H}^{\mathrm{a}}$ de la Literatura Española, Metodología de la Lengua & 3 \\
\hline Geografía e Historia & 3 & Física & 3 & $\mathrm{H}^{\mathrm{a}}$ Natural & 2 \\
\hline Fisiología e Higiene & 1 & Química & 3 & Francés & 2 \\
\hline Lengua Española & 3 & Pedagogía & 3 & Pedagogía & 3 \\
\hline & & Música & 2 & Música & 2 \\
\hline Labores y Enseñanzas del Hogar & 2 & Labores y Enseñanzas del Hogar & 2 & Agricultura e industrias agrícolas & 2 \\
\hline Filosofía & 3 & Filosofía & 2 & Geografía e Historia & 3 \\
\hline Educación física & 3 & Educación física & 3 & Educación física & 3 \\
\hline Formación político-social & 2 & Formación político-social & 2 & Formación político-social & 1 \\
\hline Practica de enseñanza & 1 & Practica de enseñanza & 1 & Practica de enseñanza & 1 \\
\hline Trabajos Manuales & 2 & Trabajos Manuales & 0,5 & & \\
\hline Caligrafía & 1 & Caligrafía & 1 & & \\
\hline & & Dibujo y su Metodología & 1 & Dibujo del natural & 1 \\
\hline & & Psicología & 1 & & \\
\hline
\end{tabular}


La Educación Artística en los planes de estudio de Magisterio de la Comunitat Valenciana. Visión para el siglo XXI

\begin{tabular}{|c|c|c|c|c|c|c|}
\hline \multicolumn{7}{|c|}{ Plan de estudios de 1967} \\
\hline \multirow{2}{*}{\begin{tabular}{|c|} 
Primer curso \\
Pedagogía e Historia de la Educación
\end{tabular}} & \multicolumn{2}{|c|}{ Horas semanales por cuatrimestre } & \multirow{2}{*}{\begin{tabular}{|c} 
Segundo curso \\
Filosofía y Sociología de la Educación
\end{tabular}} & \multicolumn{2}{|c|}{ Horas semanales por cuatrimestre } & \multirow[t]{2}{*}{ Tercer curso } \\
\hline & 3 & 3 & & 4 & 4 & \\
\hline Psicología general y evolutiva & 3 & 3 & Didáctica y Organización escolar & 6 & 6 & \\
\hline Didáctica de las Matemáticas & 3 & 3 & Didáctica de las Matemáticas & 3 & 0 & \\
\hline $\begin{array}{l}\text { Didáctica de la Lengua Española y } \\
\text { Literatura }\end{array}$ & 3 & 3 & Didáctica de la Lengua Española y Literatura & 2 & 2 & \\
\hline Didáctica de la Geografía e Historia & 2 & 2 & Didáctica de la Geografía e Historia & 0 & 3 & \\
\hline Didáctica de las Ciencias Naturales & 2 & 2 & Didáctica de la Física y la Química & 2 & 2 & Curso de \\
\hline Idioma (ingles o francés y su didáctica) & 2 & 2 & Idioma (ingles o francés y su didáctica) & 2 & 2 & Prácticas \\
\hline Didáctica de la Religión & 2 & 2 & Didáctica de la Religión & 1 & 1 & \\
\hline $\begin{array}{l}\text { Didáctica de la Formación del Espíritu } \\
\text { Nacional }\end{array}$ & 1 & 1 & Didáctica de la Formación del Espíritu Nacional & 1 & 1 & \\
\hline Educación Física & 3 & 3 & Educación Física & 3 & 3 & \\
\hline Música & 2 & 2 & Música & 2 & 2 & \\
\hline Practicas de Enseñanza & 2 & 2 & Practicas de Enseñanza & 2 & 2 & \\
\hline $\begin{array}{l}\text { Manualizaciones y Enseñanzas del } \\
\text { Hogar }\end{array}$ & 2 & 2 & Manualizaciones y Enseñanzas del Hogar & 2 & 2 & \\
\hline \multirow[t]{2}{*}{ Dibujo } & 2 & 2 & Dibujo & 2 & 2 & \\
\hline & 32 & 32 & & 32 & 32 & \\
\hline
\end{tabular}

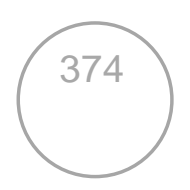




\section{ALICANTE}

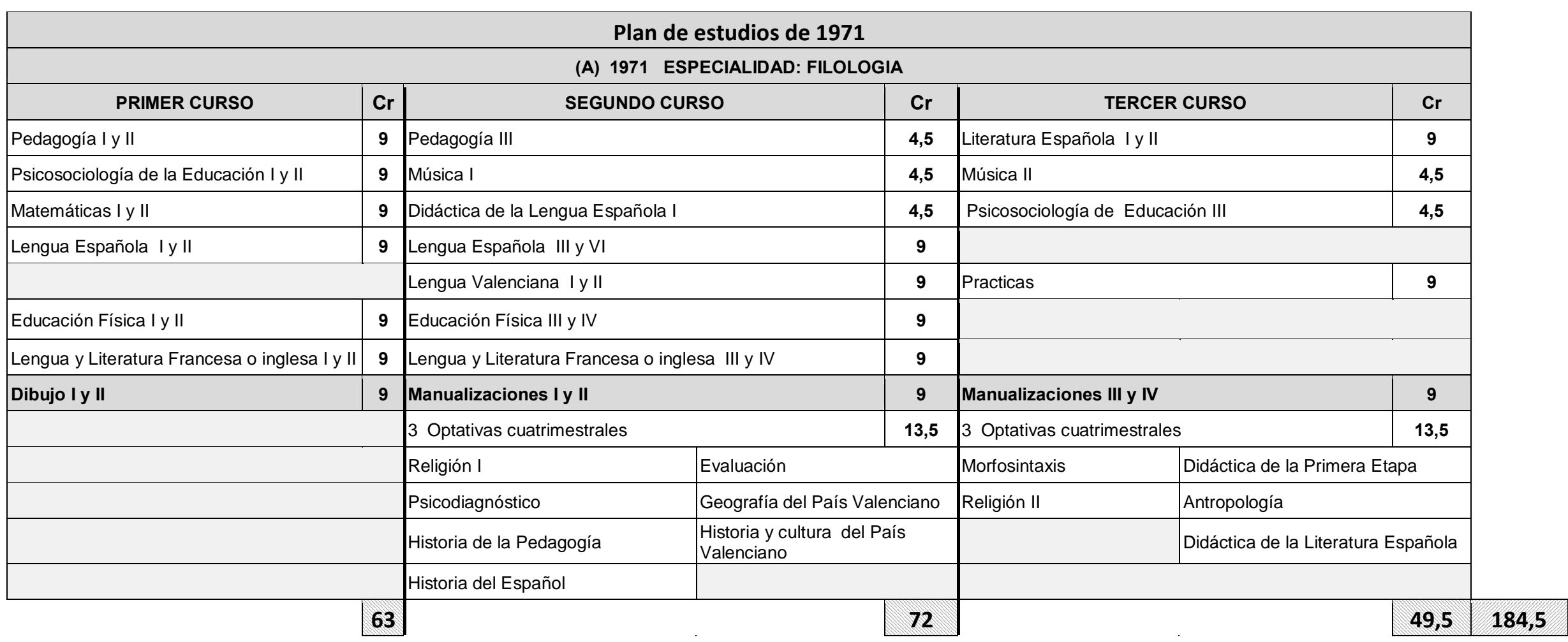

\begin{tabular}{|c|c|c|c|c|c|}
\hline \multicolumn{9}{|c|}{ (A) 1971 ESPECIALIDAD: CIENCIAS } \\
\hline PRIMER CURSO & $\mathrm{Cr}$ & SEGUNDO CURSO & Cr & TERCER CURSO \\
\hline Pedagogía I & $\mathbf{4 , 5}$ & Pedagogía III & & $\mathbf{4 , 5}$ & Literatura Española I y II \\
\hline
\end{tabular}


La Educación Artística en Ios planes de estudio de Magisterio de la Comunitat Valenciana. Visión para el siglo XXI

\begin{tabular}{|c|c|c|c|c|c|c|c|}
\hline Pedagogía II & 4,5 & \multicolumn{2}{|l|}{ Música I } & 4,5 & \multicolumn{2}{|l|}{ Música II } & 4,5 \\
\hline Psicosociología de la Educación I & 4,5 & \multicolumn{2}{|l|}{ Didáctica de las Matemáticas } & 4,5 & \multicolumn{2}{|c|}{ Psicosociología de Educación III } & 4,5 \\
\hline Psicosociología de la Educación II & 4,5 & \multicolumn{2}{|l|}{ Química I } & 4,5 & \multicolumn{2}{|l|}{ Química II } & 4,5 \\
\hline Lengua Española | y || & 9 & \multicolumn{2}{|l|}{ Biología I } & 4,5 & \multicolumn{2}{|l|}{ Biología II } & 4,5 \\
\hline Geología I & 4,5 & \multicolumn{2}{|l|}{ Geología II } & 4,5 & \multicolumn{2}{|l|}{ Practicas } & 9 \\
\hline Física I & 4,5 & \multicolumn{2}{|l|}{ Física II } & 4,5 & & & \\
\hline Educación Física I y II & 9 & \multicolumn{2}{|l|}{ Educación Física III y IV } & 9 & & & \\
\hline Dibujo I y II & 9 & \multicolumn{2}{|l|}{ Manualizaciones I y II } & 9 & \multicolumn{2}{|c|}{ Manualizaciones III y IV } & 9 \\
\hline & & \multicolumn{2}{|l|}{2 Optativas Cuatrimestrales } & 9 & \multicolumn{2}{|c|}{2 Optativas Cuatrimestrales } & 9 \\
\hline & & Mecánica y calor & \multicolumn{2}{|l|}{ Evaluación } & Botánica & \multicolumn{2}{|c|}{ Didáctica de la Primera Etapa } \\
\hline & & Psicodiagnóstico & \multicolumn{2}{|l|}{ Religión I } & Religión II & \multicolumn{2}{|c|}{ Valenciano II } \\
\hline & & Lengua Valenciana y su didáctica & \multicolumn{2}{|l|}{$\begin{array}{l}\text { Historia y cultura del País } \\
\text { Valenciano }\end{array}$} & & \multicolumn{2}{|c|}{ Computad y enseñanza de la Física } \\
\hline & & \multicolumn{3}{|c|}{ Zoología } & \multicolumn{3}{|c|}{ 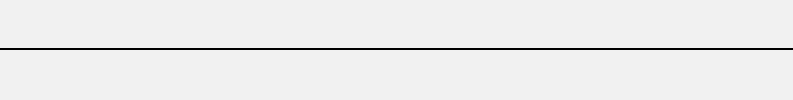 } \\
\hline & 63 & & & 67,5 & & & 63 \\
\hline
\end{tabular}

\begin{tabular}{|l|r|l|l|c|c|}
\hline \multicolumn{2}{|c|}{ (A) 1971 ESPECIALIDAD: CIENCIAS HUMANAS } \\
\hline \multicolumn{1}{|c|}{ PRIMER CURSO } & Cr & SEGUNDO CURSO & Cr & \multicolumn{1}{c|}{ TERCER CURSO } \\
\hline Pedagogía I & $\mathbf{4 , 5}$ & Pedagogía III & $\mathbf{4 , 5}$ & Practicas \\
\hline Pedagogía II & $\mathbf{4 , 5}$ & Música I & $\mathbf{4 , 5}$ & Música II \\
\hline Psicosociología de la Educación I & $\mathbf{4 , 5}$ & Didáctica de las Ciencias Humanas I & $\mathbf{4 , 5}$ & Didáctica de las Ciencias Humanas II \\
\hline Psicosociología de la Educación II & $\mathbf{4 , 5}$ & Filosofía I y II & $\mathbf{9}$ & Psicosociología de Educación III \\
\hline
\end{tabular}

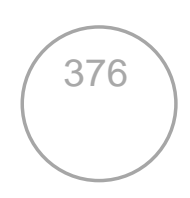




\begin{tabular}{|c|c|c|c|c|c|c|}
\hline Geografía I y II & 9 & \multicolumn{2}{|l|}{ Historia I y II } & \multicolumn{2}{|l|}{ Historia III y IV } & \\
\hline Educación Física I y II & 9 & \multicolumn{2}{|l|}{ Educación Física III y IV } & \multicolumn{2}{|c|}{ Historia de la Literatura I y II } & \\
\hline Lengua Española I y II & 9 & & & \multicolumn{2}{|l|}{ Historia del Arte I y II } & \\
\hline Matemáticas I y II & 9 & \multicolumn{2}{|l|}{ Manualizaciones I y II } & \multicolumn{2}{|l|}{ Manualizaciones III y IV } & \\
\hline Dibujo I y II & 9 & 3 Optativas Cuatrimestrales & 13,5 & \multicolumn{2}{|c|}{2 Optativas Cuatrimestrales } & \\
\hline & & Psicodiagnóstico & Evaluación & Antropología & Religión II & \\
\hline & & $\begin{array}{l}\text { Historia y cultura del País } \\
\text { Valenciano }\end{array}$ & $\begin{array}{l}\text { Lengua Valenciana y su } \\
\text { didáctica }\end{array}$ & $\begin{array}{l}\text { Didáctica de la Primera } \\
\text { Etapa }\end{array}$ & Lengua Valenciana y su didáctica & \\
\hline & & Historia de la Pedagogía & Religión I & & & \\
\hline & & Geografía Humana & Geografía del País Valenciano & & & \\
\hline & & Geografía General & Geografía Regional & & & \\
\hline & 63 & & 63 & & 67,5 & 193,5 \\
\hline
\end{tabular}

\begin{tabular}{|c|c|c|c|c|c|}
\hline \multicolumn{6}{|c|}{ (A) 1971 ESPECIALIDAD: PREESCOLAR } \\
\hline PRIMER CURSO & $\mathrm{Cr}$ & SEGUNDO CURSO & $\mathrm{Cr}$ & TERCER CURSO & $\mathrm{Cr}$ \\
\hline Pedagogía I & 4,5 & Pedagogía III & 4,5 & Psicosociología de Educación III & 4,5 \\
\hline Pedagogía II & 4,5 & Música I & 4,5 & Música II & 4,5 \\
\hline Psicosociología de la Educación I & 4,5 & Educación Medioambiental I & 4,5 & Pedagogía de la Psicomotricidad I & 4,5 \\
\hline Psicosociología de la Educación II & 4,5 & Educación Medioambiental II & 4,5 & Puericultura I & 4,5 \\
\hline Matemáticas I y |I & 9 & Didáctica de las Matemáticas & 4,5 & & \\
\hline Educación Física I y II & 9 & Educación Física III y IV & 9 & Expresión Dinámica I y II & 9 \\
\hline Psicología del Preescolar I y II & 9 & Pedagogía del Preescolar I y II & 9 & Practicas & 9 \\
\hline Dibujo I y II & 9 & Manualizaciones I y II & 9 & Manualizaciones III y IV & 9 \\
\hline
\end{tabular}

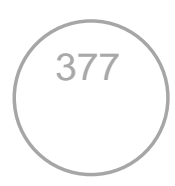


La Educación Artística en los planes de estudio de Magisterio de la Comunitat Valenciana. Visión para el siglo XXI

\begin{tabular}{|c|c|c|c|c|c|}
\hline & 2 Optativas Cuatrimestra & 9 & 2 Optativas Cuatrim & 9 & \\
\hline & Psicodiagnóstico & Evaluación & Antropología I & Didáctica de la Primera Etapa & \\
\hline & Religión I & Lengua Valenciana I & Religión II & Lengua Valenciana II & \\
\hline & Historia de la Pedagogía & $\begin{array}{l}\text { Historia y cultura del País } \\
\text { Valenciano }\end{array}$ & Expresión Musical I & & \\
\hline & \begin{tabular}{|l|} 
Expresión Plástica y \\
Pretecnología I
\end{tabular} & Geografía del País Valenciano & & & \\
\hline 63 & & 67,5 & & 58,5 & 189 \\
\hline
\end{tabular}

\begin{tabular}{|c|c|c|c|c|c|c|}
\hline \multicolumn{7}{|c|}{ (A) Plan de estudios de 1971 (por especialidades) } \\
\hline \multirow{7}{*}{ 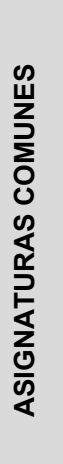 } & \multicolumn{2}{|l|}{ PRIMER CURSO } & \multicolumn{2}{|c|}{ SEGUNDO CURSO } & \multicolumn{2}{|l|}{ TERCER CURSO } \\
\hline & Pedagogía I y II & 9 & Pedagogía III & 4,5 & Psicosociología de la Educación III & 4,5 \\
\hline & Psicosociología de la Educación i y II & 9 & Música I & 4,5 & Música II & 4,5 \\
\hline & Educación Física I y II & 9 & Educación Física III y IV & 9 & & \\
\hline & Matemáticas I y II & 9 & & & Prácticas I & 9 \\
\hline & Lengua Española I y II & 9 & & & & \\
\hline & Dibujo I y II & 9 & Manualizaciones I y II & 9 & Manualizaciones III y IV & 9 \\
\hline \multirow{6}{*}{ 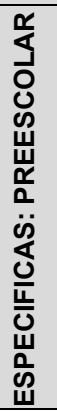 } & \multicolumn{2}{|l|}{ PRIMER CURSO } & \multicolumn{2}{|c|}{ SEGUNDO CURSO } & \multicolumn{2}{|l|}{ TERCER CURSO } \\
\hline & Psicología del Preescolar I y II & 9 & Pedagogía del Preescolar I y II & 9 & Pedagogía de la Psicomotricidad I & 4,5 \\
\hline & & & Lenguaje Preescolar I y II & 9 & Didáctica del Desarrollo Verbal I & 4,5 \\
\hline & & & Didáctica de las Matemáticas & 4,5 & Puericultura I & 4,5 \\
\hline & & & Educación Medioambiental I y II & 9 & Expresión Dinámica I y II & 9 \\
\hline & & & 2 Optativas & 9 & 2 Optativas & 9 \\
\hline
\end{tabular}

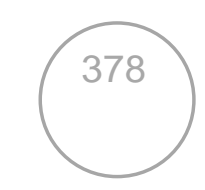




\begin{tabular}{|c|c|c|c|c|c|c|}
\hline \multirow{6}{*}{ 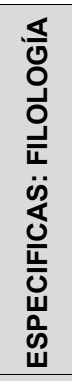 } & \multicolumn{2}{|l|}{ PRIMER CURSO } & \multicolumn{2}{|l|}{ SEGUNDO CURSO } & \multicolumn{2}{|c|}{ TERCER CURSO } \\
\hline & Lengua y Literatura Francés o Ingles I y II & 9 & Lengua y Literatura Francés o Ingles III y IV & 9 & Literatura Española I y II & 9 \\
\hline & & & Lengua Valenciana I y II & 9 & & \\
\hline & & & Didáctica de la Lengua Española I & 4,5 & & \\
\hline & & & Lengua Española III y IV & 9 & & \\
\hline & & & 3 Optativas & 13,5 & 3 Optativas & 13,5 \\
\hline \multirow{8}{*}{ 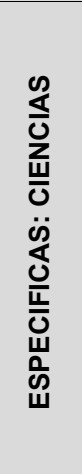 } & \multicolumn{2}{|l|}{ PRIMER CURSO } & \multicolumn{2}{|l|}{ SEGUNDO CURSO } & \multicolumn{2}{|c|}{ TERCER CURSO } \\
\hline & Física I & 4,5 & \multicolumn{2}{|l|}{ Física II } & Literatura Española I y |I & 9 \\
\hline & Geología I & 4,5 & Biología I & 4,5 & Biología II & 4,5 \\
\hline & & & Didáctica de las Matemáticas & 4,5 & Matemáticas $\vee$ y VI & 9 \\
\hline & & & Química I & 4,5 & Química II & 4,5 \\
\hline & & & Geología II & 4,5 & 2 Optativas & 9 \\
\hline & & & Matemáticas III y IV & 9 & & \\
\hline & & & 2 Optativas & 9 & & \\
\hline \multirow{6}{*}{ 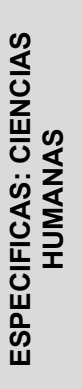 } & \multicolumn{2}{|l|}{ PRIMER CURSO } & \multicolumn{2}{|l|}{ SEGUNDO CURSO } & \multicolumn{2}{|c|}{ TERCER CURSO } \\
\hline & Geografía I y II & 9 & Didáctica CC. Humanas I & 4,5 & Didáctica CC. Humanas II & 4,5 \\
\hline & & & Filosofía I y II & 9 & $\mathrm{H}^{\mathrm{a}}$ de la Literatura I y II & 9 \\
\hline & & & Historia I y II & 9 & Historia III y IV & 9 \\
\hline & & & 3 Optativas & 13,5 & 2 Optativas & 9 \\
\hline & & & & & $\mathrm{H}^{\mathrm{a}}$ del Arte & 9 \\
\hline
\end{tabular}




\begin{tabular}{|c|c|c|c|c|c|c|c|c|}
\hline \multicolumn{9}{|c|}{ (A) 1992 ESPECIALIDAD: PRIMARIA } \\
\hline \multicolumn{2}{|c|}{$\begin{array}{c}\text { PRIMER CURSO } \\
\text { (7 tronc. }+2 \text { obl. }+3 \text { opt. }+7 \text { lib.config.) } \\
\end{array}$} & $\mathrm{Cr}$ & \multicolumn{2}{|c|}{$\begin{array}{c}\text { SEGUNDO CURSO } \\
\text { (10 tronc. }+1 \text { obl. }+3 \text { opt. }+7 \text { lib.config.) }\end{array}$} & $\mathrm{Cr}$ & \multicolumn{2}{|c|}{$\begin{array}{c}\text { TERCER CURSO } \\
(2 \text { tronc. }+1 \text { tronc. idioma }+1 \text { obl. }+3 \text { opt. }+7 \\
\text { lib.config.) }\end{array}$} & $\mathrm{Cr}$ \\
\hline \multicolumn{3}{|c|}{ TRONCALES } & \multicolumn{3}{|c|}{ TRONCALES } & \multicolumn{3}{|c|}{ TRONCALES } \\
\hline \multicolumn{2}{|l|}{ Didáctica General } & 8 & \multicolumn{2}{|c|}{ Organización del Centro Escolar } & 4 & \multicolumn{2}{|c|}{ Lengua y Literatura y su Didáctica I } & 6 \\
\hline \multicolumn{2}{|c|}{$\begin{array}{l}\text { Psicología de la Educación y del Desarrollo en la Edad } \\
\text { Escolar }\end{array}$} & 8 & \multicolumn{2}{|c|}{ Bases Psicopedagógicas de la Educación Especial } & 8 & \multicolumn{2}{|l|}{ Practicum } & 32 \\
\hline \multicolumn{2}{|l|}{ Sociología de la Educación } & 4 & \multicolumn{2}{|c|}{ Teorías e Instituciones Contemporáneos de Educación } & 4 & \multicolumn{2}{|c|}{ Idioma Extranjero y su Didáctica (Francés o Ingles) } & 4 \\
\hline \multicolumn{2}{|c|}{ Ciencias de la Naturaleza I. Física - Química } & 4 & \multicolumn{2}{|c|}{ Nuevas Tecnologías aplicadas a la Educación } & 4 & \multicolumn{3}{|c|}{ OBLIGATORIAS } \\
\hline \multicolumn{2}{|c|}{ Ciencias de la Naturaleza II. Biología - Geología } & 4 & \multicolumn{2}{|c|}{ Ciencias de la Naturaleza III. Didáctica } & 4 & \multicolumn{2}{|c|}{ Educación en las Artes Plásticas } & 6 \\
\hline \multicolumn{2}{|c|}{ Ciencias Sociales I. Geografía y su Didáctica } & 6 & \multicolumn{2}{|c|}{ Ciencias Sociales II. Historia y su Didáctica } & 6 & \multicolumn{2}{|c|}{ OPTATIVAS (4 créditos) } & 12 \\
\hline \multicolumn{2}{|l|}{ Matemáticas y su Didáctica I } & 6 & \multicolumn{2}{|l|}{ Matemáticas y su Didáctica II } & 4 & $\begin{array}{l}\text { Escola i Llengua al Pais } \\
\text { Valencia }\end{array}$ & Dramatización y Títere & \\
\hline \multicolumn{3}{|c|}{ OBLIGATORIAS } & \multicolumn{2}{|c|}{ Educación Física y su Didáctica } & 4 & $\begin{array}{l}\text { El Juego aplicado al Ritmo y al } \\
\text { Movimiento }\end{array}$ & \multicolumn{2}{|c|}{$\begin{array}{l}\text { Actividades Recreativas para } \\
\text { los niños con minusvalías }\end{array}$} \\
\hline \multicolumn{2}{|l|}{ Teoría de la Educación } & 4 & \multicolumn{2}{|c|}{ Educación Artística y su Didáctica } & 4 & $\begin{array}{l}\text { El Español en su contexto } \\
\text { Cultural }\end{array}$ & \multicolumn{2}{|l|}{ Geografía de España } \\
\hline \multicolumn{2}{|c|}{ Dicción, Redacción y Comunicación } & 4 & \multicolumn{2}{|c|}{ Lengua y Literatura y su Didáctica I } & 6 & Literatura Fantástica & \multicolumn{2}{|l|}{ Historia de España } \\
\hline OPTATIVAS $(<$ & réditos) & 12 & OBLIGA & & & Taller de Creación Verbal & $\begin{array}{l}\text { El Cuerpo como Instru } \\
\text { de Expresión y Comun }\end{array}$ & \\
\hline Historia de la Cultura & Geografía Política & & $\begin{array}{l}\text { Educación para la Salud Inte } \\
\text { Curriculares }\end{array}$ & en las Aéreas & 4 & & & \\
\hline La Música en el Tiempo & Educación de valores & & OPTATIVAS & ditos) & 12 & & & \\
\hline Idioma Extranjero ingles & Idioma Extranjero fra & hés & $\begin{array}{l}\text { Didáctica de la Educación } \\
\text { Medioambiental }\end{array}$ & Nuestro Planeta & & & & \\
\hline $\begin{array}{l}\text { Aspectos Históricos y } \\
\text { Conceptuales de la Química }\end{array}$ & $\begin{array}{l}\text { El Lenguaje Literario y } \\
\text { Cine }\end{array}$ & & $\begin{array}{l}\text { Interpretación Física de los } \\
\text { Fenómenos Naturales }\end{array}$ & $\begin{array}{l}\text { La Acción Tutorial. } \\
\text { Orientación Psicológi } \\
\text { Familiar }\end{array}$ & & & & \\
\hline
\end{tabular}




\begin{tabular}{|c|c|c|c|c|c|c|c|c|}
\hline \multirow{2}{*}{\begin{tabular}{|l|} 
Valenciano I \\
Historia General del Arte
\end{tabular}} & \multicolumn{2}{|c|}{$\begin{array}{l}\text { Religión Católica y su } \\
\text { Didáctica }\end{array}$} & Valenciano II & \multicolumn{2}{|c|}{ Religiones Comparadas } & & & \\
\hline & & & $\begin{array}{l}\text { Técnicas y Procedimientos } \\
\text { Artísticos }\end{array}$ & \multicolumn{2}{|c|}{ Educación para la Paz } & & & \\
\hline & & & Biología Ambiental & \multicolumn{2}{|c|}{$\begin{array}{l}\text { Antropología Social y } \\
\text { Cultural }\end{array}$} & & & \\
\hline & & & Dietética y Nutrición & \multicolumn{2}{|c|}{$\begin{array}{l}\text { Religión Católica II y su } \\
\text { Didáctica }\end{array}$} & & & \\
\hline & & & \multicolumn{3}{|c|}{$\begin{array}{l}\text { Nociones Básicas de Economía y su Proyección en la } \\
\text { Realidad }\end{array}$} & & & \\
\hline \multirow{2}{*}{\multicolumn{2}{|c|}{ LIBRE CONFIGURACION }} & 7 & LIBRE CONFIC & $A C I O N$ & 7 & LIBRE CONFIGURACION & 7 & \\
\hline & & 67 & & & 71 & & 67 & 201 \\
\hline
\end{tabular}

\begin{tabular}{|c|c|c|c|c|c|c|}
\hline \multicolumn{7}{|c|}{ (A) 1992 ESPECIALIDAD: INFANTIL } \\
\hline $\begin{array}{c}\text { PRIMER CURSO } \\
(6 \text { tronc. }+2 \text { obl. }+3 \text { opt. }+7 \text { lib.config. })\end{array}$ & $\mathrm{Cr}$ & $\begin{array}{c}\text { SEGUNDO CURSO } \\
\text { (8 tronc. }+3 \text { obl. }+3 \text { opt. }+7 \text { lib.config.) }\end{array}$ & $\mathrm{Cr}$ & \multicolumn{2}{|c|}{$\begin{array}{c}\text { TERCER CURSO } \\
(3 \text { tronc. }+1 \text { obl. }+3 \text { opt. }+7 \text { lib.config. })\end{array}$} & $\mathrm{Cr}$ \\
\hline \multicolumn{2}{|l|}{ TRONCALES } & \multicolumn{2}{|l|}{ TRONCALES } & \multicolumn{3}{|c|}{ TRONCALES } \\
\hline Didáctica General & 8 & Organización del Centro Escolar & 4 & \multicolumn{2}{|l|}{ Literatura Infantil } & 4 \\
\hline $\begin{array}{l}\text { Psicología de la Educación y del Desarrollo en la Edad } \\
\text { Escolar }\end{array}$ & 8 & Bases Psicopedagógicas de la Educación Especial & 8 & \multicolumn{2}{|l|}{ Practicum } & 32 \\
\hline Sociología de la Educación & 4 & Teorías e Instituciones Contemporáneos de Educación & 4 & \multicolumn{2}{|c|}{ Desarrollo de las Habilidades Lingüísticas y su Didáctica } & 6 \\
\hline Desarrollo del Pensamiento Matemático y su Didáctica & 8 & Nuevas Tecnologías aplicadas a la Educación & 4 & \multicolumn{3}{|c|}{ OBLIGATORIAS } \\
\hline Desarrollo Psicomotor & 6 & Desarrollo de la Expresión Musical y su Didáctica I & 6 & \multicolumn{2}{|c|}{$\begin{array}{l}\text { Bases Psicológicas de los Programas de Intervención en } \\
\text { Ed. Infantil }\end{array}$} & 4 \\
\hline Desarrollo de la Expresión Plástica y su Didáctica & 6 & Desarrollo de las Habilidades Lingüísticas y Didáctica I & 6 & \multicolumn{2}{|c|}{ OPTATIVAS (4 créditos) } & 12 \\
\hline \multicolumn{2}{|l|}{ OBLIGATORIAS } & Conocimiento del Medio Natural y su Didáctica & 4 & $\begin{array}{l}\text { Escola i Llengua al Pais } \\
\text { Valencia }\end{array}$ & \multicolumn{2}{|c|}{ Análisis del Lenguaje Infantil } \\
\hline Teoría de la Educación & 4 & Conocimiento del Medio Social y su Didáctica & 4 & El Juego como manifestación & Geografía Humana en la & \\
\hline
\end{tabular}

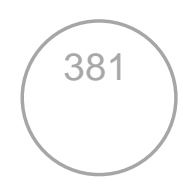


La Educación Artística en Ios planes de estudio de Magisterio de la Comunitat Valenciana. Visión para el siglo XX

\begin{tabular}{|c|c|c|c|c|c|c|c|c|}
\hline & & & & & & Social y Cultural & Educación & \\
\hline Dicción, Redacción y Comuni & ción & 4 & OBLIGATO & RIAS & & Aprendizaje de la Geometría & $\begin{array}{l}\text { Historia } \mathrm{Na} \\
\text { Comunidad }\end{array}$ & \\
\hline OPTATIVAS ( & réditos) & 12 & Dramatización y Títeres & & 4 & $\begin{array}{l}\text { Iniciación al Estudio Histórico } \\
\text { Cultural }\end{array}$ & & \\
\hline Historia de la Cultura & Geografí & & Pedagogía de 0 a 6 años & & 4 & & & \\
\hline La Música en el Tiempo & Educació & & $\begin{array}{l}\text { Educación para la Salud Integrada } \\
\text { Curriculares de Educación Infantil }\end{array}$ & $\begin{array}{l}\text { en las Aéreas } \\
\text { y Primaria }\end{array}$ & 4 & & & \\
\hline Idioma Extranjero ingles & $\begin{array}{l}\text { El Docen } \\
\text { Formacic }\end{array}$ & y su & OPTATIVAS (4 cr & ditos) & 12 & & & \\
\hline $\begin{array}{l}\text { Aspectos Históricos y } \\
\text { Conceptuales de la Química }\end{array}$ & $\begin{array}{l}\text { El Lengu } \\
\text { Cine }\end{array}$ & & $\begin{array}{l}\text { Didáctica de la Educación } \\
\text { Medioambiental }\end{array}$ & Nuestro Planeta & & & & \\
\hline Valenciano I & \begin{tabular}{|l} 
Religión \\
Didáctica
\end{tabular} & & $\begin{array}{l}\text { Interpretación Física de los } \\
\text { Fenómenos Naturales }\end{array}$ & $\begin{array}{l}\text { La Acción Tutorial. } \\
\text { Orientación Psicológica } \\
\text { Familiar }\end{array}$ & & & & \\
\hline Idioma Extranjero francés & Estadísti & & Valenciano II & Religiones Comparadas & & & & \\
\hline Historia General del Arte & & & $\begin{array}{l}\text { Técnicas y Procedimientos } \\
\text { Artísticos }\end{array}$ & Educación para la Paz & & Análisis de la Forma Bi y Tric & imensional & \\
\hline & & & Biología Ambiental & $\begin{array}{l}\text { Antropología Social y } \\
\text { Cultural }\end{array}$ & & & & \\
\hline & & & Dietética y Nutrición & $\begin{array}{l}\text { Religión Católica II y su } \\
\text { Didáctica }\end{array}$ & & & & \\
\hline & & & $\begin{array}{l}\text { Nociones Básicas de Economía y } \\
\text { su Proyección en la Realidad }\end{array}$ & & & & & \\
\hline LIBRE CONFI & RACION & 7 & LIBRE CONFIGUR & $A C I O N$ & 7 & LIBRE CONFI & UURACION & 7 \\
\hline & & 67 & & & 71 & & & 65 \\
\hline
\end{tabular}




\begin{tabular}{|c|c|c|c|c|c|c|c|c|}
\hline \multicolumn{9}{|c|}{ (A) 1992 ESPECIALIDAD: L. EXTRANJERA } \\
\hline \multicolumn{2}{|c|}{ 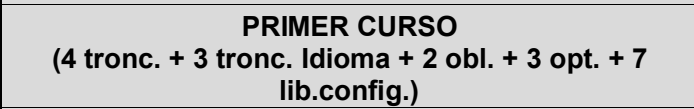 } & $\mathrm{Cr}$ & \multicolumn{2}{|c|}{$\begin{array}{c}\text { SEGUNDO CURSO } \\
\text { (8 tronc. }+1 \text { tronc.Idioma }+1 \text { obl.Idioma }+3 \text { opt. }+7 \\
\text { lib.config.) }\end{array}$} & Cr & \multicolumn{2}{|c|}{$\begin{array}{c}\text { TERCER CURSO } \\
\text { ( } 2 \text { tronc. }+2 \text { obl. Idioma }+1 \text { opt. }+7 \text { lib.config.) }\end{array}$} & $\mathrm{Cr}$ \\
\hline \multicolumn{3}{|c|}{ TRONCALES } & \multicolumn{3}{|l|}{ TRONCALES } & \multicolumn{3}{|c|}{ TRONCALES } \\
\hline \multicolumn{2}{|l|}{ Didáctica General } & 8 & \multicolumn{2}{|l|}{ Organización del Centro Escolar } & 4 & \multicolumn{2}{|c|}{ Lengua y Literatura y su Didáctica I } & 8 \\
\hline \multicolumn{2}{|c|}{$\begin{array}{l}\text { Psicología de la Educación y del Desarrollo en la Edad } \\
\text { Escolar }\end{array}$} & 8 & \multicolumn{2}{|c|}{ Bases Psicopedagógicas de la Educación Especial } & 8 & \multicolumn{2}{|l|}{ Practicum } & 32 \\
\hline \multicolumn{2}{|l|}{ Sociología de la Educación } & 4 & \multicolumn{2}{|c|}{ Teorías e Instituciones Contemporáneos de Educación } & 4 & \multicolumn{3}{|c|}{ OBLIGATORIAS } \\
\hline \multicolumn{2}{|l|}{ Lingüística } & 4 & \multicolumn{2}{|c|}{ Nuevas Tecnologías aplicadas a la Educación } & 4 & \multicolumn{2}{|c|}{ Literatura Infantil y Juvenil (Ingles o Francés) } & 8 \\
\hline \multicolumn{2}{|c|}{ Idioma Extranjero y su Didáctica (Francés o Ingles) } & 8 & \multicolumn{2}{|l|}{ Educación Física y su Didáctica } & 4 & \multicolumn{2}{|c|}{ Ingles o Francés Comunicativo II } & 6 \\
\hline \multicolumn{2}{|c|}{ Morfosintaxis y Semántica (Francés o Ingles) } & 8 & \multicolumn{2}{|l|}{ Matemáticas y su Didáctica I } & 4 & \multicolumn{2}{|c|}{ OPTATIVAS (4 créditos) } & 4 \\
\hline \multicolumn{2}{|l|}{ Fonética (Francés o Ingles) } & 4 & \multicolumn{2}{|l|}{ Educación Artística y su Didáctica } & 4 & Geografía Económica & $\begin{array}{l}\text { Cultura y Civilización } \\
\text { Anglófona }\end{array}$ & \\
\hline \multicolumn{3}{|c|}{ OBLIGATORIAS } & \multicolumn{2}{|c|}{ Conocimiento del Medio Natural, Social y Cultural } & 4 & $\begin{array}{l}\text { Literatura Comparada } \\
\text { Española/Inglesa }\end{array}$ & $\begin{array}{l}\text { Cultura y Civilización } \\
\text { Francófona }\end{array}$ & \\
\hline \multicolumn{2}{|l|}{ Teoría de la Educación } & 4 & \multicolumn{2}{|c|}{ Idioma Extranjero y su Didáctica II (Francés o Ingles) } & 8 & $\begin{array}{l}\text { Literatura Comparada } \\
\text { Española/Francesa }\end{array}$ & & \\
\hline \multicolumn{2}{|c|}{ Dicción, Redacción y Comunicación } & 4 & \multicolumn{3}{|c|}{ OBLIGATORIAS } & & & \\
\hline \multicolumn{2}{|c|}{ OPTATIVAS (4 créditos) } & 12 & Francés o Ingles Comunicativo I & & 4 & & & \\
\hline Historia de la Cultura & Geografía Política & & OPTATIVAS (4 cré & éditos) & 12 & & & \\
\hline La Música en el Tiempo & Educación de valores & & $\begin{array}{l}\text { Didáctica de la Educación } \\
\text { Medioambiental }\end{array}$ & Nuestro Planeta & & & & \\
\hline Idioma Extranjero ingles & $\begin{array}{l}\text { El Docente, su Función } \\
\text { Formación }\end{array}$ & y su & $\begin{array}{l}\text { Interpretación Física de los } \\
\text { Fenómenos Naturales }\end{array}$ & Biología Ambiental & & & & \\
\hline $\begin{array}{l}\text { Aspectos Históricos y } \\
\text { Conceptuales de la Química }\end{array}$ & $\begin{array}{l}\text { El Lenguaje Literario y } \\
\text { Cine }\end{array}$ & & $\begin{array}{l}\text { Nociones Básicas de Economía y } \\
\text { su Proyección en la Realidad }\end{array}$ & Religiones Compara & & & & \\
\hline Religión Católica y su Didáctica & Estadística y Probabilic & & $\begin{array}{l}\text { La Acción Tutorial. Orientación } \\
\text { Psicológica Familiar }\end{array}$ & Educación para la P & & & & \\
\hline Idioma Extranjero francés & Valenciano I & & Religión Católica II y su Didáctica & $\begin{array}{l}\text { Antropología Social } \\
\text { Cultural }\end{array}$ & & & & \\
\hline Historia General del Arte & & & $\begin{array}{l}\text { Técnicas y Procedimientos } \\
\text { Artísticos }\end{array}$ & Dietética y Nutrición & & $\begin{array}{l}\text { La Creatividad Plástic } \\
\text { Extranjera }\end{array}$ & idáctica de la Lengua & \\
\hline
\end{tabular}

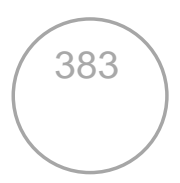


La Educación Artística en los planes de estudio de Magisterio de la Comunitat Valenciana. Visión para el siglo XXI

\begin{tabular}{|c|c|c|c|c|c|}
\hline & & Valenci & & & \\
\hline \multirow[t]{2}{*}{ LIBRE CONFIGURACION } & 7 & LIBRE CONFIGURACION & 7 & LIBRE CONFIGURACION & 7 \\
\hline & 71 & & 67 & & 65 \\
\hline
\end{tabular}

\begin{tabular}{|c|c|c|c|c|c|c|c|}
\hline \multicolumn{8}{|c|}{ (A) 1992 ESPECIALIDAD: E. FISICA } \\
\hline \multicolumn{2}{|c|}{$\begin{array}{c}\text { PRIMER CURSO } \\
\text { ( } 6 \text { tronc. }+2 \text { obl. }+3 \text { opt. }+7 \text { lib.config. })\end{array}$} & $\mathrm{Cr}$ & $\begin{array}{c}\text { SEGUNDO CURSO } \\
\text { (8 tronc. }+3 \text { obl. }+3 \text { opt. }+7 \text { lib.config.) }\end{array}$ & $\mathrm{Cr}$ & $\begin{array}{c}\text { TERC } \\
\text { (3 tronc. + } 1 \text { tronc. }\end{array}$ & $\begin{array}{l}\text { URSO } \\
\text { a }+3 \text { obl. }+1 \text { opt. }+7 \\
\text { fig.) }\end{array}$ & $\mathrm{Cr}$ \\
\hline \multicolumn{3}{|c|}{ TRONCALES } & \multicolumn{2}{|l|}{ TRONCALES } & \multicolumn{3}{|c|}{ TRONCALES } \\
\hline \multicolumn{2}{|l|}{ Didáctica General } & 8 & Organización del Centro Escolar & 4 & \multicolumn{2}{|c|}{ Lengua y Literatura y su Didáctica I } & 6 \\
\hline \multicolumn{2}{|c|}{$\begin{array}{l}\text { Psicología de la Educación y del Desarrollo en la Edad } \\
\text { Escolar }\end{array}$} & 8 & Bases Psicopedagógicas de la Educación Especial & 8 & \multicolumn{2}{|l|}{ Practicum } & 32 \\
\hline \multicolumn{2}{|l|}{ Sociología de la Educación } & 4 & Teorías e Instituciones Contemporáneos de Educación & 4 & \multicolumn{2}{|c|}{ Teoría y Práctica del Acondicionamiento Físico } & 6 \\
\hline \multicolumn{2}{|c|}{ Aprendizaje y Desarrollo Motor } & 6 & Educación Artística y su Didáctica & 4 & \multicolumn{2}{|c|}{ Idioma Extranjero y su Didáctica (Francés o Ingles) } & 4 \\
\hline \multicolumn{2}{|c|}{ Bases Biológicas y Fisiológicas del Movimiento } & 6 & Matemáticas y su Didáctica & 4 & \multicolumn{3}{|c|}{ OBLIGATORIAS } \\
\hline \multicolumn{2}{|c|}{ Educación Física y su Didáctica I } & 8 & Educación Física y su Didáctica & 4 & \multicolumn{2}{|c|}{ Actividad Física y Didáctica de la Salud } & 4 \\
\hline \multicolumn{3}{|c|}{ OBLIGATORIAS } & Conocimiento del Medio Natural, Social y Cultural & 4 & \multicolumn{2}{|c|}{ Actividades Lúdico -Deportivas II } & 2 \\
\hline \multicolumn{2}{|l|}{ Teoría de la Educación } & 4 & Nuevas Tecnologías aplicadas a la Educación & 4 & \multicolumn{2}{|c|}{ Bases rítmico Musicales en la Educación Física } & 2 \\
\hline \multicolumn{2}{|c|}{ Dicción, Redacción y Comunicación } & 4 & \multicolumn{2}{|l|}{ OBLIGATORIAS } & \multicolumn{2}{|c|}{ OPTATIVAS (4 créditos) } & 4 \\
\hline \multicolumn{2}{|c|}{ OPTATIVAS (4 créditos) } & 12 & Teoría y Pedagogía de la Acción Motriz & 4 & $\begin{array}{l}\text { Geometría: Modelo de la } \\
\text { Realidad }\end{array}$ & \multicolumn{2}{|l|}{$\begin{array}{l}\text { Economía Política del } \\
\text { Deporte }\end{array}$} \\
\hline Historia de la Cultura & \multicolumn{2}{|l|}{ Geografía Política } & Actividades Lúdico -Deportivas I & 2 & Nutrición y Deporte & \multicolumn{2}{|c|}{$\begin{array}{l}\text { Gestión y Administración de } \\
\text { Instalaciones Deportivas }\end{array}$} \\
\hline La Música en el Tiempo & \multicolumn{2}{|l|}{ Educación de valores } & Didáctica de la Expresión y la Comunicación Corporal & 4 & \\
\hline Idioma Extranjero ingles & \multicolumn{2}{|c|}{$\begin{array}{l}\text { El Docente, su Función y su } \\
\text { Formación }\end{array}$} & OPTATIVAS (4 créditos) & 12 & \\
\hline
\end{tabular}

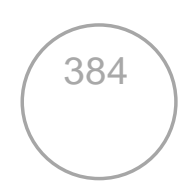




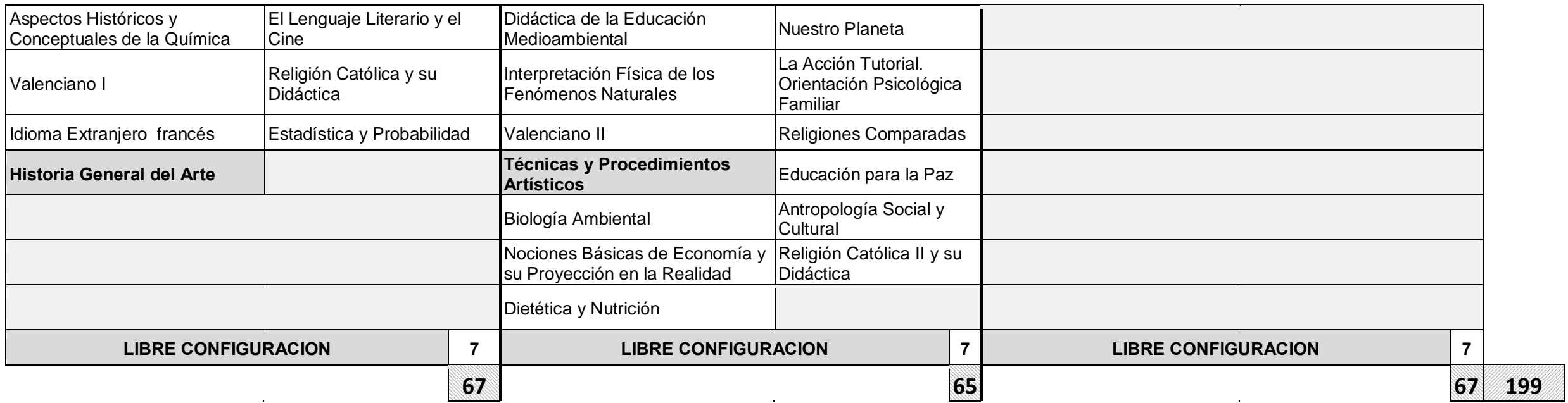

\begin{tabular}{|c|c|c|c|c|c|}
\hline \multicolumn{6}{|c|}{ (A) 1992 ESPECIALIDAD: MUSICA } \\
\hline $\begin{array}{c}\text { PRIMER CURSO } \\
\text { (8 tronc. }+2 \text { obl. }+3 \text { opt. }+7 \text { lib.config.) }\end{array}$ & $\mathrm{Cr}$ & $\begin{array}{c}\text { SEGUNDO CURSO } \\
\text { (10 tronc. }+2 \text { obl. }+3 \text { opt. }+7 \text { lib.config.) }\end{array}$ & $\mathrm{Cr}$ & $\begin{array}{c}\text { TERCER CURSO } \\
\text { (4 tronc. }+1 \text { tronc. Idioma }+1 \text { obl. }+1 \text { opt. }+7 \\
\text { lib.config.) }\end{array}$ & $\mathrm{Cr}$ \\
\hline \multicolumn{2}{|l|}{ TRONCALES } & \multicolumn{2}{|l|}{ TRONCALES } & \multicolumn{2}{|l|}{ TRONCALES } \\
\hline Didáctica General & 8 & Organización del Centro Escolar & 4 & Lengua y Literatura y su Didáctica I & 6 \\
\hline $\begin{array}{l}\text { Psicología de la Educación y del Desarrollo en la Edad } \\
\text { Escolar }\end{array}$ & 8 & Bases Psicopedagógicas de la Educación Especial & 8 & Practicum & 32 \\
\hline Sociología de la Educación & 4 & Teorías e Instituciones Contemporáneos de Educación & 4 & Agrupación Musical II & 4 \\
\hline Formación Rítmica y Danza & 4 & Nuevas Tecnologías aplicadas a la Educación & 4 & Didáctica Expresión Musical II & 4 \\
\hline Formación Vocal y Auditiva & 4 & Agrupación Musical I & 4 & Idioma Extranjero y su Didáctica (Ingles o Francés) & 4 \\
\hline Historia de la Música y del Folklore & 4 & Educación Física y su Didáctica & 4 & \multicolumn{2}{|l|}{ OBLIGATORIAS } \\
\hline Lenguaje Musical & 4 & Matemáticas y su Didáctica & 4 & Música Asistida por Ordenador & 4 \\
\hline
\end{tabular}

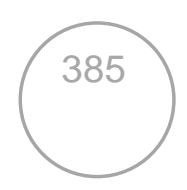


La Educación Artística en Ios planes de estudio de Magisterio de la Comunitat Valenciana. Visión para el siglo XX

\begin{tabular}{|c|c|c|c|c|c|c|c|c|}
\hline \multirow{2}{*}{\multicolumn{3}{|c|}{\begin{tabular}{|} 
Formación Instrumental I \\
OBLIGATORIAS
\end{tabular}}} & \multirow{2}{*}{\multicolumn{2}{|c|}{$\begin{array}{l}\text { Formación Instrumental II } \\
\text { Conocimiento del Medio Natural, Social y Cultural }\end{array}$}} & 4 & \multicolumn{2}{|c|}{ OPTATIVAS (4 créditos) } & \multirow[t]{2}{*}{4} \\
\hline & & & & & 4 & Acústica Musical & El Ritmo V & \\
\hline \multicolumn{2}{|l|}{ Teoría de la Educación } & \multirow{2}{*}{$\begin{array}{c}4 \\
4\end{array}$} & \multicolumn{2}{|l|}{ Didáctica Expresión Musical I } & 4 & & & \\
\hline \multicolumn{2}{|c|}{ Dicción, Redacción y Comunicación } & & \multicolumn{3}{|c|}{ OBLIGATORIAS } & & & \\
\hline \multicolumn{2}{|c|}{ OPTATIVAS (4 créditos) } & 12 & \multicolumn{2}{|c|}{ Técnicas de Armonía, Composición e Instrumentación } & 4 & & & \\
\hline Historia de la Cultura & \multicolumn{2}{|c|}{ Geografía Política } & \multicolumn{2}{|c|}{ El juego Musical Aplicado al Ritmo y al Movimiento } & 4 & & & \\
\hline La Música en el Tiempo & \multicolumn{2}{|c|}{ Educación de valores } & \multicolumn{2}{|c|}{ OPTATIVAS (4 créditos) } & 12 & & & \\
\hline Idioma Extranjero ingles & \multicolumn{2}{|c|}{$\begin{array}{l}\text { El Docente, su Función y su } \\
\text { Formación }\end{array}$} & $\begin{array}{l}\text { Didáctica de la Educación } \\
\text { Medioambiental }\end{array}$ & \multicolumn{2}{|l|}{ Nuestro Planeta } & & & \\
\hline $\begin{array}{l}\text { Aspectos Históricos y } \\
\text { Conceptuales de la Química }\end{array}$ & \multicolumn{2}{|c|}{$\begin{array}{l}\text { El Lenguaje Literario y el } \\
\text { Cine }\end{array}$} & $\begin{array}{l}\text { Interpretación Física de los } \\
\text { Fenómenos Naturales }\end{array}$ & \multicolumn{2}{|c|}{$\begin{array}{l}\text { La Acción Tutorial. } \\
\text { Orientación Psicológica } \\
\text { Familiar }\end{array}$} & & & \\
\hline Valenciano I & \multicolumn{2}{|c|}{$\begin{array}{l}\text { Religión Católica y su } \\
\text { Didáctica }\end{array}$} & Valenciano II & \multicolumn{2}{|c|}{ Religiones Comparadas } & & & \\
\hline Idioma Extranjero francés & \multicolumn{2}{|c|}{ Estadística y Probabilidad } & Dietética y Nutrición & \multicolumn{2}{|c|}{ Educación para la Paz } & & & \\
\hline \multirow[t]{3}{*}{ Historia General del Arte } & & & $\begin{array}{l}\text { Técnicas y Procedimientos } \\
\text { Artísticos }\end{array}$ & \multicolumn{2}{|l|}{$\begin{array}{l}\text { Antropología Social y } \\
\text { Cultural }\end{array}$} & \multicolumn{3}{|c|}{ La Creatividad Plástico en la Didáctica de la Música } \\
\hline & & & $\begin{array}{l}\text { Nociones Básicas de Economía y } \\
\text { su Proyección en la Realidad }\end{array}$ & \multicolumn{2}{|c|}{$\begin{array}{l}\text { Religión Católica II y su } \\
\text { Didáctica }\end{array}$} & & & \\
\hline & & & Biología Ambiental & & & & & \\
\hline \multicolumn{2}{|c|}{ LIBRE CONFIGURACION } & 7 & \multicolumn{2}{|c|}{ LIBRE CONFIGURACION } & 7 & \multicolumn{2}{|c|}{ LIBRE CONFIGURACION } & 7 \\
\hline & & 67 & & & 71 & & & 65 \\
\hline
\end{tabular}




\begin{tabular}{|c|c|c|c|}
\hline \multicolumn{4}{|c|}{ (A) Plan de estudios de 1992 (por especialidades) } \\
\hline \multirow{6}{*}{ 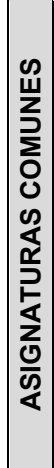 } & PRIMER CURSO & SEGUNDO CURSO & TERCER CURSO \\
\hline & Didáctica General & $\begin{array}{l}\text { Organización del Centro } \\
\text { Escolar }\end{array}$ & Practicum \\
\hline & $\begin{array}{l}\text { Psicología de la Educación y } \\
\text { del Desarrollo en la Edad } \\
\text { Escolar }\end{array}$ & $\begin{array}{l}\text { Bases Psicopedagógicas de } \\
\text { la Educación Especial }\end{array}$ & \\
\hline & Sociología de la Educación & $\begin{array}{l}\text { Teorías e Instituciones } \\
\text { Contemporáneos de } \\
\text { Educación }\end{array}$ & \\
\hline & Teoría de la Educación & $\begin{array}{l}\text { Nuevas Tecnologías } \\
\text { aplicadas a la Educación }\end{array}$ & \\
\hline & $\begin{array}{l}\text { Dicción, Redacción y } \\
\text { Comunicación }\end{array}$ & & \\
\hline
\end{tabular}

\begin{tabular}{|c|c|c|c|c|c|c|c|c|c|}
\hline & & & & & & OPT & ATIVAS & & \\
\hline & PRIMER CURSO & SEGUNDO CURSO & TERCER CURSO & $1^{\circ} \mathrm{C}$ & EURSO & $2^{\circ} \mathrm{Cl}$ & URSO & $3^{\circ} \mathrm{CU}$ & JRSO \\
\hline & $\begin{array}{l}\text { Ciencias de la Naturaleza I. } \\
\text { Física - Química }\end{array}$ & $\begin{array}{l}\text { Educación para la Salud } \\
\text { Integrada en las Aéreas } \\
\text { Curriculares }\end{array}$ & $\begin{array}{l}\text { Lengua y Literatura y su } \\
\text { Didáctica I }\end{array}$ & $\left|\begin{array}{l}\text { Historia de la } \\
\text { Cultura }\end{array}\right|$ & $\begin{array}{l}\text { Geografía } \\
\text { Política }\end{array}$ & $\begin{array}{l}\text { Didáctica de la } \\
\text { Educación } \\
\text { Medioambiental }\end{array}$ & Nuestro Planeta & $\begin{array}{l}\text { Escola i Llengua } \\
\text { al Pais Valencia }\end{array}$ & $\begin{array}{l}\text { Dramatización } \\
\text { y Títeres }\end{array}$ \\
\hline $\begin{array}{l}\frac{\Delta}{\alpha} \\
\frac{\alpha}{\alpha} \\
\frac{\alpha}{\alpha} \\
\ddot{\alpha}\end{array}$ & $\begin{array}{l}\text { Ciencias de la Naturaleza II. } \\
\text { Biología - Geología }\end{array}$ & $\begin{array}{l}\text { Ciencias de la Naturaleza III. } \\
\text { Didáctica }\end{array}$ & $\begin{array}{l}\text { Idioma Extranjero y su } \\
\text { Didáctica (Inglés o Francés) }\end{array}$ & $\left|\begin{array}{l}\text { La Música en } \\
\text { el Tiempo }\end{array}\right|$ & $\begin{array}{l}\text { Educación de } \\
\text { valores }\end{array}$ & $\begin{array}{l}\text { Interpretación } \\
\text { Física de los } \\
\text { Fenómenos } \\
\text { Naturales }\end{array}$ & \begin{tabular}{|l|} 
La Acción \\
Tutorial. \\
Orientación \\
Psicológica \\
Familiar \\
\end{tabular} & $\begin{array}{l}\text { El Juego } \\
\text { aplicado al } \\
\text { Ritmo y al } \\
\text { Movimiento }\end{array}$ & \begin{tabular}{|l} 
Actividades \\
Recreativas \\
para los niños \\
con \\
minusvalías
\end{tabular} \\
\hline$\frac{\underline{0}}{\frac{0}{u}}$ & $\begin{array}{l}\text { Ciencias Sociales I. } \\
\text { Geografía y su Didáctica }\end{array}$ & $\begin{array}{l}\text { Ciencias Sociales II. Historia } \\
\text { y su Didáctica }\end{array}$ & & \begin{tabular}{|l} 
Idioma \\
Extranjero \\
ingles
\end{tabular} & \begin{tabular}{|l} 
Idioma \\
Extranjero \\
francés \\
\end{tabular} & Valenciano II & $\begin{array}{l}\text { Religiones } \\
\text { Comparadas }\end{array}$ & $\begin{array}{l}\text { El Español en su } \\
\text { contexto Cultural }\end{array}$ & $\begin{array}{l}\text { Geografía de } \\
\text { España }\end{array}$ \\
\hline 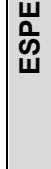 & Matemáticas y su Didáctica I & Matemáticas, su Didáctica II & & \begin{tabular}{|l|} 
Aspectos \\
Históricos y \\
Conceptuales \\
de la \\
Química
\end{tabular} & $\begin{array}{l}\text { El Lenguaje } \\
\text { Literario y el } \\
\text { Cine }\end{array}$ & \begin{tabular}{|l} 
Dietética y \\
Nutrición
\end{tabular} & $\begin{array}{l}\text { Educación para } \\
\text { la Paz }\end{array}$ & \begin{tabular}{|l} 
Literatura \\
Fantástica
\end{tabular} & $\begin{array}{l}\text { Historia de } \\
\text { España }\end{array}$ \\
\hline & & $\begin{array}{l}\text { Lengua y Literatura y su } \\
\text { Didáctica I }\end{array}$ & & Valenciano I & $\begin{array}{l}\text { Religión Católica } \\
\text { y su Didáctica }\end{array}$ & \begin{tabular}{|l} 
Biología \\
Ambiental
\end{tabular} & \begin{tabular}{|l} 
Antropología \\
Social y Cultural
\end{tabular} & Taller de Creació & n Verbal \\
\hline
\end{tabular}


La Educación Artística en los planes de estudio de Magisterio de la Comunitat Valenciana. Visión para el siglo XXI

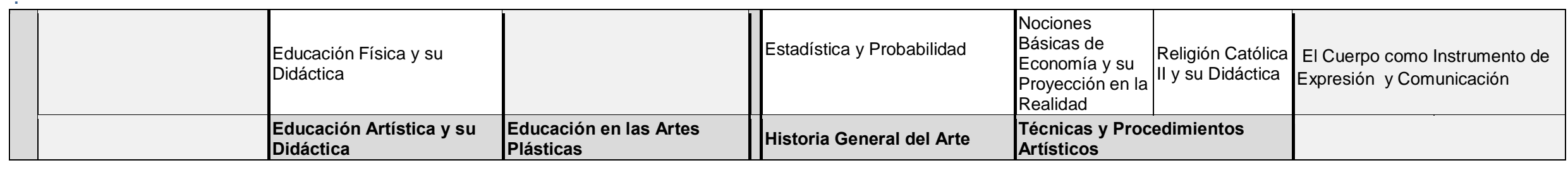

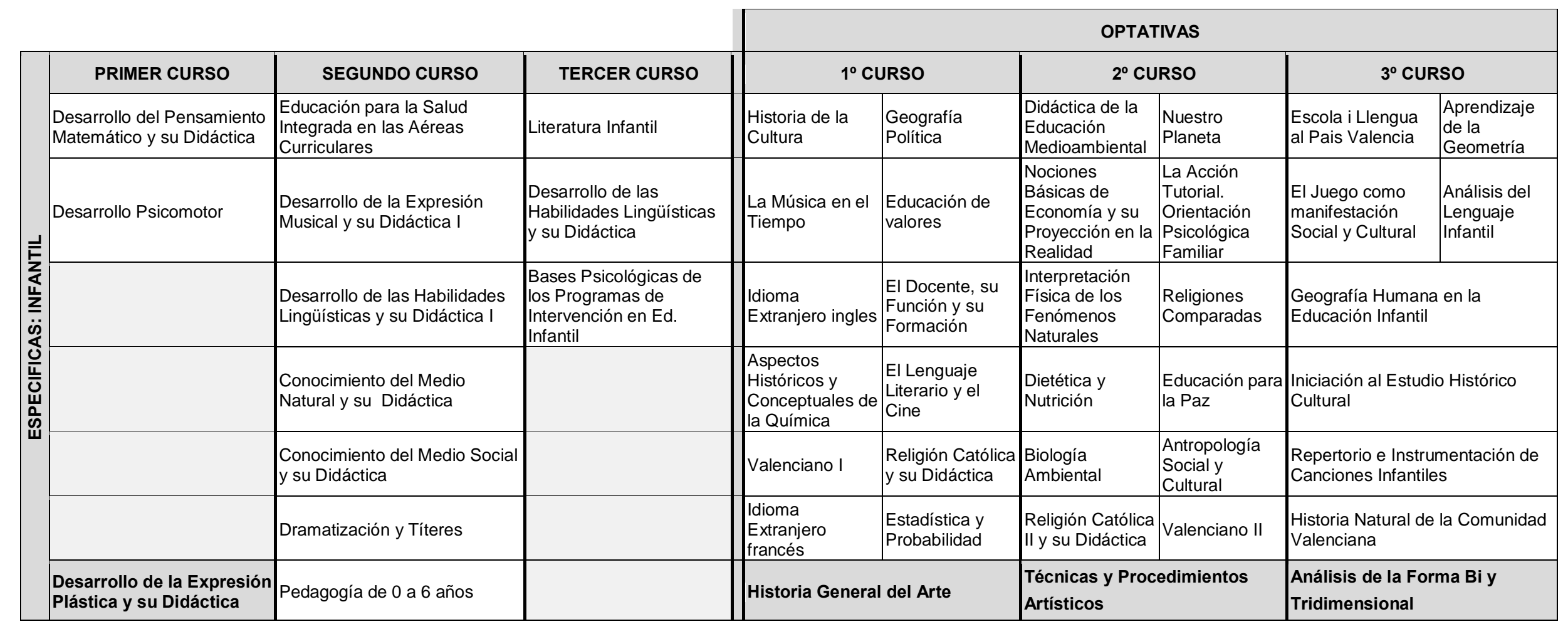




\begin{tabular}{|c|c|c|c|c|c|c|c|c|}
\hline & & & & & & OPTAT & IVAS & \\
\hline & PRIMER CURSO & SEGUNDO CURSO & TERCER CURSO & $1^{\circ} \mathrm{Cl}$ & URSO & $2^{\circ} \mathrm{CU}$ & RSO & $3^{\circ}$ CURSO \\
\hline & Fonética (Francés o Ingles) & $\begin{array}{l}\text { Idioma Extranjero y su } \\
\text { Didáctica II (Francés o Ingles) }\end{array}$ & $\begin{array}{l}\text { Lengua y Literatura y su } \\
\text { Didáctica I }\end{array}$ & $\begin{array}{l}\text { Historia de la } \\
\text { Cultura }\end{array}$ & $\begin{array}{l}\text { Geografía } \\
\text { Política }\end{array}$ & $\begin{array}{l}\text { Didáctica de la } \\
\text { Educación } \\
\text { Medioambiental }\end{array}$ & $\begin{array}{l}\text { Nuestro } \\
\text { Planeta }\end{array}$ & Geografía Económica \\
\hline 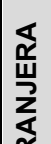 & $\begin{array}{l}\text { Idioma Extranjero y su } \\
\text { Didáctica (Francés o } \\
\text { Ingles) }\end{array}$ & Francés/ Ingles Comunicativo I & $\begin{array}{l}\text { Literatura Infantil y Juvenil } \\
\text { (Inglés o Francés) }\end{array}$ & $\begin{array}{l}\text { La Música en el } \\
\text { Tiempo }\end{array}$ & $\begin{array}{l}\text { Educación de } \\
\text { valores }\end{array}$ & $\begin{array}{l}\text { Interpretación } \\
\text { Física de los } \\
\text { Fenómenos } \\
\text { Naturales } \\
\end{array}$ & $\begin{array}{l}\text { Educación } \\
\text { para la Paz }\end{array}$ & $\begin{array}{l}\text { Literatura Comparada } \\
\text { Española/Inglesa }\end{array}$ \\
\hline 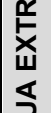 & $\begin{array}{l}\text { Morfosintaxis y Semántica } \\
\text { (Francés o Ingles) }\end{array}$ & $\begin{array}{l}\text { Conocimiento del Medio } \\
\text { Natural, Social y Cultural }\end{array}$ & $\begin{array}{l}\text { Inglés o Francés } \\
\text { Comunicativo II }\end{array}$ & $\begin{array}{l}\text { Idioma } \\
\text { Extranjero ingles }\end{array}$ & \begin{tabular}{|l|} 
El Docente, su \\
Función y su \\
Formación \\
\end{tabular} & Valenciano II & $\begin{array}{l}\text { Religiones } \\
\text { Comparadas }\end{array}$ & $\begin{array}{l}\text { Literatura Comparada } \\
\text { Española/Francesa }\end{array}$ \\
\hline 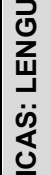 & Lingüística & Matemáticas y su Didáctica I & & $\begin{array}{l}\text { Aspectos } \\
\text { Históricos y } \\
\text { Conceptuales de } \\
\text { la Química }\end{array}$ & $\begin{array}{l}\text { El Lenguaje } \\
\text { Literario y el } \\
\text { Cine }\end{array}$ & \begin{tabular}{|l|} 
Nociones \\
Básicas de \\
Economía y su \\
Proyección en la \\
Realidad
\end{tabular} & \begin{tabular}{|l|} 
La Acción \\
Tutorial. \\
Orientación \\
Psicológica \\
Familiar \\
\end{tabular} & Cultura y Civilización Anglófona \\
\hline $\begin{array}{l}\frac{\bar{u}}{0} \\
\frac{w}{0} \\
0\end{array}$ & & $\begin{array}{l}\text { Educación Física y su } \\
\text { Didáctica }\end{array}$ & & Valenciano I & $\begin{array}{l}\text { Religión Católica } \\
\text { y su Didáctica }\end{array}$ & \begin{tabular}{|l} 
Biología \\
Ambiental
\end{tabular} & $\begin{array}{l}\text { Antropología } \\
\text { Social y } \\
\text { Cultural }\end{array}$ & Cultura y Civilización Francófona \\
\hline w & & $\begin{array}{l}\text { Educación Artística y su } \\
\text { Didáctica }\end{array}$ & & Historia General & I del Arte & $\begin{array}{l}\text { Técnicas y Proc } \\
\text { Artísticos }\end{array}$ & edimientos & $\begin{array}{l}\text { La Creatividad Plástica en la } \\
\text { Didáctica de la Lengua } \\
\text { Extranjera }\end{array}$ \\
\hline & & & & $\begin{array}{l}\text { Estadística y } \\
\text { Probabilidad }\end{array}$ & \begin{tabular}{|l|} 
Idioma \\
Extranjero \\
francés
\end{tabular} & $\begin{array}{l}\text { Dietética y } \\
\text { Nutrición }\end{array}$ & \begin{tabular}{|l|} 
Religión \\
Católica II y su \\
Didáctica \\
\end{tabular} & \\
\hline
\end{tabular}




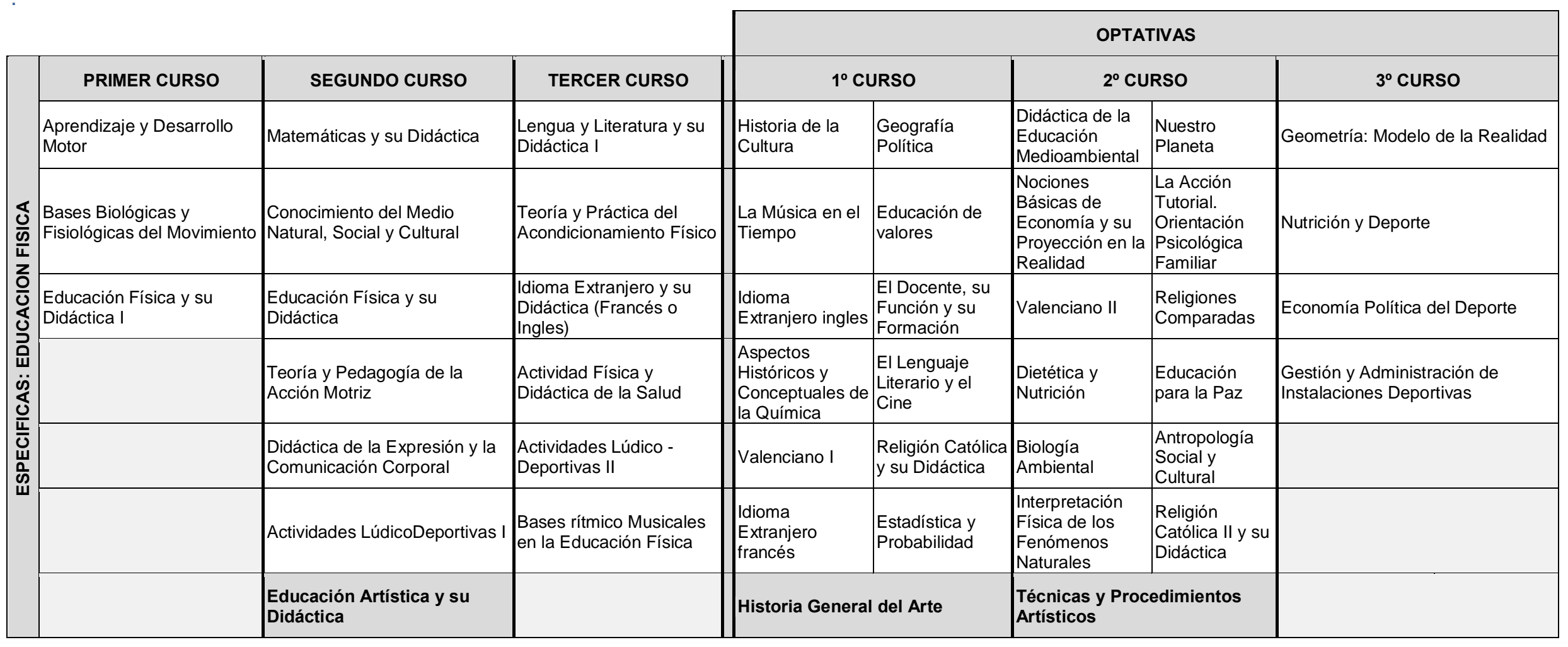




\begin{tabular}{|c|c|c|c|c|c|c|c|c|}
\hline & & & & & & OPTATI & IVAS & \\
\hline & PRIMER CURSO & SEGUNDO CURSO & TERCER CURSO & $1^{\circ} \mathrm{Cl}$ & JRSO & $2^{\circ} \mathrm{CU}$ & RSO & $3^{\circ}$ CURSO \\
\hline & $\begin{array}{l}\text { Formación Rítmica y } \\
\text { Danza }\end{array}$ & $\begin{array}{l}\text { Técnicas de Armonía, } \\
\text { Composición e Instrumentación }\end{array}$ & $\begin{array}{l}\text { Lengua y Literatura y su } \\
\text { Didáctica I }\end{array}$ & $\begin{array}{l}\text { Historia de la } \\
\text { Cultura }\end{array}$ & $\begin{array}{l}\text { Geografía } \\
\text { Política }\end{array}$ & $\begin{array}{l}\text { Didáctica de la } \\
\text { Educación } \\
\text { Medioambiental }\end{array}$ & $\begin{array}{l}\text { Nuestro } \\
\text { Planeta }\end{array}$ & Acústica Musical \\
\hline 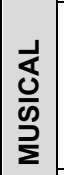 & Formación Vocal y Auditiva & Agrupación Musical I & Agrupación Musical II & $\begin{array}{l}\text { La Música en el } \\
\text { Tiempo }\end{array}$ & $\begin{array}{l}\text { Educación de } \\
\text { valores }\end{array}$ & $\begin{array}{l}\text { Nociones } \\
\text { Básicas de } \\
\text { Economía y su } \\
\text { Proyección en la } \\
\text { Realidad }\end{array}$ & \begin{tabular}{|l|} 
La Acción \\
Tutorial. \\
Orientación \\
Psicológica \\
Familiar \\
\end{tabular} & El Ritmo Verbal \\
\hline 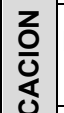 & $\begin{array}{l}\text { Historia de la Música y del } \\
\text { Folklore }\end{array}$ & Didáctica Expresión Musical I & $\begin{array}{l}\text { Didáctica Expresión } \\
\text { Musical II }\end{array}$ & $\begin{array}{l}\text { Idioma } \\
\text { Extranjero ingles }\end{array}$ & \begin{tabular}{|l|} 
El Docente, su \\
Función y su \\
Formación
\end{tabular} & Valenciano II & $\begin{array}{l}\text { Religiones } \\
\text { Comparadas }\end{array}$ & \\
\hline 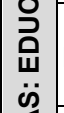 & Lenguaje Musical & $\begin{array}{l}\text { El juego Musical Aplicado al } \\
\text { Ritmo y al Movimiento }\end{array}$ & $\begin{array}{l}\text { Música Asistida por } \\
\text { Ordenador }\end{array}$ & Valenciano I & $\begin{array}{l}\text { El Lenguaje } \\
\text { Literario y el } \\
\text { Cine }\end{array}$ & \begin{tabular}{|l} 
Dietética y \\
Nutrición
\end{tabular} & $\begin{array}{l}\text { Educación } \\
\text { para la Paz }\end{array}$ & \\
\hline 造 & Formación Instrumental I & Formación Instrumental II & $\begin{array}{l}\text { Idioma Extranjero y su } \\
\text { Didáctica (Inglés o } \\
\text { Francés) }\end{array}$ & \begin{tabular}{|l|} 
Idioma \\
Extranjero \\
francés \\
\end{tabular} & $\begin{array}{l}\text { Religión Católica } \\
\text { y su Didáctica }\end{array}$ & \begin{tabular}{|l} 
Biología \\
Ambiental
\end{tabular} & \begin{tabular}{|l|} 
Antropología \\
Social y \\
Cultural \\
\end{tabular} & \\
\hline $\begin{array}{l}\mathrm{w} \\
0 \\
\mathrm{w} \\
\mathrm{w}\end{array}$ & & $\begin{array}{l}\text { Conocimiento del Medio } \\
\text { Natural, Social y Cultural }\end{array}$ & & Estadística y Prol & babilidad & Religión Católica & II y su Didáctica & \\
\hline & & $\begin{array}{l}\text { Educación Física y su } \\
\text { Didáctica }\end{array}$ & & Historia General & del Arte & \begin{tabular}{|l} 
Técnicas y Proc \\
Artísticos
\end{tabular} & edimientos & $\begin{array}{l}\text { La Creatividad Plástico en la } \\
\text { Didáctica de la Música }\end{array}$ \\
\hline & & Matemáticas y su Didáctica & & \begin{tabular}{|l} 
Aspectos Históric \\
Conceptuales de
\end{tabular} & $\begin{array}{l}\text { os y } \\
\text { la Química }\end{array}$ & \begin{tabular}{|l} 
Interpretación Fís \\
Fenómenos Natu
\end{tabular} & $\begin{array}{l}\text { ica de los } \\
\text { rales }\end{array}$ & \\
\hline
\end{tabular}




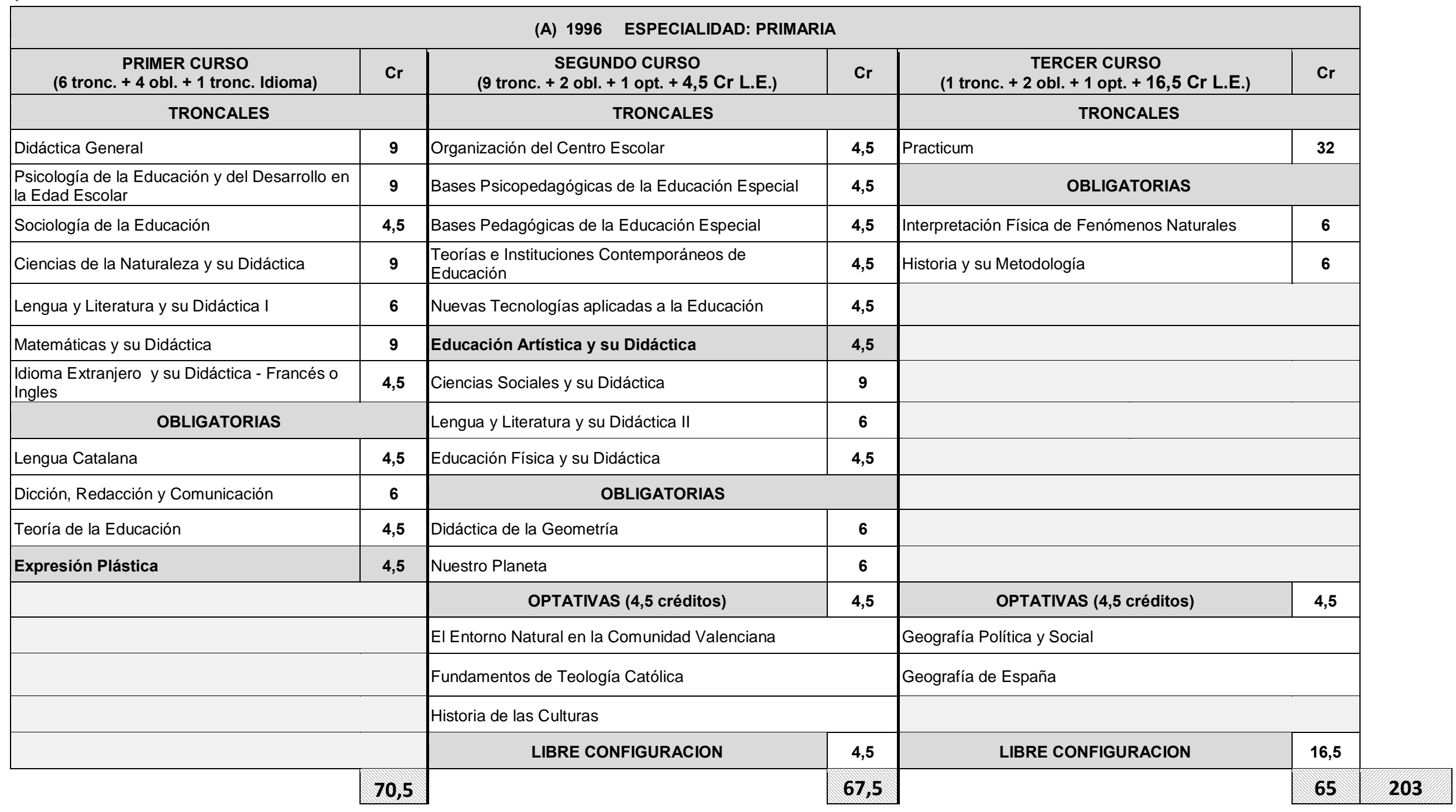




\begin{tabular}{|c|c|c|c|c|c|c|}
\hline \multicolumn{6}{|c|}{ (A) $1996 \quad$ ESPECIALIDAD: INFANTIL } & \\
\hline $\begin{array}{l}\text { PRIMER CURSO } \\
\text { ( } 6 \text { tronc. }+6 \text { obl.) }\end{array}$ & $\mathrm{Cr}$ & $\begin{array}{c}\text { SEGUNDO CURSO } \\
\text { (10 tronc. }+2 \text { obl. }+1 \text { opt. }+4,5 \text { Cr L.E.) }\end{array}$ & $\mathrm{Cr}$ & $\begin{array}{c}\text { TERCER CURSO } \\
(1 \text { tronc. }+2 \text { obl. }+1 \text { opt. }+16,5 \text { Cr L.E.) }\end{array}$ & $\mathrm{Cr}$ & \\
\hline \multicolumn{2}{|l|}{ TRONCALES } & \multicolumn{2}{|l|}{ TRONCALES } & \multicolumn{2}{|l|}{ TRONCALES } & \\
\hline Didáctica General & 9 & Organización del Centro Escolar & 4,5 & Practicum & 32 & \\
\hline $\begin{array}{l}\text { Psicología de la Educación y del Desarrollo en } \\
\text { la Edad Escolar }\end{array}$ & 9 & Bases Psicopedagógicas de la Educación Especial & 4,5 & \multicolumn{2}{|l|}{ OBLIGATORIAS } & \\
\hline Sociología de la Educación & 4,5 & Bases Pedagógicas de la Educación Especial & 4,5 & Iniciación Infantil al Entorno Social & 6 & \\
\hline $\begin{array}{l}\text { Desarrollo Pensamiento Matemático y su } \\
\text { Didáctica }\end{array}$ & 9 & $\begin{array}{l}\text { Teorías e Instituciones Contemporáneos de } \\
\text { Educación }\end{array}$ & 4,5 & Aprendizaje de la Geometría & 6 & \\
\hline $\begin{array}{l}\text { Desarrollo de la Expresión Plástica y su } \\
\text { Didáctica }\end{array}$ & 6 & Nuevas Tecnologías aplicadas a la Educación & 4,5 & & & \\
\hline Desarrollo Psicomotor & 6 & Conocimiento Medio Natural, Social y Cultural & 6 & & & \\
\hline \multicolumn{2}{|l|}{ OBLIGATORIAS } & Desarrollo de la Expresión Musical y su Didáctica & 6 & & & \\
\hline Fundamentos de Biología & 6 & Desarrollo de Habilidades Lingüísticas Didáctica & 6 & & & \\
\hline Lengua Catalana & 6 & Desplegament d'Habilitats Lingüístiques Didactica & 6 & & & \\
\hline Dicción, Redacción y Comunicación & 6 & Literatura Infantil & 4,5 & & & \\
\hline Teoría de la Educación & 4,5 & \multicolumn{2}{|l|}{ OBLIGATORIAS } & & & \\
\hline Dramatización y Títeres & 4,5 & Pedagogía de 0 a 6 años & 4,5 & & & \\
\hline \multirow[t]{7}{*}{ Dietética y Nutrición } & 4,5 & Expresión Plástica & 4,5 & & & \\
\hline & & OPTATIVAS ( 4,5 créditos) & 4,5 & OPTATIVAS ( 4,5 créditos) & 4,5 & \\
\hline & & \multicolumn{2}{|l|}{ El Juego como Método Didáctico } & \multicolumn{2}{|l|}{ Acción Tutorial y Orientación Psicológica Familiar } & \\
\hline & & \multicolumn{2}{|l|}{ Fundamentos de Moral Católica } & \multicolumn{2}{|l|}{ Educación para la Salud } & \\
\hline & & \multicolumn{2}{|l|}{ Escola i Llengua al País Valencia } & & & \\
\hline & & LIBRE CONFIGURACION & 4,5 & LIBRE CONFIGURACION & 16,5 & \\
\hline & 75 & & 69 & & 65 & 209 \\
\hline
\end{tabular}




\begin{tabular}{|c|c|c|c|c|c|}
\hline \multicolumn{6}{|c|}{ (A) 1996 ESPECIALIDAD: L. EXTRANJERA } \\
\hline $\begin{array}{c}\text { PRIMER CURSO } \\
\text { (4 tronc }+3 \text { tronc.Idioma }+1 \text { obl.Idioma }+3 \text { obl) }\end{array}$ & $\mathrm{Cr}$ & $\begin{array}{c}\text { SEGUNDO CURSO } \\
(10 \text { tronc }+1 \text { tronc.ldioma+1 obl.Idioma }+1 \text { opt }+4,5 \\
\text { CrL.E) }\end{array}$ & $\mathrm{Cr}$ & $\begin{array}{l}\text { TERCER CURSO } \\
\text { (1 tronc. }+2 \text { obl. }+1 \text { opt. }+16,5 \text { Cr L.E.) }\end{array}$ & $\mathrm{Cr}$ \\
\hline \multicolumn{2}{|l|}{ TRONCALES } & \multicolumn{2}{|l|}{ TRONCALES } & \multicolumn{2}{|l|}{ TRONCALES } \\
\hline Didáctica General & 9 & Organización del Centro Escolar & 4,5 & Practicum & 32 \\
\hline $\begin{array}{l}\text { Psicología de la Educación y del Desarrollo en } \\
\text { la Edad Escolar }\end{array}$ & 9 & Bases Psicopedagógicas de la Educación Especial & 4,5 & \multicolumn{2}{|l|}{ OBLIGATORIAS } \\
\hline Sociología de la Educación & 4,5 & Bases Pedagógicas de la Educación Especial & 4,5 & $\begin{array}{l}\text { Historia y Cultura de la Civilización anglófona y } \\
\text { francófona }\end{array}$ & 4,5 \\
\hline Lingüística & 4,5 & $\begin{array}{l}\text { Teorías e Instituciones Contemporáneos de } \\
\text { Educación }\end{array}$ & 4,5 & Literatura Infantil Inglesa o francesa & 6 \\
\hline Idioma Extranjero y Didáctica - Inglés/ Francés & 9 & Nuevas Tecnologías aplicadas a la Educación & 4,5 & & \\
\hline Fonética - Inglés o Francés & 4,5 & Conocimiento Medio Natural, Social y Cultural & 6 & & \\
\hline Morfosintaxis y Semántica - Inglés o Francés & 9 & Educación Física y su Didáctica & 4,5 & & \\
\hline \multicolumn{2}{|l|}{ OBLIGATORIAS } & Matemáticas y su Didáctica & 4,5 & & \\
\hline Lengua Catalana & 6 & Lengua y Literatura y su Didáctica & 4,5 & & \\
\hline Inglés o Francés Comunicativo I & 4,5 & Idioma Extranjero y su Didáctica - Ingles o Francés II & 9 & & \\
\hline \multirow[t]{8}{*}{ Dicción, Redacción y Comunicación } & 6 & OBLIGATORIAS & & & \\
\hline & & Inglés o Francés Comunicativo II & 4,5 & & \\
\hline & & OPTATIVAS ( 4,5 créditos) & 4,5 & OPTATIVAS ( 4,5 créditos) & 4,5 \\
\hline & & \multicolumn{2}{|l|}{ Geografía Económica } & \multicolumn{2}{|l|}{ Pedagogía y Didáctica de la Enseñanza Religiosa } \\
\hline & & \multicolumn{2}{|l|}{ Didáctica de la Imagen } & \multicolumn{2}{|l|}{ Lengua Inglesa } \\
\hline & & \multicolumn{2}{|l|}{ Literatura Comparada } & \multicolumn{2}{|l|}{ Lengua Francesa } \\
\hline & & LIBRE CONFIGURACION & 4,5 & LIBRE CONFIGURACION & 16,5 \\
\hline & 72 & & 69 & & 63,5 \\
\hline
\end{tabular}




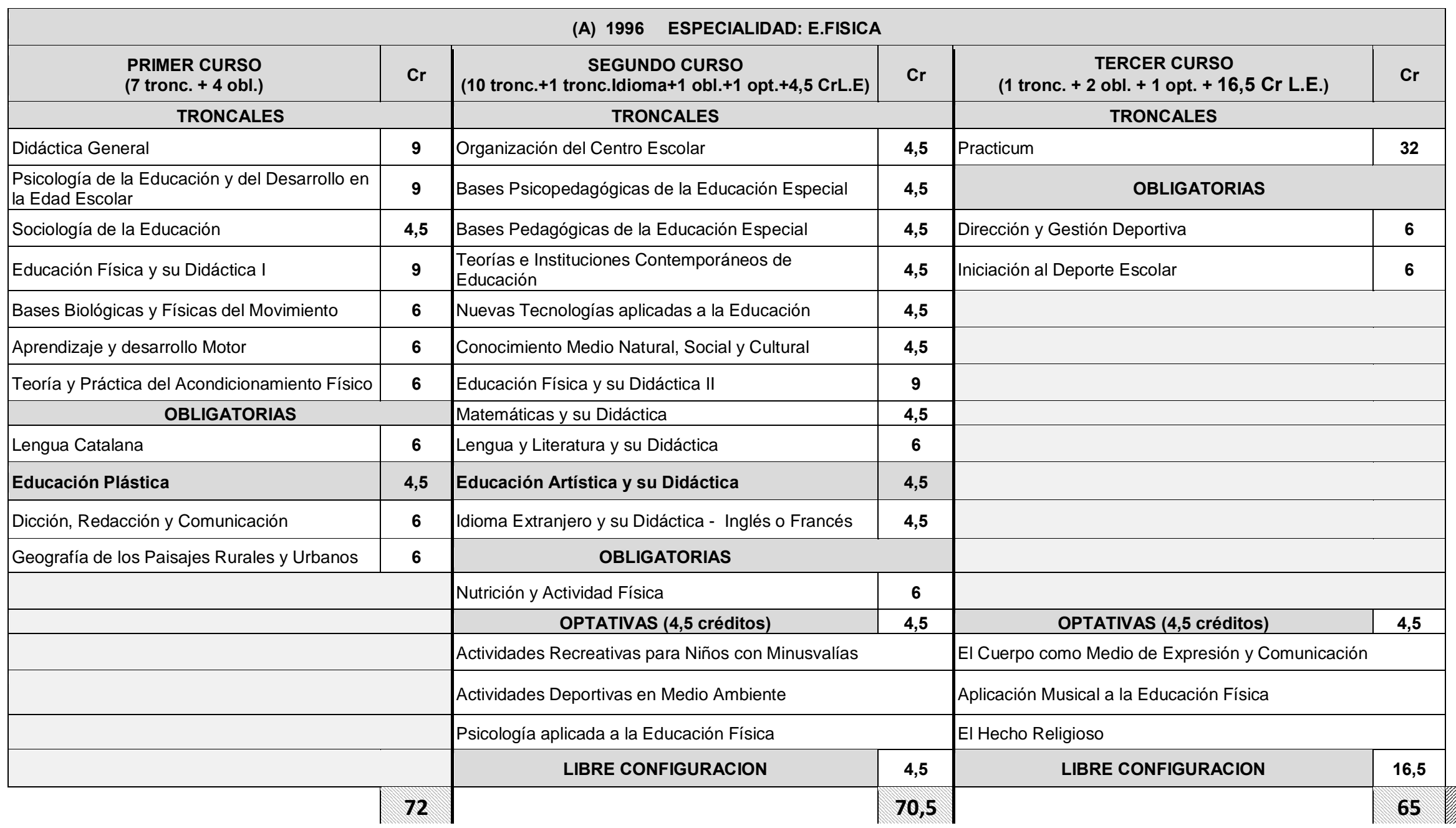




\begin{tabular}{|c|c|c|c|c|c|c|}
\hline \multicolumn{6}{|c|}{ (A) 1996 ESPECIALIDAD: E.MUSICAL } & \\
\hline $\begin{array}{c}\text { PRIMER CURSO } \\
\text { ( } 8 \text { tronc. }+3 \text { obl. }+1 \text { tronc. Idioma) } \\
\end{array}$ & $\mathrm{Cr}$ & $\begin{array}{l}\text { SEGUNDO CURSO } \\
\text { (11 tronc. }+1 \text { opt. }+4,5 \mathrm{Cr} \text { L.E.) }\end{array}$ & $\mathrm{Cr}$ & 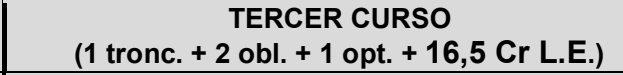 & $\mathrm{Cr}$ & \\
\hline \multicolumn{2}{|l|}{ TRONCALES } & \multicolumn{2}{|l|}{ TRONCALES } & \multicolumn{2}{|l|}{ TRONCALES } & \\
\hline Didáctica General & 9 & Organización del Centro Escolar & 4,5 & Practicum & 32 & \\
\hline $\begin{array}{l}\text { Psicología de la Educación y del Desarrollo en } \\
\text { la Edad Escolar }\end{array}$ & 9 & Bases Psicopedagógicas de la Educación Especial & 4,5 & \multicolumn{2}{|l|}{ OBLIGATORIAS } & \\
\hline Sociología de la Educación & 4,5 & Bases Pedagógicas de la Educación Especial & 4,5 & Didáctica de la Educación Medioambiental & 6 & \\
\hline Formación Rítmica y Danza & 4,5 & $\begin{array}{l}\text { Teorías e Instituciones Contemporáneos de } \\
\text { Educación }\end{array}$ & 4,5 & & & \\
\hline Formación Vocal y Auditiva & 4,5 & Nuevas Tecnologías aplicadas a la Educación & 4,5 & & & \\
\hline Historia de la Música y del Folklore & 4,5 & Conocimiento Medio Natural, Social y Cultural & 4,5 & & & \\
\hline Lenguaje Musical & 4,5 & Educación Física y su Didáctica II & 9 & & & \\
\hline Formación Instrumental & 9 & Matemáticas y su Didáctica & 4,5 & & & \\
\hline $\begin{array}{l}\text { Idioma Extranjero y su Didáctica - Ingles o } \\
\text { Francés }\end{array}$ & 4,5 & Lengua y Literatura y su Didáctica & 6 & & & \\
\hline \multicolumn{2}{|l|}{\begin{tabular}{|c|} 
OBLIGATORIAS \\
\end{tabular}} & Agrupaciones Musicales & 9 & Historia del Arte & 6 & \\
\hline Lengua Catalana & 6 & Didáctica de la Expresión Musical & 9 & & & \\
\hline Teoría de la Educación & 4,5 & OPTATIVAS ( 4,5 créditos) & 4,5 & OPTATIVAS ( 4,5 créditos) & 4,5 & \\
\hline \multirow[t]{5}{*}{ Didáctica de la Expresión Plástica y Visual } & 6 & \multicolumn{2}{|l|}{ Investigación Educativa en Ciencias Sociales } & \multicolumn{2}{|l|}{ Educación en Valores } & \\
\hline & & \multicolumn{2}{|l|}{ Didáctica de la Canción } & \multicolumn{2}{|l|}{ Técnicas y Procedimientos Artísticos } & \\
\hline & & & & \multicolumn{2}{|l|}{ El Hecho Religioso } & \\
\hline & & LIBRE CONFIGURACION & 4,5 & LIBRE CONFIGURACION & 16,5 & \\
\hline & 70,5 & & 73,5 & & 65 & 209 \\
\hline
\end{tabular}




\begin{tabular}{|c|c|c|c|c|c|}
\hline \multicolumn{4}{|c|}{ (A) Plan de estudios de 1996 (por especialidades) } & & \\
\hline \multirow{7}{*}{ 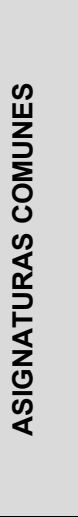 } & PRIMER CURSO & SEGUNDO CURSO & TERCER CURSO & & \\
\hline & Didáctica General & Organización del Centro Escolar & Practicum & & \\
\hline & $\begin{array}{l}\text { Psicología de la Educación y del } \\
\text { Desarrollo en la Edad Escolar }\end{array}$ & $\begin{array}{l}\text { Bases Psicopedagógicas de la } \\
\text { Educación Especial }\end{array}$ & & & \\
\hline & Sociología de la Educación & $\begin{array}{l}\text { Bases Pedagógicas de la } \\
\text { Educación Especial }\end{array}$ & & & \\
\hline & Lengua Catalana & $\begin{array}{l}\text { Teorías e Instituciones } \\
\text { Contemporáneos de Educación }\end{array}$ & & & \\
\hline & & $\begin{array}{l}\text { Nuevas Tecnologías aplicadas a } \\
\text { la Educación }\end{array}$ & & & \\
\hline & & 1 OPTATIVA & 1 OPTATIVA & & \\
\hline \multirow{8}{*}{ 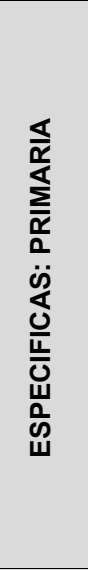 } & PRIMER CURSO $(70,5 \mathrm{cr})$ & SEGUNDO CURSO $(67,5 \mathrm{cr})$ & TERCER CURSO (65 cr) & OPTATIVAS $2^{\circ}$ y $3^{\circ}$ & 203 \\
\hline & $\begin{array}{l}\text { Ciencias de la Naturaleza y su } \\
\text { Didáctica }\end{array}$ & Educación Física y su Didáctica & \begin{tabular}{|l|} 
Interpretación Física de \\
Fenómenos Naturales
\end{tabular} & El Entorno Natural en la Comunidad Valenciana & \\
\hline & Lengua y Literatura y su Didáctica I & $\begin{array}{l}\text { Lengua y Literatura y su Didáctica } \\
\text { II }\end{array}$ & Historia y su Metodología & Fundamentos de Teología Católica & \\
\hline & Matemáticas y su Didáctica & Ciencias Sociales y su Didáctica & & Historia de las Culturas & \\
\hline & $\begin{array}{l}\text { Dicción, Redacción y } \\
\text { Comunicación }\end{array}$ & Didáctica de la Geometría & & Geografía Política y Social & \\
\hline & Teoría de la Educación & Nuestro Planeta & & Geografía de España & \\
\hline & Expresión Plástica & $\begin{array}{l}\text { Educación Artística y su } \\
\text { Didáctica }\end{array}$ & & & \\
\hline & $\begin{array}{l}\text { Idioma Extranjero y su Didáctica - } \\
\text { Ingles o Francés OP }\end{array}$ & & & & \\
\hline \multirow{2}{*}{ 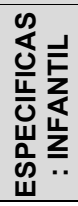 } & PRIMER CURSO $(70,5 \mathrm{cr})$ & SEGUNDO CURSO (69 cr) & TERCER CURSO (65 cr) & OPTATIVAS $2^{\circ}$ y $3^{\circ}$ & 209 \\
\hline & $\begin{array}{l}\text { Desarrollo Pensamiento } \\
\text { Matemático y su Didáctica }\end{array}$ & $\begin{array}{l}\text { Conocimiento Medio Natural, } \\
\text { Social y Cultural }\end{array}$ & $\begin{array}{l}\text { Iniciación Infantil al Entorno } \\
\text { Social }\end{array}$ & El Juego como Método Didáctico & \\
\hline
\end{tabular}




\begin{tabular}{|c|c|c|c|c|c|}
\hline & Dramatización y Títeres & $\begin{array}{l}\text { Desarrollo de la Expresión Musical } \\
\text { y su Didáctica }\end{array}$ & Aprendizaje de la Geometría & Fundamentos de Moral Católica & \\
\hline & Fundamentos de Biología & $\begin{array}{l}\text { Desarrollo de Habilidades } \\
\text { Lingüísticas Didáctica }\end{array}$ & & Escola i Llengua al País Valencia & \\
\hline & Dietética y Nutrición & $\begin{array}{l}\text { Desplegament d'Habilitats } \\
\text { Lingüístiques Didactica }\end{array}$ & & Acción Tutorial y Orientación Psicológica Familiar & \\
\hline & Desarrollo Psicomotor & Literatura Infantil & & Educación para la Salud & \\
\hline & $\begin{array}{l}\text { Dicción, Redacción y } \\
\text { Comunicación }\end{array}$ & Pedagogía de 0 a 6 años & & & \\
\hline & \begin{tabular}{|l|} 
Desarrollo de la Expresión \\
Plástica y su Didáctica
\end{tabular} & Expresión Plástica & & & \\
\hline & Teoría de la Educación & & & & \\
\hline \multirow{8}{*}{ 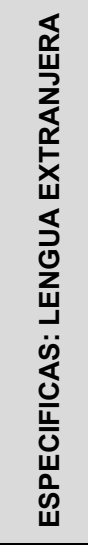 } & PRIMER CURSO $(70,5 \mathrm{cr})$ & SEGUNDO CURSO (72) & TERCER CURSO $(63,5 \mathrm{cr})$ & OPTATIVAS $2^{\circ}$ y $3^{\circ}$ & 204,5 \\
\hline & Inglés o Francés Comunicativo I & Inglés o Francés Comunicativo II & \begin{tabular}{|l|} 
Historia y Cultura de la \\
Civilización anglófona y \\
francófona
\end{tabular} & Geografía Económica & \\
\hline & $\begin{array}{l}\text { Morfosintaxis y Semántica - Inglés } \\
\text { o Francés }\end{array}$ & Educación Física y su Didáctica & $\begin{array}{l}\text { Literatura Infantil Inglesa o } \\
\text { francesa }\end{array}$ & Literatura Comparada & \\
\hline & Fonética - Inglés o Francés & Matemáticas y su Didáctica & & $\begin{array}{l}\text { Pedagogía y Didáctica de la Enseñanza } \\
\text { Religiosa }\end{array}$ & \\
\hline & $\begin{array}{l}\text { Idioma Extranjero y su Didáctica - } \\
\text { Inglés o Francés }\end{array}$ & $\begin{array}{l}\text { Idioma Extranjero y su Didáctica } \\
\text { II - Inglés o Francés }\end{array}$ & & Lengua Inglesa & \\
\hline & $\begin{array}{l}\text { Dicción, Redacción y } \\
\text { Comunicación }\end{array}$ & $\begin{array}{l}\text { Lengua y Literatura y su } \\
\text { Didáctica }\end{array}$ & & Lengua Francesa & \\
\hline & \begin{tabular}{|l|} 
Didáctica de la Expresión \\
Plástica y Visual \\
\end{tabular} & $\begin{array}{l}\text { Educación Artística y su } \\
\text { Didáctica }\end{array}$ & & Didáctica de la Imagen & \\
\hline & $\begin{array}{l}\text { Conocimiento Medio Natural, } \\
\text { Social y Cultural }\end{array}$ & Lingüística & & & \\
\hline \multirow{6}{*}{ 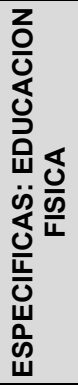 } & PRIMER CURSO $(70,5 \mathrm{cr})$ & SEGUNDO CURSO (70,5 cr) & TERCER CURSO (65 cr) & OPTATIVAS $2^{\circ}$ y $3^{\circ}$ & 207,5 \\
\hline & Aprendizaje y desarrollo Motor & Educación Física y su Didáctica & Dirección y Gestión Deportiva & Actividades Recreativas para Niños con Minusvalías & \\
\hline & $\begin{array}{l}\text { Bases Biológicas y Físicas del } \\
\text { Movimiento }\end{array}$ & Matemáticas y su Didáctica II & Iniciación al Deporte Escolar & Actividades Deportivas en Medio Ambiente & \\
\hline & Educación Física y su Didáctica I & $\begin{array}{l}\text { Lengua y Literatura y su } \\
\text { Didáctica }\end{array}$ & & Psicología aplicada a la Educación Física & \\
\hline & $\begin{array}{l}\text { Geografía de los Paisajes Rurales } \\
\text { y Urbanos }\end{array}$ & $\begin{array}{l}\text { Conocimiento Medio Natural, } \\
\text { Social y Cultural }\end{array}$ & & El Cuerpo como Medio de Expresión y Comunicación & \\
\hline & $\begin{array}{l}\text { Teoría y Práctica del } \\
\text { Acondicionamiento Físico }\end{array}$ & Nutrición y Actividad Física & & Aplicación Musical a la Educación Física & \\
\hline
\end{tabular}

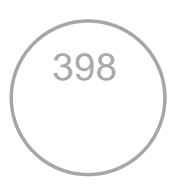




\begin{tabular}{|c|c|c|c|c|c|}
\hline & Educación Plástica & $\begin{array}{l}\text { Educación Artística y su } \\
\text { Didáctica }\end{array}$ & & El Hecho Religioso & \\
\hline & $\begin{array}{l}\text { Dicción, Redacción y } \\
\text { Comunicación }\end{array}$ & $\begin{array}{l}\text { Idioma Extranjero y su Didáctica } \\
\text { - Inglés o Francés OP }\end{array}$ & & & \\
\hline \multirow{8}{*}{ 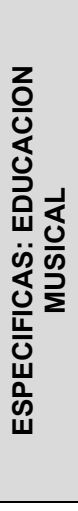 } & PRIMER CURSO $(70,5 \mathrm{cr})$ & SEGUNDO CURSO $(69 \mathrm{cr})$ & TERCER CURSO $(65 \mathrm{cr})$ & OPTATIVAS $2^{\circ}$ y $3^{\circ}$ & 209 \\
\hline & Lenguaje Musical & Educación Física y su Didáctica & $\begin{array}{l}\text { Didáctica de la Educación } \\
\text { Medioambiental }\end{array}$ & Investigación Educativa en Ciencias Sociales & \\
\hline & $\begin{array}{l}\text { Historia de la Música y del } \\
\text { Folklore }\end{array}$ & Matemáticas y su Didáctica & & Didáctica de la Canción & \\
\hline & Formación Vocal y Auditiva & $\begin{array}{l}\text { Lengua y Literatura y su } \\
\text { Didáctica }\end{array}$ & & Educación en Valores & \\
\hline & Formación Rítmica y Danza & $\begin{array}{l}\text { Conocimiento Medio Natural, } \\
\text { Social y Cultural }\end{array}$ & & El Hecho Religioso & \\
\hline & Formación Instrumental & Agrupaciones Musicales & & & \\
\hline & Teoría de la Educación & $\begin{array}{l}\text { Didáctica de la Expresión } \\
\text { Musical }\end{array}$ & & & \\
\hline & $\begin{array}{l}\text { Idioma Extranjero y su Didáctica - } \\
\text { Ingles o Francés OP } \\
\end{array}$ & $\begin{array}{l}\text { Didáctica de la Expresión } \\
\text { Plástica y Visual }\end{array}$ & Historia del Arte & Técnicas y Procedimientos Artísticos & \\
\hline
\end{tabular}




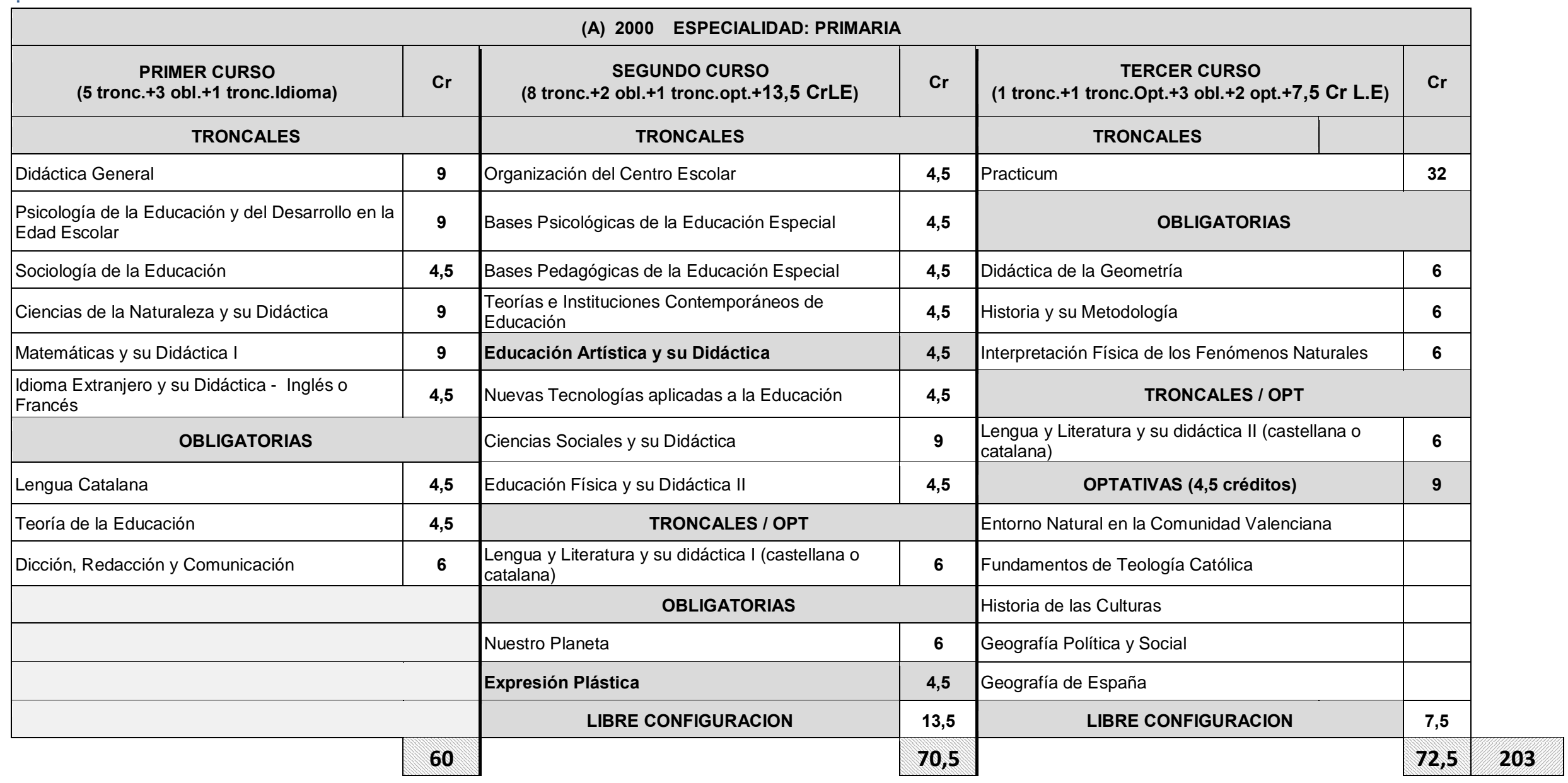




\begin{tabular}{|c|c|c|c|c|c|}
\hline \multicolumn{6}{|c|}{ (A) 2000 ESPECIALIDAD: INFANTIL } \\
\hline $\begin{array}{c}\text { PRIMER CURSO } \\
\text { (6 tronc. }+4 \text { obl. }+1 \text { Cr L.E) }\end{array}$ & $\mathrm{Cr}$ & $\begin{array}{c}\text { SEGUNDO CURSO } \\
\text { (9 tronc. }+3 \text { obl. }+13,5 \text { Cr L.E) }\end{array}$ & $\mathrm{Cr}$ & $\begin{array}{c}\text { TERCER CURSO } \\
\text { (2 tronc. }+3 \text { obl. }+2 \text { opt. }+7,5 \text { Cr L.E) }\end{array}$ & $\mathrm{Cr}$ \\
\hline \multicolumn{2}{|l|}{ TRONCALES } & \multicolumn{2}{|l|}{ TRONCALES } & TRONCALES & \\
\hline Didáctica General & 9 & Organización del Centro Escolar & 4,5 & Practicum & 32 \\
\hline $\begin{array}{l}\text { Psicología de la Educación y del Desarrollo en la } \\
\text { Edad Escolar }\end{array}$ & 9 & Bases Psicológicas de la Educación Especial & 4,5 & Desarrollo de Habilidades Lingüísticas & 6 \\
\hline Sociología de la Educación & 4,5 & Bases Pedagógicas de la Educación Especial & 4,5 & \multicolumn{2}{|l|}{ OBLIGATORIAS } \\
\hline Desarrollo Psicomotor & 6 & $\begin{array}{l}\text { Teorías e Instituciones Contemporáneos de } \\
\text { Educación }\end{array}$ & 4,5 & Iniciación Infantil al Entorno Social & 6 \\
\hline $\begin{array}{l}\text { Desarrollo de la Expresión Plástica y su } \\
\text { Didáctica }\end{array}$ & 6 & Nuevas Tecnologías aplicadas a la Educación & 4,5 & Expresión Plástica & 4,5 \\
\hline $\begin{array}{l}\text { Desarrollo del Pensamiento Matemático y su } \\
\text { Didáctica }\end{array}$ & 6 & Conocimiento Medio Natural, Social y Cultural & 6 & Aprendizaje de la Geometría & 6 \\
\hline \multicolumn{2}{|l|}{ OBLIGATORIAS } & Desarrollo Expresión Musical y su Didáctica & 6 & OPTATIVAS ( 4,5 créditos) & 9 \\
\hline Lengua Catalana & 4,5 & Desarrollo Habilidades Lingüísticas y su didáctica & 6 & El Juego como Método Didáctico & \\
\hline Teoría de la Educación & 4,5 & Literatura Infantil (castellano o valenciano) & 4,5 & Fundamentos de Moral Católica & \\
\hline Dicción, Redacción y Comunicación & 6 & \multicolumn{2}{|l|}{ OBLIGATORIAS } & Educación para la Salud & \\
\hline \multirow[t]{3}{*}{ Dramatización y Títeres } & 4,5 & Dietética y Nutrición & 4,5 & Acción Tutorial y Orientación Psico familiar & \\
\hline & & Fundamentos de Biología & 6 & Escola i Llengua al Pais Valencia & \\
\hline & & Pedagogía de 0 a 6 años & 4,5 & & \\
\hline \multirow[t]{2}{*}{ LIBRE CONFIGURACION } & 1 & LIBRE CONFIGURACION & 13,5 & LIBRE CONFIGURACION & 7,5 \\
\hline & 61 & & 73,5 & & 71 \\
\hline
\end{tabular}




\begin{tabular}{|c|c|c|c|c|c|c|}
\hline \multicolumn{6}{|c|}{ (A) 2000 ESPECIALIDAD: L.EXTRANJERA } & \\
\hline $\begin{array}{c}\text { PRIMER CURSO } \\
\text { (3 tronc }+3 \text { tronc.opt }+2 \text { obl+ } 1 \text { obl.opt) } \\
\end{array}$ & $\mathrm{Cr}$ & \begin{tabular}{|c|} 
SEGUNDO CURSO \\
(9 tronc +1 tronc.opt +1 obl+1 obl.opt+13,5 CrL.E)
\end{tabular} & $\mathrm{Cr}$ & $\begin{array}{l}\text { TERCER CURSO } \\
\text { (2 tronc. }+2 \text { obl.opt }+2 \text { opt. }+7,5 \text { Cr L.E.) } \\
\end{array}$ & $\mathrm{Cr}$ & \\
\hline \multicolumn{2}{|l|}{ TRONCALES } & \multicolumn{2}{|l|}{ TRONCALES } & \multicolumn{2}{|l|}{ TRONCALES } & \\
\hline Didáctica General & 9 & Organización del Centro Escolar & 4,5 & Practicum & 32 & \\
\hline $\begin{array}{l}\text { Psicología de la Educación y del Desarrollo en la } \\
\text { Edad Escolar }\end{array}$ & 9 & Bases Psicológicas de la Educación Especial & 4,5 & Educación Artística y su Didáctica & 4,5 & \\
\hline Sociología de la Educación & 4,5 & Bases Pedagógicas de la Educación Especial & 4,5 & $\begin{array}{l}\text { Lengua y Literatura y su Didáctica (castellana o } \\
\text { catalana) }\end{array}$ & 9 & \\
\hline \multicolumn{2}{|l|}{ TRONCALES / OPT } & $\begin{array}{l}\text { Teorías e Instituciones Contemporáneos de } \\
\text { Educación }\end{array}$ & 4,5 & \multicolumn{2}{|l|}{ OBLIGATORIAS } & \\
\hline Fonética - Ingles o Francés & 4,5 & Nuevas Tecnologías aplicadas a la Educación & 4,5 & Historia y Cultura de la Civilización Francesa o Inglesa & 4,5 & \\
\hline Morfosintaxis y Semántica - Ingles o Francés & 9 & Conocimiento Medio Natural, Social y Cultural & 4,5 & Literatura Infantil Francesa o Inglesa & 6 & \\
\hline $\begin{array}{l}\text { Idioma Extranjero y su Didáctica I - Ingles o } \\
\text { Francés }\end{array}$ & 9 & Matemáticas y su Didáctica & 4,5 & OPTATIVAS ( 4,5 créditos) & 9 & \\
\hline \multicolumn{2}{|l|}{ OBLIGATORIAS } & Educación Física y su Didáctica & 4,5 & \multicolumn{2}{|l|}{ Geografía Económica } & \\
\hline Lengua Catalana & 4,5 & Lingüística & 4,5 & \multicolumn{2}{|l|}{ Literatura Comparada } & \\
\hline Dicción, Redacción y Comunicación & 6 & \multicolumn{2}{|l|}{ TRONCALES / OPT } & \multicolumn{2}{|l|}{ Educación para la Salud } & \\
\hline \multicolumn{2}{|l|}{ OBLIGATORIAS / OPT } & $\begin{array}{l}\text { Idioma Extranjero y su Didáctica II - Inglés o } \\
\text { Francés }\end{array}$ & 9 & \multicolumn{2}{|l|}{ Pedagogía y Didáctica de la Enseñanza Religiosa } & \\
\hline \multirow[t]{6}{*}{ Inglés o Francés Comunicativo I } & 4,5 & \multicolumn{2}{|l|}{ OBLIGATORIAS } & \multicolumn{2}{|l|}{ Lengua Inglesa } & \\
\hline & & Didáctica de la Expresión Plástica y Visual & 6 & \multicolumn{2}{|l|}{ Didáctica de la Imagen } & \\
\hline & & \multicolumn{2}{|l|}{ OBLIGATORIAS / OPT } & \multicolumn{2}{|l|}{ Lengua Francesa } & \\
\hline & & Ingles o Francés Comunicativo II & 4,5 & & & \\
\hline & & LIBRE CONFIGURACION & 13,5 & LIBRE CONFIGURACION & 7,5 & \\
\hline & $60^{\circ}$ & & 73,5 & & 72,5 & 206 \\
\hline
\end{tabular}




\begin{tabular}{|c|c|c|c|c|c|c|}
\hline \multicolumn{7}{|c|}{ (A) 2000 ESPECIALIDAD: E. FISICA } \\
\hline $\begin{array}{l}\text { PRIMER CURSO } \\
\text { ( } 6 \text { tronc. }+4 \text { obl.) }\end{array}$ & $\mathrm{Cr}$ & $\begin{array}{c}\text { SEGUNDO CURSO } \\
\text { (8 tronc }+2 \text { tronc.opt }+1 \text { obl. }+13,5 \mathrm{Cr} \text { L.E) }\end{array}$ & $\mathrm{Cr}$ & \multicolumn{2}{|c|}{$\begin{array}{c}\text { TERCER CURSO } \\
\text { (3 tronc+ } 2 \text { obl. }+2 \text { opt. }+7,5 \text { Cr L.E) }\end{array}$} & $\mathrm{Cr}$ \\
\hline \multicolumn{2}{|l|}{ TRONCALES } & \multicolumn{2}{|l|}{ TRONCALES } & \multicolumn{2}{|l|}{ TRONCALES } & \\
\hline Didáctica General & 9 & Organización del Centro Escolar & 4,5 & \multicolumn{2}{|l|}{ Practicum } & 32 \\
\hline $\begin{array}{l}\text { Psicología de la Educación y del Desarrollo en la } \\
\text { Edad Escolar }\end{array}$ & 9 & Bases Psicológicas de la Educación Especial & 4,5 & \multicolumn{2}{|l|}{ Educación Artística y su Didáctica } & 4,5 \\
\hline Sociología de la Educación & 4,5 & Bases Pedagógicas de la Educación Especial & 4,5 & \multicolumn{2}{|l|}{ Educación Física y su Didáctica II } & 9 \\
\hline Aprendizaje y desarrollo Motor & 6 & $\begin{array}{l}\text { Teorías e Instituciones Contemporáneos de } \\
\text { Educación }\end{array}$ & 4,5 & \multicolumn{3}{|c|}{ OBLIGATORIAS } \\
\hline Bases Biológicas y Físicas del Movimiento & 6 & Nuevas Tecnologías aplicadas a la Educación & 4,5 & \multicolumn{2}{|l|}{ Dirección y Gestión Deportiva } & 6 \\
\hline Teoría y Práctica del Acondicionamiento Físico & 6 & Educación Física y su Didáctica & 4,5 & \multicolumn{2}{|l|}{ Iniciación al Deporte Escolar } & 6 \\
\hline \multicolumn{2}{|l|}{ OBLIGATORIAS } & Matemáticas y su Didáctica & 4,5 & \multicolumn{2}{|c|}{ OPTATIVAS ( 4,5 créditos) } & 9 \\
\hline Lengua Catalana & 6 & Conocimiento Medio Natural, Social y Cultural & 4,5 & $\begin{array}{l}\text { Fundamentos de los Deportes: } \\
\text { Voleibol }\end{array}$ & Fisiología Hu & \\
\hline Dicción, Redacción y Comunicación & 4,5 & \multicolumn{2}{|l|}{ TRONCALES / OPT } & $\begin{array}{l}\text { Fundamentos de los Deportes: } \\
\text { Yudo }\end{array}$ & \multicolumn{2}{|c|}{ Iniciación Bíblica } \\
\hline Geografía de los Paisajes Rurales y Urbanos & 6 & $\begin{array}{l}\text { Idioma Extranjero y su Didáctica II - Inglés o } \\
\text { Francés }\end{array}$ & 4,5 & $\begin{array}{l}\text { Fundamentos de los Deportes del } \\
\text { Mar }\end{array}$ & $\begin{array}{l}\text { Teoría e His } \\
\text { Deporte }\end{array}$ & \\
\hline \multirow[t]{6}{*}{ Educación Plástica } & 4,5 & Lengua y Literatura y su Didáctica (catalana) & 6 & $\begin{array}{l}\text { Fundamentos de los Deportes: } \\
\text { Atletismo }\end{array}$ & $\begin{array}{l}\text { Biomecánica } \\
\text { Física }\end{array}$ & ividad \\
\hline & & Lengua y Literatura y su Didáctica (castellana) & 6 & \begin{tabular}{|l|} 
Fundamentos de los Deportes: \\
Baloncesto
\end{tabular} & $\begin{array}{l}\text { Psicología a } \\
\text { Educación F }\end{array}$ & \\
\hline & & \multicolumn{2}{|l|}{ OBLIGATORIAS } & $\begin{array}{l}\text { Fundamentos de la Motricidad } \\
\text { Humana }\end{array}$ & \multicolumn{2}{|c|}{$\begin{array}{l}\text { Aplicación Rítmico Musical a } \\
\text { la Educación Física }\end{array}$} \\
\hline & & Nutrición y Actividad Física & 4,5 & $\begin{array}{l}\text { Actividades Recreativas para } \\
\text { Niños con Minusvalías }\end{array}$ & \multicolumn{2}{|c|}{$\begin{array}{l}\text { Actividades Deportivas en } \\
\text { Medio Ambiente }\end{array}$} \\
\hline & & LIBRE CONFIGURACION & 13,5 & \multicolumn{2}{|c|}{ LIBRE CONFIGURACION } & 7,5 \\
\hline & 61,5 & & 70,5 & & & 74 \\
\hline
\end{tabular}




\begin{tabular}{|c|c|c|c|c|c|}
\hline \multicolumn{6}{|c|}{ (A) 2000 ESPECIALIDAD: MUSICA } \\
\hline $\begin{array}{l}\text { PRIMER CURSO } \\
\text { (7 tronc. }+3 \text { obl.) }\end{array}$ & $\mathrm{Cr}$ & $\begin{array}{c}\text { SEGUNDO CURSO } \\
\text { (9 tronc }+2 \text { tronc.opt }+13,5 \text { CrLE) }\end{array}$ & $\mathrm{Cr}$ & $\begin{array}{c}\text { TERCER CURSO } \\
\text { (3 tronc }+2 \text { obl }+2 \text { opt. }+7,5 \text { CrL.E) }\end{array}$ & $\mathrm{Cr}$ \\
\hline \multicolumn{2}{|l|}{ TRONCALES } & \multicolumn{2}{|l|}{ TRONCALES } & \multicolumn{2}{|l|}{ TRONCALES } \\
\hline Didáctica General & 9 & Organización del Centro Escolar & 4,5 & Practicum & 32 \\
\hline $\begin{array}{l}\text { Psicología de la Educación y del Desarrollo en la } \\
\text { Edad Escolar }\end{array}$ & 9 & Bases Psicológicas de la Educación Especial & 4,5 & Didáctica de la Expresión Musical & 9 \\
\hline Sociología de la Educación & 4,5 & Bases Pedagógicas de la Educación Especial & 4,5 & Conocimiento del Medio Natural, Social y Cultural & 4,5 \\
\hline Agrupaciones Musicales & 9 & $\begin{array}{l}\text { Teorías e Instituciones Contemporáneos de } \\
\text { Educación }\end{array}$ & 4,5 & \multicolumn{2}{|l|}{ OBLIGATORIAS } \\
\hline Formación Vocal y Auditiva & 4,5 & Nuevas Tecnologías aplicadas a la Educación & 4,5 & Didáctica de la Educación Medioambiental & 6 \\
\hline Formación Rítmica y Danza & 4,5 & Educación Física y su Didáctica & 4,5 & Historia del Arte & 6 \\
\hline Lenguaje Musical & 4,5 & Matemáticas y su Didáctica & 4,5 & OPTATIVAS ( 4,5 créditos) & 9 \\
\hline \multicolumn{2}{|l|}{ OBLIGATORIAS } & Historia de la Música y del Folklore & 4,5 & \multicolumn{2}{|l|}{ Didáctica de la Canción } \\
\hline Lengua Catalana & 6 & Formación Instrumental & 9 & \multicolumn{2}{|l|}{ Educación en Valores } \\
\hline Teoría de la Educación & 4,5 & \multicolumn{2}{|l|}{ TRONCALES / OPT } & \multicolumn{2}{|l|}{ El Hecho Religioso } \\
\hline Didáctica de la Expresión Plástica y Visual & 6 & $\begin{array}{l}\text { Idioma Extranjero y su Didáctica II - Inglés o } \\
\text { Francés }\end{array}$ & 4,5 & \multicolumn{2}{|l|}{ Técnicas y Procedimientos Artísticos } \\
\hline & & $\begin{array}{l}\text { Lengua y Literatura y su Didáctica (castellana o } \\
\text { catalana) }\end{array}$ & 6 & \multicolumn{2}{|l|}{ Investigación Educativa en Ciencias Sociales } \\
\hline & & LIBRE CONFIGURACION & 13,5 & LIBRE CONFIGURACION & 7,5 \\
\hline & 61,5 & & 69 & & 74 \\
\hline
\end{tabular}




\begin{tabular}{|c|c|c|c|c|}
\hline \multicolumn{4}{|c|}{ (A) Plan de estudios de 2000 (por especialidades) } & \\
\hline \multirow{6}{*}{ 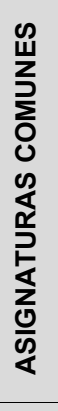 } & PRIMER CURSO & SEGUNDO CURSO & TERCER CURSO & \\
\hline & Didáctica General & Organización del Centro Escolar & Practicum & \\
\hline & \begin{tabular}{|l} 
Psicología de la Educación y del \\
Desarrollo en la Edad Escolar
\end{tabular} & $\begin{array}{l}\text { Bases Psicológicas de la } \\
\text { Educación Especial }\end{array}$ & & \\
\hline & Sociología de la Educación & $\begin{array}{l}\text { Bases Pedagógicas de la } \\
\text { Educación Especial }\end{array}$ & & \\
\hline & Lengua Catalana & \begin{tabular}{|l} 
Teorías e Instituciones \\
Contemporáneos de Educación
\end{tabular} & & \\
\hline & & $\begin{array}{l}\text { Nuevas Tecnologías aplicadas a } \\
\text { la Educación }\end{array}$ & & \\
\hline \multirow{8}{*}{ 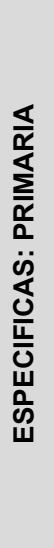 } & PRIMER CURSO & SEGUNDO CURSO & TERCER CURSO & OPTATIVAS $3^{\circ}$ \\
\hline & Teoría de la Educación & Educación Física y su Didáctica & Didáctica de la Geometría & $\begin{array}{l}\text { Entorno Natural en la Comunidad } \\
\text { Valenciana }\end{array}$ \\
\hline & Dicción, Redacción y Comunicación & Ciencias Sociales y su Didáctica & Historia y su Metodología & Fundamentos de Teología Católica \\
\hline & $\begin{array}{l}\text { Ciencias de la Naturaleza y su } \\
\text { Didáctica }\end{array}$ & Nuestro Planeta & $\begin{array}{l}\text { Interpretación Física de los } \\
\text { Fenómenos Naturales }\end{array}$ & Historia de las Culturas \\
\hline & Matemáticas y su Didáctica I & $\begin{array}{l}\text { Lengua y Literatura y su didáctica } \\
\text { I (catalana) }\end{array}$ & $\begin{array}{l}\text { Lengua y Literatura y su didáctica } \\
\text { II (catalana) }\end{array}$ & Geografía Política y Social \\
\hline & $\begin{array}{l}\text { Idioma Extranjero y su Didáctica - } \\
\text { Inglés o Francés }\end{array}$ & $\begin{array}{l}\text { Lengua y Literatura y su didáctica } \\
\text { I (castellana) }\end{array}$ & $\begin{array}{l}\text { Lengua y Literatura y su didáctica } \\
\text { II (castellana) }\end{array}$ & Geografía de España \\
\hline & & $\begin{array}{l}\text { Educación Artística y su } \\
\text { Didáctica }\end{array}$ & & \\
\hline & & Expresión Plástica & & \\
\hline \multirow{5}{*}{ 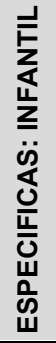 } & PRIMER CURSO & SEGUNDO CURSO & TERCER CURSO & OPTATIVAS $3^{\circ}$ \\
\hline & Teoría de la Educación & $\begin{array}{l}\text { Conocimiento Medio Natural, } \\
\text { Social y Cultural }\end{array}$ & $\begin{array}{l}\text { Desarrollo de Habilidades } \\
\text { Lingüísticas }\end{array}$ & El Juego como Método Didáctico \\
\hline & Dicción, Redacción y Comunicación & $\begin{array}{l}\text { Desarrollo Expresión Musical y su } \\
\text { Didáctica }\end{array}$ & Iniciación Infantil al Entorno Social & Fundamentos de Moral Católica \\
\hline & Desarrollo Psicomotor & $\begin{array}{l}\text { Desarrollo Habilidades } \\
\text { Lingüísticas y su didáctica }\end{array}$ & Aprendizaje de la Geometría & Educación para la Salud \\
\hline & \begin{tabular}{|l} 
Desarrollo del Pensamiento \\
Matemático y su Didáctica
\end{tabular} & $\begin{array}{l}\text { Literatura Infantil (castellano o } \\
\text { valenciano) }\end{array}$ & & $\begin{array}{l}\text { Acción Tutorial y Orientación Psico } \\
\text { familiar }\end{array}$ \\
\hline
\end{tabular}

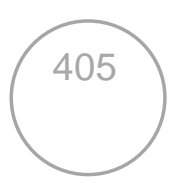


La Educación Artística en los planes de estudio de Magisterio de la Comunitat Valenciana. Visión para el siglo XXI

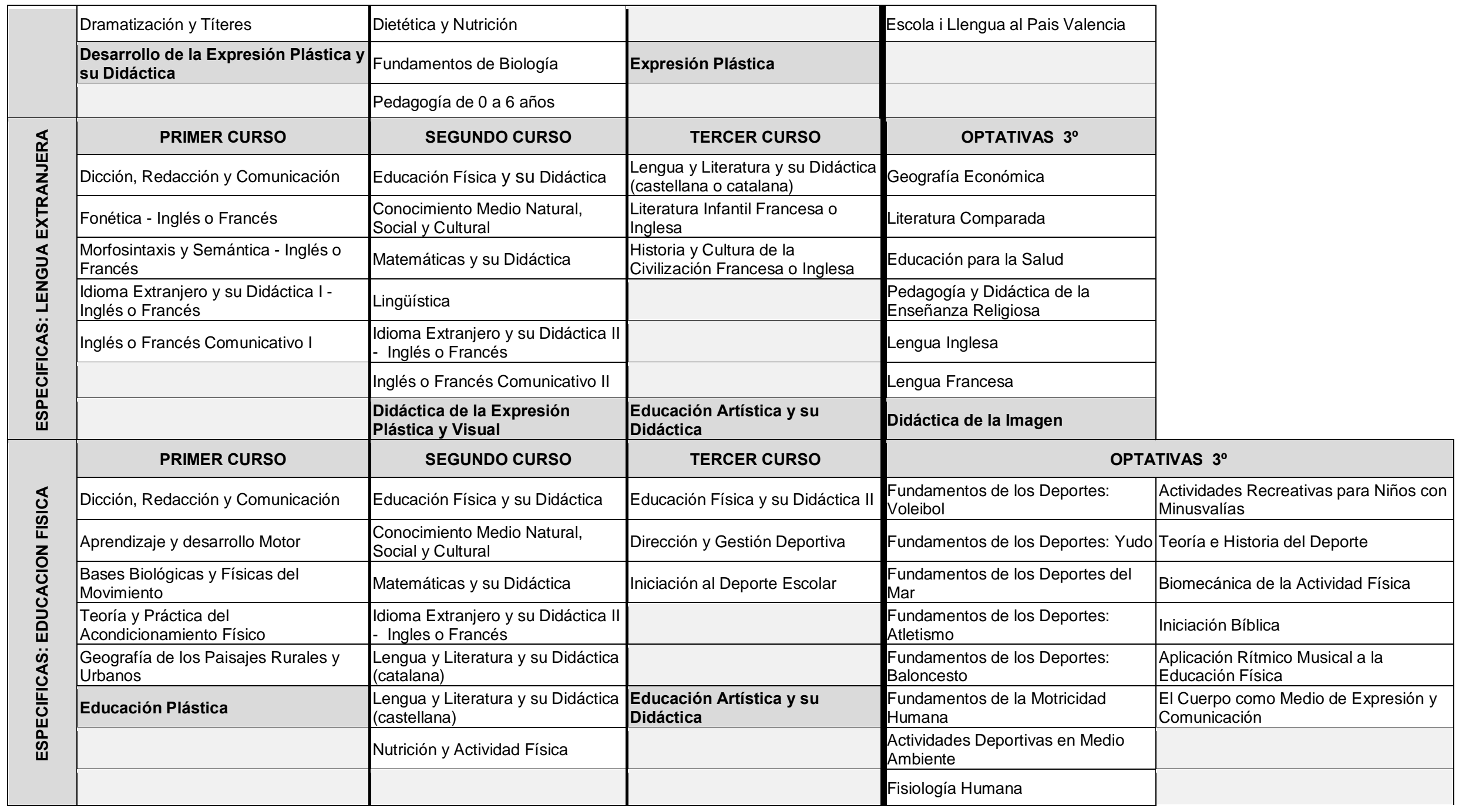

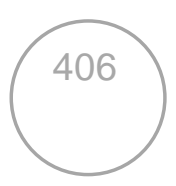




\begin{tabular}{|c|c|c|c|c|}
\hline \multirow{7}{*}{ 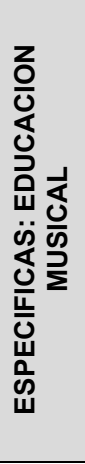 } & PRIMER CURSO & SEGUNDO CURSO & TERCER CURSO & OPTATIVAS $3^{\circ}$ \\
\hline & Teoría de la Educación & Educación Física y su Didáctica & Didáctica de la Expresión Musical & Didáctica de la Canción \\
\hline & Agrupaciones Musicales & Matemáticas y su Didáctica & $\begin{array}{l}\text { Conocimiento del Medio Natural, } \\
\text { Social y Cultural }\end{array}$ & Educación en Valores \\
\hline & Formación Vocal y Auditiva & $\begin{array}{l}\text { Historia de la Música y del } \\
\text { Folklore }\end{array}$ & $\begin{array}{l}\text { Didáctica de la Educación } \\
\text { Medioambiental }\end{array}$ & El Hecho Religioso \\
\hline & Formación Rítmica y Danza & Formación Instrumental & & $\begin{array}{l}\text { Investigación Educativa en Ciencias } \\
\text { Sociales }\end{array}$ \\
\hline & Lenguaje Musical & $\begin{array}{l}\text { Idioma Extranjero y su Didáctica II } \\
\text { - Inglés o Francés }\end{array}$ & & \\
\hline & $\begin{array}{l}\text { Didáctica de la Expresión Plástica y } \\
\text { Visual }\end{array}$ & $\begin{array}{l}\text { Lengua y Literatura y su Didáctica } \\
\text { (castellana o catalana) }\end{array}$ & Historia del Arte & $\begin{array}{l}\text { Técnicas y Procedimientos } \\
\text { Artísticos }\end{array}$ \\
\hline
\end{tabular}




\begin{tabular}{|c|c|c|c|c|c|c|c|}
\hline \multicolumn{8}{|c|}{ (A) 2007 GRADO ESPECIALIDAD: INFANTIL } \\
\hline $\begin{array}{l}\text { PRIMER CURSO } \\
\text { ( } 6 \text { básicas }+4 \text { obl.) }\end{array}$ & $\mathrm{Cr}$ & $\begin{array}{l}\text { SEGUNDO CURSO } \\
\text { ( } 5 \text { básicas }+3 \text { obl.) }\end{array}$ & $\mathrm{Cr}$ & $\begin{array}{c}\text { TERCER CURSO } \\
\text { ( } 3 \text { básicas }+3 \text { obl. }+2 \text { op.) }\end{array}$ & $\mathrm{Cr}$ & $\begin{array}{l}\text { CUARTO CURSO } \\
\text { (1 básica+ } 4 \text { obl. }+2 \text { op.) }\end{array}$ & $\mathrm{Cr}$ \\
\hline \multicolumn{2}{|l|}{ BÁSICAS } & \multicolumn{2}{|l|}{ BÁSICAS } & \multicolumn{2}{|l|}{ BÁSICAS } & BÁSICAS & \multirow[b]{2}{*}{6} \\
\hline Psicología Evolutiva de 0 a 3 años & 6 & $\begin{array}{l}\text { Dificultades de aprendizaje y trastornos } \\
\text { del desarrollo: Respuestas especificas } \\
\text { en contextos inclusivos }\end{array}$ & 9 & Teoría e Historia de la Ed. Infantil & 6 & $\begin{array}{l}\text { Innovaciones en los Proyectos Educativos } \\
\text { de la Ed. Infantil }\end{array}$ & \\
\hline Psicología de la Educación & 6 & $\begin{array}{l}\text { Dificultades de aprendizaje y trastornos } \\
\text { del desarrollo: Características evolutivas }\end{array}$ & 9 & $\begin{array}{l}\text { Educación para el desarrollo personal, } \\
\text { social y medio ambiental }\end{array}$ & 6 & \multicolumn{2}{|l|}{ OBLIGATORIAS } \\
\hline $\begin{array}{l}\text { Organización del aula de Ed. } \\
\text { Infantil 0-3 y 3-6 años }\end{array}$ & 6 & $\begin{array}{l}\text { Desarrollo Curricular y Aulas Digitales en } \\
\text { la Ed. Infantil }\end{array}$ & 6 & $\begin{array}{l}\text { Observación, Evaluación e Innovación } \\
\text { Educativa }\end{array}$ & 6 & Practicum II & 18 \\
\hline Sociología de la Educación & 6 & $\begin{array}{l}\text { Habilidades Comunicativas y } \\
\text { Lectoescritura en Castellano }\end{array}$ & 9 & \multicolumn{2}{|l|}{ OBLIGATORIAS } & $\begin{array}{l}\text { Practicum III o Practicum III vinculado a } \\
\text { una Mención }\end{array}$ & 12 \\
\hline $\begin{array}{l}\text { Diseño de los procesos Educativos } \\
\text { en la Ed. Infantil }\end{array}$ & 6 & $\begin{array}{l}\text { Habilidades Comunicativas y } \\
\text { Lectoescritura en Catalán }\end{array}$ & 9 & Practicum I & 18 & $\begin{array}{l}\text { Trabajo Fin de Grado o Trabajo Fin de } \\
\text { Grado vinculado a una Mención }\end{array}$ & 6 \\
\hline Psicología Evolutiva de 3 a 6 años & 6 & \multicolumn{2}{|l|}{ OBLIGATORIAS } & Didáctica de la Expresión Corporal & 6 & Didáctica de la Expresión Plástica & 6 \\
\hline \multicolumn{2}{|l|}{ OBLIGATORIAS } & Aprendizaje de la Aritmética & 6 & Aprendizaje de la Geometría & 6 & \multicolumn{2}{|l|}{ OPTATIVAS } \\
\hline $\begin{array}{l}\text { Lengua Catalana I para la Ed. } \\
\text { Infantil }\end{array}$ & 6 & $\begin{array}{l}\text { Didáctica del Conocimiento del Medio } \\
\text { Social y Cultural }\end{array}$ & 6 & \multicolumn{2}{|l|}{ OPTATIVAS } & Optativa & 6 \\
\hline $\begin{array}{l}\text { Didáctica de la Lengua Castellana } \\
\text { y Literatura en Ed. Infantil }\end{array}$ & 6 & $\begin{array}{l}\text { Didáctica del Conocimiento del Medio } \\
\text { Natural }\end{array}$ & 6 & Optativa & 6 & Optativa & 6 \\
\hline Didáctica de la Expresión Musical & 6 & & & Optativa & 6 & & \\
\hline \multicolumn{2}{|l|}{ OBLIGATORIA LENGUA } & & & & & \\
\hline $\begin{array}{l}\text { Lengua Extranjera para maestros } \\
\text { en Ed. Infantil: Francés }\end{array}$ & 6 & & & & & & \\
\hline \multirow[t]{6}{*}{$\begin{array}{l}\text { Didáctica de la Lengua Inglesa en } \\
\text { Ed. Infantil }\end{array}$} & 6 & & & & & & \\
\hline & 60 & & 60 & & 60 & & 60 \\
\hline & & & & \multicolumn{4}{|c|}{ OPTATIVAS (6 créditos) } \\
\hline & & & & Didáctica de la Lengua Francesa & 6 & $\begin{array}{l}\text { Literatura Castellana infantil y juvenil y } \\
\text { Animación a la Lectura }\end{array}$ & 6 \\
\hline & & & & Educar en Igualdad de Género & 6 & $\begin{array}{l}\text { Dramatización y Teatro en el aula } \\
\text { (Castellano) }\end{array}$ & 6 \\
\hline & & & & Educación Científica para maestros & 6 & Lengua Catalana II para la Ed. Infantil & 6 \\
\hline
\end{tabular}




\begin{tabular}{|l|c|l|c|}
\hline Taller de Matemáticas & $\mathbf{6}$ & Taller de Creació Verbal en Catalá & $\mathbf{6}$ \\
\hline $\begin{array}{l}\text { Pedagogía y Didáctica de la Religión } \\
\text { escuela }\end{array}$ & $\mathbf{6}$ & Literatura Catalana Infantil & $\mathbf{6}$ \\
\hline \multicolumn{1}{|c|}{ ASIGNATURAS VINCULADAS A LA MENCIÓN EN LENGUA EXTRANJERA INGLÉS } \\
\hline $\begin{array}{l}\text { Inglés: Lecto-escritura y Metodología } \\
\text { de la enseñanza basada en el texto }\end{array}$ & $\mathbf{6}$ & $\begin{array}{l}\text { Integración de las habilidades } \\
\text { comunicativas (Integrating Skills) }\end{array}$ & $\mathbf{6}$ \\
\hline $\begin{array}{l}\text { Content and Language integrated } \\
\text { learning (CLIL) }\end{array}$ & $\mathbf{6}$ & Independent English User & $\mathbf{6}$ \\
\hline \multicolumn{2}{|c|}{ ASIGNATURAS VINCULADAS A LA MENCIÓN EN EDUCACIÓN FíSICA } \\
\hline Actividad física en el medio natural & $\mathbf{6}$ & Bases kinesiológicas de la actividad física & $\mathbf{6}$ \\
\hline Juego y deporte escolar & $\mathbf{6}$ & $\begin{array}{l}\text { Teoría y práctica del acondicionamiento } \\
\text { físico con jóvenes }\end{array}$ & $\mathbf{6}$ \\
\hline \multicolumn{3}{|c|}{ ASIGATURAS VINCULADAS A LA MENCIÓN EN MÚSICA } \\
\hline Educación Vocal y Auditiva & $\mathbf{6}$ & $\begin{array}{l}\text { La Audición como elemento educativo. } \\
\text { Historia de la Música, Patrimonio Musical } \\
\text { y Folklore }\end{array}$ & $\mathbf{6}$ \\
\hline Educación Rítmica y Movimiento & $\mathbf{6}$ & Educación Musical y su didáctica & $\mathbf{6}$ \\
\hline ASIGNATURAS VINCULADAS A LA MENCIÓN EN EDUCACIÓN ESPECIAL/PEDAGOGÍA \\
\hline $\begin{array}{l}\text { Discapacidad Intelectual, Trastornos } \\
\text { del espectro autista y Altas } \\
\text { capacidades }\end{array}$ & $\mathbf{6}$ & $\begin{array}{l}\text { Discapacidades sensoriales y Motrices: } \\
\text { Desarrollo, Comunicación e Intervención }\end{array}$ & $\mathbf{6}$ \\
\hline $\begin{array}{l}\text { Dificultades de Aprendizaje y } \\
\text { Educación Compensatoria }\end{array}$ & $\mathbf{6}$ & Problemas y Trastornos de conducta & $\mathbf{6}$ \\
\hline
\end{tabular}

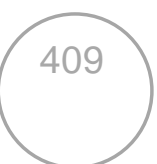




\begin{tabular}{|c|c|c|c|c|c|c|c|}
\hline \multicolumn{8}{|c|}{ (A) 2007 GRADO ESPECIALIDAD: PRIMARIA } \\
\hline $\begin{array}{l}\text { PRIMER CURSO } \\
\text { ( } 6 \text { básicas }+4 \text { obl.) }\end{array}$ & $\mathrm{Cr}$ & $\begin{array}{l}\text { SEGUNDO CURSO } \\
\text { (4 básicas }+6 \text { obl.) }\end{array}$ & $\mathrm{Cr}$ & TERCER CURSO & $\mathrm{Cr}$ & CUARTO CURSO & $\mathrm{Cr}$ \\
\hline \multicolumn{2}{|l|}{ BÁSICAS } & \multicolumn{2}{|l|}{ BÁSICAS } & \multicolumn{2}{|l|}{ OBLIGATORIAS } & \multicolumn{2}{|l|}{ OBLIGATORIAS } \\
\hline Psicología del Desarrollo & 6 & $\begin{array}{l}\text { Dificultades de Aprendizaje y } \\
\text { Trastornos del Desarrollo }\end{array}$ & 6 & Practicum I & 18 & Practicum II & 18 \\
\hline $\begin{array}{l}\text { Gestión e Innovación en } \\
\text { contextos educativos }\end{array}$ & 6 & $\begin{array}{l}\text { Atención a las necesidades Educativas } \\
\text { Específicas }\end{array}$ & 6 & $\begin{array}{l}\text { Lengua Catalana II para la Ed. } \\
\text { Primaria }\end{array}$ & 6 & Didáctica de la Lectura y la Escritura & 6 \\
\hline $\begin{array}{l}\text { Teoría e Historia de la } \\
\text { Educación }\end{array}$ & 6 & Psicología de la Instrucción & 6 & $\begin{array}{l}\text { Enseñanza y Aprendizaje de las } \\
\text { Ciencias Experimentales II }\end{array}$ & 6 & Didáctica de la Expresión Plástica & 6 \\
\hline Psicología de la Educación & 6 & $\begin{array}{l}\text { Desarrollo curricular y Aulas Digitales } \\
\text { en Ed. Primaria }\end{array}$ & 6 & $\begin{array}{l}\text { Didáctica de las Ciencias Sociales: } \\
\text { Historia }\end{array}$ & 6 & $\begin{array}{l}\text { Practicum III o Practicum III vinculado a una } \\
\text { Mención }\end{array}$ & 12 \\
\hline $\begin{array}{l}\text { Diseño de los procesos } \\
\text { educativos en la Ed. Primaria }\end{array}$ & 6 & \multicolumn{2}{|l|}{ OBLIGATORIAS } & $\begin{array}{l}\text { Enseñanza y Aprendizaje de las } \\
\text { Matemáticas en Ed. Primaria }\end{array}$ & 6 & $\begin{array}{l}\text { Trabajo Fin de Grado o Trabajo Fin de Grado } \\
\text { vinculado a una Mención }\end{array}$ & 6 \\
\hline $\begin{array}{l}\text { Cambios sociales, culturales y } \\
\text { Educación }\end{array}$ & 6 & $\begin{array}{l}\text { Enseñanza y Aprendizaje de las } \\
\text { Ciencias Experimentales I }\end{array}$ & 6 & $\begin{array}{l}\text { Didáctica de la Lengua y la Literatura } \\
\text { española para la Ed. Primaria }\end{array}$ & 6 & \multicolumn{2}{|l|}{ OPTATIVAS } \\
\hline \multicolumn{2}{|l|}{ OBLIGATORIAS } & $\begin{array}{l}\text { Didáctica de las Ciencias Sociales: } \\
\text { Geografía }\end{array}$ & 6 & \multicolumn{2}{|l|}{ OPTATIVAS } & Optativa & 6 \\
\hline $\begin{array}{l}\text { Lengua Catalana I para la Ed. } \\
\text { Primaria }\end{array}$ & 6 & $\begin{array}{l}\text { Didáctica de la Lengua Catalana para } \\
\text { la Ed. Primaria }\end{array}$ & 6 & Optativa & 6 & Optativa & 6 \\
\hline $\begin{array}{l}\text { Lengua y Literatura española } \\
\text { para la Enseñanza Primaria }\end{array}$ & 6 & $\begin{array}{l}\text { Didáctica de la Educación Física y el } \\
\text { Deporte }\end{array}$ & 6 & Optativa & 6 & & \\
\hline $\begin{array}{l}\text { Didáctica de la Matemática: } \\
\text { sentido numérico }\end{array}$ & 6 & $\begin{array}{l}\text { Didáctica de la Matemática: sentido } \\
\text { geométrico }\end{array}$ & 6 & & & & \\
\hline \multicolumn{2}{|l|}{ OBLIGATORIA LENGUA (elegir) } & Música en la Ed. Primaria & 6 & & & & \\
\hline $\begin{array}{l}\text { Lengua Extranjera para maestros } \\
\text { de Ed. Primaria: Francés }\end{array}$ & 6 & & & & & & \\
\hline \multirow[t]{7}{*}{ Didáctica de la Lengua Inglesa } & 6 & & & & & & \\
\hline & 60 & & 60 & & 60 & & 60 \\
\hline & & & \multicolumn{5}{|c|}{ OPTATIVAS ( 6 créditos) } \\
\hline & & & Didáct & ica de la Lengua Francesa & 6 & Dramatización y Teatro en el aula (Castellano) & 6 \\
\hline & & & Educa & ir en Igualdad de Género & 6 & Literatura Catalana Infantil & 6 \\
\hline & & & Educa & ción Científica para maestros & 6 & Taller de Creació Verbal en Catalá & 6 \\
\hline & & & Taller & de Matemáticas & 6 & Pedagogía y Didáctica de la Religión escuela & 6 \\
\hline
\end{tabular}


Literatura Castellana infantil y juvenil y Animación a la Lectura

$$
\text { ASIGNATURAS VINCULAD }
$$

Contenido y Lenguaje Integrado de

Aprendizaje (CLIL)

Inglés. Lectoescritura y Metodología de

Enseñanza basada en el texto para Primaria ASIGNATURAS VINC

Actividad física en el medio natura

Bases kinesiológicas de la actividad física

\section{ASIGNATURAS}

6

Integración de las habilidades comunicativas

(Integrating Skills)

6 Usuario independiente de inglés A MENCION EN EDUCACIÓN FíSICA

\begin{tabular}{|l|c|l|c|c|}
\hline \multicolumn{3}{|c|}{ ASIGNATURAS VINCULADAS A LA MENCIÓN EN MÚSICA } & \\
\hline Educación Musical y su didáctica & 6 & Educación Vocal y Auditiva & 6 & \\
\hline Educación Rítmica y Movimiento & 6 & $\begin{array}{l}\text { La Audición como elemento educativo. Historia } \\
\text { de la Música, Patrimonio Musical y Folklore }\end{array}$ & 6 & \\
\hline
\end{tabular}

ASIGNATURAS VINCULADAS A LA MENCIÓN EN EDUCACIÓN ESPECIAL/PEDAGOGÍA TERAPEUTICA

Dificultades de Aprendizaje y Educación

Compensatoria

Discapacidad Intelectual, Trastornos del

espectro autista y Altas capacidades

6 Juego y deporte escolar

Teoría y práctica del acondicionamiento físico con jóvenes

Problemas y Trastornos de conducta

6 Discapacidades sensoriales y Motrices: Desarrollo, Comunicación e Intervención 


\section{CASTELLÓN}

\begin{tabular}{|c|c|c|c|c|c|c|}
\hline \multicolumn{6}{|c|}{ (CS) 1992 ESPECIALIDAD: PRIMARIA } & \\
\hline $\begin{array}{c}\text { PRIMER CURSO } \\
\text { (10 tronc. }+5 \text { obl. + opt. + lib.config.) }\end{array}$ & $\mathrm{Cr}$ & $\begin{array}{c}\text { SEGUNDO CURSO } \\
\text { ( } 8 \text { tronc. }+3 \text { obl. }+ \text { opt. + lib.config.) }\end{array}$ & $\mathrm{Cr}$ & $\begin{array}{c}\text { TERCER CURSO } \\
\text { (4 tronc. }+2 \text { obl. }+ \text { opt. + lib.config.) }\end{array}$ & $\mathrm{Cr}$ & \\
\hline \multicolumn{2}{|l|}{ TRONCALES } & TRONCALES & & TRONCALES & & \\
\hline Educación Física y su Didáctica & 4 & Didáctica de las Ciencias Sociales & 8 & Bases Pedagógicas de la Educación Especial & 4 & \\
\hline Educación Musical y su Didáctica & 4 & Didáctica de las Ciencias Naturales & 4 & Bases Psicológicas de la Educación Especial & 4 & \\
\hline Sociología de la Educación & 4 & Didáctica de la Física y Química & 4 & Didáctica de la Lengua y Literatura Españolas & 6 & \\
\hline Historia de la Educación Contemporánea & 4 & Didáctica del Francés o Inglés & 4 & Practicum & 20 & \\
\hline La Literatura en sus Textos & 3 & Didáctica General & 8 & \multicolumn{2}{|l|}{ OBLIGATORIAS } & \\
\hline Morfosintaxis del Español & 3 & Matemáticas y su Didáctica & 8 & Teoría y Práctica en Educación Matemática & 4 & \\
\hline $\begin{array}{l}\text { Desarrollo de la Expresión Plástica y su } \\
\text { Didáctica }\end{array}$ & 4 & Nuevas Tecnologías aplicadas a la Educación & 4 & Las Técnicas Plásticas en la Ed. Primaria & 4 & \\
\hline Practicum I & 2 & Practicum II & 10 & OPTATIVAS & 20 & \\
\hline $\begin{array}{l}\text { Psicología de la Educación y del Desarrollo en la } \\
\text { Edad Escolar }\end{array}$ & 8 & \multicolumn{2}{|l|}{ OBLIGATORIAS } & LIBRE CONFIGURACIÓN & 10 & \\
\hline Organización Escolar & 6 & Desarrollo y Contextos Educativos en la Ed. Primaria & 4 & & & \\
\hline OBLIGATORIAS & & Didáctica del Catalán I & 4 & & & \\
\hline Informática & 6 & Inglés II & 3 & & & \\
\hline Inglés I & 3 & OPTATIVAS & 8 & & & \\
\hline Teoria de la Educación & 4 & LIBRE CONFIGURACIÓN & 6 & & & \\
\hline Lengua Catalana I & 4 & & & & & \\
\hline Lengua Catalana II & 4 & & & & & \\
\hline OPTATIVAS & 3 & & & & & \\
\hline \multirow[t]{2}{*}{ LIBRE CONFIGURACIÓN } & 6 & & & & & \\
\hline & 72 & & 75 & & 72 & 219 \\
\hline
\end{tabular}




\begin{tabular}{|c|c|c|c|c|c|c|}
\hline \multicolumn{6}{|c|}{ (CS) 1992 ESPECIALIDAD: INFANTIL } & \\
\hline $\begin{array}{c}\text { PRIMER CURSO } \\
\text { (9 tronc. }+4 \text { obl. }+1 \text { opt. }+ \text { lib.config.) }\end{array}$ & $\mathrm{Cr}$ & $\begin{array}{c}\text { SEGUNDO CURSO } \\
\text { (8 tronc. }+4 \text { obl. + opt. + lib.config.) }\end{array}$ & $\mathrm{Cr}$ & $\begin{array}{c}\text { TERCER CURSO } \\
\text { (4 tronc. }+3 \text { obl. + opt. + lib.config.) }\end{array}$ & $\mathrm{Cr}$ & \\
\hline \multicolumn{2}{|l|}{ TRONCALES } & \multicolumn{2}{|l|}{ TRONCALES } & \multicolumn{2}{|l|}{ TRONCALES } & \\
\hline $\begin{array}{l}\text { Desarrollo de las Habilidades Lingüísticas y su } \\
\text { Didáctica en la Lengua Española }\end{array}$ & 8 & $\begin{array}{l}\text { Desarrollo del Pensamiento Matemático y su } \\
\text { Didáctica }\end{array}$ & 6 & Literatura Infantil & 4 & \\
\hline $\begin{array}{l}\text { Psicología de la Educación y del Desarrollo en la } \\
\text { Edad Escolar }\end{array}$ & 8 & $\begin{array}{l}\text { Didáctica de las Ciencias Experimentales en la Ed. } \\
\text { Infantil }\end{array}$ & 4 & Bases Pedagógicas de la Educación Especial & 4 & \\
\hline Sociología de la Educación & 4 & Didáctica de las Ciencias Sociales & 4 & Bases Psicológicas de la Educación Especial & 4 & \\
\hline Historia de la Educación Contemporánea & 4 & Didáctica del Catalán I & 4 & Practicum III & 20 & \\
\hline Desarrollo Psicomotor & 6 & Didáctica del Catalán II & 4 & OBLIGATORIAS & & \\
\hline Música & 6 & Didáctica General & 8 & Didáctica de las Matemáticas & 4 & \\
\hline $\begin{array}{l}\text { Desarrollo de la Expresión Plástica y su } \\
\text { Didáctica }\end{array}$ & 6 & Nuevas Tecnologías aplicadas a la Educación & 4 & Las Técnicas Plásticas en la Ed. Infantil & 4 & \\
\hline Organización Escolar & 4 & Practicum II & 10 & $\begin{array}{l}\text { Técnicas Didácticas y Organizativas en Ed. } \\
\text { Infantil }\end{array}$ & 4 & \\
\hline Practicum I & 2 & OBLIGATORIAS & & OPTATIVAS & 18 & \\
\hline OBLIGATORIAS & & Desarrollo y Contextos Educativos en la Ed. Infantil & 4 & LIBRE CONFIGURACIÓN & 10 & \\
\hline Informática & 6 & Didáctica de la Expresión Musical en la Ed. Infantil & 4 & & & \\
\hline Inglés I & 3 & Educación para la Salud & 4 & & & \\
\hline La Expresión Corporal en la Educación Infantil & 4 & Inglés II & 3 & & & \\
\hline Teoría de la Educación & 4 & OPTATIVAS & 8 & & & \\
\hline OPTATIVAS & 3 & LIBRE CONFIGURACIÓN & 6 & & & \\
\hline \multirow[t]{2}{*}{ LIBRE CONFIGURACIÓN } & 6 & & & & & \\
\hline & 74 & & 73 & & 72 & 219 \\
\hline
\end{tabular}




\begin{tabular}{|c|c|c|c|c|c|c|}
\hline \multicolumn{6}{|c|}{ (CS) 1992 ESPECIALIDAD: E.FISICA } & \\
\hline $\begin{array}{c}\text { PRIMER CURSO } \\
\text { (9 tronc. + } 4 \text { obl. + opt. + lib.config.) }\end{array}$ & $\mathrm{Cr}$ & $\begin{array}{c}\text { SEGUNDO CURSO } \\
\text { ( } 8 \text { tronc. }+3 \text { obl. }+3 \text { opt. }+7 \text { lib.config.) }\end{array}$ & $\mathrm{Cr}$ & $\begin{array}{c}\text { TERCER CURSO } \\
\text { (6 tronc. + opt. + lib.config.) }\end{array}$ & $\mathrm{Cr}$ & \\
\hline \multicolumn{2}{|l|}{ TRONCALES } & TRONCALES & \multicolumn{3}{|c|}{ TRONCALES } & \\
\hline Bases Anatómicas y Fisiológicas del Movimiento & 6 & Aprendizaje y Desarrollo Motor & 6 & Bases Pedagógicas de la Ed. Especial & 4 & \\
\hline La Educación Musical y su Didáctica & 4 & Didáctica de la Educación Física I & 8 & Bases Psicológicas de la Ed. Especial & 4 & \\
\hline Historia de la Educación Contemporánea & 4 & Didáctica de las Ciencias Experimentales & 4 & Didáctica de la Educación Física II & 8 & \\
\hline Lengua y Literatura Españolas & 4 & Didáctica de las Ciencias Sociales & 4 & Didáctica del (Francés o Ingles) & 4 & \\
\hline Lengua Catalana I (elegir castellano o catalán) & 4 & Didáctica General & 8 & Didáctica del (Español o Catalán) & 4 & \\
\hline Organización Escolar & 6 & Matemáticas y su Didáctica & 4 & Practicum III & 20 & \\
\hline Practicum I & 2 & Nuevas Tecnologías aplicadas a la Educación & 4 & $\begin{array}{l}\text { Desarrollo de la Expresión Plástica y su } \\
\text { Didáctica }\end{array}$ & 4 & \\
\hline $\begin{array}{l}\text { Psicología de la Educación y del Desarrollo en la } \\
\text { Edad Escolar }\end{array}$ & 4 & Practicum II & 10 & OPTATIVAS & 18 & \\
\hline Sociología de la Educación & 4 & OBLIGATORIAS & & LIBRE CONFIGURACIÓN & 11 & \\
\hline Teoría y Práctica del Condicionamiento Físico & 6 & $\begin{array}{l}\text { Desarrollo y Contextos Educativos en la Ed. Infantil y } \\
\text { Primaria }\end{array}$ & 4 & & & \\
\hline \multicolumn{2}{|l|}{ OBLIGATORIAS } & Educación Matemática & 4 & & & \\
\hline Informática & 6 & Expresión y Comunicación Corporal & 8 & & & \\
\hline Inglés I & 3 & Inglés II & 3 & & & \\
\hline Teoría de la Educación & 4 & OPTATIVAS & 4 & & & \\
\hline Iniciación Deportiva Escolar & 8 & LIBRE CONFIGURACIÓN & 6 & & & \\
\hline OPTATIVAS & 3 & & & & & \\
\hline \multirow[t]{2}{*}{ LIBRE CONFIGURACIÓN } & 6 & & & & & \\
\hline & 74 & & 77 & & 77 & 228 \\
\hline
\end{tabular}




\begin{tabular}{|c|c|c|c|c|c|c|}
\hline \multicolumn{6}{|c|}{ (CS) 1992 ESPECIALIDAD: MUSICA } & \\
\hline $\begin{array}{c}\text { PRIMER CURSO } \\
\text { (8 tronc. }+2 \text { obl. }+3 \text { opt. }+7 \text { lib.config.) }\end{array}$ & $\mathrm{Cr}$ & $\begin{array}{c}\text { SEGUNDO CURSO } \\
\text { (8 tronc. }+3 \text { obl. + opt. + lib.config.) }\end{array}$ & $\mathrm{Cr}$ & $\begin{array}{c}\text { TERCER CURSO } \\
\begin{array}{c}\text { (4 tronc. }+1 \text { tronc. Idioma }+1 \text { obl. }+1 \text { opt. }+7 \\
\text { lib.config. })\end{array}\end{array}$ & $\mathrm{Cr}$ & \\
\hline \multicolumn{2}{|l|}{ TRONCALES } & \multicolumn{2}{|l|}{ TRONCALES } & \multicolumn{2}{|l|}{ TRONCALES } & \\
\hline Educación Física y su Didáctica & 4 & Conjunto Instrumental & 8 & Bases Pedagógicas de la Ed. Especial & 4 & \\
\hline Formación Instrumental I & 8 & Didáctica de las Ciencias Experimentales & 4 & Bases Psicológicas de la Ed. Especial & 4 & \\
\hline Formación Vocal y Auditiva & 4 & Didáctica de las Ciencias Sociales & 4 & Didáctica del (Español o Catalán) & 4 & \\
\hline Historia de la Educación Contemporánea & 4 & Didáctica General & 8 & (Francés o Ingles) y su Didáctica & 4 & \\
\hline Lengua y Literatura Españolas & 4 & Matemáticas y su Didáctica & 4 & Formación Rítmica y Danza & 4 & \\
\hline Lengua Catalana I (elegir castellano o catalán) & 4 & Nuevas Tecnologías aplicadas a la Educación & 4 & Historia de la Música y el Folklore & 4 & \\
\hline Lenguaje Musical I & 4 & Didáctica de la Expresión Musical & 8 & Practicum & 20 & \\
\hline Organización Escolar & 6 & Practicum II & 10 & \multicolumn{2}{|l|}{ OBLIGATORIAS } & \\
\hline Practicum I & 2 & OBLIGATORIAS & & $\begin{array}{l}\text { Desarrollo de la Expresión Plástica y su } \\
\text { Didáctica }\end{array}$ & 4 & \\
\hline $\begin{array}{l}\text { Psicología de la Educación y del Desarrollo en la } \\
\text { Edad Escolar }\end{array}$ & 4 & $\begin{array}{l}\text { Desarrollo y Contextos Educativos en la Ed. Infantil y } \\
\text { Primaria }\end{array}$ & 4 & OPTATIVAS & 18 & \\
\hline Sociología de la Educación & 4 & Educación Matemática & 4 & LIBRE CONFIGURACIÓN & 11 & \\
\hline \multicolumn{2}{|l|}{ OBLIGATORIAS } & Inglés II & 3 & & & \\
\hline Informática & 6 & OPTATIVAS & 8 & & & \\
\hline Inglés I & 3 & LIBRE CONFIGURACIÓN & 6 & & & \\
\hline Teoría de la Educación & 4 & & & & & \\
\hline Lenguaje Musical II & 4 & & & & & \\
\hline OPTATIVAS & 3 & & & & & \\
\hline \multirow[t]{2}{*}{ LIBRE CONFIGURACIÓN } & 6 & & & & & \\
\hline & 74 & & 75 & & 77 & 226 \\
\hline
\end{tabular}




\begin{tabular}{|c|c|c|c|}
\hline \multicolumn{2}{|c|}{$\begin{array}{l}\text { ITINERARIO TEOLOGIA Y PEDAGOGIA DE LA RELIGION Y MORAL } \\
\text { CATTLICAS }\end{array}$} & & \\
\hline Religión y Cultura (1º) & 6 & & \\
\hline EI Mensaje Cristiano: Cristología $\left(2^{\circ}\right)$ & 6 & & \\
\hline Pedagogía y Didáctica de la Religión (3º) & 6 & & \\
\hline \multicolumn{2}{|c|}{ ITINERARIO DE VALENCIANO } & & \\
\hline \multicolumn{2}{|c|}{ CERTIFICADO CAPACITACIÓN } & \multicolumn{2}{|c|}{ DIPLOMA MAESTRO EN VALENCIANO } \\
\hline Lengua Catalana I & 4 & Créditos del Certificado & 24 \\
\hline Lengua Catalana II & 4 & Lengua Catalana IV & 8 \\
\hline Lengua Catalana III & 8 & ELEGIR 8 CREDITOS & \\
\hline Didáctica del Catalán I & 4 & Dramaturgia e Historia del Teatro en Catalán & 4 \\
\hline ELEGIR 4 CREDITOS & & Los Nuevos Lenguajes Literarios Catalanes & 6 \\
\hline Análisis del discurso & 4 & Semántica del Catalán & 3 \\
\hline Dramaturgia e Historia del Teatro en Catalán & 4 & Literatura Catalana I & 4 \\
\hline Los Nuevos Lenguajes Literarios Catalanes & 6 & Literatura Catalana II & 4 \\
\hline Literatura Catalana I & 4 & Dialectología Catalana & 4 \\
\hline \multirow[t]{2}{*}{ Literatura Catalana II } & 4 & Didáctica del Catalán II & 4 \\
\hline & & Análisis del discurso & 4 \\
\hline
\end{tabular}

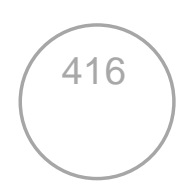




\begin{tabular}{|c|c|c|c|}
\hline OPTATIVAS para todas las especialidades & $\mathrm{Cr}$ & & $\mathrm{Cr}$ \\
\hline Historia de las Instituciones Jurídicas Europeas & 3 & Formación Instrumental II & 4 \\
\hline Historia de las Instituciones Económicas Europeas & 3 & Geografía Humana & 4 \\
\hline El Mensaje Cristiano: Cristología & 6 & Historia y Cultura del País Valenciano & 4 \\
\hline Francés Medio. Implicaciones Didácticas & 6 & Intervención Psicoeducativa en Trastornos de Conducta & 4 \\
\hline Geografía Física & 4 & Intervención Temprana & 4 \\
\hline Intervención Psicoeducativa en Problemas de Aprendizaje & 4 & Introducción a la Musicoterapia & 4 \\
\hline Sistemas Educativos Europeos & 4 & Pedagogía y Didáctica de la Religión & 6 \\
\hline Historia de Europa & 3 & Psicolingüística & 4 \\
\hline Historia del Pensamiento Europeo & 3 & Sociolingüística & 4 \\
\hline Religión y Cultura & 6 & Taller de Matemáticas & 4 \\
\hline Expresión y Comunicación Oral y Escrita para Universitarios & 4 & Técnicas de Animación en el Tiempo Libre & 4 \\
\hline Higiene & & Técnicas Experimentales de Laboratorio & 4 \\
\hline $\begin{array}{l}\text { La Expresión Oral mediante el Juego, la Canción y el Cómic. Su } \\
\text { Aplicación Didáctica a la Enseñanza de Idiomas (Francés) }\end{array}$ & 4 & Juegos Aplicados a la Educación Física & 4 \\
\hline Nuestro Medio Ambiente & 4 & Las Actividades Recreativas y en la Naturaleza & 4 \\
\hline Acústica Musical & 4 & Conjuntos Numéricos & 6 \\
\hline Didáctica de la Literatura Infantil y Juvenil & 4 & El Juego como Método Didáctico & 4 \\
\hline Educación Cívica y Social & 4 & El Trabajo Interdisciplinar: Análisis y Preparación de clases & 4 \\
\hline Educación de Adultos & 4 & Juegos para Enseñar Matemáticas & 4 \\
\hline Educación Física en niños con problemas motores & 4 & La Geometría y el Entorno: Didáctica de la Geometría & 4 \\
\hline Educación y Medio Ambiente & 4 & Geografía del País Valenciano & 4 \\
\hline Evolución & 4 & Taller de Técnicas Pictóricas y Gráficas & 4 \\
\hline Taller de Técnicas Tridimensionales & 4 & Taller de Recursos Materiales en la Expresión Plástica & 4 \\
\hline
\end{tabular}

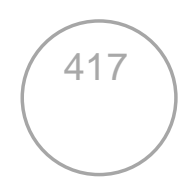




\begin{tabular}{|c|c|c|c|}
\hline \multicolumn{4}{|c|}{ (CS) Plan de estudios de 1992 (Por especialidades) } \\
\hline \multirow{11}{*}{ 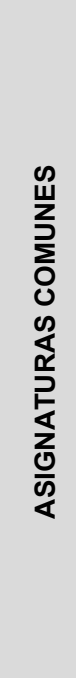 } & PRIMER CURSO & SEGUNDO CURSO & TERCER CURSO \\
\hline & Sociología de la Educación & Didáctica de las Ciencias Sociales & Bases Pedagógicas de la Educación Especial \\
\hline & Historia de la Educación Contemporánea & Didáctica General & Bases Psicológicas de la Educación Especial \\
\hline & Organización Escolar & Nuevas Tecnologías aplicadas a la Educación & Practicum \\
\hline & Practicum I & Practicum II & \\
\hline & $\begin{array}{l}\text { Psicología de la Educación y del Desarrollo en la } \\
\text { Edad Escolar }\end{array}$ & Inglés II & \\
\hline & Informática & LIBRE CONFIGURACIÓN & \\
\hline & Inglés I & & \\
\hline & Teoría de la Educación & & \\
\hline & OPTATIVAS & & \\
\hline & LIBRE CONFIGURACIÓN & & \\
\hline \multirow{9}{*}{ 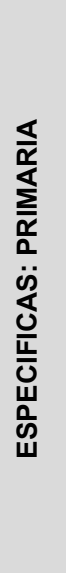 } & PRIMER CURSO & SEGUNDO CURSO & TERCER CURSO \\
\hline & Educación Física y su Didáctica & Didáctica de las Ciencias Sociales & Didáctica de la Lengua y Literatura Españolas \\
\hline & Educación Musical y su Didáctica & Didáctica de las Ciencias Naturales & Teoría y Práctica en Educación Matemática \\
\hline & La Literatura en sus Textos & Didáctica de la Física y Química & Las Técnicas Plásticas en la Ed. Primaria \\
\hline & Morfosintaxis del Español & Didáctica del Francés o Inglés & OPTATIVAS \\
\hline & Lengua Catalana I & Matemáticas y su Didáctica & LIBRE CONFIGURACIÓN \\
\hline & Lengua Catalana II & Desarrollo y Contextos Educativos en la Ed. Primaria & \\
\hline & Desarrollo de la Expresión Plástica y su Didáctica & Didáctica del Catalán I & \\
\hline & & OPTATIVAS & \\
\hline
\end{tabular}

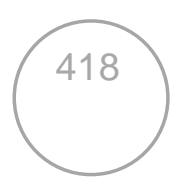




\begin{tabular}{|c|c|c|c|}
\hline \multirow{9}{*}{ 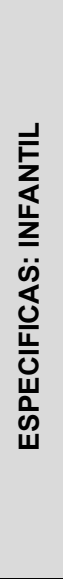 } & PRIMER CURSO & SEGUNDO CURSO & TERCER CURSO \\
\hline & $\begin{array}{l}\text { Desarrollo de las Habilidades Lingüísticas y su } \\
\text { Didáctica en la Lengua Española }\end{array}$ & Desarrollo del Pensamiento Matemático y su Didáctica & Literatura Infantil \\
\hline & Desarrollo Psicomotor & Didáctica de las Ciencias Experimentales en la Ed. Infantil & Didáctica de las Matemáticas \\
\hline & Música & Didáctica del Catalán I & Técnicas Didácticas y Organizativas en Ed. Infantil \\
\hline & La Expresión Corporal en la Educación Infantil & Didáctica del Catalán II & Las Técnicas Plásticas en la Ed. Infantil \\
\hline & Desarrollo de la Expresión Plástica y su Didáctica & Desarrollo y Contextos Educativos en la Ed. Infantil & \\
\hline & & Didáctica de la Expresión Musical en la Ed. Infantil & LIBRE CONFIGURACIÓN \\
\hline & & Educación para la Salud & \\
\hline & & OPTATIVAS & OPTATIVAS \\
\hline \multirow{9}{*}{ 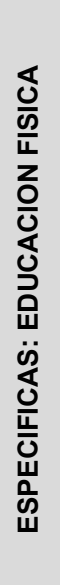 } & PRIMER CURSO & SEGUNDO CURSO & TERCER CURSO \\
\hline & Bases Anatómicas y Fisiológicas del Movimiento & Aprendizaje y Desarrollo Motor & Didáctica de la Educación Física II \\
\hline & La Educación Musical y su Didáctica & Didáctica de la Educación Física I & Didáctica del (Francés o Ingles) \\
\hline & Lengua y Literatura Españolas & Didáctica de las Ciencias Experimentales & Didáctica del (Español o Catalán) \\
\hline & Lengua Catalana I (elegir castellano o catalán) & Matemáticas y su Didáctica & Desarrollo de la Expresión Plástica y su Didáctica \\
\hline & Teoría y Practica del Condicionamiento Físico & $\begin{array}{l}\text { Desarrollo y Contextos Educativos en la Ed. Infantil y } \\
\text { Primaria }\end{array}$ & \\
\hline & Iniciación Deportiva Escolar & Educación Matemática & LIBRE CONFIGURACIÓN \\
\hline & & Expresión y Comunicación Corporal & \\
\hline & & OPTATIVAS & OPTATIVAS \\
\hline
\end{tabular}

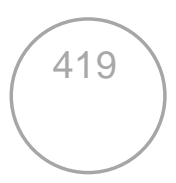


La Educación Artística en los planes de estudio de Magisterio de la Comunitat Valenciana. Visión para el siglo XXI

\begin{tabular}{|c|c|c|c|}
\hline \multirow{8}{*}{ 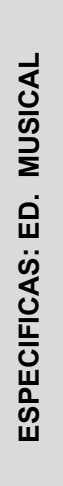 } & PRIMER CURSO & SEGUNDO CURSO & TERCER CURSO \\
\hline & Educación Física y su Didáctica & Conjunto Instrumental & Didáctica del (Español o Catalán) \\
\hline & Formación Instrumental I & Didáctica de las Ciencias Experimentales & Desarrollo de la Expresión Plástica y su Didáctica \\
\hline & Formación Vocal y Auditiva & Matemáticas y su Didáctica & Formación Rítmica y Danza \\
\hline & Lengua y Literatura Españolas & Didáctica de la Expresión Musical & Historia de la Música y el Folklore \\
\hline & Lengua Catalana I (elegir castellano o catalán) & $\begin{array}{l}\text { Desarrollo y Contextos Educativos en la Ed. Infantil y } \\
\text { Primaria }\end{array}$ & (Francés o Ingles) y su Didáctica \\
\hline & Lenguaje Musical I & Educación Matemática & LIBRE CONFIGURACIÓN \\
\hline & Lenguaje Musical II & OPTATIVAS & OPTATIVAS \\
\hline
\end{tabular}




\begin{tabular}{|c|c|c|c|c|c|c|c|}
\hline \multicolumn{8}{|c|}{ (CS) 2007 GRADO ESPECIALIDAD: INFANTIL } \\
\hline $\begin{array}{l}\text { PRIMER CURSO } \\
\text { (8 básicas }+2 \text { obl.) }\end{array}$ & $\mathrm{Cr}$ & $\begin{array}{l}\text { SEGUNDO CURSO } \\
\text { ( } 3 \text { basicas }+6 \text { obl.) }\end{array}$ & $\mathrm{Cr}$ & $\begin{array}{c}\text { TERCER CURSO } \\
\text { (3 básicas }+3 \text { obl. }+2 \text { op.) }\end{array}$ & $\mathrm{Cr}$ & $\begin{array}{l}\text { CUARTO CURSO } \\
\text { (1 básica+ } 4 \text { obl. }+2 \text { op.) }\end{array}$ & $\mathrm{Cr}$ \\
\hline \multicolumn{2}{|l|}{ BÁSICAS } & \multicolumn{2}{|l|}{ BÁSICAS } & \multicolumn{2}{|l|}{ BÁSICAS } & BÁSICAS & \\
\hline Teoría de la Educación & 6 & $\begin{array}{l}\text { Dificultades de aprendizaje en Ed. } \\
\text { Infantil }\end{array}$ & 6 & Educación para la Diversidad & 6 & Trastornos del Desarrollo (0-6 años) & 6 \\
\hline Sociología de la Educación & 6 & Didáctica General & 10 & $\begin{array}{l}\text { Nuevas Tecnologías Aplicadas a la } \\
\text { Educación }\end{array}$ & 6 & Desarrollo Profesional del Docente & 6 \\
\hline $\begin{array}{l}\text { Psicología de la Educación en la } \\
\text { Escuela Infantil y Primaria }\end{array}$ & 6 & La Educación en el Mundo Actual & 6 & \multicolumn{2}{|l|}{ OBLIGATORIAS } & Evaluación e Innovación Educativa & 6 \\
\hline $\begin{array}{l}\text { Psicología del Desarrollo (0-6 } \\
\text { años) }\end{array}$ & 6 & \multicolumn{2}{|l|}{ OBLIGATORIAS } & $\begin{array}{l}\text { Fundamentos y Didáctica de la } \\
\text { Expresión Musical en Educación Infantil }\end{array}$ & 8 & \multicolumn{2}{|l|}{ OBLIGATORIAS } \\
\hline Educación para la Salud & 6 & El Medio Natural en la Educación Infantil & 6 & Didáctica de la Lengua Inglesa & 6 & $\begin{array}{l}\text { Didáctica de la Lengua y la Literatura } \\
\text { Catalana }\end{array}$ & 6 \\
\hline Organización de la Escuela Infantil & 6 & $\begin{array}{l}\text { Didáctica de la Lengua y la Literatura } \\
\text { Española }\end{array}$ & 6 & $\begin{array}{l}\text { Didáctica de la Percepción y de la } \\
\text { Expresión Plástica }\end{array}$ & 8 & Practicum II & 24 \\
\hline Historia de la Educación & 6 & Lengua Inglesa & 6 & Practicum I & 20 & Trabajo Fin de Grado & 6 \\
\hline $\begin{array}{l}\text { El Desarrollo Motriz. Salud y } \\
\text { Crecimiento }\end{array}$ & 6 & $\begin{array}{l}\text { Desarrollo del Pensamiento Matemático } \\
\text { y su Didáctica }\end{array}$ & 8 & OPTATIVA & 6 & OPTATIVA & 6 \\
\hline \multicolumn{2}{|l|}{ OBLIGATORIAS } & $\begin{array}{l}\text { El Medio Social y Cultural en Educación } \\
\text { Infantil }\end{array}$ & 6 & & & & \\
\hline Lengua Catalana & 6 & $\begin{array}{l}\text { Fundamentos de la Expresión Corporal; } \\
\text { Juegos Motrices en Educación Infantil }\end{array}$ & 6 & & & & \\
\hline \multirow[t]{8}{*}{ Lengua Española } & 6 & & & & & & \\
\hline & 60 & & 60 & & 60 & & 60 \\
\hline & & & & \multicolumn{4}{|c|}{ OPTATIVAS (6 créditos) } \\
\hline & & & & Lengua Catalana II & 6 & $\begin{array}{l}\text { Nuevas Tecnologías Aplicadas a la } \\
\text { Música }\end{array}$ & 6 \\
\hline & & & & Recursos en Educación Física & 6 & \begin{tabular}{|l|} 
Didáctica del Modelado y la \\
Construcción
\end{tabular} & 6 \\
\hline & & & & Formas de Vida y Paisajes Históricos & 6 & Literatura Catalana & 6 \\
\hline & & & & El Laboratorio Escolar en Ciencias & 6 & Taller de Matemáticas & 6 \\
\hline & & & & $\begin{array}{l}\text { Teología y Pedagogía de la Religión } \\
\text { Católica }\end{array}$ & 6 & & \\
\hline
\end{tabular}

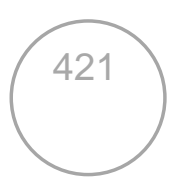




\begin{tabular}{|c|c|c|c|c|c|c|c|}
\hline \multicolumn{8}{|c|}{ (CS) 2007 GRADO ESPECIALIDAD: PRIMARIA } \\
\hline $\begin{array}{l}\text { PRIMER CURSO } \\
\text { ( } 5 \text { basicas }+5 \text { obl.) }\end{array}$ & $\mathrm{Cr}$ & $\begin{array}{l}\text { SEGUNDO CURSO } \\
\text { (4 basicas+ } 6 \text { obl.) }\end{array}$ & $\mathrm{Cr}$ & TERCER CURSO & $\mathrm{Cr}$ & CUARTO CURSO & $\mathrm{Cr}$ \\
\hline \multicolumn{2}{|l|}{ BÁSICAS } & \multicolumn{2}{|l|}{ BÁSICAS } & \multicolumn{2}{|l|}{ OBLIGATORIAS } & \multicolumn{2}{|l|}{ OBLIGATORIAS } \\
\hline Teoría de la Educación & 6 & Educación para la Diversidad & 6 & Didáctica de las Matemáticas III. & 6 & $\begin{array}{l}\text { Didáctica de la Lengua y la Literatura } \\
\text { Catalana. }\end{array}$ & 6 \\
\hline $\begin{array}{l}\text { Desarrollo y Contextos en la } \\
\text { Educación Primaria }\end{array}$ & 6 & Dificultades de Aprendizaje y Desarrollo & 6 & Didáctica de la Lengua Inglesa & 6 & Fundamentos de la Acción Motriz & 8 \\
\hline Sociología de la Educación & 6 & $\begin{array}{l}\text { Nuevas Tecnologías Aplicadas a la } \\
\text { Educación }\end{array}$ & 6 & $\begin{array}{l}\text { Didáctica de la Expresión Musical en } \\
\text { Educación Primaria }\end{array}$ & 6 & Didáctica de las Artes Plásticas II. & 8 \\
\hline $\begin{array}{l}\text { Psicología de la Educación en la } \\
\text { Escuela Infantil y Primaria }\end{array}$ & 6 & Didáctica y Organización Escolar & 12 & $\begin{array}{l}\text { Didáctica de las Ciencias Sociales: } \\
\text { Geografía. }\end{array}$ & 6 & Practicum II (Educación Primaria) & 26 \\
\hline Historia de la Educación & 6 & \multicolumn{2}{|l|}{ OBLIGATORIAS } & $\begin{array}{l}\text { Didáctica de las Ciencias Sociales: } \\
\text { Historia. }\end{array}$ & 6 & Trabajo Fin de Grado & 6 \\
\hline \multicolumn{2}{|l|}{ OBLIGATORIAS } & $\begin{array}{l}\text { Didáctica de la Lengua y la Literatura } \\
\text { Española }\end{array}$ & 6 & Didáctica de las Artes Plásticas I. & 6 & OPTATIVA & 6 \\
\hline Lengua Española & 6 & Música & 6 & Practicum I. & 18 & & \\
\hline Lengua Catalana I & 6 & Didáctica de la Física y Química & 6 & OPTATIVA & 6 & & \\
\hline Lengua Inglesa & 6 & Didáctica de las Ciencias Naturales & 6 & & & & \\
\hline Didáctica de las Matemáticas I. & 6 & Didáctica de las Matemáticas II. & 6 & & & & \\
\hline \multirow[t]{9}{*}{ Didáctica de la Educación Física. } & 6 & & & & & & \\
\hline & 60 & & 60 & & 60 & & 60 \\
\hline & & & & \multicolumn{4}{|c|}{ OPTATIVAS ( 6 créditos) } \\
\hline & & & & Lengua Catalana II & 6 & Recursos en Educación Física & 6 \\
\hline & & & & $\begin{array}{l}\text { Nuevas Tecnologías Aplicadas a la } \\
\text { Música }\end{array}$ & 6 & $\begin{array}{l}\text { Didáctica del Modelado y la } \\
\text { Construcción }\end{array}$ & 6 \\
\hline & & & & Formas de Vida y Paisajes Históricos & 6 & Literatura Catalana & 6 \\
\hline & & & & El Laboratorio Escolar en Ciencias & 6 & Taller de Matemáticas & 6 \\
\hline & & & & $\begin{array}{l}\begin{array}{l}\text { Teología y Pedagogía de la Religión } \\
\text { Católica }\end{array} \\
\end{array}$ & 6 & & \\
\hline & & & & \multicolumn{4}{|c|}{ ASIGNATURAS VINCULADAS A LA MENCIÓN EN EDUCACIÓN FÍSICA } \\
\hline
\end{tabular}




\begin{tabular}{|c|c|c|c|}
\hline Didáctica de la Educación Física $1^{\circ}$ & 6 & Recursos en Educación Física $4^{\circ}$ & 6 \\
\hline Fundamentos de la Acción Motriz $4^{\circ}$ & 8 & Practicum II (mención Educación Física). & 26 \\
\hline \multicolumn{4}{|c|}{ ASIGNATURAS VINCULADAS A LA MENCIÓN EN MÚSICA } \\
\hline Música $2^{\circ}$ & 6 & $\begin{array}{l}\text { Nuevas Tecnologías Aplicadas a la } \\
\text { Música } 4^{\circ}\end{array}$ & 6 \\
\hline $\begin{array}{l}\text { Didáctica de la Expresión Musical en } \\
\text { Educación Primaria } 3^{\circ}\end{array}$ & 6 & Practicum II (mención Música). & 26 \\
\hline
\end{tabular}




\section{VALENCIA}

\begin{tabular}{|c|c|c|c|c|c|c|}
\hline \multicolumn{7}{|c|}{ (V) Plan de estudios de 1967 NOCTURNO } \\
\hline Primer curso & H & Segundo curso & $\mathbf{H}$ & Tercer curso & $\mathbf{H}$ & \multirow{13}{*}{ Curso de Prácticas } \\
\hline Pedagogía e Historia de la Educación & 3 & Filosofía de la Educación & 2 & Filosofía de la Educación & 2 & \\
\hline Psicología general y evolutiva & 3 & Didáctica General & 3 & Organización Escolar & 3 & \\
\hline Didáctica de las Matemáticas & 203 & Didáctica de las Matemáticas & 2 & Didáctica de las Matemáticas & 2 & \\
\hline Didáctica de la Lengua Española y Literatura & 203 & Didáctica de la Lengua Española y Literatura & 2 & Didáctica de la Lengua Española y Literatura & 2 & \\
\hline Didáctica de las Ciencias Naturales & 2 & Didáctica de las Ciencias Naturales & 2 & Didáctica de la Física y Química & 2 & \\
\hline Didáctica de la Geografía e Historia & 203 & Música & 2 & Didáctica de la Geografía e Historia & 2 & \\
\hline Música & 2 & Idioma (ingles o francés y su didáctica) & 2 & Idioma (ingles o francés y su didáctica) & 2 & \\
\hline Didáctica de la Religión & 2 & Didáctica de la Formación del Espíritu Nacional & 1 & Didáctica de la Religión & 1 & \\
\hline Didáctica de la Formación del Espíritu Nacional & 1 & Educación Física & 2 & Educación Física & 2 & \\
\hline Educación Física & 2 & Dibujo & 2 & Dibujo & 2 & \\
\hline \multirow[t]{2}{*}{ Manualizaciones y Enseñanzas del Hogar } & 2 & Practicas de Enseñanza & 2 & Manualizaciones y Enseñanzas del Hogar & 2 & \\
\hline & & & & Practicas de Enseñanza & 2 & \\
\hline
\end{tabular}




\begin{tabular}{|c|c|c|c|c|c|c|}
\hline \multicolumn{7}{|c|}{ (V) Plan de estudios de 1971 no horas Cuatrimestrales } \\
\hline \multicolumn{7}{|c|}{1971 ESPECIALIDAD: LENGUA ESPAÑOLA E IDIOMA MODERNO } \\
\hline PRIMER CURSO & $H / s$ & \multicolumn{2}{|c|}{ SEGUNDO CURSO } & $H / s$ & TERCER CURSO & $\mathrm{H} / \mathrm{s}$ \\
\hline Pedagogía I y II & 3 & \multicolumn{2}{|l|}{ Pedagogía III } & $0 / 3$ & Literatura Española I y || & 3 \\
\hline Psicosociología de la Educación I y II & 3 & \multicolumn{2}{|l|}{ Música I } & $0 / 3$ & (desaparece en 81) & $3 / 0$ \\
\hline Matemáticas I y |I & 3 & \multicolumn{2}{|c|}{ Didáctica de la Lengua Española I } & $3 / 0$ & Psicosociología de Educación III & $3 / 0$ \\
\hline Lengua Española | y || & 3 & \multicolumn{2}{|l|}{ Lengua Española III y IV } & 3 & Didáctica de la Lengua II (desaparece en 84) & $0 / 3$ \\
\hline (desaparece en 81) & 2 & Religión III & (desaparece en 81) & $0 / 1$ & (desaparece en 81) & $1 / 0$ \\
\hline Educación Física I y |I & 1 & \multicolumn{2}{|l|}{ Educación Física III } & $0 / 3$ & Educación Física IV & $3 / 0$ \\
\hline Lengua y Literatura Francesa I y II (o Ingles) & 3 & \multicolumn{2}{|c|}{ Lengua y Literatura Francesa III y IV (o Ingles) } & 3 & Lengua y Literatura Francesa $\vee$ y VI (o Ingles) & 3 \\
\hline (aparece en 84) & 3 & Valenciano & (aparece en 81) & 3 & $\begin{array}{r}\text { Didáctica de la Lengua Francesa (o Ingles) } \\
\text { (aparece en 81) }\end{array}$ & \\
\hline & & & & & Lengua y Literatura Catalana (aparece en 86) & \\
\hline Formación Política I y II $\quad$ (desaparece en 81) & 1 & Formación Política III & (desaparece en 81) & $0 / 1$ & Formación Política IV & $1 / 0$ \\
\hline \multirow[t]{3}{*}{ Dibujo I y II } & 3 & \multicolumn{2}{|l|}{ Practicas I } & $3 / 0$ & Practicas II & $0 / 3$ \\
\hline & & Manualizaciones I y II & (desaparece en 81) & 2 & Manualizaciones III y & 2 \\
\hline & & \multicolumn{2}{|c|}{$1+2$ Optativas/cuatrimestrales } & 3 y 6 & $2+1$ Optativas cuatrimestrales & 6 y 3 \\
\hline
\end{tabular}


La Educación Artística en los planes de estudio de Magisterio de la Comunitat Valenciana. Visión para el siglo XXI

\begin{tabular}{|c|c|c|c|c|c|}
\hline \multicolumn{6}{|c|}{ (V) 1971 ESPECIALIDAD: CIENCIAS } \\
\hline PRIMER CURSO & $H / s$ & SEGUNDO CURSO & $H / s$ & TERCER CURSO & $H / s$ \\
\hline Pedagogía I y II & 3 & Pedagogía III & $3 / 0$ & Psicosociología de Educación III & $3 / 0$ \\
\hline Psicosociología de la Educación I y II & 3 & Didáctica de las Matemáticas & $0 / 3$ & $\begin{array}{l}\text { Didáctica de Ciencias Naturales o de Física y } \\
\text { Química }\end{array}$ & $0 / 3$ \\
\hline Matemáticas I y |I & 3 & Matemáticas III y IV & 3 & Matemáticas V y VI & 3 \\
\hline Lengua Española | y || & 3 & \multicolumn{2}{|l|}{ 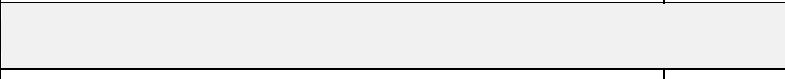 } & (pasa a $2^{\circ}$ en 81$)$ & 3 \\
\hline Religión I y II $\quad$ (desaparece en 81) & 2 & Religión III $\quad$ (desaparece en 81) & $1 / 0$ & (desaparece en 81) & $1 / 0$ \\
\hline $\begin{array}{l}\text { Formación Política I y II } \\
\text { (desaparece en 81) }\end{array}$ & 1 & Física I y II (pasa a 1º) / Química & 3 & Biología I & $3 / 0$ \\
\hline Educación Física I y II & 1 & Educación Física III & $3 / 0$ & Educación Física IV & $3 / 0$ \\
\hline Dibujo I y II & 3 & Manualizaciones I y II & 2 & Manualizaciones III y IV $\quad$ (pasa a 3 h. en 81) & 2 \\
\hline (aparece en 81) & 3 & Formación Política III & $1 / 0$ & Formación Política IV & $1 / 0$ \\
\hline (aparece en 84) & 3 & Geología I y II & 3 & & \\
\hline $\begin{array}{r}2 \text { Optativas cuatrimestrales } \\
\text { (desaparece en 81) }\end{array}$ & 3 y 3 & Música I & $3 / 0$ & (desaparece en 81) & $3 / 0$ \\
\hline & & Practicas I & & Practicas II & $0 / 3$ \\
\hline & & 1 Optativa (Cuatrimestral) & $3 / 0$ & 1 Optativa (Cuatrimestral) & $0 / 3$ \\
\hline
\end{tabular}

\begin{tabular}{|l|c|l|c|c|c|}
\hline \multicolumn{2}{|c|}{ (V) 1971 ESPECIALIDAD: CIENCIAS HUMANAS } \\
\hline PRIMER CURSO & H/s & \multicolumn{2}{|c|}{ SEGUNDO CURSO } & H/s & TERCER CURSO \\
\hline Pedagogía I y II & $\mathbf{3}$ & Pedagogía III & $\mathbf{3} / \mathbf{0}$ & Psicosociología de Educación III \\
\hline Psicosociología de la Educación I y II & $\mathbf{3}$ & Música I & $\mathbf{3} / \mathbf{0}$ & $\begin{array}{l}\text { Música II } \\
\text { (desaparece en } \mathbf{8 1} \text { ) }\end{array}$ \\
\hline Matemáticas I y II & $\mathbf{3}$ & Didáctica de las Ciencias Humanas I & $\mathbf{0} / \mathbf{3}$ & Didáctica de las Ciencias Humanas II \\
\hline Lengua Española I y II & $\mathbf{3}$ & Filosofía I y II & $\mathbf{3}$ & Historia de la Literatura I y II & $\mathbf{3}$ / $\mathbf{0}$ \\
\hline
\end{tabular}

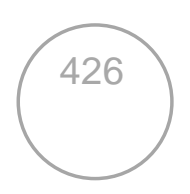




\begin{tabular}{|c|c|c|c|c|c|c|}
\hline (desaparece en 81) & 2 & Religión III & (desaparece en 81) & $1 / 0$ & (desaparece en 81) & $1 / 0$ \\
\hline Formación Política I y II & 1 & Formación Política III & (desaparece en 81) & $1 / 0$ & Formación Política IV & $1 / 0$ \\
\hline Educación Física I y II & 3 & Educación Física III & & $3 / 0$ & Educación Física IV & $3 / 0$ \\
\hline (aparece en 81) & 3 & Geografía I y II & (pasa a $1^{\circ}$ en 81$)$ & 3 & Historia del Arte I y II & 3 \\
\hline & & & & & $\begin{array}{l}\text { Historia de la Literatura Catalana } \quad \text { (aparece en } \\
\text { 86) }\end{array}$ & 3 \\
\hline (desaparece en 81) & 3 y 3 & Practicas I & & $3 / 0$ & Practicas II & $0 / 3$ \\
\hline & & 1 Optativa (Cuatrimestral) & & $3 / 0$ & 1 Optativa Cuatrimestral & $3 / 0$ \\
\hline
\end{tabular}

\begin{tabular}{|c|c|c|c|c|c|c|}
\hline & & (V) 1971 & ESPECIALIDAD: PREESCOLAR & Curso 81. & & \\
\hline PRIMER CURSO & $H / s$ & & SEGUNDO CURSO & $\mathrm{H} / \mathrm{s}$ & TERCER CURSO & $\mathrm{H} / \mathrm{s}$ \\
\hline Pedagogía I y II & 3 & \multicolumn{2}{|l|}{ Pedagogía III } & $3 / 0$ & Psicosociología de Educación III & 3 \\
\hline Matemáticas I y II & 3 & \multicolumn{2}{|c|}{$\begin{array}{l}\text { Lenguaje del Preescolar I y II (Castellano o } \\
\text { Valenciano 86) }\end{array}$} & 3 & Pedagogía del Preescolar & 3 \\
\hline Lengua Española I y II & 3 & \multicolumn{2}{|c|}{ Desarrollo Biológico del Preescolar } & 1,5 & El Medio y el Hombre & 3 \\
\hline Psicología del Preescolar I y II & 3 & \multicolumn{2}{|c|}{ Educación Física del Preescolar } & 1,5 & Matemáticas del Preescolar & 3 \\
\hline Dibujo I y II & 3 & \multicolumn{2}{|c|}{ Educación Plástica } & 3 & Manualizaciones III y IV & 3 \\
\hline (aparece en 84) & 3 & \multicolumn{2}{|l|}{ Practicas I } & $3 / 0$ & Practicas II & \\
\hline & & \multicolumn{2}{|c|}{1 Optativa (Cuatrimestral) } & & 1 Optativa Cuatrimestral & $0 / 3$ \\
\hline & & \multicolumn{2}{|l|}{ Valenciano $2^{\circ}$} & 3 & & \\
\hline
\end{tabular}

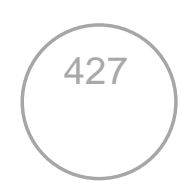


La Educación Artística en los planes de estudio de Magisterio de la Comunitat Valenciana. Visión para el siglo XXI

\begin{tabular}{|c|c|c|c|c|c|}
\hline \multicolumn{6}{|c|}{ (V) 1971 ESPECIALIDAD: E. ESPECIAL curso 82-83 } \\
\hline PRIMER CURSO & $\mathrm{H} / \mathrm{s}$ & SEGUNDO CURSO & $H / s$ & TERCER CURSO & $H / s$ \\
\hline Pedagogía I y II & 3 & Pedagogía III & 3 & Psicosociología de la Educación III & 3 \\
\hline Matemáticas I y II & 3 & Psicomotricidad & 3 & Expresión Lógico-Matemática & 1,5 \\
\hline Lengua Española | y || & 3 & Lenguaje en la Educación Especial & 3 & & \\
\hline Educación Física I y II & 1 & Educación Física III y IV & 1 & Educación Física IV & 1 \\
\hline Educación Especial & 3 & $\begin{array}{l}\text { Psicología (Técnica, Diagnóstico y Psicología } \\
\text { Infantil) }\end{array}$ & 3 & Manualizaciones III y IV & 3 \\
\hline (aparece en 84) & 3 & (aparece en 84) & 3 & Expresión Plástica & 3 \\
\hline \multirow[t]{3}{*}{ Dibujo I y II } & 3 & & & $\begin{array}{l}\text { Ergoterapia y Terapia Ocupacional } \\
\text { (Manualidades) }\end{array}$ & 3 \\
\hline & & Practicas I & & Practicas & \\
\hline & & 1 Optativa Cuatrimestral & & 1 Optativa (Cuatrimestral) & \\
\hline
\end{tabular}

\begin{tabular}{|l|l|l|l|}
\hline \multicolumn{2}{|l|}{ OPTATIVAS CUATRIMESTRALES 3h } \\
\hline Mecánica y Termología & Geometría & Geografía General \\
\hline Química Inorgánica & Cálculo diferencial & Geografía Humana & Historia del Español \\
\hline Óptica y Electricidad & Física teórica & Geografía Regional & Morfosintaxis del Español \\
\hline Química Orgánica & Petrología & Historia de la Cultura & Lógica \\
\hline Análisis matemático & Botánica & Latín & Antropología cultural \\
\hline Paleontología & Zoología & Lingüística general & Ética \\
\hline Historia de la Educación & Filosofía de la Educación & Psicodiagnóstico \\
\hline
\end{tabular}

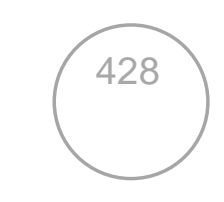




\begin{tabular}{|l|l|l|l|}
\hline \multicolumn{2}{|c|}{ SEGUNDO CURSO OPTATIVAS ANUALES 3h $\quad$ (se introducen en reestructuraciones 82-83) } \\
\hline Ampliación de Física & Geografía Descriptiva & Prácticas de Francés \\
\hline Fonología Inglesa y Didáctica del Inglés & Historia de España & Psicodiagnóstico & Didáctica de las Matemáticas de EGB \\
\hline Educación para la Salud y Zoología & Historia de la Educación & Técnicas de Manualizaciones & Técnicas y Tecnología de la Imagen \\
\hline Enseñanza de la Doctrina Católica y su Pedagogía I & La Constitución Española & Valenciano I & TERCER CURSO OPTATIVAS ANUALES 3h (81-82) \\
\hline Ampliación de Química & Ética y Antropología & Geometría \\
\hline Didáctica de la Literatura, Literatura Infantil Dramática & $\begin{array}{l}\text { Enseñanza de la Doctrina Católica y su } \\
\text { Pedagogía II }\end{array}$ & Historia de la Cultura \\
\hline Didáctica de la Música & Filosofía y Sociología de la Educación & Ecología y Botánica \\
\hline Educación Física en el Ciclo Superior & Geografía General y Humana & Historia del Español con Fundamentos de Latín & Teoría y Práctica de la Evaluación \\
\hline
\end{tabular}




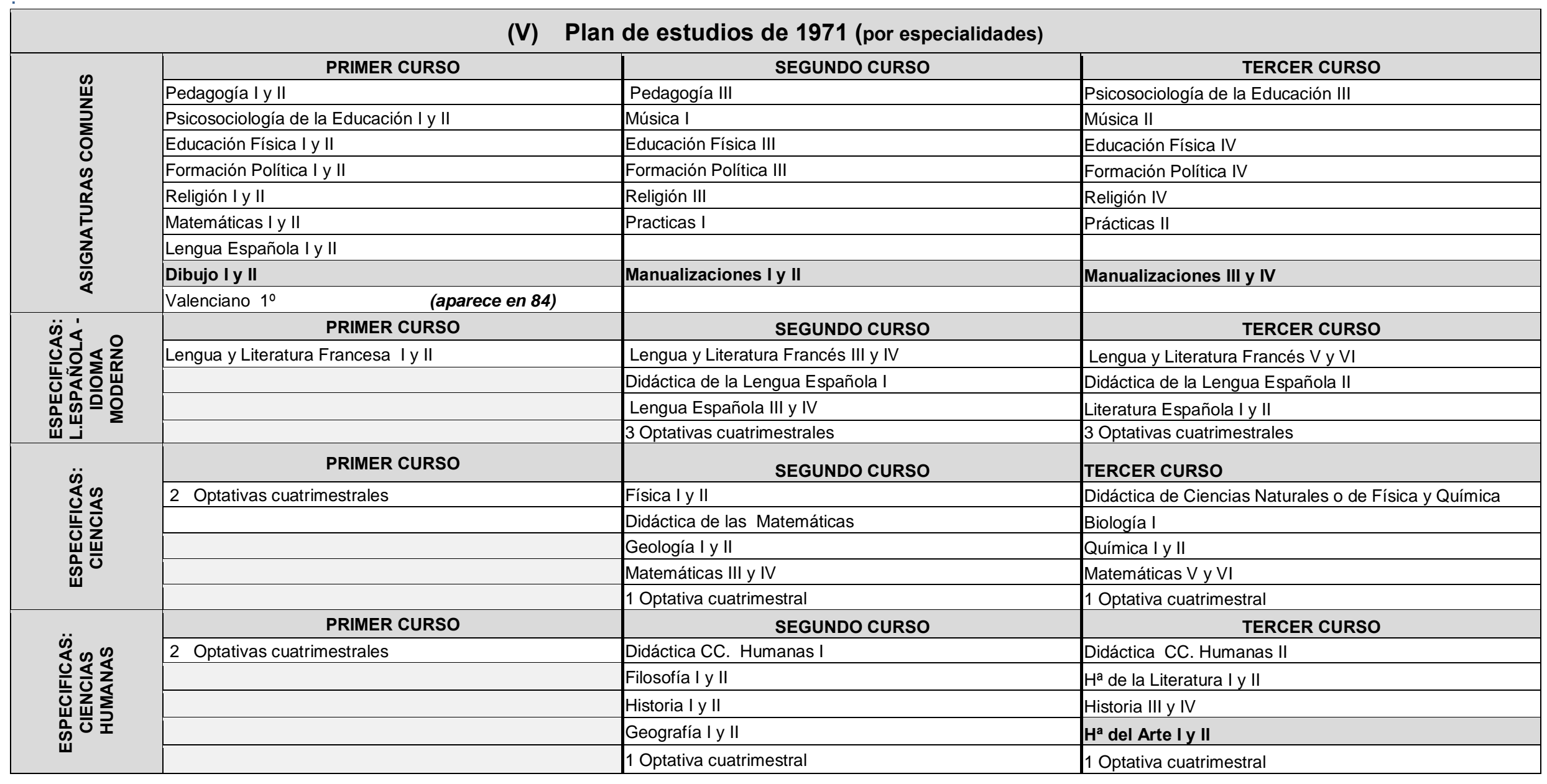




\begin{tabular}{|c|c|c|c|}
\hline \multirow{6}{*}{ 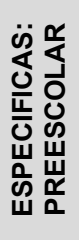 } & PRIMER CURSO & SEGUNDO CURSO & TERCER CURSO \\
\hline & Psicosociología del Preescolar I y II & Desarrollo Biológico del Preescolar & Pedagogía del Preescolar \\
\hline & & Lenguaje Preescolar I y II & El Medio y el Hombre \\
\hline & & Ed. Física del Preescolar & Matemáticas del Preescolar \\
\hline & & Educación Plástica & Sensibilización musical Preescolar \\
\hline & & 1 Optativa cuatrimestral & 1 Optativa cuatrimestral \\
\hline \multirow{6}{*}{ 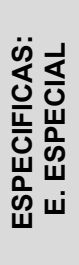 } & PRIMER CURSO & SEGUNDO CURSO & TERCER CURSO \\
\hline & Educación Especial & Psicomotricidad & Musicoterapia \\
\hline & & Lenguaje en la Educación Especial & Expresión Lógico-Matemática \\
\hline & & Psicología (Técnica, Diagnóstico y Psicología Infantil) & Ergoterapia y Terapia Ocupacional (Manualidades) \\
\hline & & 1 Optativa cuatrimestral & Expresión Plástica en EE \\
\hline & & & 1 Optativa cuatrimestral \\
\hline
\end{tabular}




\begin{tabular}{|c|c|c|c|c|c|c|}
\hline \multicolumn{7}{|c|}{ especialidades) } \\
\hline \multirow{6}{*}{ 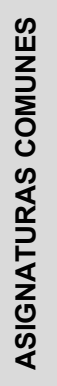 } & TRONCALES COMUNES & $\mathrm{Cr}$ & TRONCALES COMUNES & $\mathrm{Cr}$ & & $\mathrm{Cr}$ \\
\hline & Bases Psicológicas de la Educación Especial & 4 & Psicología del Desarrollo en la Edad Escolar & 4 & & \\
\hline & Educación Especial & 4 & Sociología de la Educación & 4 & & \\
\hline & Didáctica General & 8 & $\begin{array}{l}\text { Teorías e Instituciones Contemporáneos de } \\
\text { Educación }\end{array}$ & 4 & & \\
\hline & Organización del Centro Escolar & 4 & Nuevas Tecnologías aplicadas a la Educación & 4 & & \\
\hline & Psicología de la Educación en la Edad Escolar & 4 & Optativas & & & \\
\hline \multirow{6}{*}{ 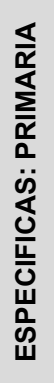 } & \multicolumn{2}{|l|}{ TRONCALES ESPECIALIDAD } & TRONCALES ESPECIALIDAD & & OBLIGATORIAS DE UNIVERSIDAD & \\
\hline & Ciencias de la Naturaleza y su Didáctica & 8 & Lengua Española para la Ed. Primaria & 6 & Lengua Catalana para la Educación & 6 \\
\hline & Ciencias Sociales y su Didáctica & 8 & Matemáticas y su Didáctica I & 8 & Didáctica de la Lengua y Literatura Catalana & 6 \\
\hline & Educación Física y su Didáctica & 4 & Educación Artística y su Didáctica I & 4 & Educación Artística y su Didáctica II & 4 \\
\hline & $\begin{array}{l}\text { Idioma Extranjero y su Didáctica (Inglés o } \\
\text { Francés) }\end{array}$ & 4 & Practicum & 32 & Materias de Libre Elección & 20 \\
\hline & Didáctica de la Lengua y Literatura Española & 6 & & & Optativas & 42 \\
\hline \multirow{6}{*}{ 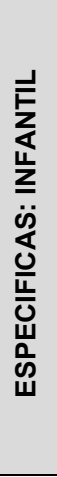 } & TRONCALES ESPECIALIDAD & & TRONCALES ESPECIALIDAD & & OBLIGATORIAS DE UNIVERSIDAD & \\
\hline & $\begin{array}{l}\text { Conocimiento del Medio Natural, Social y } \\
\text { Cultural }\end{array}$ & 6 & Desarrollo Psicomotor. Actividades Psicomotoras & 6 & Lengua Española para la Ed. Infantil & 6 \\
\hline & $\begin{array}{l}\text { Desarrollo de la Expresión Musical y su } \\
\text { Didáctica I }\end{array}$ & 6 & Literatura Infantil & 4 & Lengua Catalana & 6 \\
\hline & $\begin{array}{l}\text { Desarrollo de las Habilidades Lingüísticas en } \\
\text { la Lengua Española y su Didáctica }\end{array}$ & 6 & $\begin{array}{l}\text { Desarrollo de la Expresión Plástica y su } \\
\text { Didáctica }\end{array}$ & 6 & & \\
\hline & $\begin{array}{l}\text { Desarrollo de las Habilidades Lingüísticas en } \\
\text { Lengua Catalana y su Didáctica }\end{array}$ & 6 & Practicum & 32 & & \\
\hline & $\begin{array}{l}\text { Desarrollo del Pensamiento Matemático y su } \\
\text { Didáctica }\end{array}$ & 6 & Optativas & 48 & & \\
\hline
\end{tabular}




\begin{tabular}{|c|c|c|c|c|c|c|}
\hline \multirow{8}{*}{ 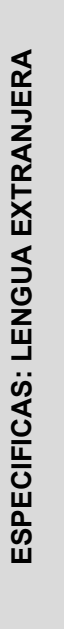 } & TRONCALES ESPECIALIDAD & & TRONCALES ESPECIALIDAD & & & \\
\hline & $\begin{array}{l}\text { Conocimiento del Medio Natural, Social y } \\
\text { Cultural }\end{array}$ & 4 & $\begin{array}{l}\text { Idioma Extranjero y su Didáctica I (Francés o } \\
\text { Ingles) }\end{array}$ & 8 & & \\
\hline & Educación Musical y su Didáctica & 2 & $\begin{array}{l}\text { Idioma Extranjero y su Didáctica II (Francés o } \\
\text { Ingles) }\end{array}$ & 8 & & \\
\hline & Educación Física y su Didáctica & 4 & Fonética (Francés o Ingles) & 4 & & \\
\hline & Matemáticas y su Didáctica I & 4 & Lingüística & 4 & & \\
\hline & Educación Plástica y su Didáctica & 2 & Morfosintaxis y Semántica (Francés o Ingles) & 8 & & \\
\hline & Lengua Española & 4 & Practicum & 32 & & \\
\hline & Didáctica de la Lengua y Literatura Española & 4 & Optativas & 42 & & \\
\hline \multirow{7}{*}{ 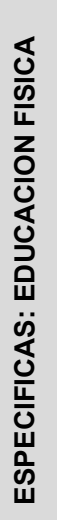 } & TRONCALES ESPECIALIDAD & & TRONCALES ESPECIALIDAD & & TRONCALES ESPECIALIDAD & \\
\hline & $\begin{array}{l}\text { Conocimiento del Medio Natural, Social y } \\
\text { Cultural }\end{array}$ & 4 & Educación Física y su Didáctica & 6 & Habilidades Perceptivo-Motoras Básicas & 4 \\
\hline & Educación Musical y su Didáctica & 2 & $\begin{array}{l}\text { Idioma Extranjero y su Didáctica I (Francés o } \\
\text { Ingles) }\end{array}$ & 4 & Habilidades Perceptivo-Motoras Contextuales & 4 \\
\hline & Matemáticas y su Didáctica & 4 & Bases Biológicas y Fisiológicas del Movimiento & 6 & Habilidades Perceptivo-Motoras Expresivas & 4 \\
\hline & Didáctica de la Lengua y Literatura Española & 3 & Educación Plástica y su Didáctica & 2 & Practica del Acondicionamiento Físico & 3 \\
\hline & Lengua Española & 3 & & & Teoría del Acondicionamiento Físico & 3 \\
\hline & Aprendizaje y Desarrollo Motor & 6 & Optativas & 44 & Practicum & 32 \\
\hline
\end{tabular}


La Educación Artística en Ios planes de estudio de Magisterio de la Comunitat Valenciana. Visión para el siglo XXI

\begin{tabular}{|c|c|c|c|c|c|c|}
\hline \multirow{8}{*}{ 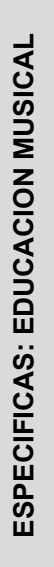 } & TRONCALES ESPECIALIDAD & & TRONCALES ESPECIALIDAD & & TRONCALES ESPECIALIDAD & \\
\hline & $\begin{array}{l}\text { Conocimiento del Medio Natural, Social y } \\
\text { Cultural }\end{array}$ & 4 & Idioma Extranjero y su Didáctica (Ingles o Francés) & 4 & Formación Vocal y Auditiva (Teoría) & 2 \\
\hline & Didáctica de la Expresión Musical I & 4 & Formación Instrumental I & 4 & Formación Vocal y Auditiva (Practica) & 2 \\
\hline & Didáctica de la Expresión Musical II & 4 & Formación Instrumental II & 4 & Historia de la Música y del Folklore & 4 \\
\hline & Educación Física y su Didáctica & 4 & Agrupaciones Instrumentales Escolares & 4 & Lenguaje Musical & 4 \\
\hline & Matemáticas y su Didáctica & 4 & Agrupaciones Vocales Escolares & 4 & Practicum & 32 \\
\hline & Didáctica de la Lengua y Literatura Española & 3 & Formación Rítmica y Danza (Teoría) & 2 & Optativas & 38 \\
\hline & Lengua Española & 3 & Formación Rítmica y Danza (Practica) & 2 & & \\
\hline \multirow{8}{*}{ 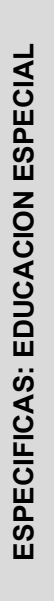 } & TRONCALES ESPECIALIDAD & & TRONCALES ESPECIALIDAD & & TRONCALES ESPECIALIDAD & \\
\hline & Didáctica de la Ed. Especial & 3 & Desarrollo Psicológico de la Deficiencia Motórica & 3 & $\begin{array}{l}\text { Educación Física con alumnado con Necesidades } \\
\text { Educativas Especiales }\end{array}$ & 4 \\
\hline & Organización de la Ed. Especial & 3 & Tratamiento Psicológico de la Deficiencia Motórica & 3 & Expresión Plástica en la Ed. Especial & 2 \\
\hline & $\begin{array}{l}\text { Desarrollo Psicológico de la Deficiencia } \\
\text { Auditiva }\end{array}$ & 3 & Desarrollo Psicológico de la Deficiencia Mental & 2 & Trastornos en la Conducta y la Personalidad & 6 \\
\hline & $\begin{array}{l}\text { Tratamiento Psicológico de la Deficiencia } \\
\text { Auditiva }\end{array}$ & 3 & Educación de la Deficiencia Mental & 4 & $\begin{array}{l}\text { Intervención Evolutiva y Educativa en los Trastornos de la } \\
\text { Lengua Escrita }\end{array}$ & 6 \\
\hline & Desarrollo Psicológico de la Deficiencia Visual & 3 & Tratamiento Psicológico de la Deficiencia Mental & 3 & $\begin{array}{l}\text { Intervención Psicológica en los Trastornos de la Lengua } \\
\text { Escrita }\end{array}$ & 3 \\
\hline & $\begin{array}{l}\text { Tratamiento Psicológico de la Deficiencia } \\
\text { Visual }\end{array}$ & 3 & Expresión Musical en la Ed. Especial & 2 & Practicum & 32 \\
\hline & & & & & Optativas & 48 \\
\hline
\end{tabular}

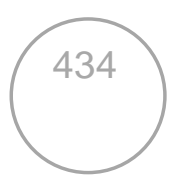




\begin{tabular}{|c|c|c|c|c|c|c|}
\hline \multirow{7}{*}{ 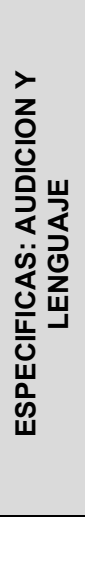 } & TRONCALES ESPECIALIDAD & & TRONCALES ESPECIALIDAD & & TRONCALES ESPECIALIDAD & \\
\hline & $\begin{array}{l}\text { Anatomía, Fisiología y Neurología del } \\
\text { Lenguaje }\end{array}$ & 4 & Sistemas Alternativos de Comunicación & 4 & $\begin{array}{l}\text { Intervención Evolutiva y Educativa de los Trastornos de la } \\
\text { Audición del Lenguaje }\end{array}$ & 4 \\
\hline & $\begin{array}{l}\text { Aspectos Evolutivos del Pensamiento y el } \\
\text { Lenguaje }\end{array}$ & 4 & $\begin{array}{l}\text { Teorías e Instituciones Contemporáneas de } \\
\text { Educación }\end{array}$ & 4 & $\begin{array}{l}\text { Intervención Psicológica de los Trastornos de la Audición } \\
\text { del Lenguaje }\end{array}$ & 4 \\
\hline & Desarrollo de Habilidades Lingüísticas & 4 & $\begin{array}{l}\text { Intervención Psicológica en la Psicopatología de la } \\
\text { Audición y Lenguaje }\end{array}$ & 4 & $\begin{array}{l}\text { Intervención Evolutiva y Educativa de los Trastornos de la } \\
\text { Lengua Oral y Escrita }\end{array}$ & 4 \\
\hline & Habilidades Lingüísticas & 4 & Psicopatología de la Audición y Lenguaje & 4 & $\begin{array}{l}\text { Intervención Psicológica de los Trastornos de la Lengua } \\
\text { Oral y Escrita }\end{array}$ & 4 \\
\hline & Lingüística I & 4 & Lingüística II & 4 & Practicum & 32 \\
\hline & & & & & Optativas & 50 \\
\hline
\end{tabular}

\begin{tabular}{|c|c|c|c|c|c|c|}
\hline \multicolumn{7}{|c|}{ (V)Plan de estudios de 1993} \\
\hline TOTAL 198 cr. & Troncales comunes & $\begin{array}{c}\text { Troncales } \\
\text { Especialidad }\end{array}$ & Practicum Especialidad & Obligatorias & Optativas & $\begin{array}{c}\text { Libre } \\
\text { disposición }\end{array}$ \\
\hline PRIMARIA & 40 & 48 & 32 & 16 & 42 & 20 \\
\hline ED. ESPECIAL & 40 & 56 & 32 & 0 & 50 & 20 \\
\hline ED. FISICA & 40 & 56 & 32 & 6 & 44 & 20 \\
\hline ED. INFANTIL & 40 & 46 & 32 & 12 & 48 & 20 \\
\hline ED. MUSICAL & 40 & 62 & 32 & 6 & 38 & 20 \\
\hline LENGUA EXT. & 40 & 56 & 32 & 8 & 42 & 20 \\
\hline ED. AUD-LEN. & 40 & 56 & 32 & 0 & 50 & 20 \\
\hline
\end{tabular}




\begin{tabular}{|c|c|c|c|c|c|}
\hline \multicolumn{6}{|c|}{ OPTATIVAS } \\
\hline Actividad Física y Salud en la Escuela & 4 & Juegos Populares y Tradicionales & 4 & Educación Ambiental y su Didáctica & 8 \\
\hline $\begin{array}{l}\text { Adquisición-Aprendizaje de una Lengua } \\
\text { Extranjera y Elaboración de Materiales (Francés } \\
\text { o Ingles) }\end{array}$ & 4 & La Enseñanza de Lenguas en Contacto & 4 & Educación Auditiva en la Escuela & 4 \\
\hline Antropología Filosófica & 8 & La Pedagogía como Ciencia de la Educación & 4 & Educación en Valores y Actitudes & 4 \\
\hline $\begin{array}{l}\text { Aplicación Didáctica de un instrumento } \\
\text { harmónico }\end{array}$ & 4 & El Laboratorio Escolar de Matemáticas & 4 & Educación Física Adaptada & 4 \\
\hline Comentario de textos & 4 & Lengua Española Aplicada & 8 & Educación para la Salud y su Didáctica & 8 \\
\hline Comentario de Textos Franceses I & 4 & Lengua Francesa & 4 & Educación Vial & 4 \\
\hline Comentario de Textos Franceses II & 4 & Lengua Inglesa. Expresión Oral & 4 & El Juego en la Educación Física Infantil & 4 \\
\hline $\begin{array}{l}\text { Iniciación a la Investigación en la Didáctica de las } \\
\text { Ciencias }\end{array}$ & 4 & Lengua y Civilización Francesa y su Didáctica & 4 & Elementos de Sociología & 4 \\
\hline Conjunto Coral & 4 & Lengua y Civilización Inglesa y su Didáctica & 4 & $\begin{array}{l}\text { Enseñanza de las Matemáticas en Entornos } \\
\text { Informáticos }\end{array}$ & 4 \\
\hline Constitución Española y Educación & 4 & Literatura Catalana I & 4 & Epistemología de la Educación Física & 4 \\
\hline Cultura y Literatura ingleses & 4 & Literatura Catalana II & 4 & Ergoterapia y Terapia Ocupacional & 4 \\
\hline $\begin{array}{l}\begin{array}{l}\text { Iniciación Deportiva y actividades de Tiempo } \\
\text { Libre }\end{array} \\
\end{array}$ & 4 & Lengua Catalana Aplicada & 4 & Estudio Literario y Teatral & 4 \\
\hline Deportes Colectivos & 4 & Música, Movimiento y Dramatización & 4 & Expresión y Comunicación Corporal & 4 \\
\hline $\begin{array}{l}\text { Desarrollo Curricular y Organización en Ed. } \\
\text { Infantil }\end{array}$ & 4 & Musicoterapia en Ed. Especial & 4 & Filosofía de la Historia & 4 \\
\hline \begin{tabular}{|l|} 
Desarrollo Curricular y Organización en Ed. De \\
Adultos
\end{tabular} & 4 & Nuevas Tecnologías Aplicadas a la Música & 4 & Filosofía del Conocimiento y de la Acción & 4 \\
\hline Didáctica de la Aritmética & 4 & Percepción y Análisis de la Imagen y su Didáctica & 4 & Investigación Musical en el Aula. Recursos Didácticos & 4 \\
\hline Didáctica de la Geometría del Espacio & 4 & Practica de la Lengua y su Didáctica I (Francés) & 4 & Teoría de la Escuela & 4 \\
\hline Didáctica de la Geometría del Plano & 4 & Practica de la Lengua y su Didáctica I (Ingles) & 4 & $\begin{array}{l}\text { Tratamiento de la Información Educativa: Introducción } \\
\text { a Aplicaciones Informáticas en Educación }\end{array}$ & 4 \\
\hline
\end{tabular}

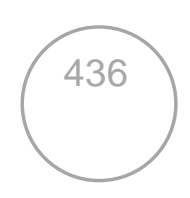




\begin{tabular}{|c|c|c|c|c|c|}
\hline Didáctica de la Literatura Catalana & 4 & Practica de la Lengua y su Didáctica II (Francés) & 4 & Tratamiento de los Trastornos de Lectura y Escritura & 4 \\
\hline Didáctica de la Literatura Española & 4 & Practica de la Lengua y su Didáctica II (Ingles) & 4 & Fonética Francesa y su Didáctica & 4 \\
\hline Didáctica de la Literatura Infantil y el Folklore & 4 & $\begin{array}{l}\text { Procedimientos y Recursos para la Adquisición y el } \\
\text { Desarrollo de la Lengua Catalana }\end{array}$ & 8 & Fonética Inglesa y su Didáctica & 4 \\
\hline $\begin{array}{l}\text { Didáctica de la Probabilidad y la Estadística en } \\
\text { Primaria }\end{array}$ & 4 & Profundización musical en Ed. Infantil & 4 & Fonética Inglesa y su Didáctica II & 4 \\
\hline $\begin{array}{l}\text { Didáctica de la Resolución de Problemas y } \\
\text { Heurística Matemática }\end{array}$ & 4 & $\begin{array}{l}\text { Profundización en la Expresión Plástica de Ed. } \\
\text { Infantil }\end{array}$ & 4 & Geografía de España & 4 \\
\hline $\begin{array}{l}\text { Didáctica de las Estructuras Gramaticales en el } \\
\text { Lenguaje Oral y Escrito }\end{array}$ & 4 & $\begin{array}{l}\text { Proyecto y Elaboración de Materiales Didácticos en } \\
\text { Expresión Plástica }\end{array}$ & 4 & Geografía del País Valencia & 4 \\
\hline Didáctica del Gesto y el Signo Gráfico & 4 & Psicodiagnóstico & 4 & Historia I & 4 \\
\hline Didáctica del Lenguaje Oral y Escrito & 4 & $\begin{array}{l}\text { Psicología de la Instrucción en las Áreas Curriculares de } \\
\text { ED. Primaria }\end{array}$ & 4 & Historia II & 4 \\
\hline $\begin{array}{l}\text { Didáctica del Medio Geográfico, Histórico y } \\
\text { Cultural }\end{array}$ & 8 & Psicología del Desarrollo Infantil & 4 & Historia de la Educación & 4 \\
\hline Dirección e Innovación en Centros Escolares & 4 & Psicopatología Infantil & 4 & Historia de la Educación en la Comunidad Valenciana & 4 \\
\hline Doctrina Católica y su Pedagogía I & 4 & Sociología de la Cultura & 4 & Historia del País Valencia & 4 \\
\hline Doctrina Católica y su Pedagogía II & 4 & Sociología de la Familia & 4 & Historia Social de la Lengua & 4 \\
\hline Doctrina Católica y su Pedagogía III & 4 & Técnicas Audiovisuales y su Didáctica & 4 & Intervención en el Comportamiento & 4 \\
\hline Doctrina Católica y su Pedagogía IV & 4 & Técnicas Plásticas en el Marco Escolar & 4 & $\begin{array}{l}\text { Intervención Psicoeducativa en el Área Afectiva y } \\
\text { Socio-Moral }\end{array}$ & 4 \\
\hline Intervención Psicológica en Procesos Cognitivos & 4 & & & & \\
\hline
\end{tabular}


La Educación Artística en los planes de estudio de Magisterio de la Comunitat Valenciana. Visión para el siglo XX

\begin{tabular}{|c|c|c|c|c|c|}
\hline \multicolumn{6}{|c|}{ PLAN DE ESTUDIOS 1993 - ESCUELA DE CHESTE } \\
\hline \multicolumn{6}{|c|}{1993 ESPECIALIDAD: PRIMARIA - ESPAÑOL, INGLES O FRANCES } \\
\hline PRIMER CURSO & $H / s$ & SEGUNDO CURSO & $H / s$ & TERCER CURSO & $H / s$ \\
\hline Pedagogía & 4 & Organización Escolar & 2 & Sociología & 2 \\
\hline Psicosociología de la Educación & 4 & Música I & 2 & Música II & 2 \\
\hline Lengua Española I & 4 & Lengua Española II & 4 & Historia de la Literatura Española & 4 \\
\hline Matemáticas I & 4 & Didáctica de la Lengua & 2 & Didáctica de la Literatura Española & 2 \\
\hline Educación Física I & 2 & Educación Física II & 2 & Educación Física III & 2 \\
\hline Valenciano I & 4 & Valenciano II & 2 & & \\
\hline Conocimiento de la Sociedad Valenciana & 2 & Didáctica del Inglés o Francés & 2 & & \\
\hline Lengua y Literatura I (Francés o Ingles) & 4 & Lengua y Literatura II (Francés o Ingles) & 4 & Lengua y Literatura III (Francés o Ingles) & 4 \\
\hline \multirow[t]{3}{*}{ Dibujo } & 3 & Manualizaciones I & 2 & Manualizaciones II & 2 \\
\hline & & Practicas de Enseñanza & 2 & Practicas de Enseñanza & 2 \\
\hline & & 2 Optativas & & 2 Optativas & \\
\hline
\end{tabular}

\begin{tabular}{|c|c|c|c|c|c|}
\hline \multicolumn{6}{|c|}{ CIALIDAD: PREESCOLAR } \\
\hline PRIMER CURSO & $\mathrm{H} / \mathrm{s}$ & SEGUNDO CURSO & $H / s$ & TERCER CURSO & $H / s$ \\
\hline Pedagogía & 4 & Organización Escolar & 2 & Sociología & 2 \\
\hline Psicosociología de la Educación & 4 & Música I & 4 & & \\
\hline Lengua Española I & 4 & Lenguaje del Preescolar & 4 & Pedagogía del Preescolar & 3 \\
\hline Matemáticas & 4 & Educación Física del Preescolar & 2 & Matemáticas del Preescolar & 2 \\
\hline Educación Física I & 4 & Educación Física II & 2 & Educación Física III & 2 \\
\hline
\end{tabular}

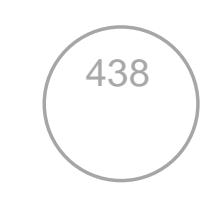




\begin{tabular}{|c|c|c|c|c|c|}
\hline Valenciano I & 4 & Valenciano II & 2 & El Medio y el Hombre & 3 \\
\hline Conocimiento de la Sociedad Valenciana & 4 & Desarrollo Biológico del Preescolar & 2 & Sensibilización musical del preescolar & 2 \\
\hline Psicosociología del Preescolar & 4 & Practicas de Enseñanza & 2 & Practicas de Enseñanza & 2 \\
\hline \multirow[t]{2}{*}{ Dibujo } & 4 & Educación Plástica & 4 & Manualizaciones & 4 \\
\hline & & 2 Optativas & & 2 Optativas & \\
\hline
\end{tabular}

\begin{tabular}{|c|c|c|c|c|c|}
\hline \multicolumn{6}{|c|}{1993 ESPECIALIDAD: HUMANAS / CIENCIAS } \\
\hline PRIMER CURSO & $H / s$ & SEGUNDO CURSO & $H / s$ & TERCER CURSO & $H / s$ \\
\hline Pedagogía & 4 & Organización Escolar & 2 & Sociología & 2 \\
\hline Psicosociología de la Educación & 4 & Música I & 2 & Música II & 2 \\
\hline Lengua Española I & 4 & $\begin{array}{l}\text { Didáctica de las Ciencias Humanas / de Matemáticas } \\
(2 \mathrm{H})\end{array}$ & 4 & Historia de la Literatura / Biología & 4 \\
\hline Matemáticas & 4 & Matemáticas II & 4 & $\begin{array}{l}\text { Historia Moderna y Contemporánea / Didáctica de } \\
\text { las Ciencias }\end{array}$ & 4 \\
\hline Educación Física I & 2 & Educación Física II & 2 & Educación Física III & 2 \\
\hline Valenciano I & 4 & Valenciano li & 2 & Geografía Regional & 2 \\
\hline Conocimiento de la Sociedad Valenciana & 2 & Historia Antigua y Media / Geología & 4 & Practicas de Enseñanza & 2 \\
\hline Geografía General & 4 & Geografía General de España / & 4 & Historia del Arte I & 4 \\
\hline \multirow[t]{5}{*}{ Dibujo } & 3 & Manualizaciones & 2 & Manualizaciones & 2 \\
\hline & & Practicas de Enseñanza & 2 & 1 Optativa & \\
\hline & & 1 Optativa & & & \\
\hline & \multicolumn{3}{|c|}{ OPTATIVAS ANUALES $2^{\circ}$ ( 2 horas semanales) } & \multicolumn{2}{|l|}{ OPTATIVAS ANUALES $3^{\circ}$ ( 2 horas semanales) } \\
\hline & \multicolumn{2}{|c|}{ Historia del Español } & 2 & Evaluación & 2 \\
\hline
\end{tabular}

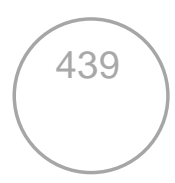


La Educación Artística en los planes de estudio de Magisterio de la Comunitat Valenciana. Visión para el siglo XXI

\begin{tabular}{|l|l|l|l|}
\hline Diseño de Experiencias & $\mathbf{2}$ & Estadística & $\mathbf{2}$ \\
\hline Psicodiagnóstico & $\mathbf{2}$ & Literatura Infantil & $\mathbf{2}$ \\
\hline Dramatización & $\mathbf{2}$ & Expresión Corporal & Filosofía de la Educación \\
\hline Informática I & $\mathbf{2}$ & Didáctica de las Ciencias Humanas & $\mathbf{2}$ \\
\hline Religión I & $\mathbf{2}$ & Didáctica del Francés II & $\mathbf{2}$ \\
\hline Historia de la Educación & $\mathbf{2}$ & Tecnología de la Imagen II & $\mathbf{2}$ \\
\hline Tecnología de la Imagen I & & Religión II & $\mathbf{2}$ \\
\hline & & Informática II & $\mathbf{2}$ \\
\hline & & Pedagogía del Preescolar & $\mathbf{2}$ \\
\hline & & Valenciano III & $\mathbf{2}$ \\
\hline & & Historia de la Cultura & $\mathbf{2}$ \\
\hline & & Didáctica del Inglés II & $\mathbf{2}$ \\
\hline
\end{tabular}




\begin{tabular}{|c|c|c|c|c|c|c|c|}
\hline \multicolumn{6}{|c|}{ (V) 2000 ESPECIALIDAD: PRIMARIA } & \multirow{3}{*}{\begin{tabular}{l}
\multicolumn{1}{c}{ OPTATIVAS } \\
Tratamiento de los \\
Trastornos de Lecto - \\
escritura
\end{tabular}} & \multirow{3}{*}{$\begin{array}{c}\text { OPTATIVAS } 6 \mathrm{Cr} \text {. } \\
\text { para todas las } \\
\text { especialidades }\end{array}$} \\
\hline PRIMER CURSO & $\mathrm{Cr}$ & SEGUNDO CURSO & $\mathrm{Cr}$ & TERCER CURSO & $\mathrm{Cr}$ & & \\
\hline Didáctica General & 9 & Ciencias Sociales y su Didáctica & 9 & Practicum & 32 & & \\
\hline $\begin{array}{l}\text { Bases Psicológicas de la Educación } \\
\text { Especial }\end{array}$ & 4,5 & Organización del Centro Escolar & 4,5 & Sociología de la Educación & 4,5 & & Cuatrimestrales \\
\hline $\begin{array}{l}\text { Lengua y literatura española y su } \\
\text { didáctica }\end{array}$ & 12 & $\begin{array}{l}\text { Lengua y Literatura catalana y su } \\
\text { didáctica I }\end{array}$ & 12 & $\begin{array}{l}\text { Nuevas Tecnologías aplicadas a la } \\
\text { Educación }\end{array}$ & 4,5 & & $\begin{array}{l}\text { Análisis y Producción de } \\
\text { Textos en Catalán }\end{array}$ \\
\hline Educación especial & 4,5 & Matemáticas y su didáctica & 9 & Lengua francesa/inglesa y su didáctica & 4,5 & & Ciencia para no Científicos \\
\hline $\begin{array}{l}\text { Psicología de la educación y del } \\
\text { desarrollo en la edad escolar }\end{array}$ & 9 & & & Educación física y su didáctica & 4,5 & & $\begin{array}{l}\text { Desarrollo Curricular y } \\
\text { Organización de la Ed. } \\
\text { Infantil }\end{array}$ \\
\hline Ciencias de la naturaleza y su didáctica & 9 & & & Educación musical y su didáctica & 4,5 & & Educación Ambiental \\
\hline $\begin{array}{l}\text { Teorías y instituciones contemporáneas } \\
\text { de educación }\end{array}$ & 4,5 & & & OPTATIVAS & 30 & & Educación para la Salud \\
\hline \multirow[t]{2}{*}{ Educación plástica y su didáctica } & 4,5 & & & LIBRE ELECCION & 22 & & Educación Vial \\
\hline & 57 & & 34,5 & & 54,5 & 198 & Francés \\
\hline
\end{tabular}

\begin{tabular}{|c|c|c|c|c|c|c|c|}
\hline \multicolumn{6}{|c|}{2000 ESPECIALIDAD: INFANTIL } & & Filosofía de la Cultura \\
\hline PRIMER CURSO & $\mathrm{Cr}$ & SEGUNDO CURSO & $\mathrm{Cr}$ & TERCER CURSO & $\mathrm{Cr}$ & & $\begin{array}{l}\text { Enseñanza de las } \\
\text { Matemáticas en entornos } \\
\text { informáticos }\end{array}$ \\
\hline \multicolumn{2}{|l|}{ TRONCALES } & TRONCALES & & TRONCALES & & OPTATIVAS & Geografía Regional \\
\hline Didáctica General & 9 & $\begin{array}{l}\text { Desarrollo de habilidades lingüísticas } \\
\text { y su didáctica : español }\end{array}$ & 9 & Practicum & 32 & $\begin{array}{l}\text { Tratamiento de los } \\
\text { Trastornos de Lecto - } \\
\text { escritura }\end{array}$ & $\begin{array}{l}\text { Historia Antigua y } \\
\text { Medieval }\end{array}$ \\
\hline \begin{tabular}{|l|} 
Psicología de la Educación y del \\
Desarrollo en la Edad Escolar
\end{tabular} & 9 & Organización del Centro Escolar & 4,5 & Sociología de la Educación & 4,5 & & Historia de la Escuela \\
\hline $\begin{array}{l}\text { Bases Psicológicas de la Educación } \\
\text { Especial }\end{array}$ & 4,5 & $\begin{array}{l}\text { Desarrollo Habilidades Lingüísticas y } \\
\text { su didáctica: catalán }\end{array}$ & 9 & $\begin{array}{l}\text { Nuevas Tecnologías aplicadas a la } \\
\text { Educación }\end{array}$ & 4,5 & & Historia del País Valencia \\
\hline
\end{tabular}

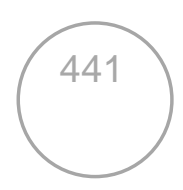




\begin{tabular}{|c|c|c|c|c|c|c|}
\hline Desarrollo Psicomotor & 6 & & Literatura Infantil & 4,5 & & $\begin{array}{l}\text { Historia Moderna y } \\
\text { Contemporánea }\end{array}$ \\
\hline \begin{tabular}{|l|} 
Desarrollo del Pensamiento \\
Matemático y su Didáctica
\end{tabular} & 6 & & $\begin{array}{l}\text { Conocimiento del medio natural, social } \\
\text { y cultural }\end{array}$ & 6 & & $\begin{array}{l}\text { Enseñanza de las } \\
\text { Lenguas en Contacto }\end{array}$ \\
\hline Educación Especial & 4,5 & & OPTATIVAS & 48 & & $\begin{array}{l}\text { Laboratorio escolar de } \\
\text { Matemáticas }\end{array}$ \\
\hline $\begin{array}{l}\text { Desarrollo de la Educación musical y } \\
\text { su didáctica }\end{array}$ & 6 & & LIBRE ELECCION & 20,5 & & Lengua Española Aplicada \\
\hline $\begin{array}{l}\text { Teorías y instituciones contemporáneas } \\
\text { de educación }\end{array}$ & 4,5 & & & & & $\begin{array}{l}\text { Lenguaje Oral y Escrito y } \\
\text { su Didáctica }\end{array}$ \\
\hline \multirow[t]{2}{*}{$\begin{array}{l}\text { Desarrollo de la Educación Plástica } \\
\text { y su Didáctica }\end{array}$} & \multirow[b]{2}{*}{55,5} & \multirow[b]{2}{*}{22,5} & & & & Literatura Catalana \\
\hline & & & & 51,5 & 198 & $\begin{array}{l}\text { Literatura de Transmisión } \\
\text { Oral y Lenguaje Literario }\end{array}$ \\
\hline
\end{tabular}

\begin{tabular}{|c|c|c|c|c|c|}
\hline \multicolumn{6}{|c|}{ TRANJEF } \\
\hline PRIMER CURSO & $\mathrm{Cr}$ & SEGUNDO CURSO & $\mathrm{Cr}$ & TERCER CURSO & $\mathrm{Cr}$ \\
\hline \multicolumn{2}{|l|}{ TRONCALES } & TRONCALES & & TRONCALES & \\
\hline Didáctica General & 9 & $\begin{array}{l}\text { Lengua Extranjera y su Didáctica II } \\
\text { - Ingles o Francés }\end{array}$ & 9 & Practicum & 32 \\
\hline $\begin{array}{l}\text { Bases Psicológicas de la Educación } \\
\text { Especial }\end{array}$ & 4,5 & Lingüística & 4,5 & Sociología de la Educación & 4,5 \\
\hline Educación Especial & 4,5 & $\begin{array}{l}\text { Lengua y Literatura Catalana y su } \\
\text { Didáctica }\end{array}$ & 9 & $\begin{array}{l}\text { Nuevas Tecnologías aplicadas a la } \\
\text { Educación }\end{array}$ & 4,5 \\
\hline $\begin{array}{l}\text { Lengua y Literatura Española y su } \\
\text { Didáctica }\end{array}$ & 9 & Organización del Centro Escolar & 4,5 & $\begin{array}{l}\text { Conocimiento del medio natural, social } \\
\text { y cultural }\end{array}$ & 6 \\
\hline Fonética - Ingles o Francés & 4,5 & Matemáticas y su Didáctica & 9 & Educación Musical y su Didáctica & 4,5 \\
\hline $\begin{array}{l}\text { Psicología de la Educación y del } \\
\text { Desarrollo en la Edad Escolar }\end{array}$ & 9 & $\begin{array}{l}\text { Morfosintaxis y Semántica: Inglés } \\
\text { o Francés }\end{array}$ & 9 & Educación Artística y su Didáctica & 4,5 \\
\hline
\end{tabular}

\begin{tabular}{|c|c|}
\hline & $\begin{array}{l}\text { Materiales Curriculares } \\
\text { para Conocimiento del } \\
\text { Medio Social }\end{array}$ \\
\hline & $\begin{array}{l}\text { Pedagogía de los Valores y } \\
\text { las Actitudes }\end{array}$ \\
\hline OPTATIVAS $6 \mathrm{Cr}$. & $\begin{array}{l}\text { Percepción y Análisis de } \\
\text { la imagen }\end{array}$ \\
\hline $\begin{array}{l}\text { Adquisición y Aprendizaje } \\
\text { de Lengua Extranjera }\end{array}$ & $\begin{array}{l}\text { Psicología del Desarrollo } \\
\text { Infantil }\end{array}$ \\
\hline $\begin{array}{l}\text { Cultura francesa y su } \\
\text { Didáctica }\end{array}$ & $\begin{array}{l}\text { Resolución de Problemas y } \\
\text { Heurística Matemática }\end{array}$ \\
\hline $\begin{array}{l}\text { Cultura inglesa y su } \\
\text { Didáctica }\end{array}$ & Sociología de la Familia \\
\hline Practica de Inglés escrito & $\begin{array}{l}\text { Sociología de Género: } \\
\text { Taller de coeducación }\end{array}$ \\
\hline Practica de Inglés oral & Técnicas Audiovisuales \\
\hline $\begin{array}{l}\text { Tratamiento de los } \\
\text { Trastornos de Lecto- } \\
\text { escritura }\end{array}$ & $\begin{array}{l}\text { Técnicas Plásticas en el } \\
\text { Marco Escolar }\end{array}$ \\
\hline
\end{tabular}

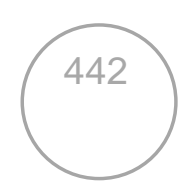




\begin{tabular}{|l|c|c|c|c|c|}
\hline $\begin{array}{l}\text { Lengua Extranjera y su Didáctica I - } \\
\text { Ingles o Francés }\end{array}$ & $\mathbf{9}$ & & Educación Física y su Didáctica & $\mathbf{4 , 5}$ \\
\hline $\begin{array}{l}\text { Teorías y instituciones contemporáneas } \\
\text { de educación }\end{array}$ & $\mathbf{4 , 5}$ & & $\begin{array}{l}\text { Tratamiento de la } \\
\text { información educativa: } \\
\text { introducción a aplicaciones } \\
\text { informáticas en educación. }\end{array}$ \\
\hline & & & OPTATIVAS & $\mathbf{1 8}$ \\
\hline & & LIBRE ELECCION & $\mathbf{2 0 , 5}$ & \\
\hline
\end{tabular}

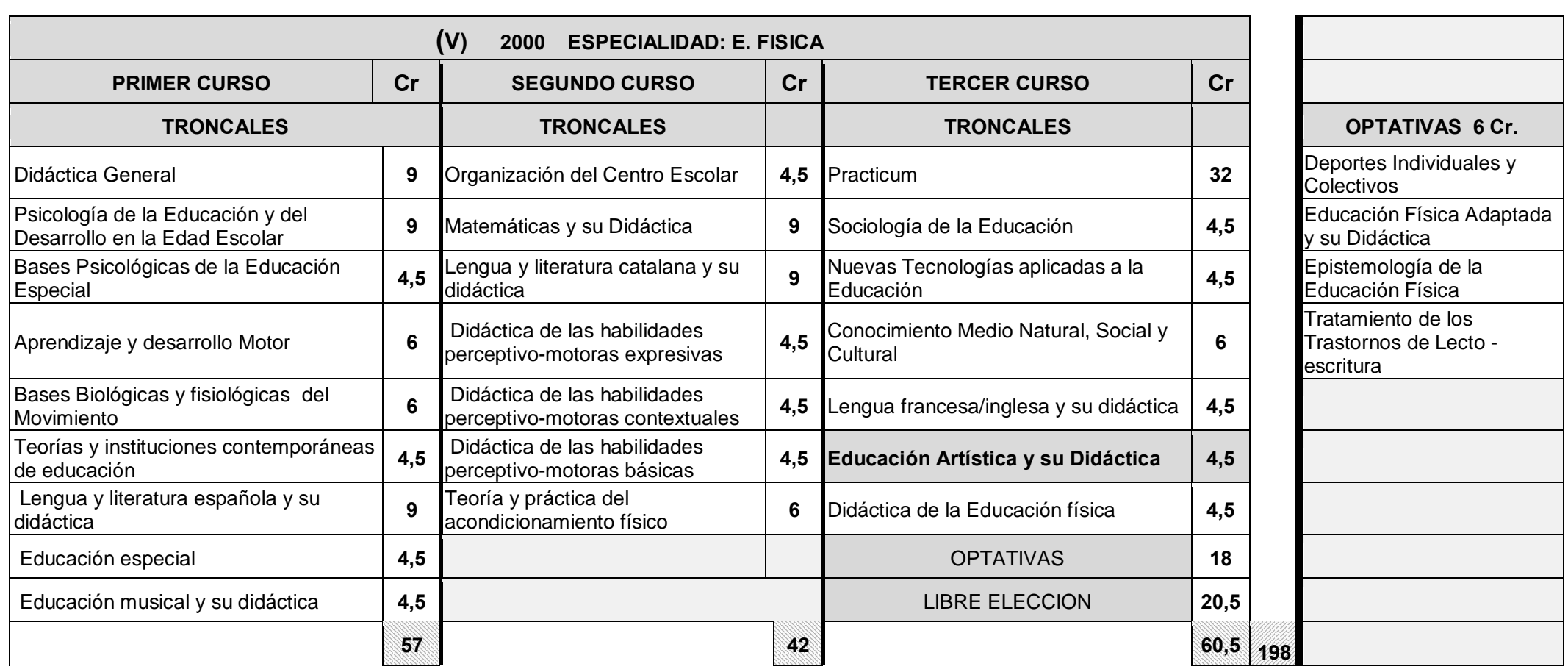

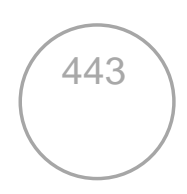




\begin{tabular}{|c|c|c|c|c|c|c|c|}
\hline \multicolumn{6}{|c|}{ ESPECIALIDAD: MUSICA } & & \\
\hline PRIMER CURSO & $\mathrm{Cr}$ & SEGUNDO CURSO & $\mathrm{Cr}$ & TERCER CURSO & $\mathrm{Cr}$ & & \\
\hline \multicolumn{2}{|l|}{ TRONCALES } & TRONCALES & & TRONCALES & & & OPTATIVAS $6 \mathrm{Cr}$. \\
\hline Didáctica General & 9 & Organización del Centro Escolar & 4,5 & Practicum & 32 & & $\begin{array}{l}\text { Investigación Musical en el } \\
\text { Aula. Recursos Didácticos }\end{array}$ \\
\hline $\begin{array}{l}\text { Bases Psicológicas de la Educación } \\
\text { Especial }\end{array}$ & 4,5 & Agrupaciones Musicales & 9 & Sociología de la Educación & 4,5 & & Musicoterapia \\
\hline $\begin{array}{l}\text { Psicología de la Educación y del } \\
\text { Desarrollo en la Edad Escolar }\end{array}$ & 9 & $\begin{array}{l}\text { Lengua y literatura catalana y su } \\
\text { didáctica }\end{array}$ & 9 & $\begin{array}{l}\text { Nuevas Tecnologías aplicadas a la } \\
\text { Educación }\end{array}$ & 4,5 & & $\begin{array}{l}\text { Nuevas Tecnologías } \\
\text { aplicadas a la Música }\end{array}$ \\
\hline Formación Instrumental & 9 & Matemáticas y su Didáctica & 9 & $\begin{array}{l}\text { Conocimiento del Medio Natural, } \\
\text { Social y Cultural }\end{array}$ & 6 & & $\begin{array}{l}\text { Tratamiento de los } \\
\text { Trastornos de Lecto- } \\
\text { escritura }\end{array}$ \\
\hline Lenguaje Musical & 4,5 & Formación vocal i auditiva & 4,5 & Lengua francesa/inglesa y su didáctica & 4,5 & & \\
\hline $\begin{array}{l}\text { Teorías y instituciones } \\
\text { contemporáneas de educación }\end{array}$ & 4,5 & $\begin{array}{l}\text { Didáctica de la Expresión } \\
\text { musical }\end{array}$ & 9 & Educación física y su didáctica & 4,5 & & \\
\hline $\begin{array}{l}\text { Lengua y literatura española y su } \\
\text { didáctica }\end{array}$ & 9 & Formación rítmica y danza & 4,5 & Historia de la música y el folklore & 4,5 & & \\
\hline \multirow[t]{3}{*}{ Educación especial } & 4,5 & & & OPTATIVAS & 18 & & \\
\hline & & & & LIBRE ELECCION & 20,5 & & \\
\hline & 54 & & 49,5 & & 60,5 & 203 & \\
\hline
\end{tabular}

\begin{tabular}{|c|c|c|c|c|c|c|}
\hline \multicolumn{2}{|c|}{ (V) } & \multicolumn{4}{|c|}{2000 ESPECIALIDAD: EDUCACION ESPECIAL } & \\
\hline PRIMER CURSO & $\mathrm{Cr}$ & SEGUNDO CURSO & $\mathrm{Cr}$ & TERCER CURSO & $\mathrm{Cr}$ & \\
\hline \multicolumn{2}{|l|}{ TRONCALES } & TRONCALES & & TRONCALES & & OPTATIVAS $6 \mathrm{Cr}$. \\
\hline Didáctica General & 9 & Organización del Centro Escolar & 4,5 & Practicum & 32 & Musicoterapia \\
\hline $\begin{array}{l}\text { Bases Psicológicas de la Educación } \\
\text { Especial }\end{array}$ & 4,5 & $\begin{array}{l}\text { Tratamiento educativo de los } \\
\text { trastornos de la lengua escrita }\end{array}$ & 9 & Sociología de la Educación & 4,5 & \\
\hline $\begin{array}{l}\text { Psicología de la Educación y del } \\
\text { Desarrollo en la Edad Escolar }\end{array}$ & 9 & Lengua catalana y su didáctica & 6 & $\begin{array}{l}\text { Nuevas Tecnologías aplicadas a la } \\
\text { Educación }\end{array}$ & 4,5 & \\
\hline
\end{tabular}




\begin{tabular}{|c|c|c|c|c|c|c|}
\hline $\begin{array}{l}\text { Aspectos evolutivos y educativos de la } \\
\text { deficiencia auditiva }\end{array}$ & 6 & $\begin{array}{l}\text { Trastornos de conducta y } \\
\text { personalidad }\end{array}$ & 6 & $\begin{array}{l}\text { Aspectos didácticos y organizativos de } \\
\text { la educación especial }\end{array}$ & 6 & \\
\hline $\begin{array}{l}\text { Aspectos evolutivos y educativos de la } \\
\text { deficiencia motora }\end{array}$ & 6 & Expresión musical & 4,5 & OPTATIVAS & 18 & \\
\hline $\begin{array}{l}\text { Aspectos evolutivos y educativos de la } \\
\text { deficiencia visual }\end{array}$ & 6 & $\begin{array}{l}\text { Aspectos evolutivos y educativos } \\
\text { de la deficiencia mental }\end{array}$ & 9 & LIBRE ELECCION & 23,5 & \\
\hline $\begin{array}{l}\text { Teorías y instituciones } \\
\text { contemporáneas de educación }\end{array}$ & 4,5 & $\begin{array}{l}\text { Educación física en alumnos con } \\
\text { necesidades educativas } \\
\text { especiales }\end{array}$ & 4,5 & & & \\
\hline $\begin{array}{l}\text { Lengua y literatura española y su } \\
\text { didáctica }\end{array}$ & 6 & Expresión plástica & 4,5 & & & \\
\hline Educación especial & 4,5 & & & & & \\
\hline \multirow[t]{2}{*}{$\begin{array}{l}\text { Iniciación a la aritmética y a la } \\
\text { geometría y sus didácticas }\end{array}$} & 6 & & & & & \\
\hline & 61,5 & & 48 & & 47 & 198 \\
\hline
\end{tabular}

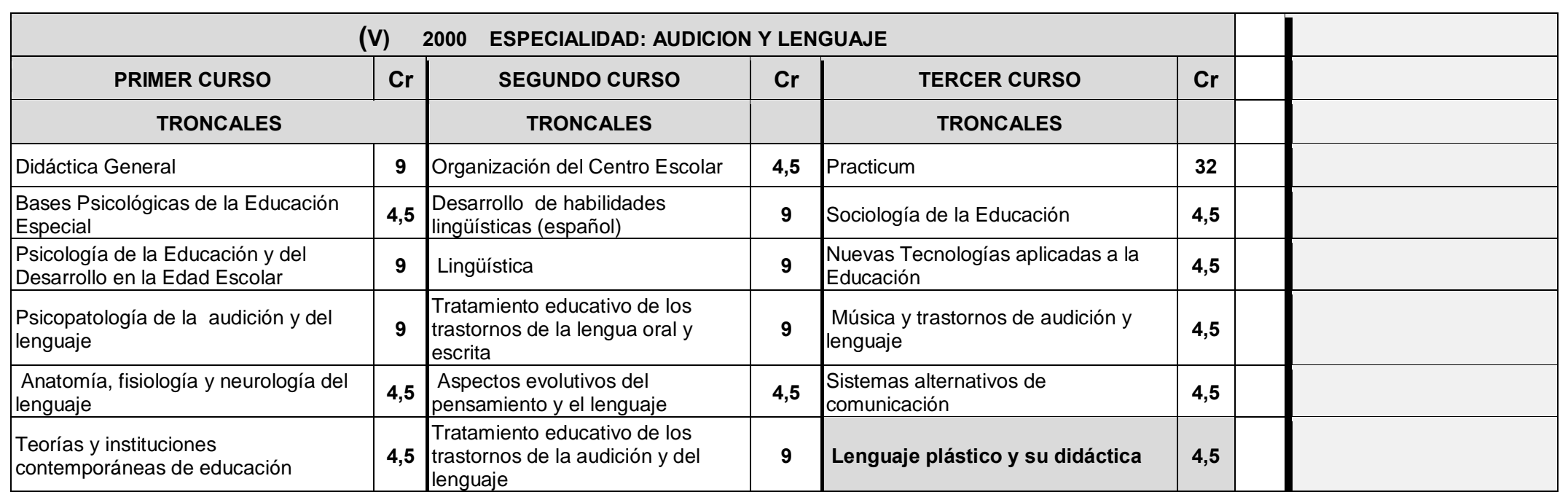


La Educación Artística en los planes de estudio de Magisterio de la Comunitat Valenciana. Visión para el siglo XXI

\begin{tabular}{|l|c|c|c|c|c|c|}
\hline $\begin{array}{l}\text { Desarrollo de habilidades lingüísticas } \\
\text { (catalán) }\end{array}$ & $\mathbf{9}$ & & & & \\
\hline Educación especial & $\mathbf{4 , 5}$ & OPTATIVAS 2 & $\mathbf{8 , 5}$ & OPTATIVAS & $\mathbf{1 2}$ & \\
\hline \multicolumn{1}{|c|}{ LIBRE ELECCION } & $\mathbf{1 2}$ & LIBRE ELECCION & $\mathbf{1 2}$ & & \\
\hline & 54 & $\mathbf{6 5 , 5}$ & $\mathbf{6 6 , 5}$ & $\mathbf{1 8 6}$ & \\
\hline
\end{tabular}




\begin{tabular}{|c|c|c|c|c|}
\hline \multicolumn{4}{|c|}{ (V) Plan de estudios de 2000 (por especialidades) } & \\
\hline \multirow{6}{*}{ 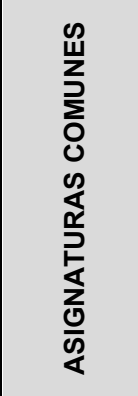 } & PRIMER CURSO & SEGUNDO CURSO & TERCER CURSO & \\
\hline & Didáctica General & Organización del Centro Escolar & Practicum & \\
\hline & $\begin{array}{l}\text { Psicología de la Educación y del Desarrollo en } \\
\text { la Edad Escolar }\end{array}$ & & Sociología de la Educación & \\
\hline & Educación especial & & $\begin{array}{l}\text { Nuevas Tecnologías aplicadas a la } \\
\text { Educación }\end{array}$ & \\
\hline & $\begin{array}{l}\text { Teorías y instituciones contemporáneas de } \\
\text { educación }\end{array}$ & & & \\
\hline & Bases Psicológicas de la Educación Especial & & & \\
\hline \multirow{4}{*}{ 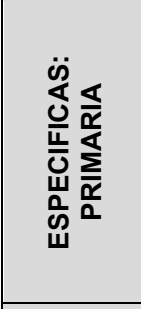 } & PRIMER CURSO & SEGUNDO CURSO & TERCER CURSO & OPTATIVAS \\
\hline & Lengua y literatura española y su didáctica & Matemáticas y su didáctica & Lengua francesa/inglesa y su didáctica & \\
\hline & Ciencias de la naturaleza y su didáctica & Ciencias Sociales y su Didáctica & Educación física y su didáctica & \\
\hline & Educación plástica y su didáctica & Lengua y Literatura catalana y su didáctica I & Educación musical y su didáctica & $\begin{array}{l}\text { Tratamiento de los Trastornos de Lecto- } \\
\text { escritura }\end{array}$ \\
\hline \multirow{5}{*}{ 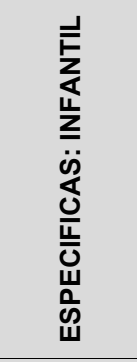 } & PRIMER CURSO & SEGUNDO CURSO & TERCER CURSO & OPTATIVAS \\
\hline & Desarrollo Psicomotor & $\begin{array}{l}\text { Desarrollo de habilidades lingüísticas y su } \\
\text { didáctica : español }\end{array}$ & Literatura Infantil & \\
\hline & $\begin{array}{l}\text { Desarrollo del Pensamiento Matemático y su } \\
\text { Didáctica }\end{array}$ & $\begin{array}{l}\text { Desarrollo Habilidades Lingüísticas y su } \\
\text { didáctica: catalán }\end{array}$ & $\begin{array}{l}\text { Conocimiento del medio natural, social y } \\
\text { cultural }\end{array}$ & \\
\hline & $\begin{array}{l}\text { Desarrollo de la Educación musical y su } \\
\text { didáctica }\end{array}$ & & & \\
\hline & $\begin{array}{l}\text { Desarrollo de la Expresión Plástica y su } \\
\text { Didáctica }\end{array}$ & & & $\begin{array}{l}\text { Tratamiento de los Trastornos de Lecto- } \\
\text { escritura }\end{array}$ \\
\hline \multirow{3}{*}{ 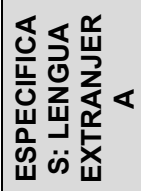 } & PRIMER CURSO & SEGUNDO CURSO & TERCER CURSO & OPTATIVAS $6 \mathrm{Cr}$. \\
\hline & Lengua y Literatura Española y su Didáctica & $\begin{array}{l}\text { Lengua Extranjera y su Didáctica II - Ingles } \\
\text { o Francés }\end{array}$ & $\begin{array}{l}\text { Conocimiento del medio natural, social y } \\
\text { cultural }\end{array}$ & $\begin{array}{l}\text { Adquisición y Aprendizaje de Lengua } \\
\text { Extranjera }\end{array}$ \\
\hline & Fonética - Ingles o Francés & Lingüística & Educación Musical y su Didáctica & Cultura francesa y su Didáctica \\
\hline
\end{tabular}

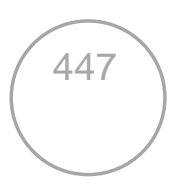


La Educación Artística en los planes de estudio de Magisterio de la Comunitat Valenciana. Visión para el siglo XXI

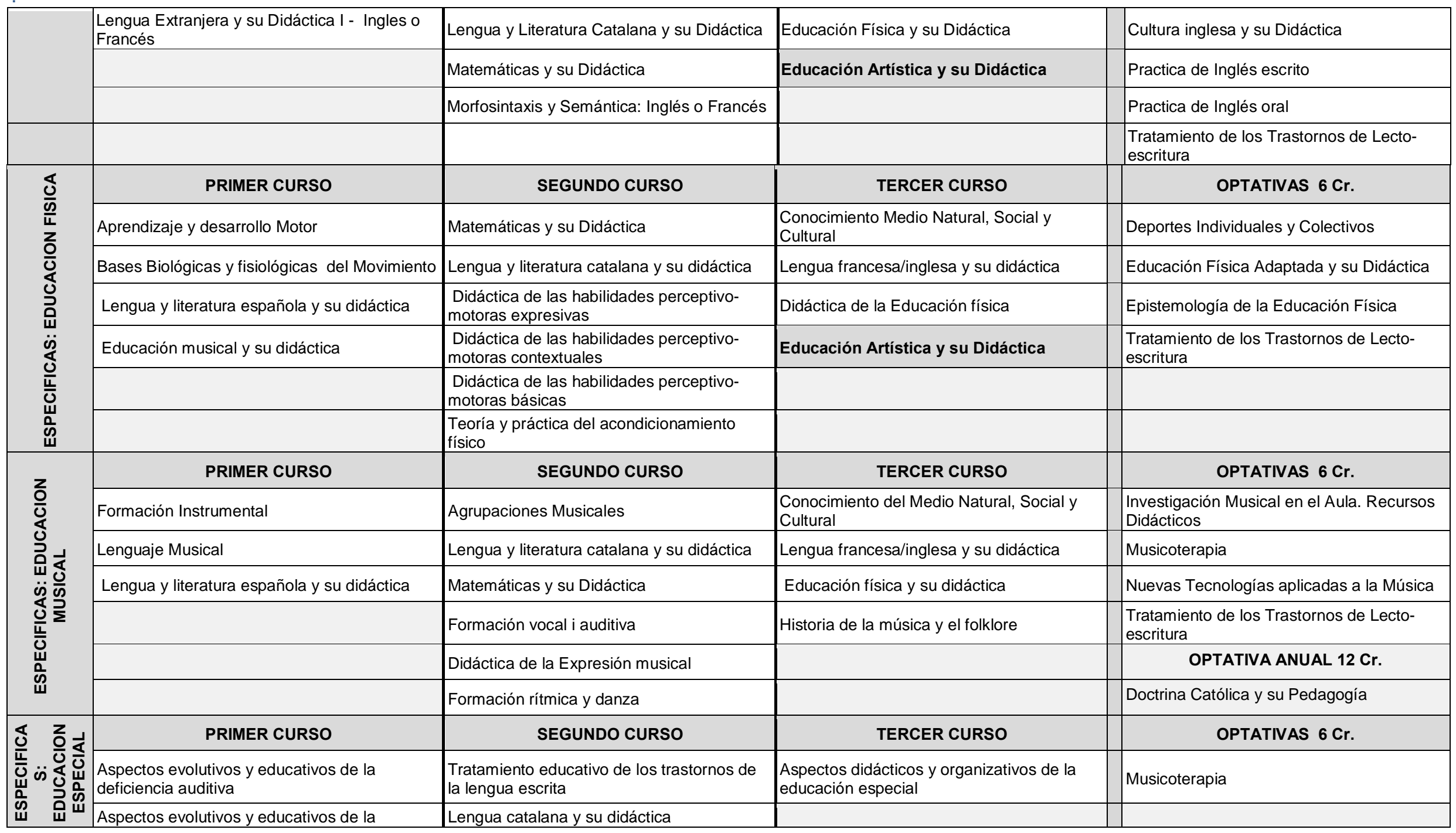

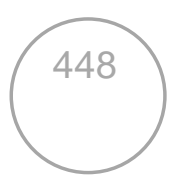




\begin{tabular}{|c|c|c|c|c|}
\hline & deficiencia motora & & & \\
\hline & $\begin{array}{l}\text { Aspectos evolutivos y educativos de la } \\
\text { deficiencia visual }\end{array}$ & Expresión plástica & & \\
\hline & Lengua y literatura española y su didáctica & Expresión musical & & \\
\hline & $\begin{array}{l}\text { Iniciación a la aritmética y a la geometría y sus } \\
\text { didácticas }\end{array}$ & $\begin{array}{l}\text { Aspectos evolutivos y educativos de la } \\
\text { deficiencia mental }\end{array}$ & & \\
\hline & & $\begin{array}{l}\text { Educación física en alumnos con } \\
\text { necesidades educativas especiales }\end{array}$ & & \\
\hline & & Trastornos de conducta y personalidad & & \\
\hline \multirow{6}{*}{ 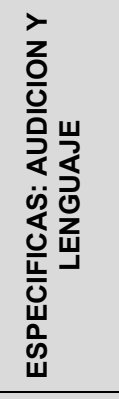 } & PRIMER CURSO & SEGUNDO CURSO & TERCER CURSO & OPTATIVAS \\
\hline & Psicopatología de la audición y del lenguaje & $\begin{array}{l}\text { Desarrollo de habilidades lingüísticas } \\
\text { (español) }\end{array}$ & Música y trastornos de audición y lenguaje & \\
\hline & Anatomía, fisiología y neurología del lenguaje & Lingüística & Sistemas alternativos de comunicación & \\
\hline & Desarrollo de habilidades lingüísticas (catalán) & $\begin{array}{l}\text { Tratamiento educativo de los trastornos de } \\
\text { la lengua oral y escrita }\end{array}$ & Lenguaje plástico y su didáctica & \\
\hline & & $\begin{array}{l}\text { Aspectos evolutivos del pensamiento y el } \\
\text { lenguaje }\end{array}$ & & \\
\hline & & $\begin{array}{l}\text { Tratamiento educativo de los trastornos de } \\
\text { la audición y del lenguaje }\end{array}$ & & \\
\hline \multirow{8}{*}{ 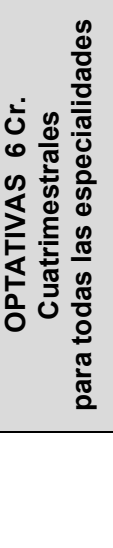 } & Análisis y Producción de Textos en Catalán & Ciencia para no Científicos & Laboratorio escolar de Matemáticas & Lengua Española Aplicada \\
\hline & $\begin{array}{l}\text { Desarrollo Curricular y Organización de la Ed. } \\
\text { Infantil }\end{array}$ & Educación Ambiental & $\begin{array}{l}\text { Literatura de Transmisión Oral y Lenguaje } \\
\text { Literario }\end{array}$ & Lenguaje Oral y Escrito y su Didáctica \\
\hline & $\begin{array}{l}\text { Resolución de Problemas y Heurística } \\
\text { Matemática }\end{array}$ & Educación para la Salud & Literatura Catalana & Filosofía de la Cultura \\
\hline & $\begin{array}{l}\text { Enseñanza de las Matemáticas en entornos } \\
\text { informáticos }\end{array}$ & Francés & Percepción y Análisis de la imagen & Pedagogía de los Valores y las Actitudes \\
\hline & Enseñanza de las Lenguas en Contacto & Educación Vial & Técnicas Audiovisuales & Geografía Regional \\
\hline & $\begin{array}{l}\text { Tratamiento de la información educativa: } \\
\text { introducción a aplicaciones informáticas en } \\
\text { educación. }\end{array}$ & $\begin{array}{l}\text { Materiales Curriculares para Conocimiento } \\
\text { del Medio Social }\end{array}$ & Técnicas Plásticas en el Marco Escolar & $\begin{array}{l}\text { Sociología de Género: Taller de } \\
\text { coeducación }\end{array}$ \\
\hline & Historia Moderna y Contemporánea & Historia Antigua y Medieval & Historia de la Escuela & Psicología del Desarrollo Infantil \\
\hline & Historia del País Valencia & Sociología de la Familia & & \\
\hline
\end{tabular}

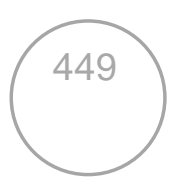




\begin{tabular}{|c|c|c|c|c|c|c|c|c|}
\hline \multicolumn{8}{|c|}{2007 GRADO ESPECIALIDAD: INFANTIL } & \\
\hline $\begin{array}{l}\text { PRIMER CURSO } \\
\text { ( } 8 \text { básicas }+2 \text { obl.) }\end{array}$ & $\mathrm{Cr}$ & $\begin{array}{l}\text { SEGUNDO CURSO } \\
\text { ( } 6 \text { básicas }+3 \text { obl.) }\end{array}$ & $\mathrm{Cr}$ & $\begin{array}{c}\text { TERCER CURSO } \\
\text { (3 básicas }+5 \text { obl.+1 op.) }\end{array}$ & $\mathrm{Cr}$ & $\begin{array}{l}\text { CUARTO CURSO } \\
\text { (1 básica+ } 6 \text { obl.+1 op.) }\end{array}$ & $\mathrm{Cr}$ & \\
\hline \multicolumn{2}{|l|}{ BÁSICAS } & \multicolumn{2}{|l|}{ BÁSICAS } & \multicolumn{2}{|l|}{ BÁSICAS } & BÁSICAS & & \\
\hline Didáctica general & 6 & Historia de la Escuela & 6 & \begin{tabular}{|l|} 
Estimulación e intervención temprana: \\
Música, Grafismo y movimiento
\end{tabular} & 6 & Dificultades en el Lenguaje Oral y Escrito & 4,5 & \\
\hline Estructura social y Educación & 6 & Necesidades Educativas Especiales & 6 & La Escuela en Ed. Infantil & 4,5 & \multicolumn{2}{|l|}{ OBLIGATORIAS } & \\
\hline Lengua catalana para maestros & 6 & Sociología de la Educación & 6 & Taller del juego en Ed. Infantil & 4,5 & $\begin{array}{l}\text { Didáctica de las Ciencias Naturales en } \\
\text { Ed. Infantil }\end{array}$ & 6 & \\
\hline Lengua española para maestros & 6 & $\begin{array}{l}\text { Adquisición y Desarrollo del Lenguaje } \\
\text { Oral }\end{array}$ & 4,5 & \multicolumn{2}{|l|}{ OBLIGATORIAS } & $\begin{array}{l}\text { Didáctica de las Ciencias Sociales en Ed. } \\
\text { Infantil }\end{array}$ & 6 & \\
\hline $\begin{array}{l}\text { Organización y Dirección de } \\
\text { Centros }\end{array}$ & 6 & $\begin{array}{l}\text { Observación e Innovación sobre la } \\
\text { práctica en el aula de Ed. Infantil }\end{array}$ & 6 & $\begin{array}{l}\text { Didáctica de la Educación Física en } \\
\text { Ed. Infantil }\end{array}$ & 6 & $\begin{array}{l}\text { Didáctica de las Matemáticas en Ed. } \\
\text { Infantil }\end{array}$ & 6 & \\
\hline Psicología de la Educación & 6 & $\begin{array}{l}\text { Organización del Espacio Escolar, } \\
\text { Materiales y Habilidades Docentes }\end{array}$ & 9 & Iniciación a la Lectura y Escritura & 4,5 & $\begin{array}{l}\text { La planificación de la Lengua y la } \\
\text { Literatura en la Ed. Infantil }\end{array}$ & 4,5 & \\
\hline Psicología del Desarrollo & 6 & \multicolumn{2}{|l|}{ OBLIGATORIAS } & Procesos Musicales en Ed. Infantil & 6 & Prácticas Escolares III & 21 & \\
\hline Infancia, Salud y Alimentación & 4,5 & Ciencias Naturales para Maestros & 9 & $\begin{array}{l}\text { Didáctica de la Educación Plástica y } \\
\text { Visual en la Ed. Infantil }\end{array}$ & 6 & Trabajo Fin de Grado & 6 & \\
\hline \multicolumn{2}{|l|}{ OBLIGATORIAS } & Formación literaria el aula de Ed. Infantil & 4,5 & Prácticas Escolares II & 16,5 & OPTATIVA & 6 & \\
\hline $\begin{array}{l}\text { Lengua Extranjera para maestros: } \\
\text { Francés o Inglés }\end{array}$ & 6 & Matemáticas para Maestros & 9 & OPTATIVA & 6 & & & \\
\hline \multirow[t]{6}{*}{ Prácticas Escolares I } & 7,5 & & & & & & & \\
\hline & 60 & & 60 & & 60 & & 60 & 240 \\
\hline & & & & OPTATIVA (6 créditos) & $3^{\circ}$ & OPTATIVAS (6 créditos) & $4^{\circ}$ & \\
\hline & & & & & & $\begin{array}{l}\text { Taller multidisciplinar del área de } \\
\text { Conocimiento de sí mismo y Autonomía } \\
\text { Personal }\end{array}$ & 6 & \\
\hline & & & & \begin{tabular}{|l|}
$\begin{array}{l}\text { Taller Multidisciplinar de Proyectos } \\
\text { de Expresión Musical, Plástica y } \\
\text { Corporal }\end{array}$ \\
\end{tabular} & 6 & $\begin{array}{l}\text { Taller multidisciplinar del área de los } \\
\text { Lenguajes: Comunicación y } \\
\text { Representación }\end{array}$ & 6 & \\
\hline & & & & & & $\begin{array}{l}\text { Taller multidisciplinar del área del Mundo } \\
\text { Físico, Natural, Social y Cultural }\end{array}$ & 6 & \\
\hline
\end{tabular}

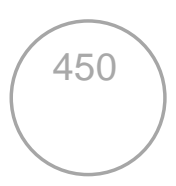




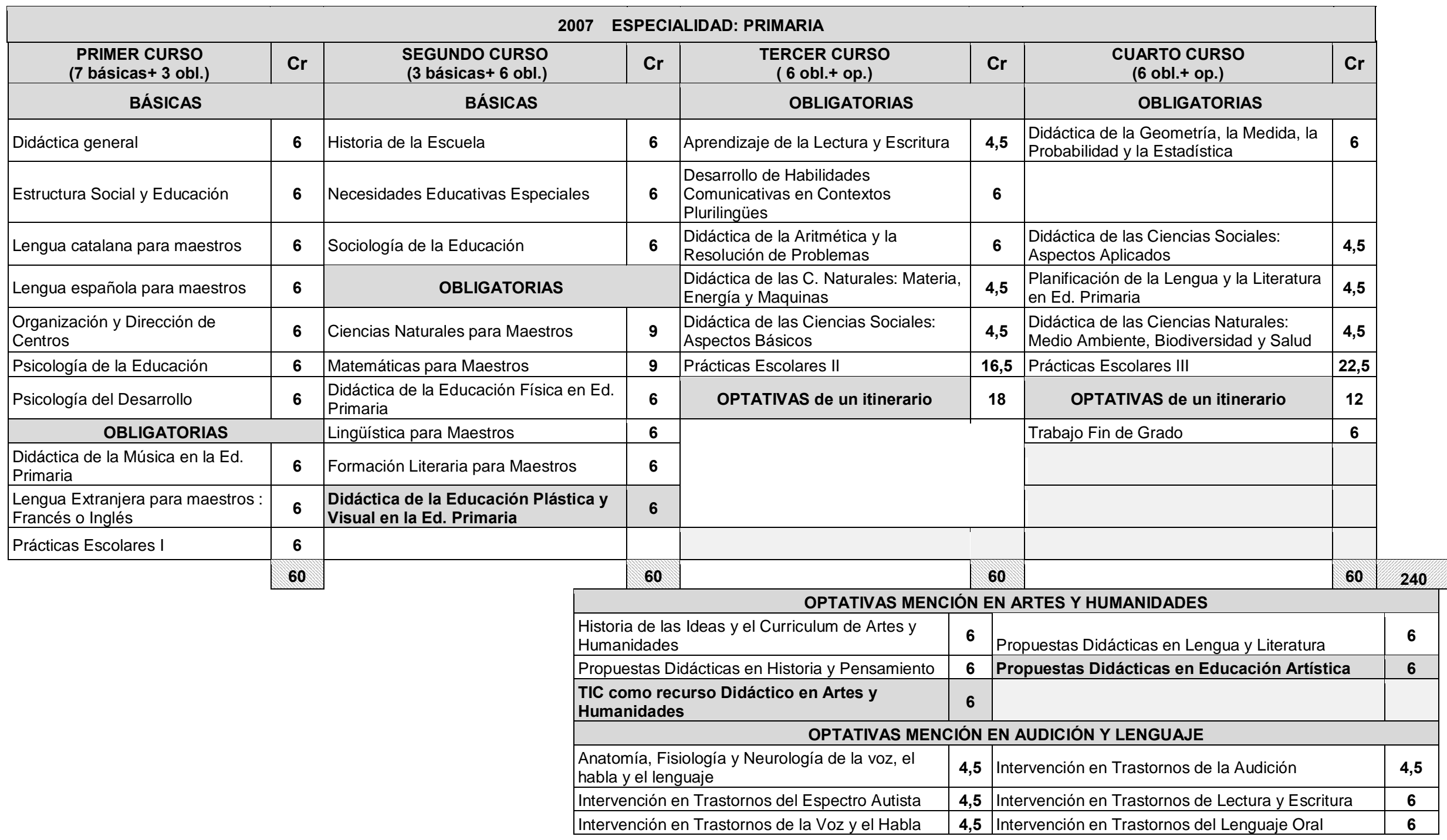

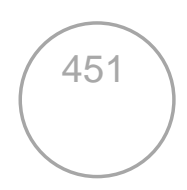




\section{OPTATIVAS MENCIÓN EN CIENCIAS Y MATEMATICAS}

\begin{tabular}{|c|c|c|c|}
\hline $\begin{array}{l}\text { Historia de las Ideas y el Curriculum de Ciencias y } \\
\text { Matemáticas }\end{array}$ & 6 & Propuestas Didácticas en Ciencias & 6 \\
\hline TIC, recurso Didáctico en Ciencias y Matemáticas & 6 & Prop. Didácticas con Ciencias y Matemáticas & 6 \\
\hline Propuestas Didácticas en Matemáticas & 6 & & \\
\hline \multicolumn{4}{|c|}{ OPTATIVAS MENCIÓN EN EDUCACIÓN FISICA } \\
\hline Didáctica de la Educación Física & 6 & $\begin{array}{l}\text { Didáctica de las Habilidades Perceptivo motoras y } \\
\text { Básicas }\end{array}$ & 6 \\
\hline Didáctica de la Educación Física para la Salud & 6 & Didáctica de los juegos y las activ. deportivas & 6 \\
\hline Didáctica de las Activ. Físicas Expresivas & 6 & & \\
\hline \multicolumn{4}{|c|}{ OPTATIVAS MENCIÓN EN EDUCACION MUSICAL } \\
\hline Audición Musical & 4,5 & Educación Vocal & 6 \\
\hline Didáctica Musical & 6 & Música y Movimiento & 4,5 \\
\hline Educación Instrumental & 4,5 & $\begin{array}{l}\text { Música y Tecnologías de la Información y la } \\
\text { Comunicación }\end{array}$ & 4,5 \\
\hline \multicolumn{4}{|c|}{ OPTATIVAS MENCIÓN EN LENGUA EXTRANJERA (INGLÉS O FRANCÉS) } \\
\hline Didáctica de la Lengua Extranjera I & 6 & Lengua Extranjera I & 6 \\
\hline Didáctica de la Lengua Extranjera II & 6 & Lengua Extranjera II & 6 \\
\hline $\begin{array}{l}\text { La Cultura en la Enseñanza de Lenguas } \\
\text { Extranjeras }\end{array}$ & 6 & & \\
\hline \multicolumn{4}{|c|}{ OPTATIVAS MENCIÓN EN PEDAGOGÍA TERAPEUTICA } \\
\hline Autorregulación y Problemas de Conducta & 4,5 & $\begin{array}{l}\text { Intervención en problemas del Lenguaje Oral y } \\
\text { Escrito }\end{array}$ & 6 \\
\hline Intervención en Discapacidad Intelectual & 4,5 & Intervención en Trast. del Espectro Autista & 4,5 \\
\hline $\begin{array}{l}\text { Intervención en Discapacidades sensoriales y } \\
\text { motrices }\end{array}$ & 4,5 & $\begin{array}{l}\text { La Educación Física, Plástica y Musical y su } \\
\text { Didáctica en las necesidades Educativas Especiales }\end{array}$ & 6 \\
\hline \multicolumn{4}{|c|}{ OPTATIVAS MENCIÓN EN TECNOLOGÍAS DE LA INFORMACIÓN Y COMUNICACIÓN } \\
\hline Diseño de Materiales Educativos & 6 & TIC, Recurso Didáctico en Artes y Humanidades & 6 \\
\hline $\begin{array}{l}\text { Programación y Maquina en Contextos } \\
\text { Educativos }\end{array}$ & 6 & TIC, Recurso Didáctico en Ciencias y Matemáticas & 6 \\
\hline Educación y TIC & 6 & & \\
\hline
\end{tabular}

Educación y TIC

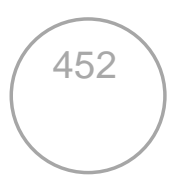


ANEXO V - Analisis de los datos.

\section{Alicante}

Plan 1992

\section{ESPECIALIDADES}

\begin{tabular}{|c|c|c|c|c|c|c|c|}
\hline & Plan 1992 & & & ;PECIALIDA & DES & & \\
\hline curso & Bloque Académico & PRIMARIA & INFANTIL & $\begin{array}{c}\text { LENGUAS } \\
\text { EXTRANJERAS }\end{array}$ & $\begin{array}{l}\text { EDUCACIÓN } \\
\text { FÍSICA }\end{array}$ & $\begin{array}{l}\text { EDUCACIÓN } \\
\text { MUSICAL }\end{array}$ & Valor medio \\
\hline \multirow{6}{*}{ Primero } & Ciencias & 14 & 8 & & & & 4,4 \\
\hline & Letras & 10 & 4 & 28 & 4 & 4 & 10 \\
\hline & Profesional & 24 & 30 & 24 & 24 & 24 & 25,2 \\
\hline & Otras+Específicas & 12 & 12 & 12 & 32 & 32 & 20 \\
\hline & Educación Artística & 0 & 6 & & & & 1,2 \\
\hline & Libre Configuración & 7 & 7 & 7 & 7 & 7 & 7 \\
\hline & Total & 67 & 67 & 71 & 67 & 67 & 67,8 \\
\hline \multirow{7}{*}{ Segundo } & Ciencias & 8 & 4 & 4 & 4 & 4 & 4,8 \\
\hline & Letras & 12 & 10 & 16 & 4 & 4 & 9,2 \\
\hline & Profesional & 20 & 24 & 20 & 20 & 20 & 20,8 \\
\hline & Otras+Específicas & 20 & 26 & 16 & 26 & 36 & 24,8 \\
\hline & Educación Artística & 4 & & 4 & 4 & & 2,4 \\
\hline & Libre Configuración & 7 & 7 & 7 & 7 & 7 & 7 \\
\hline & Total & 71 & 71 & 67 & 65 & 71 & 69 \\
\hline \multirow{7}{*}{ Tercero } & Ciencias & & & & & & 0 \\
\hline & Letras & 10 & 10 & 22 & 10 & 10 & 12,4 \\
\hline & Profesional & 32 & 36 & 32 & 32 & 32 & 32,8 \\
\hline & Otras+Específicas & 12 & 12 & 4 & 18 & 16 & 12,4 \\
\hline & Educación Artística & 6 & & & & & 1,2 \\
\hline & Libre Configuración & 7 & 7 & 7 & 7 & 7 & 7 \\
\hline & Total & 67 & 65 & 65 & 67 & 65 & 65,8 \\
\hline
\end{tabular}


La Educación Artística en los planes de estudio de Magisterio de la Comunitat Valenciana. Visión para el siglo XXI

\begin{tabular}{|c|c|c|c|c|c|c|c|}
\hline MÍNIMOS & Bloque Académico & PRIMARIA & INFANTIL & \begin{tabular}{|c|} 
LENGUAS \\
EXTRANJERAS
\end{tabular} & $\begin{array}{c}\text { EDUCACIÓN } \\
\text { FÍSICA }\end{array}$ & $\begin{array}{c}\text { EDUCACIÓN } \\
\text { MUSICAL }\end{array}$ & Valor medio \\
\hline \multirow{7}{*}{ Totales } & Ciencias & 22 & 12 & 4 & 4 & 4 & 9,2 \\
\hline & Letras & 32 & 24 & 66 & 18 & 18 & 31,6 \\
\hline & Profesional & 76 & 90 & 76 & 76 & 76 & 78,8 \\
\hline & Otras+Específicas & 44 & 50 & 32 & 76 & 84 & 57,2 \\
\hline & Educación Artística & 10 & 6 & 4 & 4 & 0 & 4,8 \\
\hline & Libre Configuración & 21 & 21 & 21 & 21 & 21 & 21 \\
\hline & Total & 205 & 203 & 203 & 199 & 203 & 202,6 \\
\hline MÁXIMOS & Bloque Académico & PRIMARIA & INFANTIL & $\begin{array}{c}\text { LENGUAS } \\
\text { EXTRANJERAS } \\
\end{array}$ & $\begin{array}{c}\text { EDUCACIÓN } \\
\text { FÍSICA } \\
\end{array}$ & $\begin{array}{c}\text { EDUCACIÓN } \\
\text { MUSICAL }\end{array}$ & Valor medio \\
\hline \multirow{7}{*}{ Totales } & Ciencias & 22 & 12 & 4 & 4 & 4 & 9,2 \\
\hline & Letras & 32 & 24 & 66 & 18 & 18 & 31,6 \\
\hline & Profesional & 76 & 90 & 76 & 76 & 76 & 78,8 \\
\hline & Otras+Específicas & 32 & 38 & 20 & 64 & 72 & 45,2 \\
\hline & Educación Artística & 22 & 18 & 16 & 16 & 12 & 16,8 \\
\hline & Libre Configuración & 21 & 21 & 21 & 21 & 21 & 21 \\
\hline & Total & 205 & 203 & 203 & 199 & 203 & 202,6 \\
\hline
\end{tabular}


Plan 1996

\begin{tabular}{|c|c|c|c|c|c|c|c|}
\hline & Plan 1996 & & & ESPECIALIDA & DES & & \\
\hline curso & Bloque Académico & PRIMARIA & INFANTIL & $\begin{array}{c}\text { LENGUAS } \\
\text { EXTRANJERAS }\end{array}$ & $\begin{array}{l}\text { EDUCACIÓN } \\
\text { FÍSICA }\end{array}$ & $\begin{array}{l}\text { EDUCACIÓN } \\
\text { MUSICAL }\end{array}$ & Valor medio \\
\hline \multirow{7}{*}{ Primero } & Ciencias & 18 & 15 & & & & 6,6 \\
\hline & Letras & 21 & 12 & 43,5 & 18 & 10,5 & 21 \\
\hline & Profesional & 27 & 27 & 22,5 & 22,5 & 27 & 25,2 \\
\hline & Otras+Específicas & 12 & 15 & 0 & 27 & 27 & 16,2 \\
\hline & Educación Artística & 4,5 & 6 & 6 & 4,5 & 6 & 5,4 \\
\hline & Libre Configuración & 0 & 0 & 0 & 0 & 0 & 0 \\
\hline & Total & 82,5 & 75 & 72 & 72 & 70,5 & 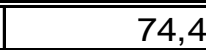 \\
\hline \multirow{7}{*}{ Segundo } & Ciencias & 6 & 0 & 4,5 & 4,5 & 4,5 & 3,9 \\
\hline & Letras & 21 & 22,5 & 24 & 15 & 10,5 & 18,6 \\
\hline & Profesional & 22,5 & 27 & 22,5 & 22,5 & 22,5 & 23,4 \\
\hline & Otras+Específicas & 9 & 10,5 & 9 & 19,5 & 31,5 & 15,9 \\
\hline & Educación Artística & 4,5 & 4,5 & 4,5 & 4,5 & 0 & 3,6 \\
\hline & Libre Configuración & 4,5 & 4,5 & 4,5 & 4,5 & 4,5 & 4,5 \\
\hline & Total & 67,5 & 69 & 69 & 70,5 & 73,5 & 69,9 \\
\hline \multirow{7}{*}{ Tercero } & Ciencias & 6 & 6 & 0 & & & 2,4 \\
\hline & Letras & 6 & 0 & 10,5 & 0 & 0 & 3,3 \\
\hline & Profesional & 32 & 38 & 32 & 32 & 32 & 33,2 \\
\hline & Otras+Específicas & 4,5 & 4,5 & 4,5 & 16,5 & 10,5 & 8,1 \\
\hline & Educación Artística & 0 & 0 & & 0 & 6 & 1,2 \\
\hline & Libre Configuración & 16,5 & 16,5 & 16,5 & 16,5 & 16,5 & 16,5 \\
\hline & Total & 65 & 65 & 63,5 & $\overline{265}$ & 65 & 64,7 \\
\hline
\end{tabular}


La Educación Artística en los planes de estudio de Magisterio de la Comunitat Valenciana. Visión para el siglo XXI

\begin{tabular}{|c|c|c|c|c|c|c|c|}
\hline MÍNIMOS & Bloque Académico & PRIMARIA & INFANTIL & \begin{tabular}{|c|} 
LENGUAS \\
EXTRANJERAS \\
\end{tabular} & $\begin{array}{c}\text { EDUCACIÓN } \\
\text { FÍSICA }\end{array}$ & $\begin{array}{c}\text { EDUCACIÓN } \\
\text { MUSICAL }\end{array}$ & Valor medio \\
\hline \multirow{7}{*}{ Totales } & Ciencias & 30 & 21 & 4,5 & 4,5 & 4,5 & 12,9 \\
\hline & Letras & 48 & 34,5 & 78 & 33 & 21 & 42,9 \\
\hline & Profesional & 81,5 & 92 & 77 & 77 & 81,5 & 81,8 \\
\hline & Otras+Específicas & 25,5 & 30 & 13,5 & 63 & 69 & 40,2 \\
\hline & Educación Artística & 9 & 10,5 & 10,5 & 9 & 12 & 10,2 \\
\hline & Libre Configuración & 21 & 21 & 21 & 21 & 21 & 21 \\
\hline & Total & 215 & 209 & 204,5 & 207,5 & 209 & 209 \\
\hline MÁXIMOS & Bloque Académico & PRIMARIA & INFANTIL & \begin{tabular}{|c|} 
LENGUAS \\
EXTRANJERAS
\end{tabular} & $\begin{array}{c}\text { EDUCACIÓN } \\
\text { FÍSICA }\end{array}$ & $\begin{array}{c}\text { EDUCACIÓN } \\
\text { MUSICAL }\end{array}$ & Valor medio \\
\hline \multirow{7}{*}{ Totales } & Ciencias & 30 & 21 & 4,5 & 4,5 & 4,5 & 12,9 \\
\hline & Letras & 48 & 34,5 & 78 & 33 & 21 & 42,9 \\
\hline & Profesional & 81,5 & 92 & 77 & 77 & 81,5 & 81,8 \\
\hline & Otras+Específicas & 25,5 & 30 & 9 & 63 & 64,5 & 38,4 \\
\hline & Educación Artística & 9 & 10,5 & 15 & 9 & 16,5 & 12 \\
\hline & Libre Configuración & 21 & 21 & 21 & 21 & 21 & 21 \\
\hline & Total & 215 & 209 & 204,5 & 207,5 & 209 & 209 \\
\hline
\end{tabular}




\begin{tabular}{|c|c|c|c|c|c|c|c|}
\hline \multirow[b]{2}{*}{ curso } & Plan 2000 & \multicolumn{5}{|c|}{ ESPECIALIDADES } & \multirow[b]{2}{*}{ Valor medio } \\
\hline & Bloque Académico & PRIMARIA & INFANTIL & $\begin{array}{c}\text { LENGUAS } \\
\text { EXTRANJERAS }\end{array}$ & $\begin{array}{l}\text { EDUCACIÓN } \\
\text { FÍSICA }\end{array}$ & $\begin{array}{c}\text { EDUCACIÓN } \\
\text { MUSICAL }\end{array}$ & \\
\hline \multirow{7}{*}{ Primero } & Ciencias & 18 & 6 & & & & 4,8 \\
\hline & Letras & 15 & 10,5 & 37,5 & 16,5 & 6 & 17,1 \\
\hline & Profesional & 27 & 27 & 22,5 & 22,5 & 27 & 25,2 \\
\hline & Otras+Específicas & & 10,5 & & 18 & 22,5 & 10,2 \\
\hline & Educación Artística & & 6 & & 4,5 & 6 & 3,3 \\
\hline & Libre Configuración & & 1 & & & & 0,2 \\
\hline & Total & 60 & 61 & 60 & 61,5 & 61,5 & 60,8 \\
\hline \multirow{7}{*}{ Segundo } & Ciencias & 6 & 6 & 4,5 & 4,5 & 4,5 & 5,1 \\
\hline & Letras & 15 & 16,5 & 22,5 & 21 & 10,5 & 17,1 \\
\hline & Profesional & 18 & 22,5 & 18 & 18 & 18 & 18,9 \\
\hline & Otras+Específicas & 9 & 15 & 9 & 13,5 & 22,5 & 13,8 \\
\hline & Educación Artística & 9 & & 6 & & & 3 \\
\hline & Libre Configuración & 13,5 & 13,5 & 13,5 & 13,5 & 13,5 & 13,5 \\
\hline & Total & 70,5 & 73,5 & 73,5 & 70,5 & 69 & 71,4 \\
\hline \multirow{7}{*}{ Tercero } & Ciencias & 12 & 6 & & & & 3,6 \\
\hline & Letras & 12 & 6 & 19,5 & & 10,5 & 9,6 \\
\hline & Profesional & 32 & 38 & 32 & 32 & 32 & 33,2 \\
\hline & Otras+Específicas & 9 & 9 & 9 & 30 & 18 & 15 \\
\hline & Educación Artística & & 4,5 & 4,5 & 4,5 & 6 & 3,9 \\
\hline & Libre Configuración & 7,5 & 7,5 & 7,5 & 7,5 & 7,5 & 7,5 \\
\hline & Total & 72,5 & 71 & 72,5 & 74 & 74 & 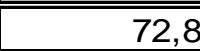 \\
\hline
\end{tabular}


La Educación Artística en los planes de estudio de Magisterio de la Comunitat Valenciana. Visión para el siglo XXI

\begin{tabular}{|c|c|c|c|c|c|c|c|}
\hline MÍNIMOS & Bloque Académico & PRIMARIA & INFANTIL & \begin{tabular}{|c|} 
LENGUAS \\
EXTRANJERAS
\end{tabular} & $\begin{array}{l}\text { EDUCACIÓN } \\
\text { FÍSICA }\end{array}$ & $\begin{array}{c}\text { EDUCACIÓN } \\
\text { MUSICAL }\end{array}$ & Valor medio \\
\hline \multirow{7}{*}{ Totales } & Ciencias & 36 & 18 & 4,5 & 4,5 & 4,5 & 13,5 \\
\hline & Letras & 42 & 33 & 79,5 & 37,5 & 27 & 43,8 \\
\hline & Profesional & 77 & 87,5 & 72,5 & 72,5 & 77 & 77,3 \\
\hline & Otras+Específicas & 18 & 34,5 & 18 & 61,5 & 63 & 39 \\
\hline & Educación Artística & 9 & 10,5 & 10,5 & 9 & 12 & 10,2 \\
\hline & Libre Configuración & 21 & 22 & 21 & 21 & 21 & 21,2 \\
\hline & Total & 203 & 205,5 & 206 & 206 & 204,5 & 205 \\
\hline MÁXIMOS & Bloque Académico & PRIMARIA & INFANTIL & \begin{tabular}{|c|} 
LENGUAS \\
EXTRANJERAS
\end{tabular} & $\begin{array}{l}\text { EDUCACIÓN } \\
\text { FÍSICA }\end{array}$ & $\begin{array}{c}\text { EDUCACIÓN } \\
\text { MUSICAL }\end{array}$ & Valor medio \\
\hline \multirow{7}{*}{ Totales } & Ciencias & 36 & 18 & 4,5 & 4,5 & 4,5 & 13,5 \\
\hline & Letras & 42 & 33 & 79,5 & 37,5 & 27 & 43,8 \\
\hline & Profesional & 77 & 87,5 & 72,5 & 72,5 & 77 & 77,3 \\
\hline & Otras+Específicas & 18 & 34,5 & 10,5 & 61,5 & 58,5 & 36,6 \\
\hline & Educación Artística & 9 & 10,5 & 18 & 9 & 16,5 & 12,6 \\
\hline & Libre Configuración & 21 & 22 & 21 & 21 & 21 & 21,2 \\
\hline & Total & 203 & 205,5 & 206 & 206 & 204,5 & 205 \\
\hline
\end{tabular}




\begin{tabular}{|c|c|c|c|c|c|}
\hline & & Mínimos & & Máximos & \\
\hline & & \multicolumn{2}{|c|}{ Grado } & & \\
\hline curso & Bloque Académico & Infantil & Primaria & Infantil & Primaria \\
\hline \multirow{6}{*}{ Primero } & Ciencias & & 6 & & 6 \\
\hline & Letras & 18 & 18 & 18 & 18 \\
\hline & Profesional & 36 & 36 & 36 & 36 \\
\hline & Otras & & & & \\
\hline & Educación Artística & 6 & & 6 & \\
\hline & Total & 60 & 60 & 60 & 60 \\
\hline \multirow{6}{*}{ Segundo } & Ciencias & 12 & 12 & 12 & 12 \\
\hline & Letras & 24 & 12 & 24 & 12 \\
\hline & Profesional & 24 & 24 & 24 & 24 \\
\hline & Otras & & 12 & & 12 \\
\hline & Educación Artística & & & & \\
\hline & Total & 60 & 60 & 60 & 60 \\
\hline \multirow{6}{*}{ Tercero } & Ciencias & 6 & 12 & 6 & 12 \\
\hline & Letras & & 18 & & 18 \\
\hline & Profesional & 36 & 18 & 36 & 18 \\
\hline & Otras & 18 & 12 & 18 & 12 \\
\hline & Educación Artística & & & & \\
\hline & Total & 60 & 60 & 60 & 60 \\
\hline \multirow{6}{*}{ Cuarto } & Ciencias & & & & \\
\hline & Letras & & 6 & & 6 \\
\hline & Profesional & 42 & 36 & 42 & 36 \\
\hline & Otras & 12 & 12 & 12 & 12 \\
\hline & Educación Artística & 6 & 6 & 6 & 6 \\
\hline & Total & 60 & 60 & 60 & 60 \\
\hline
\end{tabular}


La Educación Artística en los planes de estudio de Magisterio de la Comunitat Valenciana. Visión para el siglo XX

\begin{tabular}{|r|l|r|r|r|r|}
\hline \multicolumn{1}{c|}{} & Bloque Académico & \multicolumn{1}{|c|}{ INF m } & PRI m & \multicolumn{1}{|c|}{ INF M } & PRI M \\
\hline \multirow{5}{*}{ Totales } & Ciencias & 18 & 30 & 18 & 30 \\
\cline { 2 - 7 } & Letras & 42 & 54 & 42 & 54 \\
\cline { 2 - 6 } & Profesional & 138 & 114 & 138 & 114 \\
\cline { 2 - 6 } & Otras+Específicas & 30 & 36 & 30 & 36 \\
\cline { 2 - 6 } & Educación Artística & 12 & 6 & 12 & 6 \\
\hline & Total & 240 & 240 & 240 & 240 \\
\hline
\end{tabular}




\section{Castellón}

\begin{tabular}{|c|c|c|c|c|c|c|c|}
\hline \multirow[b]{2}{*}{ curso } & \multirow{2}{*}{\begin{tabular}{|l|} 
Plan 1992 \\
Bloque Académico
\end{tabular}} & \multicolumn{5}{|c|}{ ESPECIALIDADES } & \multirow[b]{2}{*}{ Valor medic } \\
\hline & & PRIMARIA & INFANTIL & $\begin{array}{c}\text { LENGUAS } \\
\text { EXTRANJERAS }\end{array}$ & $\begin{array}{l}\text { EDUCACIÓN } \\
\text { FÍSICA }\end{array}$ & $\begin{array}{l}\text { EDUCACIÓN } \\
\text { MUSICAL }\end{array}$ & \\
\hline \multirow{7}{*}{ Primero } & Ciencias & 4 & & & & & 1 \\
\hline & Letras & 17 & 11 & & 11 & 11 & 12,5 \\
\hline & Profesional & 28 & 26 & & 24 & 24 & 25,5 \\
\hline & Otras+Específicas & 13 & 25 & & 33 & 33 & 26 \\
\hline & Educación Artística & 4 & 6 & & & & 2,5 \\
\hline & Libre Configuración & 6 & 6 & & 6 & 6 & 6 \\
\hline & Total & 72 & 74 & 0 & 74 & 74 & 73,5 \\
\hline \multirow{7}{*}{ Segundo } & Ciencias & 16 & 10 & & 12 & 12 & 12,5 \\
\hline & Letras & 19 & 15 & & 7 & 7 & 12 \\
\hline & Profesional & 26 & 22 & & 22 & 22 & 23 \\
\hline & Otras+Específicas & 8 & 20 & & 30 & 28 & 21,5 \\
\hline & Educación Artística & & 0 & & & & 0 \\
\hline & Libre Configuración & 6 & 6 & & 6 & 6 & 6 \\
\hline & Total & 75 & 73 & 0 & 77 & 75 & 75 \\
\hline \multirow{7}{*}{ Tercero } & Ciencias & 4 & 4 & & & & 2 \\
\hline & Letras & 6 & 4 & & 8 & 8 & 6,5 \\
\hline & Profesional & 28 & 32 & & 28 & 28 & 29 \\
\hline & Otras+Específicas & 20 & 18 & & 26 & 26 & 22,5 \\
\hline & Educación Artística & 4 & 4 & & 4 & 4 & 4 \\
\hline & Libre Configuración & 10 & 10 & & 11 & 11 & 10,5 \\
\hline & Total & 72 & 72 & 0 & 77 & 77 & 74,5 \\
\hline
\end{tabular}


La Educación Artística en los planes de estudio de Magisterio de la Comunitat Valenciana. Visión para el siglo XXI

\begin{tabular}{|c|c|c|c|c|c|c|c|c|}
\hline & Bloque Académico & PRIMARIA & INFANTIL & $\begin{array}{c}\text { LENGUAS } \\
\text { EXTRANJERAS }\end{array}$ & $\begin{array}{l}\text { EDUCACIÓN } \\
\text { FÍSICA }\end{array}$ & $\begin{array}{c}\text { EDUCACIÓN } \\
\text { MUSICAL }\end{array}$ & $\begin{array}{c}\text { Valor medio } \\
\text { mínimos }\end{array}$ & $\begin{array}{c}\text { Valor medio } \\
\text { Máximos }\end{array}$ \\
\hline \multirow{7}{*}{ Totales } & Ciencias & 24 & 14 & 0 & 12 & 12 & 15,5 & 15,5 \\
\hline & Letras & 42 & 30 & 0 & 26 & 26 & 31 & 31 \\
\hline & Profesional & 82 & 80 & 0 & 74 & 74 & 77,5 & 77,5 \\
\hline & Otras+Específicas & 41 & 63 & & 89 & 87 & 70 & 67 \\
\hline & Educación Artística & 8 & 10 & & 4 & 4 & 6,5 & 9,5 \\
\hline & Libre Configuración & 22 & 22 & 0 & 23 & 23 & 22,5 & 22,5 \\
\hline & Total & 219 & 219 & 0 & 228 & 226 & 223 & 224 \\
\hline
\end{tabular}




\begin{tabular}{|c|c|c|c|c|c|}
\hline \multirow[b]{3}{*}{ curso } & \multirow[b]{3}{*}{ Bloque Académico } & Mínimos & & \multirow{3}{*}{$\begin{array}{l}\text { Máximos } \\
\text { Infantil } \\
\end{array}$} & \multirow[b]{3}{*}{ Primaria } \\
\hline & & \multicolumn{2}{|c|}{ Grado } & & \\
\hline & & Infantil & Primaria & & \\
\hline \multirow{6}{*}{ Primero } & Ciencias & & 6 & & 6 \\
\hline & Letras & 12 & 18 & 12 & 18 \\
\hline & Profesional & 48 & 30 & 48 & 30 \\
\hline & Otras & & 6 & & 6 \\
\hline & Educación Artística & & & & \\
\hline & Total & 60 & 60 & 60 & $\overline{660}$ \\
\hline \multirow{6}{*}{ Segundo } & Ciencias & 14 & 18 & 14 & 18 \\
\hline & Letras & 18 & 6 & 18 & 6 \\
\hline & \begin{tabular}{|l|} 
Profesional \\
\end{tabular} & 22 & 30 & 22 & 30 \\
\hline & Otras & 6 & 6 & 6 & 6 \\
\hline & Educación Artística & & & & \\
\hline & Total & 60 & 60 & 60 & 60 \\
\hline \multirow{6}{*}{ Tercero } & Ciencias & & 6 & & 6 \\
\hline & Letras & 6 & 18 & 6 & 18 \\
\hline & Profesional & 32 & 18 & 32 & 18 \\
\hline & Otras & 14 & 12 & 8 & 6 \\
\hline & Educación Artística & 8 & 6 & 14 & 12 \\
\hline & Total & 60 & 60 & 60 & 60 \\
\hline \multirow{6}{*}{ Cuarto } & Ciencias & 6 & 6 & 6 & 6 \\
\hline & Letras & & & & \\
\hline & Profesional & 48 & 40 & 48 & 40 \\
\hline & Otras & 6 & 6 & 6 & 6 \\
\hline & Educación Artística & & 8 & & 8 \\
\hline & Total & 60 & 60 & 60 & 60 \\
\hline
\end{tabular}


La Educación Artística en los planes de estudio de Magisterio de la Comunitat Valenciana. Visión para el siglo XX

\begin{tabular}{|r|l|r|r|r|r|}
\hline \multicolumn{1}{|c|}{} & Bloque Académico & \multicolumn{1}{|c|}{ INF m } & \multicolumn{1}{|c|}{ PRI m } & \multicolumn{1}{c|}{ INF M } & \multicolumn{1}{c|}{ PRI M } \\
\hline \multirow{5}{*}{ Totales } & Ciencias & 20 & 36 & 20 & 36 \\
\cline { 2 - 6 } & Letras & 36 & 42 & 36 & 42 \\
\cline { 2 - 6 } & Profesional & 150 & 118 & 150 & 118 \\
\cline { 2 - 6 } & Otras+Específicas & 26 & 30 & 20 & 24 \\
\cline { 2 - 6 } & Educación Artística & 8 & 14 & 14 & 20 \\
\hline Total & 240 & 240 & 240 & 240 \\
\hline
\end{tabular}




\section{Valencia}

\begin{tabular}{|c|c|c|c|c|c|c|c|c|c|}
\hline \multirow[b]{2}{*}{ MíNIMOS } & \multirow{2}{*}{\begin{tabular}{|l|} 
Plan 1992 \\
Bloque Académico
\end{tabular}} & \multicolumn{5}{|c|}{ ESPECIALIDADES } & \multirow[b]{2}{*}{$\begin{array}{l}\text { EDUCACIÓN } \\
\text { ESPECIAL }\end{array}$} & \multirow[b]{2}{*}{$\begin{array}{l}\text { AUDICIÓN } \\
\text { LENGUAJE }\end{array}$} & \multirow[b]{2}{*}{$\begin{array}{l}\text { Valores } \\
\text { medios }\end{array}$} \\
\hline & & PRIMARIA & INFANTIL & $\begin{array}{c}\text { LENGUAS } \\
\text { EXTRANJERAS }\end{array}$ & $\begin{array}{l}\text { EDUCACIÓN } \\
\text { FÍSICA }\end{array}$ & $\begin{array}{l}\text { EDUCACIÓN } \\
\text { MUSICAL }\end{array}$ & & & \\
\hline \multirow{7}{*}{ Totales } & Ciencias & 16 & 12 & 4 & 4 & 4 & 0 & 0 & 5,7 \\
\hline & Letras & 36 & 28 & 52 & 20 & 20 & 0 & 20 & 25,1 \\
\hline & Profesional & 72 & 72 & 72 & 72 & 72 & 72 & 72 & 72 \\
\hline & Otras+Específicas & 46 & 60 & 48 & 80 & 82 & 104 & 86 & 72,3 \\
\hline & Educación Artística & 8 & 6 & 2 & 2 & 0 & 2 & 0 & 2,9 \\
\hline & Libre Configuración & 20 & 20 & 20 & 20 & 20 & 20 & 20 & 20 \\
\hline & Total & 198 & 198 & 198 & 198 & 198 & 198 & 198 & 198 \\
\hline MÁXIMOS & Bloque Académico & PRIMARIA & INFANTIL & $\begin{array}{c}\text { LENGUAS } \\
\text { EXTRANJERAS }\end{array}$ & $\begin{array}{l}\text { EDUCACIÓN } \\
\text { FÍSICA } \\
\end{array}$ & $\begin{array}{c}\text { EDUCACIÓN } \\
\text { MUSICAL }\end{array}$ & $\begin{array}{l}\text { EDUCACIÓN } \\
\text { ESPECIAL }\end{array}$ & $\begin{array}{l}\text { AUDICIÓN } \\
\text { LENGUAJE }\end{array}$ & $\begin{array}{l}\text { Valores } \\
\text { medios }\end{array}$ \\
\hline \multirow{7}{*}{ Totales } & Ciencias & 16 & 12 & 4 & 4 & 4 & 0 & 0 & 5,7 \\
\hline & Letras & 36 & 28 & 52 & 20 & 20 & 0 & 20 & 25,1 \\
\hline & Profesional & 72 & 72 & 72 & 72 & 72 & 72 & 72 & 72 \\
\hline & Otras+Específicas & 26 & 40 & 28 & 60 & 62 & 84 & 66 & 52,3 \\
\hline & Educación Artística & 28 & 26 & 22 & 22 & 20 & 22 & 20 & 22,9 \\
\hline & Libre Configuración & 20 & 20 & 20 & 20 & 20 & 20 & 20 & 20 \\
\hline & Total & 198 & 198 & 198 & 198 & 198 & 198 & 198 & 198 \\
\hline
\end{tabular}


La Educación Artística en los planes de estudio de Magisterio de la Comunitat Valenciana. Visión para el siglo XXI

\begin{tabular}{|c|c|c|c|c|c|c|c|c|c|}
\hline \multirow[b]{2}{*}{ curso } & \multirow{2}{*}{\begin{tabular}{|l|} 
Plan 2000 \\
Bloque Académico
\end{tabular}} & \multicolumn{5}{|c|}{ ESPECIALIDADES } & \multirow[b]{2}{*}{$\begin{array}{l}\text { EDUCACIÓN } \\
\text { ESPECIAL }\end{array}$} & \multirow[b]{2}{*}{$\begin{array}{l}\text { AUDICIÓN } \\
\text { LENGUAJE }\end{array}$} & \multirow[b]{2}{*}{$\begin{array}{l}\text { Valor } \\
\text { medio }\end{array}$} \\
\hline & & PRIMARIA & INFANTIL & $\begin{array}{c}\text { LENGUAS } \\
\text { EXTRANJERAS }\end{array}$ & $\begin{array}{l}\text { EDUCACIÓN } \\
\text { FÍSICA } \\
\end{array}$ & $\begin{array}{c}\text { EDUCACIÓN } \\
\text { MUSICAL }\end{array}$ & & & \\
\hline \multirow{7}{*}{ Primero } & Ciencias & 9 & 6 & & 9 & & 6 & & 4,3 \\
\hline & Letras & 12 & & & & 9 & 6 & 9 & 5,1 \\
\hline & Profesional & 31,5 & 31,5 & 31,5 & 31,5 & 31,5 & 31,5 & 31,5 & 31,5 \\
\hline & Otras+Específicas & & 12 & 22,5 & 16,5 & 13,5 & 18 & 13,5 & 13,7 \\
\hline & Educación Artística & 4,5 & 6 & & & & & & 1,5 \\
\hline & Libre Configuración & & & & & & & & 0 \\
\hline & Total & 57 & 55,5 & 54 & 57 & 54 & 61,5 & 54 & 56,1 \\
\hline \multirow{7}{*}{ Segundo } & Ciencias & 9 & & 9 & 9 & 9 & & & 5,1 \\
\hline & Letras & 21 & 18 & 31,5 & 9 & 9 & 6 & 18 & 16,1 \\
\hline & Profesional & 4,5 & 4,5 & 4,5 & 4,5 & 4,5 & 4,5 & 4,5 & 4,5 \\
\hline & Otras+Específicas & & & & 19,5 & 27 & 33 & 22,5 & 14,6 \\
\hline & Educación Artística & & & & & & 4,5 & & 0,6 \\
\hline & Libre Configuración & & & & & & & & 0 \\
\hline & Total & 34,5 & 22,5 & 45 & 42 & 49,5 & 48 & 45 & 40,9 \\
\hline \multirow{7}{*}{ Tercero } & Ciencias & & & & & & & & 0 \\
\hline & Letras & 4,5 & 10,5 & 6 & 10,5 & 10,5 & & & 6 \\
\hline & Profesional & 36,5 & 36,5 & 36,5 & 36,5 & 36,5 & 36,5 & 36,5 & 36,5 \\
\hline & Otras+Específicas & 13,5 & 4,5 & 13,5 & 9 & 13,5 & 10,5 & 13,5 & 11,1 \\
\hline & Educación Artística & & & 4,5 & 4,5 & & & 4,5 & 1,9 \\
\hline & Libre Configuración & & & & & & & & 0 \\
\hline & Total & 54,5 & 51,5 & 60,5 & 60,5 & 60,5 & 47 & 54,5 & 55,6 \\
\hline
\end{tabular}




\begin{tabular}{|c|c|c|c|c|c|c|c|c|c|}
\hline MÍNIMOS & Bloque Académico & PRIMARIA & INFANTIL & $\begin{array}{c}\text { LENGUAS } \\
\text { EXTRANJERAS }\end{array}$ & $\begin{array}{c}\text { EDUCACIÓN } \\
\text { FÍSICA }\end{array}$ & $\begin{array}{c}\text { EDUCACIÓN } \\
\text { MUSICAL }\end{array}$ & $\begin{array}{c}\text { EDUCACIÓN } \\
\text { ESPECIAL }\end{array}$ & $\begin{array}{l}\text { AUDICIÓN } \\
\text { LENGUAJE }\end{array}$ & $\begin{array}{l}\text { Valores } \\
\text { medios }\end{array}$ \\
\hline \multirow{6}{*}{ Totales } & Ciencias & 18 & 6 & 9 & 18 & 9 & 6 & 0 & 9,4 \\
\hline & Letras & 37,5 & 28,5 & 37,5 & 19,5 & 28,5 & 12 & 27 & 27,2 \\
\hline & Profesional & 72,5 & 72,5 & 72,5 & 72,5 & 72,5 & 72,5 & 72,5 & 72,5 \\
\hline & Otras+Específicas & 43,5 & 64,5 & 54 & 63 & 72 & 79,5 & 70 & 63,8 \\
\hline & Educación Artística & 4,5 & 6 & 4,5 & 4,5 & 0 & 4,5 & 4,5 & 4,1 \\
\hline & Libre Configuración & 22 & 20,5 & 20,5 & 20,5 & 20,5 & 23,5 & 24 & 21,6 \\
\hline & Total & 198 & 198 & 198 & 198 & 202,5 & 198 & 198 & 198,6 \\
\hline & & & & & & & & & \\
\hline MÁXIMOS & Bloque Académico & PRIMARIA & INFANTIL & $\begin{array}{c}\text { LENGUAS } \\
\text { EXTRANJERAS }\end{array}$ & $\begin{array}{l}\text { EDUCACIÓN } \\
\text { FÍSICA }\end{array}$ & $\begin{array}{l}\text { EDUCACIÓN } \\
\text { MUSICAL }\end{array}$ & $\begin{array}{l}\text { EDUCACIÓN } \\
\text { ESPECIAL }\end{array}$ & $\begin{array}{l}\text { AUDICIÓN } \\
\text { LENGUAJE }\end{array}$ & $\begin{array}{l}\text { Valores } \\
\text { medios }\end{array}$ \\
\hline \multirow{7}{*}{ Totales } & Ciencias & 18 & 6 & 9 & 18 & 9 & 6 & 0 & 9,4 \\
\hline & Letras & 37,5 & 28,5 & 37,5 & 19,5 & 28,5 & 12 & 27 & 27,2 \\
\hline & Profesional & 72,5 & 72,5 & 72,5 & 72,5 & 72,5 & 72,5 & 72,5 & 72,5 \\
\hline & Otras+Específicas & 25,5 & 46,5 & 36 & 45 & 54 & 61,5 & 52 & 45,8 \\
\hline & Educación Artística & 22,5 & 24 & 22,5 & 22,5 & 18 & 22,5 & 22,5 & 22,1 \\
\hline & Libre Configuración & 22 & 20,5 & 20,5 & 20,5 & 20,5 & 23,5 & 24 & 21,6 \\
\hline & Total & 198 & 198 & 198 & 198 & 202,5 & 198 & 198 & 198,6 \\
\hline
\end{tabular}




\begin{tabular}{|c|c|c|c|c|c|}
\hline \multirow[b]{3}{*}{ curso } & \multirow[b]{3}{*}{ Bloque Académico } & Mínimos & & \multirow{3}{*}{\begin{tabular}{|r|} 
Máximos \\
Infantil \\
\end{tabular}} & \multirow[b]{3}{*}{ Primaria } \\
\hline & & \multicolumn{2}{|c|}{ Grado } & & \\
\hline & & Infantil & Primaria & & \\
\hline \multirow{6}{*}{ Primero } & Ciencias & & & & \\
\hline & Letras & 18 & 18 & 18 & 18 \\
\hline & Profesional & 42 & 36 & 42 & 36 \\
\hline & Otras & & 6 & & 6 \\
\hline & Educación Artística & & & & \\
\hline & Total & 60 & 60 & 60 & 60 \\
\hline \multirow{6}{*}{ Segundo } & Ciencias & 18 & 18 & 18 & 18 \\
\hline & Letras & 4,5 & 12 & 4,5 & 12 \\
\hline & Profesional & 37,5 & 18 & 37,5 & 18 \\
\hline & Otras & & 6 & & 6 \\
\hline & Educación Artística & & 6 & & 6 \\
\hline & Total & 60 & 60 & 60 & 60 \\
\hline \multirow{6}{*}{ Tercero } & Ciencias & & 10,5 & & 10,5 \\
\hline & Letras & 4,5 & 15 & 4,5 & 15 \\
\hline & Profesional & 25,5 & 16,5 & 25,5 & 16,5 \\
\hline & Otras & 22 & 18 & 22 & 12 \\
\hline & Educación Artística & 8 & 0 & 8 & 6 \\
\hline & Total & 60 & 60 & 60 & 60 \\
\hline \multirow{6}{*}{ Cuarto } & Ciencias & 12 & 10,5 & 12 & 10,5 \\
\hline & Letras & 15 & 9 & 15 & 9 \\
\hline & Profesional & 27 & 28,5 & 27 & 28,5 \\
\hline & Otras & 6 & 12 & 4 & 6 \\
\hline & Educación Artística & 0 & & 2 & 6 \\
\hline & Total & 60 & 60 & 60 & 60 \\
\hline
\end{tabular}




\begin{tabular}{|r|l|r|r|r|r|}
\hline \multicolumn{1}{|c|}{} & Bloque Académico & \multicolumn{1}{|c|}{ INF m } & PRI m & \multicolumn{1}{|c|}{ INF M } & \multicolumn{1}{c|}{ PRI M } \\
\hline \multirow{5}{*}{ Totales } & Ciencias & 30 & 39 & 30 & 39 \\
\cline { 2 - 6 } & Letras & 42 & 54 & 42 & 54 \\
\cline { 2 - 6 } & Profesional & 132 & 99 & 132 & 99 \\
\cline { 2 - 6 } & Otras+Específicas & 28 & 42 & 26 & 30 \\
\cline { 2 - 6 } & Educación Artística & 8 & 6 & 10 & 18 \\
\hline Total & 240 & 240 & 240 & 240 \\
\hline
\end{tabular}




\section{Comunidad Valenciana}

\begin{tabular}{|c|c|c|c|c|c|c|c|c|}
\hline & & & \multicolumn{6}{|c|}{ Planes } \\
\hline & Bloque Académico & P1858 & 1857 & 1914 & 1931 & $1940-42$ & 1950 & 1967 \\
\hline \multirow{5}{*}{ Primero } & Ciencias & 9 & 3 & 4,5 & 6 & 5 & 3 & 5 \\
\hline & Letras & 22,5 & 9 & 13,5 & 11 & 9 & 9 & 7 \\
\hline & Profesional & 1,5 & 4 & & 3 & & 1 & 8 \\
\hline & Otras & & 7 & 18 & 2 & 13 & 10 & 8 \\
\hline & Educación Artística & & 5 & 7,5 & 8 & 3 & 3 & 4 \\
\hline curso & Total & 33 & 28 & 43,5 & 30 & 30 & 26 & 32 \\
\hline \multirow{6}{*}{ Segundo } & Ciencias & & 6 & 4,5 & 6 & 4 & 8 & 3,5 \\
\hline & Letras & 27 & 6 & 13,5 & 8 & 6 & 2 & 5,5 \\
\hline & Profesional & 3 & 7 & 4,5 & 3 & & 5 & 12 \\
\hline & Otras & 4,5 & 4 & 18 & 5 & 11 & 11 & 7 \\
\hline & Educación Artística & 4,5 & 2 & 6 & 8 & 3 & 3 & 4 \\
\hline & Total & 39 & 25 & 46,5 & 30 & 24 & 29 & 32 \\
\hline \multirow{6}{*}{ Tercero } & Ciencias & 7,5 & 6 & 9 & & 4 & 2 & \\
\hline & Letras & 8 & 6 & 21 & & 8 & 7 & \\
\hline & Profesional & 1,5 & 4 & 9 & 25 & & 4 & \\
\hline & Otras & 4,5 & 8 & 6 & 5 & 6 & 8 & \\
\hline & Educación Artística & 2 & 3 & & & 4 & 1 & \\
\hline & Total & 23,5 & 27 & 45 & 30 & 22 & 22 & 0 \\
\hline \multirow{6}{*}{ Cuarto } & Ciencias & & 9 & 9 & & & & \\
\hline & Letras & & 9 & 15 & & & & \\
\hline & Profesional & 6 & 4 & 13,5 & 30 & 12 & & \\
\hline & Otras & 6 & 5 & 9 & & 6 & & \\
\hline & Educación Artística & & 2 & & & 2 & & \\
\hline & Total & 12 & 29 & 46,5 & 30 & 20 & 0 & 0 \\
\hline
\end{tabular}




\begin{tabular}{|l|l|r|r|r|r|r|r|r|}
\multicolumn{1}{c|}{} & Bloque Académico & \multicolumn{1}{c|}{$\mathrm{P} 1858$} & \multicolumn{1}{c|}{1857} & \multicolumn{1}{c|}{1914} & \multicolumn{1}{c|}{1931} & $1940-42$ & \multicolumn{1}{c|}{1950} & 1967 \\
\hline \multirow{5}{*}{ Totales } & Ciencias & 16,5 & 24 & 27 & 12 & 13 & 13 & 8,5 \\
\cline { 2 - 9 } & Letras & 57,5 & 30 & 63 & 19 & 23 & 18 & 12,5 \\
\cline { 2 - 9 } & Profesional & 12 & 19 & 27 & 61 & 12 & 10 & 20 \\
\cline { 2 - 9 } & Otras & 15 & 24 & 51 & 12 & 36 & 29 & 15 \\
\cline { 2 - 9 } & Educación Artística & 6,5 & 12 & 13,5 & 16 & 12 & 7 & 8 \\
\hline Total & 107,5 & 109 & 181,5 & 120 & 96 & 77 & 64 \\
\hline
\end{tabular}




\begin{tabular}{|c|c|c|c|c|c|}
\hline \multicolumn{3}{|c|}{ Planes } & & & \\
\hline curso & Bloque Académico & 1971 & & & \\
\hline \multirow{6}{*}{ Primero } & Ciencias & 9 & & & \\
\hline & Letras & 9 & & & \\
\hline & Profesional & 18 & & & \\
\hline & Otras+Específicas & 18 & & & \\
\hline & Educación Artística & 9 & & & \\
\hline & Total & 63 & & Bloque Académico & 1971 \\
\hline \multirow{6}{*}{ Segundo } & Ciencias & 0 & \multirow{5}{*}{ Totales } & Ciencias & 9 \\
\hline & Letras & 0 & & Letras & 9 \\
\hline & Profesional & 4,5 & & Profesional & 36 \\
\hline & Otras+Específicas & 54 & & Otras+Específicas & 108 \\
\hline & Educación Artística & 9 & & Educación Artística & 27 \\
\hline & Total & 67,5 & & Total & 189 \\
\hline \multirow{6}{*}{ Tercero } & Ciencias & 0 & & & \\
\hline & Letras & 0 & & & \\
\hline & Profesional & 13,5 & & Total Plástica & 27 \\
\hline & Otras+Específicas & 36 & & Total Créditos & 189 \\
\hline & Educación Artística & 9 & & & \\
\hline & Total & 58,5 & & & \\
\hline
\end{tabular}




\begin{tabular}{|c|c|c|c|}
\hline & Bloque Académico & $1992 m$ & 1992M \\
\hline \multirow{10}{*}{ Totales } & Ciencias & 10,1 & 10,1 \\
\hline & Letras & 29,2 & 29,2 \\
\hline & Profesional & 76,1 & 76,1 \\
\hline & Otras+Específicas & 66,5 & 54,8 \\
\hline & Educación Artística & 4,7 & 16,4 \\
\hline & Libre Configuración & 21,2 & 21,2 \\
\hline & Total & 207,9 & 208,2 \\
\hline & & & \\
\hline & & & \\
\hline & Bloque Académico & $2000 \mathrm{~m}$ & $2000 \mathrm{M}$ \\
\hline \multirow{7}{*}{ Totales } & Ciencias & 11,5 & 11,5 \\
\hline & Letras & 35,5 & 35,5 \\
\hline & Profesional & 74,9 & 74,9 \\
\hline & Otras+Específicas & 51,4 & 41,2 \\
\hline & Educación Artística & 7,2 & 17,4 \\
\hline & Libre Configuración & 21,4 & 21,4 \\
\hline & Total & 201,8 & 201,8 \\
\hline
\end{tabular}




\begin{tabular}{|c|c|c|c|c|c|}
\hline & & Mínimos & & Máximos & \\
\hline & & \multicolumn{2}{|c|}{ Grado } & & \\
\hline curso & Bloque Académico & Infantil & Primaria & Infantil & Primaria \\
\hline \multirow{6}{*}{ Primero } & Ciencias & 0 & 4 & 0 & 4 \\
\hline & Letras & 16 & 18 & 16 & 18 \\
\hline & Profesional & 42 & 34 & 42 & 34 \\
\hline & Otras & 0 & 4 & 0 & 4 \\
\hline & Educación Artística & 2 & 0 & 2 & 0 \\
\hline & Total & 60 & 60 & 60 & 60 \\
\hline \multirow{6}{*}{ Segundo } & Ciencias & 14,7 & 16 & 14,7 & 16 \\
\hline & Letras & 15,5 & 10 & 15,5 & 10 \\
\hline & Profesional & 27,8 & 24 & 27,8 & 24 \\
\hline & Otras & 2 & 8 & 2 & 8 \\
\hline & Educación Artística & 0 & 2 & 0 & 2 \\
\hline & Total & 60 & 60 & 60 & 60 \\
\hline \multirow{6}{*}{ Tercero } & Ciencias & 2 & 9,5 & 2 & 9,5 \\
\hline & Letras & 3,5 & 17 & 3,5 & 17 \\
\hline & Profesional & 31,2 & 17,5 & 31,2 & 17,5 \\
\hline & Otras & 18 & 14 & 16 & 10 \\
\hline & Educación Artística & 5,3 & 2 & 7,3 & 6 \\
\hline & Total & 60 & 60 & 60 & 60 \\
\hline \multirow{6}{*}{ Cuarto } & Ciencias & 6 & 5,5 & 6 & 5,5 \\
\hline & Letras & 5 & 5 & 5 & 5 \\
\hline & Profesional & 39 & 34,8 & 39 & 34,8 \\
\hline & Otras & 8 & 10 & 7,3 & 8 \\
\hline & Educación Artística & 2 & 4,7 & 2,7 & 6,7 \\
\hline & Total & 60 & 60 & 60 & 60 \\
\hline
\end{tabular}




\begin{tabular}{|r|l|r|r|r|r|}
\hline \multicolumn{1}{|c|}{} & Bloque Académico & INF m & PRI m & INF M & \multicolumn{1}{|c|}{ PRI M } \\
\hline \multirow{5}{*}{ Totales } & Ciencias & 22,7 & 35 & 22,7 & 35 \\
\cline { 2 - 6 } & Letras & 40 & 50 & 40 & 50 \\
\cline { 2 - 6 } & Profesional & 140 & 110,3 & 140 & 110,3 \\
\cline { 2 - 6 } & Otras+Específicas & 28 & 36 & 25,3 & 30 \\
\cline { 2 - 6 } & Educación Artística & 9,3 & 8,7 & 12 & 14,7 \\
\hline Total & 240 & 240 & 240 & 240 \\
\hline
\end{tabular}

